University of Rhode Island

DigitalCommons@URI

Open Access Dissertations

2017

\title{
Spatial Distribution, Air-Water Exchange, and Toxicity of Organic Pollutants Using Passive Samplers
}

Carrie A. McDonough

University of Rhode Island, carriemc@my.uri.edu

Follow this and additional works at: https://digitalcommons.uri.edu/oa_diss

\section{Recommended Citation}

McDonough, Carrie A., "Spatial Distribution, Air-Water Exchange, and Toxicity of Organic Pollutants Using Passive Samplers" (2017). Open Access Dissertations. Paper 586.

https://digitalcommons.uri.edu/oa_diss/586

This Dissertation is brought to you for free and open access by DigitalCommons@URI. It has been accepted for inclusion in Open Access Dissertations by an authorized administrator of DigitalCommons@URI. For more information, please contact digitalcommons-group@uri.edu. 


\begin{abstract}
SPATIAL DISTRIBUTION, AIR-WATER EXCHANGE, AND
TOXICITY OF ORGANIC POLLUTANTS USING PASSIVE SAMPLERS

BY
\end{abstract}

CARRIE A. MCDONOUGH

A DISSERTATION SUBMITTED IN PARTIAL FULFILLMENT OF THE REQUIREMENTS FOR THE DEGREE OF

DOCTOR OF PHILOSOPHY

IN

OCEANOGRAPHY

UNIVERSITY OF RHODE ISLAND 
DOCTOR OF PHILOSOPHY

OF

CARRIE A. MCDONOUGH

APPROVED:

Dissertation Committee:

$\begin{array}{ll}\text { Major Professor } & \text { Rainer Lohmann } \\ & \text { Brian Heikes } \\ & \text { Gavino Puggioni } \\ & \text { Nasser H. Zawia } \\ & \text { DEAN OF THE GRADUATE SCHOOL }\end{array}$

UNIVERSITY OF RHODE ISLAND

2017 


\begin{abstract}
Thousands of hydrophobic organic contaminants (HOCs) are present in air and water worldwide, yet we know little about how these chemicals' concentrations vary spatially and temporally, or what biological effects they have in concert. The first four studies described in this dissertation present data from a sampling campaign in which passive polyethylene samplers (PEs) deployed throughout the lower Great Lakes region (Lake Erie and Lake Ontario) from 2011 to 2014. Results were used to deduce air-water fluxes and analyze spatial trends of the truly gaseous and dissolved fraction of three distinct groups of HOCs: polycyclic aromatic hydrocarbons (PAHs), polycyclic musks (PCMs), and organic flame retardants (OFRs), with the goal of better understanding how sources and physico-chemical properties determine the environmental transport and spatial distribution of these HOCs. The specific objectives of these studies were to determine whether gaseous and dissolved HOCs exhibited positive correlation with regional population density within $25 \mathrm{~km}$ of each site in the lower Great Lakes region, investigate whether diffusive air-water exchange of HOCs was primarily leading to volatilization from, or absorption into, the lakes' surface waters, and investigate health risks of ambient urban air by measuring aromatic hydrocarbon receptor (AhR)-mediated potency of the truly gaseous mixture of HOCs accumulated in PEs deployed in air on the Lake Erie shoreline near Cleveland $(\mathrm{OH})$. Results showed that the radius at which strongest correlation between gaseous HOC concentration and human population was observed depended on vapor pressure, and a relationship between the maximum distance where significant correlation occurred and compound vapor pressure is presented for amassed $\mathrm{PAH}$,
\end{abstract}


PBDE, and PCM data. Air-water exchange calculations based on simultaneously deployed air and water PEs indicated that diffusive exchange of PAHs was variable based on compound and season. PCMs were found to be volatilizing from the lakes' surface waters, suggesting that Lake Erie and Lake Ontario were acting as secondary sources of PCMs, while PBDEs were absorbed into surface waters. Bioassay experiments performed on PE extracts showed that $<30 \%$ of AhR-mediated potency for gaseous air extracts was explained by target compounds measured via chemical analysis, suggesting that targeted analysis may underestimate health risks posed by gas-phase ambient air.

The fifth and sixth studies described in this dissertation focused on measuring uptake of emerging and legacy HOCs into PEs to inform future calculation of ambient air and water concentrations from PE measurements. PE uptake profiles over 21-day deployments were used to determine whether target compounds reached equilibrium during deployment, and PE-water and PE-air partitioning coefficients ( $\mathrm{K}_{\mathrm{PEW}}$ and $\left.\mathrm{K}_{\mathrm{PEA}}\right)$ were calculated. $\mathrm{K}_{\mathrm{PEW}}$ values for PAHs agreed fairly well with empirical values from literature in most cases, while values for PCMs and OPEs were generally lower than predicted based on chemical properties, suggesting that PE-derived concentrations for these compounds may be underestimated when using this approach.

The seventh and final study included in this dissertation presents concentrations of dissolved organophosphate esters (OPEs), a group of emerging OFRs with atypical physico-chemical properties, derived from PEs deployed in the North Atlantic deep ocean from 2014-2015 and in Canadian Arctic surface waters during the summers of 2015 and 2016 to investigate long-range transport of OPEs to 
remote aquatic environments. For the first time, estimated concentrations of OPEs in polar ocean surface water and remote ocean deep water are reported. The greatest concentrations of OPEs were measured in Canadian Arctic surface waters, with the chlorinated OPE species most abundant. OPEs exhibited unexpectedly flat vertical profiles in the North Atlantic Fram Strait, possibly due to a high degree of mixing and/or release of dissolved-phase OPEs from sinking particles. This study demonstrated that OPEs are widespread, even in remote environments, and that concentrations are much greater than those of other OFRs in the Arctic, suggesting that OPEs should be a priority for further study. 


\section{ACKNOWLEDGMENTS}

Funding for this dissertation research was provided primarily by a U.S. EPA Great Lakes Restoration Initiative grant to Rainer Lohmann (GLAS \#00E00597-0), along with a University of Rhode Island Graduate Fellowship (2016-2017) to Carrie McDonough and a Hudson River Foundation Mark B. Bain Graduate Fellowship (2016-2017) to Carrie McDonough.

Firstly, I want to thank my family for their support and love through the ups and downs of the past five years, especially my wonderfully strong and intelligent mother, and my sisters Rose and Elise for always being there when I need a pick-meup, and Uncle John and Aunt Kate for offering me a home away from home.

I would like to thank my advisor Rainer Lohmann for everything he has done and continues to do to support me on my path to an academic career. Rainer has done an excellent job as an advisor, encouraging me to become an independent and confident researcher. I am very lucky that Rainer provided not only funding for my research, but also guidance on research directions and many valuable networking opportunities and recommendation letters, without which I am sure I would not have such an exciting postdoctoral position lined up.

I would also like to thank my core committee members Gavino Puggioni and Brian Heikes, who are both excellent teachers and always willing to take time to answer questions, as well as Brice Loose for his input and time, and Angela Slitt for helping me to pursue my interest in environmental toxicology. I thank Mark Hahn and Diana Franks at Woods Hole Oceanographic Institution for their collaboration and input during my foray into bioassay experiments, Peter August for GIS support and 
guidance, Caroline Gottschalk Druschke and Judith Swift for helping me to pursue public engagement projects, and David Smith for his advice and encouragement. I also thank Soni Pradhanang for serving on my defense committee.

Thank you to Paul Helm, Derek Muir, Thomas Soltwedel, Eduard Bauerfiend, and all of the workers at Environment Canada, Ontario Ministry of the Environment, Alfred Wegener Institute, South Kingstown Regional Wastewater Treatment Facility, and Rhode Island Department of Environmental Monitoring, as well as all of the citizen scientist volunteers throughout the Great Lakes region who made the extensive field work involved in this project possible.

I am grateful to the former and current members of the Lohmann Lab group, including Zoe Ruge, Kari St. Laurent, Mohammed Khairy, Dave Adelman, Erin Markham, Michael Vansco, and Erik Dixon Anderson for their knowledge and help. I also thank my current officemates Rachel Miller and Anna Robuck, for being excellent, fun people.

Last, but certainly not least, I thank Dylan Eberle for his support and love, and for being a source of calmness and pragmatism when things get crazy. Thanks also to my awesome BFF Harold Cooper for helping me function, reminding me that things other than science exist, and for insights on the size and location of Alaska and Hawaii, and to all of my extraordinary friends from coast to coast (Bill, Anjuli, Marissa, Tony, Matt G., Dalis, Zach, Okie, Justen, Julia, Mali, Cha, Ryan, Matt H., Catherine, Rosalie, Chris B., Christopher B., and on and on...) - thank you all for making life interesting and musical. I also thank Turtle for being slow and steady, and Tiny Grimes for ten years of furry companionship. 


\section{DEDICATION}

This dissertation is dedicated to my wonderful father, Dennis P. McDonough, who always believed my sisters and I were capable of amazing things. He taught us to dream big, but never take ourselves too seriously, and he was always so proud of everything we accomplished. 


\section{PREFACE}

This dissertation is written and organized in the manuscript format according to URI Graduate School guidelines for dissertation preparation. It is a compilation of 7 manuscripts, 3 of which have been published. The first manuscript (Chapter 2) was published in Environmental Science \& Technology in June 2014 with authors C. McDonough, M. Khairy, D. Muir, and R. Lohmann. The second manuscript (Chapter 3) was published in Environmental Science \& Technology in August 2016 with authors C. McDonough, G. Puggioni, P. Helm, D. Muir, and R. Lohmann. The third manuscript (Chapter 4) was published in Environmental Science \& Technology in September 2016 with authors C. McDonough, P. Helm, D. Muir, G. Puggioni, and R. Lohmann. The fourth manuscript is formatted for submission to Environmental Health Perspectives, the fifth manuscript is formatted for submission to Environmental Science \& Technology Letters, the sixth manuscript is formatted for submission to Chemosphere, and the seventh manuscript is formatted for submission to Environmental Science \& Technology. Appendix A contains a list of acronyms used throughout the dissertation. Appendix B is a compilation of Great Lakes passive sampling campaign data for additional sampling years not presented in the manuscripts. 


\section{TABLE OF CONTENTS}

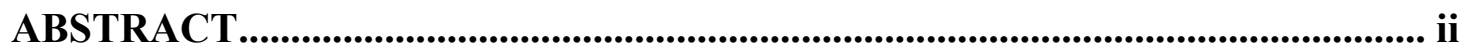

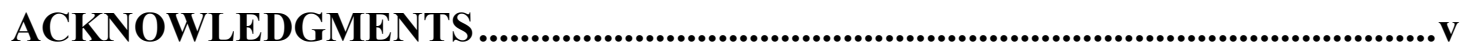

DEDICATION ................................................................................................... vii

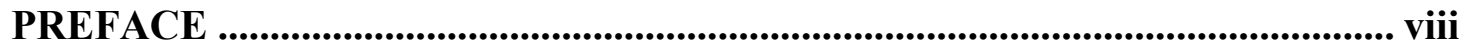

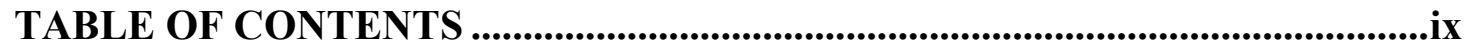

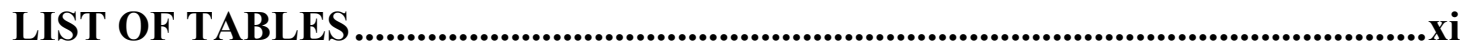

LIST OF FIGURES ..........................................................................................

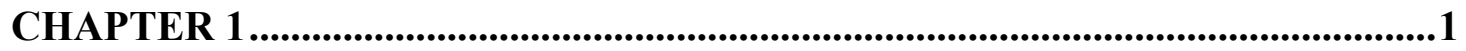

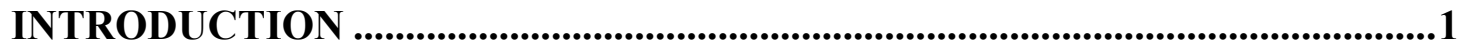

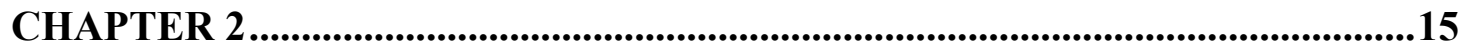

SIGNIFICANCE OF POPULATION CENTERS AS SOURCES OF GASEOUS AND DISSOLVED PAHS IN THE LOWER GREAT LAKES ..............................15

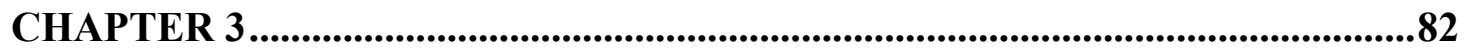

POLYCYCLIC MUSKS IN THE AIR AND WATER OF THE LOWER GREAT LAKES: SPATIAL DISTRIBUTION AND VOLATILIZATION FROM SURFACE WATERS ........................................................................................82

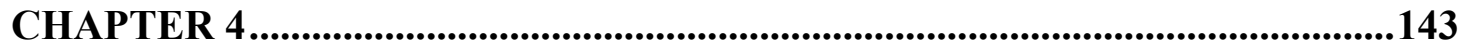

SPATIAL DISTRIBUTION AND AIR-WATER EXCHANGE OF ORGANIC FLAME RETARDANTS IN THE LOWER GREAT LAKES ...............................143

CHAPTER 5 .

INVESTIGATING ARYL HYDROCARBON-MEDIATED POTENCY OF GAS-PHASE AMBIENT AIR USING IN VITRO BIOASSAYS AND PASSIVE

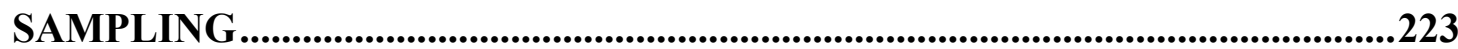

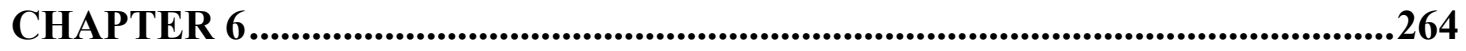

PARTITIONING OF DISSOLVED ORGANIC FLAME RETARDANTS AND SYNTHETIC FRAGRANCES FROM WASTEWATER INTO POLYETHYLENE PASSIVE SAMPLERS .......................................................264

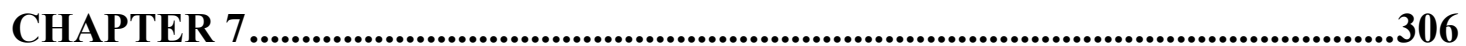

DIFFUSIVE UPTAKE OF GASEOUS HYDROPHOBIC ORGANIC CONTAMINANTS FROM AMBIENT AIR INTO POLYETHYLENE PASSIVE SAMPLERS .306

CHAPTER 8 .342 
DISSOLVED ORGANOPHOSPHATE ESTERS IN THE NORTH ATLANTIC

OCEAN AND ARCTIC OCEAN ................................................................342

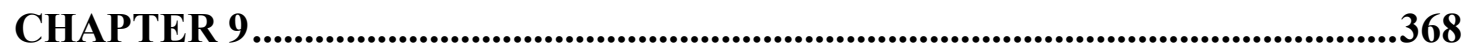

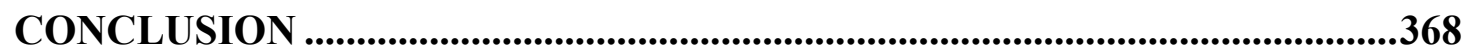

APPENDIX A.................................................................................................376

LIST OF ABBREVIATIONS ..........................................................................376

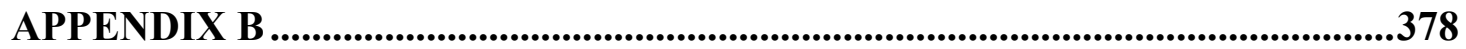

ADDITIONAL GREAT LAKES HOC CONCENTRATIONS FROM 2011-2014

PASSIVE SAMPLER CAMPAIGNS IN AIR AND WATER...........................378 


\section{LIST OF TABLES}

Table 2-1. Average gaseous and dissolved PAH concentrations in Lake Erie and Lake

Ontario. .46

Table S2-1. Lake Erie Monitoring Summary for Air and Water Passive Samplers, 2011. 55

Table S2-2. Lake Ontario Monitoring Summary for Air and Water Passive Samplers, 2011. 56

Table S2-3. Over-Land and Over-Water Trajectories Arriving at Coastal Sites 59

Table S2-4. Major Rivers within $10 \mathrm{~km}$ of Aqueous Sampling Sites. .59

Table S2-5. Percent Recovery for Internal Standard Spikes. 62

Table S2-6. Detection Limits and Percent Detection. .62

Table S2-7. Physico-chemical Parameters Used in This Study. 63

Table S2-8. Characterization of Sampling Sites Using Population Data Extracted from GRUMPv1

Table S2-9. Atmospheric PAHs $\left(\mathrm{pg} / \mathrm{m}^{3}\right)$ .65

Table S2-10. Aqueous PAHs (pg/L) .68

Table S2-11. Mass Transfer Coefficient........................................................ 74

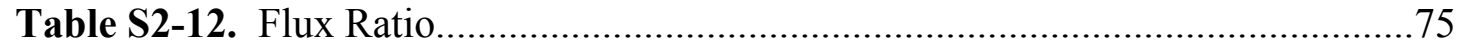

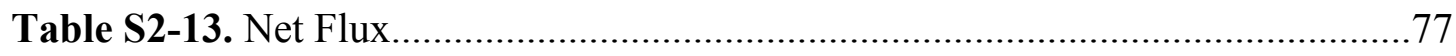

Table 3-1. Average Dissolved PCMs (pg/L) Summarized Regionally.....................108

Table 3-2. Average Gaseous PCMs $\left(\mathrm{pg} / \mathrm{m}^{3}\right)$ Grouped By Site Type.........................108

Table 3-3. Comparison of Simulated Air-Water Exchange Fluxes to PE-Derived and Grab Sample-Derived Exchange Fluxes .112 
Table S3-1: Deployment Summary for 2011-2012 Air and Water PEs.

Table S3-2. Buoys Used for Temperature and Wind Data.

Table S3-3. Average Matrix Spike Recoveries. 128

Table S3-4. Relative Percent Difference (RPD) between Duplicate Samples. 128

Table S3-5. Mean Blank Concentrations and Detection Limits 128

Table S3-6. Typical Detection Limits per Volume Air or Water

Table S3-7. Percent Detection of PCMs in Air and Water. 129

Table S3-8. Selected and Derived Physico-Chemical Properties 130

Table S3-9. Average Estimated Percent Equilibration. 131

Tabls S3-10. PCM Fugacity Ratios. 135

Table S3-11. PCM Air-Water Exchange Mass Transfer Coefficients 136

Table S3-12. PCM Air-Water Exchange Fluxes. 137

Table 4-1. Average Dissolved PBDEs (pg/L) \pm Standard Deviation. 170

Table 4-2. Average Gaseous PBDEs $\left(\mathrm{pg} / \mathrm{m}^{3}\right) \pm$ Standard Deviation. 170

Table S4-1. Deployment Summary. 183

Table S4-2. Buoys Used for Temperature and Wind Data. 186

Table S4-3. Average Matrix Spikes. 187

Table S4-4. Mean Blank Concentration and Detection Limits. 188

Table S4-5. Typical Detection Limits per Volume Air or Water. 189

Table S4-6. Percent Detection in Air and Water PEs. 190

Table S4-7. Selected and Derived Physico-Chemical Properties.

Table S4-8. Mean Percent Equilibrium 192

Table S4-9. Dissolved Organic Flame Retardant Concentrations. 193 
Table S4-10. Gaseous Organic Flame Retardant Concentrations............................197

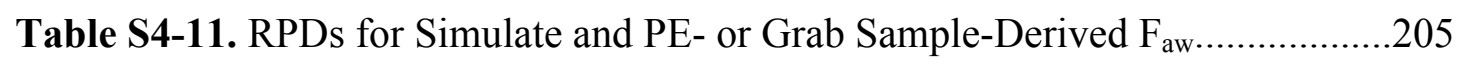

Table S4-12. Best-fit [DOC] from Active-Passive Comparison...............................208

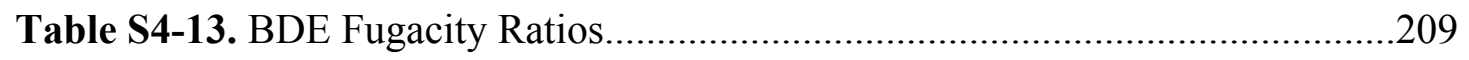

Table S4-14. Mean Summer PAH Concentrations in Air......................................210

Table S4-15. Mean Summer PAH Concentrations in Water...................................221

Table S4-16. Average Wind Direction During Deployments...............................215

Table S4-17. Predicted Average Wind Direction at Sampling Sites........................218

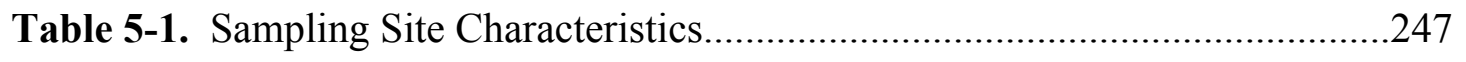

Table 5-2. Relative Potency and Maximum Efficacy of PE Extracts.....................251

Table 5-3. BaP Equivalents Derived from Chemical Analysis and Bioassays.........251

Table S5-1. Target compounds and abbreviations used.....................................255

Table S5-2. Summary of all PAH concentrations in dosing solutions......................258

Table S5-3: Summary of all OPE concentrations in dosing solutions.....................259

Table S5-4: Summary of all BFR concentrations in dosing solutions.....................260

Table S5-5. Correlation $\left(\mathrm{r}^{2}\right)$ between groups of PAHs in dosing solutions..............262

Table S5-6. Correlation $\left(\mathrm{r}^{2}\right)$ between OPEs in dosing solutions............................262

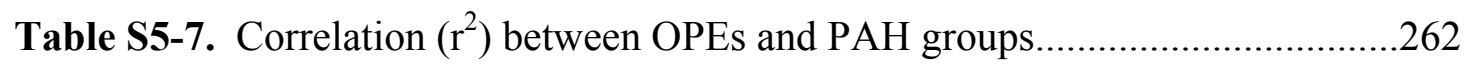

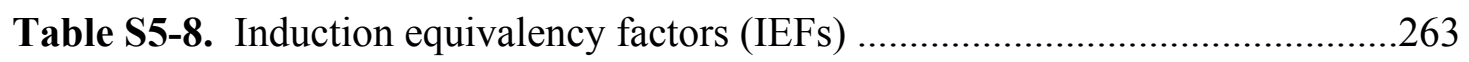

Table S6-1. List of Study Target Compounds ...............................290

Table S6-2. PE Field Blank results and detection limits.......................291

Table S6-3. Percent extraction efficiency for target compounds...................292

Table S6-4. PUF Field Blank Concentrations...............................293 
Table S6-5. Selected and derived physico-chemical properties from literature for target PAHs .294

Table S6-6. Selected and derived physico-chemical properties from literature for target PCMs and nitromusks.

Table S6-7. Selected and derived physico-chemical properties from literature for target OPEs .296

Table S6-8. DOC concentrations and percent in the truly dissolved phase 300

Table S6-9. Comparison of PE-derived and active sampling-derived water concentrations for PAHs and PCMs. 301

Table S6-10. Comparison of PE-derived and active sampling-derived water concentrations for OPEs.

Table S6-11. $\log \mathrm{K}_{\mathrm{PEW}}$ values derived from active and passive sampling data......303

Table 7-1. $\mathrm{K}_{\mathrm{PEA}}(298 \mathrm{~K})$ or lower-bound estimates from 21-day PEs and mean activederived gaseous concentrations

Table S7-1. List of target compounds. .330

Table S7-2. Physico-chemical properties for target compounds. .332

Table S7-3. Ambient Concentrations Derived from Active Sampling. .335

Table S7-4. Concentrations Accumulated in Polyethylene Over Time .338

Table S8-1. Summary of Samples .362

Table S8-2. Blank concentrations. 363

Table S8-3. PRC loss data from deep mooring PEs. .363 
Table S8-4. Percent equilibrium predicted to be reached by each OPE during deep

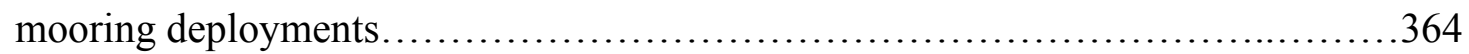

Table S8-5. Percent equilibrium predicted to be reached by each OPE during surface

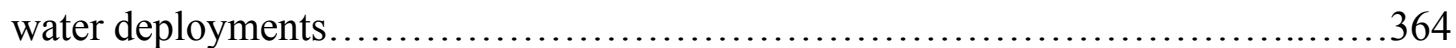

Table S8-6: Selected Physicochemical Properties of Target Compounds.............365 


\section{LIST OF FIGURES}

Figure 2-1. Average gaseous $\Sigma_{15} \mathrm{PAH}(\mathrm{A})$ and dissolved $\Sigma_{18} \mathrm{PAH}(\mathrm{B})$ in Lake Erie and Lake Ontario.

Figure 2-2. Average atmospheric concentrations of gaseous PAHs at each site

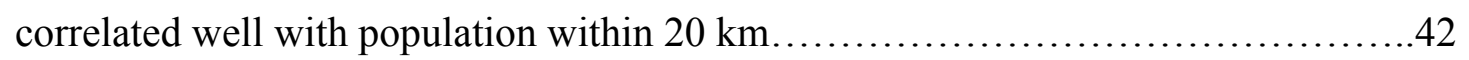

Figure 2-3. Correlation strength varied with population radius considered...........43

Figure 2-4. Relative significance of population within $20 \mathrm{~km}$ and $3 \mathrm{~km} \ldots \ldots \ldots \ldots . . .44$

Figure 2-5. Net air-water flux of four PAHs.............................45

Figure S2-1. 2011 Air and Water Deployment Locations and Abbreviations.........54

Figure S2-2. Prevailing Wind Direction.................................58

Figure S2-3. Lake Erie and Lake Ontario Watershed........................6 60

Figure S2-4. Percent Composition of PAHs................................. 70

Figure S2-5. Principal Component Analysis of Air and Water PAH Profiles...........71

Figure S2-6. Vapor Pressure and Radius of Max Concentration-Population

Correlation............................................................ 72

Figure S2-7. Temperature and Gaseous $\Sigma_{15} \mathrm{PAH}$ Concentration. ..................72

Figure S2-8. Temporal Trends in Precipitation and River Discharge.................73

Figure S2-9. Flux Ratio $\left(\mathrm{C}_{\mathrm{PEw}} / \mathrm{C}_{\mathrm{PEa}}-1\right)$ with Propagated Error.................. 78

Figure 3-1. Average summer HHCB and AHTN ( $\left.\Sigma_{2} \mathrm{PCM}\right)$ concentrations throughout the lower Great Lakes .109

Figure 3-2. Correlation of dissolved and gaseous $\Sigma_{5} \mathrm{PCM}$ and surrounding population density .110 
Figure 3-3. Predicted air-water exchange fluxes based on simulated air and water HHCB concentrations.

Figure 3-4. Summer air-water exchange fluxes of AHTN and HHCB..............113

Figure S3-1. Locations of Air Sites Relative to Buoys......................... 127

Figure S3-2. HHCB and AHTN Fugacity Ratios............................. 132

Figure S3-3. Summary of Dissolved PCMs Over Multiple Deployments...........133

Figure S3-4. Summary of Gaseous PCMs Over Multiple Deployments............ 134

Figure S3-5. PE-Derived Air-Water Exchange Fluxes for Scenario 1............138

Figure S3-6. Great Lakes Coastal Boundary Zone from Bathymetry................139

Figure 4-1. Average Dissolved (top) and Gaseous (bottom) PBDEs during Summer Deployments 171

Figure 4-2. Average Summer PBDE Air-Water Exchange Fluxes (pg/m²/day)......172

Figure 4-3. Maximum Distance $(\mathrm{km})$ Yielding Significant Correlation between Gaseous Concentration and Population. 172

Figure 4-4. Dissolved PBDEs and Population Density .173

Figure 4-5. Predicted Dissolved $\sum_{12} \mathrm{BDE}(\mathrm{pg} / \mathrm{L})$ Across Lake Erie and Lake Ontario. 174

Figure S4-1. BDE 47 Air-Water Exchange Fluxes: Scenario 1..................204

Figure S4-2. BDE 47 Air-Water Exchange Fluxes: Scenario 2.................205

Figure S4-3. Average Percent Composition of Major Congeners: Dissolved PBDEs. .206

Figure S4-4. Average Percent Composition of Major Congeners: Gaseous PBDEs. 206 
Figure S4-5. Comparison between Southern Population Wedge and Circular Radius

Figure S4-6. Average Wind Direction During Deployments at Available Meteorological Buoys................................................216

Figure S4-7. Predicted Average Wind Direction from Ordinary Kriging...........217

Figure S4-8. Variance or Dissolved PBDE Predictions from Bayesian Kriging.....218

Figure S4-9. Distributions of Estimated Parameters for Bayesian Kriging.........219

Figure S4-10. Cross-Validation for Bayesian Kriging of Dissolved PBDEs........219

Figure 5-1. Map of PE deployment sites in the Greater Cleveland Area............257

Figure 5-2. Concentration and composition of PAHs and OPEs in dosing solutions and ambient air. .249

Figure 5-3. Dose-response curves for triplicate cell exposures to PE extract dilution curves. 250

Figure 5-4. Map of $\mathrm{BaPEq}_{\mathrm{bio}}$ and dosing solution $\Sigma_{40} \mathrm{PAH}$ and $\Sigma_{12} \mathrm{OPE}$ concentrations from each site. .252

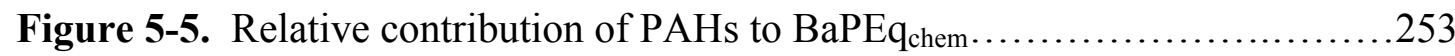

Figure S5-1. Schematic of sample treatment.............................250

Figure S5-2. BaP Dose-Response Curve...............................261

Figure S5-3. Principal component analysis (PCA) of PAHs in dosing solutions........................................................... 261

Figure 6-1. Ambient concentrations of PCMs and OPEs.......................283

Figure 6-2. PCM and nitromusk concentration in PEs over the 21-day deployment.......................................................... 284 
Figure 6-3. Concentrations of PAHs in PEs over the 21-day deployment. .285

Figure 6-4. Concentrations of OPEs in PEs over the 21-day deployment .286

Figure 6-5. Percent equilibrium reached by PRCs during deployment. .287

Figure 6-6. Comparison of $\mathrm{K}_{\mathrm{PEW}}$ values for PAHs from this study and from literature. 287

Figure 6-7. Comparison of $\mathrm{K}_{\mathrm{PEW}}$ values for OPEs from this study and derived from chemical properties from literature. .288

Figure 6-8. Comparison of $\mathrm{K}_{\mathrm{PEW}}$ values for $\mathrm{PCMs}$ from this study and derived from chemical properties from literature. 289

Figure S6-1. Water concentrations of PAHs from high-volume active water sampling. .297

Figure S6-2. Predicted PE uptake profiles.................................298

Figure S6-3. Best-fit value for thickness of the diffusive boundary layer..........299

Figure 7-1. Gaseous concentrations of PAHs, PCMs, and OPEs in East Providence air from active sampling 324

Figure 7-2. Concentrations of BDEs and NHFRs in East Providence air from active sampling .325

Figure 7-3. Uptake profiles of OPEs, BDEs, NHFRs, and PCMs in PEs over 2-day deployment. .326

Figure S7-1. Sampling set up at the East Providence. 321

Figure S7-2. Concentrations of gaseous HMW PAHs and alkyl/sub-PAHs derived from active air sampling. 334

Figure S7-3. Percent equilibration of performance reference compounds. .336 
Figure S7-4. Uptake profile examples for PAHs in PEs

Figure 8-1. Locations of surface water deployments in lakes and seawater, air monitoring sites, and deep moorings

Figure 8-2. Depth profiles showing estimated dissolved concentrations of $\mathrm{Cl} / \mathrm{Br}$ OPEs .360

Figure 8-3. Surface water concentrations of Cl-OPEs .360

Figure 8-4. Depth profiles showing estimated dissolved concentrations of alkyl/arylOPEs .361

Figure 8-5. Surface water concentrations of alkyl/aryl-OPEs. 361

Figure S8-1. Best-fit value for the thickness of the water boundary layer. 366

Figure S8-2. Range of OPE concentrations estimated depending on physico-chemical properties chosen

Figure 9-1. Interpolated dissolved $\Sigma_{5} \mathrm{PCM}$ concentrations. 374

Figure 9-2. Linear correlation between dissolved PCM concentrations and PCM volatilization fluxes .374

Figure 9-3. Interpolated gaseous $\Sigma_{12} \mathrm{BDE}$ concentrations. .375

Figure 9-4. Inverse linear correlation between gaseous BDE concentrations and absorptive BDE fluxes .375 


\section{CHAPTER 1}

\section{INTRODUCTION}

Thousands of hydrophobic organic contaminants (HOCs) are present in air and water worldwide, yet we know little about how these chemicals' concentrations vary spatially and temporally or what biological effects they have as a complex mixture. ${ }^{1}$ HOCs are of particular concern because they are often persistent, capable of longrange transport, and bioaccumulative. In this dissertation, three types of HOCs representing distinct use patterns and sources were investigated: polycyclic aromatic hydrocarbons (PAHs), polycyclic musks (PCMs), and organic flame retardants (OFRs).

Compounds Included in This Study. PAHs are ubiquitous HOCs that originate as byproducts of incomplete combustion of carbonaceous material. PAHs, along with their substituted analogs, are the principle carcinogenic component of ambient atmospheric aerosol. ${ }^{2,3}$ Major sources of atmospheric PAHs include emissions from vehicles, coal burning power plants, and biomass burning. ${ }^{4}$ Concentrations of PAHs in urban areas near the Great Lakes are typically in the $40-100 \mathrm{ng} / \mathrm{m}^{3}$ range, with lower concentrations in residential and rural areas. ${ }^{5-7}$ One of the few studies to measure aqueous PAHs in Great Lakes surface waters observed that concentrations were greatest in Lakes Erie and Ontario, where they reached about $5 \mathrm{ng} / \mathrm{L}{ }^{8}$

PCMs are synthetic fragrance compounds widely used as additives in personal care products and household cleaners. ${ }^{9}$ They are ubiquitous in aquatic environments, with concentrations generally in the $1-1000 \mathrm{ng} / \mathrm{L}$ range in rivers and lakes. ${ }^{10-13}$ AHTN 
and HHCB, two of the most widely used PCMs, have been measured previously in Lake Erie and Lake Ontario sediment $\operatorname{cores}^{14}$ and in water and air of Lakes Michigan, Erie, and Ontario. ${ }^{11,15,16}$ PCMs have also been detected recently in remote open ocean and polar environments. ${ }^{17,18}$ PCMs in both air and water are found at greater concentrations in more populated areas, ${ }^{15,19}$ and wastewater treatment plants outfalls have been identified as importance point sources of these compounds to the aquatic environment. $^{20,21}$

PCMs accumulate in biota, including marine mammals, fish, birds, shrimp, and mussels. ${ }^{22,23}$ A significant fraction of PCMs is present in the gaseous fraction of ambient air, and they are capable of being absorbed through human skin. ${ }^{15,24,25}$ While PCMs are not acutely toxic at typical environmental concentrations, sub-lethal effects such as impaired estrogenic function and weakened xenobiotic defense responses have been observed. ${ }^{26,27}$

OFRs are added to consumer goods such as furniture upholstery, textiles, and electronics to slow combustion and meet flammability standards. Three groups of OFRs, polybrominated diphenyl ethers (PBDEs), organophosphate esters (OPEs), and novel halogenated flame retardants (NHFRs), were investigated in this study.

Previous studies have shown that PBDEs are toxic, persistent, and bioaccumulative, and so they have been phased out of usage and manufacture in the United States and Canada, with the last formulation no longer used as of 2013. Despite regulation, PBDEs continue to be found in Great Lakes air and water, and in-use products are expected to act as continuous sources of PBDEs past $2020 .^{28}$ 
NHFRs and OPEs are increasingly being used as replacements for the PBDEs, and OPEs, in particular, have often been presented as safer alternatives. ${ }^{29}$ NHFRs have been measured in the Great Lakes air in the low $\mathrm{pg} / \mathrm{m}^{3}$ range, and in water intermittently at low concentrations. ${ }^{8,30,31}$ While PBDEs and many NHFRs display properties typical of other legacy HOCs of concern, some OPEs, particularly the chlorinated OPEs, are distinct in that they are more polar and more soluble, and are sometimes designated as persistent, mobile organic chemicals (PMOCs) because of their propensity for waterborne transport. ${ }^{32}$ For this reason, many traditional modeling tools predict that OPEs should be incapable of long-range transport. ${ }^{33}$ However, OPEs have been measured in air at much greater concentrations than PBDEs and NHFRs in the Great Lakes region, ${ }^{8,34,35}$ and have recently been detected at concentrations an order of magnitude greater than other OFRs in the atmosphere of remote polar and open ocean regions. ${ }^{36-38}$ The transport mechanisms by which OPEs are reaching these remote locations are largely unknown. In Chapter 8 of this dissertation, retrospective analysis of passive samplers deployed at North Atlantic deep mooring and Canadian Arctic surface water sites was done to measure dissolved OPEs in these remote environments and learn more about their long-range transport.

Polyethylene Passive Samplers. Polyethylene passive samplers (PEs) are sheets of low-density polyethylene that accumulate HOCs passively over time via diffusion. Passive samplers have been used to analyze spatial trends and identify sources of emerging and legacy contaminants on global, regional, and citywide scales, ${ }^{19,39-42}$ and are also being developed as personal exposure monitors. ${ }^{43-45}$ While total and particlebound concentrations of many HOCs have been measured in many previous studies, 
much less is known about the concentration, composition, and health effects of truly gaseous and dissolved HOCs, which is the fraction PEs select for. Due to this selectivity, PEs simultaneously deployed in different media are becoming an increasingly popular approach for measuring diffusive fluxes of HOCs, including airwater exchange fluxes. ${ }^{46-48}$ Furthermore, PEs are promising tools for achieving high spatial resolution and monitoring remote areas because they are cost-effective, require no electricity, and can be deployed with little training.

Despite the many advantages of using PEs, interpreting results can be challenging because the rate at which air or water is sampled cannot be set at a constant value, as with active sampling techniques. To allow for in situ calibration, PEs are often loaded with performance reference compounds (PRCs), which are nonnative compounds with similar properties to the compounds of interest, prior to deployment. ${ }^{49}$ Numerous models have been developed to use PRC loss data to approximate the percent equilibration $(f)$ reached by target compounds during PE deployment, which allows for calculation of ambient concentrations in the surrounding media. ${ }^{50-53}$ The rate of uptake into PEs depends on a compound's affinity for the membrane, represented by its PE-air or PE-water partitioning coefficient ( $\mathrm{K}_{\mathrm{PEA}}$ or $\mathrm{K}_{\mathrm{PEW}}$, respectively), and its molecular diffusivity in air, water, and PE. This presents a challenge in interpreting passive sampling data for emerging contaminants with poorly constrained physico-chemical properties. In Chapters 6 and 7 of this dissertation, uptake of PAHs, PCMs, and OFRs into PEs from water and air are investigated. In these studies, results are compared to measurements from co-deployed active air and water sampling and $\mathrm{K}_{\mathrm{PEA}}$ and $\mathrm{K}_{\mathrm{PEW}}$ values are estimated. 
Pollutants and Population. Numerous studies have described relationships between air pollutant concentrations and population density, proximity to urban centers, building density, or percent urban land cover. ${ }^{6,19,41,54,55}$ Concentrations of many of the target compounds in this study have been shown to decrease with distance from urban centers, identifying urban/industrialized regions as sources to the surrounding environment. Hafner et al. showed that concentrations of atmospheric PAHs were significantly linearly correlated with population density within $25 \mathrm{~km}$ of sampling sites around the world. ${ }^{56}$ This same $25 \mathrm{~km}$ radius has since been used in other studies to characterize sites in the Great Lakes region, and significant correlations between atmospheric HOCs and human population have been observed. ${ }^{6}$ However, most of these studies have focused on one population center, or measured concentrations at only a handful of sampling sites. Furthermore, very few studies have analyzed the relationship between population and aqueous concentrations of HOCs.

Understanding how HOCs correlate with easily attainable geographical parameters like population density allows for more accurate spatial predictions of air and water HOC concentrations in areas where it is not feasible to measure directly, and helps to identify areas in need of future monitoring. In Chapters 2 to 4 of this dissertation, the relationship between human population density and concentrations of PAHs, PCMs, and PBDEs were investigated.

Air-Water Exchange of HOCs. Many previous studies have identified atmospheric deposition as an important source of HOCs in aqueous environments. ${ }^{57,58}$ Air-water diffusive exchange fluxes, however, have not been measured in Lakes Erie and Ontario. Melymuk et al. postulated that gaseous absorption may be a significant 
source of PAHs to Lake Ontario, and volatilization from surface waters may account for significant losses of volatile PAHs from near-shore surface waters. ${ }^{16}$ Volatilization was also estimated to be a significant loss mechanism for PCMs in Lake Michigan and Lake Ontario, suggesting that the Great Lakes may be a secondary source of PCMs to the atmosphere. ${ }^{11,16}$ In Chapters 2 to 4 of this dissertation, simultaneously deployed air and water PE pairs were used to calculate air-water exchange fluxes of PAHs, PCMs, and PBDEs in the lower Great Lakes.

AhR-Mediated Potency of Gaseous Environmental Mixtures. Extensive research has established that particle-phase HOCs, particularly PAHs, pose a serious health risk to humans. ${ }^{2,59}$ However, few studies have investigated health risks associated with the gaseous fraction of ambient air, which humans are exposed to via respiration and dermal uptake. ${ }^{60}$ The gaseous fraction of ambient air has a distinct composition compared to the particle-bound fraction, and so health risks associated with this fraction are not readily predictable from studies of particulate matter. ${ }^{3}$

Previous studies have shown that the gaseous fraction of ambient air pollutants appears to be responsible for a significant portion of the aryl hydrocarbon receptor (AhR)-mediated potency associated with ambient air, though measured compounds in these studies could account for less than $30 \%$ of the potency measured from bioassays. ${ }^{61-64} \mathrm{AhR}$ activation is linked to a wide variety of biological effects including cell growth and proliferation, tumor promotion, immunological effects, and endocrine disruption. ${ }^{65}$

While previous studies have noted that gaseous HOCs should not be ignored in risk assessments, they were all carried out using high-volume air samplers or 
passive polyurethane foam (PUF) samplers, which are less selective for gaseous HOCs than PEs. ${ }^{66}$ In Chapter 5 of this dissertation, in vitro bioassays were used to measure AhR-mediated potency of extracts from PEs deployed in air along the Lake Erie shoreline to investigate the biological relevance of the truly gaseous fraction of ambient air and identify compounds that correlate with, and may possibly contribute to, observed AhR-mediated potency.

Overall, this dissertation contributes to scientific knowledge of how HOCs with diverse properties, sources, and uses enter both heavily industrialized and remote aquatic environments, and how these compounds affect human health as environmentally relevant mixtures. The work also demonstrates a wide range of applications for PEs, from obtaining ambient air and water concentrations of a variety of gaseous and dissolved HOCs, to calculate air-water diffusive fluxes and measuring biological potency of gas-phase mixtures isolated from urban ambient air. 


\section{LITERATURE CITED IN THE INTRODUCTION}

(1) Muir, D. C. G.; Howard, P. H. Are there other persistent organic pollutants? A challenge for environmental chemists. Environ. Sci. Technol. 2006, 40, $7157-$ 7166. DOI: $10.1021 /$ es061677a.

(2) Grimmer, G.; Brune, H.; Dettbarn, G.; Jacob, J.; Misfeld, J.; Mohr, U.; Naujack, K.-W.; Timm, J.; Wenzel-Hartung, R. Relevance of polycyclic aromatic hydrocarbons as environmental carcinogens. Fresenius J. Anal. Chem. 1991, 339, 792-795, DOI:10.1007/BF00321747.

(3) Boström, C.-E.; Gerde, P.; Hanberg, A.; Jernström, B.; Johansson, C.; Kyrklund, T.; Rannug, A.; Törnqvist, M.; Victorin, K.; Westerholm, R. Cancer risk assessment, indicators, and guidelines for polycyclic aromatic hydrocarbons in the ambient air. Environ. Health Perspect. 2002, 110, 451488. DOI: 10.1289/ehp.02110s3451.

(4) Shen, H.; Huang, Y.; Wang, R.; Zhu, D.; Li, W.; Shen, G.; Wang, B.; Zhang, Y.; Chen, Y.; Lu, Y.; Chen, H.; Li, T.; Sun, K.; Li, B.; Liu, W.; Liu, J. Global Atmospheric Emissions of Polycyclic Aromatic Hydrocarbons from 1960 to 2008 and Future Predictions. Environ. Sci. Technol. 2013, 47, 6415-6424, DOI:10.1021/es400857z.

(5) Melymuk, L.; Robson, M.; Helm, P. A.; Diamond, M. L. PCBs, PBDEs, and PAHs in Toronto air: Spatial and seasonal trends and implications for contaminant transport. Sci. Total Environ. 2012, 429, 272-280, DOI:10.1016/j.scitotenv.2012.04.022.

(6) Sun, P.; Blanchard, P.; Brice, K. A.; Hites, R. A. Trends in polycyclic aromatic hydrocarbon concentrations in the Great Lakes atmosphere. Environ. Sci.

Technol. 2006, 40, 6221-6227, DOI:10.1021/es0607279.

(7) Motelay-Massei, A.; Harner, T.; Shoeib, M.; Diamond, M.; Stern, G.; Rosenberg, B. Using passive air samplers to assess urban-rural trends for persistent organic pollutants and polycyclic aromatic hydrocarbons. 2. Seasonal trends for PAHs, PCBs, and organochlorine pesticides. Environ. Sci. Technol. 2005, 39, 5763-5773, DOI:10.1021/es0504183.

(8) Venier, M.; Dove, A.; Romanak, K.; Backus, S.; Hites, R. A. Flame retardants and legacy chemicals in Great Lakes' water. Environ. Sci. Technol. 2014, 48, 9563-9572, DOI:10.1021/es501509r.

(9) Hornbuckle, K.; Peck, A. M. Environmental sources, occurrence, and effects of synthetic musk fragrances. J. Environ. Monit. 2006, 8, 874-879, DOI:10.1039/b608170n. 
(10) Rimkus, G. G. Polycyclic musk fragrances in the aquatic environment. Toxicol. Lett. 1999, 111, 37-56, DOI:10.1016/S0378-4274(99)00191-5.

(11) Peck, A. M.; Hornbuckle, K. C. Synthetic musk fragrances in Lake Michigan. Environ. Sci. Technol. 2004, 38, 367-372, DOI:10.1021/es034769y.

(12) Bester, K. Polycyclic musks in the Ruhr catchment area: Transport, discharges of waste water, and transformations of HHCB, AHTN, and HHCB-lactone. $J$. Environ. Monit. 2005, 7, 43-51, DOI:10.1039/b409213a.

(13) Andresen, J. A.; Muir, D.; Ueno, D.; Darling, C.; Theobald, N.; Bester, K. Emerging pollutants in the North Sea in comparison to Lake Ontario, Canada, data. Environ. Toxicol. Chem. 2007, 26, 1081-1089, DOI:10.1897/06-416R.1.

(14) Peck, A. M.; Linebaugh, E. K.; Hornbuckle, K. C. Synthetic musk fragrances in Lake Erie and Lake Ontario sediment cores. Environ. Sci. Technol. 2006, 40, 5629-5635. DOI: 10.1021/es060134y.

(15) Peck, A.; Hornbuckle, K. Synthetic musk fragrances in urban and rural air of Iowa and the Great Lakes. Atmos. Environ. 2006, 40, 6101-6111, DOI:10.1016/j.atmosenv.2006.05.058.

(16) Melymuk, L.; Robson, M.; Csiszar, S.; Diamond, M.; Helm, P.; Kaltenecker, G. From the city to the lake : Loadings of PCBs, PBDEs, PAHs and PCMs from Toronto to Lake Ontario. Environ. Sci. Technol. 2014, 48, 3732-3741, DOI: $10.1021 / \mathrm{es} 403209 \mathrm{z}$.

(17) Xie, Z.; Ebinghaus, R.; Temme, C.; Heemken, O.; Ruck, W. Air-sea exchange fluxes of synthetic polycyclic musks in the North Sea and the Arctic. Environ. Sci. Technol. 2007, 41, 5654-5659, DOI:10.1021/es0704434.

(18) Ferrario, C.; Finizio, A.; Villa, S. Legacy and emerging contaminants in meltwater of three Alpine glaciers. Sci. Total Environ. 2017, 574, 350-357, DOI:10.1016/j.scitotenv.2016.09.067.

(19) Melymuk, L.; Robson, M.; Helm, P. A.; Diamond, M. L. Application of land use regression to identify sources and assess spatial variation in urban SVOC concentrations. Environ. Sci. Technol. 2013, 47, 1887-1895, DOI:10.1021/es3043609.

(20) Simonich, S. L.; Begley, W. M.; Debaere, G.; Eckhoff, W. S. Trace analysis of fragrance materials in wastewater and treated wastewater. Environ. Sci.

Technol. 2000, 34, 959-965, DOI:10.1021/es991018g. 
(21) Sun, P.; Casteel, K.; Dai, H.; Wehmeyer, K. R.; Kiel, B.; Federle, T. Distributions of polycyclic musk fragrance in wastewater treatment plant (WWTP) effluents and sludges in the United States. Sci. Total Environ. 2014, 493, 1073-1078, DOI:10.1016/j.scitotenv.2014.04.038.

(22) Reiner, J. L.; Kannan, K. Polycyclic musks in water, sediment, and fishes from the upper Hudson River, New York, USA. Water, Air, Soil Pollut. 2010, 214, 335-342, DOI:10.1007/s11270-010-0427-8.

(23) Gatermann, R.; Biselli, S.; Hühnerfuss, H.; Rimkus, G. G.; Hecker, M.; Karbe, L. Synthetic musks in the environment. Part 1: Species-dependent bioaccumulation of polycyclic and nitro musk fragrances in freshwater fish and mussels. Arch. Environ. Contam. Toxicol. 2002, 42, 437-446, DOI:10.1007/s00244-001-0041-2.

(24) Correia, P.; Cruz, A.; Santos, L.; Alves, A. Human dermal exposure to galaxolide from personal care products. Int. J. Cosmet. Sci. 2013, 35, 1-11, DOI:10.1111/ics.12043.

(25) Weschler, C. J.; Nazaroff, W. W. Dermal uptake of organic vapors commonly found in indoor air. Environ. Sci. Technol. 2014, 48, 1230-1237, DOI: 10.1021/es405490a.

(26) Parolini, M.; Magni, S.; Traversi, I.; Villa, S.; Finizio, A.; Binelli, A. Environmentally relevant concentrations of galaxolide (HHCB) and tonalide (AHTN) induced oxidative and genetic damage in Dreissena polymorpha. $J$. Hazard. Mater. 2015, 285, 1-10, DOI:10.1016/j.jhazmat.2014.11.037.

(27) Carlsson, G.; Norrgren, L. Synthetic musk toxicity to early life stages of zebrafish (Danio rerio). Arch. Environ. Contam. Toxicol. 2004, 46, 102-105, DOI:10.1007/s00244-003-2288-2.

(28) Abbasi, G.; Buser, A. M.; Soehl, A.; Murray, M. W.; Diamond, M. L. Stocks and flows of PBDEs in products from use to waste in the U.S. and Canada from 1970 to 2020. Environ. Sci. Technol. 2015, 49, 1521-1528, DOI:10.1021/es504007v.

(29) Dodson, R. E.; Perovich, L. J.; Covaci, A.; Van den Eede, N.; Ionas, A. C.; Dirtu, A. C.; Brody, J. G.; Rudel, R. A. After the PBDE phase-out: a broad suite of flame retardants in repeat house dust samples from California. Environ. Sci. Technol. 2012, 46, 13056-13066, DOI:10.1021/es303879n.

(30) Venier, M.; Ma, Y.; Hites, R. A. Bromobenzene flame retardants in the Great Lakes atmosphere. Environ. Sci. Technol. 2012, 46, 8653-8660, DOI:10.1021/es3015919. 
(31) Salamova, A.; Hites, R. Discontinued and alternative brominated flame retardants in the atmosphere and precipitation from the Great Lakes basin. Environ. Sci. Technol. 2011, 45, 8698-8706. DOI: 10.1021/es2020378.

(32) Reemtsma, T.; Berger, U.; Arp, H. P. H.; Gallard, H.; Knepper, T. P.; Neumann, M.; Quintana, J. B.; de Voogt, P. Mind the gap: Persistent and mobile organic compounds - water contaminants that slip through. Environ. Sci. Technol. 2016, 50, 10308-10315, DOI:10.1021/acs.est.6b03338.

(33) Zhang, X.; Suhring, R.; Serodio, D.; Bonnell, M.; Sundin, N.; Diamond, M. L. Novel flame retardants: Estimating the physical-chemical properties and environmental fate of 94 halogenated and organophosphate PBDE replacements. Chemosphere 2016, 144, 2401-2407, DOI:10.1016/j.chemosphere.2015.11.017.

(34) Salamova, A.; Ma, Y.; Venier, M.; Hites, R. A. High levels of organophosphate flame retardants in the Great Lakes atmosphere. Environ. Sci. Technol. Lett. 2014, 1, 8-14, DOI:10.1021/ez400034n.

(35) Peverly, A. A.; Ma, Y.; Venier, M.; Rodenburg, Z.; Spak, S. N.; Hornbuckle, K. C.; Hites, R. A. Variations of flame retardant, polycyclic aromatic hydrocarbon, and pesticide concentrations in Chicago's atmosphere measured using passive sampling. Environ. Sci. Technol. 2015, 49, 5371-5379, DOI:10.1021/acs.est.5b00216.

(36) Salamova, A.; Hermanson, M. H.; Hites, R. A. Organophosphate and halogenated flame retardants in atmospheric particles from a European Arctic site. Environ. Sci. Technol. 2014, 48, 6133-6140, DOI:10.1021/es500911d.

(37) Sühring, R.; Diamond, M. L.; Scheringer, M.; Wong, F.; Pućko, M.; Stern, G.; Burt, A.; Hung, H.; Fellin, P.; Li, H.; Jantunen, L. M. Organophosphate esters in Canadian Arctic air: Occurrence, levels and trends. Environ. Sci. Technol. 2016, 50, 7409-7415, DOI:10.1021/acs.est.6b00365.

(38) Castro Jimenez, J.; González-Gaya, B.; Pizarro, M.; Casal, P.; Pizarro-Alvarez, C.; Dachs, J. Organophosphate ester flame retardants and plasticizers in the global oceanic atmosphere. Environ. Sci. Technol. 2016, 50, 12831-12839, DOI:10.1021/acs.est.6b04344.

(39) McDonough, C. A.; Khairy, M. A.; Muir, D. C. G.; Lohmann, R. Significance of population centers as sources of gaseous and dissolved PAHs in the lower Great Lakes. Environ. Sci. Technol. 2014, 48, 7789-7797, DOI:10.1021/es501074r. 
(40) Khairy, M. A.; Lohmann, R. Field validation of polyethylene passive air samplers for parent and alkylated PAHs in Alexandria, Egypt. Environ. Sci. Technol. 2012, 46, 3990-3998, DOI:10.1021/es300012u.

(41) Hearn, L. K.; Kennedy, K.; Hawker, D. W.; Toms, L.-M. L.; Alberts, V.; Mueller, J. F. Spatial mapping of city-wide PBDE levels using an exponential decay model. J. Environ. Monit. 2012, 14, 643-650, DOI:10.1039/c2em10656f.

(42) Gawor, A.; Shunthirasingham, C.; Hayward, S. J.; Lei, Y. D.; Gouin, T.; Mmereki, B. T.; Masamba, W.; Ruepert, C.; Castillo, L. E.; Shoeib, M.; Lee, S. C.; Harner, T.; Wania, F. Neutral polyfluoroalkyl substances in the global atmosphere. Environ. Sci. Process. Impacts 2014, 16, 404-413, DOI:10.1039/c3em00499f.

(43) Kennedy, K.; Macova, M.; Leusch, F.; Bartkow, M. E.; Hawker, D. W.; Zhao, B.; Denison, M. S.; Mueller, J. F. Assessing indoor air exposures using passive sampling with bioanalytical methods for estrogenicity and aryl hydrocarbon receptor activity. Anal. Bioanal. Chem. 2009, 394, 1413-1421, DOI:10.1007/s00216-009-2825-6.

(44) Wilford, B. H.; Harner, T.; Zhu, J.; Shoeib, M.; Jones, K. C. Passive sampling survey of polybrominated diphenyl ether flame retardants in indoor and outdoor air in Ottawa, Canada: implications for sources and exposure. Environ. Sci. Technol. 2004, 38, 5312-5318, DOI:10.1021/es049260x.

(45) O’Connell, S. G.; Kincl, L. D.; Anderson, K. A. Silicone wristbands as personal passive samplers. Environ. Sci. Technol. 2014, 48, 3327-3335, DOI:10.1021/es405022f.

(46) Lohmann, R.; Dapsis, M.; Morgan, E. J.; Dekany, V.; Luey, P. J. Determining air-water exchange, spatial and temporal trends of freely dissolved PAHs in an urban estuary using passive polyethylene samplers. Environ. Sci. Technol. 2011, 45, 2655-2662, DOI:10.1021/es1025883.

(47) Morgan, E. J.; Lohmann, R. Detecting air-water and surface-deep water gradients of PCBs using polyethylene passive samplers. Environ. Sci. Technol. 2008, 42, 7248-7253, DOI:10.1021/es800518g.

(48) Tidwell, L. G.; Allan, S. E.; Connell, S. G. O.; Hobbie, K. A.; Smith, B. W.; Kim, A. PAH and OPAH air and water exchange during the Deepwater Horizon Incident. Environ. Sci. Technol. 2016, 50, 7489-7497, DOI:10.1021/acs.est.6b02784.

(49) Booij, K.; Smedes, F.; van Weerlee, E. M. Spiking of performance reference compounds in low density polyethylene and silicone passive water samplers. Chemosphere 2002, 46, 1157-1161, DOI:10.1016/S0045-6535(01)00200-4. 
(50) Booij, K.; Smedes, F. An improved method for estimating in situ sampling rates of nonpolar passive samplers. Environ. Sci. Technol. 2010, 44, 6789-6794, DOI:10.1021/es101321v.

(51) Tcaciuc, P. A.; Apell, J. N.; Gschwend, P. M. Modeling the transport of organic chemicals between polyethylene passive samplers and water in finite and infinite bath conditions. Environ. Toxicol. Chem. 2015, 34, 2739-2749, DOI:10.1002/etc.3128.

(52) Thompson, J. M.; Hsieh, C.-H.; Luthy, R. G. Modeling uptake of hydrophobic organic contaminants into polyethylene passive samplers. Environ. Sci. Technol. 2015, 49, 2270-2277, DOI:10.1021/es504442s.

(53) Fernandez, L. A.; Lao, W.; Maruya, K. A.; White, C.; Burgess, R. M. Passive sampling to measure baseline dissolved persistent organic pollutant concentrations in the water column of the Palos Verdes Shelf Superfund site. Environ. Sci. Technol. 2012, 46, 11937-11947, DOI:10.1021/es302139y.

(54) Harner, T.; Shoeib, M.; Diamond, M.; Ikonomou, M.; Stern, G. Passive sampler derived air concentrations of PBDEs along an urban-rural transect: Spatial and temporal trends. Chemosphere 2006, 64, 262-267, DOI:10.1016/j.chemosphere.2005.12.018.

(55) Venier, M.; Hites, R. Flame retardants in the atmosphere near the Great Lakes. Environ. Sci. Technol. 2008, 42, 4745-4751. DOI: 10.1021/es800313z.

(56) Hafner, W. D.; Carlson, D. L.; Hites, R. A. Influence of local human population on atmospheric polycyclic aromatic hydrocarbon concentrations. Environ. Sci. Technol. 2005, 39, 7374-7379, DOI:10.1021/es0508673.

(57) Offenberg, J.; Simcik, M.; Baker, J.; Eisenreich, S. J. The impact of urban areas on the deposition of air toxics to adjacent surface waters: A mass budget of PCBs in Lake Michigan in 1994. Aquat. Sci. 2005, 67, 79-85, DOI:10.1007/s00027-004-0737-2.

(58) Blanchard, P.; Audette, C. V.; Hulting, M. L.; Basu, I.; Brice, K. A.; Backus, S. M.; Dryfhout-Clark, H.; Froude, F.; Hites, R. A.; Neilson, M.; Wu, R. Atmospheric deposition of toxic substances to the Great Lakes: IADN results through 2005, Published by Environment Canada and the United States Environmental Protection Agency, 2005.

(59) Gungormus, E.; Tuncel, S.; Hakan Tecer, L.; Sofuoglu, S. C. Inhalation and dermal exposure to atmospheric polycyclic aromatic hydrocarbons and associated carcinogenic risks in a relatively small city. Ecotoxicol. Environ. Saf. 2014, 108, 106-113, DOI:10.1016/j.ecoenv.2014.06.015. 
(60) Weschler, C. J.; Nazaroff, W. W. SVOC exposure indoors: Fresh look at dermal pathways. Indoor Air 2012, 22, 356-377, DOI:10.1111/j.1600-

0668.2012.00772.x.

(61) Ramírez, N.; Cuadras, A.; Rovira, E.; Marcé, R. M.; Borrull, F. Risk assessment related to atmospheric polycyclic aromatic hydrocarbons in gas and particle phases near industrial sites. Environ. Health Perspect. 2011, 119, 1110 1116, DOI:10.1289/ehp.1002855.

(62) Klein, G. P.; Hodge, E. M.; Diamond, M. L.; Yip, A.; Dann, T.; Stern, G.; Denison, M. S.; Harper, P. A. Gas-phase ambient air contaminants exhibit significant dioxin-like and estrogen-like activity in vitro. Environ. Health Perspect. 2005, 114, 697-703, DOI:10.1289/ehp.8496.

(63) Novák, J.; Giesy, J. P.; Klánová, J.; Hilscherová, K. In vitro effects of pollutants from particulate and volatile fractions of air samples-day and night variability. Environ. Sci. Pollut. Res. Int. 2013, 20, 6620-6627, DOI:10.1007/s11356-013-1726-6.

(64) Kennedy, K.; Macova, M.; Bartkow, M. E.; Hawker, D. W.; Zhao, B.; Denison, M. S.; Mueller, J. F. Effect based monitoring of seasonal ambient air exposures in Australia sampled by PUF passive air samplers. Atmos Pollut Res. 2010, 1, 50-58, DOI:10.1007/s10661-014-3667-z.

(65) Denison, M. S.; Soshilov, A. A.; He, G.; Degroot, D. E.; Zhao, B. Exactly the same but different: Promiscuity and diversity in the molecular mechanisms of action of the aryl hydrocarbon (dioxin) receptor. Toxicol. Sci. 2011, 124, 1-22, DOI:10.1093/toxsci/kfr218.

(66) Melymuk, L.; Robson, M.; Helm, P. A.; Diamond, M. L. Evaluation of passive air sampler calibrations: Selection of sampling rates and implications for the measurement of persistent organic pollutants in air. Atmos. Environ. 2011, 45 , 1867-1875, DOI:10.1016/j.atmosenv.2011.01.011. 


\section{CHAPTER 2}

SIGNIFICANCE OF POPULATION CENTERS AS SOURCES OF GASEOUS AND DISSOLVED PAHS IN THE LOWER GREAT LAKES

This manuscript has been published in and is formatted for the journal Environmental Science and Technology, 2014, 48(14), pp 7789-7797, DOI: 10.1021/es501074r.

Carrie A. McDonough ${ }^{\dagger}$, Mohammed A. Khairy ${ }^{\dagger}+$, Derek C. G. Muir ${ }^{\mathcal{s}}$, Rainer $\operatorname{Lohmann~}^{\dagger *}$

${ }^{\dagger}$ University of Rhode Island Graduate School of Oceanography

${ }^{\ddagger}$ Alexandria University, Department of Environmental Sciences, Alexandria, Egypt

$\S$ Environment Canada, Aquatic Contaminants Research Division, Burlington, Ontario, Canada L7S 1A1

*Corresponding author email: rlohmann@uri.edu; phone: 401.874.6612; fax:

401.874 .6811 


\section{ABSTRACT}

Polyethylene passive samplers (PEs) were used to measure concentrations of gaseous and dissolved polycyclic aromatic hydrocarbons (PAHs) in the air and water throughout the lower Great Lakes during summer and fall of 2011. Atmospheric $\Sigma_{15} \mathrm{PAH}$ concentrations ranged from $2.1 \mathrm{ng} / \mathrm{m}^{3}$ in Cape Vincent (NY) to $76.4 \mathrm{ng} / \mathrm{m}^{3}$ in downtown Cleveland $(\mathrm{OH})$. Aqueous $\Sigma_{18} \mathrm{PAH}$ concentrations ranged from $2.4 \mathrm{ng} / \mathrm{L}$ at an offshore Lake Erie site to $30.4 \mathrm{ng} / \mathrm{L}$ in Sheffield Lake $(\mathrm{OH})$. Gaseous PAH concentrations correlated strongly with population within $3-40 \mathrm{~km}$ of the sampling site depending on the compound considered, suggesting that urban centers are a primary source of gaseous PAHs (except retene) in the lower Great Lakes region. The significance of distant population (within $20 \mathrm{~km}$ ) versus local population (within 3 $\mathrm{km}$ ) increased with sub-cooled liquid vapor pressure. Most dissolved aqueous PAHs did not correlate significantly with population, nor were they consistently related to river discharge, wastewater effluents, or precipitation. Air-water exchange calculations implied that diffusive exchange was a source of phenanthrene to surface waters, while acenaphthylene volatilized out of the lakes. Comparison of air-water fluxes with temperature suggested that the significance of urban centers as sources of dissolved PAHs via diffusive exchange may decrease in warmer months.

\section{INTRODUCTION}

Polycyclic aromatic hydrocarbons (PAHs) are ubiquitous pollutants that originate from oil spills as well as anthropogenic and natural combustion processes. Major sources include fossil fuel combustion, metal production, waste incineration, 
residential and commercial biomass burning, and vehicular emissions. ${ }^{1-5}$ PAHs are often associated with densely populated areas, especially in industrialized countries. ${ }^{3,4,6,7}$ PAHs and their transformation products are a primary carcinogenic component of urban air pollution and health effects resulting from chronic exposure are a serious concern. ${ }^{8,9}$

Polyethylene passive samplers (PEs) are cost-effective, simple tools with lower detection limits than traditional active sampling techniques. Instead of pumping air or water through a filter, PEs accumulate hydrophobic organic contaminants (HOCs) over time via diffusion, accumulating only truly dissolved or gas-phase molecules. ${ }^{10}$ Concentrations of truly dissolved HOCs are of interest because this fraction is available for direct diffusive exchange between water and other reservoirs such as air, biota, or sediment.

The use of PEs facilitates simultaneous spatially resolved measurements and calculations of air-water diffusive exchange rates. For most HOCs, concentrations measured by PEs reflect a time-integrated concentration representative of the entire deployment period. For compounds that equilibrate during deployment, concentrations reflect the most recent concentration the sampler was exposed to. PEs have previously been used to measure HOCs in water and air ${ }^{1-13}$ and to calculate airwater gradients of HOCs, but this method has not been applied to the lower Great Lakes. $^{14-16}$

Lake Erie and Lake Ontario are the smallest of the Great Lakes by volume and have estimated residence times of 2.7 and 7.5 years, respectively. ${ }^{17}$ About $80 \%$ of Lake Erie's water is supplied by the Detroit River, which is fed by Lake Huron via 
Lake St. Claire. Among the Great Lakes, Lake Erie is the shallowest (average depth $19 \mathrm{~m}$ ), warmest, and most biologically productive. ${ }^{18,19}$ Lake Ontario is much deeper (average depth $86 \mathrm{~m}$ ) and primarily receives water from Lake Erie via the Niagara River. ${ }^{19}$ Currents in the Great Lakes are weak (a few $\mathrm{cm} / \mathrm{s}$ ) with complex temporal variability that depends on recent atmospheric conditions. In the summertime, circulation is generally counterclockwise (Figure S2-3). ${ }^{20}$ The lakes are stratified from May through October and well-mixed for the remainder of the year. ${ }^{20}$

Heavy urbanization and valuable ecosystems often coincide along the shores of the lower Great Lakes. Atmospheric deposition from urban sources has been identified as a major source of gaseous and particle-bound HOCs to the region's aquatic environment. ${ }^{2,7,21,22}$ Concentrations of total atmospheric PAHs have been shown to correlate strongly with population in this region and urban centers have been linked to significantly increased loadings of contaminants to the lakes. ${ }^{23,24}$ In some cases, however, the lakes have been found to act as a source of HOCs via revolatilization. $^{25,26}$ Much of the previous work describing sources of atmospheric pollution to the Great Lakes is based on a limited number of air monitoring sites as part of the Integrated Atmospheric Deposition Network (IADN). While this data is indispensible in determining baseline concentrations and temporal trends of persistent organic pollutants (POPs) in the Great Lakes, more detailed knowledge of spatial trends is crucial to identify major sources and transport pathways.

The objectives of this study were to (i) provide baseline concentrations of gaseous and dissolved PAHs in Great Lakes air and water, (ii) evaluate the importance of urban regions as sources of dissolved PAHs by investigating the relationship 
between population and PAH concentration, and (iii) determine whether the lower Great Lakes are sources or sinks for dissolved PAHs.

\section{MATERIALS AND METHODS}

Passive Sampling Procedures. A map of all monitoring sites and a table outlining temporal coverage and meteorology are provided in the Supporting Information (Figure S2-1, Table S2-1 \& S2-2) along with information on sampler preparation and deployment. PEs were spiked with performance reference compounds (PRCs) via a method adapted from Booij et al. ${ }^{27}$ and sent to trained volunteers throughout the Great Lakes region with the aim of completing three 8-week deployments at each site. After deployment, volunteers returned samplers via overnight delivery.

Four sites formed an east-west transect along Lake Ontario's southern shore. The westernmost site, Grimsby (ON), was an offshore buoy monitored by Environment Canada. On Lake Erie, samplers were deployed at nine US shoreline sites and six offshore sites monitored by Environment Canada. Samplers were deployed at the offshore sites once, during late summer. Samplers at Gibraltar Island $(\mathrm{OH})$ and Toledo $(\mathrm{OH})$ were deployed once during late spring/early summer.

Meteorological Information \& Site Characteristics. Monthly wind speed averages during the sampling campaign ranged from $3.8 \mathrm{~m} / \mathrm{s}$ in July to $6.1 \mathrm{~m} / \mathrm{s}$ in November, with the greatest average wind speeds offshore of Toledo. Average air temperatures ranged from $7.7{ }^{\circ} \mathrm{C}$ in April to $24.3{ }^{\circ} \mathrm{C}$ in July and the mean deployment temperature for all sampling periods was $18.6 \pm 1.8^{\circ} \mathrm{C}$. Surface water temperatures were generally very similar to air temperatures and ranged from $3.7^{\circ} \mathrm{C}$ (Lake Ontario in May) to 
$25.1^{\circ} \mathrm{C}$ (Lake Erie in July). ${ }^{28}$ There were westerly prevailing winds during the sampling campaign for most of the study region (Figure S2-2, Table S2-3). ${ }^{29,30}$ Precipitation and river discharge were lowest during June and July while flows in late spring and early fall were similar. ${ }^{31}$ Locations near major rivers are listed in Table S4. Sample Analysis. All PEs were spiked with deuterated PAHs and extracted twice, each time for 18 hours. Air PEs were extracted with ethyl acetate followed by hexane. Aqueous PEs were extracted with dichloromethane followed by hexane. Extracts were concentrated to approximately $100 \mu \mathrm{L}$ and p-terphenyl- $\mathrm{d}_{14}$ was added as an injection standard. Extracts were analyzed using an Agilent $6890 \mathrm{GC}$ coupled to an Agilent 5973 MSD in electron ionization (EI) selected ion monitoring (SIM) mode. PAH analysis and quality control procedures are further outlined by Khairy et al. ${ }^{11}$ PAH concentrations were corrected for internal standard recoveries (Table S5) and blank-subtracted using the field blank relevant to the sampling site. If no field blank for the site was available, the average concentration from all available field blanks was used. More information on quality assurance and quality control is in the Supporting Information.

Determination of Sampling Rate and Ambient Concentration. The uptake of HOCs by PEs is described in detail by Lohmann ${ }^{32}$ and PE-air partitioning is detailed by Khairy et al. ${ }^{11}$ To determine ambient PAH concentrations from concentrations in polyethylene, site-specific sampling rates were estimated via a method adapted from Booij et al. ${ }^{33}$ The average air sampling rate was $28 \pm 17 \mathrm{~m}^{3} /$ day and the average aqueous sampling rate was $112 \pm 57 \mathrm{~L} /$ day. For more details, see the Supporting Information and Tables S1 and S2. 
Physico-chemical Parameters. Sampler-matrix partition coefficients used to calculate ambient concentrations for each PAH are listed in Table S7, along with other physico-chemical properties. Temperature-adjusted partition coefficients were obtained using mean temperature during the deployment period for the nearest meteorological buoy or weather station and the modified van't Hoff equation, as in Khairy et al. ${ }^{11}$ The enthalpy of vaporization $\left(\Delta \mathrm{H}_{\mathrm{vap}}\right)$ was used to account for $\mathrm{K}_{\mathrm{PEA}^{-}}$ temperature sensitivity and internal energy of dissolution $\left(\Delta \mathrm{U}_{\mathrm{w}}\right)$ for $\mathrm{K}_{\mathrm{PEW}}$-temperature sensitivity.

Population Analysis. Population data for each sampling site are presented in Table S8. Total population within a circular area with a 1-cell (about $1 \mathrm{~km})$ radius was calculated using the Focal Statistics tool in ArcMap. The process was repeated for larger radii to create a dataset of the total population within $1,2,3,5,10,15,20,25$, 30,40 , and $50 \mathrm{~km}$ of each of the sampling locations. More information about the population dataset is in the Supporting Information.

Air-Water Exchange Rates. The difference between equilibrium concentrations of an HOC in two PEs deployed in different matrices is proportional to the difference in the compound's chemical activity between those two matrices. ${ }^{14,15}$ Air-water exchange gradients can therefore be determined from the ratio of PAH concentrations in PEs deployed simultaneously in air and water, corrected to equilibrium concentrations using PRC loss data. Details of air-water exchange calculations are shown in the Supporting Information. 


\section{RESULTS AND DISCUSSION}

PAHs in Air. Average atmospheric $\Sigma_{15} \mathrm{PAH}$ ranged from $2.1 \mathrm{ng} / \mathrm{m}^{3}$ in Cape Vincent (NY) to $76.4 \mathrm{ng} / \mathrm{m}^{3}$ at George T. Craig air sampling station in downtown Cleveland $(\mathrm{OH})$. The spatial distribution of $\Sigma_{15} \mathrm{PAH}$ is shown in Figure 2-1A. Concentrations of all PAHs during each deployment are detailed in Table S9. Gaseous PAHs were dominated by phenanthrene (28-60\%) and fluorene (6-48\%) (Figure S2-4). Typical concentrations ranged from below the detection limit to $40.3 \mathrm{ng} / \mathrm{m}^{3}$ and $14.6 \mathrm{ng} / \mathrm{m}^{3}$ for phenanthrene and fluorene, respectively. Methylphenanthrenes accounted for 3-5\% of $\Sigma_{15} \mathrm{PAH}$ at the offshore sites and 6-10\% of $\Sigma_{15} \mathrm{PAH}$ at shoreline sites. 4-5-ring PAHs made up no more than $10 \%$ of total PAHs, with PAHs of greater molecular weight than chrysene (high molecular weight (HMW) PAHs) accounting for $<1 \%$ of $\Sigma_{15} \mathrm{PAH}$. Ratios of gaseous Flra/Flra+Pyr were $\geq 0.6$ and $\mathrm{Phn} / \Sigma \mathrm{MPhns}>1$ at all sites, suggesting that gaseous PAHs were primarily combustion-derived. ${ }^{34}$

The two sites in Cleveland consistently displayed the greatest concentrations of gaseous PAHs except retene throughout the deployment season. Retene is often considered to be indicative of wood smoke or pulp/paper mill effluent, as opposed to fossil fuel combustion. ${ }^{35,36}$ Retene was greatest west of Cleveland in Sheffield Lake, but even here accounted for less than $0.7 \%$ of total gaseous PAHs. In contrast, Ruge found retene to be a significant component of gaseous PAH profiles at many sites on Lake Superior. $^{37}$

Principal component analysis (PCA) using the FactoMineR package ${ }^{38}$ in the statistical programming language $\mathrm{R}^{39}$ was employed to visualize similarities and differences between PAH profiles (Figure S2-5). Profiles were similar at all sites with 
the exception of Sheffield Lake, Rochester, and the Cleveland sites, which were clustered separately. The clustering of most sites in the same region of the plot suggests that sources of PAHs were similar across the study region. Profiles in Cleveland may have been distinct due to nearby point sources. In addition to impacts from vehicular emissions associated with heavy traffic in downtown areas, these sites were within $5 \mathrm{~km}$ of a greater number of industrial point sources (primarily chemical manufacturing, petroleum industry, and metalworking facilities) compared to the other sites using the EPA Toxic Release Inventory (TRI). ${ }^{40}$

Comparison with Literature Values. Sun et al. reported mean gaseous concentrations from the 1990s to 2003 of 16 PAHs, 13 of which were measured here. ${ }^{23}$ They reported $7.2 \mathrm{ng} / \mathrm{m}^{3}$ at Sturgeon Point, a semi-urban site south of Buffalo, $1.2 \mathrm{ng} / \mathrm{m}^{3}$ at Point Petre, a northern Lake Ontario site representative of background, and $73.4 \mathrm{ng} / \mathrm{m}^{3}$ in Chicago (IL). ${ }^{23}$ Concentrations of individual PAHs in Cleveland reported here were comparable to those reported by IADN for Chicago. Gaseous PAH profiles showed dominance of phenanthrene and fluorene, as reported here.

PAH concentrations in this study were comparable to those measured by Ruge at urban locations along the shore of Lake Superior. ${ }^{37}$ Melymuk et al. measured a total gaseous PAH concentration of $51 \mathrm{ng} / \mathrm{m}^{3}$ in downtown Toronto (ON), comparable to Cleveland and Rochester concentrations in this study. ${ }^{6}$ Concentrations in this study were lower than those reported for Alexandria, Madrid, or Lake Chaohu, China and greater than concentrations on the Taiwan coast. ${ }^{11,41-43}$ Total (aerosol and dissolved) 2-3-ring PAHs near Lake Victoria, East Africa were lower than 2-3-ring gaseous PAHs in Cleveland, but greater than the remainder of the deployment sites. ${ }^{44}$ 
Gaseous PAHs and Population. Sampling sites were classified as urban, semi-urban, rural, or remote based on population within $3 \mathrm{~km}$ (Table S8). Mean $\Sigma_{15} \mathrm{PAH}$ for each type of site are summarized in Table 1. For both lakes, the greatest concentrations of gaseous PAHs were observed at urban sites. However, $\Sigma_{15} \mathrm{PAH}$ was not significantly different based on site classification using a one-way analysis of variance (ANOVA; $p>0.05$ ). There were no obvious changes in PAH profile composition based on whether the site was urban, semi-urban, rural, or remote (Figure S2-4A).

To explore relationships with population in more detail, population within discrete radii of 1 to $40 \mathrm{~km}$ from each site were compared to average atmospheric PAH concentrations to determine the importance of local versus distant contributions in determining PAH concentrations. Total gaseous PAHs correlated most strongly with population within a $20 \mathrm{~km}$ radius around each site $\left(\mathrm{r}^{2}{ }_{20 \mathrm{~km}}=0.73, \mathrm{p}<0.001, \mathrm{n}=\right.$ 17, $\mathrm{SE}=11.3)$ (Figure 2-2). Significant correlations $\left(0.58<\mathrm{r}^{2}<0.77, \mathrm{p}<0.001\right)$ were observed for all measured PAHs at some radius, with retene exhibiting the weakest correlation $\left(\mathrm{r}^{2}{ }_{1 \mathrm{~km}}=0.30\right.$ at a radius of $\left.1 \mathrm{~km}, \mathrm{p}=0.02, \mathrm{SE}=0.02\right)$. This is most likely due to retene's association with wood smoke, as opposed to fossil fuel combustion. ${ }^{35}$, ${ }^{36}$ Strong correlations suggest that urban centers are a primary source of gaseous PAHs (except retene) in the lower Great Lakes region.

For each PAH, the strength of the correlation between population and concentration varied as we changed the radius used to characterize population at the site (Figure 2-3). All compounds except retene displayed a bimodal relationship, with two radii of maximum correlation. This relationship was less pronounced for the low 
molecular weight (LMW) PAHs than HMW PAHs. Strong similarities between correlation profiles (e.g., the 5-6-ring PAHs) suggest similar sources and affinities for transport.

Hafner and Hites suggested that the significance of local sources in determining Great Lakes HOC concentrations varies based on a compound's atmospheric lifetime. $^{7}$ The atmospheric lifetimes of gaseous PAHs are determined primarily by susceptibility to hydroxyl degradation and gas-particle partitioning. ${ }^{7}$ Anthracene exhibited a distinctly shaped correlation curve with two maxima at radii $25 \mathrm{~km}\left(\mathrm{r}_{25 \mathrm{~km}}^{2}=0.77\right)$ and $5 \mathrm{~km}\left(\mathrm{r}_{5 \mathrm{~km}}^{2}=0.77\right)$ (Figure 2-3). Anthracene has a short lifetime (1.5 hrs) with respect to hydroxyl radical degradation relative to other PAHs, which may explain why stronger correlation is observed at short distances than for other 3-ring PAHs, ${ }^{45,46}$ but this does not explain the comparable correlation at $25 \mathrm{~km}$. Acenaphthylene is expected to have a similar lifetime to anthracene $(1.6 \mathrm{hrs})^{45}$ and exhibited stronger correlations with more local population than fluorene.

Fluorene is often observed to be more stable with respect to photochemical oxidation than similarly-sized PAHs (average lifetime 22 - $26 \mathrm{hrs})^{45,47}$ but more distant sources did not become more significant for this compound due to its longer lifetime. Fluorene correlated less strongly with population than acenaphthylene at all radii, but the divergence was largest at shorter distances.

Gaseous HMW PAHs are expected to have short atmospheric residence times due to reaction with hydroxyl radicals, which may contribute to the increased relevance of local versus long-range sources that was observed for these compounds. ${ }^{7}$ 
These results suggest that reaction with hydroxyl radicals limited the importance of sources distant from sampling sites.

The degree to which a given PAH partitions from gaseous to particulate phase and thus is not detected by PEs depends on the composition and concentration of ambient aerosol as well as temperature and vapor pressure. ${ }^{48-50}$ Sub-cooled liquid vapor pressures $\left(\mathrm{p}_{\mathrm{L}} / \mathrm{Pa}\right)$ for all PAHs (except methylphenanthrenes and retene, for which data was not available) were determined for average deployment temperature $\left(18.6{ }^{\circ} \mathrm{C}\right)$ using empirical regressions from Paasivirta et al. ${ }^{51} \mathrm{Log}\left(\mathrm{p}_{\mathrm{L}} / \mathrm{Pa}\right)$ was plotted against the radius where maximum population-concentration correlation was seen for each compound in Figure S2-6. Excluding anthracene, PAHs with $\mathrm{p}_{\mathrm{L}}>10^{-4} \mathrm{~Pa}$ were most highly correlated with population within a $20 \mathrm{~km}$ radius, while PAHs with $\mathrm{p}_{\mathrm{L}}<$ $10^{-4} \mathrm{~Pa}$ were most highly correlated with population within $3 \mathrm{~km}$. Other studies have observed similar values for $\log \left(\mathrm{p}_{\mathrm{L}}\right)$ at which PAHs transition from being primarily gaseous to particle-bound. ${ }^{26,52,53}$

While S2-6 highlights maximum correlation, many PAHs exhibited significant correlation with population at both $20 \mathrm{~km}$ and $3 \mathrm{~km}$. As shown in Figure 2-4, the relative significance of correlation at $20 \mathrm{~km}$ versus $3 \mathrm{~km}\left(\mathrm{r}^{2}{ }_{20 \mathrm{~km}} / \mathrm{r}^{2}{ }_{3 \mathrm{~km}}\right)$ was significantly correlated with $\log \left(\mathrm{p}_{\mathrm{L}}\right)\left(\mathrm{r}^{2}=0.62, \mathrm{p}<0.005, \mathrm{n}=13, \mathrm{STE}=0.1\right)$, suggesting the existence of two sources of varying importance depending on PAH volatility. The relatively greater importance of local sources in determining concentrations of gaseous HMW PAHs could be due to the partitioning of these compounds to relatively cleaner background aerosols at remote sites as described by Gustafson et al. ${ }^{54}$ Due to their lower vapor pressure, gaseous HMW PAHs are more 
likely than 2-3-ring PAHs to partition into the particulate phase where they will not be measured by PEs and may be deposited more readily via wet or dry deposition. ${ }^{43,55,56}$

Previous studies have reported that coastal areas receiving cleaner air from over water bodies exhibit lower atmospheric PAH concentrations than would be predicted based on surrounding population. ${ }^{57}$ Concentrations of total atmospheric PAHs were lower in Buffalo and Oswego than Cleveland or Rochester, though these sites were classified similarly in terms of population. One explanation is that prevailing westerly winds brought over-lake air towards Buffalo and Oswego, diluting the urban plume. Offshore measurements confirmed that air masses over Lake Erie had relatively lower PAH concentrations than shoreline sites (Table 1).

To further explore this hypothesis, 6-hour HYSPLIT ${ }^{58}$ back trajectories were calculated every 30 hours during the entire deployment period at Cleveland, Buffalo, Rochester, and Oswego using EDAS $40 \mathrm{~km}$ archived meteorology. The number of trajectories arriving from over water versus over land is presented in Table S3. This analysis supports the idea that Oswego's urban plume could be diluted by over-water air masses, but suggests that Buffalo was impacted similarly by over-water and overland air masses.

Another explanation for lower concentrations at Oswego and Buffalo could be the amount or type of industry nearby. EPA TRI ${ }^{40}$ reported 109, 54, and 37 regulated facilities within $20 \mathrm{~km}$ of Cleveland Edgewater, Buffalo, and Rochester, respectively, but there were only 4 within $20 \mathrm{~km}$ of Oswego. However, this does not explain lower PAH concentrations at Buffalo and it is difficult to use TRI data to accurately gauge the volume of relevant emissions near each site. 
PAHs in Water. Average concentrations of $\Sigma_{18} \mathrm{PAH}$ ranged from $2.38 \mathrm{ng} / \mathrm{L}$ off Long Point (Stn 452) to $30.4 \mathrm{ng} / \mathrm{L}$ in Sheffield Lake, directly west of Cleveland (Figure 21B, Table S10). Average dissolved $\Sigma_{18} \mathrm{PAH}$, shown in Table 1, was somewhat greater in Lake Erie than in Lake Ontario when similar sites were compared, but not significantly (one-way ANOVA, $\mathrm{p}>0.05$ ). Dissolved $\Sigma_{18}$ PAH exhibited less spatial variation $(\mathrm{STDEV}=6.3 \mathrm{ng} / \mathrm{L})$ than gaseous $\Sigma_{15 \mathrm{PAH}}\left(\mathrm{STDEV}=19.6 \mathrm{ng} / \mathrm{m}^{3}\right)$.

Aqueous PAHs were dominated by phenanthrene $(8-41 \%$; $<\mathrm{DL}-2.4 \mathrm{ng} / \mathrm{L})$, fluoranthene $(9-37 \%$; $<\mathrm{DL}-8.7 \mathrm{ng} / \mathrm{L})$, and pyrene $(8-31 \%$; $<\mathrm{DL}-8.5 \mathrm{ng} / \mathrm{L})$ (Figure S2-4B). Methylphenanthrenes accounted for $7-11 \%$ of $\Sigma_{18} \mathrm{PAH}$ at offshore sites and $11-35 \%$ of $\Sigma_{18} \mathrm{PAH}$ at shoreline sites. HMW PAHs accounted for $<2 \%$ of $\Sigma_{18} \mathrm{PAH}$ at all sites. Retene accounted for $0.1-2 \% \Sigma_{18} \mathrm{PAH}$ and was greatest in Oswego (NY). The diagnostic ratio $\mathrm{Phn} / \Sigma \mathrm{MPhn}$ ranged from 0.6 at Fairport Harbor and Sheffield Lake to 3.7 at the central and eastern Lake Erie buoy sites. Ratios of Flra/Flra + Pyr were $>0.5$ at all sites except Gibraltar Island (Flra/Flra + Pyr $=0.3$, $\mathrm{Phn} / \Sigma \mathrm{MPhn}=1.2)$ suggesting that dissolved PAHs originated primarily from combustion, with possible contributions from petroleum spills at Gibraltar. ${ }^{14,34}$

PCA results for dissolved PAHs showed locations clustered differently than for gaseous PAH composition, suggesting that source profiles differed for atmospheric and aqueous PAHs. This may be because in addition to atmospheric deposition, runoff and sediment-water exchange contributed to dissolved concentrations. The dissolved PAH profile was most distinct at Sheffield Lake, while Toledo and Buffalo, both expected to be impacted by river discharge, were clustered together (Figure S2$5)$. 
Comparison with Literature Values. Dissolved PAH concentrations were similar to those reported by Ruge for heavily impacted sites on Lake Superior. ${ }^{37}$ Previous work in Lake Michigan reported average total dissolved aqueous PAH concentrations of $9 \mathrm{ng} / \mathrm{L}$ from shipboard measurements, which was similar to the mean dissolved $\Sigma_{18} \mathrm{PAH}$ concentration of all sites in this study $(9.1 \mathrm{ng} / \mathrm{L}){ }^{2}$ Concentrations reported here were generally greater than surface waters of Narragansett Bay (RI) ${ }^{14}$ or the Patapsco River (MD), ${ }^{59}$ though maximum concentrations measured on the Patapsco exceeded maximum concentrations measured here. Concentrations were lower than dissolved PAHs in a freshwater lake in China. ${ }^{43}$ PAH profiles were similar to those reported for Narragansett Bay. ${ }^{14}$

Potential Sources of Dissolved PAHs. Linear correlation with population was not significant $\left(\mathrm{r}^{2}<0.3, \mathrm{p}>0.05\right)$ for dissolved PAHs, with the exception of fluorene $\left(\mathrm{r}^{2}{ }_{15 \mathrm{~km}}=0.36, \mathrm{p}<0.05\right)$, perylene $\left(\mathrm{r}^{2}{ }_{1 \mathrm{~km}}=0.38, \mathrm{p}<0.01\right)$, and retene $\left(\mathrm{r}^{2}{ }_{1 \mathrm{~km}}=0.59, \mathrm{p}<\right.$ 0.001). The explanation for correlations observed for these three compounds is unknown. One possible reason for the weak correlation for most aqueous PAHs is that the two most populated sites in downtown Cleveland were absent from the aqueous dataset. Aqueous sampling near Cleveland was not done at the same sites as air sampling, rather PEs were deployed further from shore.

The lack of strong correlations also suggests that sources other than atmospheric deposition, such as river discharge and wastewater treatment plant (WWTP) effluent, could have been significant in determining dissolved PAH concentrations in surface waters. In addition, longer-term reservoirs that are not representative of current emissions, such as PAHs from sediments or from deeper in 
the water column, could be contributing to surface concentrations so that aqueous concentrations reflect longer term deposition while atmospheric concentrations reflect recent emissions. However, summertime stratification is expected to reduce the importance of these contributions in surface waters.

Concentrations at offshore Lake Erie sites were greatest in the western basin where the lake is shallowest and inputs from the Detroit and Maumee watersheds, both US EPA Areas of Concern (AOCs), were expected to be significant (S2-3A). Due to the central Erie basin's counterclockwise circulation during the study season, ${ }^{20}$ it is unlikely that elevated dissolved PAHs in Sheffield Lake resulted from aqueous transport from Cleveland. Black River, a historically polluted AOC, discharges $8 \mathrm{~km}$ west of the Sheffield Lake site and may have contributed to dissolved PAH concentrations there. More measurements over time are needed to determine whether elevated dissolved PAHs at Sheffield Lake were episodic or chronic. Unexpectedly, concentrations near Cleveland were lower than at Sheffield Lake. This may be because of sampler placement, as PEs at Cleveland were farther offshore where water was deeper and currents carrying more highly impacted water may have been entrained closer to shore.

Besides Sheffield Lake, the greatest dissolved PAHs were measured in Toledo, Buffalo, and Erie. Average dissolved PAH concentrations in Erie sampled from early June to early September were greater $\left(\Sigma_{18} \mathrm{PAH}=11.4 \mathrm{ng} / \mathrm{L}\right)$ and showed a lower percent contribution from LMW PAHs (Figure S2-4) than other rural sites, possibly due to contributions from contaminated sediments or WWTP effluent. The Erie site was within the recently delisted Presque Isle Bay AOC, which was dredged for the 
first time in 20 years during summer of 2011, possibly releasing elevated

concentrations of PAHs into the water column. ${ }^{15,60,61}$ The greatest concentrations were seen during the second deployment, which took place in early fall $\left(\Sigma_{18} \mathrm{PAH}=15.6\right.$ ng/L), perhaps due to the weakening of summertime stratification. The site was also within $5 \mathrm{~km}$ of a major ( 150 million L/day) WWTP (Figure S2-3A).

Air-Water Exchange. Mass transfer coefficients and flux gradients are listed in Tables S11 and S12 and flux gradients for select PAHs are presented in Figure S2-9. Mass transfer velocity ranged from $0.2 \mathrm{~cm} /$ day to $73 \mathrm{~cm} /$ day and values decreased with decreasing volatility. Uncertainty in flux gradients was $<30 \%$ for all compounds with lower molecular weight than benz(a)anthracene except retene. Flux gradients for HMW PAHs were not different from equilibrium within the $95 \%$ confidence level.

Net flux rates (ng/ $\mathrm{m}^{2} /$ day) are provided in Table S13. Patterns in flux direction were similar to those reported by Bamford et al. in that LMW PAHs were volatilizing and phenanthrene was being absorbed, but less volatilization was seen here than in Patapsco River and depositional fluxes of phenanthrene in our study were greater on average. ${ }^{59}$ Fluxes for acenaphthylene, phenanthrene, methylphenanthrenes, and pyrene at each site were summarized in Figure 2-5 over three time periods: April June, June - August, and August - November.

Acenaphthylene volatilized from surface waters during most deployments, with volatilization fluxes ranging from $19.3 \mathrm{ng} / \mathrm{m}^{2} /$ day in Niagara to $363 \mathrm{ng} / \mathrm{m}^{2} /$ day in Erie. Phenanthrene was absorbed at all sites with the exception of Niagara during the second deployment, where a volatilization flux of $236 \mathrm{ng} / \mathrm{m}^{2} /$ day was measured. Phenanthrene deposition fluxes ranged from $237 \mathrm{ng} / \mathrm{m}^{2} /$ day at Cape Vincent in early 
fall to $3271 \mathrm{ng} / \mathrm{m}^{2} /$ day at Dunkirk in summer. This suggests that during the study period the lakes were primarily a source of acenaphthylene to the atmosphere, while the atmosphere was a source of dissolved phenanthrene to the lakes. However, dissolved phenanthrene concentrations in air and water were not significantly correlated, suggesting that diffusive exchange was not the only mechanism influencing aqueous phenanthrene concentrations. Blanchard et al. estimated annual net absorption of phenanthrene for Lake Erie and Lake Ontario to be $1020 \mathrm{ng} / \mathrm{m}^{2} /$ day and $310 \mathrm{ng} / \mathrm{m}^{2} /$ day, respectively, in $2005 .^{24}$

The greatest depositional fluxes were measured at Dunkirk and Grimsby, particularly during June - August. Though average temperatures during deployment were warm $\left(17.0-21.4{ }^{\circ} \mathrm{C}\right)$, all PAHs except acenaphthylene were absorbed at these sites. Deposition at Grimsby suggests that the Toronto/Hamilton conurbation acted as a source of dissolved PAHs to the open water. Deposition at Dunkirk was driven by the greater gaseous PAH concentrations at this site and clean surface waters.

At Erie, Niagara, Sheffield, and Buffalo (second deployment only), the majority of PAHs were volatilizing. Erie and Sheffield exhibited the strongest volatilization, driven by elevated aqueous concentrations. The greatest volatilization fluxes measured at the two sites were for fluoranthene $\left(927 \mathrm{ng} / \mathrm{m}^{2} /\right.$ day at Erie, 879 $\mathrm{ng} / \mathrm{m}^{2} /$ day at Sheffield Lake) and pyrene $\left(591 \mathrm{ng} / \mathrm{m}^{2} /\right.$ day at Erie, $857 \mathrm{ng} / \mathrm{m}^{2} /$ day at Sheffield Lake). Volatilization was comparable at the two sites, though anthracene and benz(a)anthracene volatilized more strongly at Sheffield Lake. Lohmann et al. observed volatilization of PAHs in an urbanized portion of Narragansett Bay and suggested that river input and runoff were more significant sources of dissolved PAHs 
than atmospheric deposition. ${ }^{14}$ Volatilization at Niagara may indicate that river discharge was a significant source of PAHs at this site.

Air-water exchange is strongly influenced by air temperature, wind speed, and wind direction and large daily variations in fluxes have been observed. ${ }^{59}$ During deployments where mean temperature was greater than $19^{\circ} \mathrm{C}$, phenanthrene and anthracene were the only PAHs being absorbed into surface waters, with the exception

of measurements from Oswego ( $3^{\text {rd }}$ deployment) as well as Dunkirk. In Buffalo, most PAH fluxes changed from net deposition during the first deployment (mean temperature of $11^{\circ} \mathrm{C}$ ) to net volatilization during the second deployment (mean temperature $19-20.5^{\circ} \mathrm{C}$ ). During the third deployment, most fluxes were not significantly different from equilibrium. In Oswego, the temperature dependency observed in Buffalo was not evident.

\section{IMPLICATIONS}

Strong correlation with population suggests that urban centers played an important role in determining spatial distributions of gaseous PAHs. However, airwater fluxes and distributions of dissolved PAHs implied that additional sources beyond diffusive exchange influenced aqueous distributions, especially in urban areas. In some cases surface waters acted as a source of PAHs to the atmosphere. Enhanced spatial coverage near AOCs and major urban areas like Toronto, as well as consistent temporal coverage, could help explain how river discharge, sediment-water exchange, WWTP effluent, and other sources influence dissolved PAH concentrations in the lower Great Lakes. 


\section{ASSOCIATED CONTENT}

Supporting Information. Detailed information on sampler deployments, site characteristics, compound properties, and boundary layer thickness is available in the SI. This material is available free of charge via the Internet at http://pubs.acs.org.

\section{AUTHOR INFORMATION}

Corresponding Author. Rainer Lohmann

Author Contributions. The manuscript was written through contributions of all authors. All authors have given approval to the final version of the manuscript.

\section{ACKNOWLEDGMENTS}

We would like to acknowledge funding from the US EPA Great Lakes Restoration Initiative GLAS \#00E00597-0, project officer Todd Nettesheim. We would like to thank Peter August (URI) for assistance with GIS, David Adelman (URI) for organizing deployments, Camilla Teixeira and the field staff of the Emergencies, Operational Analytical Laboratories, and Research Support group (Environment Canada Burlington) for open-lake deployments, Zoe Ruge (URI) for assistance with data analysis and interpretation, Ali Brandeis (URI) for laboratory work, and all of the volunteers who deployed PEs in the region. 


\section{LITERATURE CITED}

(1) Brown, A. S.; Brown, R. J. C. Correlations in polycyclic aromatic hydrocarbon (PAH) concentrations in UK ambient air and implications for source apportionment. J. Environ. Monit. 2012, 14, 2072-2082, DOI:10.1039/c2em10963h.

(2) Simcik, M. F.; Eisenreich, S. J.; Lioy, P. J. Source apportionment and source/sink relationships of PAHs in the coastal atmosphere of Chicago and Lake Michigan. Atmos. Environ. 1999, 33, 5071-5079, DOI:10.1016/S13522310(99)00233-2.

(3) Shen, H.; Huang, Y.; Wang, R.; Zhu, D.; Li, W.; Shen, G.; Wang, B.; Zhang, Y.; Chen, Y.; Lu, Y.; Chen, H.; Li, T.; Sun, K.; Li, B.; Liu, W.; Liu, J. Global atmospheric emissions of polycyclic aromatic hydrocarbons from 1960 to 2008 and future predictions. Environ. Sci. Technol. 2013, 47, 6415-6424, DOI:10.1021/es400857z.

(4) Melymuk, L.; Robson, M.; Helm, P. A.; Diamond, M. L. Application of land use regression to identify sources and assess spatial variation in urban SVOC concentrations. Environ. Sci. Technol. 2013, 47, 1887-1895, DOI:10.1021/es3043609.

(5) Galarneau, E.; Makar, P. A.; Sassi, M.; Diamond, M. L. Estimation of atmospheric emissions of six semivolatile polycyclic aromatic hydrocarbons in southern canada and the United States by use of an emissions processing system. Environ. Sci. Technol. 2007, 41, 4205-4213, DOI:10.1021/es062303k.

(6) Melymuk, L.; Robson, M.; Helm, P. A.; Diamond, M. L. PCBs, PBDEs, and PAHs in Toronto air: spatial and seasonal trends and implications for contaminant transport. Sci. Total Environ. 2012, 429, 272-280, DOI:10.1016/j.scitotenv.2012.04.022.

(7) Hafner, W.; Hites, R. Potential sources of pesticides, PCBs, and PAHs to the atmosphere of the Great Lakes. Environ. Sci. Technol. 2003, 37, 3764-3773, DOI:10.1021/es034021f.

(8) Grimmer, G.; Brune, H.; Dettbarn, G.; Jacob, J.; Misfeld, J.; Mohr, U.; Naujack, K.-W.; Timm, J.; Wenzel-Hartung, R. Relevance of polycyclic aromatic hydrocarbons as environmental carcinogens. Fresenius J. Anal. Chem. 1991, 339, 792-795, DOI:10.1007/BF00321747. 
(9) Boström, C.-E.; Gerde, P.; Hanberg, A.; Jernström, B.; Johansson, C.; Kyrklund, T.; Rannug, A.; Törnqvist, M.; Victorin, K.; Westerholm, R. Cancer risk assessment, indicators, and guidelines for polycyclic aromatic hydrocarbons in the ambient air. Environ. Health Perspect. 2002, 110, 451488. DOI: 10.1289/ehp.02110s3451.

(10) Adams, R. G.; Lohmann, R.; Fernandez, L. A.; Macfarlane, J. K.; Gschwend, P. M. Polyethylene devices :Passive samplers for measuring dissolved hydrophobic organic compounds in aquatic environments. Environ. Sci. Technol. 2007, 41, 1317-1323, DOI:10.1021/es0621593.

(11) Khairy, M. A.; Lohmann, R. Field validation of polyethylene passive air samplers for parent and alkylated PAHs in Alexandria, Egypt. Environ. Sci. Technol. 2012, 46, 3990-3998, DOI:10.1021/es300012u.

(12) Allan, I. J.; Harman, C.; Ranneklev, S. B.; Thomas, K. V; Grung, M. Passive sampling for target and nontarget analyses of moderately polar and nonpolar substances in water. Environ. Toxicol. Chem. 2013, 32, 1718-1726, DOI:10.1002/etc.2260.

(13) Sacks, V. P.; Lohmann, R. Freely dissolved PBDEs in water and porewater of an urban estuary. Environ. Pollut. 2012, 162, 287-293, DOI:10.1016/j.envpol.2011.11.028.

(14) Lohmann, R.; Dapsis, M.; Morgan, E. J.; Dekany, V.; Luey, P. J. Determining air-water exchange, spatial and temporal trends of freely dissolved PAHs in an urban estuary using passive polyethylene samplers. Environ. Sci. Technol. 2011, 45, 2655-2662, DOI:10.1021/es1025883.

(15) Morgan, E. J.; Lohmann, R. Detecting air-water and surface-deep water gradients of PCBs using polyethylene passive samplers. Environ. Sci. Technol. 2008, 42, 7248-7253, DOI:10.1021/es800518g.

(16) Lohmann, R.; Klánová, J.; Kukucka, P.; Yonis, S.; Bollinger, K. Concentrations, fluxes, and residence time of PBDEs across the tropical Atlantic Ocean. Environ. Sci. Technol. 2013, 47, 13967-13975, DOI:10.1021/es403494b.

(17) Quinn, F. H. Hydraulic residence times for the Laurentian Great Lakes. J. Gt. Lakes Res. 1992, 18, 22-28, DOI:10.1016/S0380-1330(92)71271-4.

(18) NY Sea Grant; Domske, H. M. "Lake Erie Factsheet" http://www.seagrant.sunysb.edu/Images/Uploads/PDFs/LakeErieFactSheet0413 .pdf (accessed Feb 13, 2014). 
(19) Environment Canada; US EPA. The Great Lakes: An environmental atlas and resource book, 3rd ed. http://www.epa.gov/glnpo/atlas/ (accessed Feb 13, 2014).

(20) Beletsky, D.; Saylor, J. H.; Schwab, D. J. Mean circulation in the Great Lakes. J. Great Lakes Res. 1999, 25, 78-93, DOI:10.1016/S0380-1330(99)70718-5.

(21) Salamova, A.; Pagano, J. J.; Holsen, T. M.; Hites, R. A. Post-1990 Temporal trends of PCBs and organochlorine pesticides in the atmosphere and in fish from Lakes Erie, Michigan, and Superior. Environ. Sci. Technol. 2013, 47, 9109-9114, DOI:10.1021/es401895g.

(22) Melymuk, L.; Robson, M.; Csiszar, S. A.; Helm, P. A.; Kaltenecker, G.; Backus, S.; Bradley, L.; Gilbert, B.; Blanchard, P.; Jantunen, L. M.; Diamond, M. L. From the city to the lake: Loadings of PCBs, PBDEs, PAHs and PCMs from Toronto to Lake Ontario. Environ. Sci. Technol. 2014, 48, 3732-3741, DOI:10.1021/es403209z.

(23) Sun, P.; Blanchard, P.; Brice, K. A.; Hites, R. A. Trends in polycyclic aromatic hydrocarbon concentrations in the Great Lakes atmosphere. Environ. Sci.

Technol. 2006, 40, 6221-6227, DOI:10.1021/es0607279.

(24) Blanchard, P.; Audette, C. V.; Hulting, M. L.; Basu, I.; Brice, K. A.; Backus, S. M.; Dryfhout-Clark, H.; Froude, F.; Hites, R. A.; Neilson, M.; Wu, R. Atmospheric deposition of toxic substances to the Great Lakes: IADN results through 2005, Published by Environment Canada and the United States Environmental Protection Agency, 2005.

(25) Swackhamer, D. L.; Schottler, S.; Pearson, R. F. Air-water exchange and mass balance of toxaphene in the Great Lakes. Environ. Sci. Technol. 1999, 33, 3864-3872, DOI:10.1021/es990280m.

(26) Baker, J. E.; Eisenreich, S. J. Concentrations and fluxes of polycyclic aromatic hydrocarbons and polychlorinated biphenyls across the air-water interface of Lake Superior. Environ. Sci. Technol. 1990, 24, 342-352, DOI:10.1021/es00073a009.

(27) Booij, K.; Smedes, F.; van Weerlee, E. M. Spiking of performance reference compounds in low density polyethylene and silicone passive water samplers. Chemosphere 2002, 46, 1157-1161, DOI:10.1016/S0045-6535(01)00200-4.

(28) NOAA National Data Buoy Center Historical Archive http://www.ndbc.noaa.gov/hmd.shtml (accessed Dec 15, 2013).

(29) Minar, N. Wind History http://windhistory.com/ (accessed Dec 15, 2013). 
(30) Csiszar, S. A; Diamond, M. L.; Daggupaty, S. M. The magnitude and spatial range of current-use urban PCB and PBDE emissions estimated using a coupled multimedia and air transport model. Environ. Sci. Technol. 2014, 48, 10751083, DOI:10.1021/es403080t.

(31) NOAA. NOAA National Climatic Data Center http://www.ncdc.noaa.gov/ (accessed Feb 1, 2014).

(32) Lohmann, R. Critical review of low-density polyethylene's partitioning and diffusion coefficients for trace organic contaminants and implications for its use as a passive sampler. Environ. Sci. Technol. 2012, 46, 606-618, DOI:10.1021/es202702y.

(33) Booij, K.; Smedes, F. An improved method for estimating in situ sampling rates of nonpolar passive samplers. Environ. Sci. Technol. 2010, 44, 6789-6794, DOI:10.1021/es101321v.

(34) Yunker, M. B.; Macdonald, R. W.; Vingarzan, R.; Mitchell, R. H.; Goyette, D.; Sylvestre, S. PAHs in the Fraser River basin: A critical appraisal of PAH ratios as indicators of PAH source and composition. Org. Geochem. 2002, 33, 489515, DOI:10.1016/S0146-6380(02)00002-5.

(35) Ramdahl, T. Retene - a molecular marker of wood combustion in ambient air. Nature 1983, 306, 580-582, DOI:10.1038/306580a0.

(36) Leppanen, H.; Oikari, A. Occurrence of retene and resin acids in sediments and fish bile from a lake receiving pulp and paper mill effluents. Environ. Toxicol. Chem 1999, 18, 1498-1505, DOI:10.1002/etc.5620180723.

(37) Ruge, Z. Air-water exchange and trends of persistent bioaccumulative toxics (PBTs) across Lake Superior. Master's Thesis, University of Rhode Island, 2013.

(38) Husson, F.; Josse, J.; Le, S.; Mazet, J. FactoMineR http://factominer.free.fr (accessed Jan 2, 2014).

(39) R Core Team. R: A language and environment for statistical computing (version 3.1.0), 2014.

(40) US EPA. TRI NET http://www.epa.gov/tri/tridotnet/index.html (accessed Jan 11, 2013).

(41) Cheng, J.-O.; Ko, F.-C.; Lee, C.-L.; Fang, M.-D. Air-water exchange fluxes of polycyclic aromatic hydrocarbons in the tropical coast, Taiwan. Chemosphere 2012, 90, 2614-2622, DOI:10.1016/j.chemosphere.2012.11.020. 
(42) Barrado, A. I.; García, S.; Sevillano, M. L.; Rodríguez, J. A.; Barrado, E. Vapor-phase concentrations of PAHs and their derivatives determined in a large city: Correlations with their atmospheric aerosol concentrations. Chemosphere 2013, 93, 1-7, DOI:10.1016/j.chemosphere.2013.05.031.

(43) Qin, N.; He, W.; Kong, X.-Z.; Liu, W.-X.; He, Q.-S.; Yang, B.; Ouyang, H.-L.; Wang, Q.-M.; Xu, F.-L. Atmospheric partitioning and the air-water exchange of polycyclic aromatic hydrocarbons in a large shallow Chinese lake (Lake Chaohu). Chemosphere 2013, 93, 1685-1693, DOI:10.1016/j.chemosphere.2013.05.038.

(44) Arinaitwe, K.; Kiremire, B. T.; Muir, D. C. G.; Fellin, P.; Li, H.; Teixeira, C.; Mubiru, D. N. Atmospheric concentrations of polycyclic aromatic hydrocarbons in the watershed of Lake Victoria, East Africa. Environ. Sci. Technol. 2012, 46, 11524-11531, DOI:10.1021/es302238w.

(45) Atkinson, R.; Arey, J. Atmospheric chemistry of gas-phase polycyclic aromatic hydrocarbons: formation of atmospheric mutagens. Environ. Health Perspect. 1994, 102, 117-126, DOI:10.2307/3431940.

(46) Bunce, N. J.; Dryfhout, H. G. Diurnal and seasonal modeling of the tropospheric half-lives of polycyclic aromatic hydrocarbons. Can. J. Chem 1992, 70, 1966-1970, DOI:10.1139/v92-246.

(47) Brubaker, W. W.; Hites, R. A. OH Reaction kinetics of polycyclic aromatic hydrocarbons and polychlorinated dibenzo-p-dioxins and dibenzofurans. $J$. Phys. Chem. A. 1998, 102, 915-921, DOI:10.1021/jp9721199.

(48) Galarneau, E.; Bidleman, T. F.; Blanchard, P. Seasonality and interspecies differences in particle/gas partitioning of PAHs observed by the Integrated Atmospheric Deposition Network (IADN). Atmos. Environ. 2006, 40, 182-197, DOI:10.1016/j.atmosenv.2005.09.034.

(49) Offenberg, J. H.; Baker, J. E. The influence of aerosol size and organic carbon content on gas/particle partitioning of polycyclic aromatic hydrocarbons (PAHs). Atmos. Environ. 2002, 36, 1205-1220, DOI:10.1016/S13522310(01)00427-7.

(50) Simcik, M. F. Gas-particle partitioning of PCBs and PAHs in the Chicago urban and adjacent coastal atmosphere: States of equilibrium. Environ. Sci. Technol. 1998, 32, 251-257, DOI:10.1021/es970557n.

(51) Paasivirta, J.; Sinkkonen, S.; Mikkelson, P.; Rantio, T.; Wania, F. Estimation of vapor pressures, solubilities, and Henry's Law constants of selected persistent organic pollutants as functions of temperature. Chemosphere 1999, 39, 811832, DOI:10.1016/S0045-6535(99)00016-8. 
(52) Lohmann, R.; Harner, T.; Thomas, G. O.; Jones, K. C. A comparative study of the gas-particle partitioning of PCDD/Fs, PCBs, and PAHs. Environ. Sci.

Technol. 2000, 34, 4943-4951, DOI:10.1021/es9913232.

(53) Su, Y.; Lei, Y. D.; Wania, F.; Shoeib, M.; Harner, T. Regressing gas/particle partitioning data for polycyclic aromatic hydrocarbons. Environ. Sci. Technol. 2006, 40, 3558-3564, DOI:10.1021/es052496w.

(54) Gustafson, K. E.; Dickhut, R. M. Particle/gas concentrations and distributions of PAHs in the atmosphere of southern Chesapeake. Environ. Sci. Technol. 1997, 31, 140-147, DOI:10.1021/es9602197.

(55) Bidleman, T. F. Atmospheric processes - Wet and dry deposition. Environ. Sci. Technol. 1988, 22, 361-367, DOI:10.1021/es00169a002.

(56) Akyüz, M.; Çabuk, H. Gas-particle partitioning and seasonal variation of polycyclic aromatic hydrocarbons in the atmosphere of Zonguldak, Turkey. Sci. Total Environ. 2010, 408, 5550-5558, DOI:10.1016/j.scitotenv.2010.07.063.

(57) Hafner, W.; Carlson, D.; Hites, R. Influence of local human population on atmospheric polycyclic aromatic hydrocarbon concentrations. Environ. Sci. Technol. 2005, 39, 7374-7379, DOI:10.1021/es0508673.

(58) Draxler, R. R.; Rolph, G. D. HYSPLIT (HYbrid Single-Particle Lagrangian Integrated Trajectory) model access via NOAA ARL READY Website (http://www.arl.noaa.gov/HYSPLIT.php) (accessed Jun 9, 2014).

(59) Bamford, H. A.; Offenberg, J. H.; Larsen, R. K.; Ko, F.; Baker, J. E. Diffusive exchange of polycyclic aromatic hydrocarbons across the air-water interface of the Patapsco River, an urbanized subestuary of the Chesapeake Bay. Environ. Sci. Technol. 1999, 33, 2138-2144, DOI:10.1021/es981324e.

(60) US EPA. Great Lakes Areas of Concern http://www.epa.gov/glnpo/aoc/ (accessed Nov 2, 2014).

(61) Martin, J. "Dredging barge goes to work in Presque Isle Bay", Erie Times News http://www.goerie.com (accessed Dec 3, 2013). 


\section{TABLES AND FIGURES}

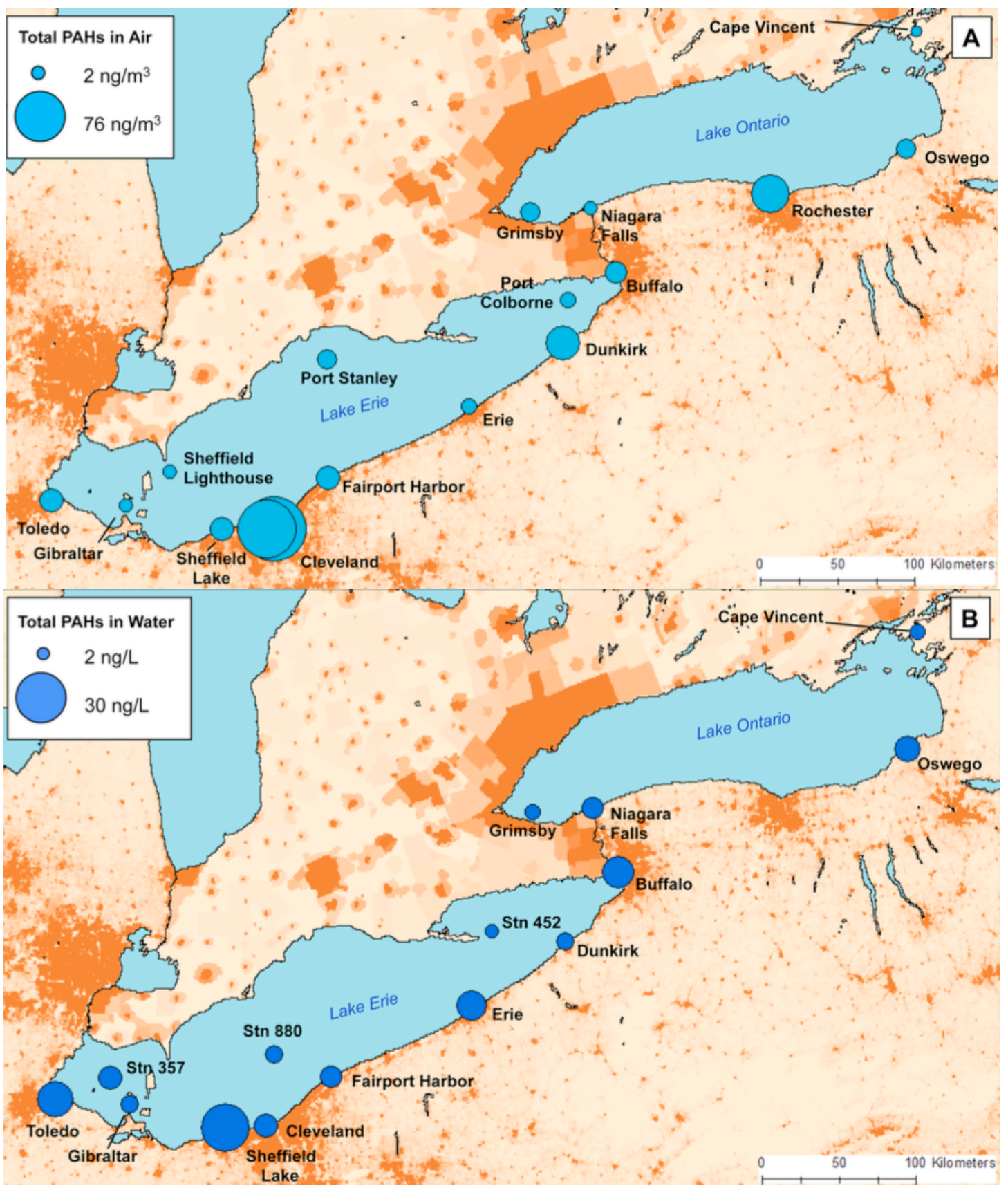

Figure 2-1. Average gaseous $\Sigma_{15} \mathrm{PAH}(\mathrm{A})$ and dissolved $\Sigma_{18} \mathrm{PAH}(\mathrm{B})$ in Lake Erie and Lake Ontario. Orange shading delineates population centers. 


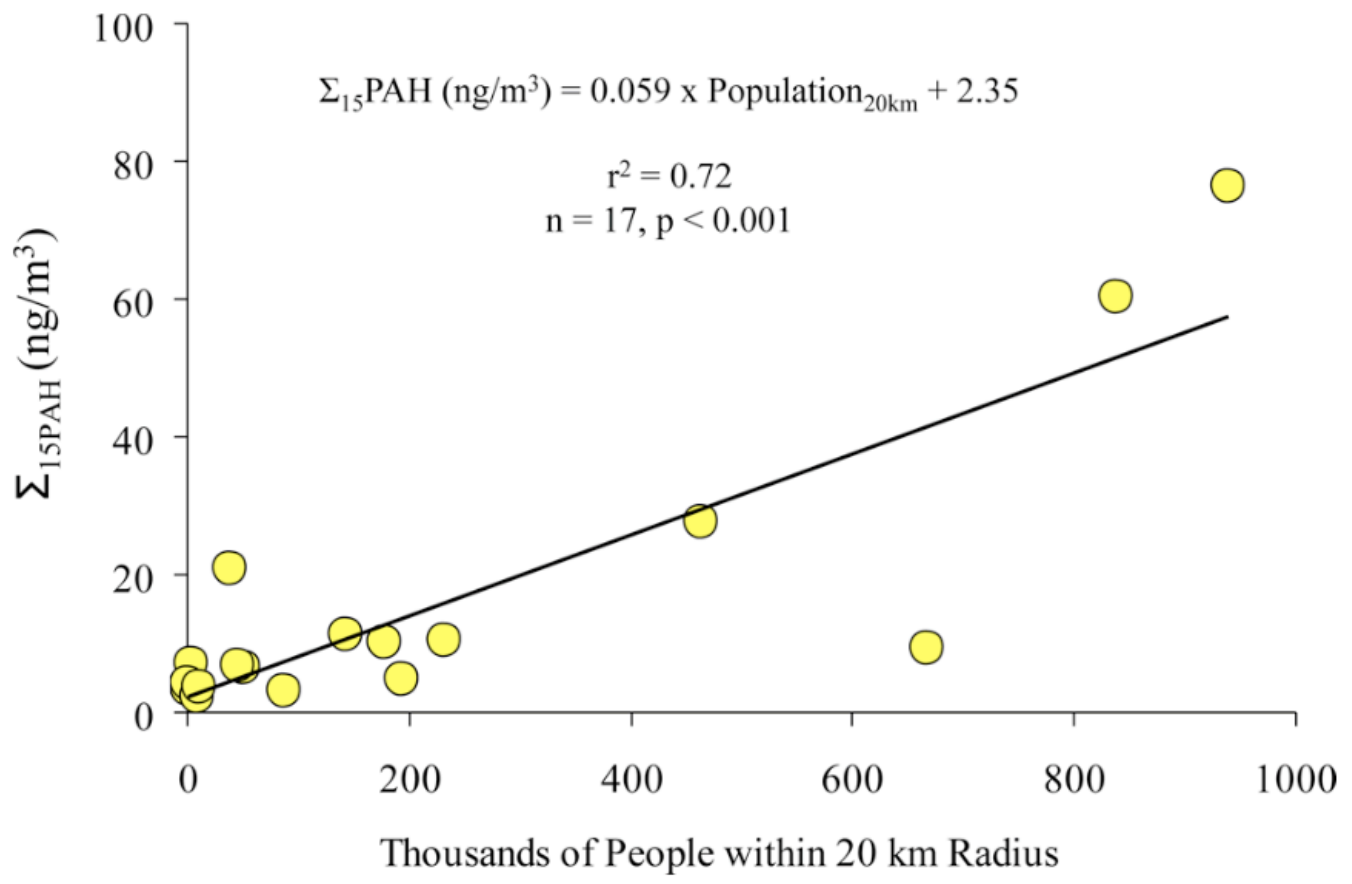

Figure 2-2. Average atmospheric concentrations of gaseous PAHs at each site correlated well with population within $20 \mathrm{~km}$. The two sites in downtown Cleveland exhibited the greatest $\Sigma_{15} \mathrm{PAH}$ concentrations while concentrations in Buffalo were lower than would be predicted by the regression. 


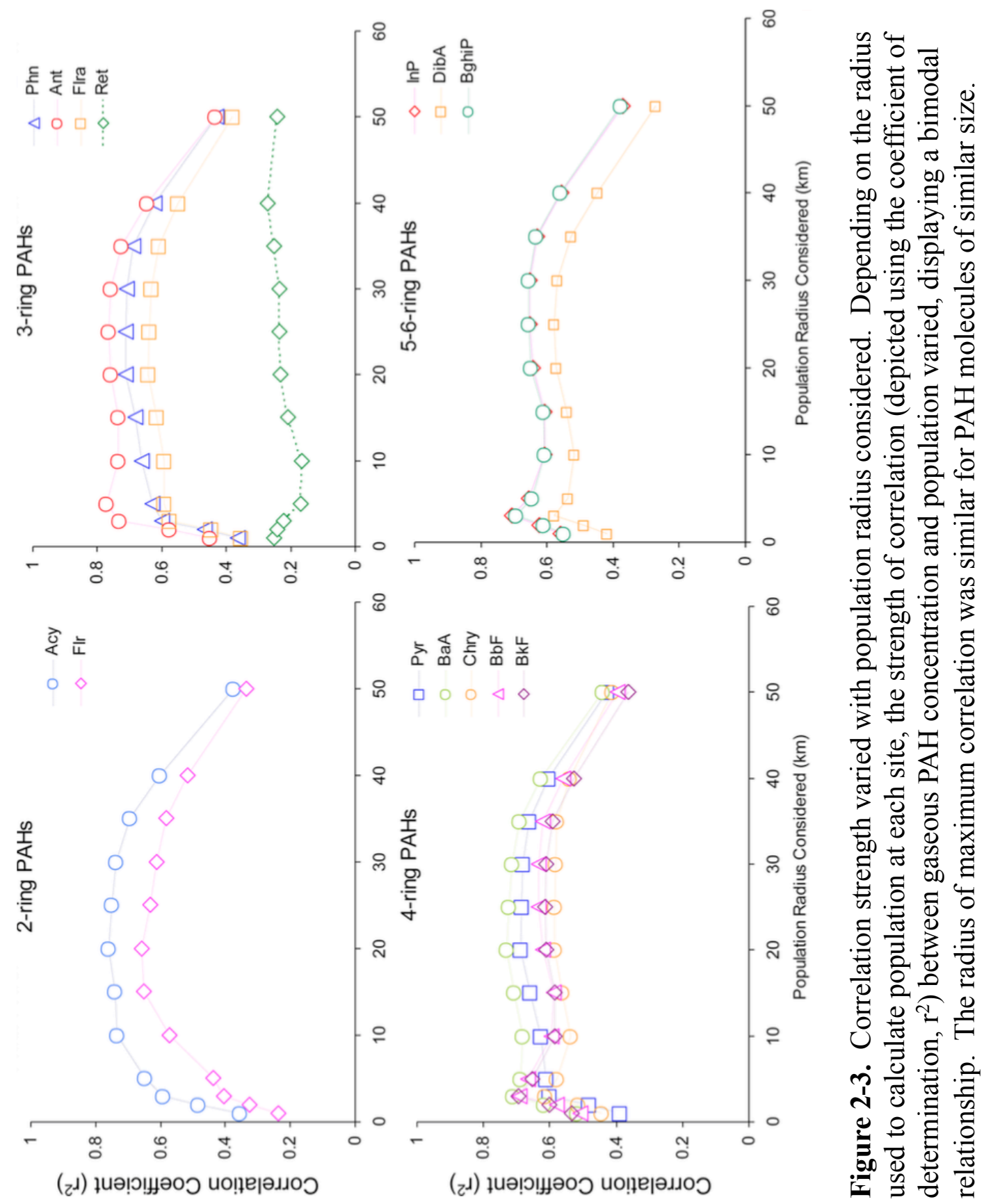




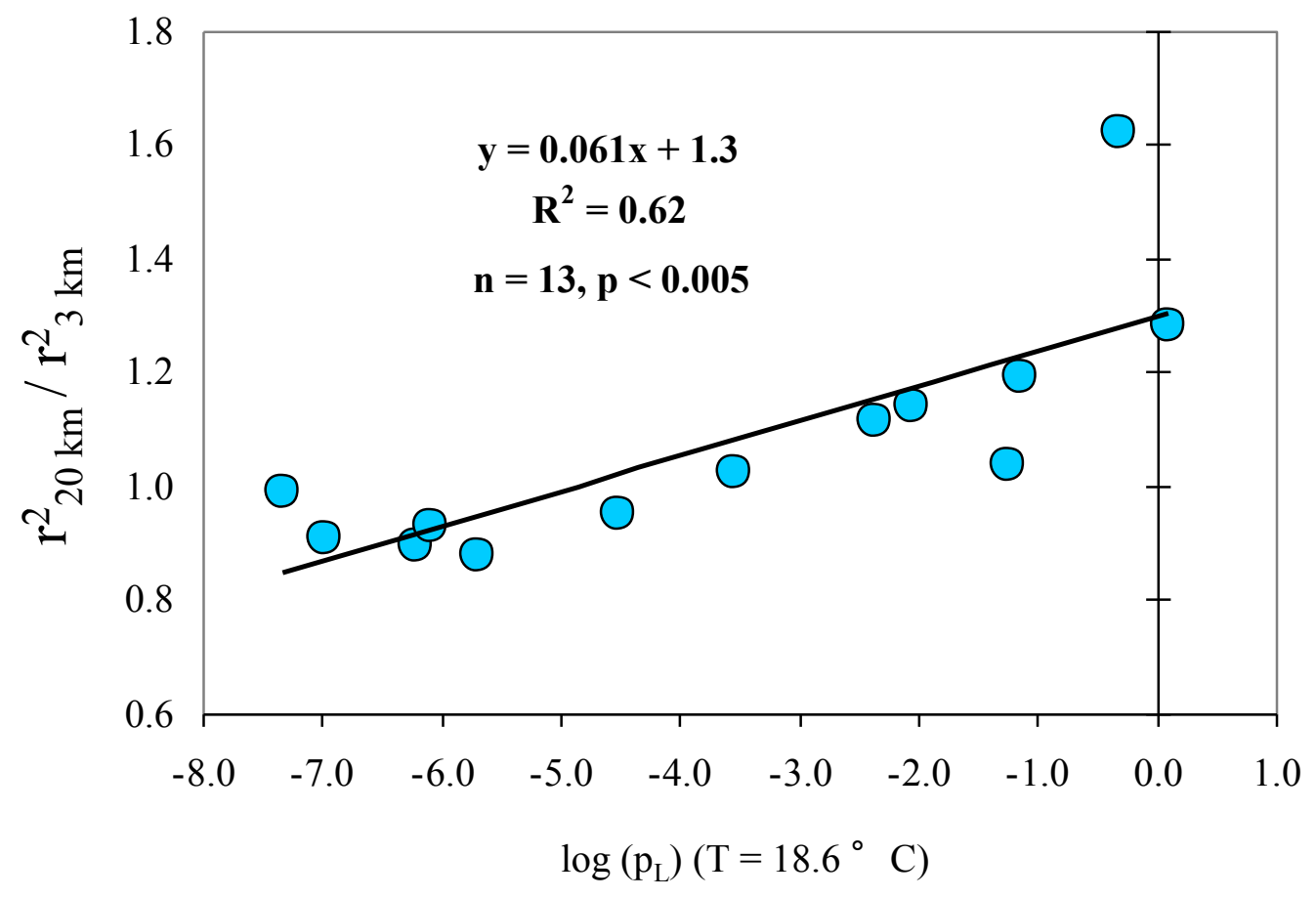

Figure 2-4. Relative significance of population within $20 \mathrm{~km}$ and $3 \mathrm{~km}$. The ratio of $\mathrm{r}_{20 \mathrm{~km}}^{2}$ to $\mathrm{r}_{3 \mathrm{~km}}$ correlated well with sub-cooled liquid vapor pressure at mean deployment temperature, suggesting that distant sources were more significant for volatile PAHs. 


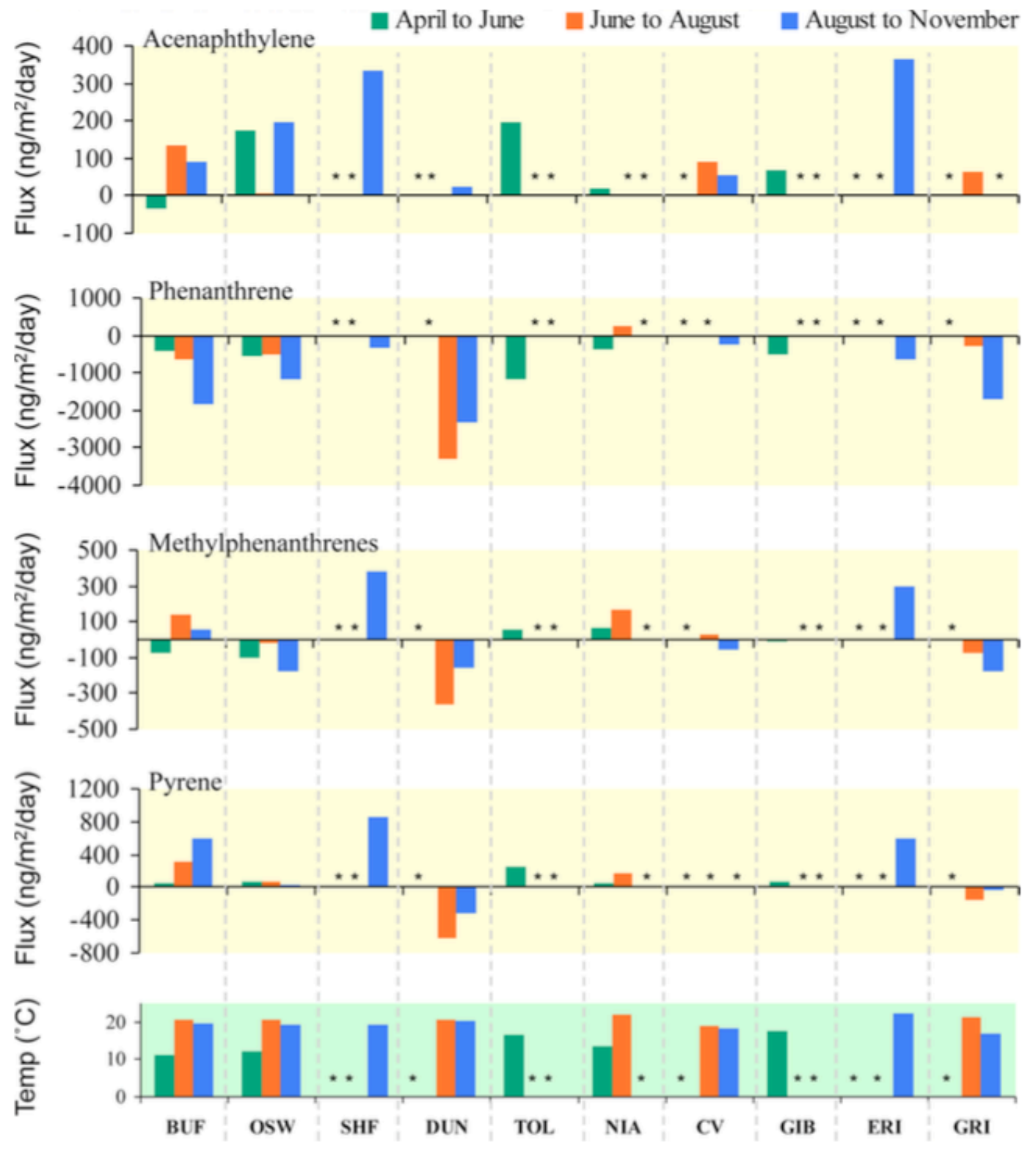

Figure 2-5. Net air-water flux of four PAHs. Air-water fluxes $\left(\mathrm{ng} / \mathrm{m}^{2} /\right.$ day) for four PAHs during three deployment periods with mean air temperature at the bottom. Negative values indicate absorption into surface waters and positive values indicate volatilization. Sites where no data was available or air and water concentrations were both $<$ DL are marked with *. 


\begin{tabular}{|l|c|c|c|c|c|c|c|c|c|c|c|c|}
\hline & \multicolumn{4}{|c|}{ ATMOSPHERIC PAHs $\left(\mathrm{ng} / \mathrm{m}^{3}\right)$} & \multicolumn{4}{c|}{ AQUEOUS PAHS (ng/L) } \\
\hline & \multicolumn{3}{|c|}{ Lake Erie } & \multicolumn{2}{|c|}{ Lake Ontario } & \multicolumn{3}{c|}{ Lake Erie } & \multicolumn{3}{c|}{ Lake Ontario } \\
\hline & $\mathbf{n}$ & PAH & STDEV & $\mathbf{n}$ & PAH & STDEV & $\mathbf{n}$ & PAH & STDEV & $\mathbf{n}$ & PAH & STDEV \\
\hline Offshore & 3 & 4.7 & 1.7 & 1 & 6.0 & NA & 3 & 4.2 & 2.3 & 1 & 3.1 & NA \\
\hline Rural & 2 & 3.9 & 0.7 & 1 & 2.0 & NA & 2 & 6.7 & 4.4 & 1 & 2.7 & NA \\
\hline Semi-Urban & 4 & 12.2 & 5.0 & 1 & 2.8 & NA & 4 & 12.7 & 10.4 & 1 & 5.9 & NA \\
\hline Urban & 3 & 45.4 & 32.6 & 2 & 15.8 & 13.8 & 2 & 9.1 & 4.2 & 1 & 7.9 & NA \\
\hline
\end{tabular}

Table 2-1. Average gaseous and dissolved PAH concentrations in Lake Erie and Lake Ontario. The number of sites within each category (n) is listed along with mean PAH concentrations and standard deviation. Sites were classified based on population within $3 \mathrm{~km}$ to facilitate comparison between lakes: 0-100 people: Offshore; 1001000: Rural; 1000-10,000: Semi-urban; >10,000: Urban. 


\title{
SUPPORTING INFORMATION:
}

\section{SIGNIFICANCE OF POPULATION CENTERS AS SOURCES OF GASEOUS AND DISSOLVED PAHS IN THE LOWER GREAT LAKES}

\author{
Carrie A. McDonough, Mohammed Khairy, Derek C. G. Muir, Rainer Lohmann \\ Total number of pages: 35 \\ Total number of tables: 13 \\ Total number of figures: 9
}

Meteorological Information and Site Characteristics. Meteorological information from the National Oceanic and Atmospheric Administration (NOAA) National Data Buoy Center (NDBC) ${ }^{1}$ for the buoy nearest to each site is provided in Tables S1 and S2. Temperature varied little between locations and was colder during April - June deployments (mean temperature $14 \pm 3.3^{\circ} \mathrm{C}$ ) than during June - August deployments $\left(22 \pm 0.9^{\circ} \mathrm{C}\right)$ or August - October deployments $\left(19 \pm 0.5^{\circ} \mathrm{C}\right)$. Surface water temperatures from the NDBC were used when available, but if only air temperatures were provided, they were used for calculations for both air and water samplers. Wind roses built for April to October from 2006-2010 historical NOAA wind data showed westerly prevailing winds during the sampling campaign for most of the study region (Figure S2-2). ${ }^{2}$

Data from NOAA's National Climatic Data Center (NCDC) for all locations showed that precipitation was lowest during June and July while similar levels were reported in late spring and early fall. ${ }^{3}$ River discharge was generally highest during early spring and tapered off during mid-summer and early fall. ${ }^{4}$ Additional regional features that were taken into account, including wastewater treatment plants (WWTPs) 
and Areas of Concern (AOCs) designated by Environment Canada and the EPA are detailed in Figure S2-3 along with mean circulation patterns. Locations expected to be impacted by major rivers are listed in Table S4. WWTPs and rivers channel larger urbanized watersheds into point sources and have previously been identified as a significant source of HOCs to Great Lakes surface waters. ${ }^{5,6}$

Population Analysis. Population analyses were carried out using a 30-arc second (1$\mathrm{km}$ ) gridded raster population dataset from the Global Rural-Urban Mapping Project, v1 (GRUMPv1) provided for free online by Columbia University's Center for International Earth Science Information Network (CIESIN). ${ }^{7}$ The most recent North American GRUMPv1 dataset, which uses population data from 2000 along with satellite imagery of nightlights and other resources to model population, was loaded into ArcMap 10.1 along with coordinates for each sampling site. Data was projected using the NAD 1983 Great Lakes Basin Albers projection. Relative population in the Great Lakes region was not expected to have changed drastically within 10 years based on ground-truthing and observed trends.

Passive Sampling Procedures. Volunteers deployed samplers 1 - 3 times from April through November, 2011 at each site. Temporal coverage depended on volunteer availability. When possible, air and water samplers were deployed simultaneously at the same location.

$50 \mu$ m-thick low-density polyethylene (LDPE) commercial sheeting (Carlisle Plastics, Inc., Minneapolis, MN) was cut into strips of 10x40 cm. The strips were cleaned by incubation for one day each in DCM and hexane. Batches of about 40 
strips were spiked with performance reference compounds (PRCs) via a method adapted from Booij et al. (2002) ${ }^{8}$ and wrapped in muffled aluminum foil.

Samplers were sent to volunteers throughout the Great Lakes region who had been trained in the procedures for handling and setting up PEs. Water PEs were fastened to an anchored rope and suspended in surface water. Air samplers were hung inside inverted stainless steel bowls to guard against sunlight and precipitation. After samplers were recovered from the field, volunteers repackaged the samplers in their original foil wrappings and returned them via overnight delivery.

Field blank and method blank PEs were used to control for background contamination associated with field deployments and laboratory extraction. Field blank PEs were sent along with ordinary samplers. They were unwrapped and handled by the volunteer at the deployment site before being sent back for analysis. Method blanks were refrigerated after preparation and extracted along with deployed samplers from the same preparation batch. PRC concentrations in field and method blanks from each batch were used to determine initial PRC concentrations in deployed samplers from the same batch.

Quality Assurance \& Quality Control. Detection limits (DL), defined as 3 times the standard deviation of all field blanks, are listed in Table S6, along with percent detection. Concentrations $<\mathrm{DL}$ were reported as half of the DL, as recommended by Antweiler et al..$^{9}$ Compounds that were measured above the DL in less than $20 \%$ of samples were omitted from discussion. Duplicate or triplicate PEs were extracted at some sites to analyze method repeatability. Relative standard deviation (RSD), 
calculated for all compounds that were $>$ DL in all replicates, was greater between aqueous replicates $(\mathrm{RSD}<70 \%)$ than atmospheric replicates $(\mathrm{RSD}<21 \%)$.

Data from all available samplers during all deployments (April - November) at each site were averaged for discussion. This means that some sites were represented by only one sampler deployed during one period, while other sites were represented by an average concentration obtained from samplers deployed throughout three deployment periods.

Determination of Sampling Rate and Ambient Concentration. The percent loss of each PRC was plotted as a function of its PE-water partitioning coefficient and fitted using a nonlinear least squares fitting function using Excel Solver to obtain a sampling rate of best fit, $R_{S}\left(L /\right.$ day). Calculated $R_{s}$ values (Table $S 1 \& S 2$ ) were used to determine the percent equilibrium achieved for each target compound. Equation (1) (written for air) was used to determine ambient concentration, where $\mathrm{C}_{\mathrm{PE}}$ is the concentration (ng/g) measured in the PE, $\mathrm{K}_{\mathrm{PEA}}$ is the temperature-corrected PE-air partitioning coefficient, $\mathrm{C}_{\mathrm{A}}$ is the ambient air concentration, and $f$ is the calculated percent equilibrium reached by the compound during deployment.

$$
C_{w}=\frac{C_{P E}}{f \cdot K_{P E w}}
$$

Sampling Rates. Air sampling rates ranged from $7 \mathrm{~m}^{3} /$ day to $75 \mathrm{~m}^{3} /$ day with two outliers replaced by more plausible values. Aqueous sampling rates ranged from 34 L/day to $285 \mathrm{~L} /$ day. Results and comparison to literature are in the Supporting Information. RSDs between sampling rates calculated for replicate atmospheric samplers ranged from $1 \%-102 \%$ with an average of $32 \%$. Passive sampling rates are 
known to be affected by meteorological factors like wind speed and temperature ${ }^{10,11}$ but no significant relationship was observed between air sampling rates and nearby wind speeds, most likely because sampling rates depended on features of the specific site and regional wind speed values did not capture this local variability. RSDs between rates calculated for replicate aqueous samplers ranged from 10\%-36\% with an average of $21 \%$.

Few studies were available for direct comparison of $\mathrm{R}_{\mathrm{s}}$ values. Allan et al. (2013) estimated riverine sampling rates for $300 \mathrm{~cm}^{2}$ low-density polyethylene (LDPE) samplers to be 6.4-18.5 L/d. ${ }^{12}$ Air sampling rates determined by Ruge (2013) for PEs in Lake Superior air $\left(0.6-70 \mathrm{~m}^{3} /\right.$ day $)$ were of similar magnitude and variability to those reported here, though aqueous sampling rates were lower in that study $(2-25 \mathrm{~L} /$ day $) .^{13}$

Air-Water Exchange Rates. The direction of flux was determined from the flux ratio as shown in Equation (2), with values $>0$ indicating volatilization and values $<0$ indicating absorption into surface waters.

$$
\text { Air -Water Flux Ratio }=\frac{C_{P E w, e q}}{C_{P E a, e q}}-1
$$

If a compound was below the detection limit in both air and water, no flux was calculated. The standard deviation of the flux ratio was calculated via error propagation based on sampling rates and analytical repeatability (both assumed to contribute $10 \%$ uncertainty), and temperature-corrected partitioning coefficients (assumed $50 \%$ and $30 \%$ uncertainty for $\Delta \mathrm{U}_{\mathrm{w}}$ and $\Delta \mathrm{H}_{\mathrm{vap}}$, respectively, as in Morgan et al. (2008)). ${ }^{14}$ The standard deviation of the flux ratio was used to determine whether 
flux ratios were significantly different from equilibrium. Ratios that were not significantly different from equilibrium are flagged in data tables.

Total flux of PAHs (ng/ $\mathrm{m}^{2} /$ day) was calculated from the air-water flux gradient and mass transfer coefficient as in Equation (3), based on a modified two-film resistance model. Total mass transfer coefficients $\left(\mathrm{k}_{\mathrm{ol}}\right)$ were calculated as in Schwarzenbach et al. (2002) from the mass transfer velocity on either side of the airwater boundary. ${ }^{15}$ Mass transfer velocity of each PAH in water $\left(v_{\text {iw }}\right)$ was calculated by scaling the mass transfer velocity of $\mathrm{CO}_{2}\left(v_{\mathrm{CO} 2, \mathrm{w}}\right)$ at $25^{\circ} \mathrm{C}$ using the Schmidt number $(\mathrm{Sc})$, where Sc was determined from each compound's diffusivity in water $\left(\mathrm{D}_{\text {iw }}\right)$. Mass transfer velocity in air $\left(v_{\text {ia }}\right)$ was determined by scaling the velocity of water vapor in air $\left(v_{\text {wa }}\right)$ using the ratio of the PAHs's diffusivity in air $\left(\mathrm{D}_{\mathrm{ia}}\right)$ to water's diffusivity in air $\left(\mathrm{D}_{\mathrm{wa}}\right)$ at $25^{\circ} \mathrm{C} . v_{\mathrm{wa}}$ was determined from an empirical regression with wind speed at $10 \mathrm{~m}$ above sea surface $\left(\mathrm{u}_{10}\right)$ as shown in Schwarzenbach et al. (2002). ${ }^{15}$ $\mathrm{D}_{\mathrm{ia}}$ and $\mathrm{D}_{\mathrm{iw}}$ at $25^{\circ} \mathrm{C}$ were calculated from molecular weight using the relation in Schwarzenbach et al. (2002). ${ }^{15}$ Air-water partitioning coefficients $\left(K_{a w}\right)$ were corrected for temperature using the internal energy of air-water exchange, $\Delta \mathrm{U}_{\mathrm{aw}}$ (Table S7). ${ }^{15}$

$$
F_{a / w}=k_{o l} \times\left(\frac{C_{P E w, e q}-C_{P E a, e q}}{K_{P E w}}\right)
$$

Gaseous PAHs and Temperature. A positive correlation between gaseous PAH concentration and temperature has been observed in previous studies and linked to temperature-dependent local processes such as revolatilization from contaminated surfaces as well as decreased condensation of PAHs onto particulate matter. ${ }^{16,17}$ To examine the effect of temperature on total gaseous PAHs, locations where data was 
available for three deployments (Buffalo, Dunkirk, Fairport Harbor, Niagara, Oswego, Rochester, and Erie) were plotted with mean temperature during deployment (Figure S2-7). During colder deployments $\left(\mathrm{T}<17^{\circ} \mathrm{C}\right)$, mean $\Sigma_{15} \mathrm{PAH}=3.6 \pm 1.2 \mathrm{ng} / \mathrm{m}^{3}$. During warmer deployments at the same sites, mean $\Sigma_{15} \mathrm{PAH}=13.1 \pm 13.4 \mathrm{ng} / \mathrm{m}^{3}$. All three Dunkirk deployments took place at mean temperature $>20^{\circ} \mathrm{C}$ and so data for this site was not used in calculating averages. No increase in gaseous PAH concentration with temperature was observed at the rural Erie or semi-urban Niagara locations. Both of these locations were within parks and most likely less exposed to surfaces like asphalt they may act as significant sources of revolatilizing gaseous PAHs. Small increases in $\Sigma_{15} \mathrm{PAH}$ were observed at urban locations Oswego and Buffalo and at semi-urban Fairport Harbor, while concentrations increased greatly at urban Rochester.

Temporal Fluctuations of Dissolved PAHs. No obvious spatial differences were observed in dissolved PAH concentration or composition at sites expected to be heavily impacted by river discharge, listed in Table S4. To further investigate whether discharge affected dissolved concentrations, temporal changes in $\Sigma_{18} \mathrm{PAH}$ were compared to precipitation and tributary discharge for sites where more than one deployment was undertaken. In Oswego, Buffalo, and Cleveland, dissolved $\Sigma_{18} \mathrm{PAH}$ increased from summer to early fall (deployment 1 and 2) along with precipitation and river discharge. However, $\Sigma_{18} \mathrm{PAH}$ also increased from spring to summer at Buffalo and Oswego, while river discharge and precipitation decreased. Cleveland was not monitored during this time period. Data for Buffalo and Oswego are shown in Figure S2-8. 







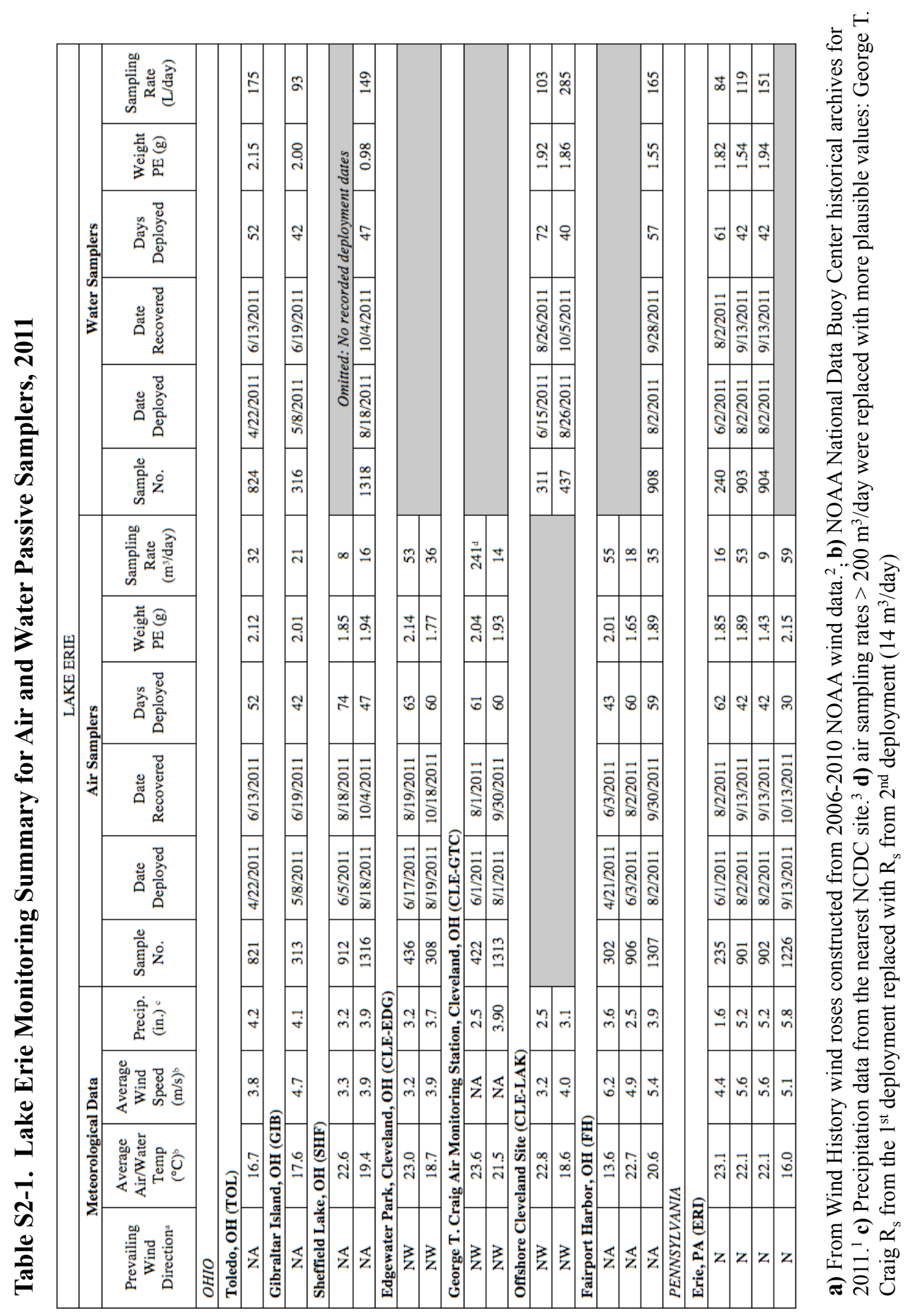




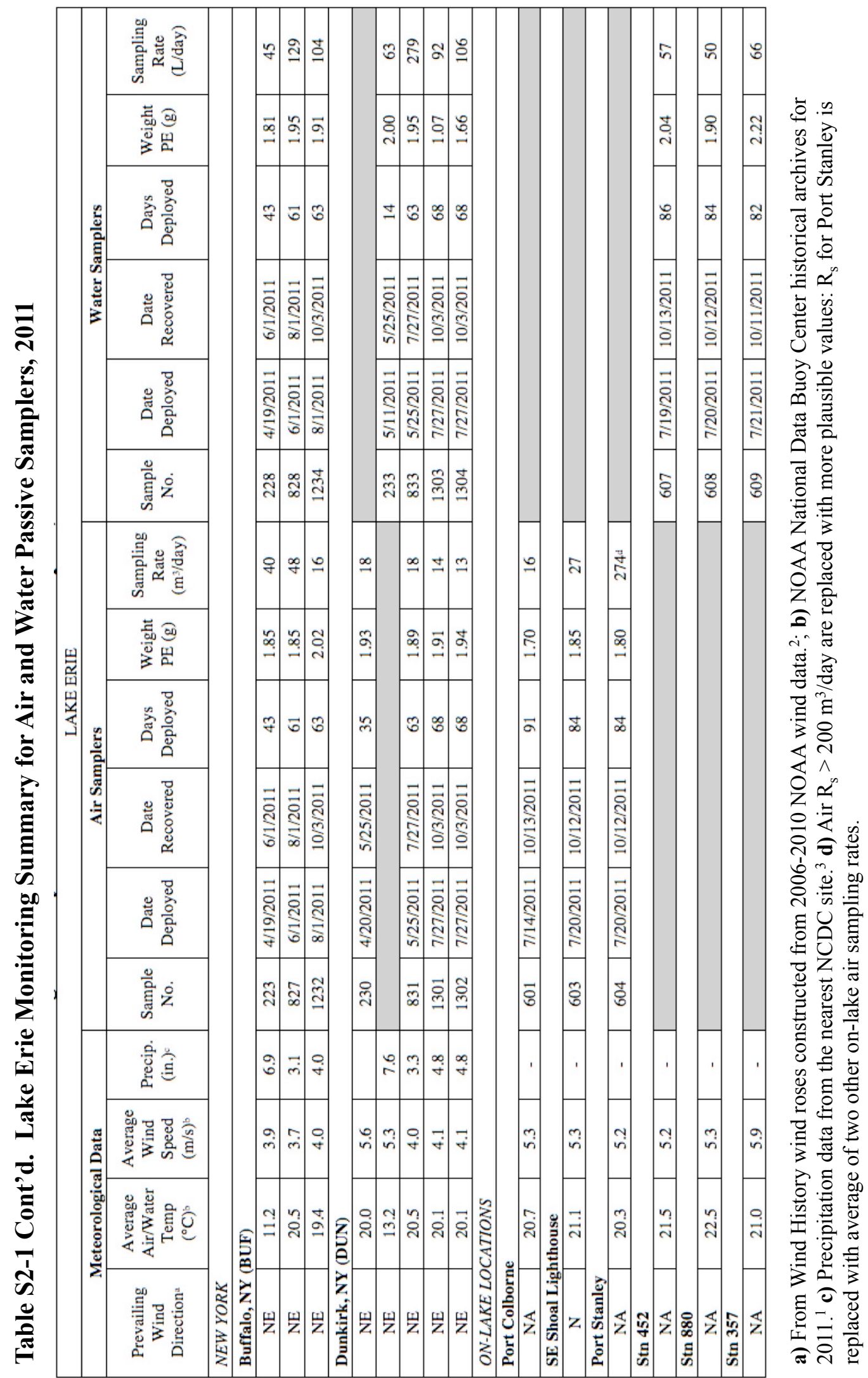




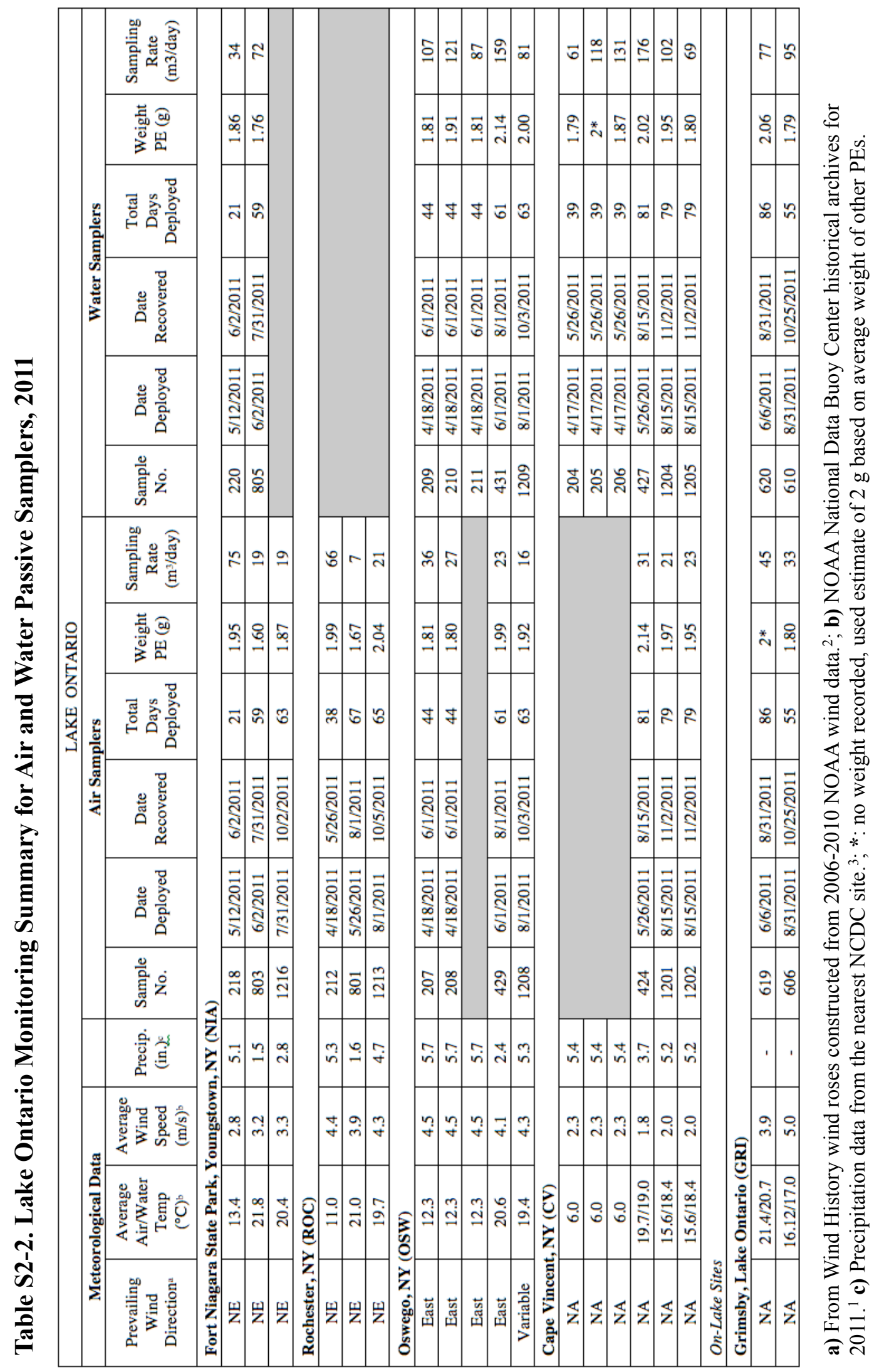




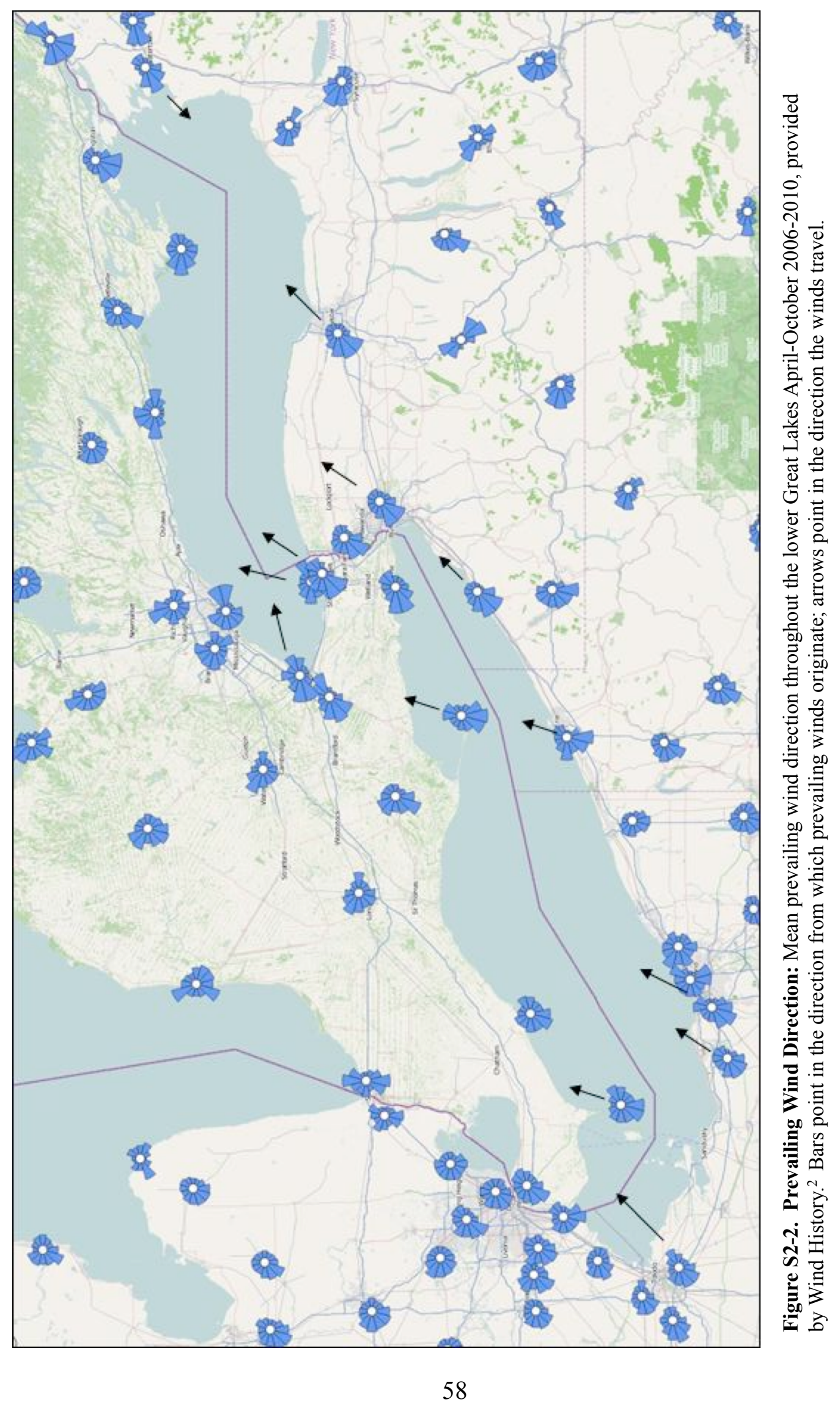


Table S2-3. Over-Land and Over-Water Trajectories Arriving at Coastal Sites. 6-hour air mass back trajectories were calculated every 30 hours over the entire deployment period for Cleveland, Buffalo, Oswego, and Rochester to determine whether lower PAH concentrations in Buffalo and Oswego could be explained by a larger contribution from over-lake air masses diluting the urban plume at these locations.

\begin{tabular}{|l|c|c|}
\cline { 2 - 3 } \multicolumn{1}{c|}{} & $\begin{array}{c}\text { \%Over- } \\
\text { land }\end{array}$ & $\begin{array}{c}\text { \%Over- } \\
\text { lake }\end{array}$ \\
\hline ROC & 61 & 39 \\
\hline OSW & 38 & 62 \\
\hline BUF & 56 & 44 \\
\hline CLE-EDG & 60 & 40 \\
\hline
\end{tabular}

Table S2-4. Major Rivers within 10 km of Aqueous Sampling Sites: Compiled from USGS discharge records. ${ }^{4}$

\begin{tabular}{|l|c|c|}
\hline \multicolumn{1}{|c|}{ River Name } & $\begin{array}{c}\text { Mean 2011 } \\
\text { Discharge } \\
\left(\mathbf{m}^{\mathbf{3} / \mathbf{s})}\right.\end{array}$ & $\begin{array}{c}\text { Water Sampling } \\
\text { Sites within 10 km }\end{array}$ \\
\hline Niagara River & 6134 & NIA \\
\hline Oswego River & 256 & OSW \\
\hline Maumee River & 251 & TOL \\
\hline Grand River & 160 & FH \\
\hline Buffalo River & 50 & BUF \\
\hline Cuyahoga River & 43 & CLE-LAK \\
\hline Black River & 42 & SHF \\
\hline
\end{tabular}




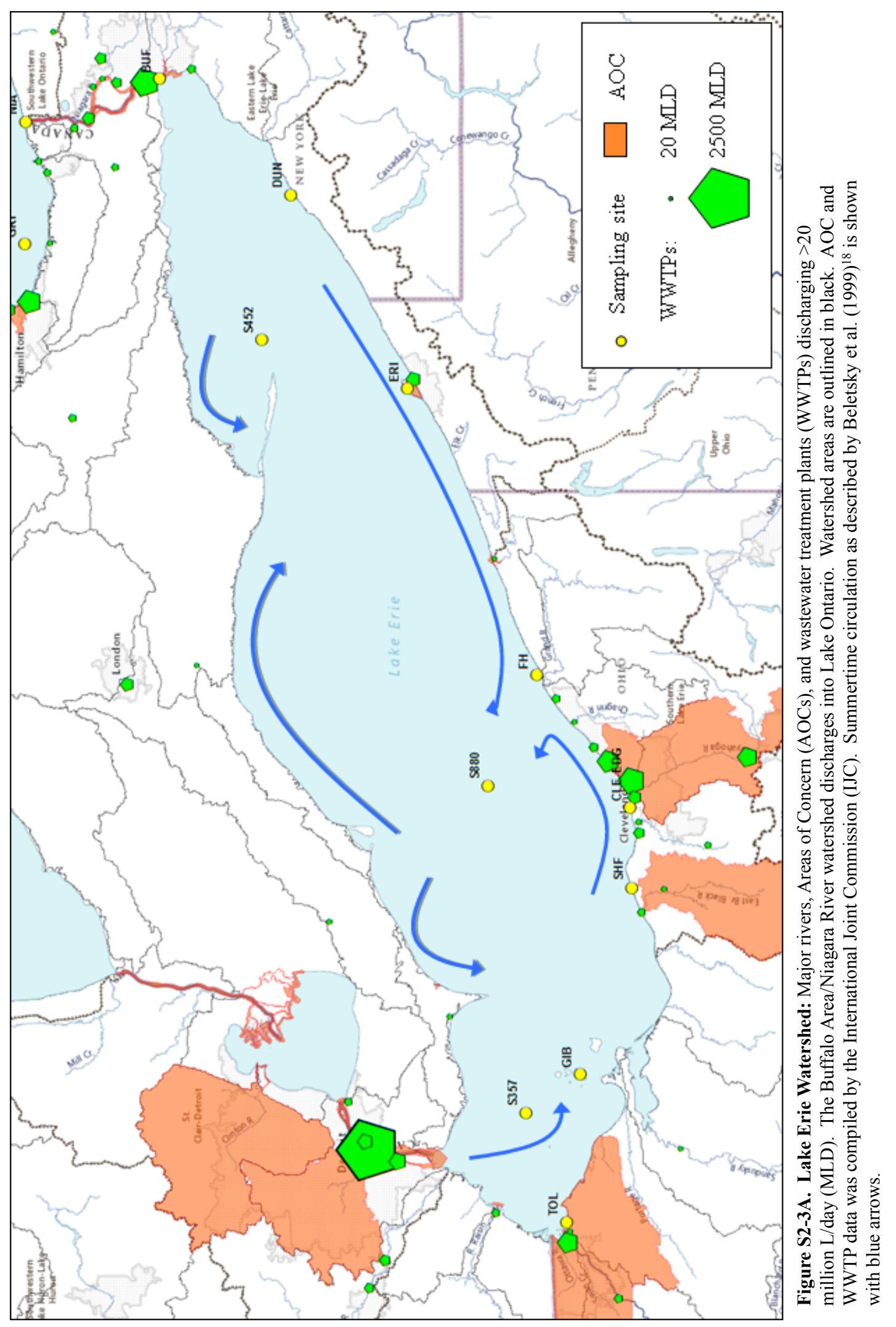




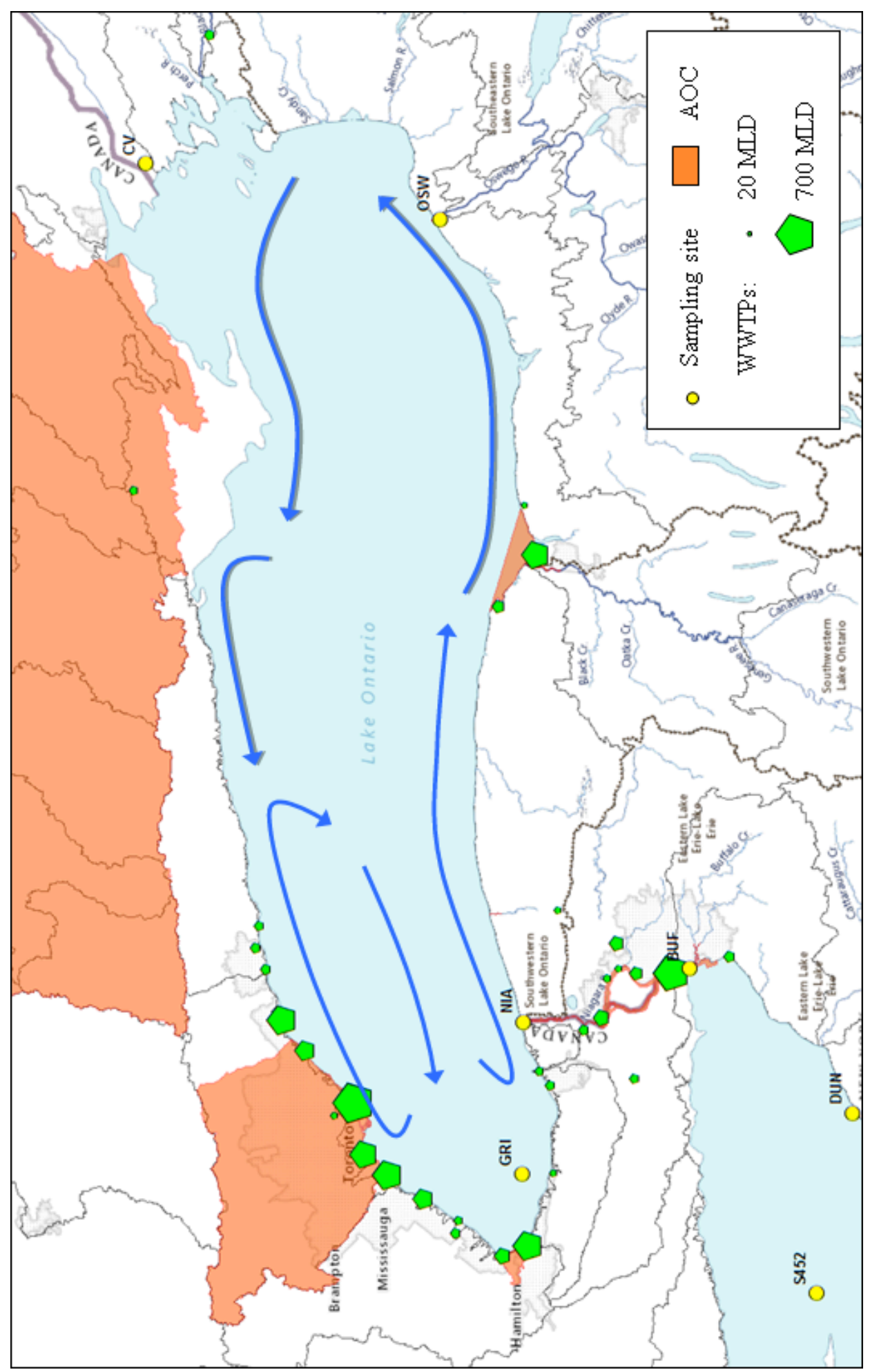

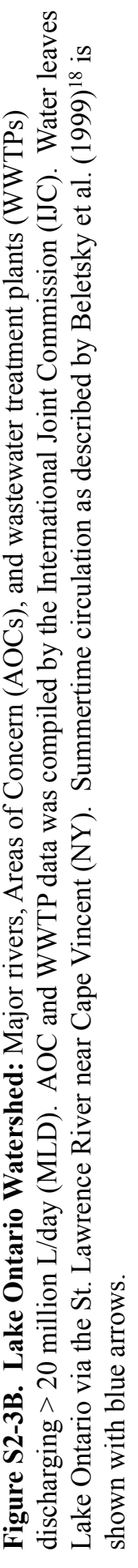


Table S2-5. Percent Recovery for Internal Standard Spikes in Passive Sampler Extracts

\begin{tabular}{|l|c|c|c|c|}
\hline Atmospheric Extracts & MIN & MAX & MEAN & STDEV \\
\hline Compound & $34 \%$ & $152 \%$ & $78 \%$ & 0.21 \\
\hline Acenaphthene-d10 & $40 \%$ & $155 \%$ & $87 \%$ & 0.21 \\
\hline Phenanthrene-d10 & $50 \%$ & $163 \%$ & $90 \%$ & 0.16 \\
\hline Chrysene-d12 & $19 \%$ & $112 \%$ & $67 \%$ & 0.20 \\
\hline Perylene-d12 & \multicolumn{5}{|l|}{} \\
\hline Aqueous Extracts & $22 \%$ & $100 \%$ & $69 \%$ & 0.26 \\
\hline Acenaphthene-d10 & $35 \%$ & $104 \%$ & $79 \%$ & 0.21 \\
\hline Phenanthrene-d10 & $60 \%$ & $114 \%$ & $92 \%$ & 0.14 \\
\hline Chrysene-d12 & $49 \%$ & $109 \%$ & $86 \%$ & 0.15 \\
\hline Perylene-d12
\end{tabular}

Table S2-6. Detection Limits and Percent Detection

\begin{tabular}{|c|c|c|c|c|c|c|c|}
\hline Compound & $\begin{array}{c}\text { Average Field } \\
\text { Blank } \\
\text { Concentration } \\
\text { (ng/g PE) }\end{array}$ & STDEV & $\begin{array}{c}\text { Detection } \\
\text { Limit } \\
\text { (ng/g PE) }\end{array}$ & $\begin{array}{c}\text { Detection } \\
\text { Limit } \\
\text { (pg/L) }\end{array}$ & $\begin{array}{c}\text { Detection } \\
\text { Limit } \\
\left(\mathrm{pg} / \mathrm{m}^{3}\right)\end{array}$ & $\begin{array}{l}\% \text { Detection } \\
>\text { DL for Air } \\
\text { Samplers } \\
(n=40)\end{array}$ & $\begin{array}{c}\text { \% Detection } \\
\text { > DL in } \\
\text { Water } \\
\text { Samples } \\
(n=34)\end{array}$ \\
\hline Nap & 2.3 & 1.7 & 5.0 & 1556 & 9023 & 0 & 9 \\
\hline Biph & 2.9 & 1.6 & 4.8 & 465 & 478 & 15 & 0 \\
\hline Ace & 1.7 & 2.1 & 6.3 & 361 & 720 & 15 & 3 \\
\hline Flr & 1.6 & 0.9 & 2.7 & 70 & 107 & 75 & 26 \\
\hline Phn & 8.8 & 11 & 33 & 689 & 300 & 88 & 21 \\
\hline Ant & 0.73 & 0.9 & 2.8 & 204 & 15 & 55 & 56 \\
\hline 1-MPhn & 1.2 & 0.9 & 2.8 & 421 & 4.2 & 98 & 100 \\
\hline Ret & 3.5 & 4.0 & 12 & 69 & 5.3 & 55 & 59 \\
\hline $\mathrm{BaA}$ & 2.3 & 2.3 & 7.0 & 13 & 3.0 & 35 & 79 \\
\hline Chry & 6.2 & 7.5 & 22 & 119 & 9.4 & 53 & 97 \\
\hline $\mathrm{BbF}$ & 2.3 & 2.6 & 7.8 & 6.3 & 3.2 & 23 & 97 \\
\hline $\mathrm{BkF}$ & 2.5 & 2.4 & 7.3 & 5.5 & 3.0 & 28 & 97 \\
\hline $\mathrm{BeP}$ & 3.7 & 3.9 & 12 & 5.8 & 4.8 & 13 & 88 \\
\hline $\mathrm{BaP}$ & 1.0 & 1.2 & 3.6 & 4.7 & 1.5 & 18 & 85 \\
\hline Per & 1.1 & 1.7 & 5.1 & 1.2 & 2.1 & 8 & 76 \\
\hline $\mathrm{BjF}$ & 0.5 & 1.1 & 3.2 & 2.6 & 1.3 & 15 & 18 \\
\hline
\end{tabular}

a) Estimated typical ambient detection limit using deployment time 56 days, sampler mass $2 \mathrm{~g}$, and mean air and water sampling rates $\left(40 \mathrm{~m}^{3} /\right.$ day and $112 \mathrm{~L} /$ day, respectively). 


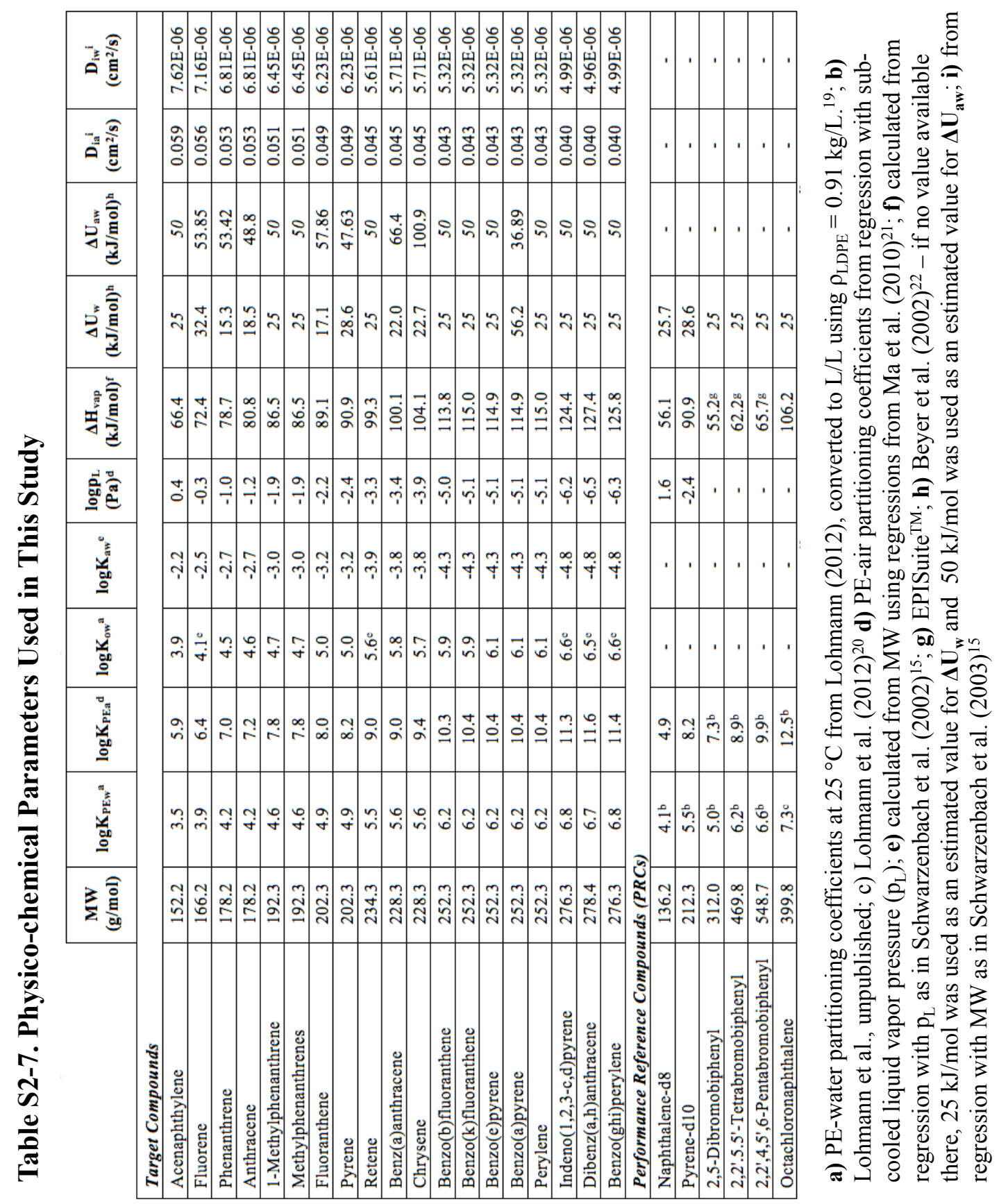




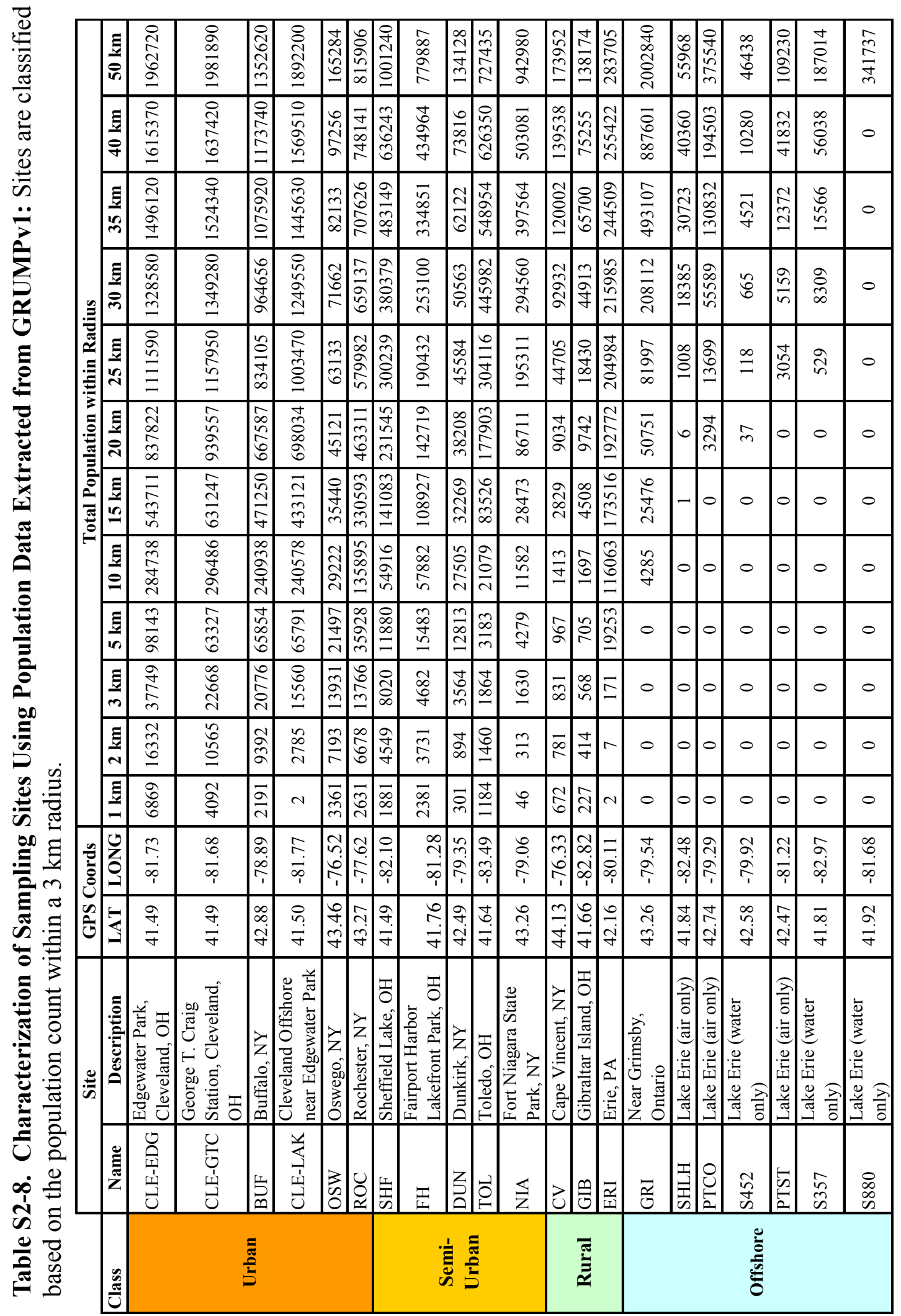




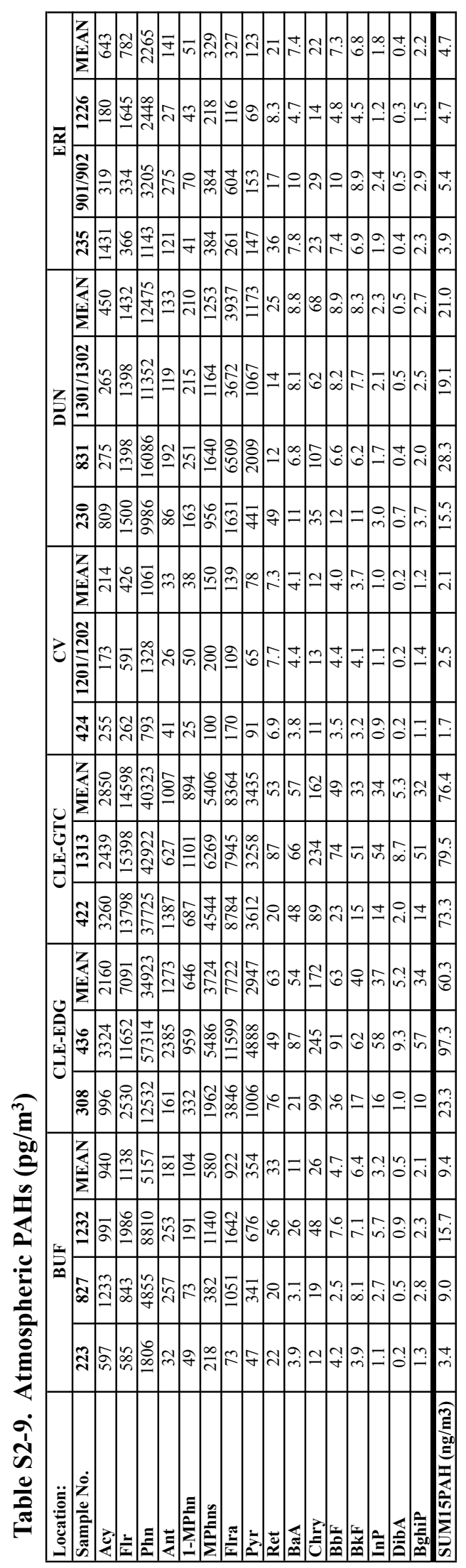




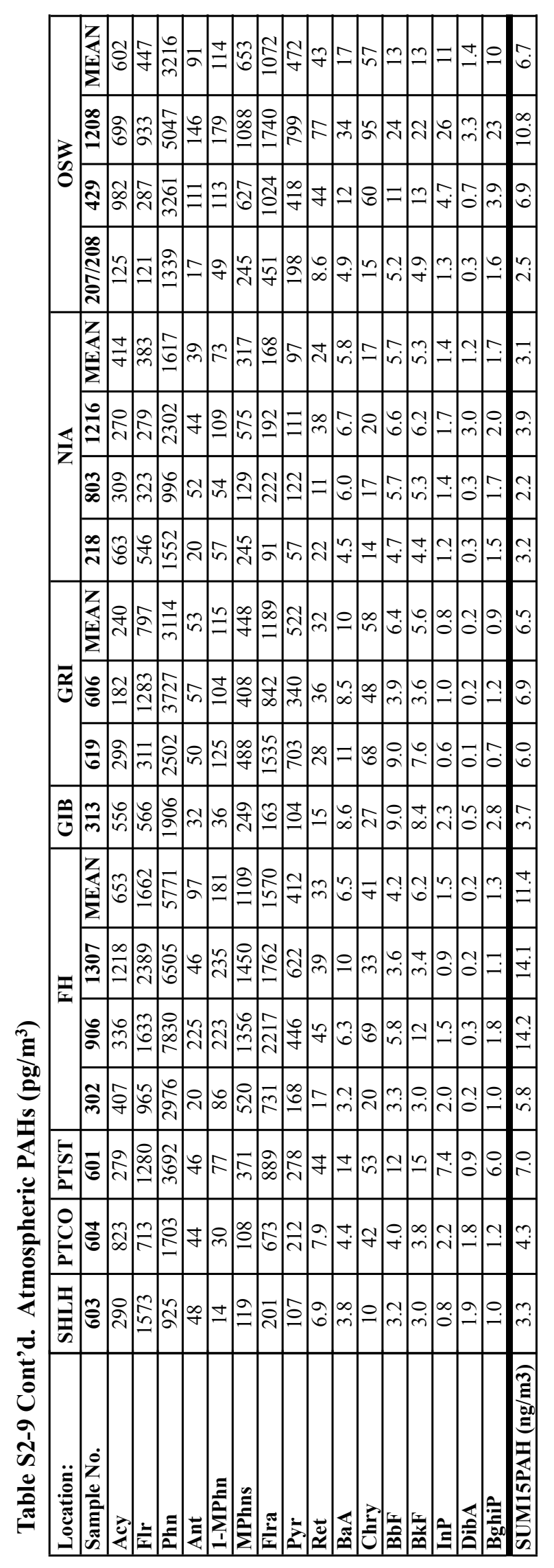




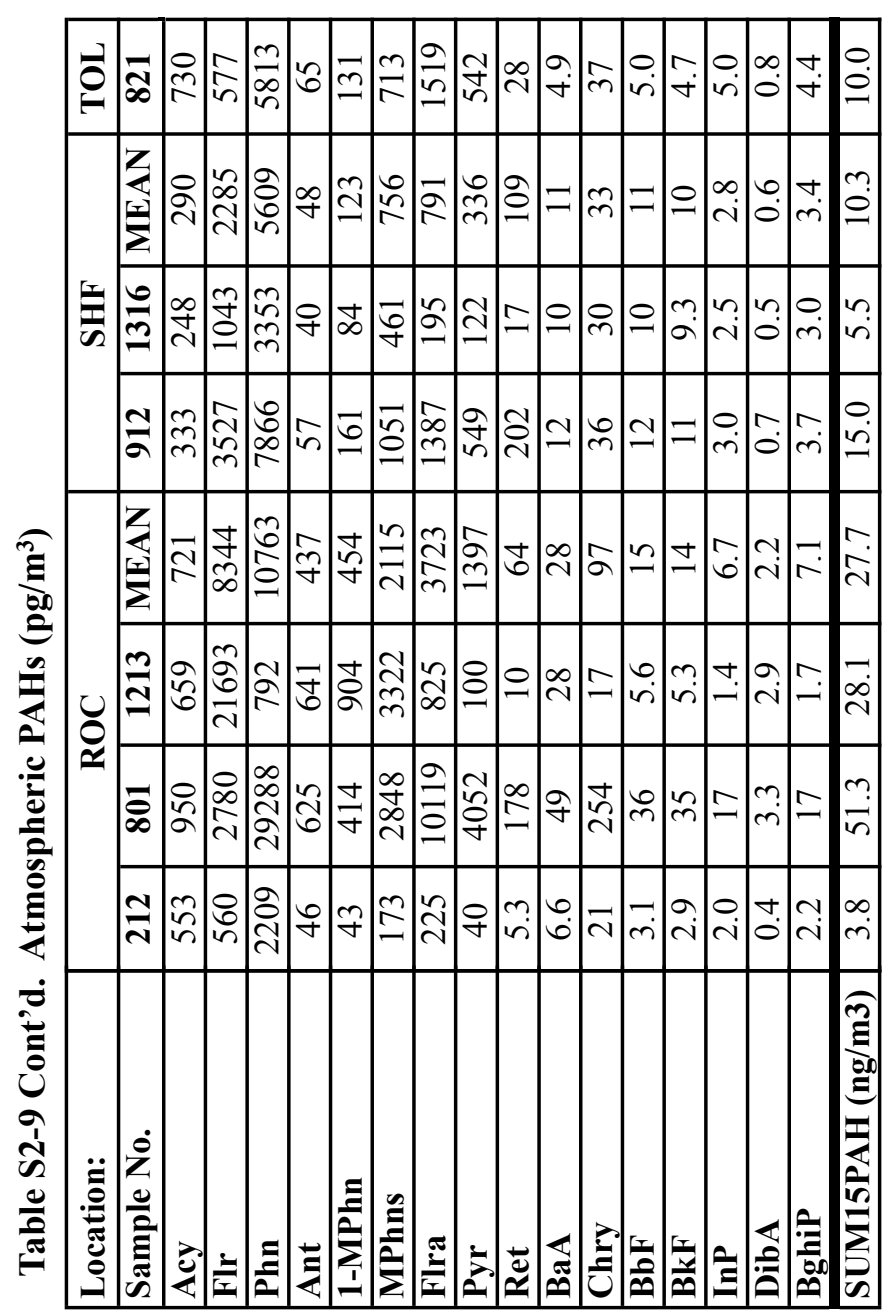




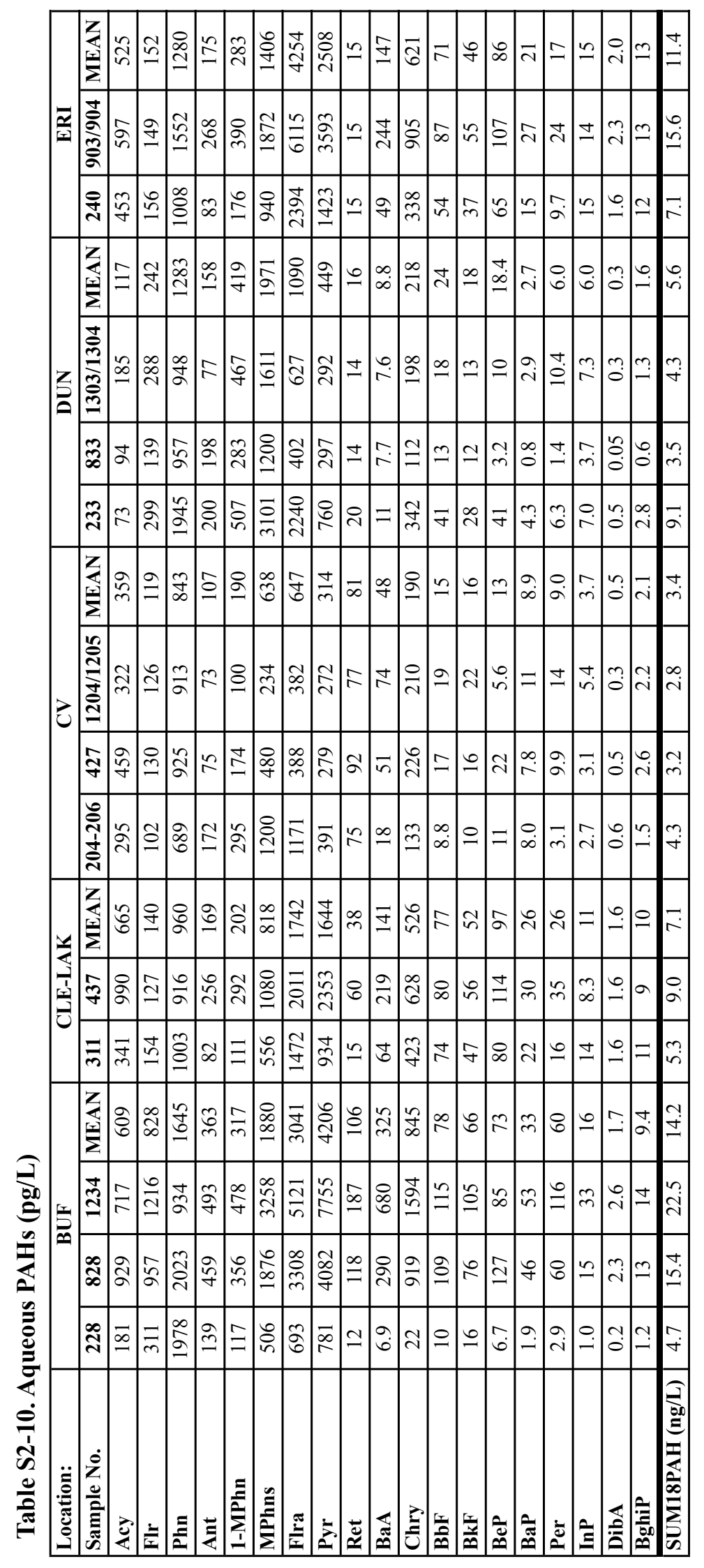




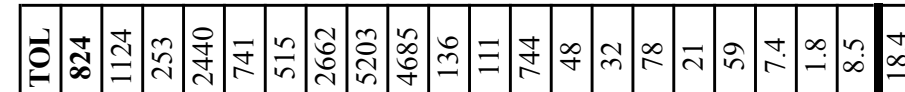

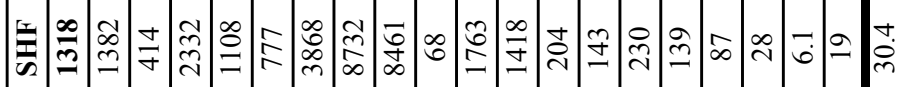

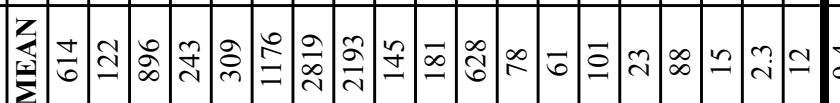

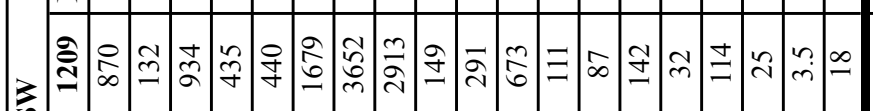

政

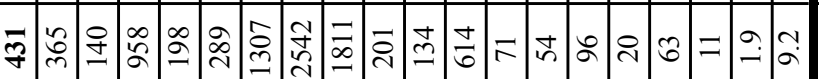

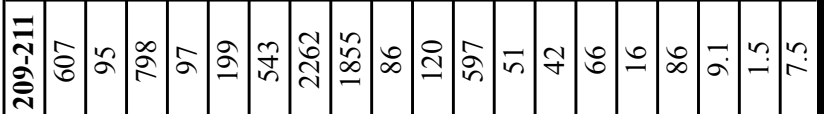

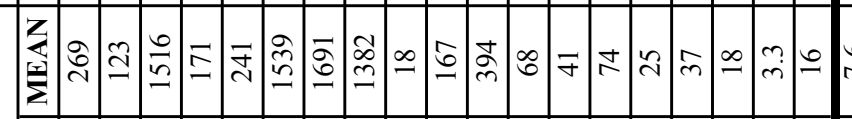

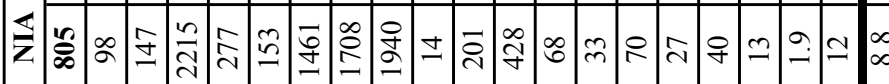

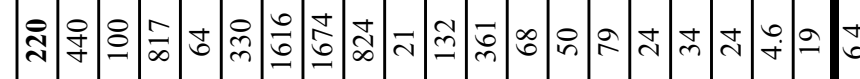

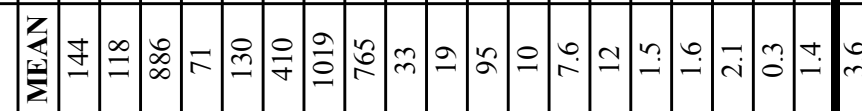

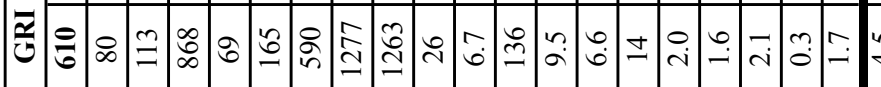

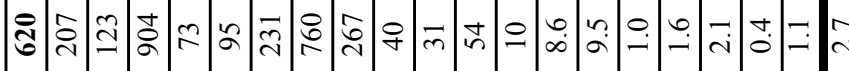

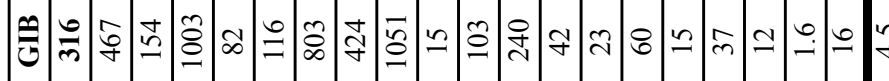

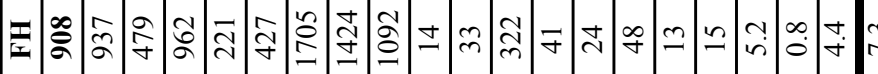

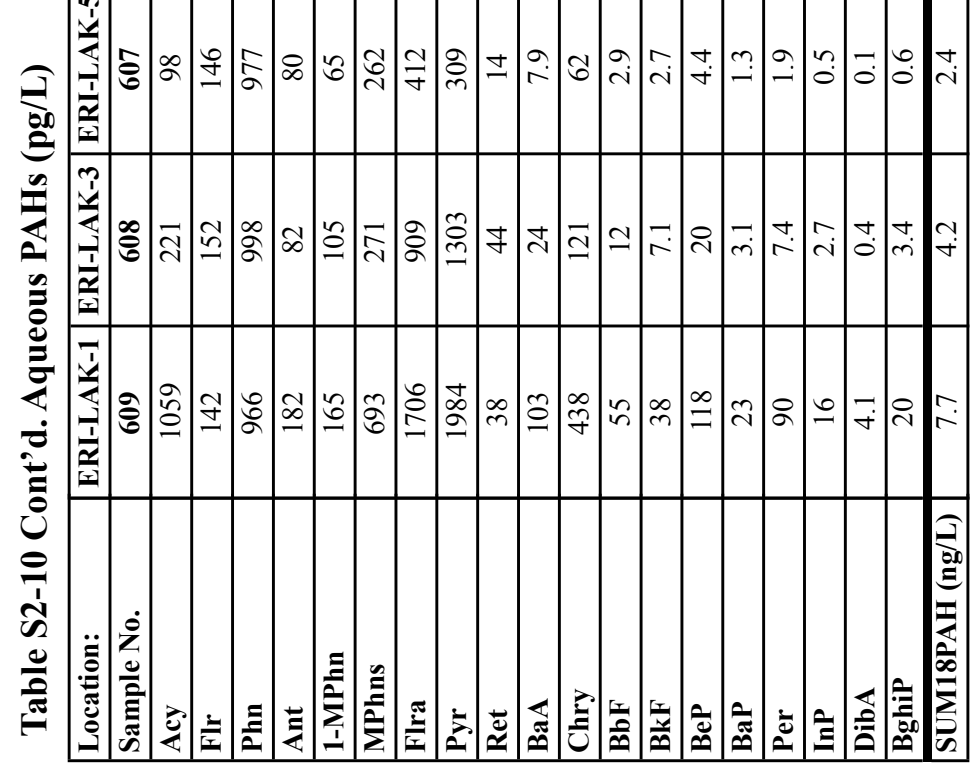


Figure S2-4. Percent Composition of Total Vapor Phase (A) and Aqueous Dissolved (B) PAHs: Sites are classified based on population within $3 \mathrm{~km}$, as described in Table S8.
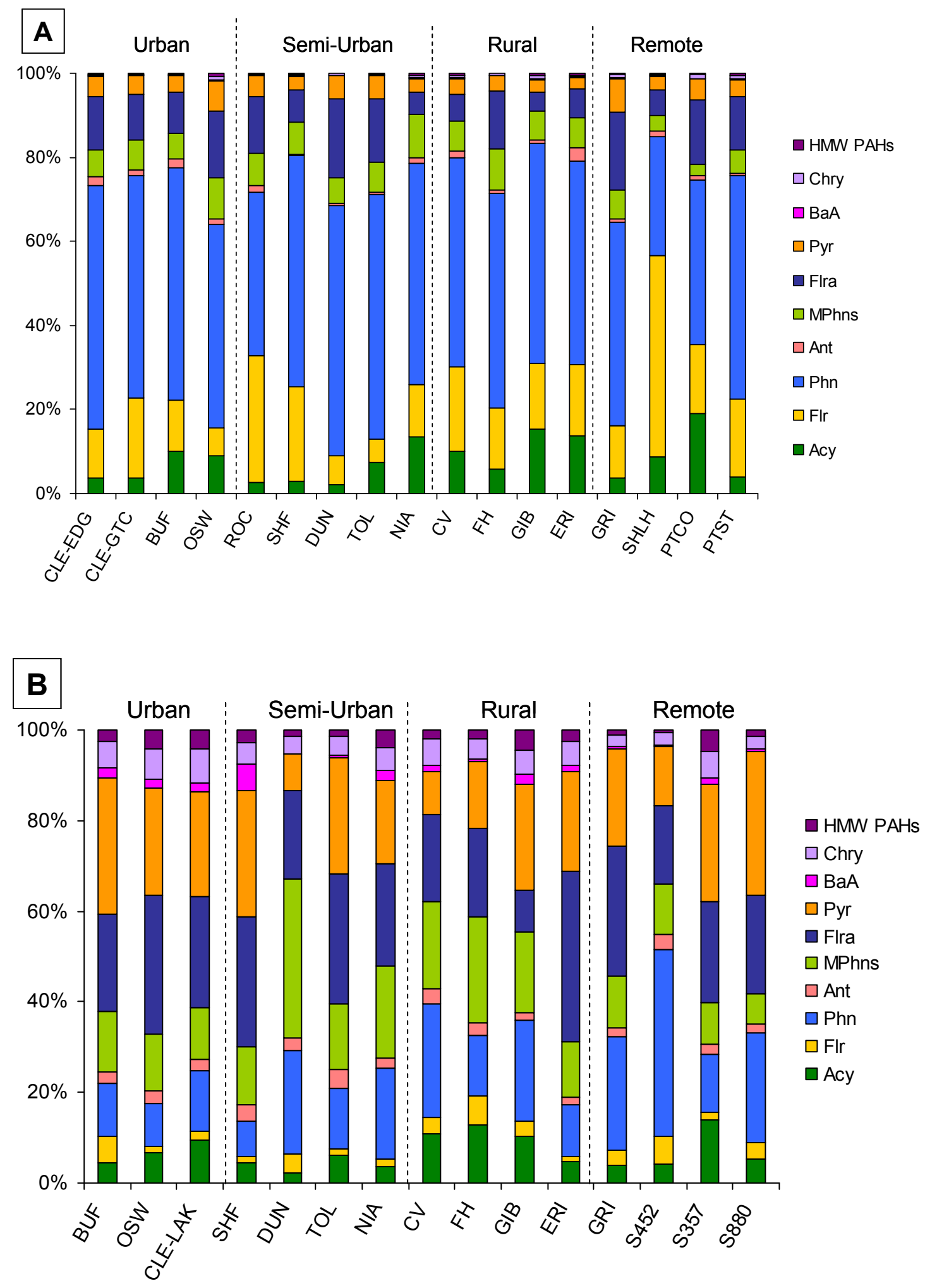
Figure S2-5. Principal Component Analysis (PCA) of Air (A) and Water (B) PAH Profiles

Individuals factor map (PCA)

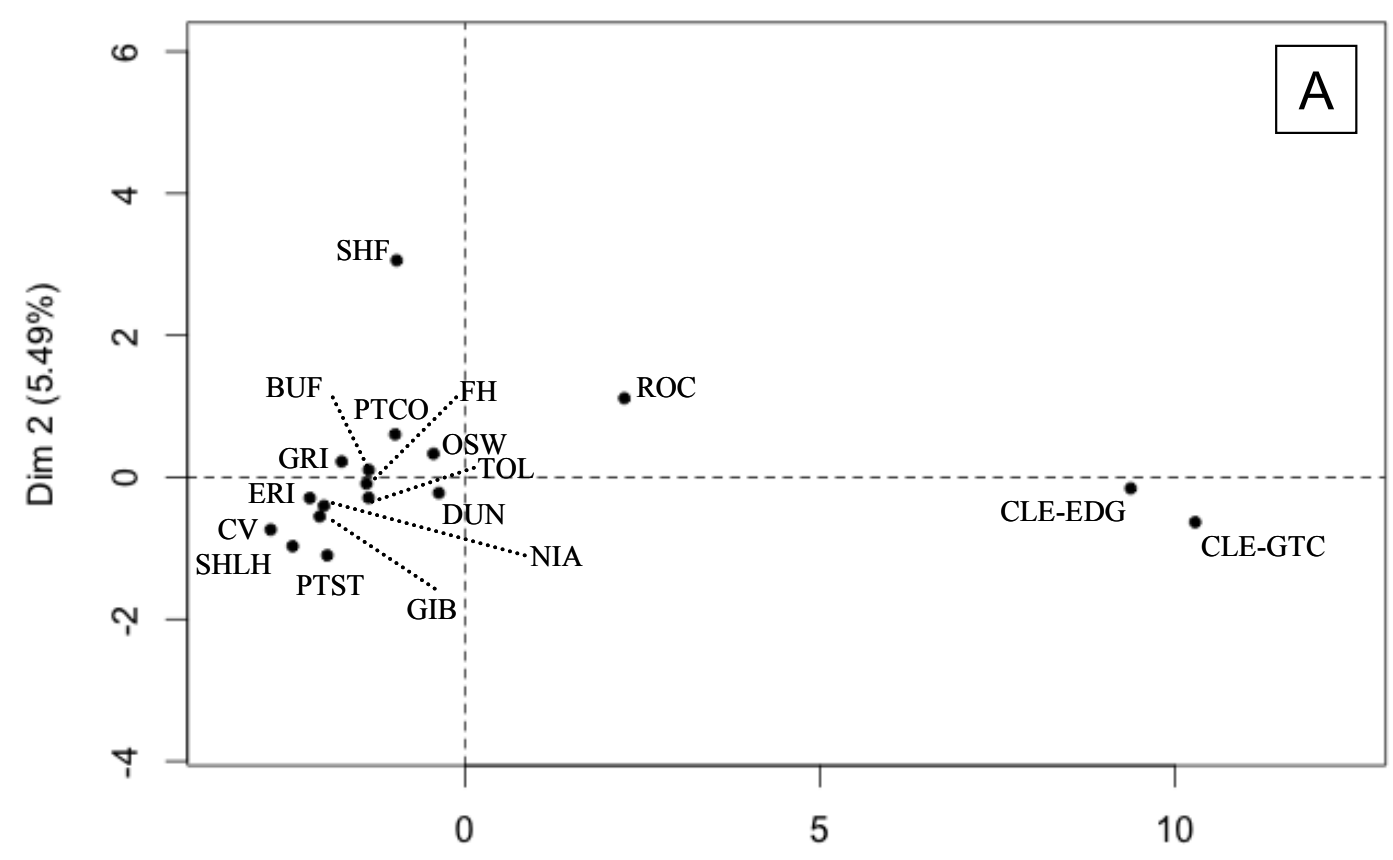

$\operatorname{Dim} 1(88.12 \%)$

Individuals factor map (PCA)

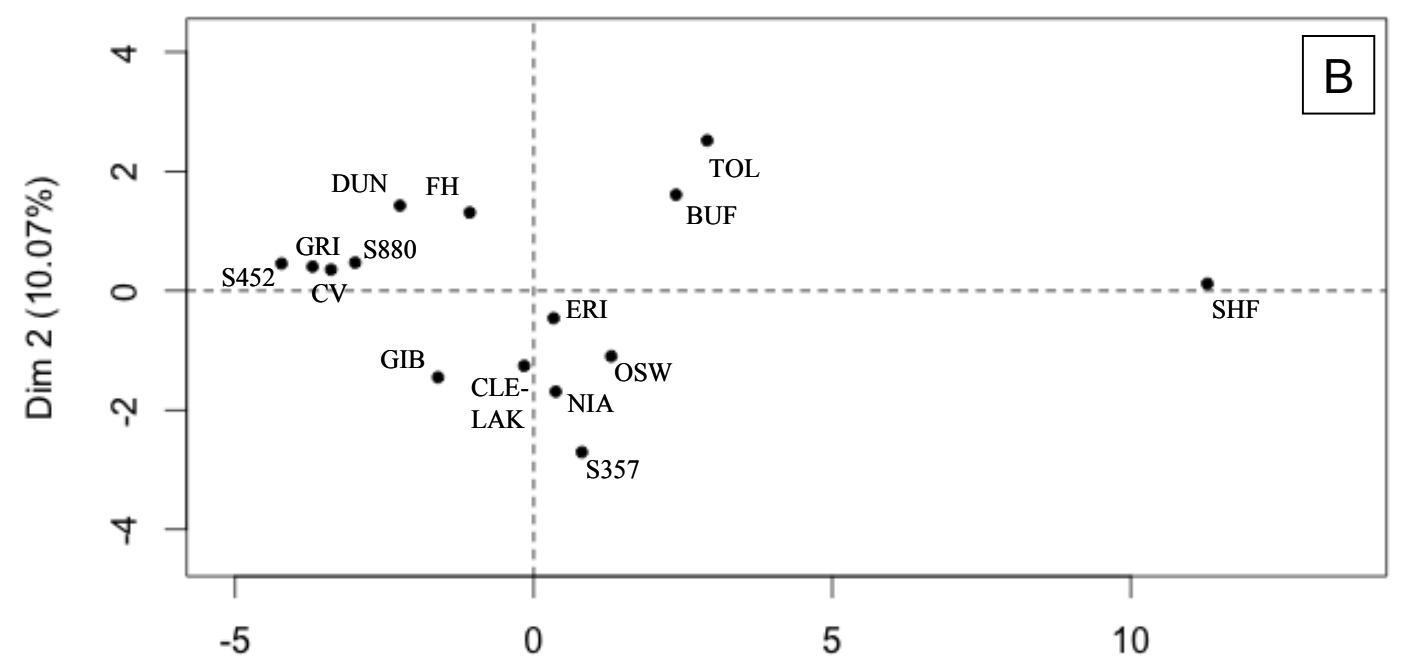

$\operatorname{Dim} 1(71.85 \%)$ 
Figure S2-6. Vapor Pressure and Radius of Max Concentration-Population Correlation:

๑: 4-5-ring PAHs; $\diamond$ : 2-3-ring PAHs; $\square$ : anthracene

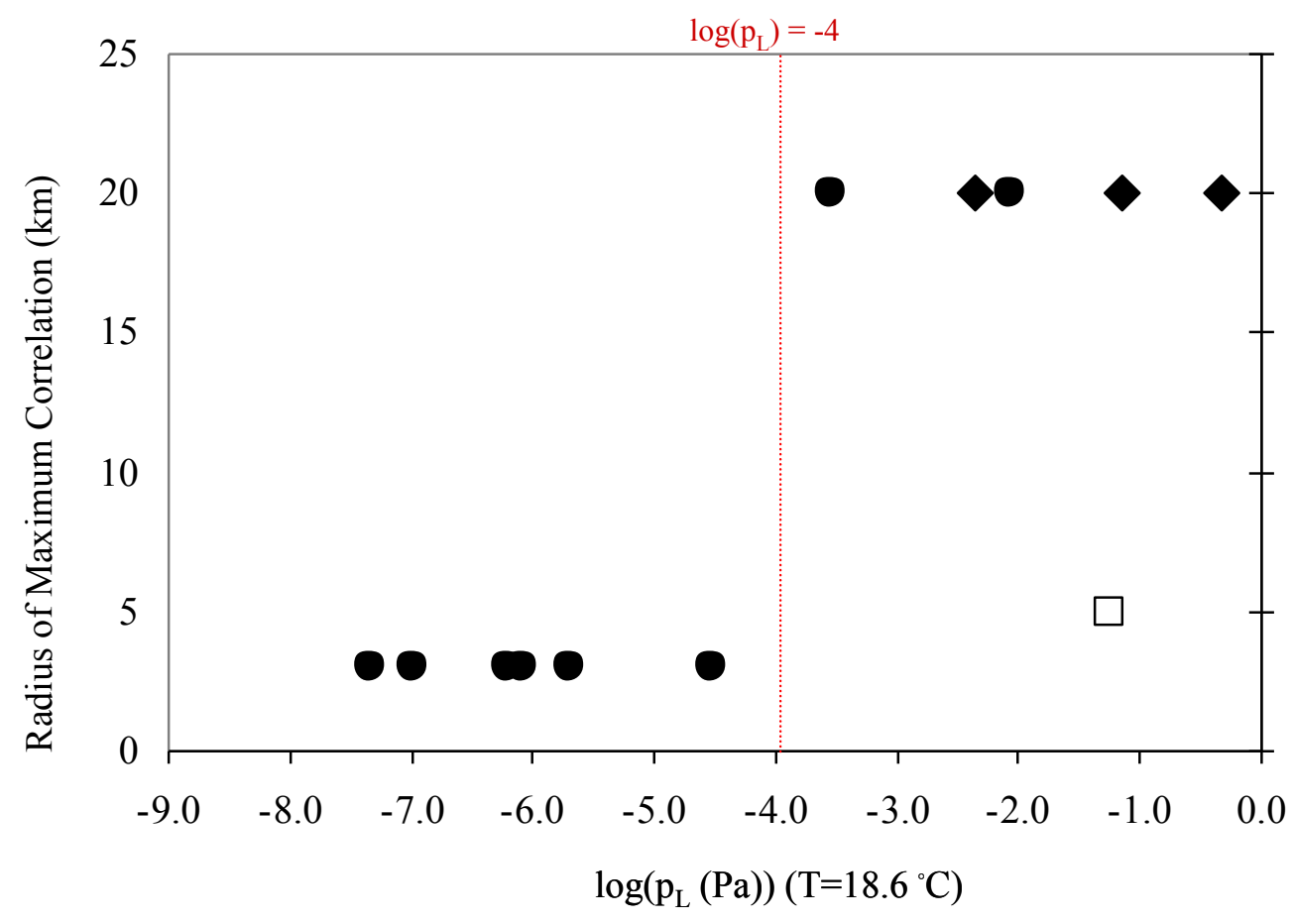

Figure S2-7. Temperature and Gaseous $\Sigma_{15}$ PAH Concentration.

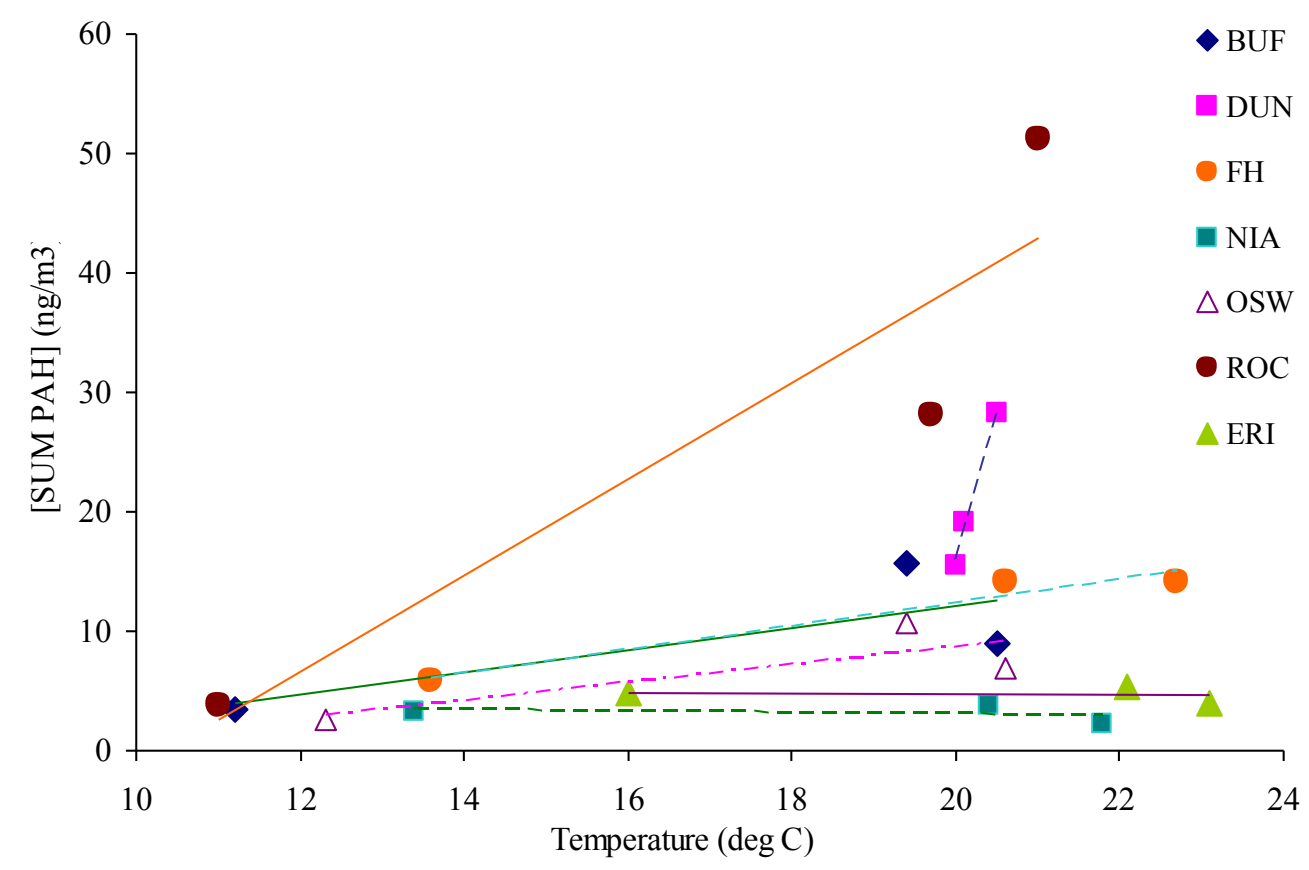



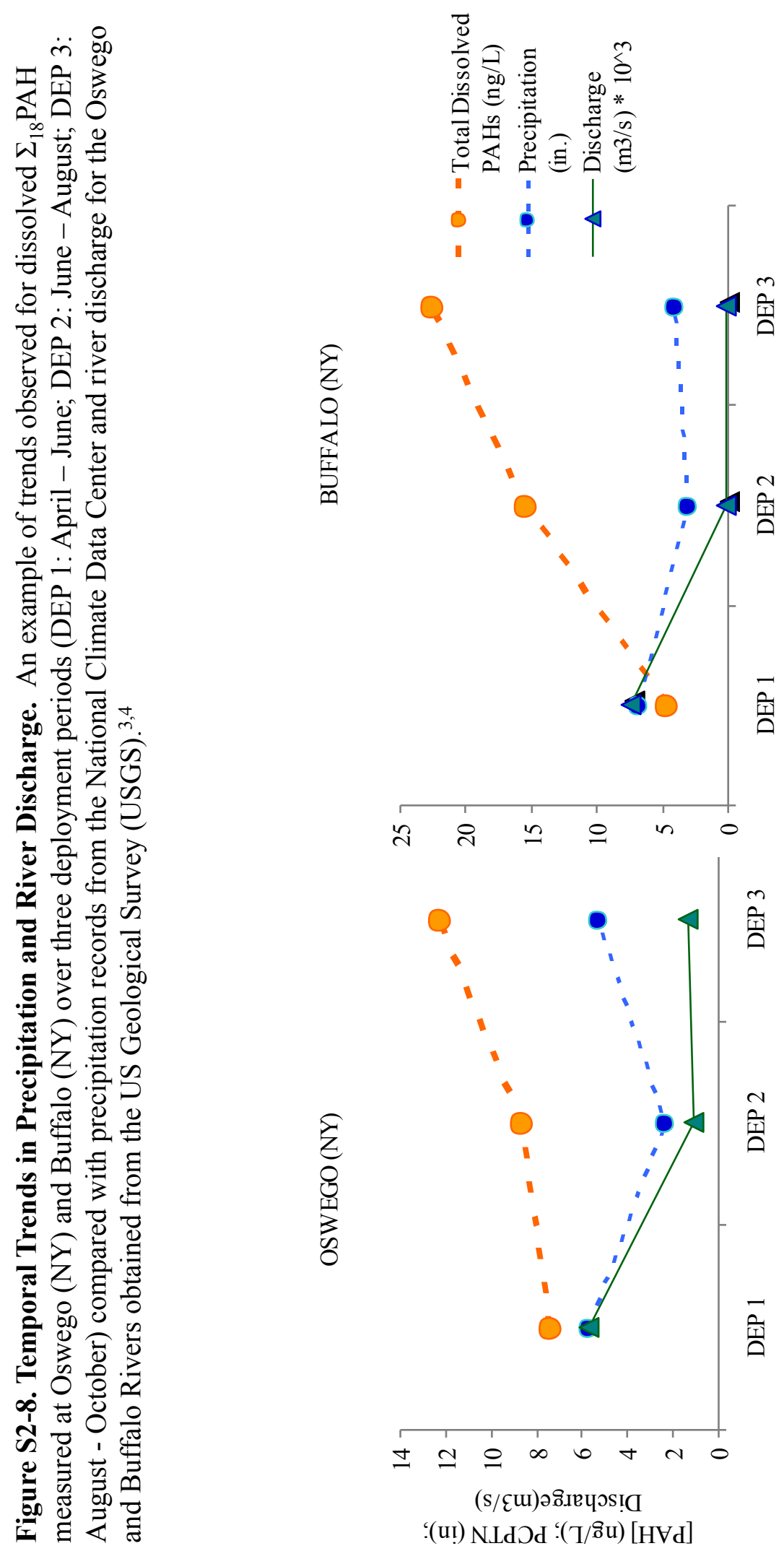


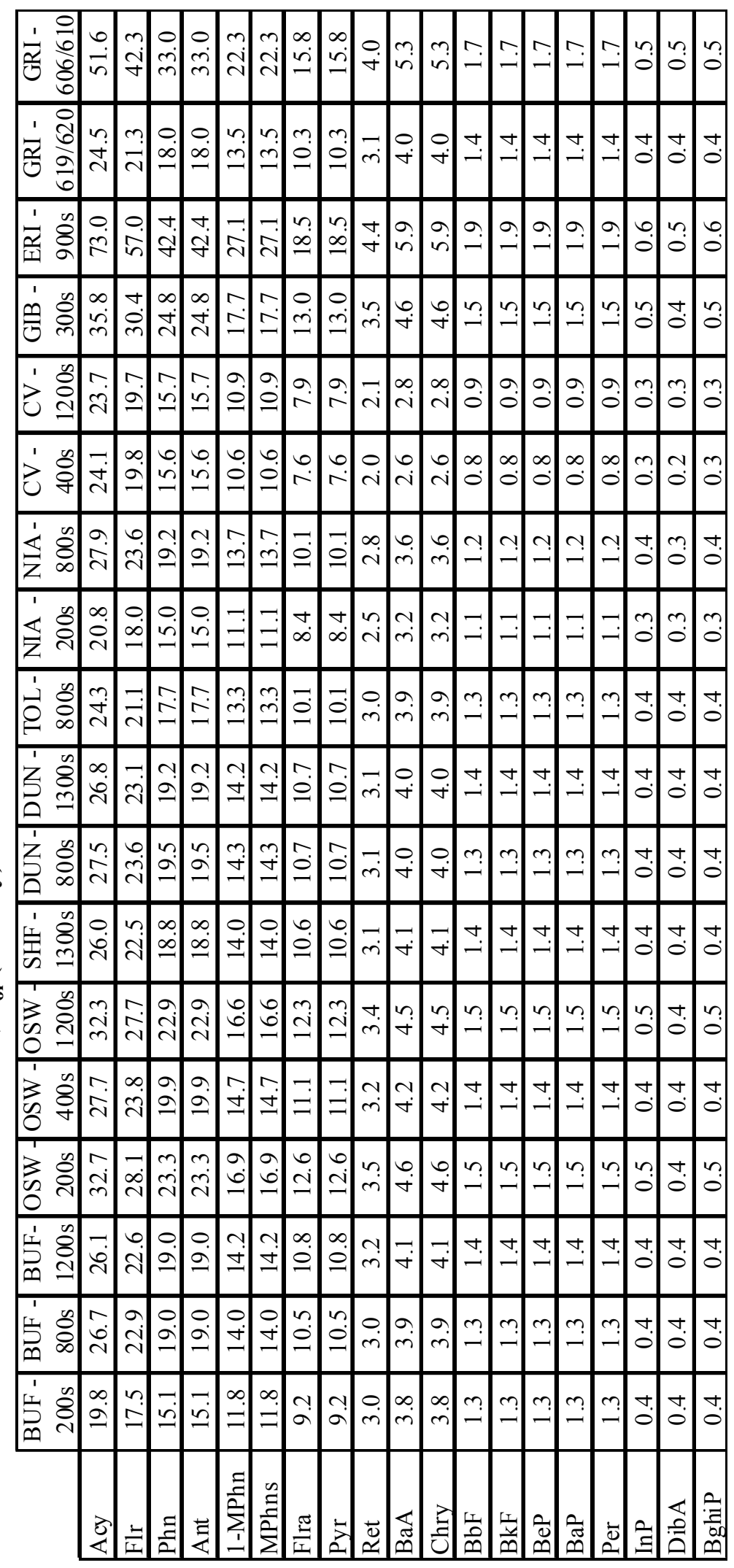




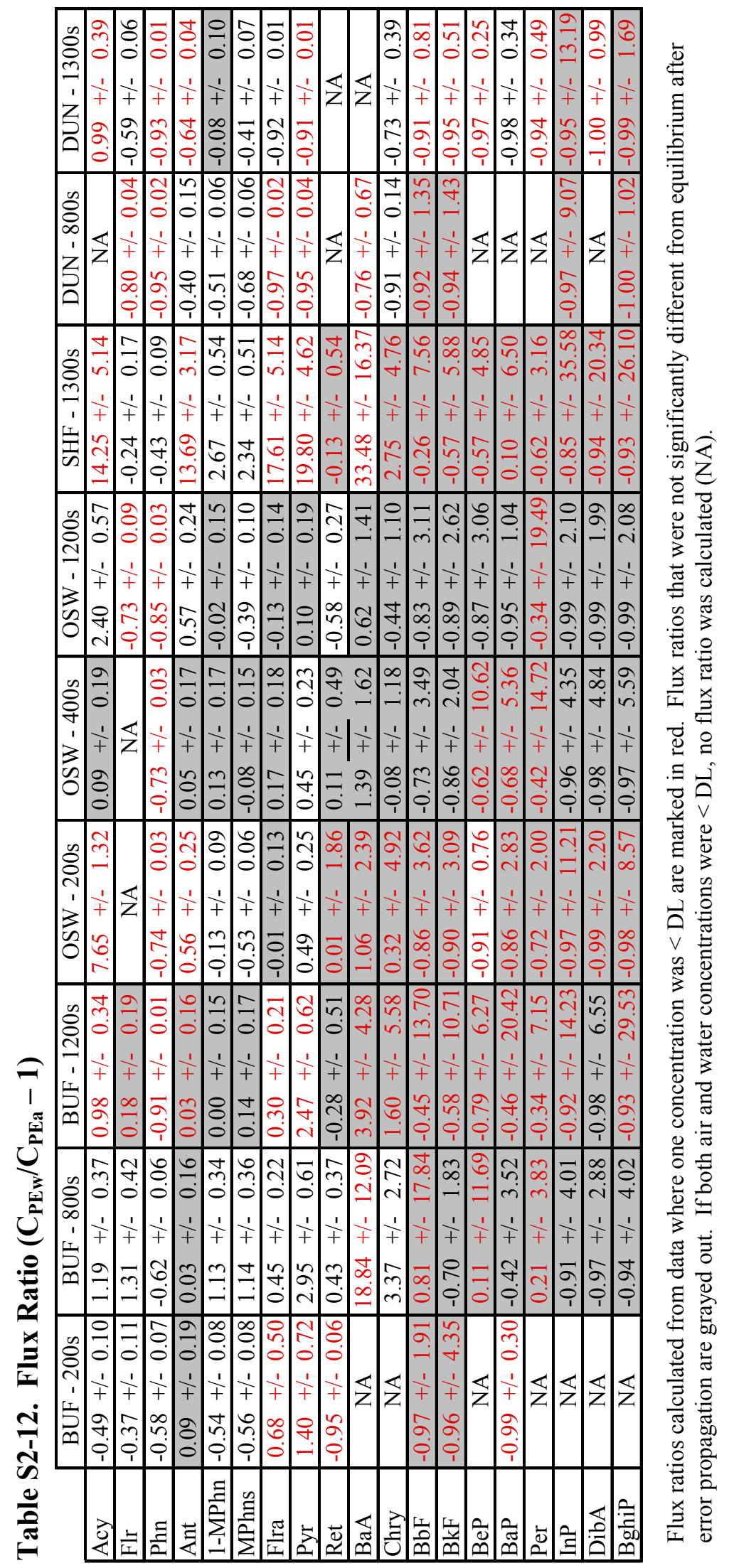




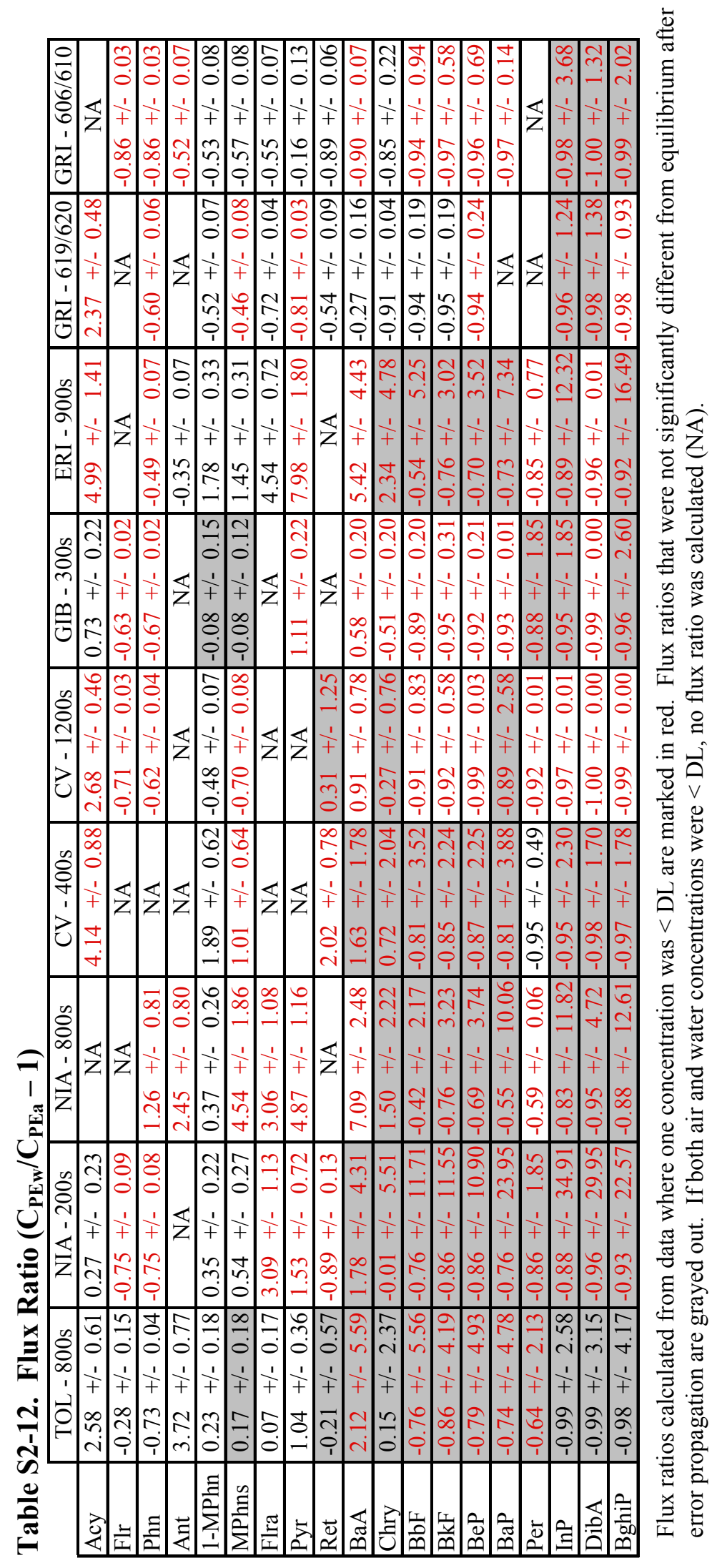




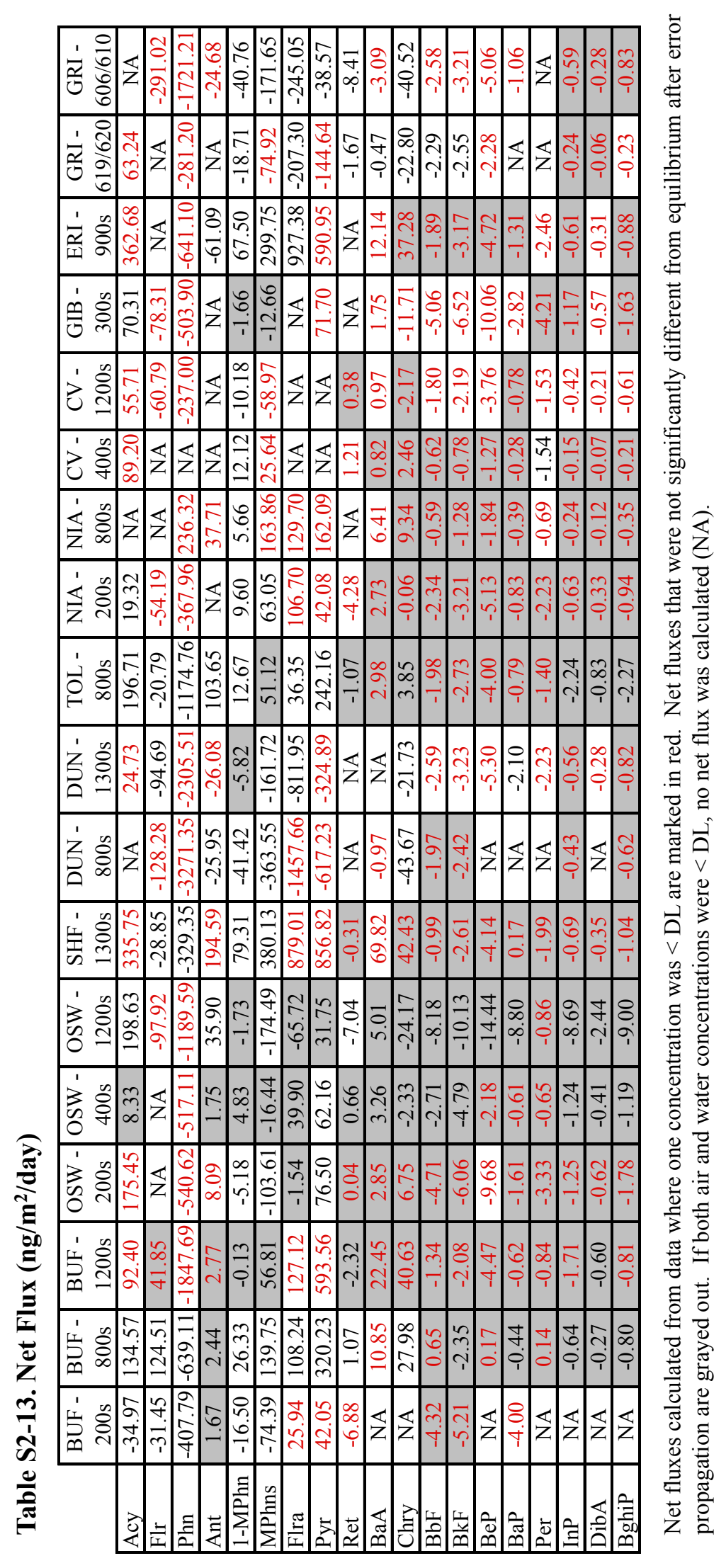


Figure S2-9. Flux Ratio $\left(\mathrm{C}_{\mathrm{PEw}} / \mathrm{C}_{\mathrm{PEa}}-1\right)$ with Propagated Error
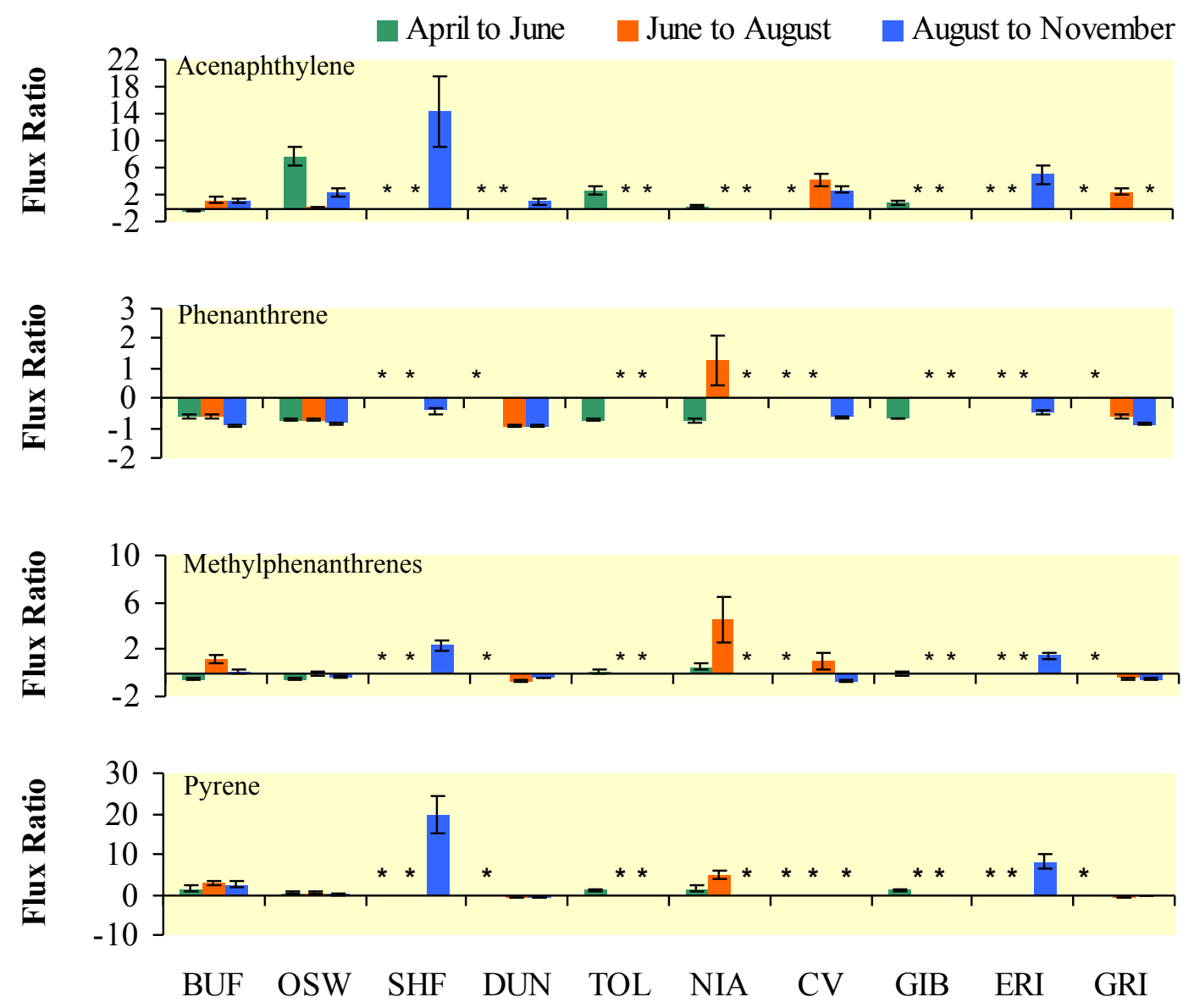

'*' marks samples for which no data was available or both air and water concentrations were $<$ DL. 


\section{LITERATURE CITED IN SUPPORTING INFORMATION}

(1) NOAA National Data Buoy Center Historical Archive http://www.ndbc.noaa.gov/hmd.shtml (accessed Dec 15, 2013).

(2) Minar, N. Wind History http://windhistory.com/ (accessed Dec 15, 2013).

(3) NOAA. NOAA National Climatic Data Center http://www.ncdc.noaa.gov/ (accessed Feb 1, 2014).

(4) USGS. USGS National Water Information System: Web Interface http://www.usgs.gov/water/ (accessed Jan 22, 2014).

(5) Melymuk, L.; Robson, M.; Csiszar, S. A.; Helm, P. A.; Kaltenecker, G.; Backus, S.; Bradley, L.; Gilbert, B.; Blanchard, P.; Jantunen, L. M.; Diamond, M. L. From the city to the lake: Loadings of PCBs, PBDEs, PAHs and PCMs from Toronto to Lake Ontario. Environ. Sci. Technol. 2014, 48, 3732-3741, DOI:10.1021/es403209z.

(6) Arvai, A.; Klecka, G.; Jasim, S.; Melcer, H.; Laitta, M. T. Protecting our Great Lakes: Assessing the effectiveness of wastewater treatments for the removal of chemicals of emerging concern. Water Qual. Res. J. Canada 2014, 49, 23-31, DOI:10.2166/wqrjc.2013.104.

(7) Center for International Earth Science Information Network (CIEISIN); Columbia University; International Food Policy Research Institute (IFPRI); The World Bank; Centro Internacional de Agricultura Tropical (CIAT). Global Rural-Urban Mapping Project, Version 1 (GRUMPv1): Population Count Grid http://sedac.ciesin.columbia.edu/data/set/grump-v1-population-count. (accessed Jun 3, 2013).

(8) Booij, K.; Smedes, F.; van Weerlee, E. M. Spiking of performance reference compounds in low density polyethylene and silicone passive water samplers. Chemosphere 2002, 46, 1157-1161, DOI:10.1016/S0045-6535(01)00200-4.

(9) Antweiler, R. C.; Taylor, H. E. Evaluation of statistical treatments of leftcensored environmental data using coincident uncensored data sets: I. Summary statistics. Environ. Sci. Technol. 2008, 42, 3732-3738, DOI:10.1021/es071301c.

(10) Petrich, N. T.; Spak, S. N.; Carmichael, G. R.; Hu, D.; Martinez, A.; Hornbuckle, K. C. Simulating and explaining passive air sampling rates for semivolatile compounds on polyurethane foam passive samplers. Environ. Sci. Technol. 2013, 47, 8591-8598, DOI:10.1021/es401532q. 
(11) Klánová, J.; Eupr, P.; Kohoutek, J.; Harner, T. Assessing the influence of meteorological parameters on the performance of polyurethane foam-based passive air samplers. Environ. Sci. Technol. 2008, 42, 550-555, DOI:10.1021/es072098o.

(12) Allan, I. J.; Harman, C.; Ranneklev, S. B.; Thomas, K. V; Grung, M. Passive sampling for target and nontarget analyses of moderately polar and nonpolar substances in water. Environ. Toxicol. Chem. 2013, 32, 1718-1726, DOI:10.1002/etc.2260.

(13) Ruge, Z. Air-water exchange and trends of persistent bioaccumulative toxics (PBTs) across Lake Superior. Master's Thesis., University of Rhode Island, 2013.

(14) Morgan, E. J.; Lohmann, R. Detecting air-water and surface-deep water gradients of PCBs using polyethylene passive samplers. Environ. Sci. Technol. 2008, 42, 7248-7253, DOI:10.1021/es800518g.

(15) Schwarzenbach, R. P.; Gschwend, P. M.; Imboden, D. M. Environmental Organic Chemistry; 2nd ed; Wiley Interscience, 2002.

(16) Melymuk, L.; Robson, M.; Helm, P. A.; Diamond, M. L. PCBs, PBDEs, and PAHs in Toronto air: spatial and seasonal trends and implications for contaminant transport. Sci. Total Environ. 2012, 429, 272-280, DOI:10.1016/j.scitotenv.2012.04.022.

(17) Gustafson, K. E.; Dickhut, R. M. Particle / Gas Concentrations and distributions of PAHs in the atmosphere of Southern Chesapeake. Environ. Sci. Technol. 1997, 31, 140-147, DOI:10.1021/es9602197.

(18) Beletsky, D.; Saylor, J. H.; Schwab, D. J. Mean circulation in the Great Lakes. J. Great Lakes Res. 1999, 25, 78-93, DOI:10.1016/S0380-1330(99)70718-5.

(19) Lohmann, R. Critical review of low-density polyethylene's partitioning and diffusion coefficients for trace organic contaminants and implications for its use as a passive sampler. Environ. Sci. Technol. 2012, 46, 606-618, DOI:10.1021/es202702y.

(20) Lohmann, R.; Klánová, J.; Kukucka, P.; Yonis, S.; Bollinger, K. PCBs and OCPs on a east-to-west transect: The importance of major currents and net volatilization for PCBs in the Atlantic Ocean. Environ. Sci. Technol. 2012, 46, 10471-10479, DOI:10.1021/es203459e. 
(21) Ma, Y.-G.; Lei, Y. D.; Xiao, H.; Wania, F.; Wang, W.-H. Critical review and recommended values for the physical-chemical property data of 15 polycyclic aromatic hydrocarbons at $25{ }^{\circ} \mathrm{C}$. J. Chem. Eng. Data 2010, 55, 819-825, DOI:10.1021/je900477x.

(22) Beyer, A.; Wania, F.; Gouin, T.; Mackay, D.; Matthies, M. Selecting internally consistent physicochemical properties of organic compounds. Environ. Toxicol. Chem. 2002, 21, 941-953, DOI:10.1002/etc.5620210508. 


\section{CHAPTER 3}

\section{POLYCYCLIC MUSKS IN THE AIR AND WATER OF THE LOWER GREAT}

LAKES: SPATIAL DISTRIBUTION AND VOLATILIZATION FROM SURFACE WATERS

This manuscript has been published in and is formatted for the journal Environmental Science and Technology, 2016, 50(21), pp 11575-11583, DOI:

10.1021/acs.est.6b03657.

Carrie A. McDonough ${ }^{\dagger}$, Paul A. Helm ${ }^{*}$, Derek C. G. Muir ${ }^{\S}$, Gavino Puggionill, Rainer $\operatorname{Lohmann}^{\dagger *}$

${ }^{\dagger}$ University of Rhode Island Graduate School of Oceanography

Ontario Ministry of the Environment and Climate Change, Toronto, Ontario, Canada M9P 3V6

${ }^{\S}$ Environment and Climate Change Canada, Aquatic Contaminants Research Division, Ontario, Canada L7S 1A1

"Department of Computer Science and Statistics, University of Rhode Island

*Corresponding author email: rlohmann@uri.edu; phone: 401.874.6612; fax:

401.874 .6811 


\section{ABSTRACT}

Polycyclic musks (PCMs) are synthetic fragrance compounds used in personal care products and household cleaners. Previous studies have indicated that PCMs are introduced to aquatic environments via wastewater and river discharge. Polyethylene passive samplers (PEs) were deployed in air and water during winter 2011 and summer 2012 to investigate the role of population centers as sources of these contaminants to the Great Lakes and determine whether the lakes were acting as sources of PCMs via volatilization. Average gaseous $\Sigma_{5} \mathrm{PCM}$ ranged from below detection limits $(<\mathrm{DL})$ to $3.2 \mathrm{ng} / \mathrm{m}^{3}$ on the western shoreline of Lake Erie in Toledo. Average dissolved $\Sigma_{5} \mathrm{PCM}$ ranged from $<\mathrm{DL}$ to $2.6 \mathrm{ng} / \mathrm{L}$ on the southern shore of Lake Ontario near the mouth of the Oswego River. Significant correlations were observed between population density and $\Sigma_{5} \mathrm{PCM}$ in both air and water, with strongest correlations within a 25 and $40 \mathrm{~km}$ radius, respectively. At sites where $\mathrm{HHCB}$ was detected it was generally volatilizing, while the direction of AHTN air-water exchange was variable. Volatilization fluxes of $\mathrm{HHCB}$ ranged from $11 \pm 6$ to $341 \pm 127$ $\mathrm{ng} / \mathrm{m}^{2} /$ day, while air-water exchange fluxes of AHTN ranged from $-3 \pm 2$ to $28 \pm 10$ $\mathrm{ng} / \mathrm{m}^{2} /$ day. Extrapolation of average air-water exchange flux values over the surface area of the lakes' coastal boundary zone suggested volatilization may be responsible for the loss of 64-213 kg/year of dissolved $\Sigma_{5} \mathrm{PCM}$ from the lakes. 


\section{INTRODUCTION}

Polycyclic musks (PCMs) are ubiquitous pollutants widely used as additives in personal care products and household cleaners to lend them a long-lasting, pleasing odor. $^{1-3}$ Previous studies have indicated that PCMs are introduced to aquatic environments, including the Great Lakes, via effluent from wastewater treatment plants (WWTPs) and river discharge..$^{3-6}$ One of the most widely used PCMs, 1,3,4,6,7,8-hexahydro-4,6,6,7,8,8-hexamethylcyclopenta-(g)-2-benzopyran (HHCB, or Galaxolide), was listed as one of Howard and Muir's top 50 high priority pollutants with persistence and bioaccumulation potential in need of increased monitoring. ${ }^{7}$ The effects of PCMs on aquatic organisms are largely unknown, but they have been found to bioaccumulate ${ }^{8-10}$ and recent studies suggest environmentally relevant concentrations may cause oxidative stress and genetic damage in some organisms. ${ }^{11}$

Polyethylene passive samplers (PEs) are promising tools for measuring hydrophobic organic contaminants (HOCs) at high spatial resolution because they are cost-effective, require no electricity, and are simple to deploy. ${ }^{12}$ PEs sequester the dissolved or gaseous fraction of HOCs from the surrounding water or air over time, allowing measurement of time-integrated concentrations. ${ }^{13-16}$ They have been used to measure a wide variety of HOCs in air and water and to calculate air-water exchange fluxes, ${ }^{17-20}$ but they have not been applied to the study of air-water exchange for PCMs.

The use of PEs in this study provided a unique opportunity to measure the truly gaseous and dissolved fraction of PCMs available for air-water exchange and determine whether gaseous PCMs were volatilizing from surface waters in Lake Erie 
and Lake Ontario. On the basis of previous work, volatilization may be an important loss route for PCMs in the Great Lakes, ${ }^{4,5}$ but fluxes had not been determined by simultaneous air and water sampling. In this study, PEs were deployed in air and water during winter 2011 and summer 2012 to (i) measure baseline gaseous and dissolved concentrations of PCMs in and above Lakes Erie and Ontario, (ii) investigate the role of population centers as sources of these contaminants, (iii) determine whether the lakes were acting as sources of PCMs via volatilization, and (iv) explore how PE-derived PCM air-water exchange fluxes respond to non steadystate conditions.

\section{MATERIALS AND METHODS}

Sampler Preparation and Deployment. Prior to deployment, PEs were preextracted in solvent and loaded with performance reference compounds (PRCs) dibromobiphenyl, tetrabromobiphenyl, pentabromobiphenyl, naphthalene- $\mathrm{d}_{8}$, pyrene$\mathrm{d}_{10}$, and benzo(a)pyrene- $\mathrm{d}_{12}$ as described previously. ${ }^{19}$ The PE deployment schedule and meteorological parameters, including the number of days each PE was deployed, are summarized in Supporting Information (SI) Table S1. Average temperature and wind speed were determined using data from the nearest available meteorological buoy (Table S3-2, Figure S3-1).

Shoreline PEs were deployed by trained volunteers as previously described. ${ }^{19}$ Briefly, volunteers hung air PEs inside protective metal bowls at a height of about 1.5 $\mathrm{m}$, and tethered water PEs to an anchored line so that they would be secured about $1 \mathrm{~m}$ beneath the water's surface. Offshore and nearshore deployments were carried out by 
workers at Environment Canada and the Ontario Ministry of the Environment, as described previously by Liu et al. ${ }^{17}$ Air PEs were secured in a protective chamber $2 \mathrm{~m}$ above the water's surface on a buoy and water PEs were enclosed within a perforated metal cage and secured to the buoy about $4 \mathrm{~m}$ below the water's surface. After the PEs were recovered, they were shipped back to the laboratory overnight on ice and frozen until extraction.

Extraction and Analysis. PEs from 56 atmospheric deployments (including 9 overwinter deployments) and 39 aqueous deployments were extracted and analyzed. All PEs were spiked with labeled PAHs (acenaphthene- $\mathrm{d}_{10}$, phenanthrene- $\mathrm{d}_{10}$, chrysene- $\mathrm{d}_{12}$, and perylene- $\mathrm{d}_{12}$ ) and extracted for $18-24 \mathrm{~h}$ in pentane, concentrated to $<100 \mu \mathrm{L}$, and spiked with injection standard p-terphenyl-d $\mathrm{d}_{14}$. All extracts from aqueous PEs were passed through silica gel/sodium sulfate cleanup columns. Extracts were analyzed for five PCMs: 1,3,4,6,7,8-hexahydro-4,6,6,7,8,8hexamethylcyclopenta-(g)-2-benzopyran (HHCB, or Galaxolide), 7-acetyl-1,1,3,4,4,6hexamethyl-1,2,3,4-tetrahydronaphthalene (AHTN, or Tonalide), 4-acetyl-1,1dimethyl-6-tert-butylindan (ADBI, or Celestolide), 6-acetyl-1,1,2,3,3,5hexamethylindan (AHMI, or Phantolide), 5-acetyl-1,1,2,6-tetramethyl-3isopropylindane (ATII, or Traesolide) and two nitromusks: 1-tert-butyl-3,5-dimethyl2,4,6-trinitrobenzene (musk xylene) and 4-acetyl-1-tert-butyl-3,5-dimethyl-2,6dinitrobenzene (musk ketone). This was done using an Agilent 6890 gas chromatograph (GC) with a J\&W Scientific DB-5 MS fused silica capillary column (30 $\mathrm{m} \times 0.25 \mathrm{~mm}$ i.d.) with the injection port set to $275^{\circ} \mathrm{C}$ and helium flow set to 1.9 $\mathrm{mL} / \mathrm{min}$, coupled to an Agilent 5973 mass spectrometric detector (MSD) in electron 
ionization (EI) mode with ion source at $230{ }^{\circ} \mathrm{C}$, quadrupole at $150{ }^{\circ} \mathrm{C}$, and transfer line at $250^{\circ} \mathrm{C}$. Concentrations were corrected for internal standard recoveries.

Quality Control. Every batch of PEs was extracted alongside a laboratory blank and two additional blanks extracted in solvent spiked with all target compounds. Spiked samples were used to track losses during extraction, concentration, and cleanup. Average recoveries ranged from $79 \%$ for musk xylene to $145 \%$ for musk ketone (Table S3). The relative percent differences (RPD) between ambient concentrations from duplicate samplers are shown in Table S4. For air PEs, the mean RPD was 18\% for HHCB and $21 \%$ for AHTN ( $\mathrm{n}=18$ ). For water PEs, the mean RPD was $15 \%$ for HHCB and $25 \%$ for AHTN ( $\mathrm{n}=14)$.

Field blanks were sent to each volunteer along with PEs intended for deployment. Field blanks were transported to the sampling site along with other PEs, taken out of their packaging, handled by the volunteer, and then immediately repackaged and shipped back to the laboratory for analysis. Concentrations of target compounds in deployed PEs were blank-subtracted using the most relevant field blank. For offshore deployments done from research vessels, all field blanks taken during the cruise were averaged and the average field blank value was subtracted from all samples collected.

After blank subtraction, the detection limit (DL) in ng/g PE was defined as twice the standard deviation for all 11 laboratory blanks, as these samples were representative of the typical variability in background concentrations in the laboratory. Concentrations below detection limits were replaced with zero. Average blank concentrations and detection limits per gram of polyethylene are shown in Table S5. 
For HHCB, which was typically found at greater concentrations than the other PCMs in the blanks, average blank concentrations were $13 \mathrm{ng} / \mathrm{g} \mathrm{PE}, 28 \mathrm{ng} / \mathrm{g} \mathrm{PE}$, and $4 \mathrm{ng} / \mathrm{g}$ PE in laboratory blanks, shoreline volunteer field blanks, and shipboard field blanks, respectively.

To better describe the detection limits for PEs, typical DLs in ng/g PE were translated to air and water concentrations using the average percent equilibration for each site type and assuming an average temperature of $18.85^{\circ} \mathrm{C}$ for summer deployments and $4.85^{\circ} \mathrm{C}$ for winter deployments (Table S6). For air samples, typical ambient detection limits were about $0.9 \mathrm{ng} / \mathrm{m}^{3}$ for $\mathrm{HHCB}$ and $0.07 \mathrm{ng} / \mathrm{m}^{3}$ for AHTN at summer shoreline and offshore sites, and $0.2 \mathrm{ng} / \mathrm{m}^{3}$ for HHCB and $0.01 \mathrm{ng} / \mathrm{m}^{3}$ for AHTN at winter shoreline sites. In water samples, typical detection limits were about $0.6 \mathrm{ng} / \mathrm{L}$ for $\mathrm{HHCB}$ and $0.04 \mathrm{ng} / \mathrm{L}$ for $\mathrm{AHTN}$, with no significant difference between offshore and shoreline samples. Actual detection limits varied from site to site depending on the PE's sampling rate, and all blank subtraction was done using concentrations per weight of polyethylene, before conversion to ambient air and water concentrations.

Percent detection for target compounds is presented in Table S7. HHCB and AHTN were found in $15 \%$ and $68 \%$ of all shoreline air PEs deployed in this study and in $38 \%$ and $54 \%$ of offshore/nearshore air PEs. In water, HHCB and AHTN were found in $45 \%$ and $60 \%$ of shoreline PEs and in $47 \%$ and $79 \%$ of offshore PEs.

Physico-Chemical Properties. Physico-chemical properties of all target analytes and PRCs are presented in Table S8. PE-air partitioning coefficients $\left(\mathrm{K}_{\mathrm{PEA}}\right)$ were determined from regression with subcooled liquid vapor pressure as in Khairy and 
Lohmann. ${ }^{15}$ PE-water partitioning coefficients $\left(\mathrm{K}_{\mathrm{PEW}}\right)$ were calculated from solubility as in Lohmann. ${ }^{21} \mathrm{~K}_{\mathrm{PEA}}, \mathrm{K}_{\mathrm{PEW}}$, and diffusivity in air $\left(\mathrm{D}_{\mathrm{a}}\right)$ and water $\left(\mathrm{D}_{\mathrm{w}}\right)$ for each compound were corrected for each deployment's mean temperature, as detailed further in the SI.

Sampling Rates and Ambient Concentrations. To determine ambient concentration $\left(\mathrm{C}_{\mathrm{a}}\right)$, the concentration in the $\mathrm{PE}\left(\mathrm{C}_{\mathrm{PE}}\right)$ was adjusted for the percent equilibration $(f)$ reached during deployment as in Equation 1. A detailed summary of these calculations is presented in the SI. Briefly, percent loss of each PRC (1-f) was plugged into a generalized exponential model for PE uptake (Equation 2) to derive a best-fit value for the thickness of the diffusive boundary layer $\left(\delta_{\mathrm{DBL}}\right)$ using a nonlinear least-squares fitting method adapted from Booij et al. ${ }^{22}$ In Equation 2, $t$ is total deployment time (listed for each deployment in Table $\mathrm{S} 1$ ), $l_{\mathrm{PE}}$ is half the PE thickness, $\mathrm{K}_{\mathrm{PEM}}$ is the PE-matrix partitioning coefficient, and $\mathrm{k}_{\mathrm{o}}$ is the mass transfer coefficient, which represents the reciprocal sum of PE-side resistance $\left(\mathrm{k}_{\mathrm{PE}}^{-1}\right)$, which is dependent on $\mathrm{D}_{\mathrm{PE}}$ and $l_{\mathrm{PE}}$, and environmental matrix-side resistance $\left(\mathrm{k}_{\mathrm{m}}{ }^{-1}\right)$, which is dependent on $\mathrm{D}_{\mathrm{a}}$ or $\mathrm{D}_{\mathrm{w}}$ and $\delta_{\mathrm{DBL}}$. Best-fit $\delta_{\mathrm{DBL}}$ values were used to estimate $f$ reached by each PCM during each deployment.

$$
\begin{gathered}
C_{a}=\frac{C_{P E}}{K_{P E A} \cdot f} \\
f=1-e^{\frac{-t \cdot k_{0} \cdot A_{P E}}{K_{P E M} \cdot V_{P E}}}
\end{gathered}
$$


Average $f$ values for each PCM are presented in Table S9 and show that HHCB and AHTN generally reached $\geq 95 \%$ equilibrium in both air and water. Average $\delta_{\mathrm{DBL}} \mathrm{S}$ for air boundary layers $\left(\delta_{\mathrm{ABL}}\right)$ were lower for offshore/nearshore PEs $(0.2 \pm 0.1 \mathrm{~mm}$; average $\pm \mathrm{SD})$ than for shoreline PEs $(1.8 \pm 1.4 \mathrm{~mm}$ in summer and $1.4 \pm 0.5 \mathrm{~mm}$ in winter). This translated to average HHCB sampling rates of $5.7 \pm 0.9$ $\mathrm{m}^{3} /$ day for winter PEs, $6.9 \pm 2.3 \mathrm{~m}^{3} /$ day for shoreline summer PEs, and $13 \pm 0.9 \mathrm{~m}^{3} /$ day for offshore PEs. Average water boundary layer thickness $\left(\delta_{\mathrm{WBL}}\right)$ was $170 \pm 63 \mu \mathrm{m}$ at shoreline sites and $82 \pm 25 \mu \mathrm{m}$ at offshore sites, which translated to average sampling rates for $\mathrm{HHCB}$ of $16 \pm 3.8 \mathrm{~L} /$ day for shoreline PEs and 9.2 $\pm 4.1 \mathrm{~L} /$ day for offshore PEs.

Best-fit $\delta_{\mathrm{DBL}}$ and other compound-specific and site-specific parameters were plugged into the equation for $f$ to determine typical equilibration times for the PCMs measured in this study. HHCB and AHTN tended to equilibrate within about 25 days in water and 19 days in air, so mean concentrations were representative of these time lengths, though PEs were often deployed for longer. Use of thicker polyethylene sheeting in future deployments would allow for time-integrated concentrations of HHCB and AHTN to be measured over longer time periods.

Data Analysis and Statistical Methods. Human population data were extracted from the Global Rural-Urban Mapping Project (GRUMP) Population Count Grid data set provided by Columbia University ${ }^{23}$ and maps were constructed in ArcMap for Desktop 10.3.1. To find the radii at which population and $\Sigma_{5} \mathrm{PCM}$ correlated most strongly, the model with the lowest residual standard error (RSE) was identified using the ordinary least-squares linear modeling function $(l m)$ in $\mathrm{R}^{24}$ Linear models were 
further refined using the robust linear model $(\mathrm{rlm})$ function in the MASS package in $\mathrm{R},{ }^{25}$ which iteratively fits data to a linear model, weighting outliers depending on their distance from the best-fit line. All presented relationships were found to be statistically significant $(\mathrm{p}<0.01)$ using both approaches. Results were plotted using $\mathrm{R}$ package ggplot $2{ }^{26}$

Air-Water Exchange Calculations. Thirty-two pairs of codeployed air and water PEs were used to investigate time-integrated air-water exchange fluxes. The direction of exchange was determined by calculating the ratio of fugacity in water to fugacity in $\operatorname{air}\left(f_{\mathrm{w}} / f_{\mathrm{a}}\right)$ as in Equation 3, where $\mathrm{C}_{\infty, \mathrm{w}}$ and $\mathrm{C}_{\infty, \mathrm{a}}$ represent the concentration of the compound in the PE once it has reached equilibrium with surrounding water and air, respectively.

$$
\frac{f_{w}}{f_{a}}=\frac{C_{\infty, w}}{C_{\infty, a}}
$$

A value of $f_{\mathrm{w}} / f_{\mathrm{a}}>1$ indicates volatilization, while $f_{\mathrm{w}} / f_{\mathrm{a}}<1$ indicates absorption. In cases where the concentration in both air and water were $<\mathrm{DL}$, no fugacity ratio was calculated. In cases where the concentration in one medium was $<\mathrm{DL}$, but was $>\mathrm{DL}$ in the other medium, a fugacity ratio was calculated by replacing the $<$ DL value with the DL value, as this resulted in the most conservative estimate for the fugacity ratio (see Figure S3-2).

Values for $\mathrm{C}_{\infty, \mathrm{w}}$ and $\mathrm{C}_{\infty, \mathrm{a}}$ were determined by correcting the concentration in the $\mathrm{PE}\left(\mathrm{C}_{\mathrm{PE}}\right)$ using the calculated percent equilibrium $(f)$ reached by each compound during deployment. In most cases for $\mathrm{AHTN}$ and $\mathrm{HHCB}, \mathrm{C}_{\infty} \sim \mathrm{C}_{\mathrm{PE}}$ because they equilibrated during deployment. The uncertainty in the fugacity ratio was calculated by propagating the uncertainty in the parameters used to calculate $\mathrm{C}_{\infty, \mathrm{a}}$ and $\mathrm{C}_{\infty, \mathrm{w}}$, which 
is detailed further in the SI. In cases where the fugacity ratio was within one standard deviation from equilibrium, it was not considered significantly different from equilibrium and no flux was calculated.

Air-water exchange fluxes $\left(\mathrm{F}_{a / w}\right)$ were calculated using an approach based on the Whitman two-film model ${ }^{27}$ as described in Schwarzenbach et al. ${ }^{28}$ with wind speed's effect on water-side mass transfer determined using a Weibull distribution to account for the nonlinearity of the effect of wind speed on mass transfer. ${ }^{29}$ The mass transfer coefficient $\left(v_{\mathrm{a} / \mathrm{w}}\right)$ was multiplied by the concentration gradient as in Equation 4, where $\mathrm{K}_{\mathrm{PEW}, \mathrm{T} 2}$ is the PE-water partitioning coefficient corrected for deployment temperature. Similar approaches have previously been used to estimate air-water exchange fluxes from PE pairs for polychlorinated biphenyls (PCBs), polybrominated diphenyl ethers (PBDEs), and polycyclic aromatic hydrocarbons (PAHs) in the Great Lakes, ${ }^{20,17,30}$ but PCMs have not been investigated. Uncertainty in exchange fluxes was calculated using the uncertainty of the parameters used to calculate $\mathrm{C}_{\infty, \mathrm{a}}, \mathrm{C}_{\infty, \mathrm{w}}$, and $\mathrm{K}_{\mathrm{PEW}, \mathrm{T} 2}$, and assuming $30 \%$ relative uncertainty in $v_{\mathrm{a} / \mathrm{w} .}{ }^{31}$ Calculations and error propagation are detailed further in the SI.

$$
F_{a / w}=v_{a / w} \cdot \frac{\left(C_{\infty, w}-C_{\infty, a}\right)}{K_{P E W, T 2}}
$$

\section{RESULTS AND DISCUSSION}

Dissolved PCM Concentrations. Average dissolved $\Sigma_{5} \mathrm{PCM}$ ranged from $<\mathrm{DL}$ at Cape Vincent (CV) in eastern Lake Ontario to $2.6 \mathrm{ng} / \mathrm{L}$ near the mouth of the Oswego 
River (OSW) on the southern shoreline of Lake Ontario. Average dissolved concentrations of AHTN and HHCB are shown in Figure 3-1A.

Average dissolved PCMs are summarized in Table 3-1. Along the southeastern shore of Lake Erie and the northeastern shore of Lake Ontario, concentrations were similar to offshore levels $\left(\Sigma_{5} \mathrm{PCM}<100 \mathrm{pg} / \mathrm{L}\right)$ and $\mathrm{HHCB}$ was generally $<\mathrm{DL}$, while concentrations were elevated nearer to the urban centers of Toronto and Cleveland and along the southern shore of Lake Ontario. Variation in dissolved $\Sigma_{5} \mathrm{PCM}$ over multiple deployments is shown in Figure S3-3.

Overall, concentrations reported from PEs were similar but lower than previous results: Peck and Hornbuckle measured PCMs in Lake Michigan in 19992000 using shipboard active sampling with XAD-2 resin and reported means of $5 \mathrm{ng} / \mathrm{L}$ for HHCB and $1 \mathrm{ng} / \mathrm{L}$ for AHTN. ${ }^{4}$ Helm et al. estimated concentrations of $0.2-10$ $\mathrm{ng} / \mathrm{L}$ and $0.1-10 \mathrm{ng} / \mathrm{L}$ for HHCB and AHTN, respectively, east of Toronto in June 2008 using semipermeable membrane devices (SPMDs). ${ }^{32}$ In offshore Lake Ontario, Andresen et al. measured HHCB and AHTN by liquid-liquid extraction of water samples at $2.0 \mathrm{ng} / \mathrm{L}$ and $0.2 \mathrm{ng} / \mathrm{L}$, with concentrations increasing to $7.0 \mathrm{ng} / \mathrm{L}$ for HHCB and $0.8 \mathrm{ng} / \mathrm{L}$ for AHTN in Hamilton Harbor. ${ }^{33}$ Concentrations in this study were typically lower than those in urban creeks near Toronto $(2-1000 \mathrm{ng} / \mathrm{L}$, with lower concentrations $(0.04-18 \mathrm{ng} / \mathrm{L})$ in the less populated Rouge River watershed). ${ }^{5}$ This was expected, as the sites monitored in this study were not as directly representative of upriver source regions.

At sites where both HHCB and AHTN were detected, the ratio of HHCB:AHTN ranged from 7 to 12 , with an average of $10 \pm 2$, which was similar to that 
reported by Buerge et al. for summertime surface waters in a Swiss lake (HHCB:AHTN 6 - 9) and by Andresen et al. in Lake Ontario in 2005 ( 10). ${ }^{33,34}$ HHCB:AHTN ratios were, in most cases, greater than those measured in source region studies. Buerge et al. estimated that the half-life of HHCB with respect to photolysis in water was about 25 times longer than for AHTN, so increasing HHCB:AHTN ratio in water with distance from source was expected. ${ }^{34}$

Nitromusks were not found above a 3:1 signal/noise level in the majority of water samples and were therefore omitted from discussion. Previous studies generally found musk xylene and musk ketone at levels near or below this study's typical detection limits (19 pg/L for musk xylene and $225 \mathrm{pg} / \mathrm{L}$ for musk ketone). Peck and Hornbuckle found median concentrations in Lake Michigan of $49 \mathrm{pg} / \mathrm{L}$ for musk xylene and $81 \mathrm{pg} / \mathrm{L}$ for musk ketone, and Andresen et al. measured both nitromusks at about $40 \mathrm{pg} / \mathrm{L}$ in Hamilton Harbor, Lake Ontario., ${ }^{4,33}$

Gaseous PCM Concentrations. Average summertime $\Sigma_{5} \mathrm{PCM}$ ranged from $<\mathrm{DL}$ at sites in Erie (ERI) and Sheffield Lake (SHF) on the southern Lake Erie shoreline, Prince Edward Point (PEP) in northern nearshore Lake Ontario, and eastern offshore Lake Erie (EERI), to $3.2 \mathrm{ng} / \mathrm{m}^{3}$ in Toledo (TOL). Concentrations of all gaseous PCMs are summarized in Table 3-2. Average summertime HHCB and AHTN concentrations are displayed in Figure 3-1B. Summertime concentrations were lowest at offshore buoy sites $\left(<300 \mathrm{pg} / \mathrm{m}^{3}\right.$, with HHCB $\left.<\mathrm{DL}\right)$, with the exception of three buoy sites near the Toronto waterfront, where concentrations were comparable to or greater than those at shoreline sites. Concentrations at shoreline sites were generally greater in the 
summer than in the winter. Variations in $\Sigma_{5} \mathrm{PCM}$ over multiple deployments are depicted in Figure S3-4.

A possible explanation for the low incidence of detection of $\mathrm{HHCB}$ in this study is its short atmospheric lifetime (about $5.3 \mathrm{~h}$ ) with respect to photolysis. ${ }^{35}$ HHCB:AHTN ratios in air have previously been shown to decrease with distance from source regions, suggesting that gaseous HHCB may degrade more rapidly than AHTN. ${ }^{36}$ At sites where both AHTN and HHCB were $>$ DL, the average HHCB:AHTN ratio ranged from 3.8 in eastern nearshore Toronto (ETOR) to 6.6 in Toledo (TOL), with an average value of $5 \pm 1$, somewhat similar to ratios measured by Xie et al. in rural Germany (median 3.5). ${ }^{36}$

PCMs are relatively volatile $(0.02-1.2 \mathrm{~Pa})^{4}$ compared to other semivolatile organic contaminants (SVOCs) and a significant fraction of these compounds $(>80 \%)$ is typically found in the gaseous phase, suggesting that PE-derived concentrations should match those from other air sampling techniques. Indeed, results from previous studies were similar: Peck and Hornbuckle measured gas-phase PCMs in 1999-2001 using XAD-2 resin throughout the Great Lakes and found average urban $\sum_{2} \mathrm{PCM}$ $(\mathrm{AHTN}+\mathrm{HHCB})$ around $1-5 \mathrm{ng} / \mathrm{m}^{3}$ with mean offshore Lake Erie and Lake Ontario concentrations $<0.5 \mathrm{ng} / \mathrm{m}^{3}{ }^{37}$ Furthermore, average $\sum_{2} \mathrm{PCM}$ concentrations in Toronto nearshore air measured in this study $\left(1.6-3.1 \mathrm{ng} / \mathrm{m}^{3}\right)$ were comparable to those measured by Melymuk et al. during 2007-2008 using polyurethane foam (PUF) samplers within $10 \mathrm{~km}$ of the Toronto central business district $\left(0.89-3.5 \mathrm{ng} / \mathrm{m}^{3}\right) .{ }^{38}$

As in water, the nitromusks were not found above 3:1 signal/noise levels in the majority of air samples and were therefore omitted from discussion. In previous work 
by Peck and Hornbuckle in the lower Great Lakes region, nitromusks in air were found above method reporting limits only intermittently and at levels under 80 $\mathrm{pg} / \mathrm{m}^{3} \cdot{ }^{37}$

Correlation of PCM Concentrations with Population Density. Previous studies have identified population centers as sources of gaseous PCMs to ambient air ${ }^{37}$ and have shown correlations between population density and PCMs in air and water. ${ }^{34,39,40}$ To investigate the relationship between PCMs and population density in the lower Great Lakes, average summertime concentrations were compared to population within 2 to $50 \mathrm{~km}$ of each site. The strongest correlations found for gaseous and dissolved PCMs are displayed in Figure 3-2.

Gaseous $\Sigma_{5} \mathrm{PCM}$ exhibited significant $(\mathrm{p}<0.01)$ correlation with population within a $15-50-\mathrm{km}$ radius of each site. The correlation was strongest when considering population within $25 \mathrm{~km}(\mathrm{p}<0.001 ; \mathrm{SE}=0.33 ; n=22)$. The two locations with the greatest residuals were Toledo (TOL) and Cleveland Edgewater (CLE), both of which exhibited greater gaseous $\Sigma_{5} \mathrm{PCM}$ than would be predicted from population based on the presented regression. This suggests elevated concentrations in these areas may be caused by nearby point sources not representative of the surrounding region.

Dissolved $\Sigma_{5}$ PCM exhibited significant $(\mathrm{p}<0.01)$ correlation with population within a $20-40-\mathrm{km}$ radius of each site, with the strongest correlation observed when considering population within $40 \mathrm{~km}(\mathrm{p}<0.005 ; \mathrm{SE}=0.26 ; n=20)$. The strong correlation at such a large radius may be because spatial distributions are influenced by wastewater outfalls and river mouths, both of which are point sources that represent 
a much larger area's population (the watershed). Concentrations near the mouth of Oswego River exhibited the greatest residuals, again suggesting a nearby point source. River and Wastewater Discharge. Dissolved PCMs were elevated at many shoreline sites impacted by nearby WWTPs designated as major dischargers by the U.S. Environmental Protection Agency (EPA) National Pollutant Discharge Elimination System (NPDES), ${ }^{41}$ many of which discharged directly into the lakes. More details on sites with elevated concentrations and possible sources are included in the SI.

Air-Water Exchange. Fugacity Ratios. Fugacity ratios for all air-water PE pairs are displayed in Table S3-10 and depicted in Figure S3-2. At all sites where HHCB was detected in air and/or water, fugacity ratios suggested it was volatilizing out of surface waters. Fugacity ratios for AHTN also suggested volatilization from surface waters near Toronto and along the southern shore of Lake Ontario, though AHTN was near equilibrium or absorbed into surface waters at some other sites.

The greatest fugacity ratios for both $\operatorname{AHTN}\left(f_{w} / f_{a}=7\right)$ and $\operatorname{HHCB}\left(f_{w} / f_{a}=18\right)$ were calculated for the PE pair from the late-summer deployment near the mouth of the Oswego River (OSW), during which greater dissolved PCMs were measured than during any other deployment $\left(\Sigma_{5} \mathrm{PCM}=4.8 \mathrm{ng} / \mathrm{L}\right)$. Fugacity ratios were generally not significantly different from equilibrium at sites on the southeastern shore of Lake Erie (ERI, DUN, BUF), the northeastern Lake Ontario shoreline/nearshore (CV, PEP, $\mathrm{CHB}$ ), or at the offshore sites (CERI, EERI).

\section{PE-Derived Air-Water Exchange Fluxes at Non-Steady-State Conditions.} Values of $v_{a / w}$ calculated for HHCB and AHTN ranged from 4.5-8.8 cm/day, which was somewhat slower than rates for PCBs calculated by Liu et al. (15-63 cm/day) and 
within the range for 4-ring PAHs calculated by McDonough et al. $(1-16 \mathrm{~cm} /$ day $){ }^{20}$ These rates were used along with mass transfer coefficients for PE uptake $\left(\mathrm{k}_{\mathrm{o}}\right)$ of HHCB from air (181-6,905 cm/day) and water (14-47 cm/day) to determine how airwater exchange fluxes derived from codeployed air and water PEs compared to actual values in scenarios where concentrations in air and water are not at steady state.

A model was written in $\mathrm{R}$ in which air and water concentrations of $\mathrm{HHCB}$ were set to vary every $6 \mathrm{~h}$ over 100 days. In Scenario 1, both air and water concentrations fluctuated randomly between minimum and maximum values based on realistic concentration ranges from this and previous studies $\left(1-6 \mathrm{ng} / \mathrm{m}^{3}\right.$ in air; $0.5-8$ $\mathrm{ng} / \mathrm{L}$ in water). In Scenario 2, air concentrations fluctuated randomly around a steadily increasing mean from 5 to $12 \mathrm{ng} / \mathrm{m}^{3}$ and water concentrations declined from 6 to $1 \mathrm{ng} / \mathrm{L}$, also with random fluctuations, resulting in a reversal of the flux direction during the deployment. The air-water exchange flux $\left(\mathrm{F}_{\mathrm{aw}}\right)$ at each time point was calculated from the simulated air and water concentrations at that time.

At each time point, the mass of HHCB accumulated in air and water PEs in response to the fluctuating ambient concentrations was computed, and the PE-derived air-water exchange flux $\left(\mathrm{F}_{\mathrm{aw}, \mathrm{PE}}\right)$ was calculated based on the concentrations of $\mathrm{HHCB}$ in the codeployed PEs at that time. $\mathrm{F}_{\mathrm{aw}}$ was then compared to $\mathrm{F}_{\mathrm{aw}, \mathrm{PE}}$ by calculating the RPD between the two values. An example from Scenario 2, in which $\mathrm{F}_{\text {aw }}$ decreased throughout the simulated deployment, is displayed in Figure 3-3. $F_{a w, P E}$ is shown to steadily decline over the deployment along with $\mathrm{F}_{\mathrm{aw}}$, but $\mathrm{F}_{\mathrm{aw}, \mathrm{PE}}$ does not capture rapid day-to-day changes in the flux and appears to lag behind $\mathrm{F}_{\mathrm{aw}}$ by about 20 days. A similar figure is shown for Scenario 1 in Figure S3-5. 
Each scenario was run 100 times, and each time the RPD between $F_{a w, P E}$ and $\mathrm{F}_{\mathrm{aw}}$ after 100 days of deployment was recorded. Results are presented in Table 3-3 as the mean RPD between $F_{a w, P E}$ and three values: $F_{a w}$ on the last day of the simulated deployment (Day 100), the average $\mathrm{F}_{\text {aw }}$ over the typical equilibration time for HHCB (defined as 22 days, the average of air and water PE equilibrium times), and the average $\mathrm{F}_{\mathrm{aw}}$ over the entire 100-day deployment. Results show that PE-derived exchange fluxes provide a good estimate of mean $\mathrm{F}_{\mathrm{aw}}$ over the last 22 days in both scenarios, though they were not always representative of instantaneous fluxes the day they were recovered, or of average fluxes over the entire deployment period.

Table 3-3 also shows RPDs determined by comparison of "actual” fluxes $\left(\mathrm{F}_{\mathrm{aw}}\right)$ and fluxes that would be derived from weekly grab samples. Grab samples were simulated by taking values of the "actual" concentrations of PCMs in air and water once a week, calculating instantaneous exchange fluxes, and averaging these values over the 100-day deployment, or over the last 22 days. Results suggest that $\mathrm{F}_{\mathrm{aw}, \mathrm{PE}}$ is more representative of the mean $\mathrm{F}_{\mathrm{aw}}$ over the last 22 days than taking 3 weekly grab samples, while weekly grab samples are more appropriate for capturing mean flux over 100 days in cases where the exchange flux changes steadily over time, as in Scenario 2. In summary, PEs resulted in a very good approximation of the actual airwater exchange flux during the compounds' equilibration time window, in some cases superior to weekly grab sampling.

PCM Air-Water Exchange Fluxes. Air-water exchange mass transfer coefficients and exchange fluxes for all PE pairs with fugacity ratios significantly different from equilibrium are provided in Tables S3-11 and S3-12. Figure 3-4 shows 
air-water exchange fluxes calculated for HHCB and AHTN in $\mathrm{ng} / \mathrm{m}^{2} /$ day during each deployment for which data were available. As demonstrated in the previous section, these fluxes were representative of time-averaged air-water exchange fluxes over the last 3 weeks prior to sampler recovery.

Volatilization fluxes of HHCB and AHTN ranged from $11 \pm 6 \mathrm{ng} / \mathrm{m}^{2} /$ day and $3 \pm 2 \mathrm{ng} / \mathrm{m}^{2} /$ day during the first deployment near the shore of Cleveland, OH (CLE) to $341 \pm 127 \mathrm{ng} / \mathrm{m}^{2} /$ day and $28 \pm 10 \mathrm{ng} / \mathrm{m}^{2} /$ day during late summer near the mouth of Oswego River (OSW). Few previous measurements of PCM air-water exchange fluxes are available for comparison. Xie et al. measured median net air-water volatilization of $27 \mathrm{ng} / \mathrm{m}^{2} /$ day and $14 \mathrm{ng} / \mathrm{m}^{2} /$ day for HHCB and AHTN in the North Sea, and measured net deposition of both compounds in the Arctic. ${ }^{36}$

\section{IMPLICATIONS}

Results from this study suggest that WWTPs may be responsible for influencing spatial distributions of dissolved PCMs in the lower Great Lakes, and that PCMs in the lakes were volatilizing from surface waters at many locations near urbanized shorelines. Previous studies of the Great Lakes region have estimated that volatilization is an important loss route for dissolved PCMs. Melymuk et al. estimated that volatilization removes $31 \%$ of total inputs of PCMs from the Toronto area, about $210 \pm 120 \mathrm{~kg} / \mathrm{yr}$, from Lake Ontario. ${ }^{5}$ Peck and Hornbuckle estimated that volatilization was responsible for the loss of about $290 \mathrm{~kg} / \mathrm{yr}$ of PCMs from Lake Michigan. ${ }^{4}$ 
Volatilization fluxes in this study were driven by elevated dissolved concentrations at shoreline and nearshore sites. These elevated concentrations were expected to be entrained in the nearshore coastal boundary zone, which extends from the shoreline to where the depth of the lake exceeds that of the thermocline. ${ }^{42}$ To estimate total losses of dissolved PCMs from the lakes via volatilization, fluxes were averaged over the estimated surface area of the urbanized coastal boundary zone.

The surface area of the Lake Ontario coastal boundary zone was estimated to be $6500 \mathrm{~km}^{2}$ by extracting the area with depth shallower than $50 \mathrm{~m}$ using GIS data from the Great Lakes Commission's Great Lakes Information Network (GLIN), as shown in Figure S3-6. The coastal boundary zone in Lake Erie was more difficult to define, as most of the lake is quite shallow and it does not develop a pronounced seasonal thermocline as does Lake Ontario. From GLIN data, the surface area of Lake Erie shallower than $20 \mathrm{~m}$ was estimated to be $15200 \mathrm{~km}^{2}$.

Averaging fluxes at all Lake Ontario sites yielded a mean $\Sigma_{5} \mathrm{PCM}$ flux of 58 $\mathrm{ng} / \mathrm{m}^{2} /$ day over the coastal boundary zone. Assuming fluxes of this magnitude occurred over $30 \%-100 \%$ the total coastal boundary zone and that fluxes of this magnitude occur all year long, we estimated that $41-138 \mathrm{~kg} / \mathrm{year} \Sigma_{5} \mathrm{PCM}$ could be lost to volatilization in Lake Ontario. Lake Erie data yielded an average $\Sigma_{5} \mathrm{PCM}$ flux of 13 $\mathrm{ng} / \mathrm{m}^{2} /$ day, suggesting that $22-74 \mathrm{~kg} /$ year $\Sigma_{5} \mathrm{PCM}$ could be lost to volatilization in Lake Erie. This may be an overestimate, as fluxes could be lower in the winter, when the surface waters freeze and lower temperatures drive down PCM vapor pressure, but the absence of wintertime dissolved concentration data prohibited flux calculations for these months. Although these estimations are based on temporally- and spatially- 
limited data, they are of a similar magnitude to those estimated in previous Great Lakes studies, and suggest that volatilization may be a significant loss process for dissolved PCMs in this region.

\section{ACKNOWLEDGMENTS}

We would like to acknowledge funding from the US EPA Great Lakes Restoration Initiative (GLRI) GLAS \#00E00597-0, project officer Todd Nettesheim. We would also like to express our gratitude to Professor Peter August (URI) for assistance with GIS analysis, David Adelman (URI) for sampler preparation and field deployment logistics, Camilla Teixeira and the field staff of the Emergencies, Operational Analytical Laboratories, and Research Support group (Environment Canada Burlington) for open-lake PE deployments, Great Lakes Unit field staff of the Ontario Ministry of the Environment and Climate Change for Lake Ontario nearshore deployments, and all of the volunteers who deployed PEs throughout the Great Lakes region. 


\section{LITERATURE CITED}

(1) Rimkus, G. G. Polycyclic musk fragrances in the aquatic environment. Toxicol. Lett. 1999, 111, 37-56, DOI:10.1016/S0378-4274(99)00191-5.

(2) Hornbuckle, K.; Peck, A. M. Environmental sources, occurrence, and effects of synthetic musk fagrances. J. Environ. Monit. 2006, 8, 874-879, DOI:10.1039/b608170n.

(3) Homem, V.; Silva, J. A.; Ratola, N.; Santos, L.; Alves, A. Long lasting perfume--a review of synthetic musks in WWTPs. J. Environ. Manage. 2015, 149, 168-192, DOI:10.1016/j.jenvman.2014.10.008.

(4) Peck, A. M.; Hornbuckle, K. C. Synthetic musk fragrances in Lake Michigan. Environ. Sci. Technol. 2004, 38, 367-372, DOI:10.1021/es034769y.

(5) Melymuk, L.; Robson, M.; Csiszar, S. A.; Helm, P. A.; Kaltenecker, G.; Backus, S.; Bradley, L.; Gilbert, B.; Blanchard, P.; Jantunen, L.; Diamond, M. L. From the city to the lake: Loadings of PCBs, PBDEs, PAHs and PCMs from Toronto to Lake Ontario. Environ. Sci. Technol. 2014, 48, 3732-3741, DOI:10.1021/es403209z.

(6) Bester, K. Polycyclic musks in the Ruhr catchment area--transport, discharges of waste water, and transformations of HHCB, AHTN and HHCB-lactone. $J$. Environ. Monit. 2005, 7, 43-51, DOI:10.1039/b409213a.

(7) Howard, P. H.; Muir, D. C. G. Identifying new persistent and bioaccumulative organics among chemicals in commerce. Environ. Sci. Technol. 2010, 44, 2277-2285, DOI:10.1021/es903383a.

(8) Gatermann, R.; Biselli, S.; Hühnerfuss, H.; Rimkus, G. G.; Hecker, M.; Karbe, L. Synthetic musks in the environment. Part 1: Species-dependent bioaccumulation of polycyclic and nitro musk fragrances in freshwater fish and mussels. Arch. Environ. Contam. Toxicol. 2002, 42, 437-446, DOI:10.1007/s00244-001-0041-2.

(9) O'Toole, S. O.; Metcalfe, C. Synthetic musks in fish from urbanized area of the lower Great Lakes , Canada. J. Gt. Lakes Res. 2006, 32, 361-369, DOI:10.3394/0380-1330(2006)32[361:SMIFFU]2.0.CO;2.

(10) Reiner, J. L.; Kannan, K. Polycyclic musks in water, sediment, and fishes from the upper Hudson River, New York, USA. Water, Air, Soil Pollut. 2010, 214, 335-342, DOI:10.1007/s11270-010-0427-8. 
(11) Parolini, M.; Magni, S.; Traversi, I.; Villa, S.; Finizio, A.; Binelli, A. Environmentally relevant concentrations of galaxolide (HHCB) and tonalide (AHTN) induced oxidative and genetic damage in Dreissena polymorpha. $J$. Hazard. Mater. 2015, 285, 1-10, DOI:10.1016/j.jhazmat.2014.11.037.

(12) Lohmann, R.; Muir, D. Global aquatic passive sampling (AQUA-GAPS): using passive samplers to monitor POPs in the waters of the world. Environ. Sci. Technol. 2010, 44, 860-864, DOI:10.1021/es902379g.

(13) Adams, R. G.; Lohmann, R.; Fernandez, L. A.; Macfarlane, J. K.; Gschwend, P. M. Polyethylene devices: Passive samplers for measuring dissolved hydrophobic organic compounds in aquatic environments. Environ. Sci. Technol. 2007, 41, 1317-1323, DOI:10.1021/es0621593.

(14) Lohmann, R.; Booij, K.; Smedes, F.; Vrana, B. Use of passive sampling devices for monitoring and compliance checking of POP concentrations in water. Environ. Sci. Pollut. Res. Int. 2012, 19, 1885-1895, DOI:10.1007/s11356-0120748-9.

(15) Khairy, M. A.; Lohmann, R. Field calibration of low density polyethylene passive samplers for gaseous POPs. Environ. Sci. Process. Impacts 2014, 16, 414-421, DOI:10.1039/c3em00493g.

(16) Bartkow, M. E.; Booij, K.; Kennedy, K. E.; Müller, J. F.; Hawker, D. W. Passive air sampling theory for semivolatile organic compounds. Chemosphere 2005, 60, 170-176, DOI:10.1016/j.chemosphere.2004.12.033.

(17) McDonough, C. A.; Khairy, M. A.; Muir, D. C. G.; Lohmann, R. Significance of population centers as sources of gaseous and dissolved PAHs in the lower Great Lakes. Environ. Sci. Technol. 2014, 48, 7789-7797, DOI:10.1021/es501074r.

(18) Khairy, M.; Muir, D.; Teixeira, C.; Lohmann, R. Spatial trends, sources, and air-water exchange of organochlorine pesticides in the Great Lakes basin using low density polyethylene passive samplers. Environ. Sci. Technol. 2014, 48, 9315-9324, DOI:10.1021/es501686a.

(19) Tidwell, L. G.; Allan, S. E.; Connell, S. G. O.; Hobbie, K. A.; Smith, B. W.; Kim, A. PAH and OPAH air and water exchange during the Deepwater Horizon Incident. Environ. Sci. Technol. 2016, 50, 7489-7497, DOI:10.1021/acs.est.6b02784.

(20) Liu, Y.; Wang, S.; McDonough, C. A.; Khairy, M.; Muir, D. C. G.; Helm, P. A.; Lohmann, R. Gaseous and freely-dissolved PCBs in the lower Great Lakes based on passive sampling: spatial trends and air-water exchange. Environ. Sci. Technol. 2016, 50, 4932-4939, DOI:10.1021/acs.est.5b04586. 
(21) Lohmann, R. Critical review of low-density polyethylene's partitioning and diffusion coefficients for trace organic contaminants and implications for its use as a passive sampler. Environ. Sci. Technol. 2012, 46, 606-618, DOI:10.1021/es202702y.

(22) Booij, K.; Smedes, F. An improved method for estimating in situ sampling rates of nonpolar passive samplers. Environ. Sci. Technol. 2010, 44, 6789-6794, DOI:10.1021/es101321v.

(23) Center for International Earth Science Information Network (CIEISIN); Columbia University; International Food Policy Research Institute (IFPRI); The World Bank; Centro Internacional de Agricultura Tropical (CIAT). Global Rural-Urban Mapping Project, Version 1 (GRUMPv1): Population Count Grid http://sedac.ciesin.columbia.edu/data/set/grump-v1-population-count.

(24) R Core Team. R: A language and environment for statistical computing (version 3.1.0), 2014.

(25) Venables, W. N.; Ripley, B. D. Modern Applied Statistics with S. Fourth Edition.; Springer: New York, New York, USA, 2002.

(26) Wickham, H. ggplot2: Elegant Graphics for Data Analysis; Springer-Verlag: New York, New York, USA, 2009.

(27) Whitman, W. G. A preliminary experimental confirmation of the two-film theory of gas absorption. Chem. Metall. Eng. 1923, 29, 146-148, DOI:10.1016/0017-9310(62)90032-7.

(28) Schwarzenbach, R. P.; Gschwend, P. M.; Imboden, D. M. Environmental Organic Chemistry; 2nd ed; Wiley Interscience, 2002.

(29) Zhang, H.; Eisenreich, S. J.; Franz, T. R.; Baker, J. E.; Offenberg, J. H. Evidence for increased gaseous PCB fluxes to Lake Michigan from Chicago. Environ. Sci. Technol. 1999, 33, 2129-2137, DOI:10.1021/es981073+.

(30) Ruge, Z.; Muir, D.; Helm, P.; Lohmann, R. Concentrations, trends, and airwater exchange of PAHs and PBDEs derived from passive samplers in Lake Superior in 2011. Environ. Sci. Technol. 2015, 49, 13777-13786, DOI:10.1021/acs.est.5b02611.

(31) Rowe, M. D.; Perlinger, J. A. Micrometeorological measurement of hexachlorobenzene and polychlorinated biphenyl compound air-water gas exchange in Lake Superior and comparison to model predictions. Atmos. Chem. Phys. 2012, 12, 4607-4617, DOI:10.5194/acp-12-4607-2012. 
(32) Helm, P. A.; Howell, E. T.; Li, H.; L. Metcalfe, T.; M. Chomicki, K.; D. Metcalfe, C. Influence of nearshore dynamics on the distribution of organic wastewater-associated chemicals in Lake Ontario determined using passive samplers. J. Great Lakes Res. 2012, 38, 105-115, DOI:10.1016/j.jglr.2012.01.005.

(33) Andresen, J. A.; Muir, D.; Ueno, D.; Darling, C.; Theobald, N.; Bester, K. Emerging pollutants in the North Sea in comparison to Lake Ontario, Canada, data. Environ. Toxicol. Chem. 2007, 26, 1081-1089, DOI:10.1897/06-416R.1

(34) Buerge, I. J.; Buser, H.; Mu, M. D.; Poiger, T.; Wa, C. Behavior of the polycyclic musks HHCB and AHTN in lakes, two potential anthropogenic markers for domestic wastewater in surface waters. Environ. Sci. Technol. 2003, 37, 5636-5644, DOI:10.1021/es0300721.

(35) Aschmann, S. M.; Arey, J.; Atkinson, R.; Simonich, S. L. Atmospheric lifetimes and fates of selected fragrance materials and volatile model compounds. Environ. Sci. Technol. 2001, 35, 3595-3600, DOI:10.1021/es010685i.

(36) Xie, Z.; Ebinghaus, R.; Temme, C.; Heemken, O.; Ruck, W. Air-sea exchange fluxes of synthetic polycyclic musks in the North Sea and the Arctic. Environ. Sci. Technol. 2007, 41, 5654-5659, DOI:10.1021/es0704434.

(37) Peck, A.; Hornbuckle, K. Synthetic musk fragrances in urban and rural air of Iowa and the Great Lakes. Atmos. Environ. 2006, 40, 6101-6111, DOI:10.1016/j.atmosenv.2006.05.058.

(38) Melymuk, L.; Robson, M.; Helm, P. A.; Diamond, M. L. PCBs, PBDEs, and PAHs in Toronto air: Spatial and seasonal trends and implications for contaminant transport. Sci. Total Environ. 2012, 429, 272-280, DOI:10.1016/j.scitotenv.2012.04.022.

(39) Melymuk, L.; Robson, M.; Helm, P. A.; Diamond, M. L. Application of land use regression to identify sources and assess spatial variation in urban SVOC concentrations. Environ. Sci. Technol. 2013, 47, 1887-1895, DOI:10.1021/es3043609.

(40) Lu, B.; Feng, Y.; Gao, P.; Zhang, Z.; Lin, N. Distribution and fate of synthetic musks in the Songhua River, Northeastern China: Influence of environmental variables. Environ. Sci. Pollut. Res. Int. 2015, 22, 9090-9099, DOI:10.1007/s11356-014-3973-6.

(41) US EPA. US EPA Discharge Monitoring Report (DMR) Pollutant Loading Tool, v 1.0 https://cfpub.epa.gov/dmr/index.cfm. 
(42) Rao, Y. R.; Schwab, D. J. Laurentian Great Lakes, interaction of coastal and offshore waters. Encyclopedia of Lakes and Reservoirs, 2012, 479-485. 


\section{FIGURES AND TABLES}

\section{Table 3-1. Average Dissolved PCMs (pg/L) Summarized Regionally}

\begin{tabular}{lcccccc} 
& $\mathbf{N}^{\mathbf{a}}$ & ADBI & AHMI & ATII & HHCB & AHTN \\
\hline Toronto Waterfront Nearshore & 3 & $1.1 \pm 0.7$ & $2.2 \pm 0.7$ & $37 \pm 6.6$ & $1625 \pm 242$ & $162 \pm 32$ \\
Southern L. Ontario Shoreline & 3 & $1.2 \pm 0.8$ & $2.4 \pm 1.3$ & $28 \pm 33$ & $1363 \pm 827$ & $134 \pm 66$ \\
Greater Cleveland Shoreline/Nearshore & 3 & $1.5 \pm 0.9$ & $3.9 \pm 2.2$ & $29 \pm 13$ & $697 \pm 222$ & $72 \pm 19$ \\
Southeast L. Erie Shoreline & 3 & $0.1 \pm 0.2$ & $0.8 \pm 0.3$ & $3.0 \pm 5.1$ & $23 \pm 39$ & $16 \pm 7.9$ \\
Northeast L. Ontario Nearshore & 3 & $<\mathrm{DL}$ & $0.4 \pm 0.4$ & $2.1 \pm 2.0$ & $<\mathrm{DL}$ & $14 \pm 12$ \\
Offshore L. Erie and L. Ontario & 5 & $0.9 \pm 1.2$ & $2.5 \pm 3.8$ & $16 \pm 21$ & $<\mathrm{DL}$ & $28 \pm 18$ \\
\hline
\end{tabular}

${ }^{\mathrm{a}} \mathrm{N}$ is the number of sites of each type.

\section{Table 3-2. Average Gaseous PCMs $\left(\mathrm{pg} / \mathrm{m}^{3}\right)$ Grouped By Site Type}

\begin{tabular}{lcccccc} 
& N $^{\mathbf{a}}$ & ADBI & AHMI & ATII & HHCB & AHTN \\
\hline Summer (May - November) & & & & & & \\
\hline Offshore/Nearshore Buoys & 5 & $2.1 \pm 4.6$ & $2.2 \pm 4.9$ & $47 \pm 106$ & $<\mathrm{DL}$ & $5.4 \pm 12$ \\
Toronto Waterfront Nearshore Buoys & 3 & $0.6 \pm 1.0$ & $24 \pm 17$ & $493 \pm 69$ & $1529 \pm 591$ & $302 \pm 88$ \\
L. Erie and L. Ontario Shoreline & 14 & $2.8 \pm 6.3$ & $11 \pm 9.5$ & $100 \pm 189$ & $357 \pm 836$ & $149 \pm 159$ \\
\hline Winter (December - April) & & & & & & \\
\hline L. Erie and L. Ontario Shoreline & 9 & $0.2 \pm 0.6$ & $0.8 \pm 1.5$ & $22 \pm 44$ & $29 \pm 87$ & $17 \pm 19$ \\
\hline
\end{tabular}

${ }^{\mathrm{a}} \mathrm{N}$ is the number of sites of each type. 

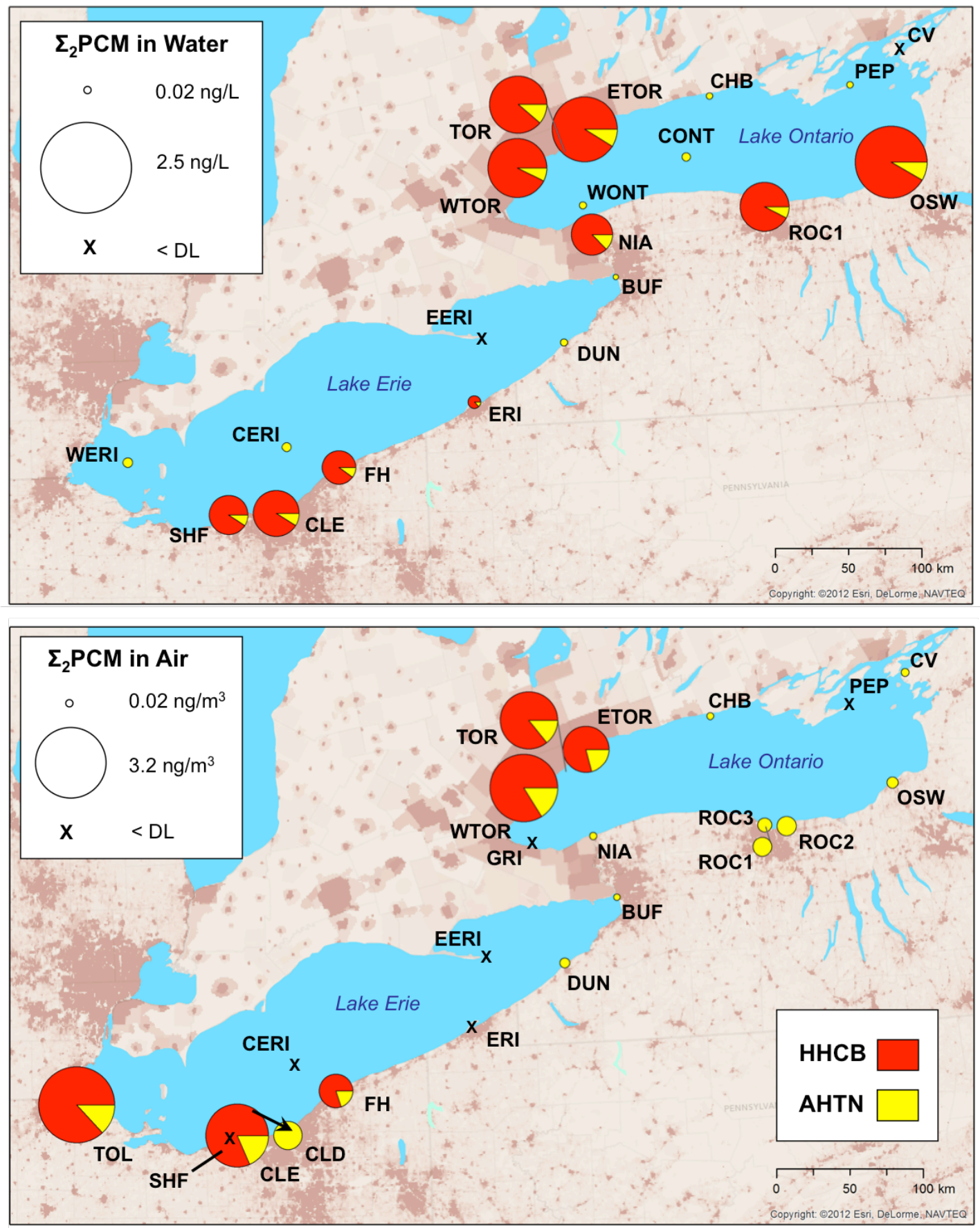

Figure 3-1. Average summer HHCB and AHTN $\left(\Sigma_{2} \mathrm{PCM}\right)$ concentrations throughout the lower Great Lakes. Average dissolved (top) and gaseous (bottom) HHCB and AHTN during summer deployments are shown with HHCB in red and AHTN in yellow. Gaseous $\Sigma_{2}$ PCM ranged from $<$ DL at sites marked by X's to 3.2 $\mathrm{ng} / \mathrm{m}^{3}$ in Toledo (TOL). Dissolved $\Sigma_{2} \mathrm{PCM}$ ranged from $<\mathrm{DL}$ at sites marked by X's to $2.5 \mathrm{ng} / \mathrm{L}$ near the mouth of Oswego River (OSW). 

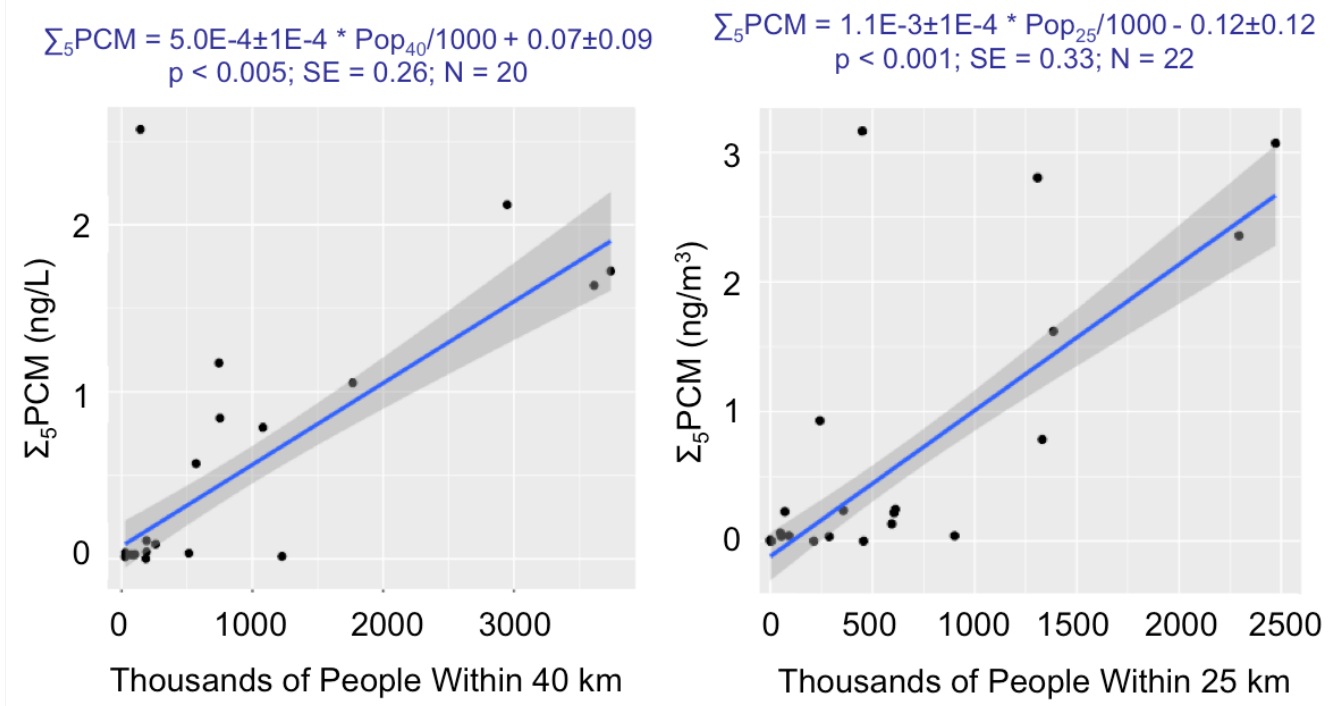

Figure 3-2. Correlation of dissolved and gaseous $\Sigma_{5} \mathrm{PCM}$ and surrounding population density. Average summer dissolved (left) and gaseous (right) $\Sigma_{5} \mathrm{PCM}$ was most strongly correlated with population within $40 \mathrm{~km}$ and $25 \mathrm{~km}$ of each site, respectively. The $95 \%$ confidence intervals for the linear models are shaded in gray. 

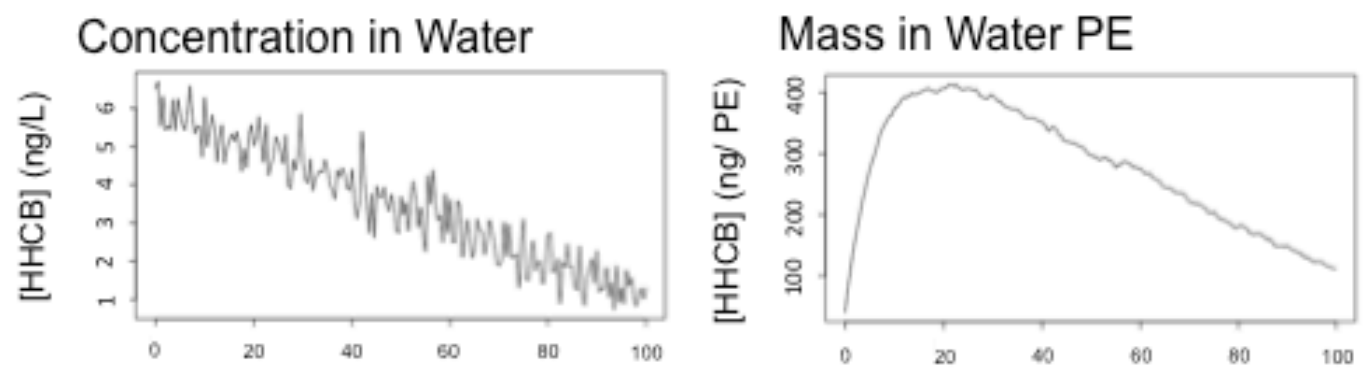

Concentration in Air
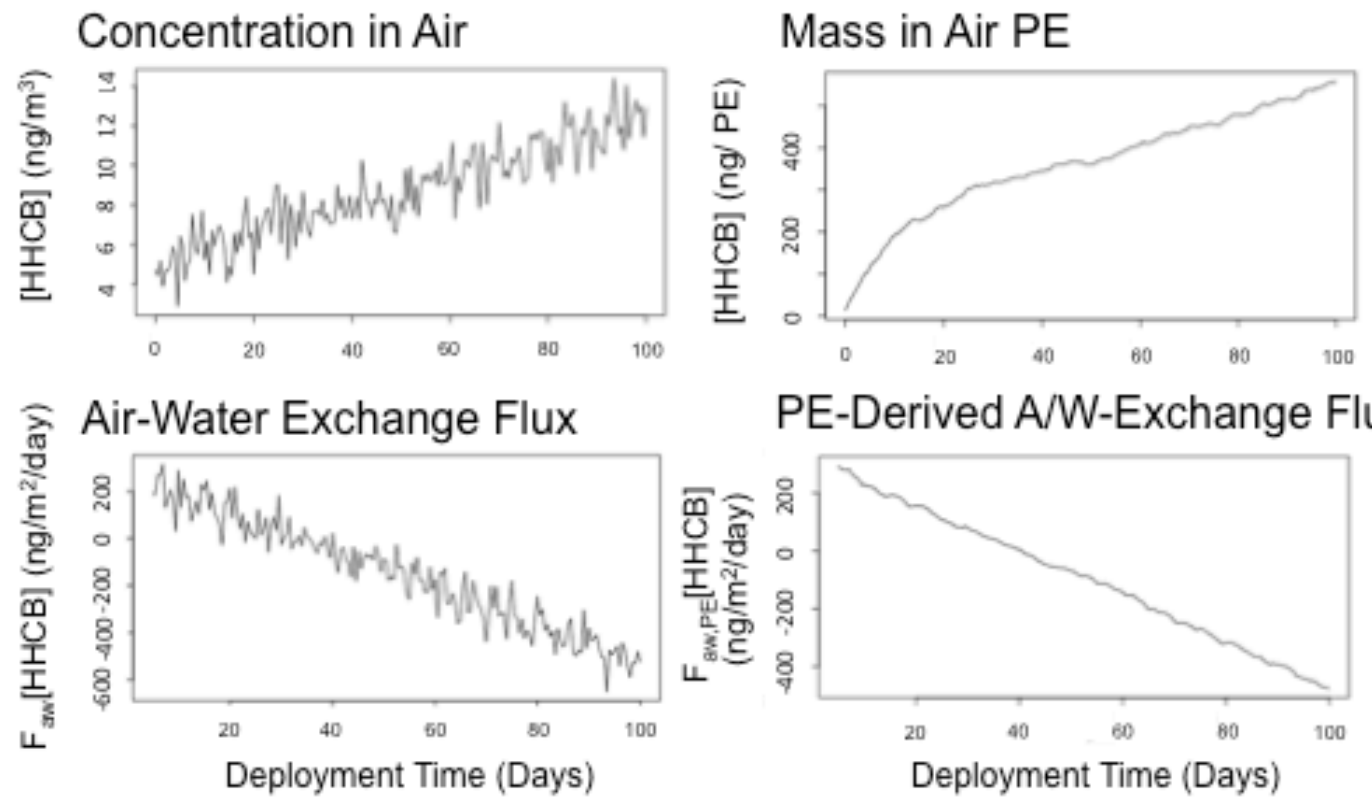

PE-Derived A/W-Exchange Flux

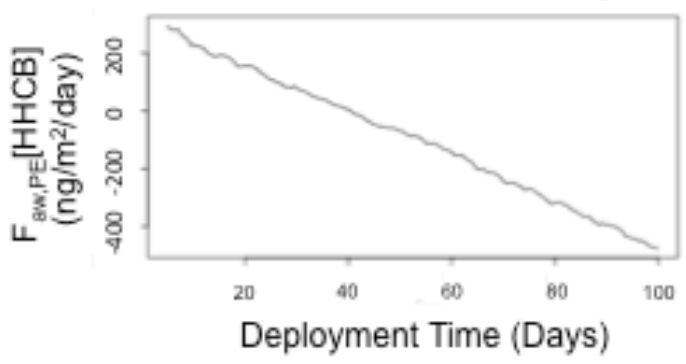

Figure 3-3. Predicted air-water exchange fluxes based on simulated air and water HHCB concentrations. Simulated water and air concentrations of HHCB and air-water exchange fluxes calculated from these concentrations are shown on the left over a 100-day simulated deployment. The mass of HHCB accumulated in a 2-g PE in response to the simulated air and water concentrations is shown on the left, along with the air-water exchange flux that would be calculated using this pair of air and water PEs. 
Table 3-3. Comparison of Simulated Air-Water Exchange Fluxes to PE-Derived and Grab Sample-Derived Exchange Fluxes.

\begin{tabular}{|l|c|c|}
\hline \multicolumn{2}{|c|}{ Relative Percent Difference (RPD) between $\mathrm{F}_{\mathrm{aw}}$ and $\mathrm{F}_{\mathrm{aw}, \mathrm{PE}}$} \\
\hline \multicolumn{1}{|c|}{$\begin{array}{c}\text { Scenario 1: Randomly } \\
\text { Fluctuating Air and Water } \\
\text { Concentrations }\end{array}$} & $\begin{array}{c}\text { Scenario 2: Steadily Increasing } \\
\text { Air and Decreasing Water }\end{array}$ \\
\hline Mean $\mathrm{F}_{\mathrm{aw}}$ Over 100 Days & $18.5+/-6.8 \%$ & $357+/-267 \%$ \\
\hline Mean $\mathrm{F}_{\mathrm{aw}}$ Over Last 22 days & $15.3+/-8.8 \%$ & $8.4+/-5.2 \%$ \\
\hline $\mathrm{F}_{\mathrm{aw}}$ on Day 100 & $351+/-219 \%$ & $12.3+/-1.2 \%$ \\
\hline \multicolumn{2}{|c|}{ Relative Percent Difference (RPD) between $\mathrm{F}_{\mathrm{aw}}$ and mean $\mathrm{F}_{\mathrm{aw}}$ from weekly grab sample } \\
\hline Mean $\mathrm{F}_{\mathrm{aw}}$ Over 100 Days & $26.9+/-15.0 \%$ & $21+/-15 \%$ \\
\hline Mean $\mathrm{F}_{\mathrm{aw}}$ Over Last 22 days & $60.4+/-34.6 \%$ & $329+/-232$ \\
\hline
\end{tabular}




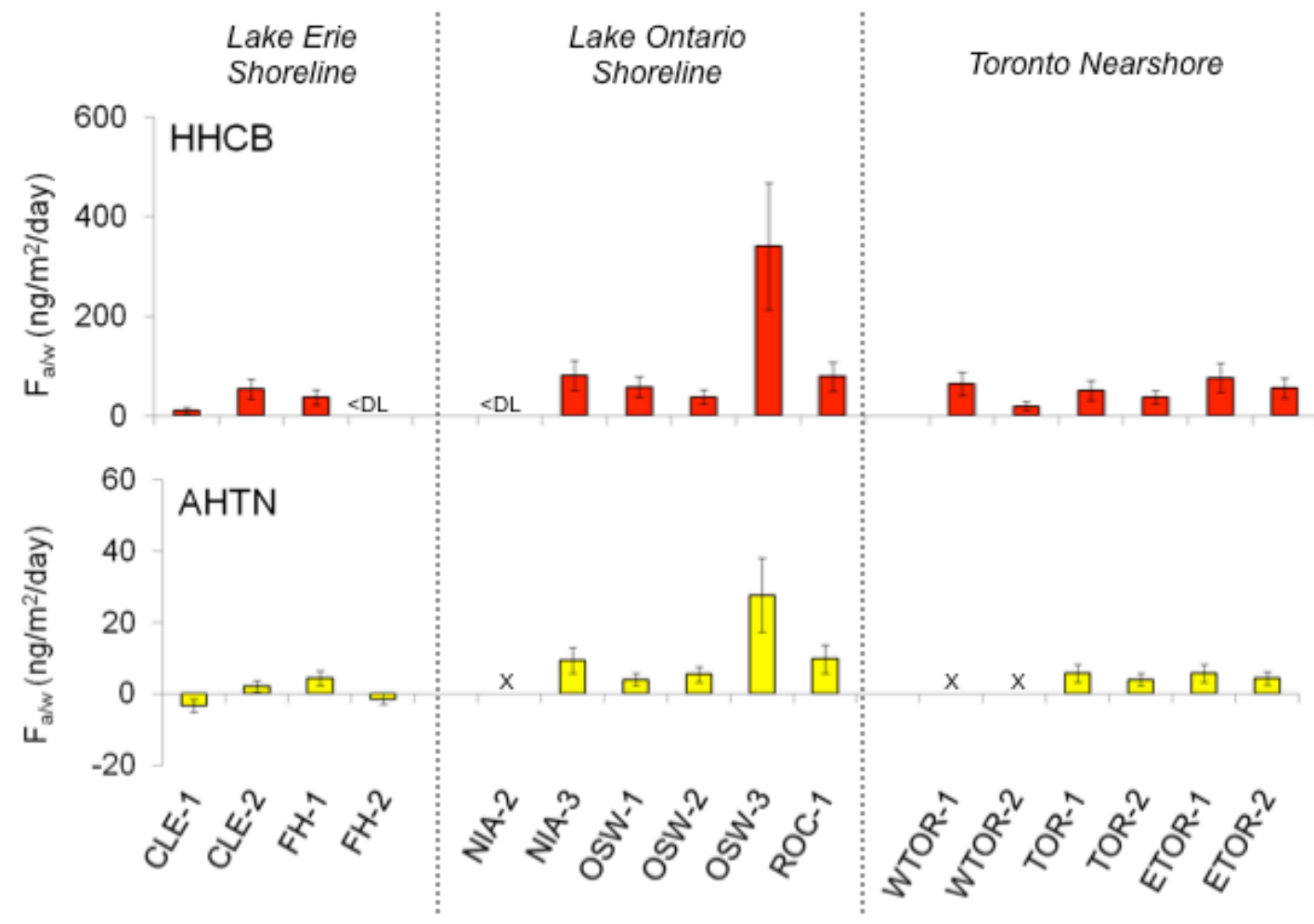

Figure 3-4. Summer air-water exchange fluxes of AHTN and HHCB. Air-water exchange fluxes are shown for shoreline Lake Erie and Lake Ontario sites, as well as nearshore Toronto buoy sites. Positive bars represent volatilization while negative bars represent absorption. Cases where both air and water concentrations were $<\mathrm{DL}$ are marked " $<$ DL". Cases where fugacity ratios were not significantly different from equilibrium are marked "X". Offshore Lake Erie and nearshore northern Lake Ontario sites as well as some shoreline sites (SHF, ERI, DUN, BUF, and CV) were omitted because no significant exchange fluxes were calculated there. Error bars represent standard deviation calculated via error propagation. 


\title{
SUPPORTING INFORMATION:
}

\section{POLYCYCLIC MUSKS IN THE AIR AND WATER OF THE LOWER GREAT LAKES: SPATIAL DISTRIBUTION AND VOLATILIZATION FROM SURFACE WATERS}

\author{
Lohmann \\ Total number of pages: 26 \\ Total number of tables: 12 \\ Total number of figures: 6
}

Carrie A. McDonough, Paul A. Helm, Derek C. G. Muir, Gavino Puggioni, Rainer

\section{Calculating Percent Equilibration Using Best-Fit DBL Thickness. In order to} determine the ambient concentration $\left(\mathrm{C}_{\mathrm{a}}\right.$ or $\left.\mathrm{C}_{\mathrm{w}}\right)$ of a hydrophobic organic contaminant (HOC) from the concentration measured in polyethylene $\left(\mathrm{C}_{\mathrm{PE}}\right)$, percent equilibration (f) reached by the compound of interest during deployment must be determined. Concentrations of performance reference compounds (PRCs) were measured in all deployed samples and in laboratory and field blanks. Masses in blanks and matrix spikes from each batch of PEs were averaged to yield initial PRC concentrations in PEs $\left(N_{0}\right)$. The ratio of the final mass of each PRC to its initial mass $\left(N / N_{0}\right)$ represents the loss during deployment, which is related to $f$ for a target compound with properties identical to the PRC. $f$ for each PRC was calculated as in Equation S1.

Loss data for benzo(a)pyrene- $d 12$ were not included in determining $f$ for target compounds because loss of this compound was generally greater than loss of pentabromobiphenyl, suggesting that loss due to processes besides PE-air or PE-water diffusive exchange may have occurred. Six air samples were found to have loss of dibromobiphenyl $<90 \%$, which is unrealistic given the deployment times for these 
samplers and may indicate some inconsistency in deployment practices.

Concentration estimates for these samples were discarded before further analysis and interpretation.

$$
f=1-\frac{N}{N_{0}}
$$

For compounds that were not identical to PRCs, PRC loss data was used to interpolate or extrapolate an estimated value of $f$. This required an understanding of how uptake rates change depending on compound properties. Diffusion of HOCs into PE from air or water can be described by a two-layer diffusion model, versions on which have previously detailed by Fernandez et al. ${ }^{1}$, Thompson et al., ${ }^{2}$ and Tcaciuc et al. ${ }^{3}$ for aqueous PE uptake. In the case of long ( $>5$ day) deployments of relatively thin $(50 \mu \mathrm{m})$ PEs, this uptake model can be simplified by using a generalized exponential approximation to calculate the uptake rate based on both air/water-side and PE-side resistance, as described by Booij et al. ${ }^{4}$

$$
f=1-e^{\frac{-t \cdot k_{0} \cdot A_{P E}}{K_{P E M} \cdot V_{P E}}}
$$

In Equation S2, $t$ is the deployment time in seconds, $\mathrm{A}_{\mathrm{PE}}$ is the sampler area in $\mathrm{m}^{2}, \mathrm{~K}_{\mathrm{PEM}}$ is the dimensionless PE-matrix partitioning coefficient (in this case the matrix is either air or water), and $\mathrm{V}_{\mathrm{PE}}$ is the PE's volume, calculated from its mass (typically around $2 \mathrm{~g}$ ) and density $(0.91 \mathrm{~kg} / \mathrm{L})$. $\mathrm{A}_{\mathrm{PE}}$ was calculated from $\mathrm{V}_{\mathrm{PE}}$ and the PE's thickness $\left(2 l_{\mathrm{PE}}\right)$, and was typically around $400 \mathrm{~cm}^{2} . \mathrm{k}_{\mathrm{o}}$ is the mass transfer 
coefficient, with units of speed, which represents the reciprocal of the sum of the matrix-side and PE-side resistance as in Equation S3.

$$
\frac{1}{k_{0}}=\frac{1}{k_{m}}+\frac{1}{k_{P E} \cdot K_{P E M}}
$$

Where

$$
\frac{1}{k_{m}}=\frac{\delta_{D B L}}{D_{m}} \quad(\mathrm{~S} 4) \quad \frac{1}{k_{P E}}=\frac{l_{P E}}{D_{P E}}
$$

$1 / k_{m}$ is the matrix-side resistance, calculated as the thickness of the diffusive boundary layer $\left(\delta_{\mathrm{DBL}}\right)$ over the diffusivity of the compound in the given matrix (air or water), and $1 / \mathrm{k}_{\mathrm{PE}}$ is the PE-side resistance, calculated as half the thickness of the PE $\left(l_{\mathrm{PE}}\right)$ over the diffusivity of the compound in PE. These values are either known $\left(l_{\mathrm{PE}}\right)$, or can be measured/estimated based on other compound properties ( $\left.\mathrm{K}_{\mathrm{PEM}}, \mathrm{D}_{\mathrm{M}}, \mathrm{D}_{\mathrm{PE}}\right)$, with the exception of $\delta_{\mathrm{DBL}}$, which is difficult to observe or measure.

To determine $\delta_{\mathrm{DBL}}$ for each deployment, PRC loss data for each sample were entered along with compound properties for each PRC: $\mathrm{K}_{\mathrm{PEW}}$ and $\mathrm{K}_{\mathrm{PEA}}$ at $298 \mathrm{~K}$, molar volume $\left(\mathrm{V}_{\mathrm{i}}\right)$, molar mass $\left(\mathrm{M}_{\mathrm{i}}\right)$, enthalpy of vaporization $\left(\Delta \mathrm{H}_{\text {vap }}\right)$ and internal energy of aqueous dissolution for the sub-cooled liquid $\left(\Delta \mathrm{U}_{\mathrm{w}}\right)$ in $\mathrm{kJ} / \mathrm{mol}$ and the bestfit $\delta_{\mathrm{DBL}}$ value was determined using the non-linear least-squares fitting function $n l s$ in $\mathrm{R}$, as was used by Booij et al. ${ }^{5,4}$ While theoretically, $\delta_{\mathrm{DBL}}$ could be affected by compound properties, previous studies have reported that variation among compounds 
is small, ${ }^{1}$ so in this study a single $\delta_{\text {DBL }}$ value was calculated for each set of PRC loss data.

Once values of $f$ were determined for all PRCs, these were used along with known and estimated physico-chemical properties for these PRCs (as listed in Table S3-8) to calculate the best-fit value of $\delta_{\mathrm{DBL}}$ for each deployment by using $n l s$ in $\mathrm{R}$ and Equation S6, where $t$ is length of the deployment time in seconds, $\mathrm{K}_{\text {PEM }}$ is the PEmatrix partitioning coefficient, $l_{\mathrm{PE}}$ is the half-thickness of the PE $(\sim 25 \mu \mathrm{m}), \mathrm{D}_{\mathrm{M}}$ is the molecular diffusivity of the target compound in air or water $\left(\mathrm{m}^{2} / \mathrm{s}\right)$, and $\mathrm{D}_{\mathrm{PE}}$ is the molecular diffusivity in $\mathrm{PE}\left(\mathrm{m}^{2} / \mathrm{s}\right) . \quad \delta_{\mathrm{DBL}}$ for each deployment was then used along with the target compound's known and estimated properties to determine $f$. $\mathrm{K}_{\mathrm{PEM}}, \mathrm{D}_{\mathrm{M}}$, and $\mathrm{D}_{\mathrm{PE}}$ were corrected to the average deployment temperature using data from nearby meteorological buoys (Table S3-2) using Equations S8 - S12.

$$
\begin{gathered}
f=1-e^{\frac{-t \cdot A_{P E}}{V_{P E} \cdot\left(\frac{\delta_{D B L} K_{P E M}}{D_{M}}+\frac{l_{P E}}{D_{P E}}\right)}} \\
D_{a, T 2}=\frac{10^{-3} \cdot T_{2}{ }^{1.75} \cdot \sqrt{\frac{1}{M M_{a}}+\frac{1}{M_{i}}}}{p_{a t m} \cdot\left(V_{a}{ }^{1 / 3}+V_{m}{ }^{1 / 3}\right)^{2}}
\end{gathered}
$$

$\mathrm{D}_{\mathrm{a}, \mathrm{T} 2}$, the diffusivity in $\mathrm{cm}^{2} / \mathrm{s}$ of the target compound in air at the mean deployment temperature $T_{2}$, was determined as in Fuller 1966, ${ }^{6}$ with gas-phase pressure $\left(\mathrm{p}_{\text {atm }}\right)$ of $1 \mathrm{~atm}$, molar mass of air $\left(\mathrm{MM}_{\mathrm{a}}\right)=28.97 \mathrm{~g} / \mathrm{mol}$, and molar volume of air $\left(\mathrm{V}_{\mathrm{a}}\right)=20.1 \mathrm{~cm}^{3} / \mathrm{mol} \mathrm{M}_{\mathrm{i}}$ and $\mathrm{V}_{\mathrm{m}}$ are the molar mass and molar volume of the compound of interest, which were obtained from SPARC.

$$
D_{w, T 2}=\frac{7.4 \cdot 10^{-12} \cdot T_{2} \cdot \sqrt{a \cdot M M_{w}}}{\nu_{w} \cdot V_{m}^{0.6}}
$$


$D_{\mathrm{w}, \mathrm{T} 2}$, the diffusivity in $\mathrm{cm}^{2} / \mathrm{s}$ in water at the mean deployment temperature $T_{2}$, was determined via the Wilke-Chang equation as in Equation S9, where $a$ is 2.6, the association parameter for water and $\mathrm{MM}_{\mathrm{w}}$ is the molar mass $(\mathrm{g} / \mathrm{mol})$ of water $(18$ $\mathrm{g} / \mathrm{mol}) . T_{2}$ is the mean deployment temperature, $V_{\mathrm{m}}$ is the molar volume of the target compound in $\mathrm{cm}^{3} / \mathrm{mol}$, and $v_{\mathrm{w}}$ is the viscosity of water at the nearest whole number temperature from Schwarzenbach et al. 2003. ${ }^{7}$

$$
D_{P E, T 2}=D_{P E, T 1} \cdot e^{\frac{E_{a}}{R} \cdot\left(\frac{1}{T 1}-\frac{1}{T 2}\right)}
$$

$\mathrm{D}_{\mathrm{PE}, \mathrm{T} 2}$ was determined from Equation $\mathrm{S} 10$, where $\mathrm{D}_{\mathrm{PE}, \mathrm{T} 1}$ is the $\mathrm{D}_{\mathrm{PE}}$ at $298 \mathrm{~K}, \mathrm{R}$ is the universal gas constant, and $\mathrm{E}_{\mathrm{a}}$ is the energy of activation, assumed to be 100,000 $\mathrm{J} / \mathrm{mol}$ based on unpublished thin-film experiments by Vansco et al. where $\mathrm{D}_{\mathrm{PE}}$ was measured at a range of different temperatures.

$$
K_{P E A, T 2}=K_{P E A, T 1} \cdot e^{\frac{H_{v a p}}{R} \cdot\left(\frac{1}{T_{2}}-\frac{1}{T_{1}}\right)}
$$

$\mathrm{K}_{\mathrm{PEA}, \mathrm{T} 2}$ was determined from $\mathrm{K}_{\mathrm{PEA}}$ via Equation $\mathrm{S} 11$, where $\mathrm{H}_{\text {vap }}$ is the enthalpy of vaporization for the target compound and $\mathrm{R}$ is the ideal gas constant.

$$
K_{P E W, T 2}=K_{P E W, T 1} \cdot e^{\frac{U_{w}}{R} \cdot\left(\frac{1}{T_{2}}-\frac{1}{T_{1}}\right)}
$$

$\mathrm{K}_{\mathrm{PEW}, \mathrm{T2}}$ was determined from $\mathrm{K}_{\mathrm{PEW}}$ via Equation $\mathrm{S} 12$, where $\mathrm{U}_{\mathrm{w}}$ is the energy of solvation in $\mathrm{J} / \mathrm{mol}$ for the target compound.

Finally, the concentration measured in $\mathrm{pg} / \mathrm{kg} \mathrm{PE}\left(\mathrm{C}_{\mathrm{PE}}\right)$ was corrected to the ambient concentration of the target PCM $\left(\mathrm{C}_{a}\right)$ using the density of PE $\left(\mathrm{d}_{\mathrm{PE}} ; 0.91 \mathrm{~kg} / \mathrm{L}\right)$, $\mathrm{K}_{\mathrm{PEM}}$, and $f$, as in Equation $\mathrm{S} 13$.

$$
C_{a}=\frac{C_{P E} \cdot d_{P E}}{f \cdot K_{P E M}}
$$


Air-Water Exchange Flux Calculations. The equilibrium concentration in $\mathrm{ng} / \mathrm{g} \mathrm{PE}$

$\left(\mathrm{C}_{\infty}\right)$ was determined from $\mathrm{C}_{\mathrm{PE}}$ as in Equation $\mathrm{S} 14$ using $f$ for the target compound.

$$
C_{\infty}=\frac{C_{P E}}{f}
$$

The fugacity ratio was then calculated as in Equation $\mathrm{S} 15$, where $\mathrm{C}_{\infty, \mathrm{w}}$ and $\mathrm{C}_{\infty, \mathrm{a}}$ are the estimated equilibrium PE concentrations in water and air samplers.

$$
\frac{f_{w}}{f_{a}}=\frac{C_{\infty, w}}{C_{\infty, a}}
$$

The air-water exchange flux, $\mathrm{F}_{\mathrm{a} / \mathrm{w}}$ in $\mathrm{pg} / \mathrm{m}^{2} /$ day was calculated using Equation $\mathrm{S} 16$, where $v_{\mathrm{a} / \mathrm{w}}$ is the mass transfer coefficient, $\mathrm{C}_{\infty, \mathrm{w}}$ and $\mathrm{C}_{\infty, \mathrm{a}}$ are the $\mathrm{PE}$ equilibrium concentrations, and $\mathrm{K}_{\mathrm{PEW}, \mathrm{T} 2}$ is the $\mathrm{PE}$-water partitioning coefficient corrected for the mean deployment temperature. Mass transfer coefficients were calculated for all PE pairs that displayed fugacity ratios significantly different from equilibrium after error propagation.

$$
F_{a / w}=v_{a / w} \cdot \frac{\left(C_{\infty, w}-C_{\infty, a}\right)}{K_{P E W, T 2}}
$$

$v_{a / w}$ was calculated as in Equation $\mathrm{S} 17$, where $\mathrm{K}_{\mathrm{aw}}$ is the air-water partitioning coefficient at the mean deployment temperature, $v_{a}$ is the air-side mass transfer velocity, and $v_{w}$ is the water-side mass transfer velocity.

$$
\frac{1}{v_{a / w}}=\frac{1}{v_{w}}+\frac{1}{v_{a} \cdot K_{a w, T 2}}
$$


$v_{\mathrm{a}}$ was determined from $v_{\mathrm{H} 2 \mathrm{O}, \mathrm{a}}(\mathrm{cm} / \mathrm{s})$, the air-side mass transfer velocity of water in air, scaled for the diffusivity of the target compound in air, $\mathrm{D}_{\mathrm{ia}}\left(\mathrm{cm}^{2} / \mathrm{s}\right)$ at 298 $\mathrm{K}$ versus the diffusivity of water in air at $298 \mathrm{~K}\left(0.27 \mathrm{~cm}^{2} / \mathrm{s}\right)$, as in Equation $\mathrm{S} 18$.

$$
v_{a}=v_{H_{2} O, a} \cdot\left(\frac{D_{a}}{D_{H_{2} O, a}}\right)^{0.67}
$$

$v_{\mathrm{H} 2 \mathrm{O}, \mathrm{a}}$ was determined as in Equation S19 from the wind speed at 10 meter height, $u_{10}$, as in Schwarzenbach et al. 2003. ${ }^{7} u_{10}$ was determined from mean wind speed, $u$, and height of the wind monitor on the meteorological buoy, $h$, as in Equation S20. In cases where the height of the monitor was not reported, the height was assumed to be 10 meters.

$$
\begin{aligned}
& v_{H_{2} O, a}=0.2 \cdot u_{10}+0.3 \\
& u_{10}=\frac{10.4}{(\ln (h)+8.1)} \cdot u
\end{aligned}
$$

$v_{\mathrm{w}, \mathrm{T} 2}$ was determined as in Equation $\mathrm{S} 21$ from the mass transfer velocity of $\mathrm{CO}_{2}(\mathrm{~cm} / \mathrm{s})$ in water $\left(v_{\mathrm{CO} 2, \mathrm{w}}\right)$, scaled to the target compound using the Schmidt number at the deployment temperature $\left(\mathrm{Sc}_{\mathrm{T} 2}\right)$, the Schmidt number for $\mathrm{CO}_{2}$ at $20{ }^{\circ} \mathrm{C}\left(\mathrm{Sc}_{\mathrm{CO} 2, \mathrm{w}}=\right.$ 600 ) and $\mathrm{a}_{\mathrm{sc}}$, a scaling factor based on wind speed ( 0.67 for mean wind speeds $\leq 4.2$ $\mathrm{m} / \mathrm{s}$, and 0.5 for higher wind speeds). The dimensionless Schmidt number is the ratio of the viscosity of the water to the diffusivity of the target compound in water.

$$
v_{w, T 2}=v_{C O_{2}, w} \cdot\left(\frac{S c_{T 2}}{S c_{C O_{2}, w}}\right)^{-a_{S c}}
$$

$v_{\mathrm{CO} 2}$, the average velocity of $\mathrm{CO}_{2}(\mathrm{~cm} / \mathrm{s})$ in water over the deployment, was determined by integrating the Weibull probability density function using all recorded 
wind speeds over the deployment from the nearest meteorological buoy, scaled to 10 $\mathrm{m}$ above the interface as in Equation S20.

$\mathrm{Sc}_{\mathrm{T} 2}$, the Schmidt number at the mean deployment temperature, was determined as in Equation S22, by scaling $\mathrm{Sc}_{\mathrm{T} 1}$, the Schmidt number at $298 \mathrm{~K}$, by the kinematic viscosity of water $\left(v_{\mathrm{w}}\right)$ at $\mathrm{T} 2$ versus $\mathrm{T} 1$.

$$
S c_{T 2}=S c_{T 1} \cdot\left(\frac{\nu_{T 2, w}}{\nu_{T 1, w}}\right)^{2} \cdot \frac{T_{1}}{T_{2}}
$$

Error Propagation in Air-Water Exchange Calculations. The variance in the equilibrium concentration $\left(\sigma_{\mathrm{C} \infty}{ }^{2}\right)$ was calculated from the variance in measured concentration in PE $\left(\sigma_{\mathrm{CPE}}{ }^{2}\right)$, as determined from the standard deviation of repeated measurements from randomly-chosen extracts, and the variance in $f\left(\sigma_{\mathrm{f}}^{2}\right)$ as in Equation S23.

$$
\sigma_{C_{\infty}}^{2}=\sigma_{C_{P E}}^{2} \cdot\left(\frac{\partial C_{\infty}}{\partial C_{P E}}\right)^{2}+\sigma_{f}^{2} \cdot\left(\frac{\partial C_{\infty}}{\partial f}\right)^{2}
$$

$\sigma_{\mathrm{f}}^{2}$ (Equation S24) was determined from the variance of the best-fit $\delta_{\mathrm{DBL}}$ estimate, taken as the standard deviation in the best-fit value from the non-linear least squares model, the variance of $\mathrm{D}_{\mathrm{M}}$ (assumed to be $50 \%$ ) and the variance of $\mathrm{K}_{\mathrm{PEM}, \mathrm{T} 2 \text {, }}$ determined as in Equation S25.

$\sigma_{f}^{2}=\sigma_{\delta_{D B L}}^{2} \cdot\left(\frac{\partial f}{\partial \delta_{D B L}}\right)^{2}+\sigma_{D_{M}}^{2} \cdot\left(\frac{\partial f}{\partial D_{M}}\right)^{2}+\sigma_{D_{P E}}^{2} \cdot\left(\frac{\partial f}{\partial D_{P E}}\right)^{2}+\sigma_{K_{P E M, T 2}}^{2} \cdot\left(\frac{\partial f}{\partial K_{P E M, T 2}}\right)^{2}$

Variance in $\mathrm{K}_{\mathrm{PEM}, \mathrm{T} 2}$ was determined from Equation S25 using the variance of $\mathrm{K}_{\mathrm{PEM}, \mathrm{T} 1}$ (assumed to be $0.2 \log$ units), and the variance of $\mathrm{H}_{\mathrm{vap}}$ (assumed to be $30 \%$ ) or $\mathrm{U}_{\mathrm{W}}$ (assumed to be $50 \%$ ), as in Morgan et al. $2008 .^{8}$

$$
\sigma_{K_{P E M, T 2}}^{2}=\sigma_{K_{P E M, T 1}}^{2} \cdot\left(\frac{\partial K_{P E M, T 2}}{\partial K_{P E M, T 1}}\right)^{2}+\sigma_{H_{v a p}}^{2} \cdot\left(\frac{\partial K_{P E M, T 2}}{\partial H_{v a p}}\right)^{2}
$$


Variance in the fugacity ratio $\left(\sigma_{f a / w}{ }^{2}\right)$ was calculated as in Equation S26. Only fugacity ratios significantly different from equilibrium $\left(f_{w} / f_{a}=1\right)$ within the $\pm 1 \sigma$ range were used in air-water exchange flux calculations.

$$
\sigma_{f_{a / w}}^{2}=\sigma_{C_{\infty, a}}^{2} \cdot\left(\frac{\partial f_{a / w}}{\partial C_{\infty, a}}\right)^{2}+\sigma_{C_{\infty, w}}^{2} \cdot\left(\frac{\partial f_{a / w}}{\partial C_{\infty, w}}\right)^{2}+\sigma_{K_{P E W, T 2}}^{2} \cdot\left(\frac{\partial f_{a / w}}{\partial K_{P E W, T 2}}\right)^{2}
$$

Variance in the air-water exchange flux $\left(\sigma_{F a / w}{ }^{2}\right)$ was calculated as in Equation S27, where the standard deviation of $v_{\mathrm{a} / \mathrm{w}}$ was assumed to be $30 \%{ }^{9}$

$\sigma_{F_{a / w}}^{2}=\sigma_{v_{a / w}}^{2} \cdot\left(\frac{\partial F_{a / w}}{\partial v_{a / w}}\right)^{2}+\sigma_{K_{P E W, T 2}}^{2} \cdot\left(\frac{\partial F_{a / w}}{\partial K_{P E W, T 2}}\right)^{2}+\sigma_{C_{\infty, w}}^{2} \cdot\left(\frac{\partial F_{a / w}}{\partial C_{\infty, w}}\right)^{2}+\sigma_{C_{\infty, a}}^{2} \cdot\left(\frac{\partial F_{a / w}}{\partial C_{\infty, a}}\right)^{2}$

These calculations were repeated for each air-water PE pair. The average percentage of total variance contributed to $\mathrm{C}_{\infty, \mathrm{w}}$ by analytical uncertainty was $85 \%$, and for $\mathrm{C}_{\infty, \mathrm{a}}$ was $96 \%$. Uncertainty in $f$, which accounts for uncertainty in partitioning coefficients and other physical properties, accounted for $15 \%$ of variance in $\mathrm{C}_{\infty, \mathrm{w}}$ and $4 \%$ of the variance in $\mathrm{C}_{\infty, \mathrm{a}}$. In situations where the compounds being measured do not approach equilibrium, $f$ would be expected to be responsible for a larger portion of total uncertainty, as demonstrated by Khairy et al. $2013 .^{10}$

Elevated Dissolved PCMs Near WWTPs. Dissolved PCMs were greatest in Oswego (OSW), which was also the site most likely to be influenced by wastewater, as two wastewater treatment plants (WWTPs) designated as major dischargers by the US Environmental Protection Agency (EPA) National Pollutant Discharge Elimination System (NPDES) ${ }^{11}$ were within $1.5 \mathrm{~km}$ of the deployment location. Though this site was near the mouth of the Oswego River, it is likely that elevated dissolved PCMs were not representative of typical river discharge. Rather, they were 
likely influenced by these nearby point sources which discharged directly into Lake Ontario.

The second-most elevated dissolved $\Sigma_{5} \mathrm{PCM}$ was measured at three Toronto nearshore sites (ETOR, TOR, and WTOR), possibly due to influences of three WWTP discharges within $1-8 \mathrm{~km}$ of the sites, combined with runoff from the densely populated Toronto conurbation. ${ }^{12,13}$ Similarly, Cleveland area sites (CLE, FH, and SHF) were likely influenced by impacted waterways such as the Cuyahoga River and Black River as well as a number of WWTPs that discharged directly into Lake Erie along this stretch of shoreline.

The water sampling site in Rochester (ROC) was placed slightly upstream of the mouth of the Genesee River, making it likely that river discharge was sampled. This site was likely representative of a mixture of urban runoff and wastewater effluent discharged into the river. In contrast, the PEs at the Buffalo site (BUF), where aqueous PCMs were $<15 \mathrm{pg} / \mathrm{L}$, were placed on the mouth of the Buffalo River, but there were no major NPDES-licensed treatment facilities on the river, and this region was characterized by a number of smaller industrial dischargers, which were expected to be much less important as sources of PCMs.

The Niagara River site (NIA) also exhibited elevated dissolved PCM concentrations during late summer. Few NPDES-designated point sources were nearby. However, due to the large volume of discharge and large plume extent from Niagara River, concentrations were expected to be representative of upriver sources channeled into Lake Ontario, including several major WWTPs. 
Table S3-1: Deployment Summary for 2011-2012 Air and Water PEs

\begin{tabular}{|c|c|c|c|c|c|c|c|c|c|}
\hline \multicolumn{2}{|c|}{ Meteorology } & \multicolumn{4}{|c|}{ Air } & \multicolumn{4}{|c|}{ Water } \\
\hline $\begin{array}{c}\text { Mean Air } \\
\mathrm{T}\left({ }^{\circ} \mathrm{C}\right)\end{array}$ & $\begin{array}{c}\text { Mean Wind } \\
\text { Speed } \\
(\mathrm{m} / \mathrm{s})\end{array}$ & $\begin{array}{c}\text { Sample } \\
\text { No. }\end{array}$ & $\begin{array}{c}\text { Date } \\
\text { Deployed }\end{array}$ & $\begin{array}{c}\text { Date } \\
\text { Recovered }\end{array}$ & $\begin{array}{c}\text { Days } \\
\text { Deployed }\end{array}$ & $\begin{array}{c}\text { Sample } \\
\text { No. }\end{array}$ & $\begin{array}{c}\text { Date } \\
\text { Deployed }\end{array}$ & $\begin{array}{c}\text { Date } \\
\text { Recovered }\end{array}$ & $\begin{array}{c}\text { Days } \\
\text { Deployed }\end{array}$ \\
\hline \multicolumn{10}{|c|}{ LAKE ONTARIO } \\
\hline \multicolumn{10}{|c|}{ NIA: Niagara Falls, NY - Fort Niagara State Park: $43.26125^{\circ} \mathrm{N}, 79.06287^{\circ} \mathrm{W}$} \\
\hline 5.5 & 4.5 & 1526 & $10 / 2 / 11$ & $4 / 24 / 12$ & 205 & & & & \\
\hline 17.0 & 3.5 & 2718 & $4 / 24 / 12$ & $7 / 2 / 12$ & 69 & & & & \\
\hline 23.4 & 3.0 & 3128 & $7 / 2 / 12$ & $8 / 30 / 12$ & 59 & 3130 & $7 / 2 / 12$ & $8 / 30 / 12$ & 59 \\
\hline 15.4 & 4.1 & 3528 & $8 / 30 / 12$ & $10 / 31 / 12$ & 62 & 3530 & $8 / 30 / 12$ & $10 / 31 / 12$ & 62 \\
\hline 15.4 & 4.1 & 3529 & $8 / 30 / 12$ & $10 / 31 / 12$ & 62 & 3531 & $8 / 30 / 12$ & $10 / 31 / 12$ & 62 \\
\hline \multicolumn{10}{|c|}{ ROC1: Rochester, NY - Coast Guard Auxiliary Base 4-2: $43.25238^{\circ} \mathrm{N}, 77.60938^{\circ} \mathrm{W}$} \\
\hline 5.5 & 5.1 & 1412 & $10 / 5 / 11$ & $4 / 30 / 12$ & 208 & & & & \\
\hline 20.3 & 4.5 & 2825 & $5 / 26 / 12$ & $6 / 30 / 12$ & 35 & 2824 & $5 / 26 / 12$ & $6 / 30 / 12$ & 35 \\
\hline 20.3 & 4.5 & & & & & 2828 & $5 / 26 / 12$ & $6 / 30 / 12$ & 35 \\
\hline 21.4 & 4.1 & 3113 & $6 / 30 / 12$ & $9 / 30 / 12$ & 92 & 3115 & $6 / 30 / 12$ & $9 / 30 / 12$ & 92 \\
\hline \multicolumn{10}{|c|}{ ROC2: Rochester, NY - US Coast Guard Station: $43.25694^{\circ} \mathrm{N}, 77.60261^{\circ} \mathrm{W}$} \\
\hline 20.4 & 4.5 & 2830 & $5 / 26 / 12$ & $7 / 1 / 12$ & 36 & & & & \\
\hline 19.7 & 4.2 & 3118 & $7 / 1 / 12$ & $10 / 22 / 12$ & 113 & & & & \\
\hline 19.7 & 4.2 & 3119 & $7 / 1 / 12$ & $10 / 22 / 12$ & 113 & & & & \\
\hline \multicolumn{10}{|c|}{ ROC 3: Rochester, NY - Beach Avenue: $43.26438^{\circ} \mathrm{N}, 77.61692^{\circ} \mathrm{W}$} \\
\hline 20.3 & 4.5 & 2835 & $5 / 26 / 12$ & $6 / 30 / 12$ & 35 & & & & \\
\hline 19.7 & 4.2 & 3123 & $7 / 1 / 12$ & $10 / 22 / 12$ & 113 & & & & \\
\hline 19.7 & 4.2 & 3124 & $7 / 1 / 12$ & $10 / 22 / 12$ & 113 & & & & \\
\hline \multirow{2}{*}{\multicolumn{10}{|c|}{ OSW: Oswego, NY: A: $43.46319^{\circ} \mathrm{N}, 76.51671^{\circ} \mathrm{W}$; W: $43.46550^{\circ} \mathrm{N}, 76.51666^{\circ} \mathrm{W}$}} \\
\hline 5.2 & 5.5 & 1521 & $10 / 3 / 11$ & $5 / 11 / 12$ & & & & & \\
\hline 19.4 & 4.1 & 2707 & $5 / 11 / 12$ & $7 / 10 / 12$ & 60 & 2711 & $5 / 11 / 12$ & $7 / 10 / 12$ & 60 \\
\hline 22.6 & 3.8 & 3108 & $7 / 10 / 12$ & $9 / 4 / 12$ & 56 & 3110 & $7 / 10 / 12$ & $9 / 4 / 12$ & 56 \\
\hline 22.6 & 3.8 & 3109 & $7 / 10 / 12$ & $9 / 4 / 12$ & 56 & 3111 & $7 / 10 / 12$ & $9 / 4 / 12$ & 56 \\
\hline 12.8 & 5.4 & 3507 & $9 / 4 / 12$ & $11 / 15 / 12$ & 72 & 3511 & $9 / 4 / 12$ & $11 / 15 / 12$ & 72 \\
\hline \multicolumn{10}{|c|}{ CV: Cape Vincent, NY: $44.13034^{\circ} \mathrm{N}, 76.33173^{\circ} \mathrm{W}$} \\
\hline 2.5 & 4.9 & 1519 & $11 / 2 / 11$ & $5 / 1 / 12$ & 181 & & & & \\
\hline 18.6 & 3.9 & 2702 & $5 / 1 / 12$ & $7 / 19 / 12$ & 79 & 2704 & $5 / 1 / 12$ & $7 / 19 / 12$ & 79 \\
\hline 18.6 & 3.9 & 2703 & $5 / 1 / 12$ & $7 / 19 / 12$ & 79 & & & & \\
\hline 22.4 & 4.3 & 3102 & $7 / 17 / 12$ & $8 / 29 / 12$ & 43 & 3104 & $7 / 17 / 12$ & $8 / 29 / 12$ & 43 \\
\hline 14.9 & 5.0 & 3502 & $8 / 29 / 12$ & $10 / 30 / 12$ & 62 & 3504 & $8 / 29 / 12$ & $10 / 30 / 12$ & 62 \\
\hline 14.9 & 5.0 & 3503 & $8 / 29 / 12$ & $10 / 30 / 12$ & 62 & 3505 & $8 / 29 / 12$ & $10 / 30 / 12$ & 62 \\
\hline \multicolumn{10}{|c|}{\begin{tabular}{|l} 
Offshore Lake Ontario (Deployed by Ontario Ministry of the Environment) \\
\end{tabular}} \\
\hline \multicolumn{10}{|c|}{ TOR: Toronto, ON (Stn AW-2): A: $43.66496^{\circ} \mathrm{N}, 79.26481^{\circ} \mathrm{W} ; \mathrm{W}: 43.66387^{\circ} \mathrm{N}, 79.26488^{\circ} \mathrm{W}$} \\
\hline 21.3 & 3.9 & 2908 & $5 / 22 / 12$ & $8 / 1 / 12$ & 71 & 2901 & $5 / 22 / 12$ & $8 / 1 / 12$ & 71 \\
\hline 21.3 & 3.9 & & & & & 2909 & $5 / 22 / 12$ & $8 / 1 / 12$ & 71 \\
\hline 17.7 & 3.8 & 3303 & $8 / 1 / 12$ & 10/16/12 & 76 & 3317 & $8 / 1 / 12$ & 10/19/12 & 79 \\
\hline
\end{tabular}




\begin{tabular}{|c|c|c|c|c|c|c|c|c|c|}
\hline \multicolumn{2}{|c|}{ Meteorology } & \multicolumn{4}{|c|}{ Air } & \multicolumn{4}{|c|}{ Water } \\
\hline \multicolumn{10}{|c|}{ WTOR: West Toronto, ON (Stn 3508): A: $43.57255^{\circ} \mathrm{N}, 79.51809^{\circ} \mathrm{W} ; \mathrm{W}: 43.571847^{\circ} \mathrm{N}, 79.51732^{\circ} \mathrm{W}$} \\
\hline 21.3 & 3.9 & 2903 & $5 / 22 / 12$ & $7 / 31 / 12$ & 70 & 2928 & $5 / 22 / 12$ & $7 / 31 / 12$ & 70 \\
\hline 21.3 & 3.9 & 2927 & $5 / 22 / 12$ & $7 / 31 / 12$ & 70 & & & & \\
\hline 17.8 & 3.7 & 3313 & $7 / 31 / 12$ & $10 / 16 / 12$ & 77 & 3329 & $7 / 31 / 12$ & $10 / 16 / 12$ & 77 \\
\hline \multicolumn{10}{|c|}{ ETOR: East Toronto, ON (Stn 708): A: $43.79478^{\circ} \mathrm{N}, 79.08620^{\circ} \mathrm{W} ; \mathrm{W}: 43.79373^{\circ} \mathrm{N}, 79.08655^{\circ} \mathrm{W}$} \\
\hline 21.3 & 3.9 & 2906 & $5 / 22 / 12$ & $8 / 1 / 12$ & 71 & 2917 & $5 / 22 / 12$ & $8 / 1 / 12$ & 71 \\
\hline 21.3 & 3.9 & & & & & 2920 & $5 / 22 / 12$ & $8 / 1 / 12$ & 71 \\
\hline 17.1 & 3.8 & 3304 & $8 / 1 / 12$ & $10 / 22 / 12$ & 82 & 3308 & $8 / 1 / 12$ & $10 / 22 / 12$ & 82 \\
\hline 17.1 & 3.8 & 3311 & $8 / 1 / 12$ & $10 / 22 / 12$ & 82 & & & & \\
\hline \multicolumn{10}{|c|}{ CHB: Chub Point, ON (Stn 3509): A: $43.95329^{\circ} \mathrm{N}, 78.01405^{\circ} \mathrm{W} ; \mathrm{W}: 43.95339^{\circ} \mathrm{N}, 78.01089^{\circ} \mathrm{W}$} \\
\hline 19.7 & 2.4 & 2914 & $5 / 23 / 12$ & $8 / 1 / 12$ & 70 & 2910 & $5 / 23 / 12$ & $8 / 1 / 12$ & 70 \\
\hline 16.4 & 2.8 & 3324 & $8 / 1 / 12$ & $10 / 22 / 12$ & 82 & 3322 & $8 / 1 / 12$ & $10 / 22 / 12$ & 82 \\
\hline 16.4 & 2.8 & & & & & 3328 & $8 / 1 / 12$ & $10 / 22 / 12$ & 82 \\
\hline \multicolumn{10}{|c|}{ PEP: Prince Edward Point, ON (Stn 3087): A: $43.95745^{\circ} \mathrm{N}, 76.81011^{\circ} \mathrm{W} ; \mathrm{W}: 43.95832^{\circ} \mathrm{N}, 76.81039^{\circ} \mathrm{W}$} \\
\hline 20.0 & 4.4 & 2919 & $5 / 23 / 12$ & $8 / 2 / 12$ & 71 & 2934 & $5 / 23 / 12$ & $8 / 2 / 12$ & 71 \\
\hline 20.0 & 4.4 & 2931 & $5 / 23 / 12$ & $8 / 2 / 12$ & 71 & & & & \\
\hline 17.6 & 6.0 & 3302 & $8 / 2 / 12$ & $10 / 25 / 12$ & 84 & 3309 & $8 / 2 / 12$ & $10 / 25 / 12$ & 84 \\
\hline \multicolumn{10}{|c|}{ Offshore Lake Ontario (Deployed by Environment Canada) } \\
\hline \multicolumn{10}{|c|}{ WONT: Western Offshore Ontario (Stn 207) offshore from Niagara: $43.32833^{\circ} \mathrm{N}, 79.13472^{\circ} \mathrm{W}$} \\
\hline 18.1 & 3.5 & & & & & 2306 & $4 / 10 / 12$ & $10 / 25 / 12$ & 198 \\
\hline \multicolumn{10}{|c|}{ GRI: Western Offshore Ontario (Grimsby Met Buoy): $43.25893^{\circ} \mathrm{N}, 79.53865^{\circ} \mathrm{W}$} \\
\hline 18.9 & 4.2 & 2325 & $5 / 14 / 12$ & $10 / 25 / 12$ & 164 & & & & \\
\hline \multicolumn{10}{|c|}{ CONT: Central Offshore Ontario (Stn 403): $43.58806^{\circ} \mathrm{N}, 78.24055^{\circ} \mathrm{W}$} \\
\hline 16.9 & 4.9 & & & & & 2321 & $4 / 3 / 12$ & $10 / 20 / 12$ & 200 \\
\hline \multicolumn{10}{|c|}{ LAKE ERIE } \\
\hline \multicolumn{10}{|c|}{ BUF: Buffalo, NY - US Coast Guard Station: $42.87758^{\circ} \mathrm{N}, 78.89047^{\circ} \mathrm{W}$} \\
\hline 4.6 & 5.3 & 1528 & $10 / 3 / 11$ & $5 / 1 / 12$ & 211 & & & & \\
\hline 4.6 & 5.3 & 1529 & $10 / 3 / 11$ & $5 / 1 / 12$ & 211 & & & & \\
\hline 17.5 & 3.5 & 2723 & $5 / 1 / 12$ & $7 / 2 / 12$ & 62 & 2725 & $5 / 1 / 12$ & $7 / 2 / 12$ & 62 \\
\hline 22.5 & 3.6 & 3133 & $7 / 2 / 12$ & $8 / 30 / 12$ & 59 & 3135 & $7 / 2 / 12$ & $8 / 30 / 12$ & 59 \\
\hline 14.8 & 4.7 & 3533 & $8 / 30 / 12$ & $11 / 1 / 12$ & 63 & & & & \\
\hline 14.8 & 4.7 & 3534 & $8 / 30 / 12$ & $11 / 1 / 12$ & 63 & & & & \\
\hline \multicolumn{10}{|c|}{ DUN: Dunkirk, NY: A: $42.49252^{\circ} \mathrm{N}, 79.35336^{\circ} \mathrm{W} ; \mathrm{W}: 42.49247^{\circ} \mathrm{N}, 79.34852^{\circ} \mathrm{W}$} \\
\hline 5.7 & 6.2 & 1530 & $10 / 3 / 11$ & $4 / 30 / 12$ & 210 & & & & \\
\hline 17.5 & 4.2 & 2728 & $4 / 30 / 12$ & $6 / 28 / 12$ & 59 & 2730 & $4 / 30 / 12$ & $6 / 28 / 12$ & 59 \\
\hline 22.7 & 3.5 & 3202 & $6 / 28 / 12$ & $8 / 29 / 12$ & 62 & 3204 & $6 / 28 / 12$ & $8 / 29 / 12$ & 62 \\
\hline 22.7 & 3.5 & 3203 & $6 / 28 / 12$ & $8 / 29 / 12$ & 62 & 3205 & $6 / 28 / 12$ & $8 / 29 / 12$ & 62 \\
\hline 15.8 & 4.2 & 3901 & $8 / 29 / 12$ & $10 / 22 / 12$ & 54 & 3903 & $8 / 29 / 12$ & $10 / 22 / 12$ & 54 \\
\hline 15.8 & 4.2 & 3902 & $8 / 29 / 12$ & $10 / 22 / 12$ & 54 & & & & \\
\hline
\end{tabular}




\begin{tabular}{|c|c|c|c|c|c|c|c|c|c|}
\hline Mete & logy & & & iir & & & & iter & \\
\hline ERI: Erie, & Presqu & sle Sta & Park: A: & $2.15585^{\circ} \mathrm{N}$ & 0.112 & $\bar{W} ; \mathrm{W}$ & $2.15199^{\circ}$ &, 80.1119 & \\
\hline 7.1 & 6.6 & 1533 & $10 / 13 / 11$ & $6 / 7 / 12$ & 238 & & & & \\
\hline 21.6 & 5.0 & 2734 & $6 / 7 / 12$ & $7 / 3 / 12$ & 26 & 2736 & $6 / 7 / 12$ & $7 / 3 / 12$ & 26 \\
\hline 21.6 & 5.0 & & & & & 2737 & $6 / 7 / 12$ & $7 / 3 / 12$ & 26 \\
\hline 22.5 & 4.6 & 3207 & $7 / 3 / 12$ & 9/7/12 & 66 & 3209 & 7/3/12 & 9/7/12 & 66 \\
\hline 16.6 & 5.5 & & & & & 3909 & $9 / 7 / 12$ & $10 / 4 / 12$ & 27 \\
\hline 16.6 & 5.5 & & & & & 3910 & $9 / 7 / 12$ & $10 / 4 / 12$ & 27 \\
\hline FH: Fairp & arbor, C & A: 41. & $835^{\circ} \mathrm{N}, 8$ & $27789^{\circ} \mathrm{W}$ & $\overline{N: 41 .}$ & $2^{\circ} \mathrm{N}, 8$ & $2439^{\circ} \mathrm{W}$ & & \\
\hline 20.9 & 5.4 & 2801 & $5 / 21 / 12$ & $7 / 2 / 12$ & 42 & 2803 & $5 / 29 / 12$ & $6 / 29 / 12$ & 31 \\
\hline 20.9 & 5.4 & 2802 & $5 / 21 / 12$ & $7 / 2 / 12$ & 42 & 2804 & $5 / 29 / 12$ & $6 / 29 / 12$ & 31 \\
\hline 21.7 & 4.6 & 3212 & $7 / 2 / 12$ & $9 / 17 / 12$ & 77 & 3214 & $6 / 29 / 12$ & $9 / 17 / 12$ & 80 \\
\hline 14.0 & 6.3 & 3912 & 9/17/12 & 10/15/12 & 28 & & & & \\
\hline 14.0 & 6.3 & 3913 & $9 / 17 / 12$ & $10 / 15 / 12$ & 28 & & & & \\
\hline CLE: Cle & $\mathrm{d}, \mathrm{OH}-$ & gewat & Park: A: 4 & $.49212^{\circ} \mathrm{N}$ & 1.7332 & N; W: & $1.50383^{\circ}$ & 81.7655 & \\
\hline 21.0 & 3.2 & 2806 & $5 / 17 / 12$ & $7 / 7 / 12$ & 51 & 2808 & $5 / 5 / 12$ & $6 / 28 / 12$ & 54 \\
\hline 21.0 & 3.2 & 2807 & $5 / 17 / 12$ & $7 / 7 / 12$ & 51 & 2809 & $5 / 5 / 12$ & $6 / 28 / 12$ & 54 \\
\hline 23.2 & 2.9 & 3218 & $7 / 7 / 12$ & $9 / 7 / 12$ & 62 & 3220 & $7 / 7 / 12$ & $9 / 7 / 12$ & 62 \\
\hline 23.2 & 2.9 & & & & & 3221 & $7 / 7 / 12$ & $9 / 7 / 12$ & 62 \\
\hline 15.6 & 3.1 & 3917 & $9 / 7 / 12$ & $10 / 9 / 12$ & 32 & & & & \\
\hline 15.6 & 3.1 & 3918 & $9 / 7 / 12$ & $10 / 9 / 12$ & 32 & & & & \\
\hline CLD: Cle & $\mathrm{dd}, \mathrm{OH}-$ & $\mathrm{HGe}$ & ge T. Crai & Air Monito & g Stati & 41.49 & $8^{\circ} \mathrm{N}, 81.6$ & $851^{\circ} \mathrm{W}$ & \\
\hline 5.8 & 4.8 & 1402 & $9 / 30 / 11$ & $5 / 1 / 12$ & 214 & & & & \\
\hline 19.2 & 3.3 & 2812 & $5 / 1 / 12$ & $7 / 2 / 12$ & 62 & & & & \\
\hline 23.4 & 2.9 & 3223 & $7 / 2 / 12$ & $8 / 31 / 12$ & 60 & & & & \\
\hline 15.1 & 4.1 & 3922 & $8 / 31 / 12$ & $11 / 1 / 12$ & 62 & & & & \\
\hline 15.1 & 4.1 & 3923 & $8 / 31 / 12$ & $11 / 1 / 12$ & 62 & & & & \\
\hline TOL: Tole & $\mathrm{OH}: 41$. & $05^{\circ} \mathrm{N}$, & $3.40189^{\circ}$ & & & & & & \\
\hline 21.9 & 3.2 & 2819 & $4 / 27 / 12$ & $8 / 20 / 12$ & 115 & & & & \\
\hline SHF: She & Lake, & 41.49 & $41^{\circ} \mathrm{N}, 82$. & $3252^{\circ} \mathrm{W}$ & & & & & \\
\hline 5.7 & 4.8 & 1404 & $10 / 4 / 11$ & $4 / 28 / 12$ & 207 & & & & \\
\hline 18.7 & 3.3 & 2713 & $4 / 28 / 12$ & $7 / 2 / 12$ & 65 & & & & \\
\hline 23.3 & 2.9 & & & & & 3227 & $7 / 5 / 12$ & $9 / 7 / 12$ & 64 \\
\hline 13.0 & 4.5 & & & & & 3927 & $9 / 7 / 12$ & $11 / 8 / 12$ & 62 \\
\hline 13.0 & 4.5 & & & & & 3928 & $9 / 7 / 12$ & $11 / 8 / 12$ & 62 \\
\hline Offshore & Erie ([ & oyed & y Enviror & nent Cana & & & & & \\
\hline EERI: Eas & Erie $(\mathrm{S}$ & $52): 4$ & $57611^{\circ} \mathrm{N}$, & $9.92417^{\circ} \mathrm{V}$ & & & & & \\
\hline 17.2 & 6.4 & 2328 & $4 / 25 / 12$ & 10/17/12 & 175 & 2322 & $4 / 25 / 12$ & $10 / 17 / 12$ & 175 \\
\hline CERI: Ce & Erie $(S t$ & 80): 4 & $30944^{\circ} \mathrm{N}$, & $1.66917^{\circ} \mathrm{V}$ & & & & & \\
\hline 22.4 & 4.9 & 2327 & $5 / 2 / 12$ & $10 / 16 / 12$ & 167 & 2330 & $5 / 2 / 12$ & $10 / 16 / 12$ & 167 \\
\hline WERI: $\mathrm{W}$ & Erie ( & 970): & $82433^{\circ}$ & 82.97497 & & & & & \\
\hline 18.7 & 5.8 & & & & & 2317 & $8 / 8 / 12$ & $10 / 9 / 12$ & 62 \\
\hline
\end{tabular}


Table S3-2. Buoys Used for Temperature and Wind Data

\begin{tabular}{|c|c|c|c|c|c|c|}
\hline \multirow[b]{2}{*}{ Site Abbreviation } & \multicolumn{3}{|c|}{ Temperature Data } & \multicolumn{3}{|c|}{ Wind Speed and Direction Data } \\
\hline & Data Source & Buoy Name & Location & Data Source & Buoy Name & Location \\
\hline BUF & NDBC & BUFN6 & $42.878 \mathrm{~N}, 78.890 \mathrm{~W}$ & NDBC & BUFN6 & $42.878 \mathrm{~N}, 78.890 \mathrm{~W}$ \\
\hline CERI & NDBC & C45164 & $41.734 \mathrm{~N}, 81.698 \mathrm{~W}$ & NDBC & C45164 & $41.734 \mathrm{~N}, 81.698 \mathrm{~W}$ \\
\hline CLD & NDBC & CNDO1 & $41.542 \mathrm{~N}, 81.637 \mathrm{~W}$ & NDBC & CNDO1 & $41.542 \mathrm{~N}, 81.637 \mathrm{~W}$ \\
\hline $\mathrm{CLE}$ & NDBC & CNDO1 & $41.542 \mathrm{~N}, 81.637 \mathrm{~W}$ & NDBC & CNDO1 & $41.542 \mathrm{~N}, 81.637 \mathrm{~W}$ \\
\hline CONT & NDBC & C45012 & $43.618 \mathrm{~N}, 77.405 \mathrm{~W}$ & NDBC & C45012 & $43.618 \mathrm{~N}, 77.405 \mathrm{~W}$ \\
\hline EERI & NDBC & THLO1 & $41.826 \mathrm{~N}, 83.194 \mathrm{~W}$ & NDBC & THLO1 & $41.826 \mathrm{~N}, 83.194 \mathrm{~W}$ \\
\hline ERI & NDBC & CBLO1 & $41.981 \mathrm{~N}, 80.556 \mathrm{~W}$ & NDBC & CBLO1 & $41.981 \mathrm{~N}, 80.556 \mathrm{~W}$ \\
\hline ETOR & OME Logger & - & Same as samplers & Environment Canada & TORONTO CITY CENTRE & $43.63 \mathrm{~N}, 79.40 \mathrm{~W}$ \\
\hline $\mathrm{FH}$ & NDBC & FAIO1 & $41.764 \mathrm{~N}, 81.281 \mathrm{~W}$ & NDBC & FAIO1 & $41.764 \mathrm{~N}, 81.281 \mathrm{~W}$ \\
\hline GRI & Environment Canada & GRIMSBY & $43.252 \mathrm{~N}, 79.535 \mathrm{~W}$ & Environment Canada & GRIMSBY & $43.252 \mathrm{~N}, 79.535 \mathrm{~W}$ \\
\hline SHF & NDBC & CNDO1 & $41.542 \mathrm{~N}, 81.637 \mathrm{~W}$ & NDBC & CNDO1 & $41.542 \mathrm{~N}, 81.637 \mathrm{~W}$ \\
\hline Stn 207 & NDBC & YGNN6 & $43.262 \mathrm{~N}, 76.064 \mathrm{~W}$ & NDBC & YGNN6 & $43.262 \mathrm{~N}, 76.064 \mathrm{~W}$ \\
\hline TOL & NDBC & THRO1 & $41.694 \mathrm{~N}, 83.473 \mathrm{~W}$ & NDBC & THRO1 & $41.694 \mathrm{~N}, 83.473 \mathrm{~W}$ \\
\hline TOR & OME Logger & - & Same as samplers & Environment Canada & TORONTO CITY CENTRE & $43.63 \mathrm{~N}, 79.40 \mathrm{~W}$ \\
\hline WERI & Environment Canada & LONG POINT (AUT) & $42.57 \mathrm{~N}, 80.05 \mathrm{~W}$ & Environment Canada & LONG POINT(AUT) & $42.57 \mathrm{~N}, 80.05 \mathrm{~W}$ \\
\hline WTOR & OME Logger & - & Same as samplers & Environment Canada & TORONTO CITY CENTRE & $43.63 \mathrm{~N}, 79.40 \mathrm{~W}$ \\
\hline
\end{tabular}

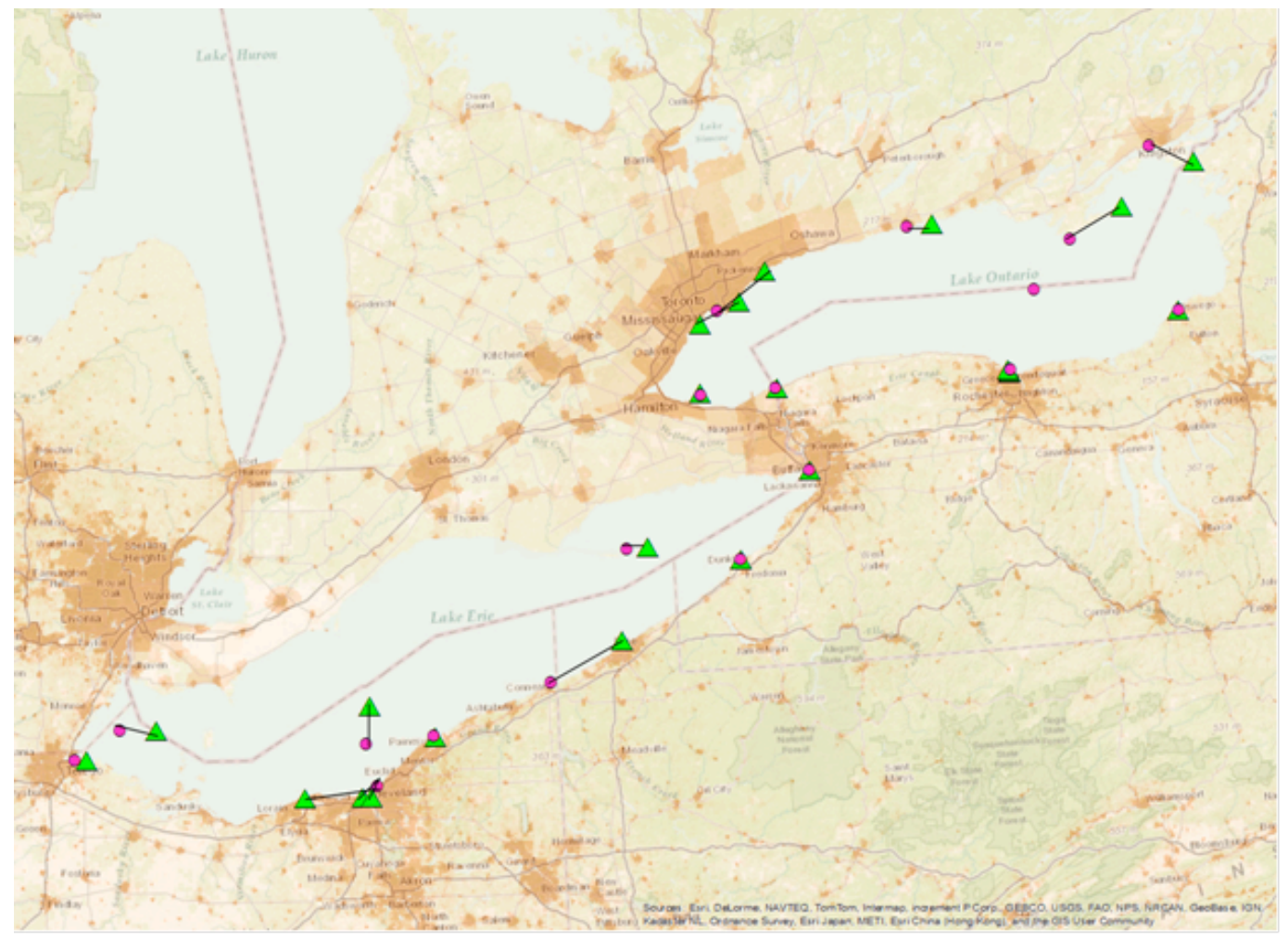

Figure S3-1. Locations of Air Sites Relative to Buoys. Black lines are used to clarify which buoy was used for which site. Green triangles show air sampling sites and pink circles show meteorological buoys. 
Table S3-3. Average Matrix Spike Recoveries.

\begin{tabular}{lc} 
Compound & $\begin{array}{c}\text { Percent } \\
\text { Recovery } \\
\mathbf{\pm 1 \sigma} \\
(\mathbf{N}=\mathbf{2 1})\end{array}$ \\
\hline ADBI & $91 \pm 33$ \\
AHMI & $104 \pm 40$ \\
ATII & $98 \pm 32$ \\
HHCB & $91 \pm 49$ \\
AHTN & $106 \pm 41$ \\
Musk Xylene & $79 \pm 26$ \\
Musk Ketone & $145 \pm 50$ \\
\hline
\end{tabular}

Table S3-4. Relative Percent Difference (RPD) between Duplicate Samples. RPDs calculated for samplers where target compound was found $>\mathrm{DL}$ in both replicates.

\begin{tabular}{lcc} 
& Mean RPD for Air PE Dups & Mean RPD for Water PE Dups \\
\hline ADBI & $41 \pm 26$ & $40 \pm 22$ \\
AHMI & $40 \pm 31$ & $35 \pm 29$ \\
ATII & $14 \pm 22$ & $22 \pm 22$ \\
HHCB & $18 \pm 14$ & $15 \pm 32$ \\
AHTN & $21 \pm 24$ & $25 \pm 40$ \\
\hline
\end{tabular}

Table S3-5. Mean Blank Concentrations and Detection Limits (ng/g PE).

\begin{tabular}{|c|c|c|c|c|c|}
\hline & $\begin{array}{c}\text { Mean Lab } \\
\text { Blank } \pm 1 \sigma \\
(N=13)\end{array}$ & $\begin{array}{c}\text { Detection } \\
\text { Limit }(95 \% \mathrm{Cl} \\
\text { of Lab Blank) }\end{array}$ & $\begin{array}{l}\text { Mean Shoreline } \\
\text { Field Blank } \pm 1 \sigma \\
\qquad(\mathrm{N}=9)\end{array}$ & $\begin{array}{l}\text { Mean OME Field } \\
\text { Blank } \pm 1 \sigma \\
(N=5)\end{array}$ & $\begin{array}{l}\text { Mean Env. Can. } \\
\text { Field Blank } \pm 1 \sigma \\
\qquad(\mathrm{N}=7)\end{array}$ \\
\hline ADBI & $0.10 \pm 0.14$ & 0.27 & $0.14 \pm 0.17$ & $0.04 \pm 0.04$ & $0.14 \pm 0.10$ \\
\hline AHMI & $0.17 \pm 0.18$ & 0.36 & $0.38 \pm 0.34$ & $0.09 \pm 0.11$ & $0.38 \pm 0.26$ \\
\hline ATII & $0.18 \pm 0.23$ & 0.47 & $13.2 \pm 38.2$ & $0.16 \pm 0.21$ & $0.02 \pm 0.05$ \\
\hline ННСВ & $12.8 \pm 11.9$ & 23.7 & $27.8 \pm 25.9$ & $3.6 \pm 3.7$ & $3.7 \pm 1.4$ \\
\hline AHTN & $1.23 \pm 1.00$ & 2.00 & $2.08 \pm 1.47$ & $0.57 \pm 0.49$ & $0.75 \pm 0.30$ \\
\hline Musk Xylene & $0.51 \pm 1.46$ & 2.92 & $35.1 \pm 104.2$ & $0.25 \pm 0.11$ & $0.08 \pm 0.11$ \\
\hline Musk Ketone & $2.07 \pm 4.03$ & 8.05 & $0.96 \pm 0.95$ & $0.37 \pm 0.18$ & $0.35 \pm 0.29$ \\
\hline
\end{tabular}



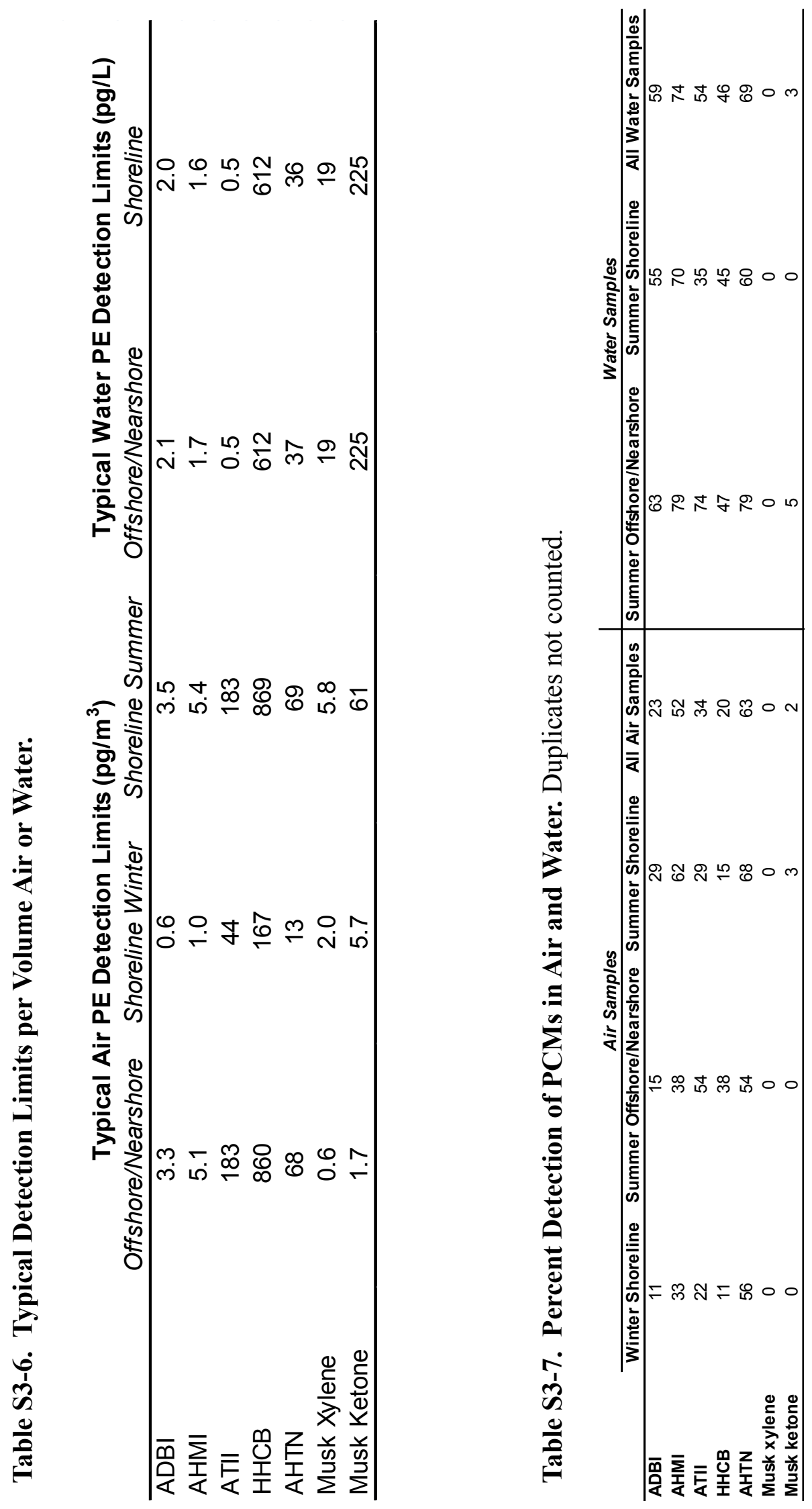

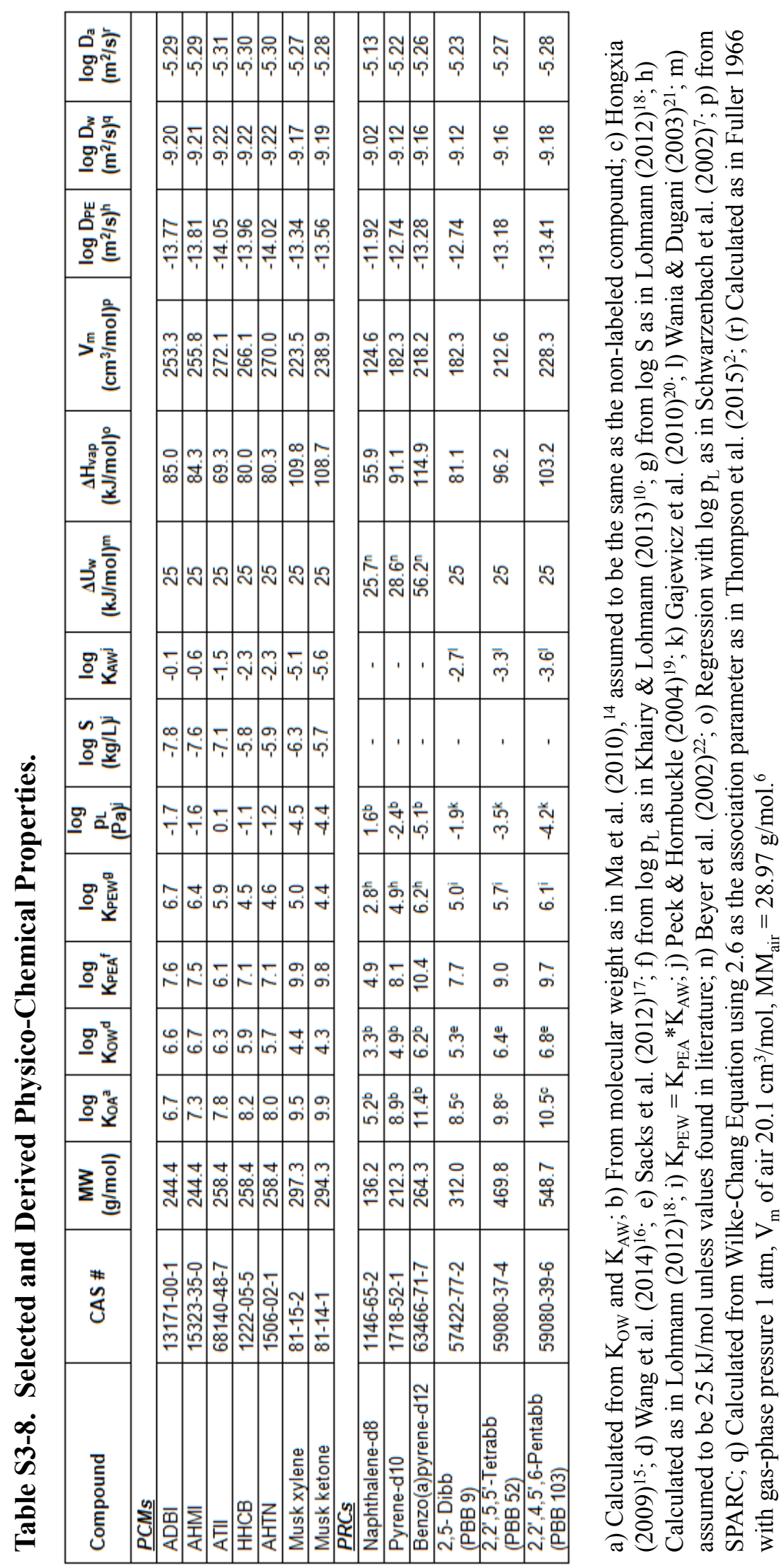


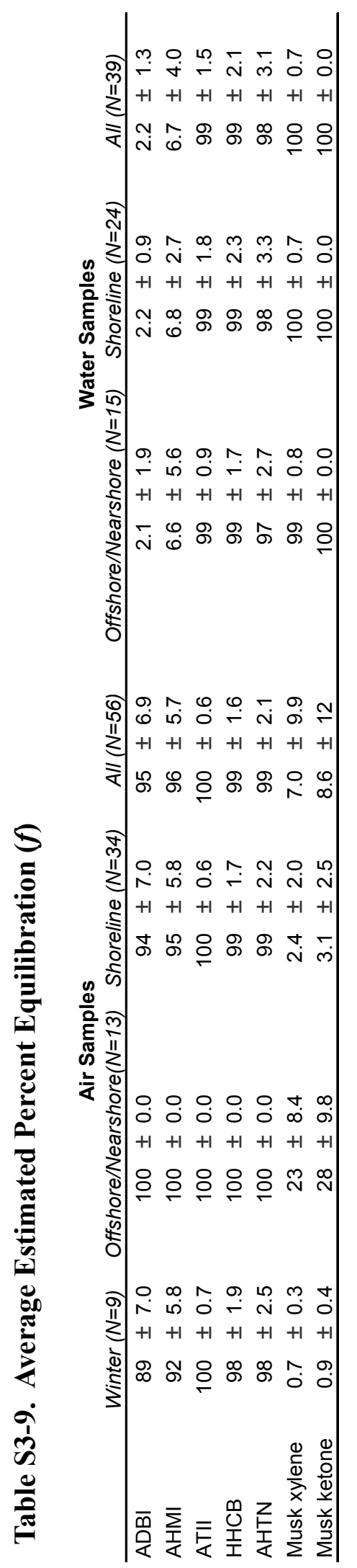


Figure S3-2. HHCB and AHTN Fugacity Ratios.

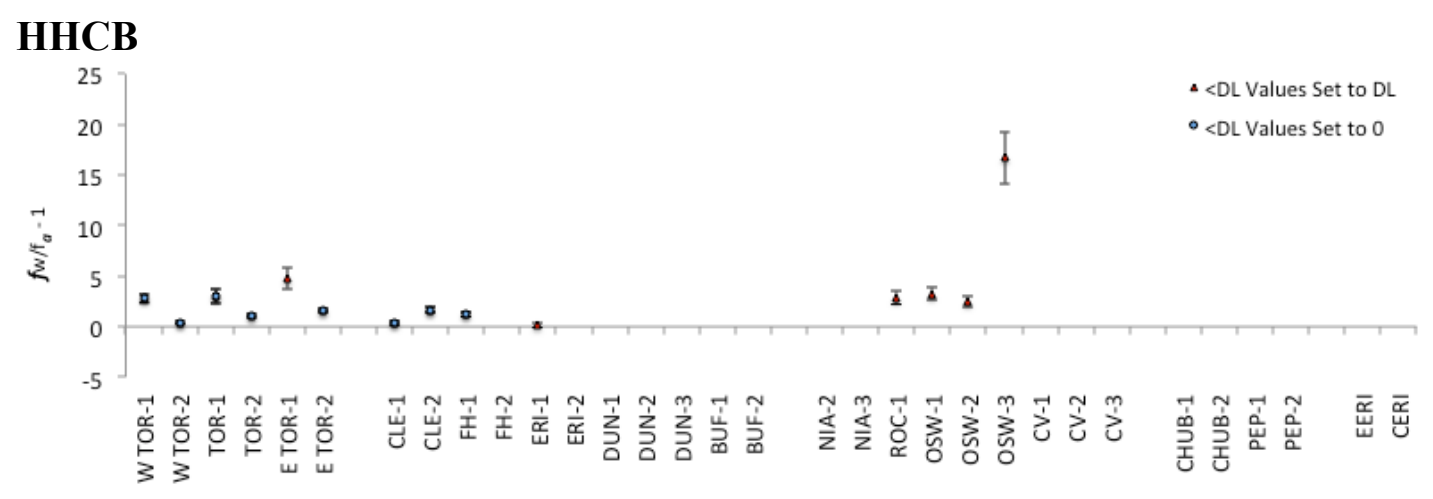

\section{AHTN}

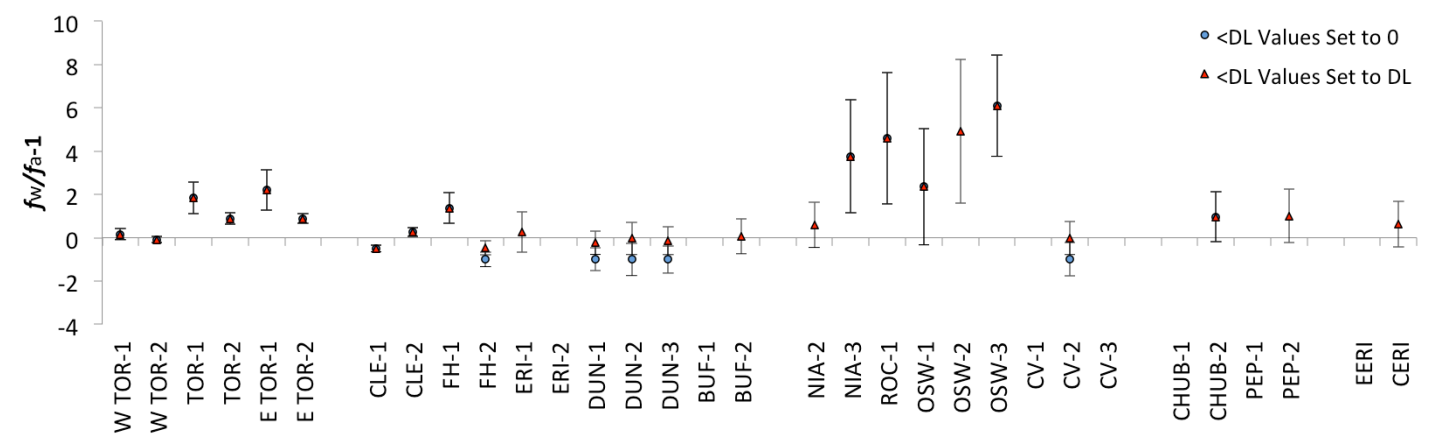


Figure S3-3. Summary of Dissolved PCMs Over Multiple Deployments. For shoreline/nearshore sites, DEP 1, 2, and 3 are early summer, mid-summer, and late summer/early fall, respectively. For nearshore Northern Ontario sites, DEP 1 is earlyto-mid-summer and DEP 2 is mid-summer to early fall. Concentrations are not available for all deployments at all sites, and the absence of a bar means no sample was retrieved or all concentrations were $<$ DL.
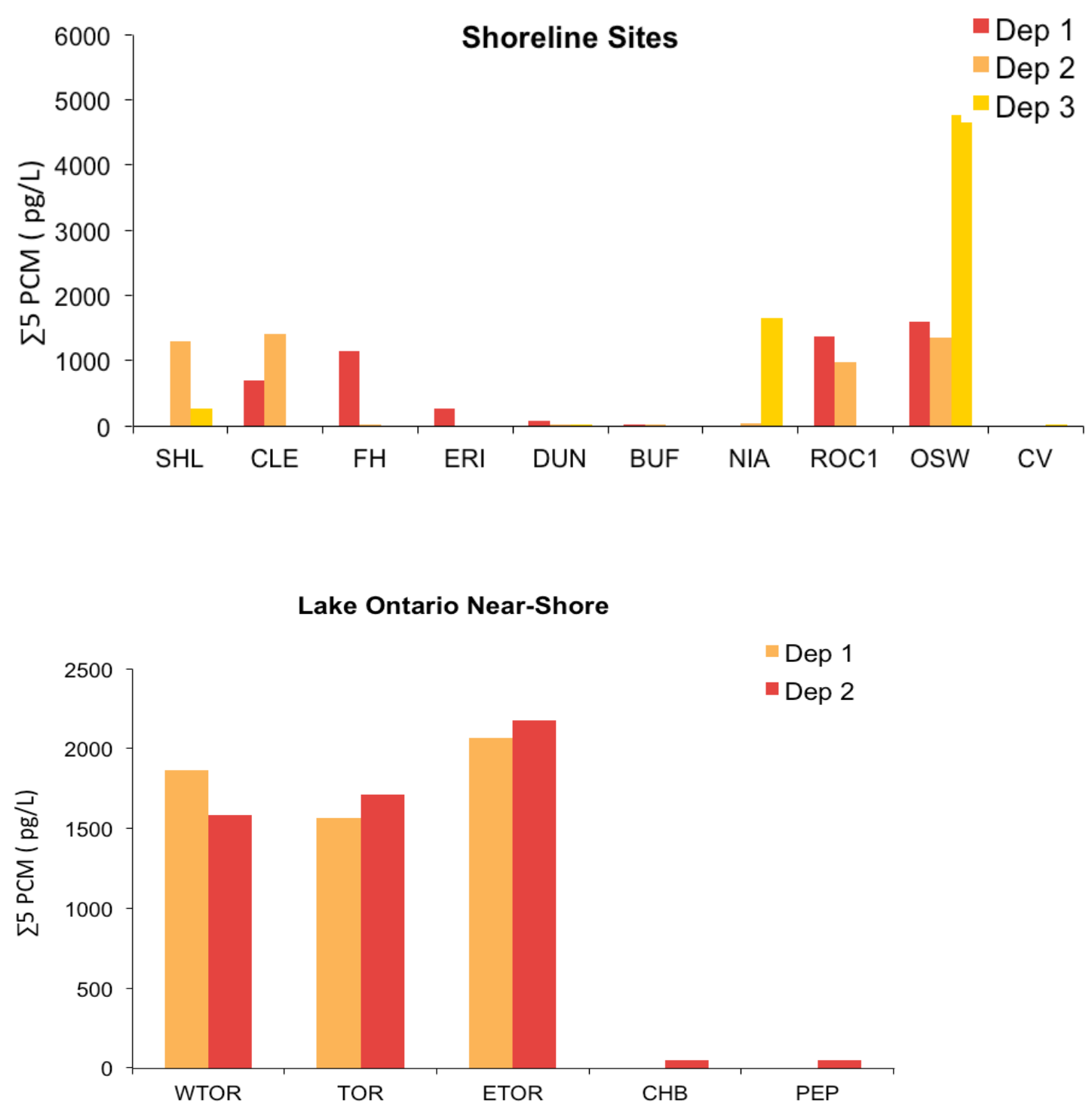
Figure S3-4. Summary of Gaseous PCMs Over Multiple Deployments. For shoreline sites, DEP 1, 2, and 3 are early summer, mid-summer, and late summer/early fall, respectively. For nearshore Northern Ontario sites, DEP 1 is early-to-mid-summer and DEP 2 is mid-summer to early fall. Concentrations are not available for all deployments at all sites, and the absence of a bar means no sample was retrieved or all concentrations were $<$ DL.
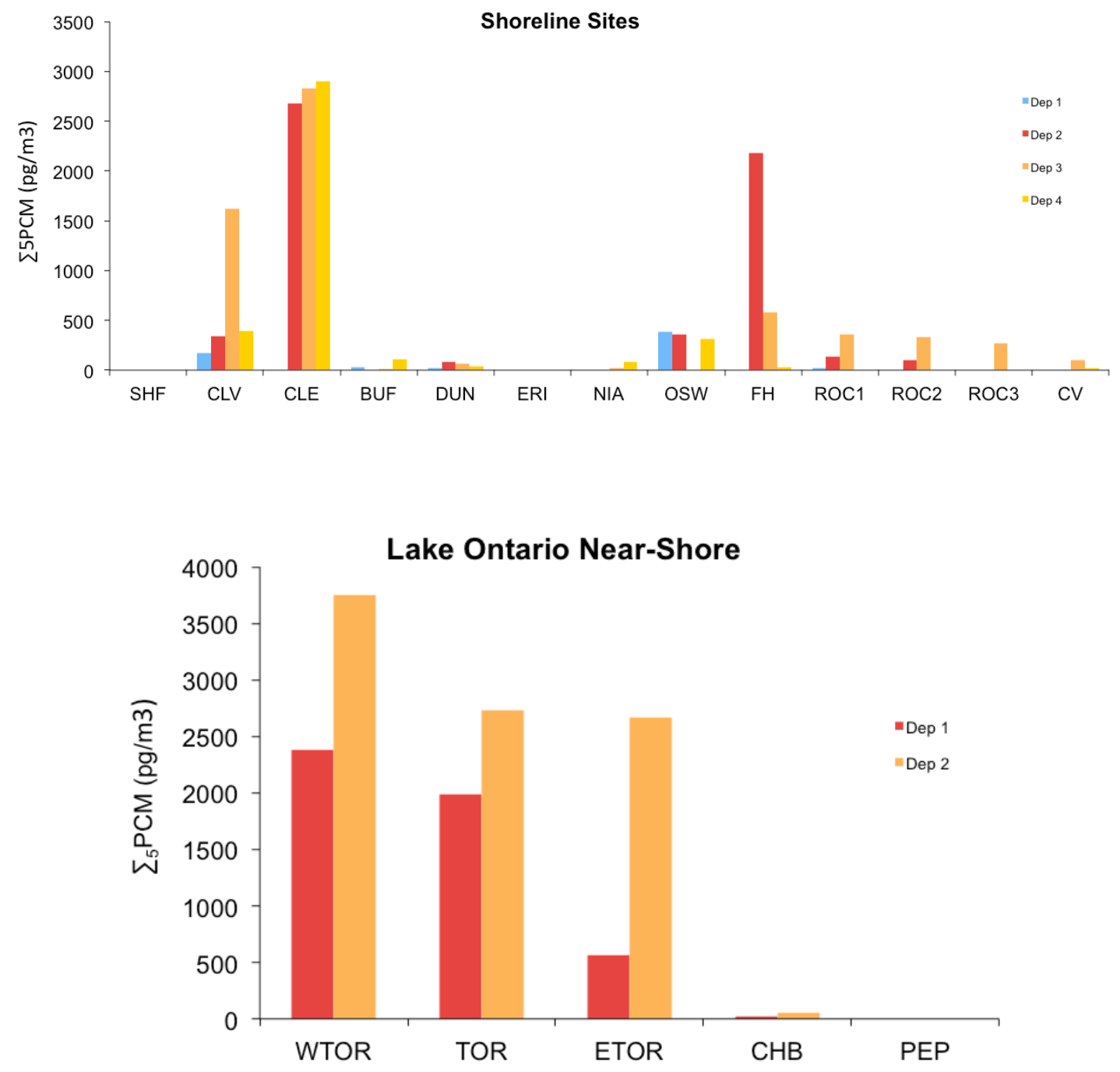
Table S3-10. PCM Fugacity Ratios. Grayed-out values were not significantly different from equilibrium after error propagation. Values in red note ratios for pairs where either the air or water concentrations was $<$ DL, and the DL values was used to calculate the fugacity ratio. NA marks pairs with concentrations $<\mathrm{DL}$ in both air and water, for which no ratio was calculated.

\begin{tabular}{|c|c|c|c|c|c|c|}
\hline Location & Dep No. & ADBI & AHMI & ATII & HHCB & AHTN \\
\hline \multicolumn{7}{|c|}{ Shoreline Air-Water Pairs } \\
\hline CLE & Dep 1 & $80 \pm 242$ & $25 \pm 33$ & $0.94 \pm 0.72$ & $1.3 \pm 0.16$ & $0.50 \pm 0.15$ \\
\hline CLE & Dep 2 & $69 \pm 276$ & $5.0 \pm 7.4$ & $2.0 \pm 2.2$ & $2.7 \pm 0.31$ & $1.3 \pm 0.21$ \\
\hline $\mathrm{FH}$ & Dep 1 & $212 \pm 741$ & $86 \pm 193$ & $2.0 \pm 1.6$ & $2.2 \pm 0.26$ & $2.4 \pm 0.72$ \\
\hline $\mathrm{FH}$ & Dep 2 & $47 \pm 203$ & $36 \pm 134$ & $0.61 \pm 1.1$ & NA & $0.54 \pm 0.34$ \\
\hline ERI & Dep 1 & NA & $51 \pm 241$ & $3.1 \pm 5.2$ & $1.1 \pm 0.25$ & $1.3 \pm 0.94$ \\
\hline ERI & Dep 2 & NA & NA & NA & NA & NA \\
\hline DUN & Dep 1 & NA & $11 \pm 43$ & NA & NA & $0.76 \pm 0.53$ \\
\hline DUN & Dep 2 & $26 \pm 126$ & $14 \pm 45$ & NA & NA & $1.0 \pm 0.75$ \\
\hline DUN & Dep 3 & NA & $4.6 \pm 19$ & NA & NA & $0.85 \pm 0.63$ \\
\hline BUF & Dep 1 & NA & $28 \pm 138$ & NA & NA & NA \\
\hline BUF & Dep 2 & NA & $16 \pm 51$ & NA & NA & $1.1 \pm 0.81$ \\
\hline NIA & Dep 2 & $80 \pm 341$ & $9.2 \pm 29$ & NA & NA & $1.6 \pm 1.04$ \\
\hline NIA & Dep 3 & $198 \pm 754$ & $19 \pm 25$ & $5.3 \pm 8.5$ & $5.4 \pm 0.81$ & $4.8 \pm 1.5$ \\
\hline ROC & Dep 1 & $28 \pm 38$ & $177 \pm 682$ & NA & $3.8 \pm 0.63$ & $5.6 \pm 3.0$ \\
\hline osw & Dep 1 & $44 \pm 222$ & $40 \pm 159$ & $4.4 \pm 5.2$ & $4.2 \pm 0.63$ & $3.4 \pm 1.5$ \\
\hline OSW & Dep 2 & $48 \pm 238$ & $49 \pm 189$ & $4.0 \pm 6.4$ & $3.5 \pm 0.52$ & $5.9 \pm 3.3$ \\
\hline osw & Dep 3 & $104 \pm 408$ & $16 \pm 28$ & $8.5 \pm 6.7$ & $18 \pm 2.6$ & $7.1 \pm 1.3$ \\
\hline CV & Dep 1 & NA & NA & NA & NA & NA \\
\hline CV & Dep 2 & NA & NA & NA & NA & $1.0 \pm 0.77$ \\
\hline $\mathrm{CV}$ & Dep 3 & NA & $3.0 \pm 12$ & NA & NA & NA \\
\hline \multicolumn{7}{|c|}{ Offshore/Near-Shore Air-Water Pairs } \\
\hline EERI & Dep 1 & NA & $16 \pm 72$ & $1.5 \pm 2.9$ & NA & NA \\
\hline CERI & Dep 1 & $16 \pm 38$ & $31 \pm 120$ & NA & NA & $1.6 \pm 1.1$ \\
\hline W TOR & Dep 1 & $183 \pm 761$ & $8.0 \pm 12$ & $1.7 \pm 1.9$ & $3.8 \pm 0.42$ & $1.2 \pm 0.25$ \\
\hline W TOR & Dep 2 & $262 \pm 893$ & $99 \pm 396$ & $1.3 \pm 0.67$ & $1.4 \pm 0.14$ & $0.92 \pm 0.15$ \\
\hline TOR & Dep 1 & NA & $70 \pm 290$ & $1.7 \pm 1.3$ & $4.0 \pm 0.77$ & $2.8 \pm 0.72$ \\
\hline TOR & Dep 2 & $136 \pm 572$ & $21 \pm 48$ & $1.7 \pm 0.98$ & $2.1 \pm 0.13$ & $1.9 \pm 0.26$ \\
\hline E TOR & Dep 1 & $106 \pm 527$ & $5.0 \pm 14$ & $2.8 \pm 3.5$ & $5.7 \pm 1.1$ & $3.2 \pm 0.93$ \\
\hline E TOR & Dep 2 & $149 \pm 629$ & $72 \pm 290$ & $2.3 \pm 1.2$ & $2.6 \pm 0.17$ & $1.9 \pm 0.24$ \\
\hline CHUB & Dep 1 & NA & $11 \pm 43$ & NA & NA & NA \\
\hline CHUB & Dep 2 & NA & $26 \pm 130$ & $1.1 \pm 2.4$ & NA & $2.0 \pm 1.2$ \\
\hline PEP & Dep 1 & NA & NA & NA & NA & NA \\
\hline PEP & Dep 2 & NA & $56 \pm 229$ & $1.1 \pm 2.3$ & NA & $2.0 \pm 1.2$ \\
\hline
\end{tabular}


Table S3-11. PCM Air-Water Exchange Mass Transfer Coefficients (cm/day). Air-water exchange mass transfer coefficients (cm/day) were calculated in cases where the fugacity ratio was significantly different from equilibrium after error propagation. All others were replaced with "NA".

\begin{tabular}{|c|c|c|c|c|c|c|}
\hline Location & Dep No. & ADBI & AHMI & ATII & HHCB & AHTN \\
\hline \multicolumn{7}{|c|}{ Shoreline Air-Water Pairs } \\
\hline CLE & Dep 1 & NA & NA & NA & 7.0 & 7.0 \\
\hline CLE & Dep 2 & NA & NA & NA & 7.0 & 7.0 \\
\hline $\mathrm{FH}$ & Dep 1 & NA & NA & NA & 6.9 & 6.9 \\
\hline $\mathrm{FH}$ & Dep 2 & NA & NA & NA & NA & 7.3 \\
\hline ERI & Dep 1 & NA & NA & NA & NA & NA \\
\hline ERI & Dep 2 & NA & NA & NA & NA & NA \\
\hline DUN & Dep 1 & NA & NA & NA & NA & NA \\
\hline DUN & Dep 2 & NA & NA & NA & NA & NA \\
\hline DUN & Dep 3 & NA & NA & NA & NA & NA \\
\hline BUF & Dep 1 & NA & NA & NA & NA & NA \\
\hline BUF & Dep 2 & NA & NA & NA & NA & NA \\
\hline NIA & Dep 2 & NA & NA & NA & NA & NA \\
\hline NIA & Dep 3 & NA & NA & NA & 7.0 & 7.0 \\
\hline ROC & Dep 1 & NA & NA & NA & 8.7 & 8.8 \\
\hline Osw & Dep 1 & NA & NA & 5.6 & 5.3 & 5.3 \\
\hline osw & Dep 2 & NA & NA & NA & 4.5 & 4.5 \\
\hline osw & Dep 3 & NA & NA & 9.3 & 8.5 & 8.5 \\
\hline CV & Dep 1 & NA & NA & NA & NA & NA \\
\hline CV & Dep 2 & NA & NA & NA & NA & NA \\
\hline CV & Dep 3 & NA & NA & NA & NA & NA \\
\hline \multicolumn{7}{|c|}{ Offshore/Near-Shore Air-Water Pairs } \\
\hline EERI & Dep 1 & NA & NA & NA & NA & NA \\
\hline CERI & Dep 1 & NA & NA & NA & NA & NA \\
\hline W TOR & Dep 1 & NA & NA & NA & 5.0 & NA \\
\hline W TOR & Dep 2 & NA & NA & NA & 4.9 & NA \\
\hline TOR & Dep 1 & NA & NA & NA & 5.0 & 5.0 \\
\hline TOR & Dep 2 & NA & NA & NA & 4.9 & 4.9 \\
\hline E TOR & Dep 1 & NA & NA & NA & 5.0 & 5.0 \\
\hline E TOR & Dep 2 & NA & NA & 4.9 & 4.7 & 4.7 \\
\hline CHUB & Dep 1 & NA & NA & NA & NA & NA \\
\hline CHUB & Dep 2 & NA & NA & NA & NA & NA \\
\hline PEP & Dep 1 & NA & NA & NA & NA & NA \\
\hline PEP & Dep 2 & NA & NA & NA & NA & NA \\
\hline
\end{tabular}


Table S3-12. PCM Air-Water Exchange Fluxes (ng/m $\left.\mathbf{m}^{2} / \mathrm{day}\right)$. Air-water exchange fluxes $\left(\mathrm{ng} / \mathrm{m}^{2} /\right.$ day) were calculated in cases where the fugacity ratio was significantly different from equilibrium after error propagation. All others are replaced with "NA".

\begin{tabular}{|c|c|c|c|c|c|c|}
\hline Location & Dep No. & ADBI & AHMI & ATII & HHCB & AHTN \\
\hline \multicolumn{7}{|c|}{ Shoreline Air-Water Pairs } \\
\hline CLE & Dep 1 & NA & NA & NA & $11 \pm 6.0$ & $-3.4 \pm 1.8$ \\
\hline CLE & Dep 2 & NA & NA & NA & $54 \pm 20$ & $2.0 \pm 1.5$ \\
\hline $\mathrm{FH}$ & Dep 1 & NA & NA & NA & $38 \pm 15$ & $4.4 \pm 2.0$ \\
\hline $\mathrm{FH}$ & Dep 2 & NA & NA & NA & NA & $-1.5 \pm 1.4$ \\
\hline ERI & Dep 1 & NA & NA & NA & NA & NA \\
\hline ERI & Dep 2 & NA & NA & NA & NA & NA \\
\hline DUN & Dep 1 & NA & NA & NA & NA & NA \\
\hline DUN & Dep 2 & NA & NA & NA & NA & NA \\
\hline DUN & Dep 3 & NA & NA & NA & NA & NA \\
\hline BUF & Dep 1 & NA & NA & NA & NA & NA \\
\hline BUF & Dep 2 & NA & NA & NA & NA & NA \\
\hline NIA & Dep 2 & NA & NA & NA & NA & NA \\
\hline NIA & Dep 3 & NA & NA & NA & $82 \pm 30$ & $9.3 \pm 3.6$ \\
\hline ROC & Dep 1 & NA & NA & NA & $79 \pm 30$ & $10 \pm 4.0$ \\
\hline OSW & Dep 1 & NA & NA & $2.3 \pm 1.4$ & $58 \pm 21$ & $4.0 \pm 1.8$ \\
\hline OSW & Dep 2 & NA & NA & NA & $38 \pm 14$ & $5.4 \pm 2.1$ \\
\hline OSW & Dep 3 & NA & NA & $8.8 \pm 3.5$ & $341 \pm 127$ & $28 \pm 10$ \\
\hline CV & Dep 1 & NA & NA & NA & NA & NA \\
\hline CV & Dep 2 & NA & NA & NA & NA & NA \\
\hline CV & Dep 3 & NA & NA & NA & NA & NA \\
\hline \multicolumn{7}{|c|}{ Offshore/Near-Shore Air-Water Pairs } \\
\hline EERI & Dep 1 & NA & NA & NA & NA & NA \\
\hline CERI & Dep 1 & NA & NA & NA & NA & NA \\
\hline W TOR & Dep 1 & NA & NA & NA & $64 \pm 23$ & NA \\
\hline W TOR & Dep 2 & NA & NA & NA & $20 \pm 10$ & NA \\
\hline TOR & Dep 1 & NA & NA & NA & $50 \pm 20$ & $5.8 \pm 2.6$ \\
\hline TOR & Dep 2 & NA & NA & NA & $37 \pm 14$ & $4.0 \pm 1.7$ \\
\hline E TOR & Dep 1 & NA & NA & NA & $77 \pm 30$ & $5.7 \pm 2.5$ \\
\hline E TOR & Dep 2 & NA & NA & $1.6 \pm 1.0$ & $56 \pm 21$ & $4.5 \pm 1.8$ \\
\hline CHUB & Dep 1 & NA & NA & NA & NA & NA \\
\hline CHUB & Dep 2 & NA & NA & NA & NA & NA \\
\hline PEP & Dep 1 & NA & NA & NA & NA & NA \\
\hline PEP & Dep 2 & NA & NA & NA & NA & NA \\
\hline
\end{tabular}


Figure S3-5. PE-Derived Air-Water Exchange Fluxes for Scenario 1.

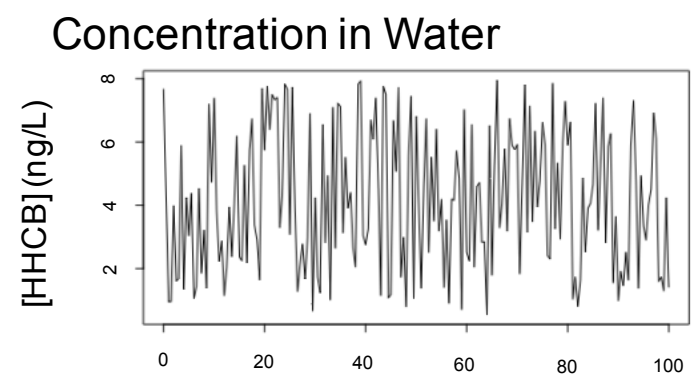

Mass in Water PE

Concentration in Air
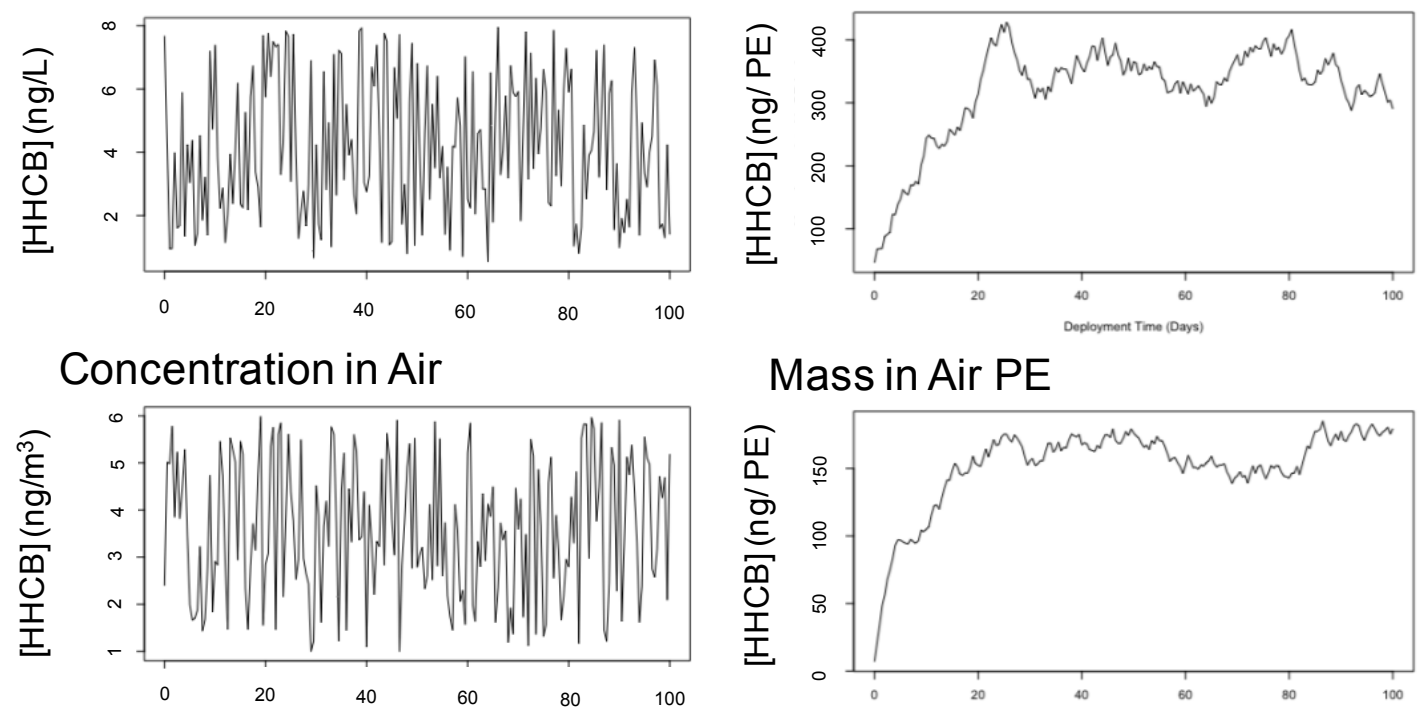

Mass in Air PE
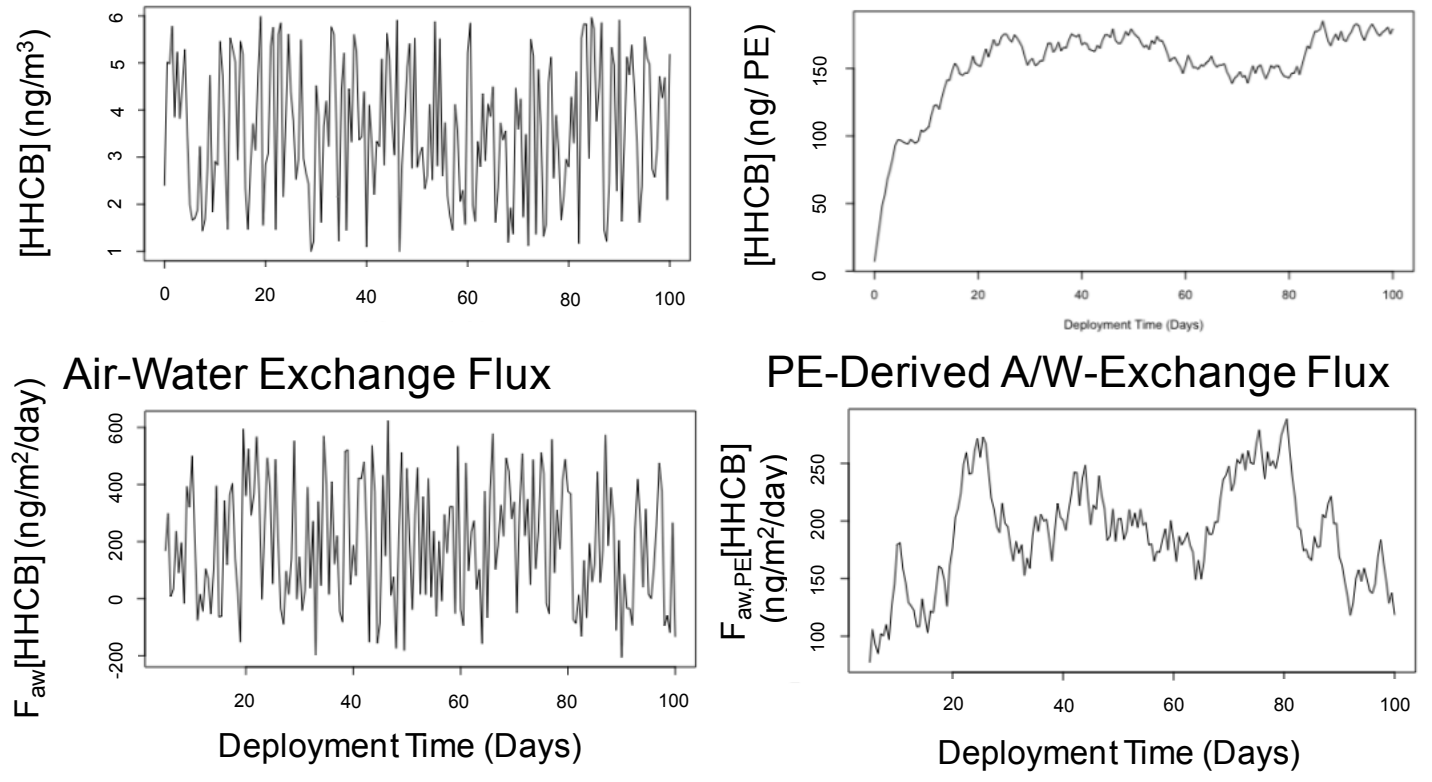
Figure S3-6. Great Lakes Coastal Boundary Zone from Bathymetry. Depth contours for every 10-meter interval were extracted from the Great Lakes Information Network (GLIN) bathymetry dataset ${ }^{23}$ and used to divide the lakes into shallower areas where water is expected to be entrained near the shoreline and more significant volatilization may occur, and deeper areas where the dissolved concentrations that drive volatilization are expected to be lower. Areas were used to attain ballpark estimates of volatilization fluxes over the lakes.

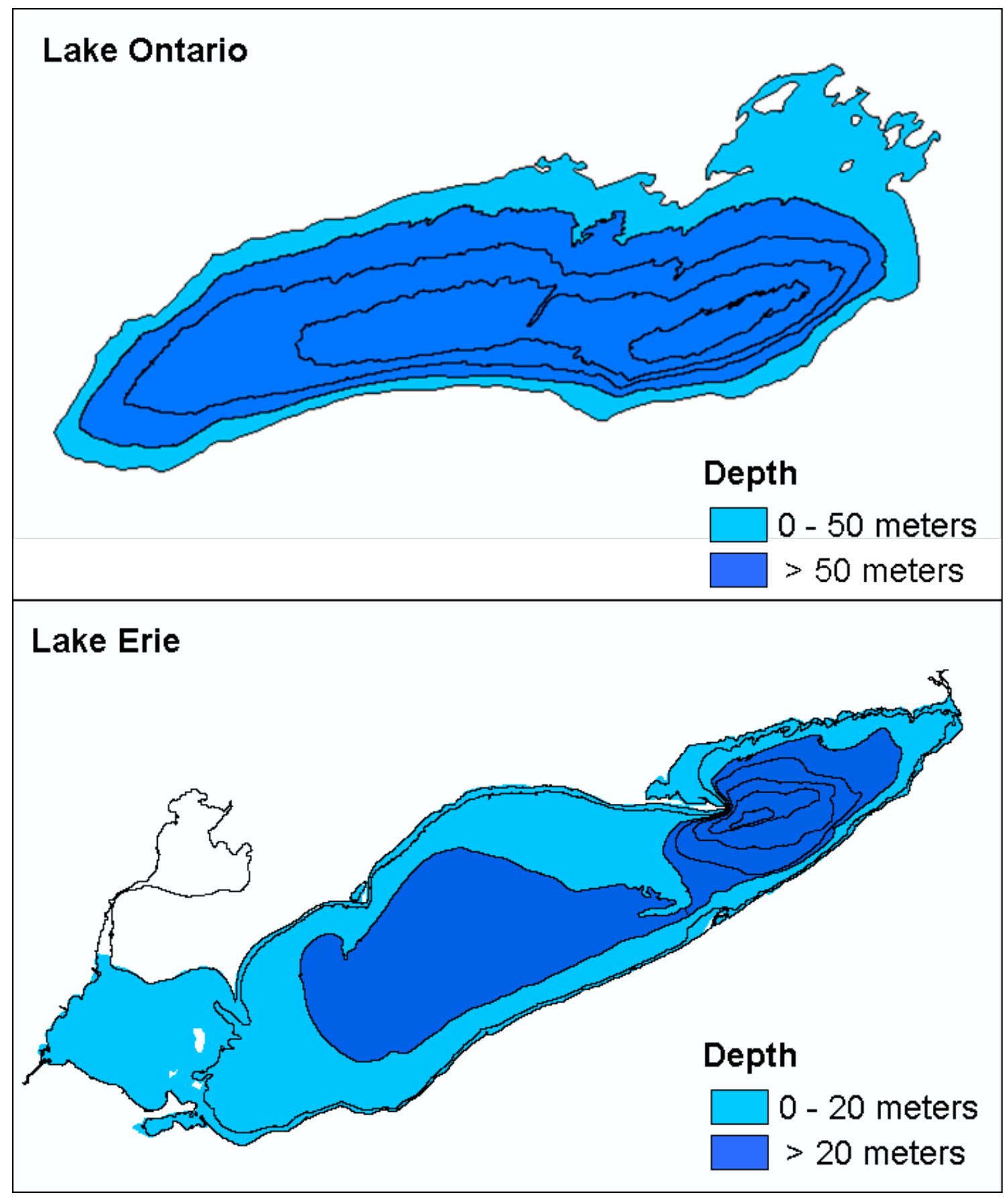




\section{LITERATURE CITED IN SUPPORTING INFORMATION}

(1) Fernandez, L. A.; Lao, W.; Maruya, K. A.; White, C.; Burgess, R. M. Passive sampling to measure baseline dissolved persistent organic pollutant concentrations in the water column of the Palos Verdes Shelf Superfund site. Environ. Sci. Technol. 2012, 46, 11937-11947, DOI:10.1021/es302139y.

(2) Thompson, J. M.; Hsieh, C.-H.; Luthy, R. G. Modeling uptake of hydrophobic organic contaminants into polyethylene passive samplers. Environ. Sci. Technol. 2015, 49, 2270-2277, DOI:10.1021/es504442s.

(3) Tcaciuc, P. A.; Apell, J. N.; Gschwend, P. M. Modeling the transport of organic chemicals between polyethylene passive samplers and water in finite and infinite bath conditions. Environ. Toxicol. Chem. 2015, 34, 2739-2749, DOI:10.1002/etc.3128.

(4) Booij, K.; Smedes, F. An improved method for estimating in situ sampling rates of nonpolar passive samplers. Environ. Sci. Technol. 2010, 44, 6789-6794, DOI:10.1021/es101321v.

(5) R Core Team. R: A language and environment for statistical computing (version 3.1.0), 2014.

(6) Fuller, E. N.; Schettler, P. D.; Giddings, J. C. A new method for prediction of binary gas-phase diffusion coefficients. Ind. Eng. Chem. 1966, 58, 18-27, DOI:10.1016/0042-207X(66)90400-3.

(7) Schwarzenbach, R. P.; Gschwend, P. M.; Imboden, D. M. Environmental Organic Chemistry; 2nd ed.; Wiley Interscience, 2002.

(8) Morgan, E. J.; Lohmann, R. Detecting air-water and surface-deep water gradients of PCBs using polyethylene passive samplers. Environ. Sci. Technol. 2008, 42, 7248-7253, DOI:10.1021/es800518g.

(9) Rowe, M. D.; Perlinger, J. A. Micrometeorological measurement of hexachlorobenzene and polychlorinated biphenyl compound air-water gas exchange in Lake Superior and comparison to model predictions. Atmos. Chem. Phys. 2012, 12, 4607-4617, DOI:10.5194/acp-12-4607-2012.

(10) Khairy, M. A.; Lohmann, R. Field calibration of low density polyethylene passive samplers for gaseous POPs. Environ. Sci. Process. Impacts 2014, 16, 414-421, DOI:10.1039/c3em00493g.

(11) US EPA. US EPA Discharge Monitoring Report (DMR) Pollutant Loading Tool, v $1.0 \mathrm{https} / / / \mathrm{cfpub} . e p a . g o v / \mathrm{dmr} /$ index.cfm. 
(12) Melymuk, L.; Robson, M.; Csiszar, S. A.; Helm, P. A.; Kaltenecker, G.; Backus, S.; Bradley, L.; Gilbert, B.; Blanchard, P.; Jantunen, L.; Diamond, M. L. From the city to the lake: Loadings of PCBs, PBDEs, PAHs and PCMs from Toronto to Lake Ontario. Environ. Sci. Technol. 2014, 48, 3732-3741, DOI:10.1021/es403209z.

(13) Helm, P. A.; Howell, E. T.; Li, H.; L. Metcalfe, T.; M. Chomicki, K.; D. Metcalfe, C. Influence of nearshore dynamics on the distribution of organic wastewater-associated chemicals in Lake Ontario determined using passive samplers. J. Great Lakes Res. 2012, 38, 105-115, DOI:10.1016/j.jglr.2012.01.005.

(14) Ma, Y.-G.; Lei, Y. D.; Xiao, H.; Wania, F.; Wang, W.-H. Critical review and recommended values for the physical-chemical property data of 15 polycyclic aromatic hydrocarbons at $25^{\circ} \mathrm{C}$. J. Chem. Eng. Data 2010, 55, 819-825, DOI:10.1021/je900477x.

(15) Hongxia, Z.; Jingwen, C.; Xie, Q.; Baocheng, Q.; Xinmiao, L. Octanol-air partition coefficients of polybrominated biphenyls. Chemosphere 2009, 74, 1490-1494, DOI:10.1016/j.chemosphere.2008.11.041.

(16) Wang, I.-T. I.; Cheng, S.-F.; Tsai, S.-W. Determinations of airborne synthetic musks by polyurethane foam coupled with triple quadrupole gas chromatography tandem mass spectrometer. J. Chromatogr. A 2014, 1330, 6168, DOI:10.1016/j.chroma.2014.01.011.

(17) Sacks, V. P.; Lohmann, R. Freely dissolved PBDEs in water and porewater of an urban estuary. Environ. Pollut. 2012, 162, 287-293, DOI:10.1016/j.envpol.2011.11.028.

(18) Lohmann, R. Critical review of low-density polyethylene's partitioning and diffusion coefficients for trace organic contaminants and implications for its use as a passive sampler. Environ. Sci. Technol. 2012, 46, 606-618, DOI:10.1021/es202702y.

(19) Peck, A. M.; Hornbuckle, K. C. Synthetic musk fragrances in Lake Michigan. Environ. Sci. Technol. 2004, 38, 367-372, DOI:10.1021/es034769y.

(20) Gajewicz, A.; Haranczyk, M.; Puzyn, T. Predicting logarithmic values of the subcooled liquid vapor pressure of halogenated persistent organic pollutants with QSPR: How different are chlorinated and brominated congeners? Atmos. Environ. 2010, 44, 1428-1436, DOI:10.1016/j.atmosenv.2010.01.041.

(21) Wania, F.; Dugani, C. B. Assessing the long-range transport potential of polybrominated diphenyl ethers: A comparison of four multimedia models. Environ. Toxicol. Chem. 2003, 22, 1252-1261, DOI:10.1002/etc.5620220610. 
(22) Beyer, A.; Wania, F.; Gouin, T.; Mackay, D.; Matthies, M. Selecting internally consistent physicochemical properties of organic compounds. Environ. Toxicol. Chem. 2002, 21, 941-953, DOI:10.1002/etc.5620210508.

(23) Great Lakes Information Network. Great Lakes Mapping and GIS. http://gis.glin.net/. Accessed online 7/10/2016. 


\section{CHAPTER 4}

\section{SPATIAL DISTRIBUTION AND AIR-WATER EXCHANGE OF ORGANIC FLAME RETARDANTS IN THE LOWER GREAT LAKES}

This manuscript has been published in and is formatted for the journal Environmental Science and Technology, 2016, 50(17), pp 9133-9141, DOI: 10.1021/acs.est.6b02496.

Carrie A. McDonough ${ }^{\dagger}$, Gavino Puggioni ${ }^{\ddagger}$, Paul A. Helm ${ }^{\S}$, Derek C. G. Muir", Rainer Lohmann $^{\dagger^{*}}$

${ }^{\dagger}$ University of Rhode Island Graduate School of Oceanography

Department of Computer Science and Statistics, University of Rhode Island

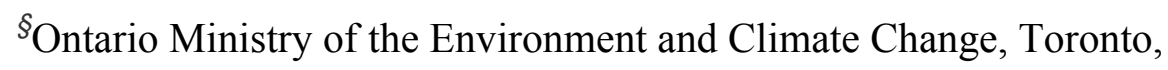
Ontario, Canada M9P 3V6

"Environment and Climate Change Canada, Aquatic Contaminants Research Division, Ontario, Canada L7S 1A1

*Corresponding author email: rlohmann@uri.edu; phone: 401.874.6612; fax: 401.874 .6811 


\section{ABSTRACT}

Organic flame retardants (OFRs) such as polybrominated diphenyl ethers (PBDEs) and novel halogenated flame retardants (NHFRs) are ubiquitous, persistent, and bioaccumulative contaminants that have been used in consumer goods to slow combustion. In this study, polyethylene passive samplers (PEs) were deployed throughout the lower Great Lakes (Lake Erie and Lake Ontario) to measure OFRs in air and water, calculate air-water exchange fluxes, and investigate spatial trends. Dissolved $\Sigma_{12}$ BDE was greatest in Lake Ontario near Toronto $(18 \mathrm{pg} / \mathrm{L})$, whereas gaseous $\Sigma_{12} \mathrm{BDE}$ was greatest on the southern shoreline of Lake Erie $\left(11 \mathrm{pg} / \mathrm{m}^{3}\right)$. NHFRs were generally below detection limits. Air-water exchange was dominated by absorption of BDEs 47 and 99, ranging from $-964 \mathrm{pg} / \mathrm{m}^{2} /$ day to $-30 \mathrm{pg} / \mathrm{m}^{2} /$ day. $\Sigma_{12} \mathrm{BDE}$ in air and water was significantly correlated with surrounding population density, suggesting that phased-out PBDEs continued to be emitted from population centers along the Great Lakes shoreline in 2012. Correlation with dissolved $\Sigma_{12} \mathrm{BDE}$ was strongest when considering population within $25 \mathrm{~km}$ while correlation with gaseous $\Sigma_{12} \mathrm{BDE}$ was strongest when using population within $3 \mathrm{~km}$ to the south of each site. Bayesian kriging was used to predict dissolved $\Sigma_{12} \mathrm{BDE}$ over the lakes, illustrating the utility of relatively highly spatially resolved measurements in identifying potential hot spots for future study. 


\section{INTRODUCTION}

Organic flame retardants (OFRs) such as the polybrominated diphenyl ethers (PBDEs) and novel halogenated flame retardants (NHFRs) are persistent bioaccumulative contaminants that have been liberally added to polymers used in consumer goods to slow combustion in the event of a fire. ${ }^{1,2}$ While PBDEs are no longer manufactured or used in North America, they are ubiquitous in the environment and continually leach out of in-use products, especially furniture, casings for electronics, and automotive upholstery. ${ }^{3}$ Numerous studies have shown that PBDEs, as well as many NHFRs, accumulate in humans ${ }^{4-6}$ and wildlife, ${ }^{7-11}$ and that concentrations are elevated in North American cities. ${ }^{12-14}$ Some studies have suggested that various NHFRs are increasingly being added to consumer products due to the PBDE phase-out, but there is uncertainty regarding which chemicals are being used in which applications, and at what production volumes. ${ }^{2,14-16}$

Previous studies have identified densely populated areas, central business districts, and indoor environments as sources of OFRs to the atmosphere via volatilization from consumer goods. ${ }^{13,14,17,18}$ Atmospheric wet and dry deposition have been identified as important pathways for these contaminants to reach the Great Lakes, ${ }^{19,20}$ though recent work has shown inputs from stormwater, tributaries, and wastewater also play a significant role. ${ }^{21,22}$ Some studies have identified absorption of gaseous PBDEs from air as a potentially significant source of some PBDEs to the Great Lakes, ${ }^{23,24}$ though others have demonstrated that volatilization from surface water can be a significant loss process for semivolatile organic compounds, especially as atmospheric concentrations decline following changes in regulation. ${ }^{25,26}$ The 
direction of air-water diffusive exchange for OFRs can be deduced by simultaneous measurement of dissolved and gaseous concentrations, which has not been undertaken previously in the lower Great Lakes (Lake Erie and Lake Ontario).

While some recent studies have measured concentrations of PBDEs and NHFRs in air, ${ }^{14,18,27,28}$ rain, ${ }^{19}$ and surface water ${ }^{29}$ of the lower Great Lakes, there are no published studies of regional spatial trends, nor are there reported measurements of air-water exchange fluxes. This information is critical to track whether changes in regulation and usage of OFRs cause changes in spatial distributions and air-water exchange. Deployment of polyethylene passive samplers (PEs) in air and water is a convenient way to deduce fugacity ratios at the air-water interface and a cost-effective approach to time-averaged monitoring at numerous sites. PEs have been used to measure PBDEs in a handful of previous studies, ${ }^{24,30-32}$ but their use to detect NHFRs has not been reported.

In this study, extracts from PEs deployed in the air and water throughout Lake Erie and Lake Ontario were analyzed for 12 PBDEs and 9 NHFRs to (i) determine baseline concentrations of PBDEs and NHFRs at shoreline, nearshore, and offshore sites, (ii) determine whether the lower Great Lakes were acting as sinks or secondary sources of PBDEs via air-water exchange, (iii) investigate spatial trends of PBDEs and their relation to population centers, and (iv) build a geostatistical interpolation model to provide estimates of dissolved PBDE concentrations across the lakes. 


\section{MATERIALS AND METHODS}

Sampler Preparation and Deployment. Air and water PEs were deployed throughout the lower Great Lakes region from April to November of 2012. Air concentrations were monitored at 22 locations (14 shoreline, 5 nearshore $(<5 \mathrm{~km}$ from the shoreline), and 3 offshore sites), while water concentrations were monitored at 20 locations ( 8 shoreline, 7 nearshore, and 5 offshore sites). Air samplers were also deployed during the 2011/2012 winter (generally from October 2011 to April 2012). Deployment times ranged from 4 to 30 weeks. The sampling schedule and site characteristics are summarized in the Supporting Information (SI) along with the length of deployment time (Table S4-1). Nearby meteorological buoys used to determine average temperature and wind speed are listed in Table S4-2.

Details of sampler preparation and deployment have been summarized previously in McDonough et al. and Liu et al. ${ }^{33,34}$ Briefly, $50 \mu \mathrm{m}$-thick PEs were precleaned with solvent and loaded with performance reference compounds (PRCs), which included deuterated polycyclic aromatic hydrocarbons (PAHs; naphthalene- $d 8$, pyrene-d12, and benzo(a)pyrene-d12) and bromobiphenyls (PBB 9, PBB 52, and PBB 103). Shoreline air PEs were secured within protective chambers constructed from two metal bowls and hung from trees or structures, generally at about $1.5 \mathrm{~m}$ height. Shoreline water PEs were fastened to rope and anchored about $1 \mathrm{~m}$ below the water's surface. Nearshore/offshore air PEs were fastened into protective chambers secured to buoys about $2 \mathrm{~m}$ above the water's surface and water PEs were placed in perforated stainless steel cages and secured to subsurface floats at a depth of about $4 \mathrm{~m}$. After 
PEs were recovered, they were mailed back to the laboratory overnight on ice and frozen until extraction.

Extraction and Analysis. PEs from 56 air and 39 aqueous deployments were spiked with non-native PBDEs (BDE 35, BDE 77, BDE 118, BDE 128, and BDE 190) and extracted for about $24 \mathrm{~h}$ in pentane, then concentrated to $\sim 50 \mu \mathrm{L}$ and spiked with injection standard (BDE 71). Water extracts were passed through silica gel/sodium sulfate cleanup columns and eluted with 60:40 pentane:DCM. Concentrations were corrected for internal standard recoveries.

Extracts were analyzed for 12 mono- to octa-brominated PBDEs (BDE 2, 8, $15,30,28,47,49,100,99,154,153$, and 183) and 9 NHFRs (tetrabromo-p-xylene (pTBX), pentabromobenzene (PBBz), pentabromotoluene (PBT), pentabromoethylbenzene (PBEB), hexabromobenzene (HBBz), hexachlorocyclopentadienyl-dibromocyclooctane (HCDBCO), 1,2-bis(2,4,6tribromophenoxy)ethane (BTBPE), and anti- and syn-isomers of Dechlorane Plus (ADP and SDP)) on an Agilent 6890N gas chromatograph coupled to a Waters Quattro Micro mass spectrometer (GC-MS/MS) in electron ionization mode (EI, 70 $\mathrm{eV}$ ) using multiple reaction monitoring (MRM). Extracts were injected in splitless mode with helium carrier gas at $2 \mathrm{~mL} / \mathrm{min}$ onto an Agilent J\&W DB-5MS fused silica capillary column (30 m x $0.25 \mathrm{~mm}$ I.D.).

Quality Control. Every batch of PEs was extracted alongside a method blank and two spiked blanks to control for compound losses during extraction, concentration, and cleanup. Average spike recoveries ranged from $67 \pm 15 \%$ for BDE 2 to $101 \pm 19 \%$ for BDE 100 (Table S4-3). 
Concentrations were blank-subtracted using the most relevant field blank and detection limits were defined as the upper limit of the $95 \%$ confidence interval for 11 laboratory blanks. Detection limits per gram PE are summarized in Table S4-4, and are converted to typical ambient air or water concentrations in Table S4-5. Percent detection for each compound is shown in Table S4-6. Concentrations below detection limits were replaced with zero.

Detection limits per gram polyethylene (PE) are summarized in Table S4-4 and are converted to typical ambient air or water concentrations in Table S4-5. Percent detection for each compound is shown in Table S4-6. For compounds not detected in the blanks, instrumental noise was integrated to define detection limits. Calculated ambient detection limits were dependent on the sampling rate and varied from sample to sample. Typical detection limits were greatest in shoreline samples, ranging from $0.1 \mathrm{pg} / \mathrm{m}^{3}$ for BDE 30 to $7.4 \mathrm{pg} / \mathrm{m}^{3}$ for HCDBCO in air, and from $0.07 \mathrm{pg} / \mathrm{L}$ for BDE 153 and $\mathrm{BDE} 30$ to $6.5 \mathrm{pg} / \mathrm{L}$ for $\mathrm{PBBz}$ in water.

For air PEs, the mean difference between ambient concentrations derived from duplicate samplers ranged from $16 \%\left(0.008 \mathrm{pg} / \mathrm{m}^{3}\right)$ for BDE 49 to $87 \%\left(0.69 \mathrm{pg} / \mathrm{m}^{3}\right)$ for BDE $100(\mathrm{~N}=18)$. For water PEs, the mean difference between ambient concentrations derived from duplicate samplers ranged from $24 \%(0.96 \mathrm{pg} / \mathrm{L})$ for BDE 28 to $43 \%(0.07 \mathrm{pg} / \mathrm{L})$ for $\mathrm{BDE} 153(\mathrm{~N}=14)$.

Sampling Rates and Ambient Concentrations. PRC loss data was entered into a generalized exponential model for PE uptake to derive best-fit values for the thickness of the diffusive boundary layer $\left(\delta_{\mathrm{DBL}}\right)$. The best-fit $\delta_{\mathrm{DBL}}$ value for each PE was then used to determine the percent equilibration $(f)$ reached by each compound during 
sampler deployment. $f$ values were used to convert concentrations in PEs to ambient concentrations, which is described in detail in the SI. Physico-chemical properties of target compounds used in these calculations are presented in Table S4-7. Average $f$ values for each compound in air and water are in Table S4-8. Mono- to dibrominated PBDEs were generally equilibrated or nearly equilibrated while tetra- to octabrominated PBDEs remained $<50 \%$ equilibrated in the majority of samples.

Best-fit $\delta_{\mathrm{DBL}}$ values and BDE 47 sampling rates are shown in Tables S4-9 and S10. Average $\delta_{\mathrm{DBL}} \mathrm{S}$ for air boundary layers $\left(\delta_{\mathrm{ABL}}\right)$ were lower for offshore/nearshore PEs $(0.2 \pm 0.1 \mathrm{~mm}$; average \pm stdev $)$ than for shoreline PEs $(1.8 \pm 1.4 \mathrm{~mm}$ in summer and $1.4 \pm 0.5 \mathrm{~mm}$ in winter). Average water boundary layer thickness ( $\left.\delta_{\mathrm{WBL}}\right)$ was $170 \pm 63$ $\mu \mathrm{m}$ at shoreline sites and $82 \pm 25 \mu \mathrm{m}$ at offshore sites. For air PEs, average sampling rates for BDE 47 were $9 \pm 3 \mathrm{~m}^{3} /$ day for winter PEs, $10 \pm 6 \mathrm{~m}^{3} /$ day for shoreline summer PEs, and $83 \pm 36 \mathrm{~m}^{3} /$ day for offshore PEs. For water PEs, average BDE 47 sampling rates were $27 \pm 8 \mathrm{~L} /$ day for shoreline PEs and $14 \pm 10 \mathrm{~L} /$ day for offshore PEs, in-line with expectations based on relative flow strengths at these locations.

Air-water exchange calculations. 32 pairs of codeployed air and water PEs were used to investigate PBDE air-water exchange. Details on calculating fugacity ratios, air-water exchange fluxes, and associated error propagation are presented in the SI. Fugacity ratios and air-water exchange fluxes were only calculated in instances where the congener was detected in both air and water. In cases where the compound was not detected in air and/or water, or where fugacity ratios were not significantly different from equilibrium after error propagation, the net air-water exchange flux was assumed to be zero. 
To determine whether PE-derived air-water exchange fluxes were representative of average exchange fluxes in nonsteady-state conditions, a model was built in $\mathrm{R}^{35}$ to compare simulated air-water exchange fluxes to PE-derived exchange fluxes (Figures S4-1, S4-2; Table S4-11).

Correlation with Population Density. Average summertime concentrations of PBDEs were compared to population within 2 - $60 \mathrm{~km}$ of each site using population data from the Columbia University Center for International Earth Science Information Network (CIESIN) Global Rural-Urban Mapping Project (GRUMP). ${ }^{36}$ To determine which radius yielded the strongest linear correlation, ordinary least squares regression was performed for each congener, as well as $\Sigma_{12} \mathrm{BDE}$, at a series of different radii in $\mathrm{R}^{35}$ to identify the model with the minimum residual standard error (RSE) in each case. This procedure was repeated for population data within $180^{\circ}$ wedges to the north, south, east, and west of each sampling site to determine whether population density within one general direction was more significant in driving spatial distributions of PBDEs.

Bayesian Kriging. Bayesian kriging is a geostatistical interpolation technique that automates the parameter estimation needed to build a kriging model, which makes it the most appropriate approach for datasets with very limited spatial resolution. ${ }^{4}$ Dissolved $\Sigma_{12} \mathrm{BDE}$ concentrations were used with population within $25 \mathrm{~km}$ as an auxiliary variable, or covariate, to predict concentrations across both lakes by Bayesian kriging using the krige.bayes function in the geoR package in $\mathrm{R}^{5,6}$ Cells on the grid that were predicted to have negative concentrations were replaced with zero. Posterior distributions for the estimated parameters $\beta_{0}, \beta, \sigma^{2}$, and $\phi$ are shown in 
Figure S4-4 and results of leave-one-out cross validation of the model are shown in Figure S4-5.

The vector containing $\Sigma_{12} \mathrm{BDE}$ concentrations for each location $\mathbf{Z}(u)$, was modeled as a deterministic term, $\beta \boldsymbol{X}(u)$, and a zero-mean stochastic term, $\boldsymbol{\varepsilon}(u)$, as shown in Equation S27. $\boldsymbol{X}$ is the vector of population at each location, $\beta$ is an unknown regression coefficient, and $\beta_{0}$ is the unknown intercept for the regression. $\boldsymbol{\varepsilon}(u)$ has variance $\sigma^{2}$ and a correlation function parameter $\phi$, and describes the residuals at each location.

$$
\mathbf{Z}(u)=\beta_{0}+\beta \boldsymbol{X}(u)+\boldsymbol{\varepsilon}(u)
$$

\section{RESULTS AND DISCUSSION}

Dissolved PBDEs in the Great Lakes. Average concentrations of dissolved PBDEs are summarized in Table 4-1 for shoreline, nearshore, and offshore sites. BDEs 100, $99,47,28$, and 49 were detected in $>70 \%$ of all water PEs. BDE 154 was detected in $53 \%$, BDE 153 in 43\%, and the remaining congeners in $\leq 15 \%$. Average dissolved $\Sigma_{12} \mathrm{BDE}$ ranged from $0.6 \mathrm{pg} / \mathrm{L}$ at Dunkirk (DUN) on Lake Erie's southern shoreline to $18 \mathrm{pg} / \mathrm{L}$ at a nearshore buoy site west of central Toronto (WTOR). Dissolved PBDE concentrations for all deployments are displayed in Table S4-9.

Average summertime concentration and composition for dissolved PBDEs at each site is shown in Figure 4-1. BDEs 47 and 99 were the dominant congeners at most sites, making up $41 \pm 15 \%$ and $29 \pm 14 \%$ of $\Sigma_{12}$ BDE, respectively. Composition of the major congeners (BDE 47, 99, and 100) was quite consistent among sites with $\Sigma_{12} \mathrm{BDE}>3 \mathrm{pg} / \mathrm{L}$, but more variable at sites with lower concentrations, likely due to 
some congeners being $<\mathrm{DL}$ at these sites. See Figure S4-3 for mean percent composition at each location. Correlations between individual congeners at different sites, as well as correlations with other compounds measured in the same extracts, are shown in the SI.

Along the southern shore of Lake Erie, $\Sigma_{12} \mathrm{BDE}$ ranged from $0.6 \mathrm{pg} / \mathrm{L}$ on the Dunkirk shoreline (DUN) to $11 \mathrm{pg} / \mathrm{L}$ in Presque Isle Bay (ERI). Concentrations at the three sites near Cleveland (CLE, SHF, and FH) were similar, with average summertime $\Sigma_{12} \mathrm{BDE}$ of 4.3-5.5 pg/L. Along the southern shore of Lake Ontario, $\Sigma_{12} \mathrm{BDE}$ was greater than what was seen on Lake Erie, ranging from $11-12 \mathrm{pg} / \mathrm{L}$. The Cape Vincent shoreline site $(\mathrm{CV})$ had a lower average $\Sigma_{12} \mathrm{BDE}(3.8 \mathrm{pg} / \mathrm{L})$, possibly due to dilution, as the site was along the St. Lawrence River, the major outflow from Lake Ontario, while the sites in Niagara (NIA), Oswego (OSW), and Rochester (ROC) were located near the mouths of tributaries.

$\Sigma_{12} \mathrm{BDE}$ at offshore sites was generally $<3 \mathrm{pg} / \mathrm{L}$, significantly lower than shoreline/nearshore concentrations ( $\mathrm{p}<0.05$ two-tailed t test with unequal variance). The greatest offshore concentrations were observed at the westernmost offshore sites on each lake, with $\Sigma_{12} \mathrm{BDE}$ of $2.8 \mathrm{pg} / \mathrm{L}$ in western Lake Erie and $3.2 \mathrm{pg} / \mathrm{L}$ in western Lake Ontario. These sites were the closest offshore sites to the major rivers feeding each lake (the Detroit River and Niagara River) and may have been influenced by inputs from these rivers.

Generally, dissolved PBDEs in this study were lower than in previous studies. This may be because the PEs used for sampling were selective for the truly dissolved phase. In previous active sampling studies on the Great Lakes, Venier et al. measured 
average $\mathrm{BDE} 28,47,99$, and 100 at a total concentration of $117 \mathrm{pg} / \mathrm{L}$ in Lake Ontario and $62 \mathrm{pg} / \mathrm{L}$ in Lake Erie surface waters in $2011-2012^{29}$ and Streets et al. measured mean total dissolved $\Sigma_{6} \mathrm{BDE}$ of $18 \mathrm{pg} / \mathrm{L}$ in offshore Lake Michigan in $2004 .^{10}$ In other regions, Zarnadze and Rodenburg reported dissolved PBDE concentrations of 44, 5.5, and 35 pg/L for BDE 47, 100, and 99 in Raritan Bay in 2001-2002 ${ }^{38}$ and Yang et al. measured dissolved $\Sigma_{10} \mathrm{BDE}$ from 13-26 pg/L in 9 English freshwater lakes from 2008 to 2012. ${ }^{39}$ In contrast, studies using PEs to measure total truly dissolved PBDEs in Narragansett Bay in 2009 and Lake Superior in 2011 found concentrations $<3$ pg/L at all sites, similar to offshore/nearshore concentrations in this study. ${ }^{18,24}$ Booij et al. measured BDEs 47, 99, and 153 in the Western Scheldt Estuary in 1999 using semipermeable membrane devices (SPMDs) and found that total concentrations generally did not exceed $2 \mathrm{pg} / \mathrm{L}{ }^{9}$

We investigated whether the discrepancy between concentrations reported by Venier et al. ${ }^{29}$ and our own could be due to the presence of dissolved organic carbon (DOC) that was likely cosampled by Venier's active sampling method. As detailed further in the SI (Table S4-12), the DOC concentrations needed to explain the discrepancy were quite high for open-lake Great Lakes sites (>3 mg/L), suggesting that the inclusion of the colloidal phase in the active sampling study was not sufficient to explain the observed differences. Seasonal variation in dissolved PBDE concentrations may explain some of the additional discrepancy, as Venier et al. sampled in April-May, while PEs from this study were representative of average summer concentrations. Another possible contributor to the discrepancy is uncertainty 
in the affinity of BDEs for DOC $\left(\mathrm{K}_{\mathrm{iDOC}}\right)$. Similar discrepancies were observed in a comparison by Ruge et al. in Lake Superior. ${ }^{24}$

Gaseous PBDEs Above the Great Lakes. BDEs 99, 100, and 47 were detected in $>75 \%$ of air PEs. BDE 28 was in 54\%, BDE 49 in 34\%, and the remaining congeners were in $\leq 15 \%$ (Table S4-6). Mean summer gaseous $\Sigma_{12}$ BDE ranged from $0.1 \mathrm{pg} / \mathrm{m}^{3}$ near the northeastern shore of Lake Ontario to $11 \mathrm{pg} / \mathrm{m}^{3}$ on the Cleveland shoreline (CLE). BDEs 47 and 99 were the dominant congeners, making up $39 \pm 21 \%$ and $34 \pm 18 \%$ of $\Sigma_{12} \mathrm{BDE}$, respectively. As with dissolved PBDEs, composition of the major congeners (BDE 47, 99, and 100) was similar at most sites, with the exception of one in northern Lake Ontario (CHB), where the difference in composition was most likely because concentrations were very low and BDE 99 and 47 were $<$ DL, and two other locations with atypical compositions, Sheffield Lake (SHL) and Rochester Site 1 (ROC1), where the explanation for the absence of BDE 99 was unknown (Figure S44). Correlations between individual congeners, as well as with other compounds measured in the same extracts, are described in the SI.

Summertime concentrations of total gaseous PBDEs are summarized in Table 4-2 for shoreline, nearshore, and offshore sites. Gaseous $\Sigma_{12} \mathrm{BDE}$ was significantly greater at the shoreline than offshore and nearshore sites $(\mathrm{p}<0.005$, two-tailed $\mathrm{t}$ test with unequal variance), and shoreline gaseous $\Sigma_{12} \mathrm{BDE}$ was greater in summer than winter $(\mathrm{p}<0.005$, two-tailed paired $\mathrm{t}$ test). Concentrations from all deployments are presented in Table S4-10.

Average summer gaseous PBDE concentration and composition are shown in Figure 4-1. Gaseous $\Sigma_{12} \mathrm{BDE}$ was lower than concentrations from previous studies in 
the region, possibly due to declining concentrations over time. Su et al. reported mean gaseous $\Sigma_{12} \mathrm{BDE}$ of $17 \mathrm{pg} / \mathrm{m}^{3}$ at a clearing in Ontario during 2001-2002. ${ }^{40}$ Ma et al. measured average gaseous $\Sigma_{34} \mathrm{BDE}$ ranging from $5 \mathrm{pg} / \mathrm{m}^{3}$ in Eagle Harbor, a remote site on Lake Superior, to $25 \mathrm{pg} / \mathrm{m}^{3}$ in Cleveland and $32 \mathrm{pg} / \mathrm{m}^{3}$ in Chicago via active sampling with XAD resin. ${ }^{14}$ They observed a significant decreasing trend from 2005 to 2011 for BDE 47 in Cleveland and Chicago, though concentrations increased or showed little change at other locations. ${ }^{14}$

During 2007-2008, Melymuk et al. monitored PBDEs throughout the greater Toronto area and found mean $\Sigma_{25} \mathrm{BDE}$ of $3 \mathrm{pg} / \mathrm{m}^{3}$ at their southernmost site, near the northern Lake Ontario shoreline. This was about two to three times greater than total mean $\Sigma_{12} \mathrm{BDE}$ measured at the nearshore Toronto sites in this study $\left(1.1-1.4 \mathrm{pg} / \mathrm{m}^{3}\right){ }^{28}$ The site monitored by Melymuk et al. was closer to the city center and polyurethane foam passive samplers (PUFs) were used, which capture both gaseous and some fraction of particle-sorbed PBDEs. ${ }^{28}$ During 2012-2013, Peverly et al. measured $\Sigma_{27}$ BDE ranging from $11-150 \mathrm{pg} / \mathrm{m}^{3}$ in the Chicago region, also using PUFs, and observed a significant contribution from BDE 209, which was not measured here. ${ }^{41}$ In the only previous study to use PEs to measure truly gaseous PBDEs in the Great Lakes region, Ruge et al. measured average summer gaseous $\Sigma_{7} \mathrm{BDE}$ of $0.02-5.5 \mathrm{pg} / \mathrm{m}^{3}$ in Lake Superior in 2011, similar to the range of values in this study. ${ }^{24}$

Gaseous and Dissolved NHFRs in the Great Lakes. Ambient concentrations of gaseous NHFRs are presented in Table S4-10. When detected, estimated gaseous bromobenzene concentrations (PBBz, $\mathrm{PBT}, \mathrm{PBEB}$, and $\mathrm{HBBz}$ ) were similar in magnitude to those measured by Venier et al. in the Great Lakes atmosphere by high- 
volume active sampling, with all concentrations $<2 \mathrm{pg} / \mathrm{m}^{3}{ }^{27}$ However, these compounds were only detected intermittently in this study and were near detection limits, so estimated concentrations are somewhat uncertain.

Venier et al. measured dissolved and colloidal NHFRs in Great Lakes water by active sampling and found mean PBEB concentrations in Lake Ontario to be $32 \pm 18$ $\mathrm{pg} / \mathrm{L}$, while in this study PBEB concentrations were $<2 \mathrm{pg} / \mathrm{L}$ (Table S4-9) ${ }^{29}$ No other NHFRs were detected in more than two aqueous PEs.

Percent detection was low for all NHFRs. As the NHFRs are low-volatility compounds that are expected to be found primarily in the particulate phase, it may be that concentrations in the truly gaseous or dissolved phase were too low to be detected here using passive samplers.

Air-water Exchange of PBDEs. Fugacity ratios $\left(f_{w} / f_{a}\right)$, which indicate the direction of air-water exchange, are presented in Table S4-13 for all PBDE congeners. In all cases where fugacity ratios were significantly different from equilibrium after error propagation, they indicated absorption into surface waters.

Exchange fluxes for all available air-water PE pairs at each site were averaged to yield mean summer air-water exchange fluxes for each location (Figure 4-2). Mean absorptive fluxes ranged from $-964 \mathrm{pg} / \mathrm{m}^{2} /$ day on the shoreline of Cape Vincent (CV) to $-30 \mathrm{pg} / \mathrm{m}^{2} /$ day at an offshore site in central Lake Erie (CERI). Absorption of BDEs 47 and 99 dominated air-water exchange fluxes at the majority of sites, with greatest absorption fluxes at shoreline sites and little to no significant exchange flux in either direction at most offshore/nearshore sites. It should be noted that aqueous PEs at Cleveland Edgewater (CLE) and Fairport Harbor (FH) were placed on nearshore 
buoys while air measurements were taken at the shoreline, which may have resulted in calculation of stronger absorption fluxes than if dissolved concentrations were monitored directly at the shoreline.

Previous measurements of PBDE air-water exchange fluxes are scarce. Xie et al. and Lohmann et al. both observed net absorption of gaseous PBDEs on transects of the Atlantic Ocean, dominated by BDEs 47 and $99 .^{31,42}$ Lohmann et al. calculated median air-water exchange fluxes of about $-325 \mathrm{pg} / \mathrm{m}^{2} /$ day for BDE 47 and about -260 $\mathrm{pg} / \mathrm{m}^{2} /$ day for BDE 99 . Xie et al. calculated fluxes ranging from -28 to -875 $\mathrm{pg} / \mathrm{m}^{2} /$ day for BDE 47 and -3 to $-170 \mathrm{pg} / \mathrm{m}^{2} /$ day for BDE 99 . In contrast to the offshore Great Lakes sites, where fluxes were mostly near equilibrium, these studies were conducted in remote regions with lower concentrations of dissolved PBDEs where atmospheric deposition was expected to be the primary source of PBDEs.

Ruge et al. observed absorption of gaseous PBDEs at shoreline sites and volatilization offshore on Lake Superior in 2011, with the greatest total absorption flux at Sault Ste. Marie $\left(-2700 \mathrm{pg} / \mathrm{m}^{2} /\right.$ day $){ }^{24}$ The occurrence of offshore volatilization in that study, compared to near-equilibrium conditions at offshore sites in this study, may have been due to the smaller surface areas and more urbanized shorelines of Lake Erie and Lake Ontario in comparison with Lake Superior.

Liu et al. observed volatilization of polychlorinated biphenyls (PCBs) at the majority of the same sites discussed here, ${ }^{34}$ suggesting that the lakes were acting as secondary sources of these legacy pollutants while continuing to absorb PBDEs.

Correlation between PBDE Congeners and Other Compounds. Dissolved concentrations of the seven PBDEs found in $>30 \%$ of water samples (BDEs 28,47 , 
$49,99,100,154$, and 153) were significantly linearly correlated with each other $(\mathrm{p}<$ $0.05,0.24 \leq \mathrm{r}^{2} \leq 0.73$ ), with the exception of BDEs 49 and 153. Correlations between the two hexabrominated congeners, BDEs 154 and 153, and other congeners were generally weaker than correlations between lower-brominated congeners. This may be because PBDEs 28, 49, 47, 99, and 100 share a common source: the Penta-BDE commercial formulation, while BDEs 154 and 153 are associated with Octa-BDE. ${ }^{16}$ BDEs 154 and 153 were strongly correlated with each other in the dissolved phase (p $<0.001, \mathrm{r}^{2}=0.63$ ). Gaseous concentrations of the five PBDEs found in $>30 \%$ of air samples (BDEs 28, 47, 49, 99, and 100) were also significantly linearly correlated with each other $\left(p<0.05,0.30 \leq \mathrm{r}^{2} \leq 0.80\right)$. Only samples in which both congeners were found $>$ DL were used in the correlation analysis for each pair.

In addition to comparisons between PBDE congeners, $\Sigma_{12} \mathrm{BDE}$ concentrations in air and water were compared to total concentrations of polycyclic musks (PCMs), polycyclic aromatic hydrocarbons (PAHs), and polychlorinated biphenyls (PCBs) measured in the same extracts. PCB data was published previously by Liu et al., ${ }^{17}$ PCM data is currently in review, and mean PAH concentrations are available in Tables S4-14 and S4-15. Dissolved $\Sigma_{12} \mathrm{BDE}$ exhibited a significant positive linear correlation with total dissolved PCMs $\left(\Sigma_{5} \mathrm{PCM} ; \mathrm{p}<0.01 ; \mathrm{r}^{2}=0.34 ; \mathrm{SE}=4.2 ; \mathrm{N}=39\right)$, but was not correlated with dissolved $\Sigma_{14} \mathrm{PAH}$ or $\Sigma_{7} \mathrm{PCB}$, suggesting that dissolved PBDEs may share more common sources with PCMs than with PAHs or PCBs in the lower Great Lakes region. Previous work by Melymuk et al. suggested that wastewater may be an important source of both PBDEs and PCMs in Lake Ontario, while not as significant for PCBs or PAHs. ${ }^{18}$ 
In contrast, gaseous $\Sigma_{12} \mathrm{BDE}$ was weakly but significantly correlated with gaseous $\Sigma_{14} \mathrm{PAH}\left(\mathrm{p}<0.01 ; \mathrm{r}^{2}=0.13 ; \mathrm{SE}=3.8 ; \mathrm{N}=56\right)$ and $\Sigma_{7} \mathrm{PCB}\left(\mathrm{p}<0.01 ; \mathrm{r}^{2}=0.16\right.$; $\mathrm{SE}=3.8 ; \mathrm{N}=54$ ), but not correlated with $\Sigma_{5} \mathrm{PCM}$, possibly due to scarcity of data, as gaseous PCMs were detected above blank levels less frequently than the other compound groups. Previous studies in the Great Lakes region have also reported significant correlation between atmospheric PBDEs and PCBs due to their elevated emissions in urban and industrial areas. ${ }^{19}$

Results of this correlation analysis suggest that PBDEs and PCMs share common sources to the aquatic environment. They may also share common sources to the atmosphere, but results for air were inconclusive. Differences in correlation strength between air and water data could be caused in part by the use of slightly different sampling locations for some air versus water PEs), but these differences were not expected to greatly affect correlation strength.

Gaseous PBDEs and Population Density. Population data within a $180^{\circ}$ wedge to the south of each site resulted in stronger correlation with gaseous $\Sigma_{12} \mathrm{BDE}$ than population within a circle around each site or population to the north, east, or west. This was also generally true for individual BDE congeners. Correlations found using a circular radius or $180^{\circ}$ southern wedge are compared in Figure S4-5.

In previous studies investigating relationships between atmospheric pollutant concentrations and population, sites have often been characterized using a circular area with a specific radius (often $20-25 \mathrm{~km}$ ). ${ }^{46}$ However, some studies have shown that directional terms should be considered when investigating atmospheric pollutants in the Great Lakes, especially for compound groups with significant local atmospheric 
emissions. ${ }^{43}$ Previous studies have also demonstrated that coastal effects can disrupt population trends when offshore air dilutes the urban plume. ${ }^{44}$ The work described here included mostly shoreline sites which had very different nearby population densities to the north and south. Furthermore, the lower Great Lakes region was generally subject to prevailing southwesterly winds during the deployment period, as is demonstrated by wind direction data (Tables S4-16 and S4-17; Figures S4-6 and S47).

Average gaseous $\Sigma_{12} \mathrm{BDE}$ exhibited significant $(\mathrm{p}<0.05)$ linear correlation with population within 1-10 km south of each site, with the strongest correlation at $3 \mathrm{~km}$ $\left(p<0.005 ; r^{2}=0.36 ; S E=2.9 ; N=22\right)$. Significant linear correlation with population was also seen for four of the five commonly detected individual congeners (BDE 28, 47, 99, and 100), with strongest correlations between 3 and $15 \mathrm{~km}$. This suggests PBDEs were significantly influenced by local sources, consistent with their low vapor pressures and significant loss via deposition. Melymuk et al. observed a swift decline in PBDE concentrations within $5 \mathrm{~km}$ south of the Toronto city center, supporting the importance of nearby populated areas in influencing distributions of these compounds. $^{28}$ BDE 49 did not exhibit significant correlation with population at any distance, perhaps due to its low frequency of detection (34\%) compared to the other congeners $(>50 \%)$.

The maximum radius where a significant $(\mathrm{p}<0.05)$ linear correlation was observed between gaseous concentration and population was plotted against $\log \mathrm{p}_{\mathrm{L}}$ at $298 \mathrm{~K}$ for four PBDEs, as well as several PAHs, PCBs, and PCMs, in Figure 4-3. As compound vapor pressure increased, the maximum distance where significant 
correlation was observed expanded, suggesting that spatial distributions of more volatile compounds like PCMs and lower molecular weight PAHs were influenced more strongly by distant emissions, while local emissions were more important in determining spatial distributions of PBDEs.

Previous data from PEs collected on the lower Great Lakes in 2011 suggested that PAHs with subcooled liquid vapor pressure $\log \mathrm{p}_{\mathrm{L}}(\mathrm{Pa})<-3$ at $298 \mathrm{~K}$ most strongly correlated with population within a radius of $3 \mathrm{~km}$, while PAHs with greater vapor pressures correlated more strongly with population within a radius of $20 \mathrm{~km} .^{33}$ In this study, PAHs, PCBs, and PCMs with $\log \mathrm{p}_{\mathrm{L}}>-2$ remained significantly correlated with population within radii $>25 \mathrm{~km}$, while less volatile compounds generally did not. BDEs 47 and 99 fell farther below the regression line in Figure 4-3 than other compounds, with significant correlation occurring only to a radius of 5-6 km. This may be due to their short lifetimes with respect to photolysis and $\mathrm{OH}$ radical degradation (4.0-8.7 h) compared to BDE 100 and 28 (26-48 h). ${ }^{20}$

Dissolved PBDEs and Population Density. Dissolved $\Sigma_{12} \mathrm{BDE}$ exhibited a significant positive linear correlation with population within a $25 \mathrm{~km}$ radius of each site $\left(\mathrm{r}^{2}=0.52 ; \mathrm{p}<0.001 ; \mathrm{SE}=0.27 ; \mathrm{N}=20\right)$, as shown in Figure 4-4. The correlation was driven primarily by the seven nearshore sites, which exhibited the broadest range in surrounding population densities. In this case, use of population extracted from wedges north, south, east, or west of each site did not result in stronger correlations. Four shoreline sites (OSW, NIA, ROC, and ERI) exhibited low surrounding population and elevated dissolved $\Sigma_{12} \mathrm{BDE}$ relative to the regression line, suggesting they may be influenced by nearby point sources. The Niagara River site (NIA) was 
likely representative of the Niagara River plume and the Oswego site (OSW) may have been influenced by two nearby (within $1.5 \mathrm{~km}$ ) wastewater treatment plants discharging directly into Lake Ontario, both identified as major dischargers by the US Environmental Protection Agency (US EPA) National Pollutant Discharge Elimination System (NPDES). ${ }^{45}$

Geostatistical Interpolation of Dissolved PBDE Concentrations. Using passive samplers enabled a much improved spatial coverage over past studies of this region (though still limited on the scale of the Great Lakes). This data set thus provided an opportunity to more accurately predict surface water concentrations over the lakes. Maps of predicted aqueous $\Sigma_{12} \mathrm{BDE}$ across Lake Erie and Lake Ontario are presented in Figure 4-5 and variance for these predictions is presented in Figure S4-8. Posterior distributions for the parameters used in the kriging model are shown in Figure S4-9 and results of cross validation in Figure S4-10.

Predictions for Lake Erie identified the area near Detroit at the western end of the lake as a possible unmonitored "hot spot", and highlighted areas around Buffalo, Cleveland, and Dunkirk as having the greatest concentrations (around $10 \pm 4 \mathrm{pg} / \mathrm{L}$ ) on the lake. Predictions for Lake Ontario highlighted the significance of the Toronto conurbation as a source of PBDEs to the lake, with elevated concentrations of 10-18 $\mathrm{pg} / \mathrm{L}$ extending about $15 \mathrm{~km}$ away from the shoreline.

The use of Bayesian kriging coupled with PE-derived concentrations to predict dissolved $\Sigma_{12} \mathrm{BDE}$ over the lakes illustrates the utility of relatively highly spatially resolved data in identifying potential hot spots for further study, like the area around Detroit. Concentrations in this area may be greater than predicted, as it is influenced 
by the Detroit River, which is the major tributary to Lake Erie. Elevated gaseous and dissolved PBDEs near population centers highlight the need to continually monitor concentrations of phased-out persistent organic pollutants in urbanized areas.

\section{ASSOCIATED CONTENT}

Supporting Information. Additional figures and tables, as well as details on sampling rate estimation and air-water exchange flux calculations, are available in the Supporting Information. This material is available free of charge via the Internet at http://pubs.acs.org.

\section{AUTHOR INFORMATION}

\section{Corresponding Author}

* Rainer Lohmann: rlohmann@uri.edu

\section{ACKNOWLEDGMENTS}

We acknowledge funding from the US EPA Great Lakes Restoration Initiative (GLRI) GLAS \#00E00597-0, project officer Todd Nettesheim. We thank Professor Peter August (URI) for assistance with GIS, David Adelman (URI) for organizing field deployments, Michael Vansco (URI) for data from thin-film experiments, Camilla Teixeira and the field staff of the Emergencies, Operational Analytical Laboratories, and Research Support group (Environment Canada Burlington) for open-lake deployments, and all of the volunteers who deployed PEs in the region. 


\section{LITERATURE CITED}

(1) Alaee, M.; Arias, P.; Sjödin, A.; Bergman, A. An overview of commercially used brominated flame retardants, their applications, their use patterns in different countries/regions and possible modes of release. Environ. Int. 2003, 29, 683-689, DOI:10.1016/S0160-4120(03)00121-1.

(2) Covaci, A.; Harrad, S.; Abdallah, M. A.-E.; Ali, N.; Law, R. J.; Herzke, D.; de Wit, C. A. Novel brominated flame retardants: A review of their analysis, environmental fate and behaviour. Environ. Int. 2011, 37, 532-556, DOI:10.1016/j.envint.2010.11.007.

(3) Abbasi, G.; Buser, A. M.; Soehl, A.; Murray, M. W.; Diamond, M. L. Stocks and flows of PBDEs in products from use to waste in the U.S. and Canada from 1970 to 2020. Environ. Sci. Technol. 2015, 49, 1521-1528, DOI:10.1021/es504007v.

(4) Leonetti, C.; Butt, C. M.; Hoffman, K.; Miranda, M. L.; Stapleton, H. M. Concentrations of polybrominated diphenyl ethers (PBDEs) and 2,4,6tribromophenol in human placental tissues. Environ. Int. 2016, 88, 23-29, DOI:10.1016/j.envint.2015.12.002.

(5) Noren, K.; Meironyte, D. Certain organochlorine and organobromine contaminants in Swedish human milk in perspective of past 20-30 years. Chemosphere 2000, 40, 1111-1123, DOI:10.1016/S0045-6535(99)00360-4.

(6) Liu, L.-Y.; Salamova, A.; He, K.; Hites, R. A. Analysis of polybrominated diphenyl ethers and emerging halogenated and organophosphate flame retardants in human hair and nails. J. Chromatogr. A, 2015, 1406, 251-257, DOI:10.1016/j.chroma.2015.06.003.

(7) Law, K.; Halldorson, T.; Danell, R.; Stern, G.; Gewurtz, S.; Alaee, M.; Marvin, C.; Whittle, M.; Tomy, G. Bioaccumulation and trophic transfer of some brominated flame retardants in a Lake Winnipeg (Canada) food web. Environ. Toxicol. Chem. 2006, 25, 2177-2186, DOI:10.1897/05-500R.1.

(8) Zhu, L. Y.; Hites, R. A. Temporal trends and spatial distributions of brominated flame retardants in archived fishes from the Great Lakes. Environ. Sci. Technol. 2004, 38, 2779-2784, DOI:10.1021/es035288h.

(9) Booij, K.; Zegers, B. N.; Boon, J. P. Levels of some polybrominated diphenyl ether (PBDE) flame retardants along the Dutch coast as derived from their accumulation in SPMDs and blue mussels (Mytilus edulis). Chemosphere 2002, 46, 683-688, DOI:10.1016/S0045-6535(01)00232-6. 
(10) Streets, S. S.; Henderson, S. A.; Stoner, A. D.; Carlson, D. L.; Simcik, M. F.; Swackhamer, D. L. Partitioning and bioaccumulation of PBDEs and PCBs in Lake Michigan. Environ. Sci. Technol. 2006, 40, 7263-7269, DOI:10.1021/es061337p.

(11) Klosterhaus, S. L.; Stapleton, H. M.; La Guardia, M. J.; Greig, D. J. Brominated and chlorinated flame retardants in San Francisco Bay sediments and wildlife. Environ. Int. 2012, 47, 56-65, DOI:10.1016/j.envint.2012.06.005.

(12) Hites, R. A. Polybrominated diphenyl ethers in the environment and in people: A meta-analysis of concentrations. Environ. Sci. Technol. 2004, 38, 945-956, DOI:10.1021/es035082g.

(13) Melymuk, L.; Robson, M.; Helm, P. A.; Diamond, M. L. Application of land use regression to identify sources and assess spatial variation in urban SVOC concentrations. Environ. Sci. Technol. 2013, 47, 1887-1895, DOI:10.1021/es3043609.

(14) Ma, Y.; Salamova, A.; Venier, M.; Hites, R. A. Has the phase-out of PBDEs affected their atmospheric levels? Trends of PBDEs and their replacements in the Great Lakes atmosphere. Environ. Sci. Technol. 2013, 47, 11457-11464, DOI:10.1021/es403029m.

(15) Stapleton, H. M.; Sharma, S.; Getzinger, G.; Ferguson, P. L.; Gabriel, M.; Webster, T. F.; Blum, A. Novel and high volume use flame retardants in US couches reflective of the 2005 PentaBDE phase out. Environ. Sci. Technol. 2012, 46, 13432-13439, DOI:10.1021/es303471d.

(16) Dodson, R. E.; Perovich, L. J.; Covaci, A.; Van den Eede, N.; Ionas, A. C.; Dirtu, A. C.; Brody, J. G.; Rudel, R. A. After the PBDE phase-out: A broad suite of flame retardants in repeat house dust samples from California. Environ. Sci. Technol. 2012, 46, 13056-13066, DOI:10.1021/es303879n.

(17) Hearn, L. K.; Kennedy, K.; Hawker, D. W.; Toms, L.-M. L.; Alberts, V.; Mueller, J. F. Spatial mapping of city-wide PBDE levels using an exponential decay model. J. Environ. Monit. 2012, 14, 643-650, DOI:10.1039/c2em10656f.

(18) Shoeib, M.; Ahrens, L.; Jantunen, L.; Harner, T. Concentrations in air of organobromine, organochlorine and organophosphate flame retardants in Toronto, Canada. Atmos. Environ. 2014, 99, 140-147, DOI:10.1016/j.atmosenv.2014.09.040.

(19) Robson, M.; Melymuk, L.; Bradley, L.; Treen, B.; Backus, S. Wet deposition of brominated flame retardants to the Great Lakes basin - status and trends.

Environ. Pollut. 2013, 182, 299-306, DOI:10.1016/j.envpol.2013.07.018. 
(20) Raff, J. D.; Hites, R. A. Deposition versus photochemical removal of PBDEs from Lake Superior air. Environ. Sci. Technol. 2007, 41, 6725-6731, DOI:10.1021/es070789e.

(21) Csiszar, S. A.; Diamond, M. L.; Daggupaty, S. M. The magnitude and spatial range of current-use urban $\mathrm{PCB}$ and PBDE emissions estimated using a coupled multimedia and air transport model. Environ. Sci. Technol. 2014, 48, 10751083, DOI:10.1021/es403080t.

(22) Melymuk, L.; Robson, M.; Csiszar, S. A.; Helm, P. A.; Kaltenecker, G.; Backus, S.; Bradley, L.; Gilbert, B.; Blanchard, P.; Jantunen, L.; Diamond, M. L. From the city to the lake: Loadings of PCBs, PBDEs, PAHs and PCMs from Toronto to Lake Ontario. Environ. Sci. Technol. 2014, 48, 3732-3741, DOI:10.1021/es403209z.

(23) Venier, M.; Hites, R. A. Atmospheric deposition of PBDEs to the Great Lakes featuring a Monte Carlo analysis of errors. Environ. Sci. Technol. 2008, 42, 9058-9064, DOI:10.1021/es8008985.

(24) Ruge, Z.; Muir, D.; Helm, P.; Lohmann, R. Concentrations, trends, and airwater exchange of PAHs and PBDEs derived from passive samplers in Lake Superior in 2011. Environ. Sci. Technol. 2015, 49, 13777-13786, DOI:10.1021/acs.est.5b02611.

(25) Lohmann, R.; Klánová, J.; Kukucka, P.; Yonis, S.; Bollinger, K. PCBs and OCPs on a east-to-west transect: The importance of major currents and net volatilization for PCBs in the Atlantic Ocean. Environ. Sci. Technol. 2012, 46, 10471-10479, DOI:10.1021/es203459e.

(26) Swackhamer, D. L.; Schottler, S.; Pearson, R. F. Air-water exchange and mass balance of toxaphene in the Great Lakes. Environ. Sci. Technol. 1999, 33, 3864-3872, DOI:10.1021/es990280m.

(27) Venier, M.; Ma, Y.; Hites, R. A. Bromobenzene flame retardants in the Great Lakes atmosphere. Environ. Sci. Technol. 2012, 46, 8653-8660, DOI:10.1021/es3015919.

(28) Melymuk, L.; Robson, M.; Helm, P. A.; Diamond, M. L. PCBs, PBDEs, and PAHs in Toronto air: Spatial and seasonal trends and implications for contaminant transport. Sci. Total Environ. 2012, 429, 272-280, DOI:10.1016/j.scitotenv.2012.04.022.

(29) Venier, M.; Dove, A.; Romanak, K.; Backus, S.; Hites, R. A. Flame retardants and legacy chemicals in Great Lakes' water. Environ. Sci. Technol. 2014, 48, 9563-9572, DOI:10.1021/es501509r. 
(30) Sacks, V. P.; Lohmann, R. Freely dissolved PBDEs in water and porewater of an urban estuary. Environ. Pollut. 2012, 162, 287-293, DOI:10.1016/j.envpol.2011.11.028.

(31) Lohmann, R.; Klánová, J.; Kukucka, P.; Yonis, S.; Bollinger, K. Concentrations, fluxes, and residence time of PBDEs across the tropical Atlantic Ocean. Environ. Sci. Technol. 2013, 47, 13967-13975, DOI:10.1021/es403494b.

(32) Khairy, M. A.; Lohmann, R. Field calibration of low density polyethylene passive samplers for gaseous POPs. Environ. Sci. Process. Impacts 2014, 16, 414-421, DOI:10.1039/c3em00493g.

(33) McDonough, C. A.; Khairy, M. A.; Muir, D. C. G.; Lohmann, R. Significance of population centers as sources of gaseous and dissolved PAHs in the lower Great Lakes. Environ. Sci. Technol. 2014, 48, 7789-7797, DOI:10.1021/es501074r.

(34) Liu, Y.; Wang, S.; McDonough, C. A.; Khairy, M.; Muir, D. C. G.; Helm, P. A.; Lohmann, R. Gaseous and freely-dissolved PCBs in the lower Great Lakes based on passive sampling: spatial trends and air-water exchange. Environ. Sci. Technol. 2016, 50, 4932-4939, DOI:10.1021/acs.est.5b04586.

(35) R Core Team. R: A language and environment for statistical computing (version 3.1.0), 2014.

(36) Center for International Earth Science Information Network (CIEISIN); Columbia University; International Food Policy Research Institute (IFPRI); The World Bank; Centro Internacional de Agricultura Tropical (CIAT). Global Rural-Urban Mapping Project, Version 1 (GRUMPv1): Population Count Grid http://sedac.ciesin.columbia.edu/data/set/grump-v1-population-count.

(37) Le, N. D.; Zidek, J. V. Interpolation with uncertain spatial covariances : A Bayesian alternative to kriging. J. Multivar. Anal. 1992, 43, 351-374, DOI:10.1016/0047-259X(92)90040-M.

(38) Zarnadze, A.; Rodenburg, L. A. Water-column concentrations and partitioning of polybrominated diphenyl ethers in the New York/new Jersey Harbor, USA. Environ. Toxicol. Chem. 2008, 27, 1636-1642, DOI:10.1897/07-619.

(39) Yang, C.; Harrad, S.; Abdallah, M. A.-E.; Desborough, J.; Rose, N. L.; Turner, S. D.; Davidson, T. A.; Goldsmith, B. Polybrominated diphenyl ethers (PBDEs) in English freshwater lakes, 2008-2012. Chemosphere 2014, 110, 41-47, DOI:10.1016/j.chemosphere.2014.03.028. 
(40) Su, Y.; Wania, F.; Lei, Y. D.; Harner, T.; Shoeib, M. Temperature dependence of the air concentrations of polychlorinated biphenyls and polybrominated diphenyl ethers in a forest and a clearing. Environ. Sci. Technol. 2007, 41, 4655-4661, DOI:10.1021/es070334p.

(41) Peverly, A. A.; Ma, Y.; Venier, M.; Rodenburg, Z.; Spak, S. N.; Hornbuckle, K. C.; Hites, R. A. Variations of flame retardant, polycyclic aromatic hydrocarbon, and pesticide concentrations in Chicago's atmosphere measured using passive sampling. Environ. Sci. Technol. 2015, 49, 5371-5379,

DOI:10.1021/acs.est.5b00216.

(42) Xie, Z.; Möller, A.; Ahrens, L.; Sturm, R.; Ebinghaus, R. Brominated flame retardants in seawater and atmosphere of the Atlantic and the Southern Ocean. Environ. Sci. Technol. 2011, 45, 1820-1826, DOI:10.1021/es103803t.

(43) Hafner, W. D.; Hites, R. A. Effects of wind and air trajectory directions on atmospheric concentrations of persistent organic pollutants near the Great Lakes. Environ. Sci. Technol. 2005, 39, 7817-7825, DOI:10.1021/es0502223.

(44) Hafner, W. D.; Carlson, D. L.; Hites, R. A. Influence of local human population on atmospheric polycyclic aromatic hydrocarbon concentrations. Environ. Sci. Technol. 2005, 39, 7374-7379, DOI:10.1021/es0508673.

(45) US EPA. US EPA Discharge Monitoring Report (DMR) Pollutant Loading Tool, v 1.0 https://cfpub.epa.gov/dmr/index.cfm. 


\section{FIGURES AND TABLES}

Table 4-1. Average Dissolved PBDEs (pg/L) \pm Standard Deviation.

\begin{tabular}{|c|c|c|c|c|c|c|c|c|c|}
\hline & $\mathrm{N}^{\mathrm{a}}$ & BDE 28 & BDE 49 & BDE 47 & BDE 100 & BDE 99 & BDE 154 & BDE 153 & $\sum_{12} \mathrm{BDE}$ \\
\hline Toronto Nearshore & 3 & $0.48 \pm 0.12$ & $0.22 \pm 0.02$ & $5.4 \pm 1.3$ & $1.8 \pm 0.76$ & $5.0 \pm 1.8$ & $0.42 \pm 0.22$ & $0.20 \pm 0.07$ & $14 \pm 4.1$ \\
\hline $\begin{array}{l}\text { Lake Erie } \\
\text { Shoreline/Nearshore }\end{array}$ & 6 & $0.23 \pm 0.22$ & $0.20 \pm 0.17$ & $2.0 \pm 1.2$ & $0.93 \pm 0.46$ & $1.9 \pm 1.4$ & $0.11 \pm 0.11$ & $0.03 \pm 0.04$ & $5.5 \pm 3.4$ \\
\hline $\begin{array}{l}\text { Lake Ontario } \\
\text { Shoreline/Nearshore }\end{array}$ & 6 & $0.28 \pm 0.16$ & $0.23 \pm 0.21$ & $3.0 \pm 2.2$ & $0.95 \pm 0.68$ & $2.0 \pm 1.8$ & $0.13 \pm 0.15$ & $0.06 \pm 0.05$ & $6.8 \pm 5.0$ \\
\hline Lake Erie Offshore & 3 & $0.17 \pm 0.15$ & $0.13 \pm 0.11$ & $0.55 \pm 0.48$ & $0.30 \pm 0.27$ & $0.63 \pm 0.74$ & $0.07 \pm 0.07$ & $0.02 \pm 0.04$ & $1.9 \pm 0.91$ \\
\hline Lake Ontario Offshore & 2 & $0.08 \pm 0.11$ & $0.11 \pm 0.06$ & $1.1 \pm 0.18$ & $0.40 \pm 0.21$ & $0.85 \pm 0.36$ & $0.09 \pm 0.12$ & $<\mathrm{DL}$ & $2.6 \pm 0.81$ \\
\hline
\end{tabular}

${ }^{\mathrm{a}} \mathrm{N}$ is the number of sites of each type.

Table 4-2. Average Gaseous PBDEs $\left(\mathrm{pg} / \mathrm{m}^{3}\right) \pm$ Standard Deviation.

\begin{tabular}{|c|c|c|c|c|c|c|c|}
\hline & $\mathrm{N}^{\mathrm{a}}$ & BDE 28 & BDE 49 & BDE 47 & BDE 100 & BDE 99 & $\overline{\Sigma_{12} \mathrm{BDE}}$ \\
\hline \multicolumn{8}{|c|}{ Summer Sites (May to November) } \\
\hline Offshore & 3 & $0.09 \pm 0.10$ & $0.03 \pm 0.02$ & $0.22 \pm 0.09$ & $0.05 \pm 0.03$ & $0.25 \pm 0.12$ & $0.74 \pm 0.15$ \\
\hline Nearshore & 5 & $0.14 \pm 0.09$ & $0.03 \pm 0.02$ & $0.28 \pm 0.24$ & $0.11 \pm 0.05$ & $0.22 \pm 0.18$ & $0.79 \pm 0.56$ \\
\hline Shoreline & 14 & $0.25 \pm 0.29$ & $0.06 \pm 0.07$ & $2.9 \pm 1.3$ & $0.59 \pm 0.25$ & $2.6 \pm 1.7$ & $6.7 \pm 2.1$ \\
\hline \multicolumn{8}{|c|}{ Winter Sites (November to May) } \\
\hline Shoreline & 9 & $0.03 \pm 0.07$ & $0.01 \pm 0.02$ & $0.55 \pm 0.62$ & $0.21 \pm 0.15$ & $1.7 \pm 0.88$ & $2.7 \pm 1.4$ \\
\hline
\end{tabular}

${ }^{\mathrm{a}} \mathrm{N}$ is the number of sites of each type. 

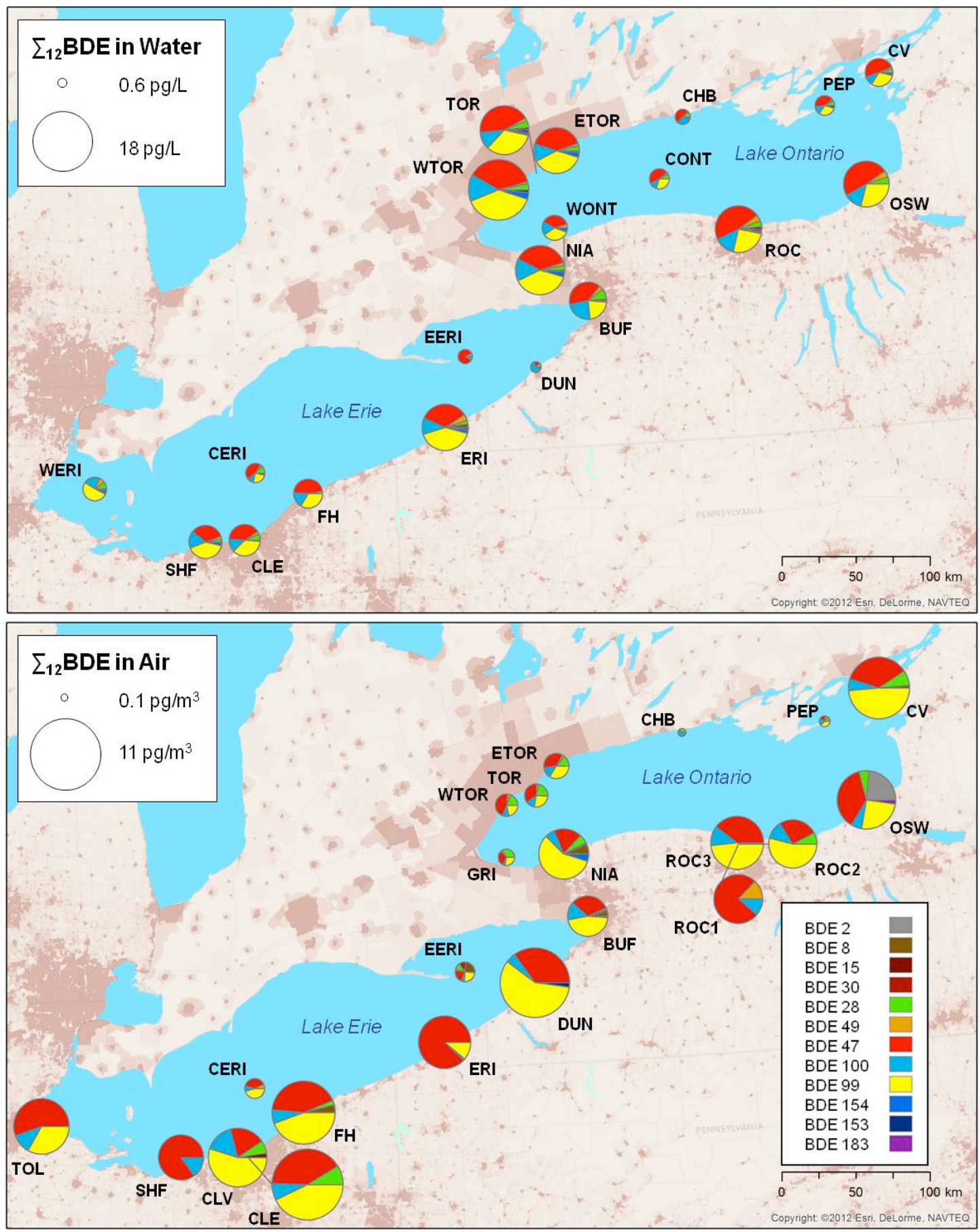

Figure 4-1. Average Dissolved (top) and Gaseous (bottom) PBDEs during Summer Deployments. $\Sigma_{12}$ BDE in water ranged from $0.6 \mathrm{pg} / \mathrm{L}$ (DUN) to $18 \mathrm{pg} / \mathrm{L}$ (WTOR). $\Sigma_{12}$ BDE in air ranged from $0.1 \mathrm{pg} / \mathrm{m}^{3}$ (CHB) to $11 \mathrm{pg} / \mathrm{m}^{3}$ (CLE). Regions on the map shaded darker brown are more densely populated. 


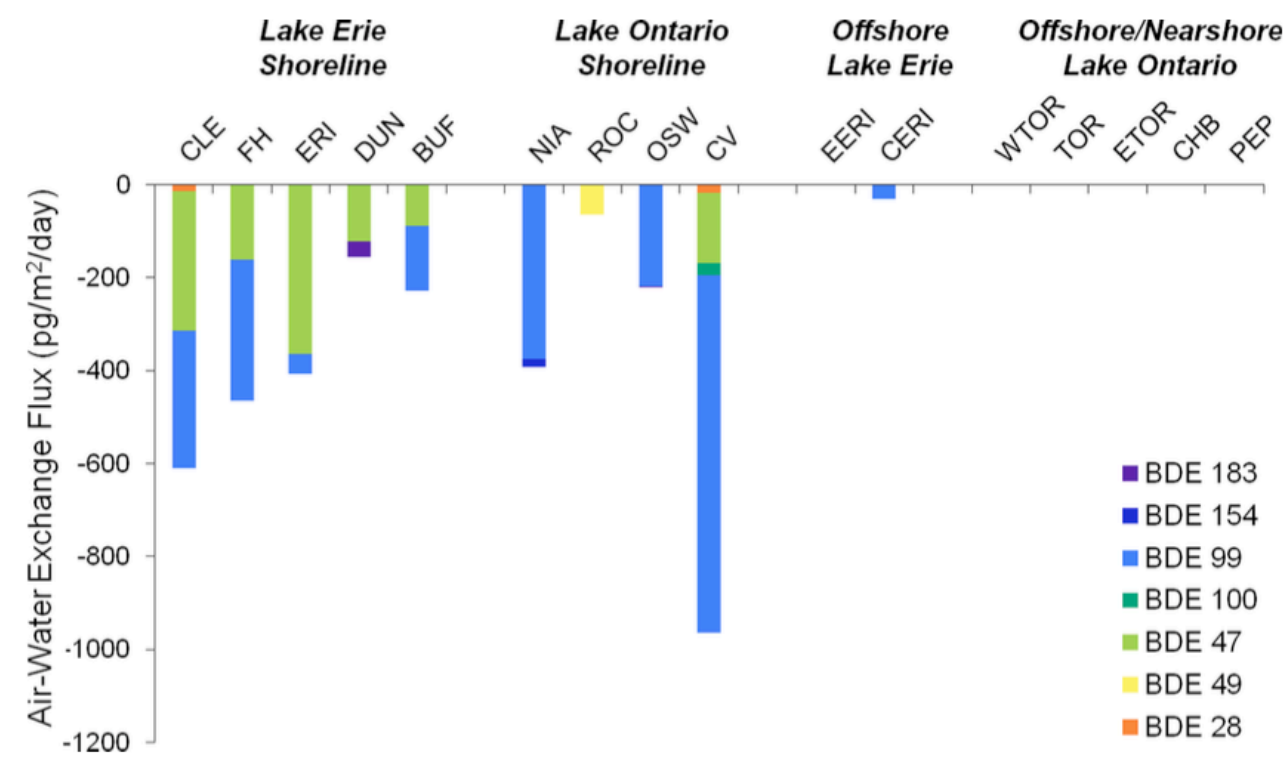

Figure 4-2. Average Summer PBDE Air-Water Exchange Fluxes (pg/ $\left.\mathbf{m}^{2} / \mathrm{day}\right)$. Bars on the negative $y$-axis represent total absorption into surface waters. Mean summertime net fluxes ranged from $-964 \mathrm{pg} / \mathrm{m}^{2} /$ day on the shoreline of Cape Vincent (CV) to $-30 \mathrm{pg} / \mathrm{m}^{2} /$ day at an offshore buoy in central Lake Erie (CERI).

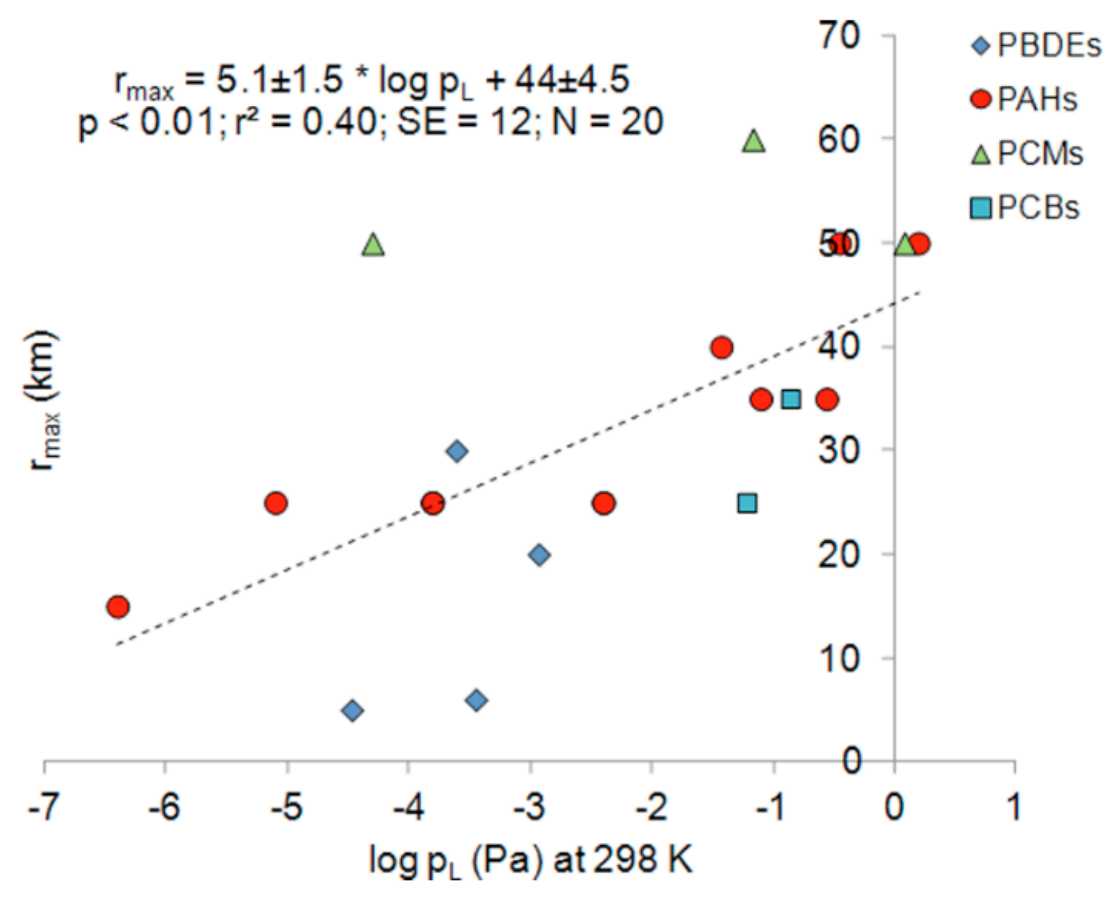

Figure 4-3. Maximum Distance $(\mathrm{km})$ Yielding Significant Correlation between Gaseous Concentration and Population. The maximum radius $\left(r_{\max }\right)$ at which there was a significant $(\mathrm{p}<0.05)$ linear correlation between gaseous concentration and population was correlated with sub-cooled liquid vapor pressure $\left(\log \mathrm{p}_{\mathrm{L}}\right)$ for four PBDEs and several PCBs, PAHs, and PCMs. 


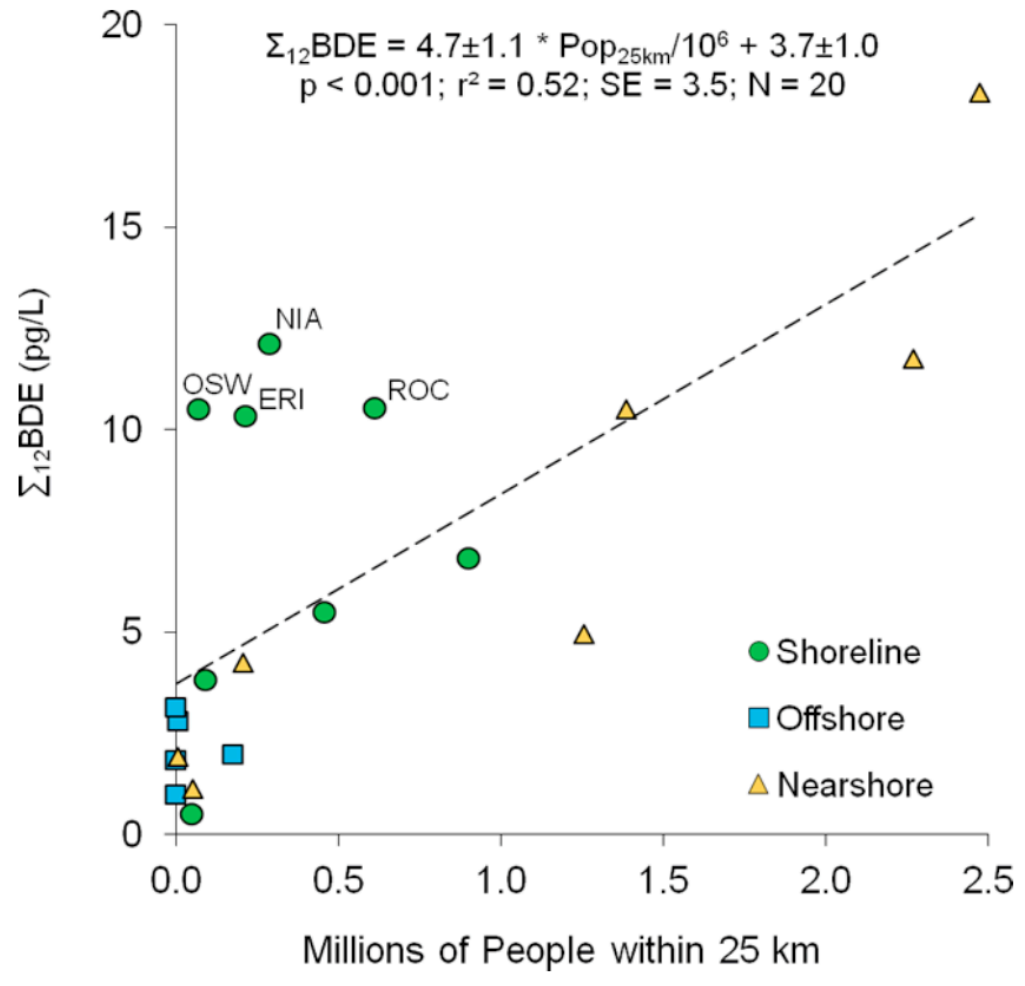

Figure 4-4. Dissolved PBDEs and Population Density. Mean summertime dissolved $\Sigma_{12} \mathrm{BDE}(\mathrm{pg} / \mathrm{L})$ exhibited significant linear correlation with population within a $25 \mathrm{~km}$ circular radius of each site $(\mathrm{p}<0.001)$. Sites are marked according to whether they were offshore $(>5 \mathrm{~km}$ from shoreline), nearshore $(<5 \mathrm{~km}$ from shoreline), or shoreline (deployed directly from shore). 


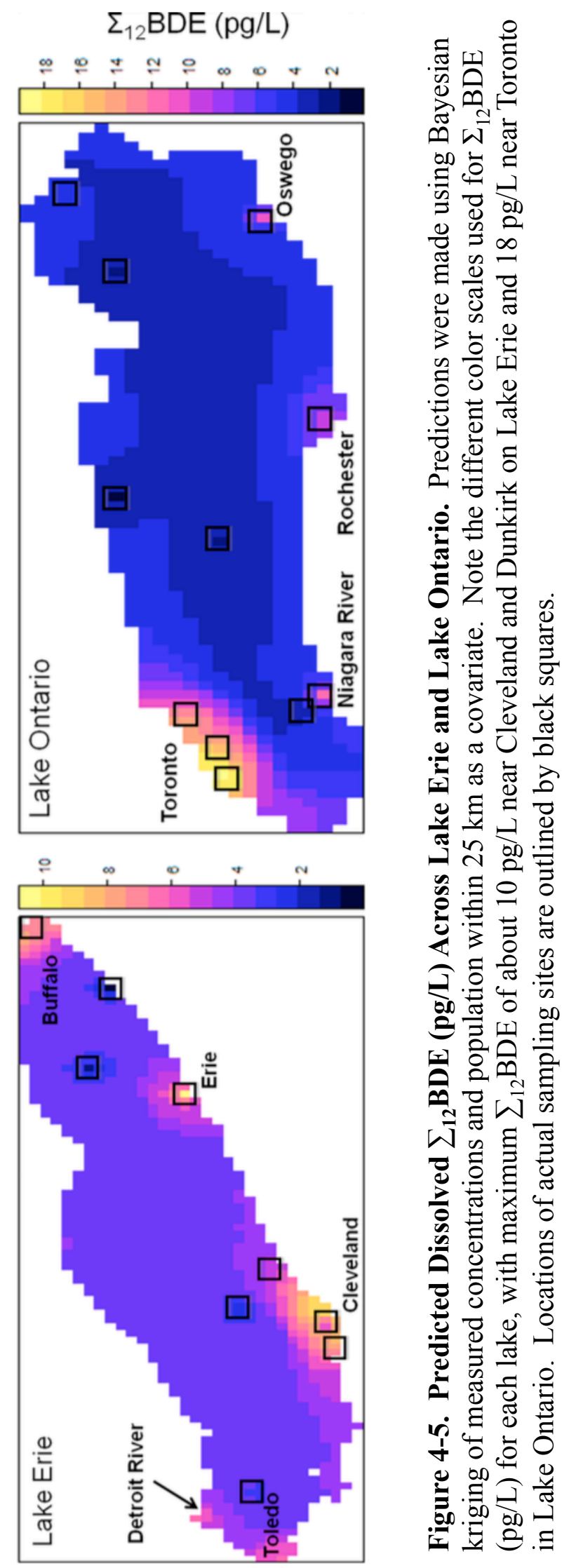




\title{
SUPPORTING INFORMATION: \\ SPATIAL DISTRIBUTION AND AIR-WATER EXCHANGE OF ORGANIC FLAME RETARDANTS IN THE LOWER GREAT LAKES
}

\author{
Carrie A. McDonough, Gavino Puggioni, Paul A. Helm, Derek C. G. Muir, Rainer \\ Lohmann
}

Total number of pages: 45

Total number of figures: 10

Total number of tables: 17

\section{Calculating Ambient Air or Water Concentration from PE. Ambient}

concentrations of target compounds in air or water were calculated from $\mathrm{C}_{\mathrm{PE}}$, the concentration measured in $\mathrm{pg} / \mathrm{kg}$ PE, $\mathrm{d}_{\mathrm{PE}}$, the density of PE $(0.91 \mathrm{~kg} / \mathrm{L}), \mathrm{K}_{\mathrm{PEM}}$, the PEmatrix partitioning coefficient in $\mathrm{L} / \mathrm{L}$, and $f$, the percent equilibration reached during deployment, (Equation S1).

$$
C_{a}=\frac{C_{P E} \cdot d_{P E}}{f \cdot K_{P E M}}
$$

$f$ was estimated using data from performance reference compounds (PRCs) that were loaded into each PE prior to deployment. The initial mass of PRC loaded into the samplers was determined by measuring PRCs in quality control samples (blanks and field blanks), which were prepared alongside those used in field deployments, but never deployed in the environment. $f$ for each PRC was calculated as in Equation S2, where $\mathrm{N}$ is the mass of PRC in the deployed PE and $\mathrm{N}_{0}$ is the mass in the nondeployed blank.

Loss data for benzo(a)pyrene- $\mathrm{d}_{12}$ were not included in determining $f$ for target compounds because loss of this compound was generally greater than loss of pentabromobiphenyl, suggesting that loss due to processes besides PE-air or PE-water 
diffusive exchange may have occurred. Six air samples were found to have loss of dibromobiphenyl $<90 \%$, which is unrealistic given the deployment times for these samplers and may indicate some inconsistency in deployment practices.

Concentration estimates for these samples were discarded before further analysis and interpretation.

$$
f=1-\frac{N}{N_{0}}
$$

Values of $f$ for all PRCs were used along with known and estimated physicochemical properties for the PRCs (Table S4-7) to determine a single best-fit value of the thickness of the diffusive boundary layer $\left(\delta_{\mathrm{DBL}}\right)$ for each deployment, as in Equation S3, using the non-linear least squares fitting function $n l s$ in R.

$$
f=1-e^{\frac{-t \cdot A_{P E}}{V_{P E} \cdot\left(\frac{\delta_{D B L} \cdot K_{P E M}}{D_{M}}+\frac{l_{P E}}{D_{P E}}\right)}}
$$

In Equation $\mathrm{S} 3, t$ is length of the deployment time in seconds, $\mathrm{K}_{\mathrm{PEM}}$ is the unitless PE-matrix partitioning coefficient, $l_{\mathrm{PE}}$ is half the thickness of the PE in meters, $D_{M}$ is the diffusivity of the target compound in air or water $\left(\mathrm{m}^{2} / \mathrm{s}\right), \mathrm{D}_{\mathrm{PE}}$ is the diffusivity of the target compound in $\mathrm{PE}\left(\mathrm{m}^{2} / \mathrm{s}\right)$, and $\delta_{\mathrm{DBL}}$ is the estimated best-fit thickness of the diffusive boundary layer in meters. Once $\delta_{\mathrm{DBL}}$ for the deployment was determined, it was used along with each target compound's known and estimated physico-chemical properties to determine $f$ for each compound of interest.

Values of $K_{\mathrm{PEM}}, \mathrm{D}_{\mathrm{M}}$, and $\mathrm{D}_{\mathrm{PE}}$ for all compounds and PRCs were corrected to the mean temperature during deployment, as estimated based on data from nearby meteorological buoys (Table S4-2). 


$$
D_{a, T 2}=\frac{10^{-3} \cdot T_{2}{ }^{1.75} \cdot \sqrt{\frac{1}{M M_{a}}+\frac{1}{M_{i}}}}{p_{a t m} \cdot\left(V_{a}{ }^{1 / 3}+V_{m}{ }^{1 / 3}\right)^{2}}
$$

$\mathrm{D}_{\mathrm{a}, \mathrm{T} 2}$, the diffusivity in $\mathrm{cm}^{2} / \mathrm{s}$ of the target compound in air at the mean deployment temperature $\mathrm{T}_{2}$, was determined as in Fuller 1966, ${ }^{1}$ with gas-phase pressure $\left(\mathrm{p}_{\text {atm }}\right)$ assumed to be $1 \mathrm{~atm}$, molar mass of air $\left(\mathrm{MM}_{\mathrm{a}}\right)$ assumed to be 28.97 $\mathrm{g} / \mathrm{mol}$, and molar volume of air $\left(\mathrm{V}_{\mathrm{a}}\right)$ assumed to be $20.1 \mathrm{~cm}^{3} / \mathrm{mol} . \mathrm{M}_{\mathrm{i}}$ and $\mathrm{V}_{\mathrm{m}}$ are the molar mass and molar volume of the compound of interest.

$$
D_{w, T 2}=\frac{7.4 \cdot 10^{-12} \cdot T_{2} \cdot \sqrt{a \cdot M M_{w}}}{\nu_{w} \cdot V_{m}^{0.6}}
$$

$\mathrm{D}_{\mathrm{w}, \mathrm{T} 2}$, the diffusivity of the target compound in water at the mean deployment temperature $\mathrm{T}_{2}$, was determined via the Wilke-Chang equation as in Equation S5, where $a$ is 2.6 , the association parameter for water, and $\mathrm{MM}_{\mathrm{w}}$ is the molar mass $(\mathrm{g} / \mathrm{mol})$ of water $(18 \mathrm{~g} / \mathrm{mol}) . V_{\mathrm{m}}$ is the molar volume of the target compound in $\mathrm{cm}^{3} / \mathrm{mol}$ and $v_{\mathrm{w}}$ is the viscosity of water determined at the nearest whole number temperature from Schwarzenbach et al. 2003. ${ }^{2}$

$$
D_{P E, T 2}=D_{P E, T 1} \cdot e^{\frac{E_{a}}{R} \cdot\left(\frac{1}{T 1}-\frac{1}{T 2}\right)}
$$

$\mathrm{D}_{\mathrm{PE}, \mathrm{T} 2}$, the diffusivity of the target compound in PE at the mean deployment temperature, was determined from Equation S6, where R is the universal gas constant $(8.3145 \mathrm{~J} / \mathrm{K} / \mathrm{mol})$ and $\mathrm{E}_{\mathrm{a}}$ is the energy of activation, assumed to be $100,000 \mathrm{~J} / \mathrm{mol}$ based on unpublished thin-film experiments by Vansco et al. measuring $D_{P E}$ for brominated flame retardants at varying temperatures.

$$
K_{P E A, T 2}=K_{P E A, T 1} \cdot e^{\frac{H_{v a p}}{R} \cdot\left(\frac{1}{T_{2}}-\frac{1}{T_{1}}\right)}
$$


The PE-air partitioning coefficient at the mean deployment temperature ( $\left.\mathrm{K}_{\mathrm{PEA}, \mathrm{T} 2}\right)$ was determined from $\mathrm{K}_{\mathrm{PEA}}$ at $298.15 \mathrm{~K}\left(\mathrm{~K}_{\mathrm{PEA}, \mathrm{T1}}\right)$ via Equation $\mathrm{S} 7$, where $\mathrm{H}_{\text {vap }}$ is the enthalpy of vaporization in $\mathrm{J} / \mathrm{mol}$ for the target compound and $\mathrm{R}$ is the ideal gas constant.

$$
K_{P E W, T 2}=K_{P E W, T 1} \cdot e^{\frac{U_{w}}{R} \cdot\left(\frac{1}{T_{2}}-\frac{1}{T_{1}}\right)}
$$

The PE-water partitioning coefficient at the mean deployment temperature ( $\left.\mathrm{K}_{\mathrm{PEW}, \mathrm{T} 2}\right)$ was determined from $\mathrm{K}_{\mathrm{PEW}, \mathrm{T} 1}$ via Equation $\mathrm{S} 8$, where $\mathrm{U}_{\mathrm{w}}$ is the energy of solvation.

To relate best-fit $\delta_{\text {DBL }}$ values to the more often-reported sampling rate $\left(\mathrm{R}_{\mathrm{s}}\right)$ for passive samplers, sampling rates for each congener were calculated as in Equation S9:

$$
R_{S}=k_{0} \cdot A_{P E}
$$

In Equation $\mathrm{S} 9, \mathrm{R}_{\mathrm{s}}$ is the sampling rate in $\mathrm{m}^{3} /$ day, calculated from the mass transfer coefficient $\mathrm{k}_{0}\left(\mathrm{~m} /\right.$ day) and $\mathrm{A}_{\mathrm{PE}}$, which is the surface area of the PE, determined as the volume of the PE $\left(\mathrm{V}_{\mathrm{PE}}\right)$ divided by the thickness of the PE $\left(2 \mathrm{x} l_{\mathrm{PE}}\right)$.

$\mathrm{k}_{0}$ is determined as in Equation $\mathrm{S} 10$, where $1 / \mathrm{k}_{\mathrm{m}}$ is the matrix-side resistance and $1 / \mathrm{k}_{\mathrm{PE}} \mathrm{K}_{\mathrm{PEM}}$ is the PE-side resistance to mass transfer.

$$
\frac{1}{k_{0}}=\frac{1}{k_{m}}+\frac{1}{k_{p e} \cdot K_{P E M}}
$$

Matrix-side resistance was determined as in Equation $\mathrm{S} 11$, where $\delta_{\mathrm{DBL}}$ is the thickness of the DBL (either the air-side boundary layer or water-side boundary layer) in meters and $D_{M}$ is the diffusivity of the target compound in air or water in $\mathrm{m}^{2} / \mathrm{s}$. 


$$
\frac{1}{k_{m}}=\frac{\delta_{D B L}}{D_{M}}
$$

PE-side resistance was determined as in Equation S12, where $l_{P E}$ is the halfthickness of the PE in meters and $\mathrm{D}_{\mathrm{PE}}$ is the diffusivity of the target compound in $\mathrm{m}^{2} / \mathrm{s}$.

$$
\frac{1}{k_{p e}}=\frac{l_{P E}}{D_{P E}}
$$

Air-Water Exchange Flux Calculations. The estimated equilibrium concentration in $n g / g$ PE $\left(\mathrm{C}_{\infty}\right)$ was determined from the measured concentration in the $\mathrm{PE}\left(\mathrm{C}_{\mathrm{PE}}\right)$ as in Equation S13, using the estimated value of $f$ for the target compound.

$$
C_{\infty}=\frac{C_{P E}}{f}
$$

The unitless fugacity ratio was then calculated as in Equation S14, where $\mathrm{C}_{\infty, \mathrm{w}}$ and $\mathrm{C}_{\infty, \mathrm{a}}$ are the estimated equilibrium PE concentrations in water and air samplers, respectively.

$$
\frac{f_{w}}{f_{a}}=\frac{C_{\infty, w}}{C_{\infty, a}}
$$

The air-water exchange flux $\left(\mathrm{F}_{\mathrm{a} / \mathrm{w}}\right)$ in $\mathrm{pg} / \mathrm{m}^{2} /$ day was calculated as in Equation $\mathrm{S} 15$, where $v_{\mathrm{a} / \mathrm{w}}$ is the mass transfer coefficient in $\mathrm{m} / \mathrm{s}, \mathrm{C}_{\infty, \mathrm{w}}$ and $\mathrm{C}_{\infty, \mathrm{a}}$ are the estimated $\mathrm{PE}$ concentrations at equilibrium in $\mathrm{pg} / \mathrm{m}^{3}$, and $\mathrm{K}_{\mathrm{PEW}, \mathrm{T} 2}$ is the $\mathrm{PE}$-water partitioning coefficient at the mean deployment temperature. $v_{\mathrm{a} / \mathrm{w}}$ was calculated for all PE pairs that displayed fugacity ratios significantly different from equilibrium after error propagation. Mean $v_{\mathrm{a} / \mathrm{w}}$ ranged from $1 \times 10^{-7} \mathrm{~m} / \mathrm{s}$ for BDE 183 to $8 \times 10^{-7} \mathrm{~m} / \mathrm{s}$ for BDE 2 .

$$
F_{a / w}=v_{a / w} \cdot \frac{\left(C_{\infty, w}-C_{\infty, a}\right)}{K_{P E W, T 2}}
$$


$v_{a / w}$ was modeled using a two-film model, much like was done for PE-matrix diffusive exchange. $v_{a / w}$ was calculated in $\mathrm{cm} / \mathrm{s}$ as in Equation $\mathrm{S} 16$, where $\mathrm{K}_{\mathrm{aw}}$ is the unitless air-water partitioning coefficient at the mean deployment temperature, $v_{a}$ is the air-side mass transfer velocity in $\mathrm{cm} / \mathrm{s}$, and $v_{w}$ is the water-side mass transfer velocity in $\mathrm{cm} / \mathrm{s}$.

$$
\frac{1}{v_{a / w}}=\frac{1}{v_{w}}+\frac{1}{v_{a} \cdot K_{a w, T 2}}
$$

$v_{\mathrm{a}}$ was determined from $v_{\mathrm{H} 2 \mathrm{O}, \mathrm{a}}(\mathrm{cm} / \mathrm{s})$, the air-side mass transfer velocity of water in air, scaled for the diffusivity of the target compound in air, $\mathrm{D}_{\mathrm{ia}}\left(\mathrm{cm}^{2} / \mathrm{s}\right)$ versus the diffusivity of water in air $\left(0.27 \mathrm{~cm}^{2} / \mathrm{s}\right)$.

$$
v_{a}=v_{H_{2} O, a} \cdot\left(\frac{D_{a}}{D_{H_{2} O, a}}\right)^{0.67}
$$

$v_{\mathrm{H} 2 \mathrm{O}, \mathrm{a}}$ was determined from the wind speed at 10 meter height, $u_{10}$, as in Equation S18 from Schwarzenbach et al. 2003. ${ }^{2} u_{10}$ was determined from mean wind speed, $u$, and height of the wind monitor on the meteorological buoy, $h$, as in Equation S19. In cases where the height of the monitor was not reported, the height was assumed to be 10 meters.

$$
\begin{aligned}
& v_{H_{2} O, a}=0.2 \cdot u_{10}+0.3 \\
& u_{10}=\frac{10.4}{(\ln (h)+8.1)} \cdot u
\end{aligned}
$$

$v_{\mathrm{w}, \mathrm{T} 2}$, the water-sid at the mean deployment temperature, was determined from the mass transfer velocity of $\mathrm{CO}_{2}(\mathrm{~cm} / \mathrm{s})$ in water $\left(v_{\mathrm{CO} 2, \mathrm{w}}\right)$, scaled to the target compound using the Schmidt number at the deployment temperature $\left(\mathrm{Sc}_{\mathrm{T} 2}\right)$, the Schmidt number for $\mathrm{CO}_{2}$ at $20^{\circ} \mathrm{C}\left(\mathrm{Sc}_{\mathrm{CO} 2, \mathrm{w}}=600\right)$ and $\mathrm{a}_{\mathrm{sc}}$, a scaling factor based on 
wind speed ( 0.67 for mean wind speeds $\leq 4.2 \mathrm{~m} / \mathrm{s}$, and 0.5 for higher wind speeds). The dimensionless Schmidt number is the ratio of the viscosity of the water to the diffusivity of the target compound in water.

$$
v_{w, T 2}=v_{C O_{2}, w} \cdot\left(\frac{S c_{T 2}}{S c_{C O_{2}, w}}\right)^{-a_{S c}}
$$

$v_{\mathrm{CO} 2}$, the average velocity of $\mathrm{CO}_{2}(\mathrm{~cm} / \mathrm{s})$ in water over the deployment, was determined by integrating the Weibull probability density function using all recorded wind speeds over the deployment from the nearest meteorological buoy, scaled to 10 $m$ above the interface as in Equation S19.

$\mathrm{Sc}_{\mathrm{T} 2}$, the Schmidt number at the mean deployment temperature, was determined as in Equation S21, by scaling $\mathrm{Sc}_{\mathrm{T} 1}$, the Schmidt number at $298.15 \mathrm{~K}$, by the kinematic viscosity of water $\left(v_{\mathrm{w}}\right)$ at $\mathrm{T} 2$ versus $\mathrm{T} 1$.

$$
S c_{T 2}=S c_{T 1} \cdot\left(\frac{\nu_{T 2, w}}{\nu_{T 1, w}}\right)^{2} \cdot \frac{T_{1}}{T_{2}}
$$

Air-Water Exchange Error Propagation. The variance of the percent equilibration, $\sigma_{\mathrm{f}}^{2}$, was determined as in Equation S22 from the variance of $\delta_{\mathrm{DBL}}$, taken as the standard deviation in the best-fit value from the non-linear least squares model, the variance of $\mathrm{D}_{\mathrm{M}}$, assumed to be $50 \%$, and the variance of $\mathrm{K}_{\mathrm{PEM} \text {, } \mathrm{T} 2}$, determined from Equation S23.

$$
\sigma_{f}^{2}=\sigma_{\delta_{D B L}}^{2} \cdot\left(\frac{\partial f}{\partial \delta_{D B L}}\right)^{2}+\sigma_{D_{M}}^{2} \cdot\left(\frac{\partial f}{\partial D_{M}}\right)^{2}+\sigma_{D_{P E}}^{2} \cdot\left(\frac{\partial f}{\partial D_{P E}}\right)^{2}+\sigma_{K_{P E M, T 2}}^{2} \cdot\left(\frac{\partial f}{\partial K_{P E M, T 2}}\right)^{2}
$$

The variance in $\mathrm{K}_{\mathrm{PEM}, \mathrm{T2}}$ was determine from Equation S23 using the variance of $\mathrm{K}_{\mathrm{PEM}, \mathrm{T} 1}$, assumed to be $0.2 \log$ units, and the variance of $\mathrm{H}_{\mathrm{vap}}$ (assumed to be $30 \%$ ) or, in the case of a water sampler, $\mathrm{U}_{\mathrm{W}}$ (assumed to be $50 \%$ ). 


$$
\sigma_{K_{P E M, T 2}}^{2}=\sigma_{K_{P E M, T 1}}^{2} \cdot\left(\frac{\partial K_{P E M, T 2}}{\partial K_{P E M, T 1}}\right)^{2}+\sigma_{H_{v a p}}^{2} \cdot\left(\frac{\partial K_{P E M, T 2}}{\partial H_{v a p}}\right)^{2}
$$

The variance in estimated equilibrium concentrations, $\sigma_{C_{\infty}}{ }^{2}$, was calculated from the variance in measured concentrations in PEs $\left(\mathrm{C}_{\mathrm{PE}}\right)$, determined by calculating the standard deviation of repeated measurements of randomly-chosen extracts, and the variance in $f$ from Equation S22.

$$
\sigma_{C_{\infty}}^{2}=\sigma_{C_{P E}}^{2} \cdot\left(\frac{\partial C_{\infty}}{\partial C_{P E}}\right)^{2}+\sigma_{f}^{2} \cdot\left(\frac{\partial C_{\infty}}{\partial f}\right)^{2}
$$

Variance in the fugacity ratio was calculated as in Equation S25 and only fugacity ratios significant within the $\pm 1 \sigma$ range were used to calculate air-water fluxes. $\sigma_{f_{a / w}}^{2}=\sigma_{C_{\infty, a}}^{2} \cdot\left(\frac{\partial f_{a / w}}{\partial C_{\infty, a}}\right)^{2}+\sigma_{C_{\infty, w}}^{2} \cdot\left(\frac{\partial f_{a / w}}{\partial C_{\infty, w}}\right)^{2}+\sigma_{K_{P E W, T 2}}^{2} \cdot\left(\frac{\partial f_{a / w}}{\partial K_{P E W, T 2}}\right)^{2}$

Variance in the air-water flux, $\mathrm{F}_{\mathrm{a} / \mathrm{w}}$, was calculated as in Equation S26. The standard deviation of $v_{\mathrm{a} / \mathrm{w}}$ was assumed to be $30 \%{ }^{3}$

$$
\sigma_{F_{a / w}}^{2}=\sigma_{v_{\alpha / w}}^{2} \cdot\left(\frac{\partial F_{a / w}}{\partial v_{a / w}}\right)^{2}+\sigma_{K_{P E W, T 2}}^{2} \cdot\left(\frac{\partial F_{a / w}}{\partial K_{P E W, T 2}}\right)^{2}+\sigma_{C_{\infty, w}}^{2} \cdot\left(\frac{\partial F_{a / w}}{\partial C_{\infty, w}}\right)^{2}+\sigma_{C_{\infty, a}}^{2} \cdot\left(\frac{\partial F_{a / w}}{\partial C_{\infty, a}}\right)^{2}
$$


Table S4-1. Deployment Summary for 2011-2012 Air and Water PEs.

\begin{tabular}{|c|c|c|c|c|c|c|c|c|c|}
\hline \multicolumn{2}{|c|}{ Meteorology } & \multicolumn{4}{|c|}{ Air } & \multicolumn{4}{|c|}{ Water } \\
\hline $\begin{array}{c}\text { Mean Air } \\
\mathrm{T}\left({ }^{\circ} \mathrm{C}\right)\end{array}$ & $\begin{array}{c}\text { Mean Wind } \\
\text { Speed } \\
(\mathrm{m} / \mathrm{s})\end{array}$ & $\begin{array}{c}\text { Sample } \\
\text { No. }\end{array}$ & $\begin{array}{c}\text { Date } \\
\text { Deployed }\end{array}$ & $\begin{array}{c}\text { Date } \\
\text { Recovered }\end{array}$ & $\begin{array}{c}\text { Days } \\
\text { Deployed }\end{array}$ & $\begin{array}{c}\text { Sample } \\
\text { No. }\end{array}$ & $\begin{array}{c}\text { Date } \\
\text { Deployed }\end{array}$ & $\begin{array}{c}\text { Date } \\
\text { Recovered }\end{array}$ & $\begin{array}{c}\text { Days } \\
\text { Deployed }\end{array}$ \\
\hline \multicolumn{10}{|c|}{ LAKE ONTARIO } \\
\hline \multicolumn{10}{|c|}{ NIA: Niagara Falls, NY - Fort Niagara State Park: $43.26125^{\circ} \mathrm{N}, 79.06287^{\circ} \mathrm{W}$} \\
\hline 5.5 & 4.5 & 1526 & $10 / 2 / 11$ & $4 / 24 / 12$ & 205 & & & & \\
\hline 17.0 & 3.5 & 2718 & $4 / 24 / 12$ & $7 / 2 / 12$ & 69 & & & & \\
\hline 23.4 & 3.0 & 3128 & $7 / 2 / 12$ & $8 / 30 / 12$ & 59 & 3130 & $7 / 2 / 12$ & $8 / 30 / 12$ & 59 \\
\hline 15.4 & 4.1 & 3528 & $8 / 30 / 12$ & $10 / 31 / 12$ & 62 & 3530 & $8 / 30 / 12$ & $10 / 31 / 12$ & 62 \\
\hline 15.4 & 4.1 & 3529 & $8 / 30 / 12$ & $10 / 31 / 12$ & 62 & 3531 & $8 / 30 / 12$ & $10 / 31 / 12$ & 62 \\
\hline \multicolumn{10}{|c|}{ ROC1: Rochester, NY - Coast Guard Auxiliary Base 4-2: $43.25238^{\circ} \mathrm{N}, 77.60938^{\circ} \mathrm{W}$} \\
\hline 5.5 & 5.1 & 1412 & $10 / 5 / 11$ & $4 / 30 / 12$ & 208 & & & & \\
\hline 20.3 & 4.5 & 2825 & $5 / 26 / 12$ & $6 / 30 / 12$ & 35 & 2824 & $5 / 26 / 12$ & $6 / 30 / 12$ & 35 \\
\hline 20.3 & 4.5 & & & & & 2828 & $5 / 26 / 12$ & $6 / 30 / 12$ & 35 \\
\hline 21.4 & 4.1 & 3113 & $6 / 30 / 12$ & $9 / 30 / 12$ & 92 & 3115 & $6 / 30 / 12$ & $9 / 30 / 12$ & 92 \\
\hline \multicolumn{10}{|c|}{ ROC2: Rochester, NY - US Coast Guard Station: $43.25694^{\circ} \mathrm{N}, 77.60261^{\circ} \mathrm{W}$} \\
\hline 20.4 & 4.5 & 2830 & $5 / 26 / 12$ & $7 / 1 / 12$ & 36 & & & & \\
\hline 19.7 & 4.2 & 3118 & $7 / 1 / 12$ & $10 / 22 / 12$ & 113 & & & & \\
\hline 19.7 & 4.2 & 3119 & $7 / 1 / 12$ & $10 / 22 / 12$ & 113 & & & & \\
\hline \multicolumn{10}{|c|}{ ROC 3: Rochester, NY - Beach Avenue: $43.26438^{\circ} \mathrm{N}, 77.61692^{\circ} \mathrm{W}$} \\
\hline 20.3 & 4.5 & 2835 & $5 / 26 / 12$ & $6 / 30 / 12$ & 35 & & & & \\
\hline 19.7 & 4.2 & 3123 & $7 / 1 / 12$ & $10 / 22 / 12$ & 113 & & & & \\
\hline 19.7 & 4.2 & 3124 & $7 / 1 / 12$ & $10 / 22 / 12$ & 113 & & & & \\
\hline \multicolumn{10}{|c|}{ OSW: Oswego, NY: A: $43.46319^{\circ} \mathrm{N}, 76.51671^{\circ} \mathrm{W} ; \mathrm{W}: 43.46550^{\circ} \mathrm{N}, 76.51666^{\circ} \mathrm{W}$} \\
\hline 5.2 & 5.5 & 1521 & $10 / 3 / 11$ & $5 / 11 / 12$ & 221 & & & & \\
\hline 19.4 & 4.1 & 2707 & $5 / 11 / 12$ & $7 / 10 / 12$ & 60 & 2711 & $5 / 11 / 12$ & $7 / 10 / 12$ & 60 \\
\hline 22.6 & 3.8 & 3108 & $7 / 10 / 12$ & $9 / 4 / 12$ & 56 & 3110 & $7 / 10 / 12$ & $9 / 4 / 12$ & 56 \\
\hline 22.6 & 3.8 & 3109 & $7 / 10 / 12$ & $9 / 4 / 12$ & 56 & 3111 & $7 / 10 / 12$ & $9 / 4 / 12$ & 56 \\
\hline 12.8 & 5.4 & 3507 & $9 / 4 / 12$ & $11 / 15 / 12$ & 72 & 3511 & $9 / 4 / 12$ & $11 / 15 / 12$ & 72 \\
\hline \multicolumn{10}{|c|}{ CV: Cape Vincent, NY: $44.13034^{\circ} \mathrm{N}, 76.33173^{\circ} \mathrm{W}$} \\
\hline 2.5 & 4.9 & 1519 & $11 / 2 / 11$ & $5 / 1 / 12$ & 181 & & & & \\
\hline 18.6 & 3.9 & 2702 & $5 / 1 / 12$ & $7 / 19 / 12$ & 79 & 2704 & $5 / 1 / 12$ & $7 / 19 / 12$ & 79 \\
\hline 18.6 & 3.9 & 2703 & $5 / 1 / 12$ & $7 / 19 / 12$ & 79 & & & & \\
\hline 22.4 & 4.3 & 3102 & $7 / 17 / 12$ & $8 / 29 / 12$ & 43 & 3104 & $7 / 17 / 12$ & $8 / 29 / 12$ & 43 \\
\hline 14.9 & 5.0 & 3502 & $8 / 29 / 12$ & $10 / 30 / 12$ & 62 & 3504 & $8 / 29 / 12$ & $10 / 30 / 12$ & 62 \\
\hline 14.9 & 5.0 & 3503 & $8 / 29 / 12$ & $10 / 30 / 12$ & 62 & 3505 & $8 / 29 / 12$ & $10 / 30 / 12$ & 62 \\
\hline \multicolumn{10}{|c|}{ Offshore Lake Ontario (Deployed by Ontario Ministry of the Environment) } \\
\hline \multicolumn{10}{|c|}{ TOR: Toronto, ON (Stn AW-2): A: $43.66496^{\circ} \mathrm{N}, 79.26481^{\circ} \mathrm{W} ; \mathrm{W}: 43.66387^{\circ} \mathrm{N}, 79.26488^{\circ} \mathrm{W}$} \\
\hline 21.3 & 3.9 & 2908 & $5 / 22 / 12$ & $8 / 1 / 12$ & 71 & 2901 & $5 / 22 / 12$ & $8 / 1 / 12$ & 71 \\
\hline 21.3 & 3.9 & & & & & 2909 & $5 / 22 / 12$ & $8 / 1 / 12$ & 71 \\
\hline 17.7 & 3.8 & 3303 & $8 / 1 / 12$ & 10/16/12 & 76 & 3317 & $8 / 1 / 12$ & $10 / 19 / 12$ & 79 \\
\hline
\end{tabular}




\begin{tabular}{|c|c|c|c|c|c|c|c|c|c|}
\hline \multicolumn{2}{|c|}{ Meteorology } & \multicolumn{4}{|c|}{ Air } & \multicolumn{4}{|c|}{ Water } \\
\hline \multicolumn{10}{|c|}{ WTOR: West Toronto, ON (Stn 3508): A: $43.57255^{\circ} \mathrm{N}, 79.51809^{\circ} \mathrm{W}$; W: $43.571847^{\circ} \mathrm{N}, 79.51732^{\circ} \mathrm{W}$} \\
\hline 21.3 & 3.9 & 2903 & $5 / 22 / 12$ & $7 / 31 / 12$ & 70 & 2928 & $5 / 22 / 12$ & $7 / 31 / 12$ & 70 \\
\hline 21.3 & 3.9 & 2927 & $5 / 22 / 12$ & $7 / 31 / 12$ & 70 & & & & \\
\hline 17.8 & 3.7 & 3313 & $7 / 31 / 12$ & $10 / 16 / 12$ & 77 & 3329 & $7 / 31 / 12$ & $10 / 16 / 12$ & 77 \\
\hline \multicolumn{10}{|c|}{ ETOR: East Toronto, ON (Stn 708): A: $43.79478^{\circ} \mathrm{N}, 79.08620^{\circ} \mathrm{W}$; W: $43.79373^{\circ} \mathrm{N}, 79.08655^{\circ} \mathrm{W}$} \\
\hline 21.3 & 3.9 & 2906 & $5 / 22 / 12$ & $8 / 1 / 12$ & 71 & 2917 & $5 / 22 / 12$ & $8 / 1 / 12$ & 71 \\
\hline 21.3 & 3.9 & & & & & 2920 & $5 / 22 / 12$ & $8 / 1 / 12$ & 71 \\
\hline 17.1 & 3.8 & 3304 & $8 / 1 / 12$ & $10 / 22 / 12$ & 82 & 3308 & $8 / 1 / 12$ & $10 / 22 / 12$ & 82 \\
\hline 17.1 & 3.8 & 3311 & $8 / 1 / 12$ & $10 / 22 / 12$ & 82 & & & & \\
\hline \multicolumn{10}{|c|}{ CHB: Chub Point, ON (Stn 3509): A: $43.95329^{\circ} \mathrm{N}, 78.01405^{\circ} \mathrm{W}$; W: $43.95339^{\circ} \mathrm{N}, 78.01089^{\circ} \mathrm{W}$} \\
\hline 19.7 & 2.4 & 2914 & $5 / 23 / 12$ & $8 / 1 / 12$ & 70 & 2910 & $5 / 23 / 12$ & $8 / 1 / 12$ & 70 \\
\hline 16.4 & 2.8 & 3324 & $8 / 1 / 12$ & $10 / 22 / 12$ & 82 & 3322 & $8 / 1 / 12$ & $10 / 22 / 12$ & 82 \\
\hline 16.4 & 2.8 & & & & & 3328 & $8 / 1 / 12$ & $10 / 22 / 12$ & 82 \\
\hline \multicolumn{10}{|c|}{ 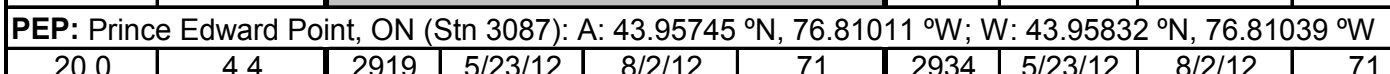 } \\
\hline 20.0 & 4.4 & 2919 & $5 / 23 / 12$ & $8 / 2 / 12$ & 71 & 2934 & $5 / 23 / 12$ & $8 / 2 / 12$ & 71 \\
\hline 20.0 & 4.4 & 2931 & $5 / 23 / 12$ & $8 / 2 / 12$ & 71 & & & & \\
\hline 17.6 & 6.0 & 3302 & $8 / 2 / 12$ & $10 / 25 / 12$ & 84 & 3309 & $8 / 2 / 12$ & $10 / 25 / 12$ & 84 \\
\hline \multicolumn{10}{|c|}{ Offshore Lake Ontario (Deployed by Environment Canada) } \\
\hline \multicolumn{10}{|c|}{ WONT: Western Offshore Ontario (Stn 207) offshore from Niagara: $43.32833^{\circ} \mathrm{N}, 79.13472^{\circ} \mathrm{W}$} \\
\hline 18.1 & 3.5 & & & & & 2306 & $4 / 10 / 12$ & $10 / 25 / 12$ & 198 \\
\hline \multicolumn{10}{|c|}{ GRI: Western Offshore Ontario (Grimsby Met Buoy): $43.25893^{\circ} \mathrm{N}, 79.53865^{\circ} \mathrm{W}$} \\
\hline 18.9 & 4.2 & 2325 & $5 / 14 / 12$ & $10 / 25 / 12$ & 164 & & & & \\
\hline \multicolumn{10}{|c|}{ CONT: Central Offshore Ontario (Stn 403): $43.58806^{\circ} \mathrm{N}, 78.24055^{\circ} \mathrm{W}$} \\
\hline 16.9 & 4.9 & & & & & 2321 & $4 / 3 / 12$ & $10 / 20 / 12$ & 200 \\
\hline \multirow{2}{*}{\multicolumn{10}{|c|}{\begin{tabular}{|c|} 
LAKE ERIE \\
BUF: Ruffalo NY - US Coact Guard Station. $4287758^{\circ} \mathrm{N} 7889047^{\circ} \mathrm{W}$
\end{tabular}}} \\
\hline \multicolumn{5}{|c|}{ BUF: Buffalo, NY - US Coast Guard Station: $42.87758^{\circ} \mathrm{N}, 78.89047^{\circ} \mathrm{W}$} & & & & & \\
\hline 4.6 & 5.3 & 1528 & $10 / 3 / 11$ & $5 / 1 / 12$ & 211 & & & & \\
\hline 4.6 & 5.3 & 1529 & $10 / 3 / 11$ & $5 / 1 / 12$ & 211 & & & & \\
\hline 17.5 & 3.5 & 2723 & $5 / 1 / 12$ & $7 / 2 / 12$ & 62 & 2725 & $5 / 1 / 12$ & $7 / 2 / 12$ & 62 \\
\hline 22.5 & 3.6 & 3133 & $7 / 2 / 12$ & $8 / 30 / 12$ & 59 & 3135 & $7 / 2 / 12$ & $8 / 30 / 12$ & 59 \\
\hline 14.8 & 4.7 & 3533 & $8 / 30 / 12$ & $11 / 1 / 12$ & 63 & & & & \\
\hline 14.8 & 4.7 & 3534 & $8 / 30 / 12$ & $11 / 1 / 12$ & 63 & & & & \\
\hline \multicolumn{10}{|c|}{ 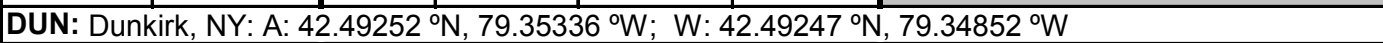 } \\
\hline 5.7 & 6.2 & 1530 & $10 / 3 / 11$ & $4 / 30 / 12$ & 210 & & & & \\
\hline 17.5 & 4.2 & 2728 & $4 / 30 / 12$ & $6 / 28 / 12$ & 59 & 2730 & $4 / 30 / 12$ & $6 / 28 / 12$ & 59 \\
\hline 22.7 & 3.5 & 3202 & $6 / 28 / 12$ & $8 / 29 / 12$ & 62 & 3204 & $6 / 28 / 12$ & $8 / 29 / 12$ & 62 \\
\hline 22.7 & 3.5 & 3203 & $6 / 28 / 12$ & $8 / 29 / 12$ & 62 & 3205 & $6 / 28 / 12$ & $8 / 29 / 12$ & 62 \\
\hline 15.8 & 4.2 & 3901 & $8 / 29 / 12$ & $10 / 22 / 12$ & 54 & 3903 & $8 / 29 / 12$ & $10 / 22 / 12$ & 54 \\
\hline 15.8 & 4.2 & 3902 & $8 / 29 / 12$ & $10 / 22 / 12$ & 54 & & & & \\
\hline
\end{tabular}




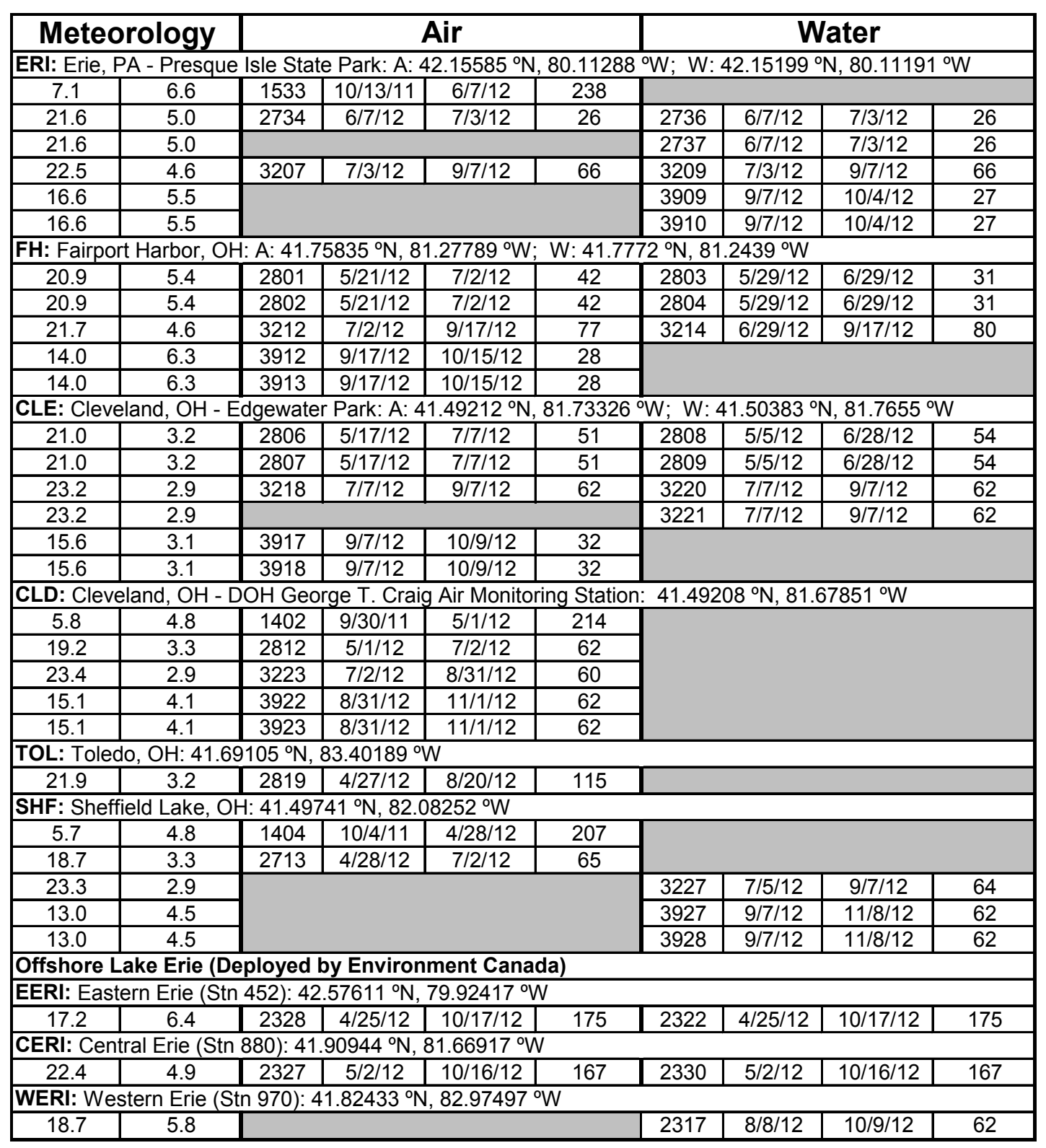


Table S4-2. Buoys Used for Temperature and Wind Data.

\begin{tabular}{|c|c|c|c|c|c|c|}
\hline \multirow[b]{2}{*}{ Site Abbreviation } & \multicolumn{3}{|c|}{ Temperature Data } & \multicolumn{3}{|c|}{ Wind Speed and Direction Data } \\
\hline & Data Source & Buoy Name & Location & Data Source & Buoy Name & Location \\
\hline BUF & NDBC & BUFN6 & $42.878 \mathrm{~N}, 78.890 \mathrm{~W}$ & NDBC & BUFN6 & $42.878 \mathrm{~N}, 78.890 \mathrm{~W}$ \\
\hline CERI & NDBC & C45164 & $41.734 \mathrm{~N}, 81.698 \mathrm{~W}$ & NDBC & C45164 & $41.734 \mathrm{~N}, 81.698 \mathrm{~W}$ \\
\hline $\mathrm{CHB}$ & OME Logger & - & Same as samplers & Environment Canada & COBOURG (AUT) & $43.95 \mathrm{~N}, 78.17 \mathrm{~W}$ \\
\hline CLD & NDBC & CNDO1 & $41.542 \mathrm{~N}, 81.637 \mathrm{~W}$ & NDBC & CNDO1 & $41.542 \mathrm{~N}, 81.637 \mathrm{~W}$ \\
\hline CLE & NDBC & CNDO1 & $41.542 \mathrm{~N}, 81.637 \mathrm{~W}$ & NDBC & CNDO1 & $41.542 \mathrm{~N}, 81.637 \mathrm{~W}$ \\
\hline CONT & NDBC & C45012 & $43.618 \mathrm{~N}, 77.405 \mathrm{~W}$ & NDBC & C45012 & $43.618 \mathrm{~N}, 77.405 \mathrm{~W}$ \\
\hline $\mathrm{CV}$ & Environment Canada & KINGSTON A & $44.22 \mathrm{~N}, 76.6 \mathrm{~W}$ & Environment Canada & KINGSTON A & $44.22 \mathrm{~N}, 76.6 \mathrm{~W}$ \\
\hline DUN & NDBC & DBLN6 & $42.494 \mathrm{~N}, 79.354 \mathrm{~W}$ & NDBC & DBLN6 & $42.494 \mathrm{~N}, 79.354 \mathrm{~W}$ \\
\hline EERI & Environment Canada & LONG POINT (AUT) & $42.57 \mathrm{~N}, 80.05 \mathrm{~W}$ & Environment Canada & LONG POINT(AUT) & $42.57 \mathrm{~N}, 80.05 \mathrm{~W}$ \\
\hline ERI & NDBC & CBLO1 & $41.981 \mathrm{~N}, 80.556 \mathrm{~W}$ & NDBC & CBLO1 & $41.981 \mathrm{~N}, 80.556 \mathrm{~W}$ \\
\hline ETOR & OME Logger & - & Same as samplers & Environment Canada & TORONTO CITY CENTRE & $43.63 \mathrm{~N}, 79.40 \mathrm{~W}$ \\
\hline $\mathrm{FH}$ & NDBC & FAIO1 & $41.764 \mathrm{~N}, 81.281 \mathrm{~W}$ & NDBC & FAIO1 & $41.764 \mathrm{~N}, 81.281 \mathrm{~W}$ \\
\hline GRI & Environment Canada & GRIMSBY & $43.252 \mathrm{~N}, 79.535 \mathrm{~W}$ & Environment Canada & GRIMSBY & $43.252 \mathrm{~N}, 79.535 \mathrm{~W}$ \\
\hline NIA & NDBC & YGNN6 & $43.262 \mathrm{~N}, 76.064 \mathrm{~W}$ & NDBC & YGNN6 & $43.262 \mathrm{~N}, 76.064 \mathrm{~W}$ \\
\hline OsW & NDBC & OSGN6 & $43.464 \mathrm{~N}, 76.511 \mathrm{~W}$ & NDBC & OSGN6 & $43.464 \mathrm{~N}, 76.511 \mathrm{~W}$ \\
\hline PEP & OME Logger & - & Same as samplers & Environment Canada & POINT PETRE (AUT) & $43.83 \mathrm{~N}, 77.15 \mathrm{~W}$ \\
\hline $\mathrm{ROC}(1-3)$ & NDBC & RPRN6 & $43.263 \mathrm{~N}, 77.598 \mathrm{~W}$ & NDBC & RPRN6 & $43.263 \mathrm{~N}, 77.598 \mathrm{~W}$ \\
\hline SHF & NDBC & CNDO1 & $41.542 \mathrm{~N}, 81.637 \mathrm{~W}$ & NDBC & CNDO1 & $41.542 \mathrm{~N}, 81.637 \mathrm{~W}$ \\
\hline Stn 207 & NDBC & YGNN6 & $43.262 \mathrm{~N}, 76.064 \mathrm{~W}$ & $\mathrm{NDBC}$ & YGNN6 & $43.262 \mathrm{~N}, 76.064 \mathrm{~W}$ \\
\hline TOL & NDBC & THRO1 & $41.694 \mathrm{~N}, 83.473 \mathrm{~W}$ & NDBC & THRO1 & $41.694 \mathrm{~N}, 83.473 \mathrm{~W}$ \\
\hline TOR & OME Logger & - & Same as samplers & Environment Canada & TORONTO CITY CENTRE & $43.63 \mathrm{~N}, 79.40 \mathrm{~W}$ \\
\hline WERI & NDBC & THLO1 & $41.826 \mathrm{~N}, 83.194 \mathrm{~W}$ & NDBC & THLO1 & $41.826 \mathrm{~N}, 83.194 \mathrm{~W}$ \\
\hline WTOR & OME Logger & - & Same as samplers & Environment Canada & TORONTO CITY CENTRE & $43.63 \mathrm{~N}, 79.40 \mathrm{~W}$ \\
\hline
\end{tabular}

Most buoy data was accessed from online databases provided by Environment Canada and the National Data Buoy Center (NDBC). In some cases, data from temperature loggers maintained by the Ontario Ministry of the Environment and Climate Change from the deployment buoys were available (OME Logger). 
Table S4-3. Average Matrix Spikes.

\begin{tabular}{lr} 
& $\begin{array}{c}\text { Mean Percent } \\
\text { Recovery (\%) } \mathbf{~ 1 \sigma} \\
(\mathbf{N}=\mathbf{2 1})\end{array}$ \\
\hline BDE 2 & $67 \pm 15$ \\
BDE 8 & $86 \pm 16$ \\
BDE 15 & $95 \pm 15$ \\
BDE 30 & $86 \pm 17$ \\
BDE 28 & $100 \pm 15$ \\
BDE 49 & $77 \pm 8$ \\
BDE 47 & $97 \pm 25$ \\
BDE 100 & $101 \pm 19$ \\
BDE 99 & $98 \pm 13$ \\
BDE 154 & $92 \pm 10$ \\
BDE 153 & $83 \pm 14$ \\
BDE 183 & $91 \pm 38$ \\
& \\
pTBX & $83 \pm 26$ \\
PBB & $94 \pm 14$ \\
PBT & $100 \pm 20$ \\
PBEB & $94 \pm 18$ \\
HBB & $88 \pm 15$ \\
HCDBCO & $72 \pm 25$ \\
BTBPE & $93 \pm 51$ \\
SDP & $89 \pm 30$ \\
ADP & $74 \pm 32$ \\
\hline
\end{tabular}


Table S4-4. Mean Blank Concentration and Detection Limits (ng/g PE).

\begin{tabular}{|c|c|c|c|c|c|c|}
\hline & $\begin{array}{c}\text { Mean Lab Blank } \\
\pm 1 \sigma(N=11)\end{array}$ & $\begin{array}{c}\text { Detection } \\
\text { Limit (95\% Cl } \\
\text { of Lab Blank) }\end{array}$ & $\begin{array}{l}\text { Mean Shoreline } \\
\text { Field Blank } \pm 1 \sigma \\
(\mathrm{N}=9)\end{array}$ & $\begin{array}{c}\text { Mean OME } \\
\text { Blank } \pm 1 \sigma\end{array}$ & $\begin{array}{l}\text { E Field } \\
\qquad(\mathrm{N}=5)\end{array}$ & $\begin{array}{c}\text { Mean Env. Can. } \\
\text { Field Blank } \pm 1 \sigma \\
(\mathrm{N}=7)\end{array}$ \\
\hline BDE 2 & $0.02 \pm 0.02$ & 0.04 & $0.07 \pm 0.07$ & $0.00 \pm$ & 0.00 & $0.02 \pm 0.04$ \\
\hline BDE 8 & $0.01 \pm 0.01$ & 0.02 & $0.02 \pm 0.02$ & $0.00 \pm$ & 0.01 & $0.01 \pm 0.02$ \\
\hline BDE 15 & $0.04 \pm 0.05$ & 0.09 & $0.08 \pm 0.08$ & $0.02 \pm$ & 0.03 & $0.07 \pm 0.09$ \\
\hline BDE 30 & $0.02 \pm 0.02$ & 0.04 & $0.03 \pm 0.04$ & $0.00 \pm$ & 0.00 & $0.00 \pm 0.01$ \\
\hline BDE 28 & $0.02 \pm 0.03$ & 0.06 & $0.04 \pm 0.03$ & $0.00 \pm$ & 0.00 & $0.02 \pm 0.03$ \\
\hline BDE 49 & $0.03 \pm 0.03$ & 0.06 & $0.03 \pm 0.02$ & $0.03 \pm$ & 0.03 & $0.04 \pm 0.03$ \\
\hline BDE 47 & $0.59 \pm 0.23$ & 0.47 & $0.67 \pm 0.33$ & $0.68 \pm$ & 0.12 & $0.30 \pm 0.10$ \\
\hline BDE 100 & $0.04 \pm 0.03$ & 0.07 & $0.05 \pm 0.03$ & $0.02 \pm$ & 0.02 & $0.01 \pm 0.02$ \\
\hline BDE 99 & $0.26 \pm 0.22$ & 0.44 & $0.23 \pm 0.15$ & $0.11 \pm$ & 0.08 & $0.14 \pm 0.14$ \\
\hline BDE 154 & $0.08 \pm 0.06$ & 0.12 & $0.06 \pm 0.03$ & $0.10 \pm$ & 0.01 & $0.03 \pm 0.03$ \\
\hline BDE 153 & $0.02 \pm 0.03$ & 0.06 & $0.02 \pm 0.02$ & $0.01 \pm$ & 0.01 & $0.00 \pm 0.00$ \\
\hline BDE 183 & $0.03 \pm 0.04$ & 0.07 & $0.04 \pm 0.05$ & $0.01 \pm$ & 0.02 & $0.06 \pm 0.07$ \\
\hline pTBX & $0.08 \pm 0.07$ & 0.14 & $0.15 \pm 0.12$ & $0.11 \pm$ & 0.08 & $0.07 \pm 0.03$ \\
\hline PBB & $0.04 \pm 0.05$ & 0.09 & $0.06 \pm 0.06$ & $0.02 \pm$ & 0.01 & $0.03 \pm 0.03$ \\
\hline PBT & $0.08 \pm 0.06$ & 0.11 & $0.10 \pm 0.12$ & $0.07 \pm$ & 0.03 & $0.10 \pm 0.08$ \\
\hline PBEB & $0.06 \pm 0.09$ & 0.18 & $0.11 \pm 0.09$ & $0.02 \pm$ & 0.02 & $0.03 \pm 0.02$ \\
\hline HBB & $0.10 \pm 0.11$ & 0.21 & $0.03 \pm 0.02$ & $0.08 \pm$ & 0.06 & $0.05 \pm 0.04$ \\
\hline $\mathrm{HCDBCO}$ & $0.05 \pm 0.05$ & 0.09 & $0.13 \pm 0.17$ & $0.07 \pm$ & 0.06 & $0.07 \pm 0.06$ \\
\hline BTBPE & $0.58 \pm 0.42$ & 0.83 & $1.12 \pm 1.49$ & $0.39 \pm$ & 0.41 & $0.50 \pm 0.35$ \\
\hline SDP & $0.17 \pm 0.13$ & 0.26 & $0.11 \pm 0.09$ & $0.07 \pm$ & 0.05 & $0.06 \pm 0.04$ \\
\hline ADP & $0.04 \pm 0.02$ & 0.05 & $0.03 \pm 0.02$ & $0.04 \pm$ & 0.01 & $0.05 \pm 0.04$ \\
\hline
\end{tabular}

"Mean OME Field Blank" is the average of all blanks from shipboard PE deployments done by the Ontario Ministry of the Environment and Climate Change. "Mean Env. Can. Field Blank" is the average of all blanks from shipboard PE deployments done by Environment Canada. 


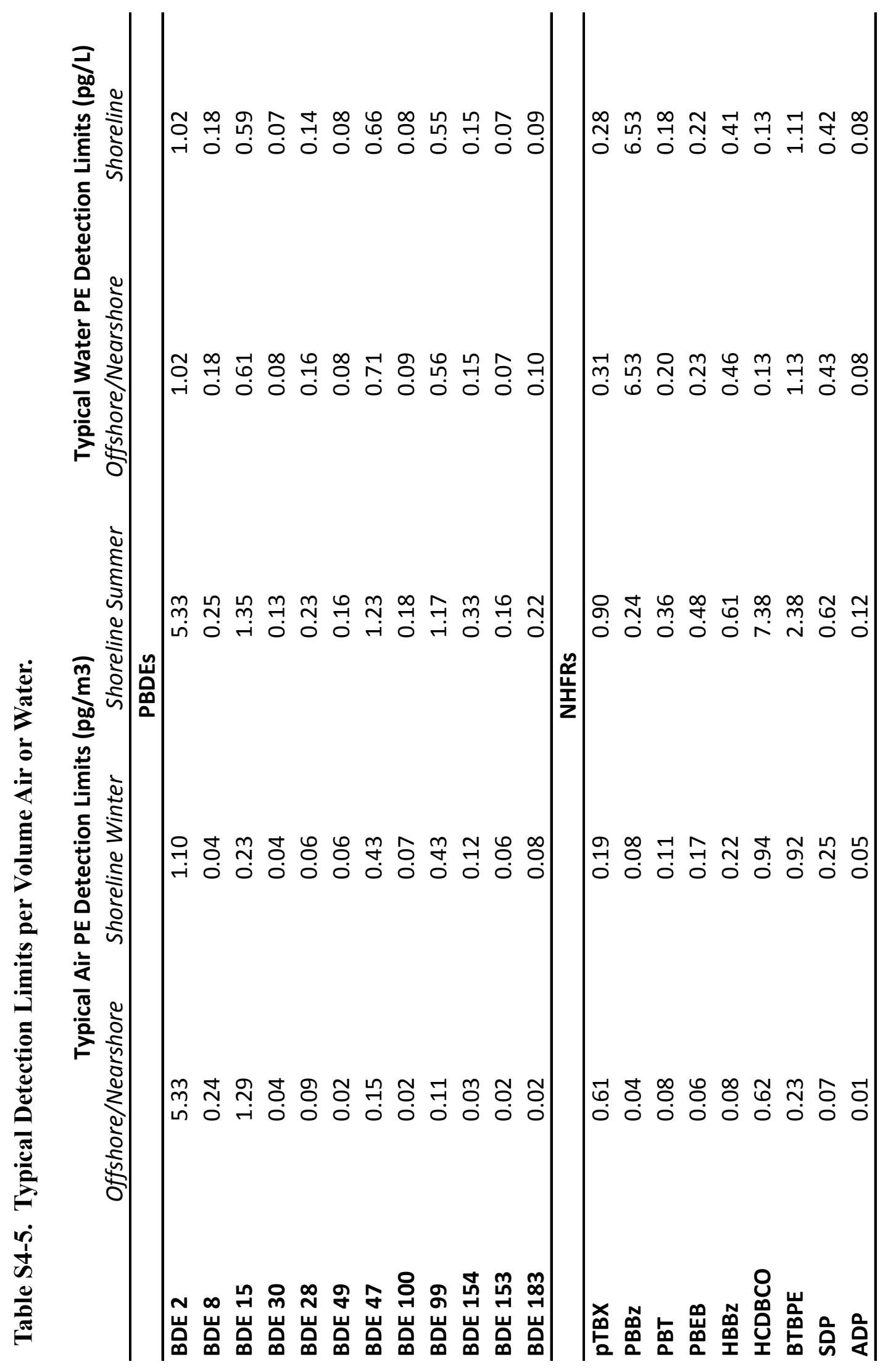




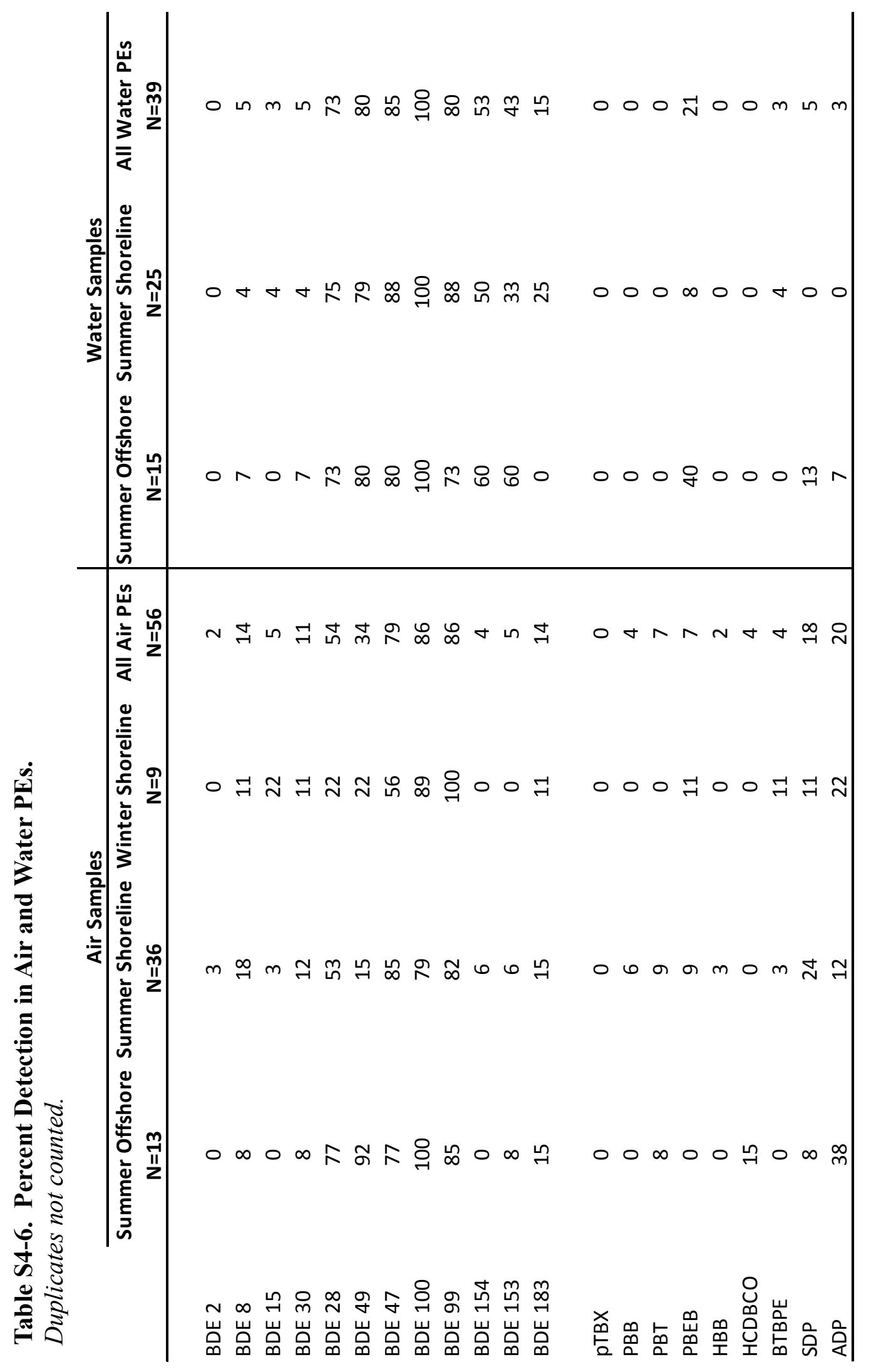



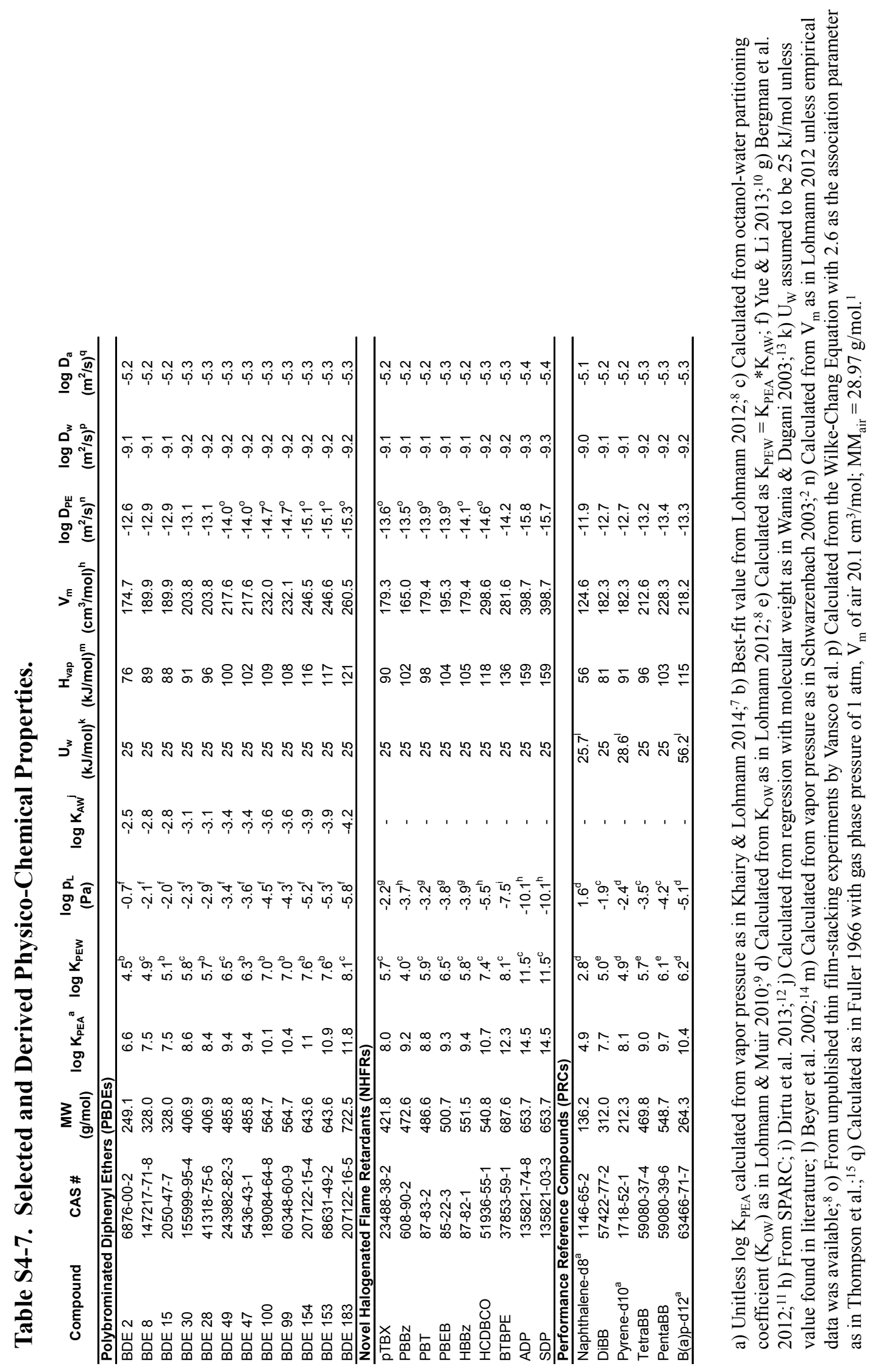


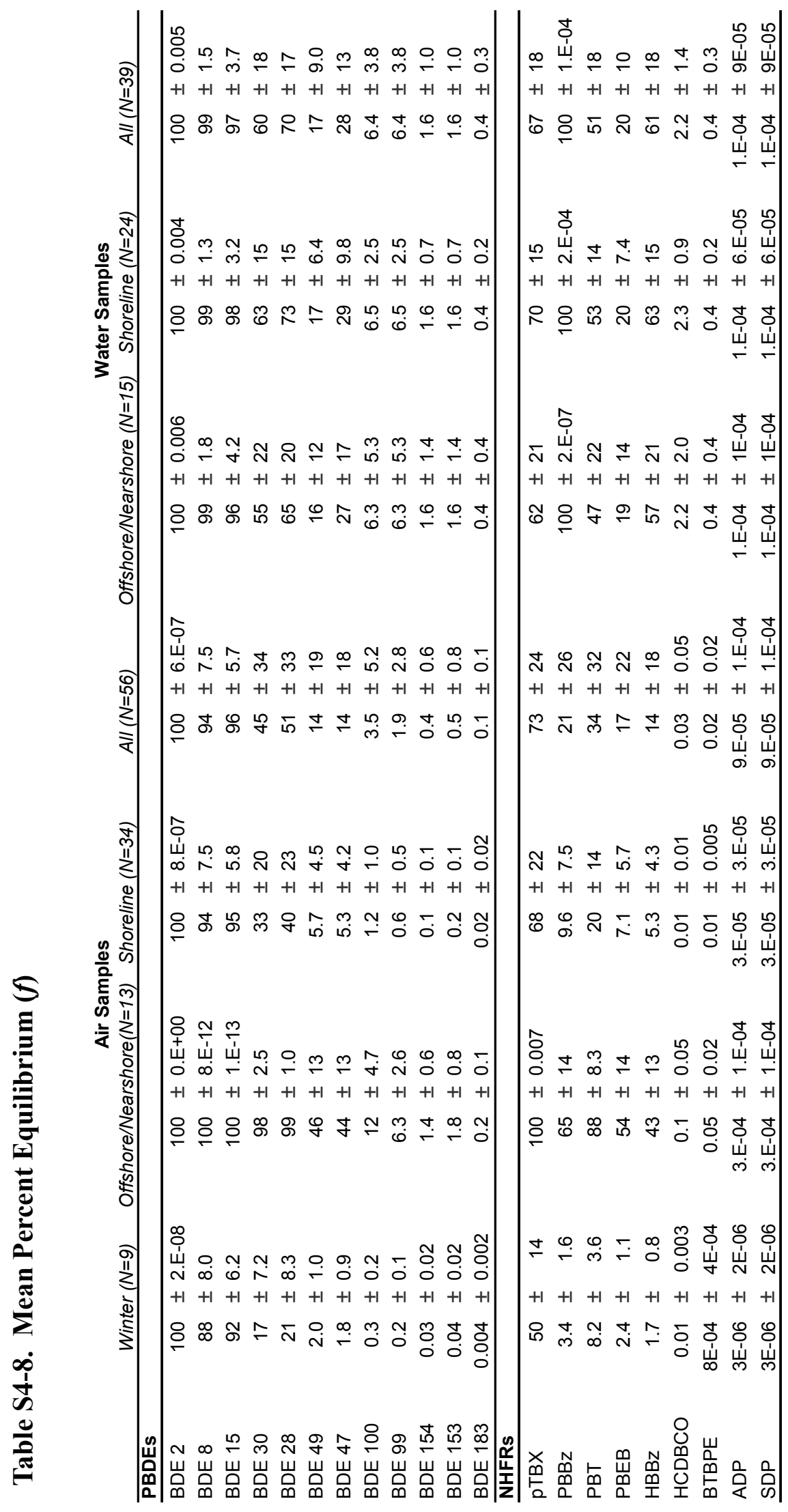




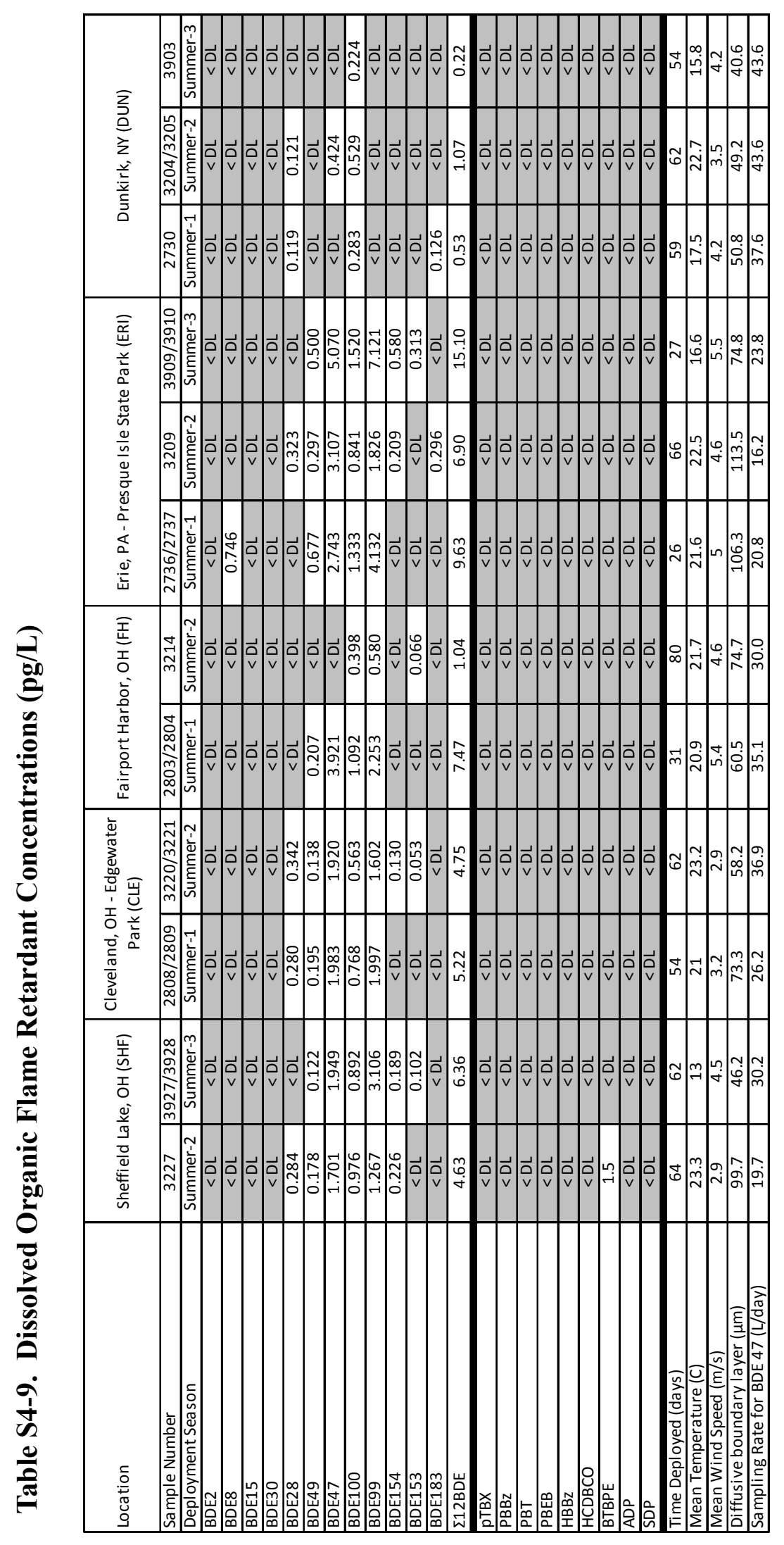




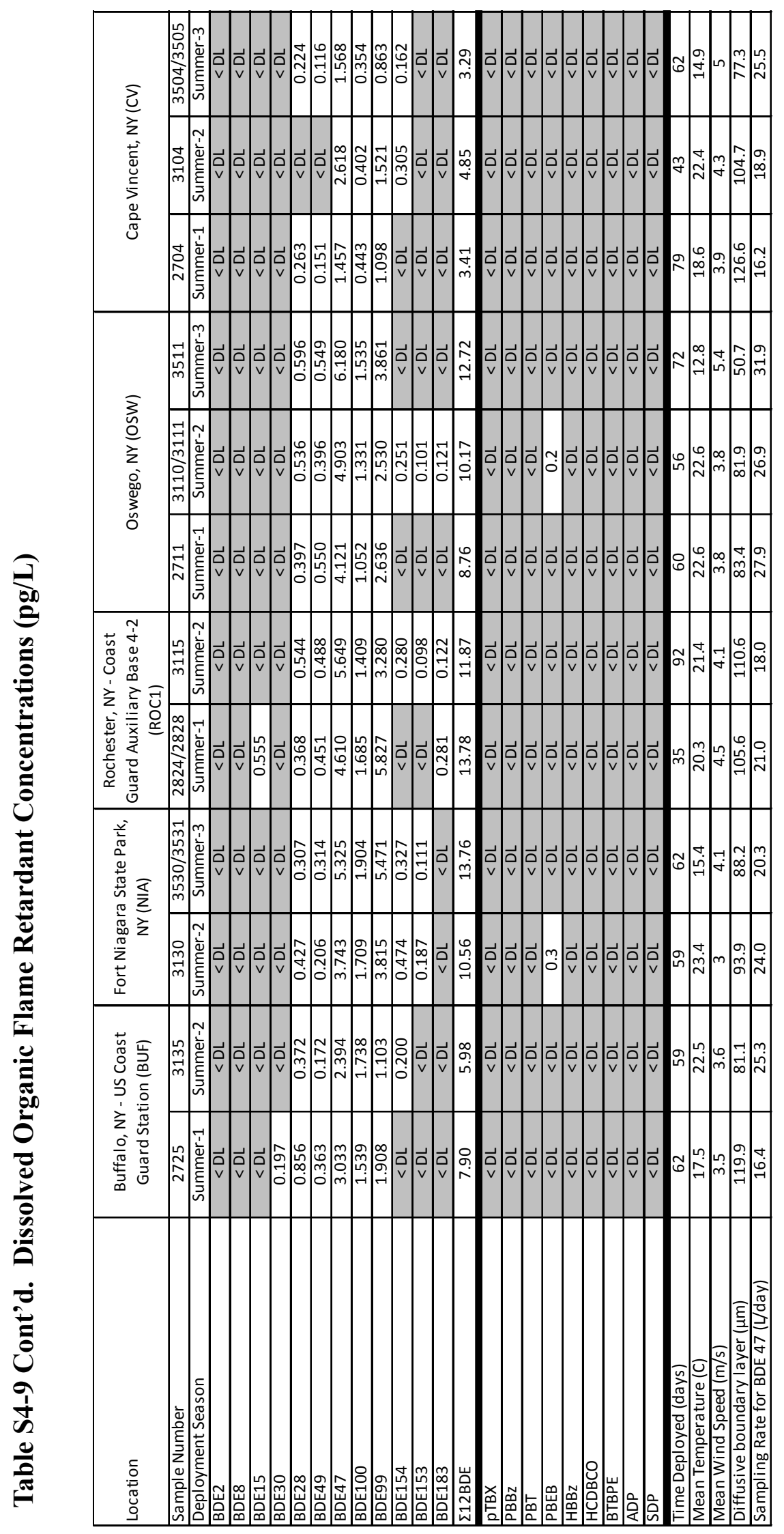




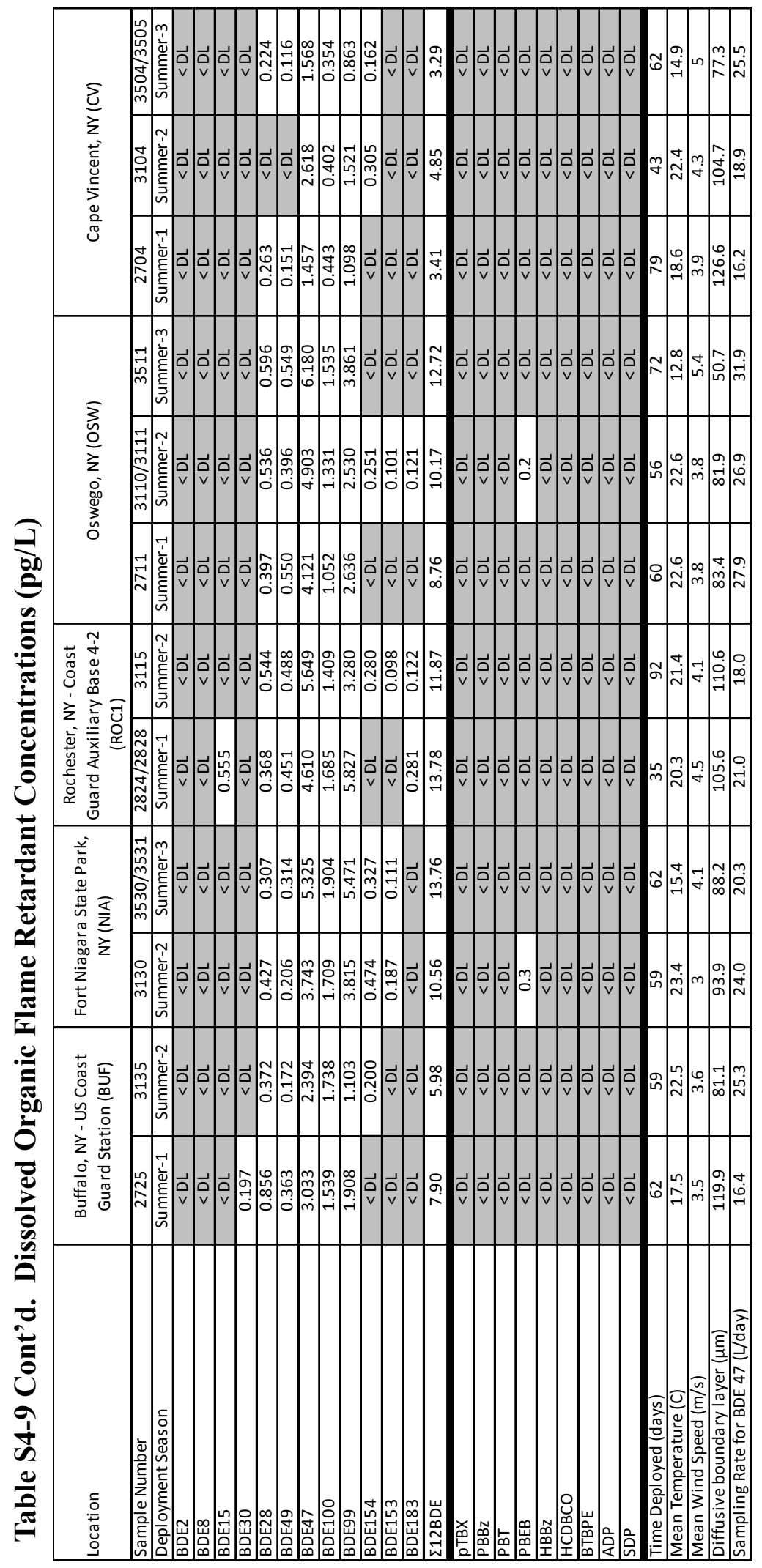




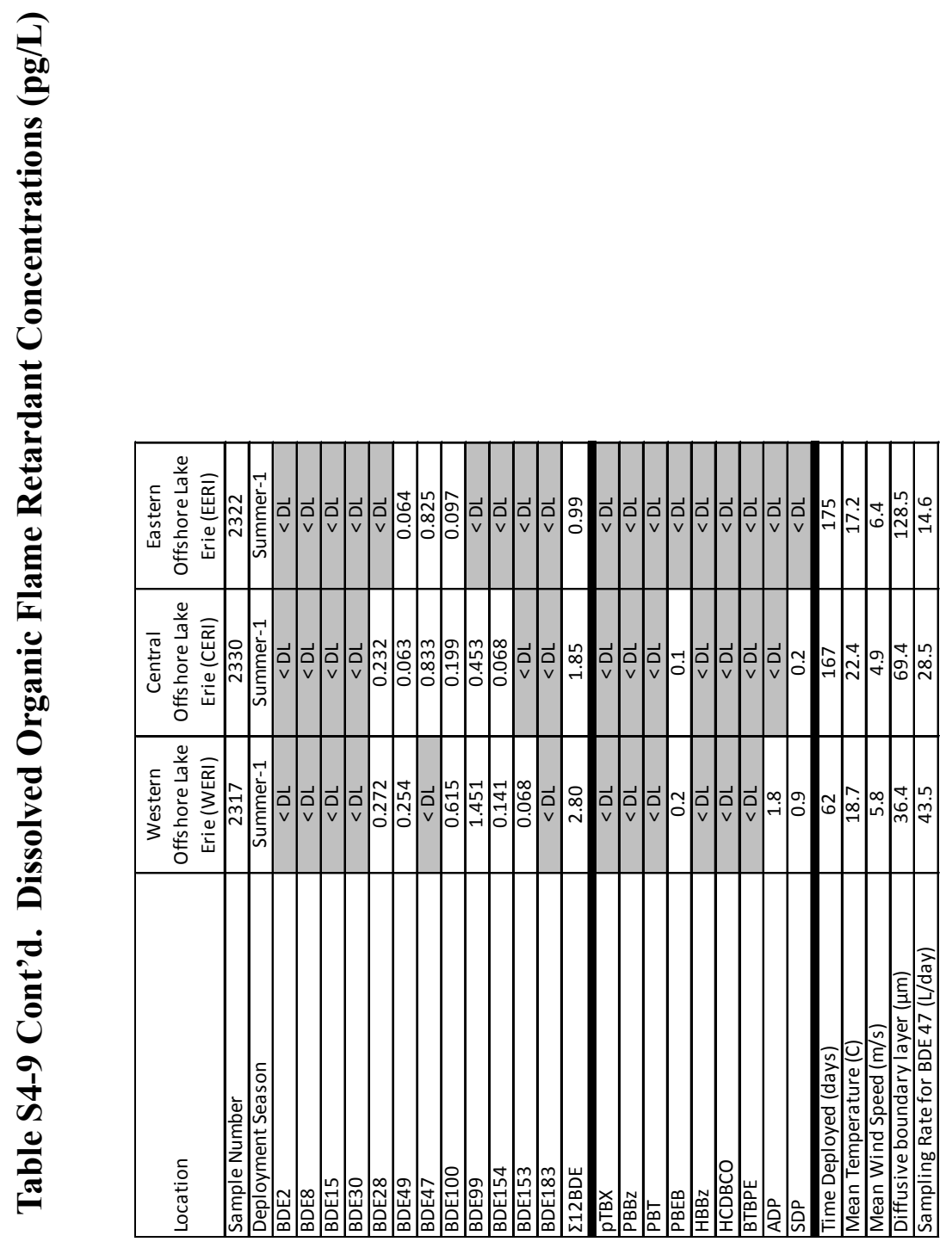




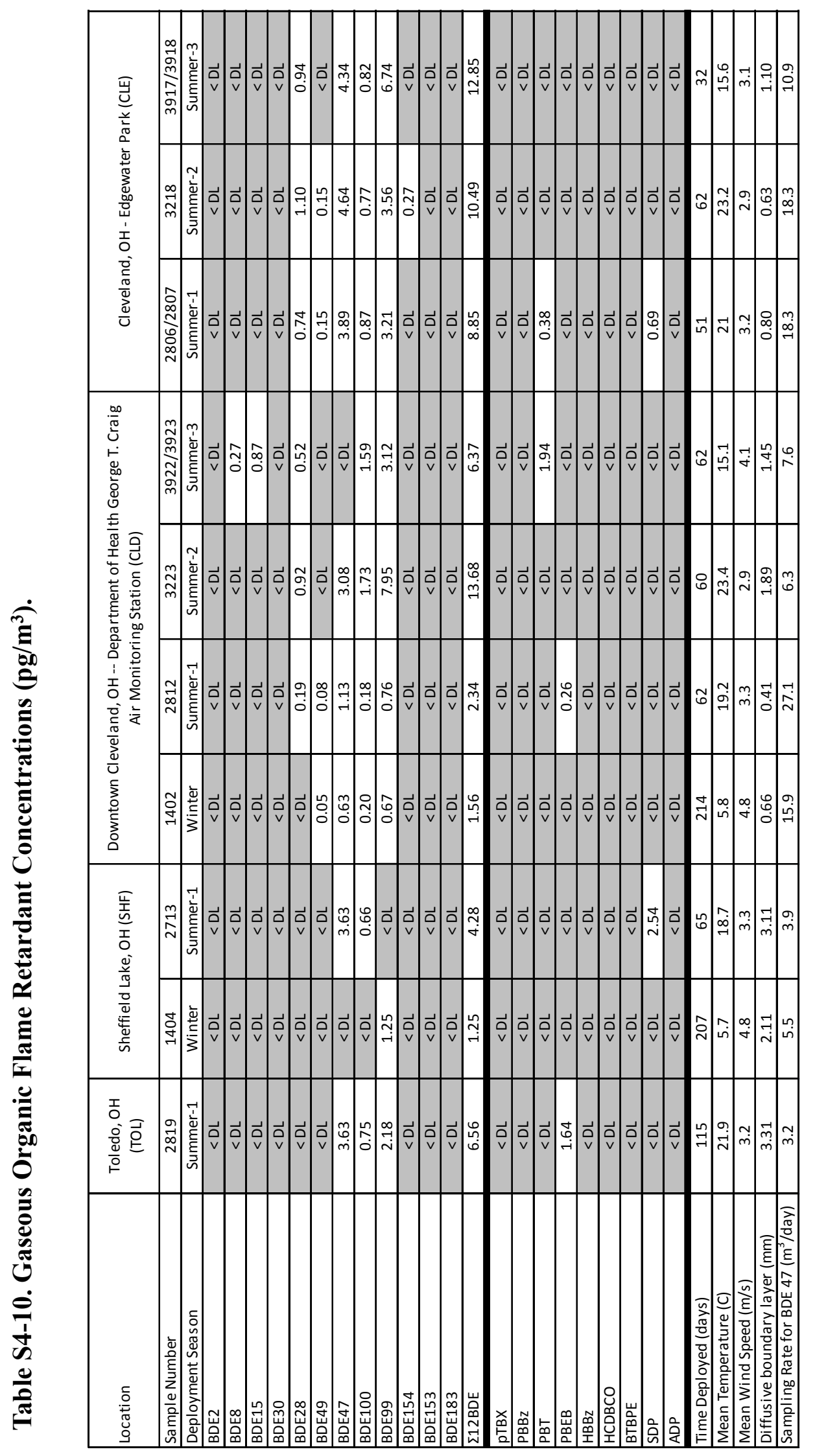




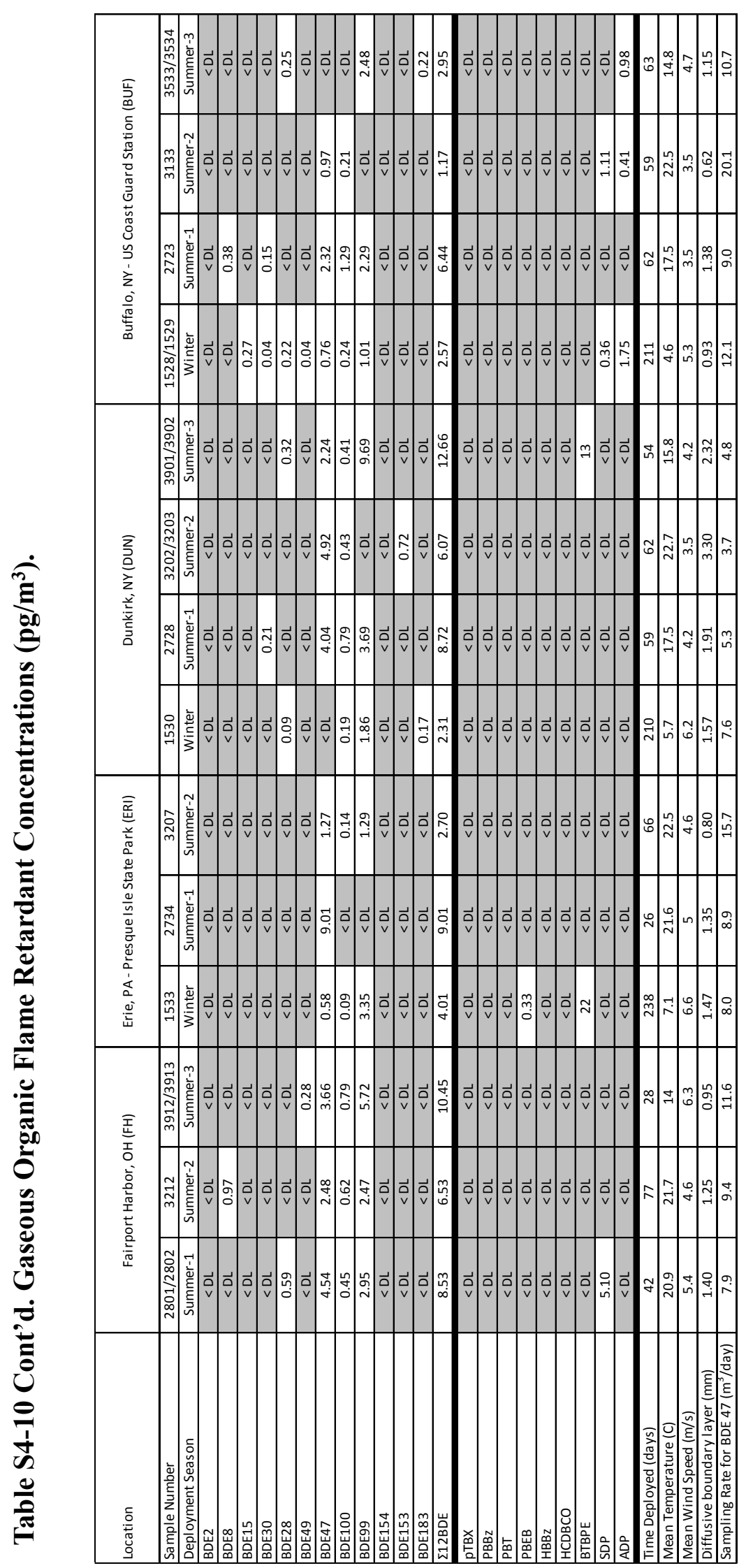




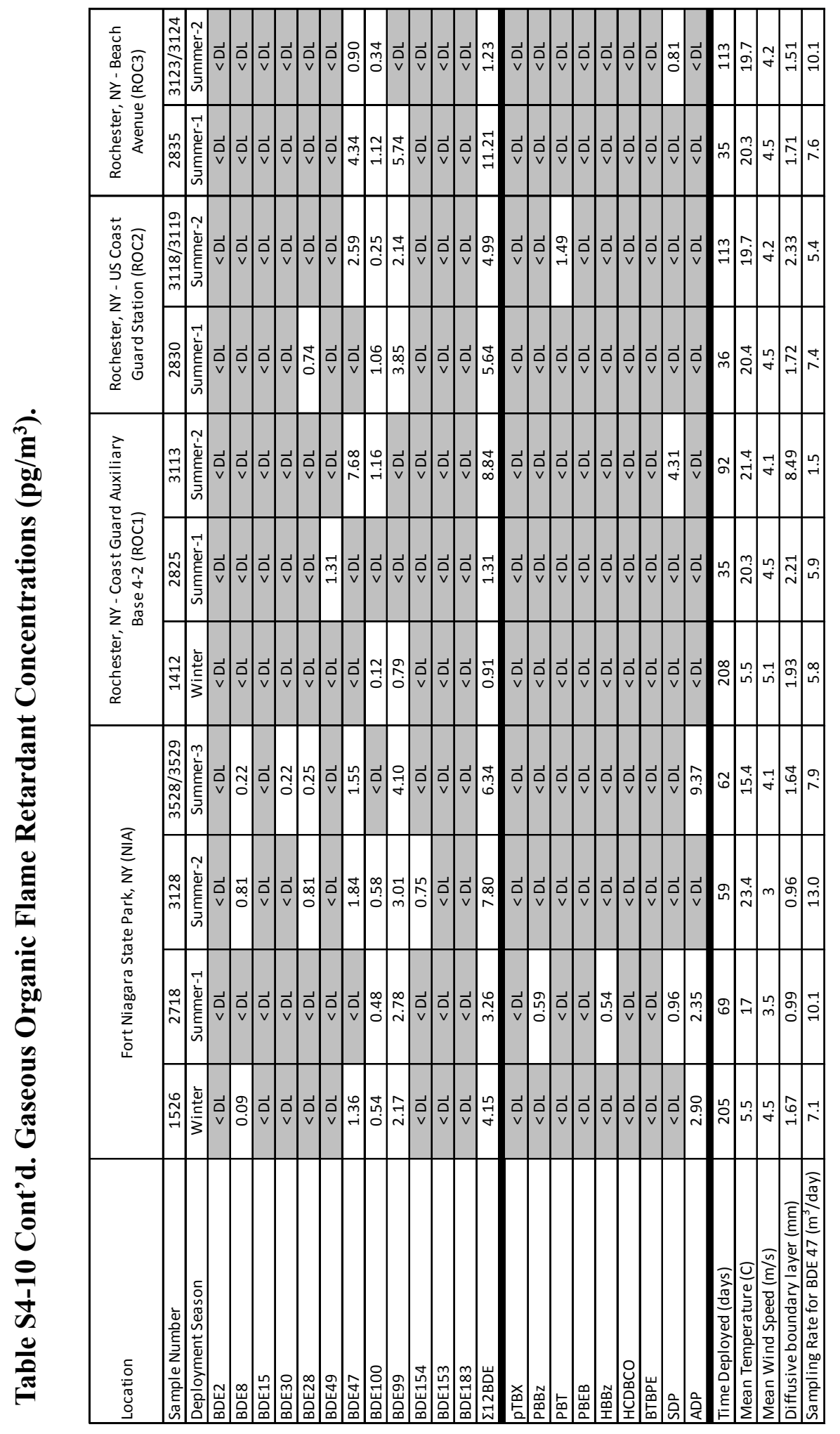




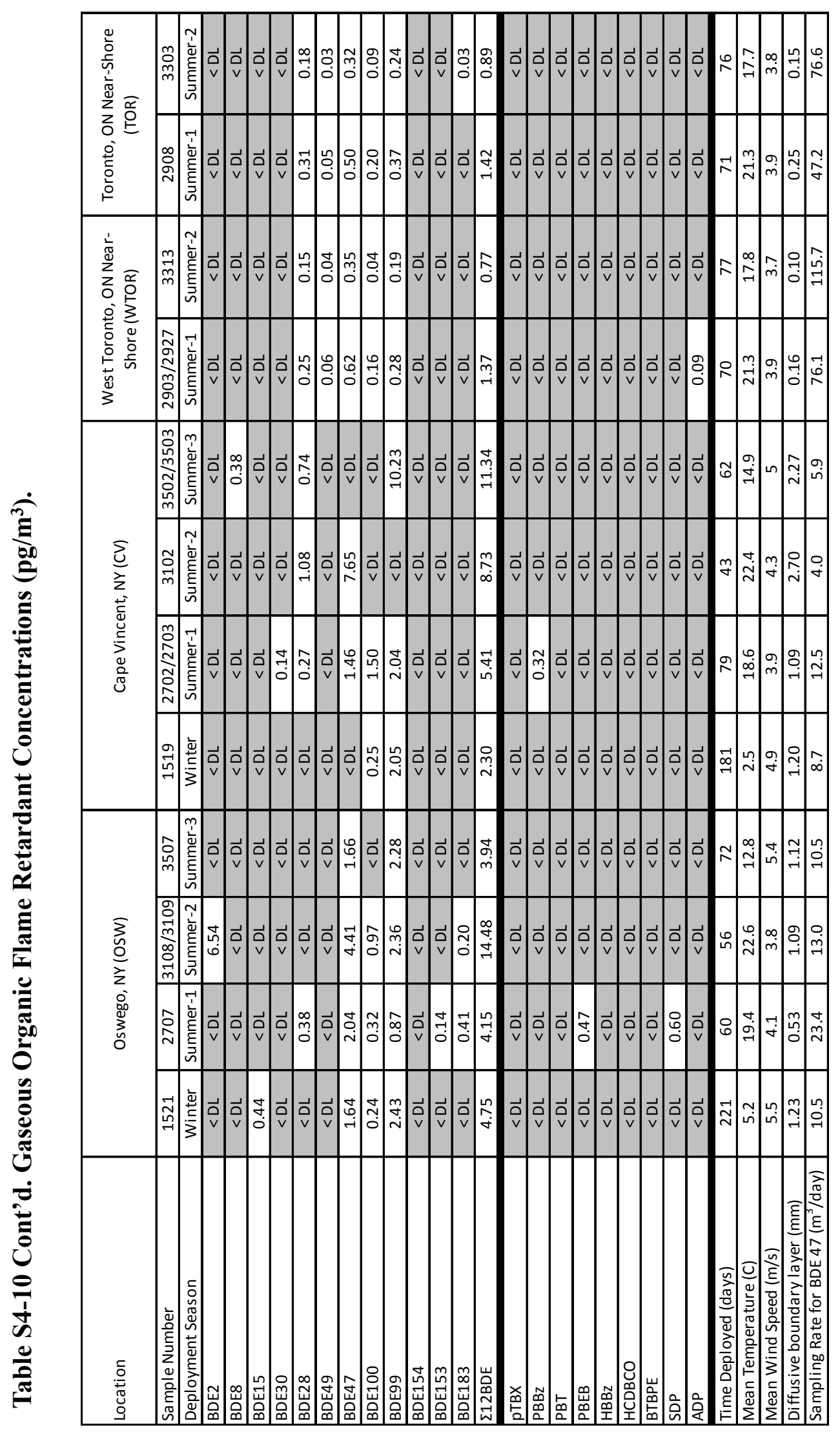




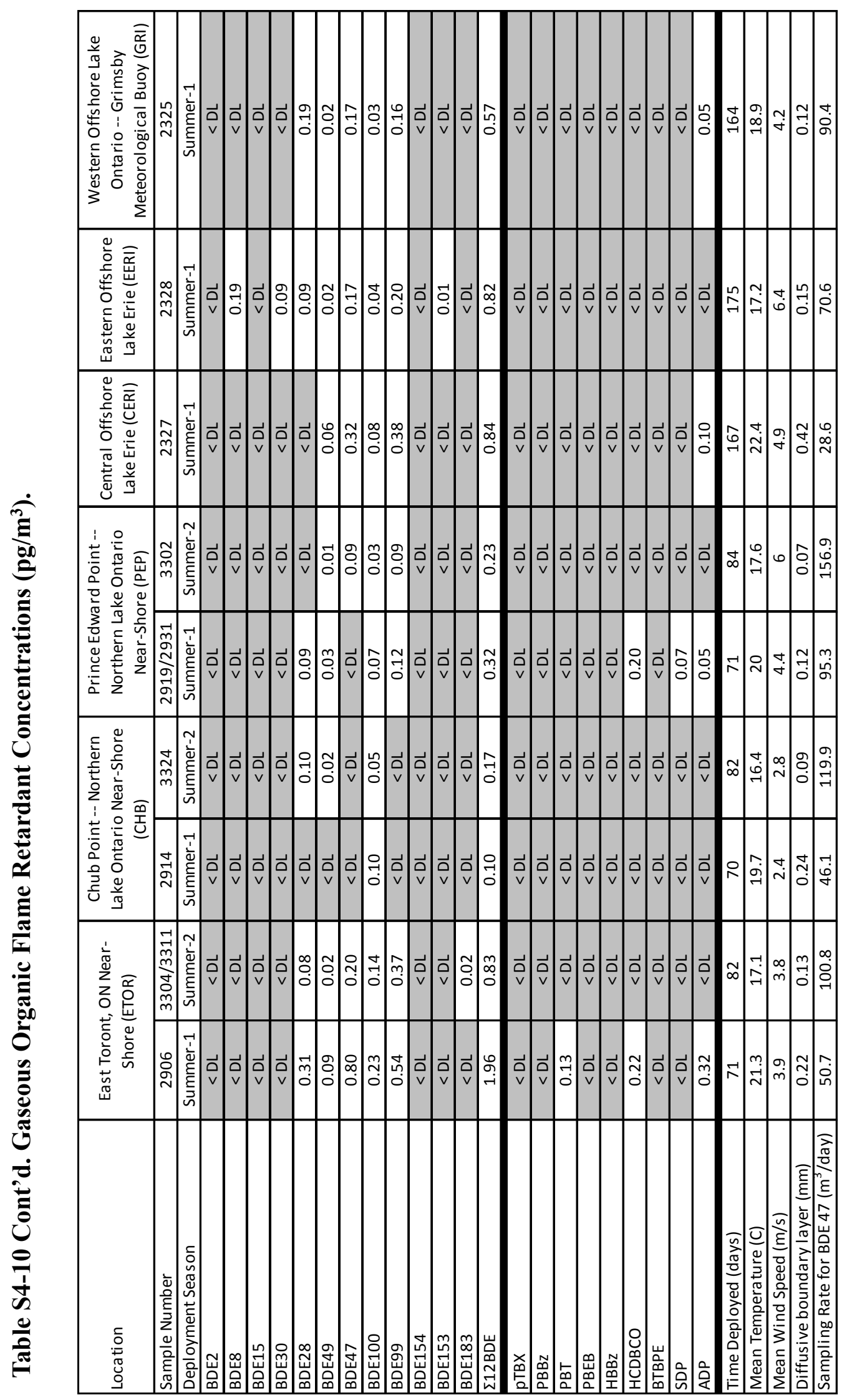


Comparison of Simulated and PE-Derived Air-Water Exchange Fluxes. The method of measuring time-averaged air-water exchange fluxes using co-deployed air and water PEs is based on the fact that passive samplers derive time-weighted averages for compound concentrations in air and water. ${ }^{20-23}$ By using two PEs in adjacent media, we can directly derive a compound's activity gradient. The PE responds slowly to changing environmental concentrations of PBDEs, as indicated by their mass transfer coefficients (for BDE 47, average $\mathrm{k}_{\mathrm{o}}$ of $6.0 \mathrm{E}-6 \mathrm{~m} / \mathrm{s}$ in water and $1.1 \mathrm{E}-2 \mathrm{~m} / \mathrm{s}$ in air), which means that PEs will lag behind environmental changes, as has been noted in previous studies. ${ }^{24}$ Therefore, the air-water exchange flux derived from co-deployed PEs is a time-weighted average of exchange fluxes over the deployment assuming the compound remains in linear uptake during deployment, as is the case for the dominant BDE congeners BDE 47 and BDE 99.

In order to demonstrate that PE-derived air-water exchange fluxes were representative of average air-water exchange fluxes over relevant deployment periods, calculated $\mathrm{v}_{\mathrm{aw}}$ and $\mathrm{k}_{\mathrm{o}}$ values for BDE 47 from each PE air-water pair used in the airwater exchange flux study were fed into a model to calculate the mass accumulated in air and water PEs in response to non-steady-state conditions for two "worst case" scenarios: Scenario 1, in which BDE 47 concentrations in water and air varied randomly every 6 hours $\left(0.1-9 \mathrm{pg} / \mathrm{m}^{3}\right.$ in air and $0.4-8 \mathrm{pg} / \mathrm{L}$ in water $)$, and Scenario 2 , in which BDE 47 concentrations in air increase steadily from 0.1 to $9 \mathrm{pg} / \mathrm{m}^{3}$ while water concentrations decrease steadily from 8 to $0.4 \mathrm{pg} / \mathrm{L}$, causing the direction of the air-water exchange flux to reverse during the deployment. These BDE 47 
concentrations were chosen because they represented the minimum and maximum values observed for concentrations of BDE 47 in all deployments from this study. Each scenario was run 100 times in $\mathrm{R}$ and the relative percent difference (RPD) between the average actual flux over the 100-day deployment and the PE-derived flux was calculated. An example of results is shown below for both scenarios (Figure S4-1 and S2). Results show that concentrations in the PE, and PE-derived air-water exchange fluxes, lag behind the simulated "actual" fluxes that are occurring. However, they do a good job of capturing average air-water exchange fluxes over time. Results for other frequently-detected BDE congeners are similar, as they all tended to remain in the linear or curvilinear uptake phase during deployment.

The average relative percent difference (RPD) between the mean simulated airwater exchange flux over a 100-day deployment (Mean $\mathrm{F}_{\mathrm{aw}}$ ) and the PE-Derived exchange flux for a PE air-water pair collected on the $100^{\text {th }}$ day $\left(\mathrm{F}_{\mathrm{aw}, \mathrm{PE}}\right)$ is shown in the Table S4-11 for each of the two scenarios. We also simulated an active sampling study by calculating the average air-water exchange flux over 100 days by taking one instantaneous air-water exchange flux value once a week at regular intervals, and averaging them all. RPDs for the average air-water exchange derived from these simulated weekly grab samples are also shown in the table for each scenario. This analysis suggests that PE-derived air-water exchange fluxes are comparable or better than collection of numerous grab samples via active sampling for estimating timeaveraged air-water exchange fluxes of PBDEs over time scales relevant to this study. 
Figure S4-1. BDE 47 Air-Water Exchange Fluxes: Scenario 1 (Random Fluctuation).
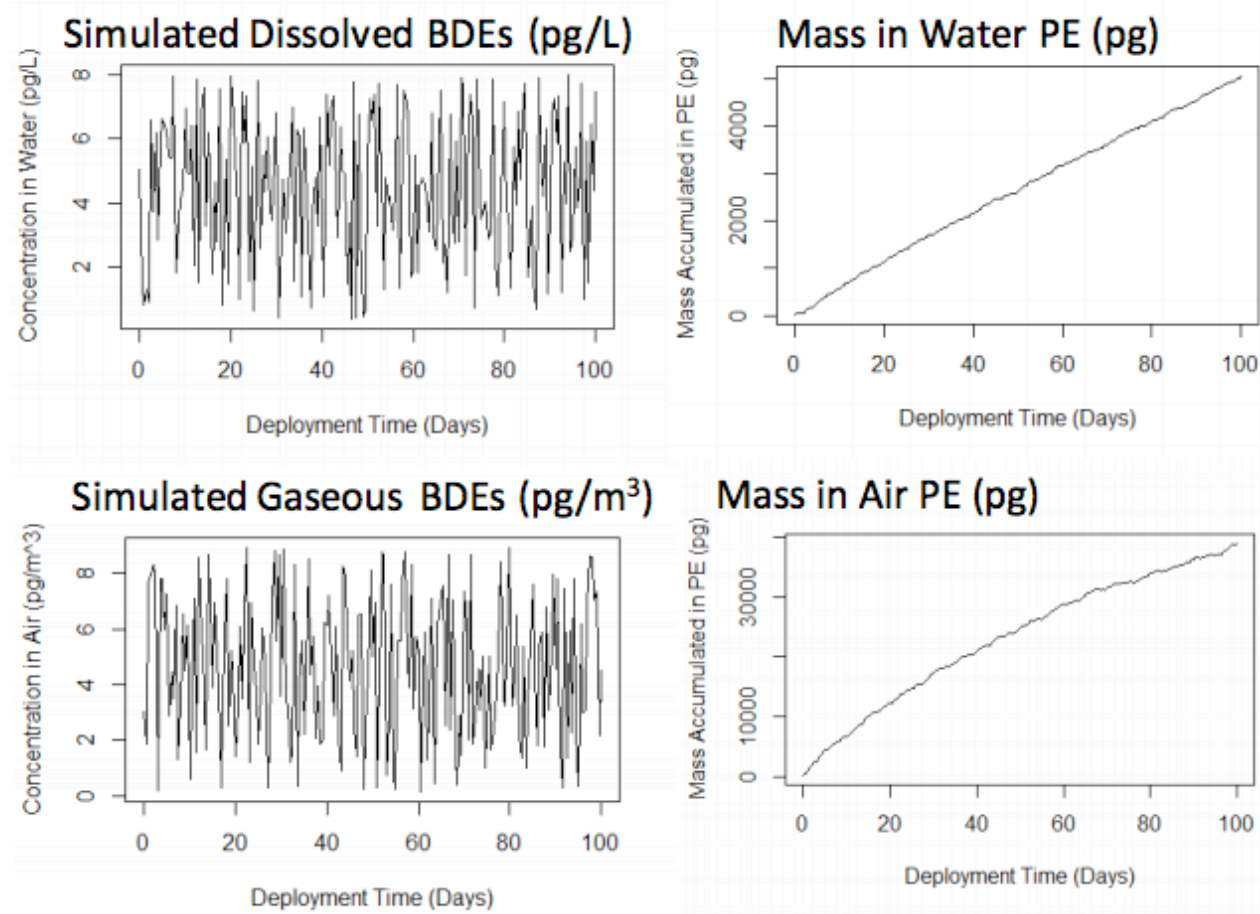

Simulated Air-Water Exchange Flux
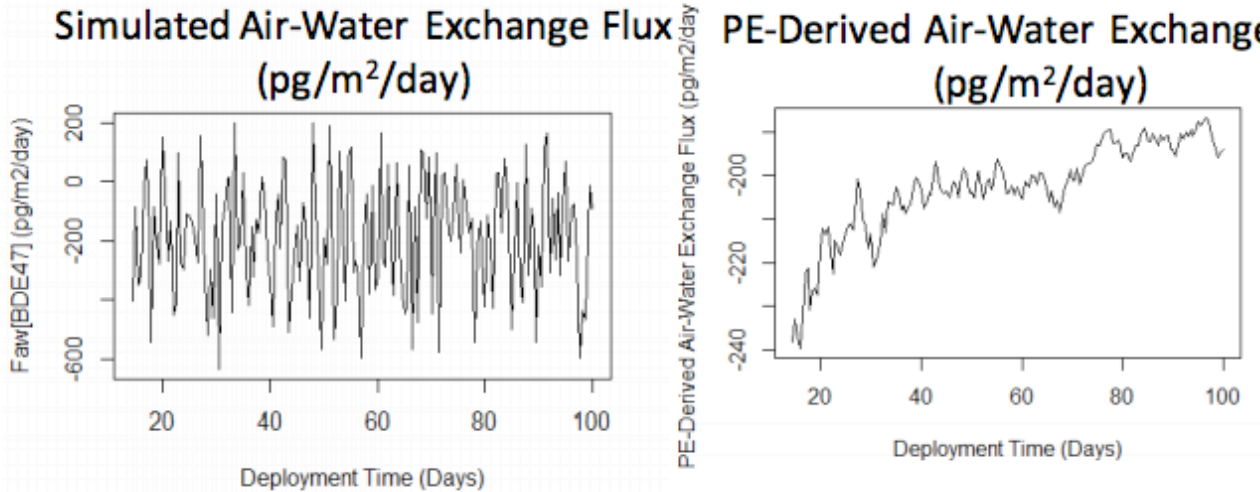
Figure S4-2. BDE 47 Air-Water Exchange Fluxes: Scenario 2 (Decreasing Flux)
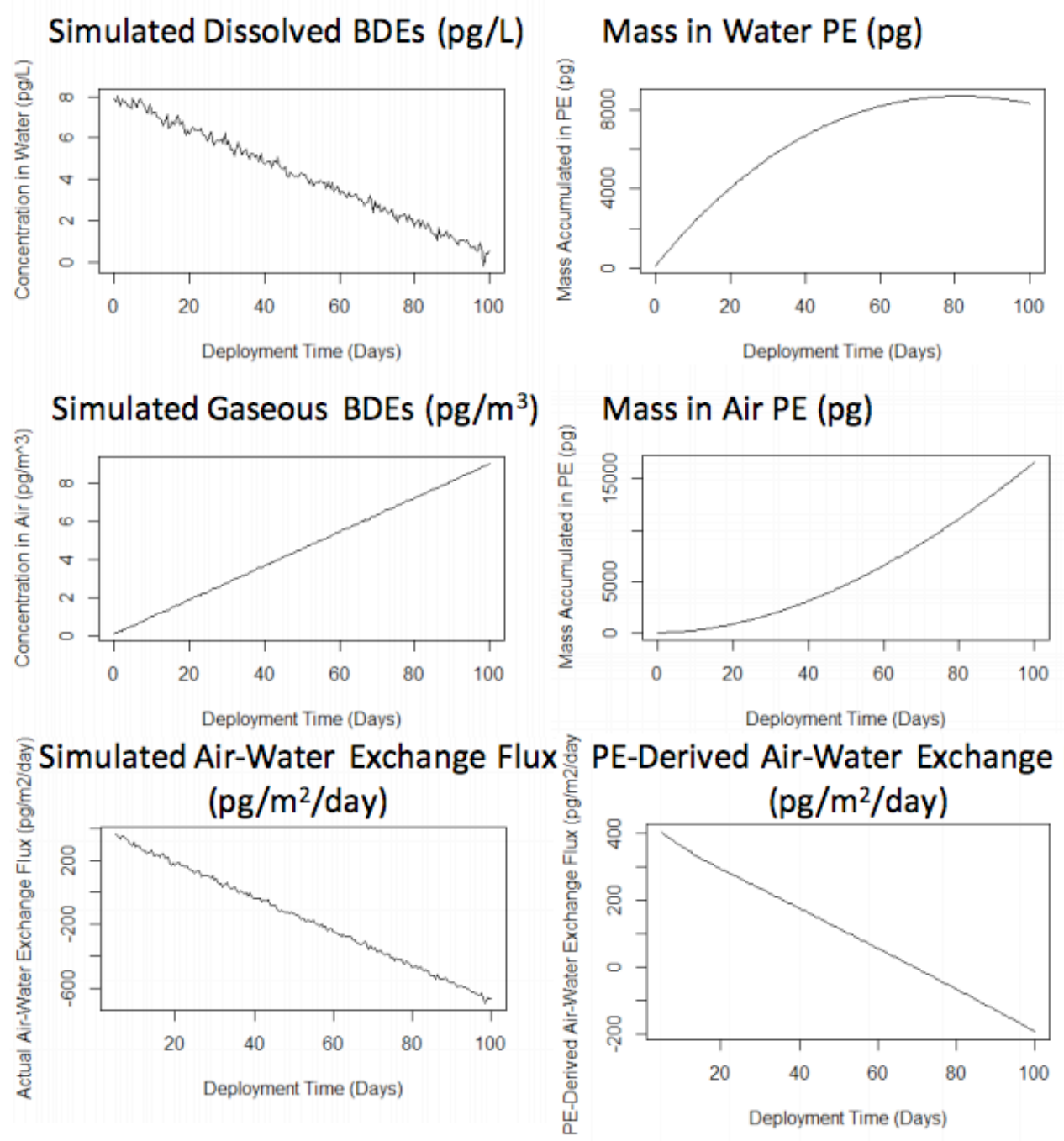

Table S4-11. RPDs for Simulate and PE- or Grab Sample-Derived $F_{\text {aw }}$

\begin{tabular}{|c|c|}
\hline $\begin{array}{l}\text { Scenario 1: Randomly Fluctuating } \\
\text { Air and Water BDE Concentrations }\end{array}$ & $\begin{array}{c}\text { Scenario 2: Steadily Increasing Air and } \\
\text { Decreasing Water Concentrations }\end{array}$ \\
\hline \multicolumn{2}{|c|}{ Relative Percent Difference (RPD) between Mean $\mathrm{F}_{\mathrm{aw}}$ and $\mathrm{F}_{\mathrm{aw}, \mathrm{PE}}$} \\
\hline $0.92+/-0.42 \%$ & $18.7 \pm 10.8 \%$ \\
\hline Relative Percent Difference (RPD) between Mean $\mathrm{F}_{\mathrm{aw}}$ and $\mathrm{F}_{\mathrm{aw}, \mathrm{grab}}$ \\
\hline $27.3+/-7.4 \%$ & $13.7 \pm 4.0 \%$ \\
\hline
\end{tabular}


Figure S4-3. Average Percent Composition of Major Congeners: Dissolved PBDEs.

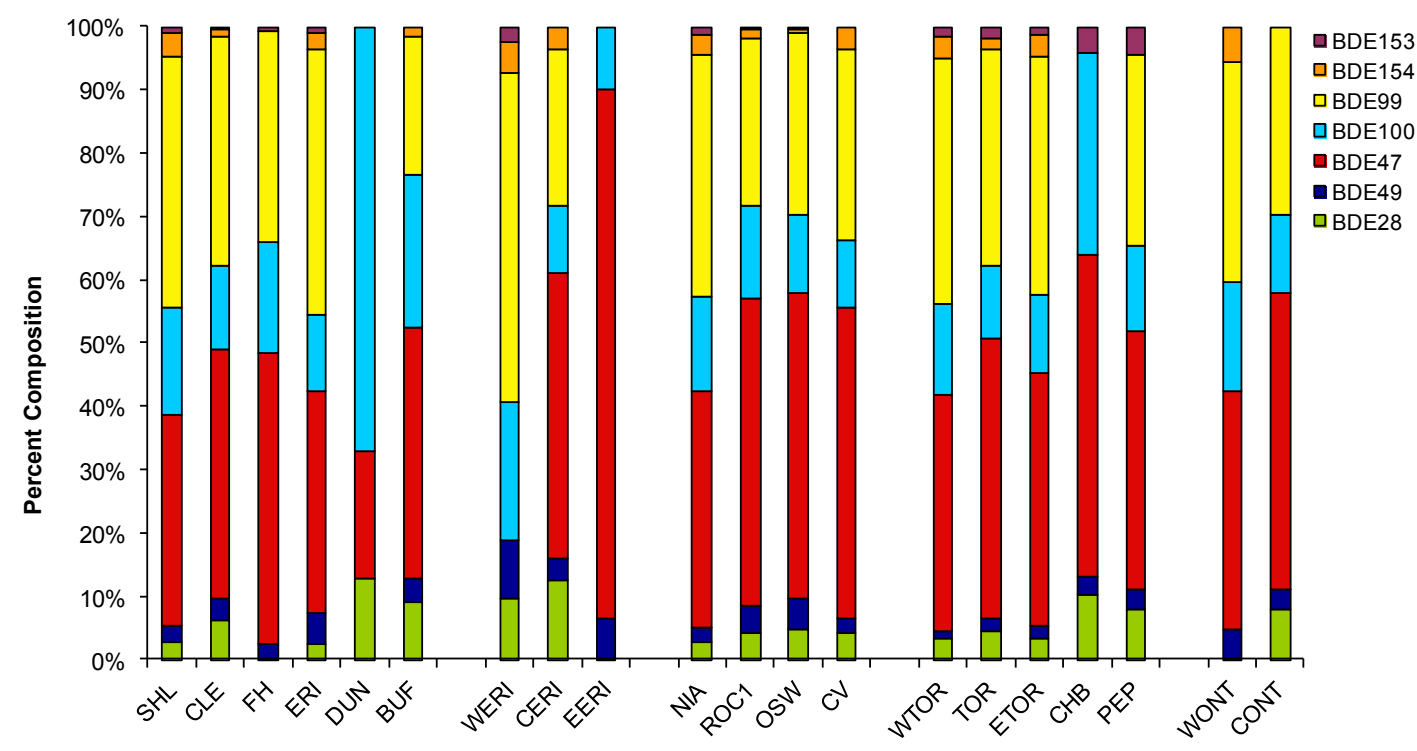

Figure S4-4. Average Percent Composition of Major Congeners: Gaseous PBDEs.

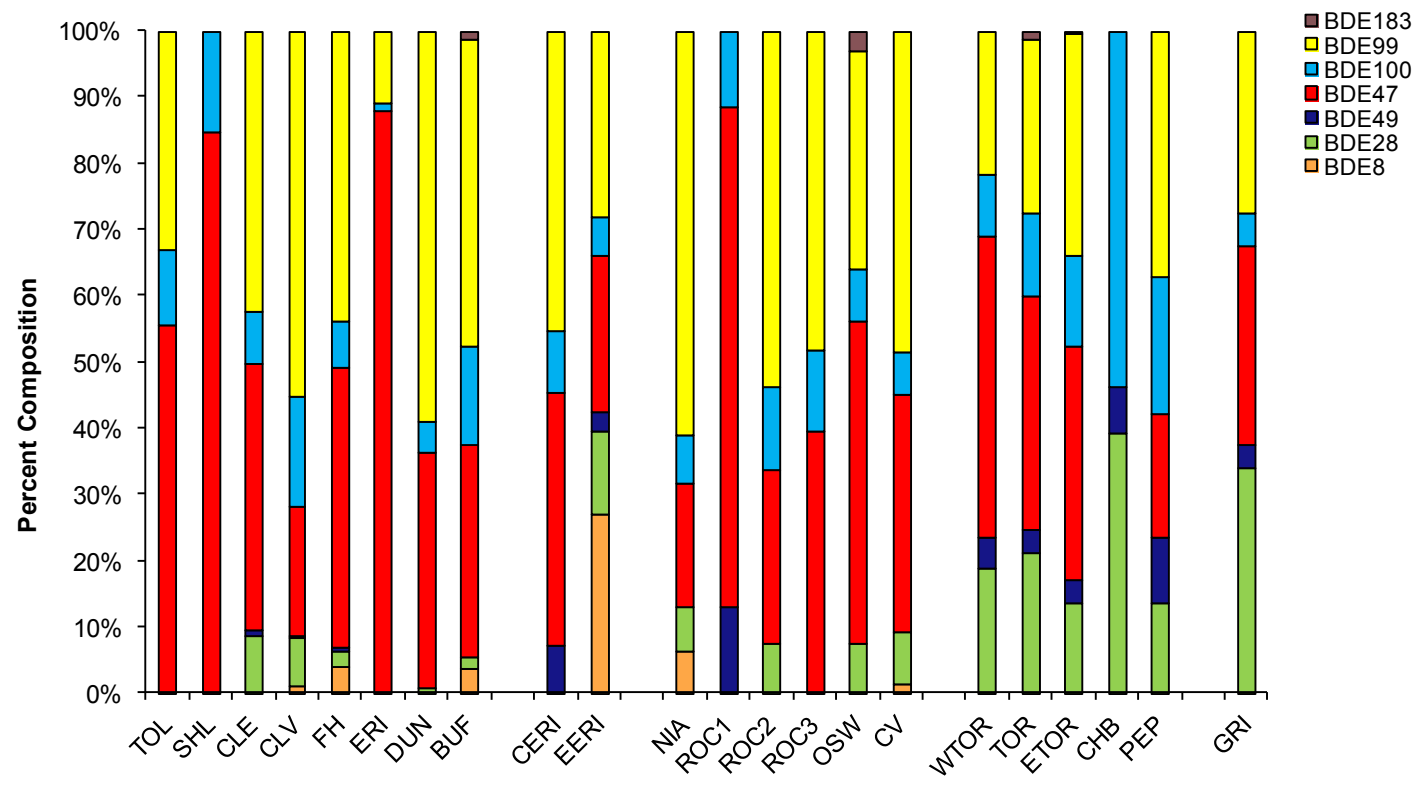


Comparison of Dissolved BDEs and Active Sampling Data. Concentrations of individual PBDEs measured by Venier et al. ${ }^{25}$ were compared to concentrations in this study measured for a collection of offshore/nearshore sites similar between the studies (CERI, EERI, WERI, CONT, and TOR). All data for Lake Erie were from 2012, though Venier et al. collected samples representative of one day each in April-May and PEs from this study represented mean summertime concentrations. Lake Ontario data from Venier et al. was collected in 2011.

The affinity of each congener for DOC $\left(\mathrm{K}_{\mathrm{iDOC}}\right)$ was calculated as $30 \%$ of the congener's octanol-water partitioning coefficient $\left(\mathrm{K}_{\mathrm{OW}}\right)$, as in Zarnadze \& Rodenburg. ${ }^{26}$ Kow values were obtained from Yue \& Li $2013 .{ }^{10}$ Concentrations from Venier et al. were plugged into Equation $\mathrm{S} 28$ as $\mathrm{C}_{\mathrm{XAD}}$ and concentrations from this study were plugged in as $\mathrm{C}_{\mathrm{iw}}$. The fraction dissolved, $f_{\mathrm{iw}}$, that would be needed to explain the difference between the two concentrations was calculated for each compound and used along with its $\mathrm{K}_{\mathrm{iDOC}}$ to derive a best-fit value of [DOC] for each location using Equation S29. This was the concentration of DOC that would have been needed at the site to explain the discrepancy between active and passive results, assuming no other sources of variation.

Studies of the Great Lakes region have shown that typical concentrations of DOC are in the range of $1-5 \mathrm{mg} / \mathrm{L}$, with greater concentrations in more productive regions along the shoreline. Best-fit DOC values needed to explain the discrepancy between this study and Venier et al. (Table S4-12) were much greater than realistic in one instance (CERI), and somewhat greater than expected in most others (EERI, CONT, TOR). Only in western Erie was the DOC concentration somewhat realistic at 
$3 \mathrm{mg} / \mathrm{L}$, as some studies have reported DOC concentrations as high as $2-5 \mathrm{mg} / \mathrm{L}$ in this region during summer. ${ }^{27-29}$ Results suggested that the discrepancies between the studies could not be entirely explained by sorption to DOC alone, as concentrations of DOC much greater than $3 \mathrm{mg} / \mathrm{L}$ would be needed in most cases, and the samples being compared were from open-lake and nearshore sites, rather than shoreline sites.

$$
\begin{gathered}
C_{i w}=f_{i w} \cdot C_{X A D} \\
f_{i w}=\frac{1}{1+[D O C(\mathrm{~kg} / \mathrm{L})] \cdot K_{i D O C}}
\end{gathered}
$$

Table S4-12. Best-fit [DOC] from Active-Passive Comparison.

\begin{tabular}{lccccccccc|c}
\multicolumn{8}{c}{ Percent Ciw/CXAD } & Best-fit [DOC] (mg/L) \\
\hline Lake & Site & BDE-28 & BDE-49 & BDE-47 & BDE-100 & BDE-99 & BDE-154+BB153 & BDE-153 & BDE-183 & \\
\hline Erie & CERI & 15 & 13 & 1.9 & 1.5 & 0.8 & 1.9 & 1.9 & 26 \\
Erie & WERI & 18 & 21 & & 10 & 5.0 & 8.8 & & 3.3 \\
Erie & EERI & & 21 & 7.7 & 3.9 & & & & 6.3 \\
Ontario & CONT & 18 & & 6.1 & 6.5 & 2.4 & & 7.9 \\
Ontario & TOR & 52 & & 6.6 & 4.1 & 2.5 & 1.6 & 1.2 & 7.1
\end{tabular}

Grayed-out cells represent compounds that were $<\mathrm{DL}$ in one or both studies and could not be used in the comparison. 


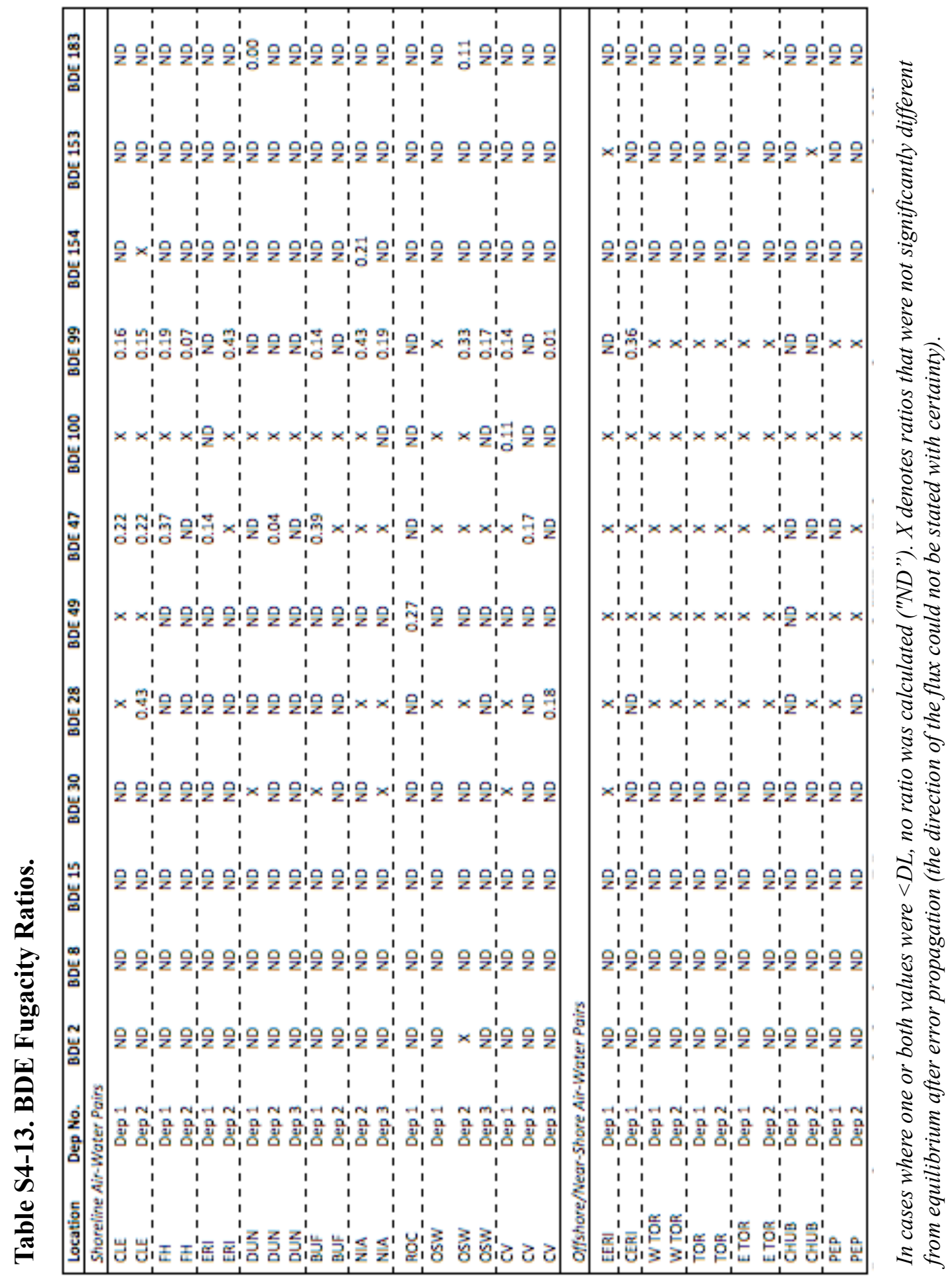




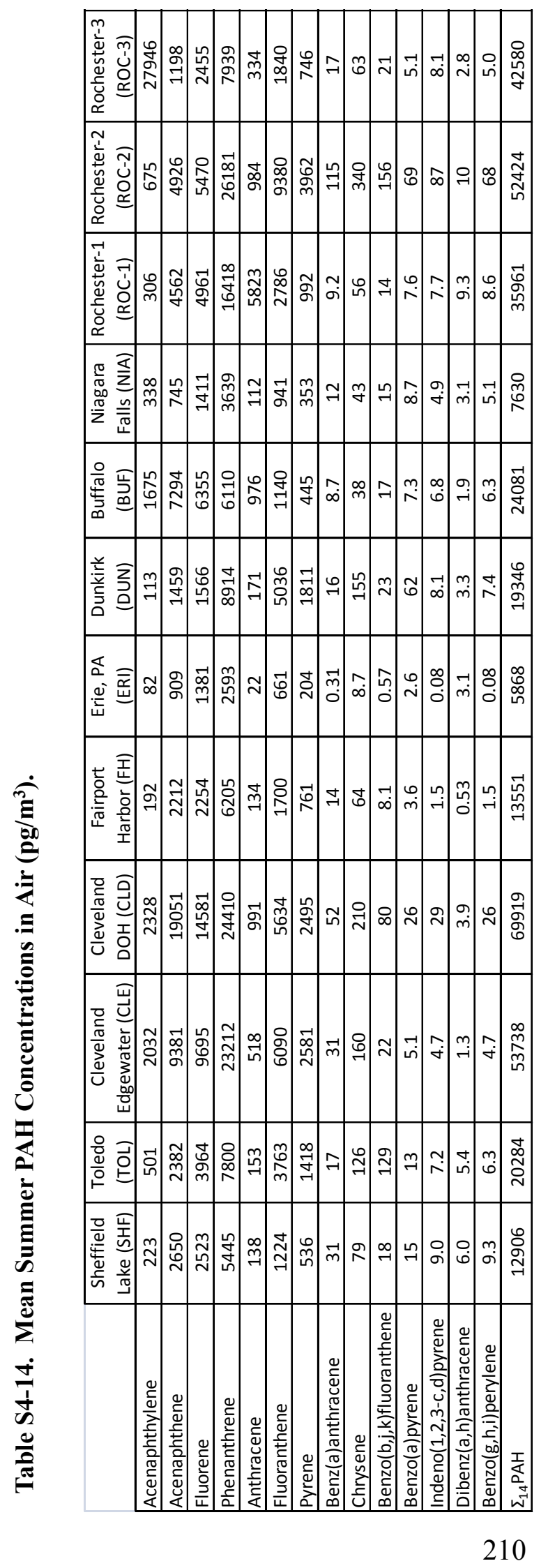




\begin{tabular}{|c|c|c|c|c|c|c|c|c|c|c|c|c|}
\hline 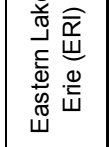 & $\bar{\sigma}$ & & & సิ & ?) & बे & & fo & 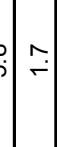 & $\stackrel{?}{-}$ & $\stackrel{+}{\leftarrow}$ & 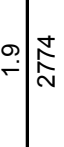 \\
\hline 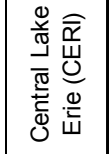 & $\bar{\sigma}$ & 足 & $\stackrel{\infty}{=}$ & & 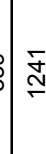 & $\left.\mid \begin{array}{l}0 \\
\infty \\
\infty\end{array}\right]$ & $\mp$ & 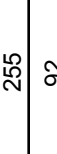 & $\stackrel{\llcorner}{\square}$ & $\stackrel{m}{=}$ & $\bar{\sim}$ & ৫) \\
\hline 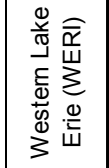 & 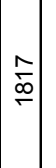 & 8 & 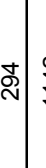 & 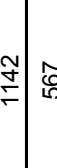 & $\overline{5}$ & 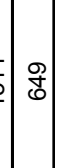 & $\stackrel{\sim}{\sim}$ & 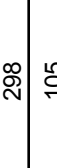 & $\therefore \approx$ & $\bar{N}$ & 字 & o| \\
\hline 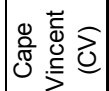 & 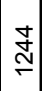 & 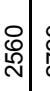 & స̃. & 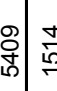 & 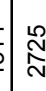 & 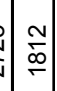 & $\stackrel{\infty}{\stackrel{一}{~}}$ & 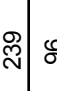 & D & ㅇ & 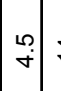 & 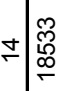 \\
\hline 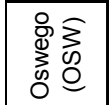 & $\bar{\delta}$ & 의 & $\begin{array}{c}\infty \\
e \\
e\end{array}$ & $\stackrel{\text { సิ }}{=}$ & 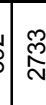 & \begin{tabular}{|l|l}
0 \\
0 \\
0
\end{tabular} & ১ & প্ল & $\stackrel{\infty}{\infty}$ & ల్ల & $\underset{*}{*}$ & 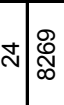 \\
\hline 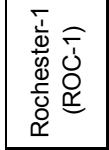 & $\mid$ & $\widehat{\widehat{N}}$ & $:$ & ఫิ & 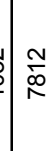 & 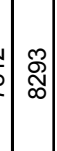 & 守 & 吕 & 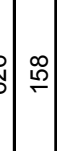 & $\stackrel{\mathscr{m}}{=}$ & 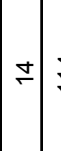 & 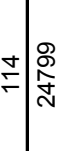 \\
\hline 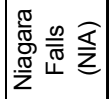 & 음 & $\underset{\sim}{\mathbb{N}}$ & $:$ & ఫ્ટે & $\frac{d}{d}$ & 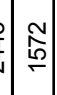 & $\hat{\infty}$ & ১) & 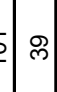 & 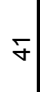 & {$\left[\begin{array}{c}\sigma \\
i \\
i\end{array}\right]$} & 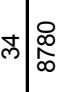 \\
\hline 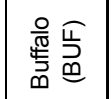 & 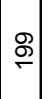 & $\bar{\infty}$ & $\frac{m}{\infty}$ & 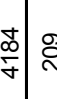 & 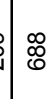 & 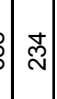 & 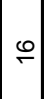 & $\infty \propto$ & $=$ & $\tau$ & $\stackrel{\leftrightarrow}{-}$ & $\stackrel{\infty}{\sigma}$ \\
\hline 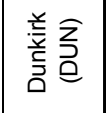 & $\stackrel{\Xi}{\sim}$ & $\widetilde{\Xi}$ & $\begin{array}{l}0 \\
f \\
7\end{array}$ & 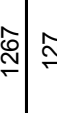 & $\checkmark \frac{7}{6}$ & {$\left[\begin{array}{l}\infty \\
\infty\end{array}\right.$} & $\mid \begin{array}{l}1 \\
\infty\end{array}$ & $\infty \propto$ & $=\begin{array}{l}0 \\
\stackrel{N}{*}\end{array}$ & 으 & $\stackrel{\leftrightarrow}{\circ}$ & 일 \\
\hline 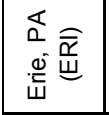 & $\begin{array}{l}\stackrel{8}{0} \\
:\end{array}$ & $\stackrel{?}{=}$ & 饮 & 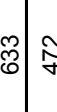 & $\begin{array}{l}v \\
\mathrm{v} \\
\end{array}$ & \begin{tabular}{l|l} 
\\
$\stackrel{\circ}{\circ}$
\end{tabular} & ळ & 它 & $2)$ & ๑ & $\stackrel{m}{\longrightarrow}$ & 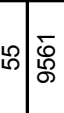 \\
\hline 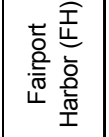 & $\begin{array}{l}9 \\
\\
0\end{array}$ & 怘 & $\begin{array}{c}\infty \\
\infty \\
\infty\end{array}$ & స్ & 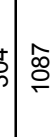 & $\begin{array}{c}0 \\
0\end{array}$ & $\approx$ & $\stackrel{\infty}{\stackrel{\infty}{\leftarrow}} 7$ & $f=$ & $\stackrel{2}{\circ}$ & $\bar{m}$ & 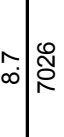 \\
\hline 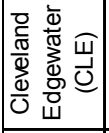 & - & $\stackrel{\nabla}{\sim}$ & న & $\begin{array}{c}0 \\
\frac{1}{\sigma}\end{array}$ & $\stackrel{\infty}{\Omega}$ & $\begin{array}{l}3 \\
\vdots\end{array}$ & ০) & $\stackrel{5}{\circ}$ & $\begin{array}{c}t \\
\infty\end{array}$ & ৪ & $\stackrel{\sim}{\sim}$ & 옹 \\
\hline 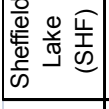 & ลิ & \begin{tabular}{c|c}
$\infty$ \\
ల్ \\
\end{tabular} & 啇 & \begin{tabular}{l|l}
0 \\
0 \\
0 \\
15
\end{tabular} & 莕 & $\begin{array}{l}\mid \\
\vdots \\
\vdots \\
\vdots\end{array}$ & 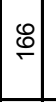 & $\widetilde{్}$ & $\stackrel{g}{\rightleftharpoons}$ & $\curvearrowright$ & $=$ & צ \\
\hline & 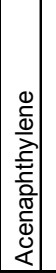 & 衰| & 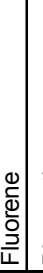 & 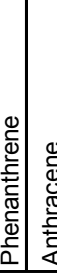 & 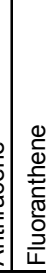 & | & 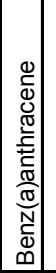 & 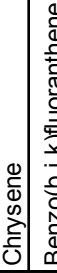 & 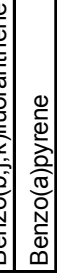 & 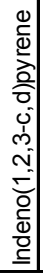 & 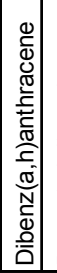 & 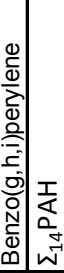 \\
\hline
\end{tabular}




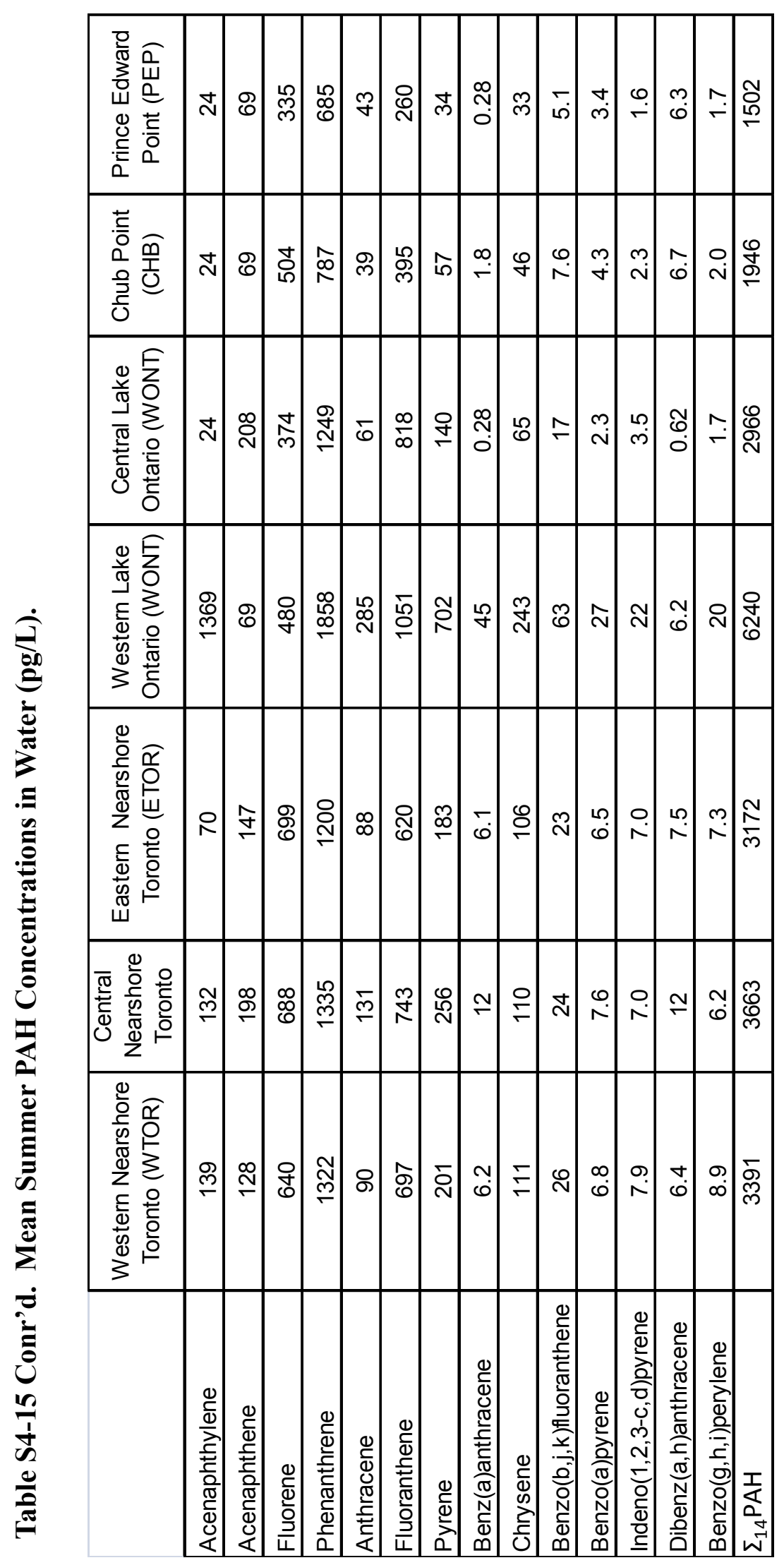


Figure S4-5. Comparison between Southern Population Wedge and Circular Radius.

Polycyclic Aromatic Hydrocarbons (PAHs) in Air $\left(\mathrm{pg} / \mathrm{m}^{3}\right)$ : Strongest Correlation with Population within a Circular Area (left) and with Population in a $180^{\circ}$ Wedge South (right)
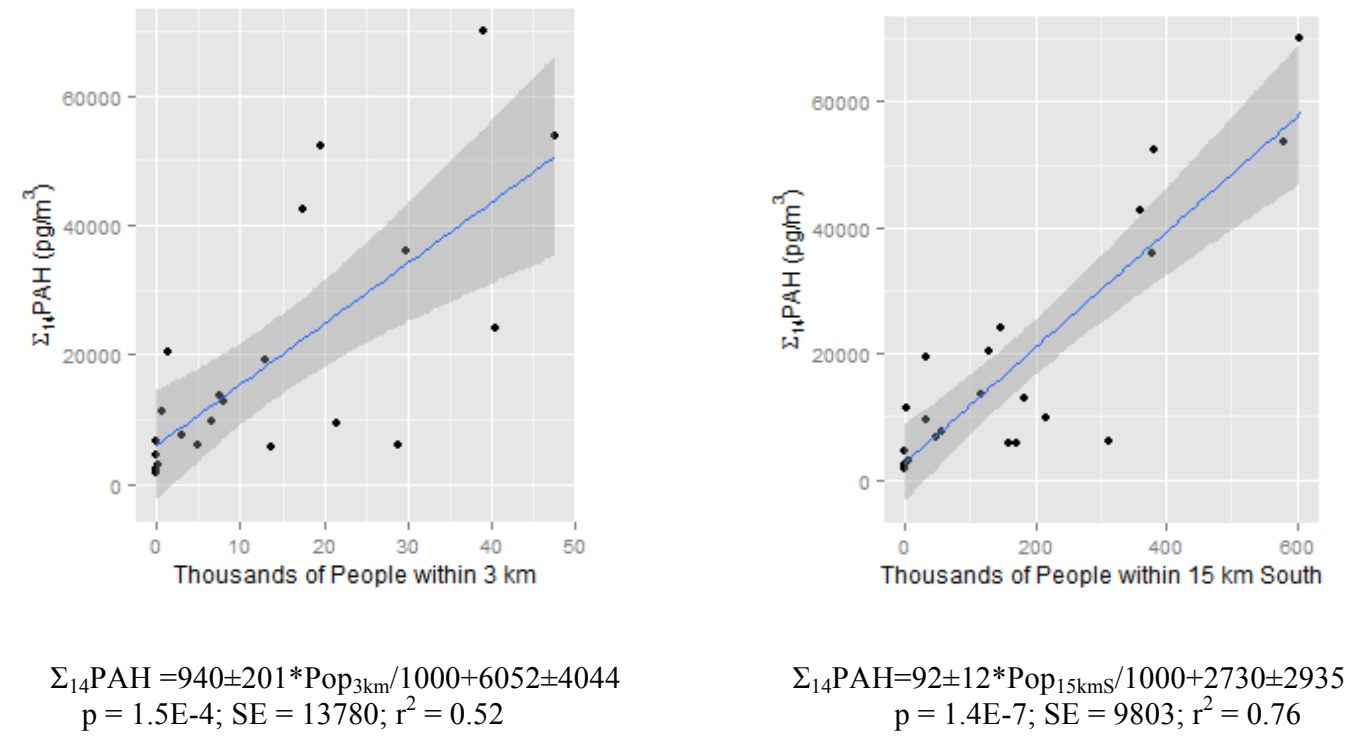

PBDEs in Air $\left(\mathrm{pg} / \mathrm{m}^{3}\right)$ : Strongest Correlation with Population within a Circular Area (left) and with Population in a $180^{\circ}$ Wedge South (right)

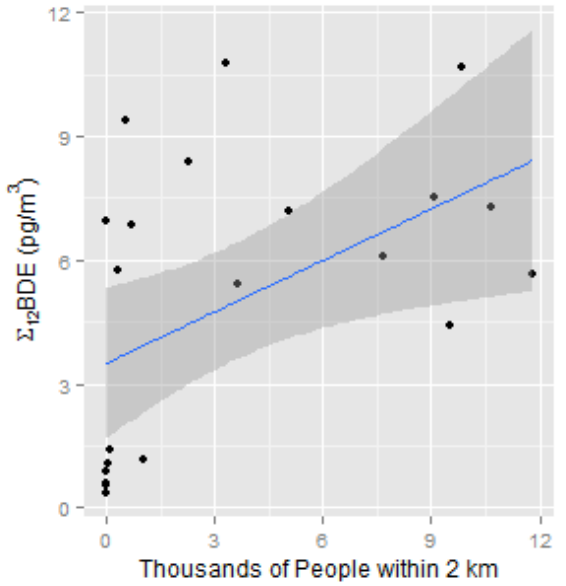

$\Sigma_{12} \mathrm{BDE}=0.42 \pm 0.16 * \mathrm{Pop}_{2 \mathrm{~km}} / 1000+3.5 \pm 0.88$ $\mathrm{p}=0.02 ; \mathrm{SE}=3.2 ; \mathrm{r}^{2}=0.25$

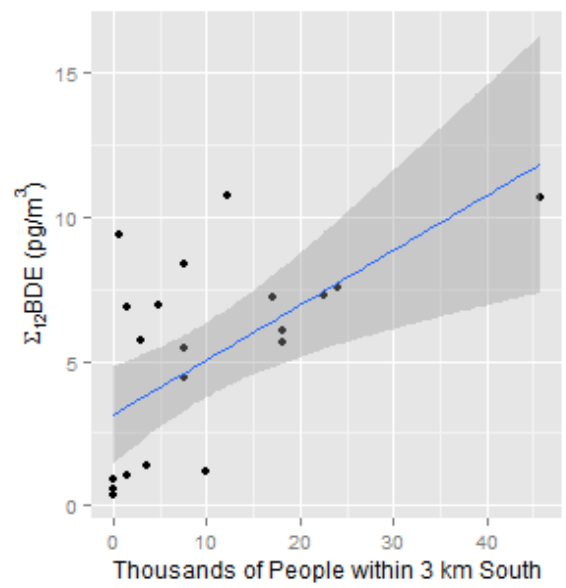

$\Sigma_{12} \mathrm{BDE}=0.19 \pm 0.06 * \mathrm{Pop}_{3 \mathrm{kmS}} / 1000+3.2 \pm 0.81$ $\mathrm{p}=0.003 ; \mathrm{SE}=2.9 ; \mathrm{r}^{2}=0.36$ 
Summary of Wind Direction during 2012 Summer Sampling. Average wind direction during the deployment period was estimated by first calculating the speedweighted average wind direction at all buoys with data available for the time period (Table S4-16), then performing a geostatistical interpolation via ordinary kriging, which used the nearby buoy data to predict average wind direction at the atmospheric sampling sites. Table S4-16 shows the locations of buoys used, dates when data was available, and the average speed-weighted wind direction, calculated from east-west and north-south components ( $u_{\text {ave }}$ and $v_{\text {ave }}$, respectively). This data is also summarized in Figure S4-5, which is a map with approximate average direction at each buoy site marked by an arrow.

To calculate average wind direction, direction in degrees was broken down into east-west and north-south components and then each component was averaged over the deployment period:

$$
\begin{aligned}
& u_{\text {ave }}=-(1 / \mathrm{n}) \sum\left(u_{i} \times \sin (2 \pi \times \Theta / 360)\right. \\
& v_{\text {ave }}=-(1 / \mathrm{n}) \sum\left(u_{i} \times \cos (2 \pi \times \Theta / 360)\right.
\end{aligned}
$$

A map and table of predicted values for each component over the study region was then created (Figure S4-6; Table S4-17). Average predicted wind direction was calculated based on the values predicted for each component at the sampling sites:

$$
\Theta_{\mathrm{ave}}=\arctan \left(u_{\text {ave }} / v_{\text {ave }}\right) \times 180 / \pi+180
$$

An angular standard deviation cannot be calculated for speed-weighted average direction, but standard deviation calculated based on non-speed-weighted direction was generally $<60^{\circ}$, which indicates that most of the small-scale variation 
caused by diurnal fluctuation was averaged out over this timespan, leaving us with a wind direction representative of larger scale meteorological patterns. ${ }^{30}$

Table S4-16. Average Wind Direction During Deployments at Available Meteorological Buoys.

\begin{tabular}{|l|c|c|c|c|c|c|c|c|}
\hline Buoy Name & $\mathbf{Y}$ & $\mathbf{X}$ & Start Date & End Date & $\mathbf{N}$ obs & u_ave & v_ave & WDIR_ave \\
\hline 45005 & 41.677 & -82.398 & $5 / 1 / 2012$ & $11 / 1 / 2012$ & 4420 & 0.38 & 0.56 & 214 \\
\hline 45012 & 43.621 & -77.406 & $5 / 1 / 2012$ & $11 / 1 / 2012$ & 4438 & 1.46 & 0.64 & 246 \\
\hline BARN6 & 42.345 & -79.595 & $5 / 1 / 2012$ & $7 / 19 / 2012$ & 9572 & 1.09 & 1.03 & 227 \\
\hline BUFN6 & 42.878 & -78.89 & $5 / 1 / 2012$ & $11 / 1 / 2012$ & 43913 & 1.35 & 0.92 & 236 \\
\hline C45132 & 42.47 & -81.22 & $5 / 11 / 2012$ & $11 / 1 / 2012$ & 3909 & 1.37 & 0.68 & 244 \\
\hline C45135 & 43.79 & -76.87 & $5 / 1 / 2012$ & $11 / 1 / 2012$ & 4224 & 1.37 & 0.80 & 240 \\
\hline C45139 & 43.252 & -79.535 & $5 / 1 / 2012$ & $11 / 1 / 2012$ & 4282 & 1.28 & 0.18 & 262 \\
\hline C45142 & 42.74 & -79.29 & $5 / 1 / 2012$ & $11 / 1 / 2012$ & 4237 & 1.94 & 0.71 & 250 \\
\hline C45159 & 43.77 & -78.98 & $5 / 1 / 2012$ & $7 / 26 / 2012$ & 2002 & 0.37 & 0.14 & 250 \\
\hline CBLO1 & 41.981 & -80.556 & $5 / 1 / 2012$ & $11 / 1 / 2012$ & 28223 & 0.80 & 0.67 & 230 \\
\hline CNDO1 & 41.542 & -81.637 & $5 / 1 / 2012$ & $10 / 18 / 2012$ & 40060 & 0.19 & -0.42 & 336 \\
\hline COBOURG & 43.95 & -78.17 & $5 / 1 / 2012$ & $10 / 31 / 2012$ & 4343 & 0.51 & -0.19 & 291 \\
\hline DBLN6 & 42.494 & -79.354 & $5 / 1 / 2012$ & $11 / 1 / 2012$ & 4437 & 1.04 & 0.80 & 232 \\
\hline FAIO1 & 41.764 & -81.281 & $5 / 1 / 2012$ & $11 / 1 / 2012$ & 40720 & 0.92 & 0.31 & 251 \\
\hline GELO1 & 41.859 & -80.975 & $5 / 1 / 2012$ & $11 / 1 / 2012$ & 9177 & 0.75 & -0.19 & 284 \\
\hline HHLO1 & 41.401 & -82.545 & $5 / 1 / 2012$ & $11 / 1 / 2012$ & 27376 & 0.19 & 0.14 & 233 \\
\hline KINGSTON & 44.22 & -76.6 & $5 / 1 / 2012$ & $10 / 31 / 2012$ & 2891 & 0.86 & 1.43 & 211 \\
\hline MRHO1 & 41.544 & -82.731 & $5 / 1 / 2012$ & $11 / 1 / 2012$ & 44162 & 0.19 & -0.37 & 333 \\
\hline OLCN6 & 43.341 & -78.719 & $5 / 1 / 2012$ & $11 / 1 / 2012$ & 23374 & 0.73 & 0.49 & 236 \\
\hline OSGN6 & 43.464 & -76.511 & $5 / 1 / 2012$ & $11 / 1 / 2012$ & 44367 & 1.06 & 0.63 & 239 \\
\hline POINT PETRE & 43.83 & -77.15 & $5 / 1 / 2012$ & $10 / 31 / 2012$ & 4397 & 1.34 & 0.82 & 239 \\
\hline SBIO1 & 41.629 & -82.841 & $5 / 1 / 2012$ & $11 / 1 / 2012$ & 4438 & 0.95 & 0.65 & 236 \\
\hline THRO1 & 41.694 & -83.473 & $5 / 1 / 2012$ & $11 / 1 / 2012$ & 44187 & 0.41 & 0.12 & 254 \\
\hline TORONTO CENTRE & 43.63 & -79.4 & $5 / 1 / 2012$ & $10 / 31 / 2012$ & 4064 & 0.29 & 0.05 & 261 \\
\hline YGNN6 & 43.262 & -79.064 & $5 / 1 / 2012$ & $11 / 1 / 2012$ & 26308 & 0.88 & 0.41 & 245 \\
\hline
\end{tabular}


Figure S4-6. Average Wind Direction During Deployments at Available Meteorological Buoys.

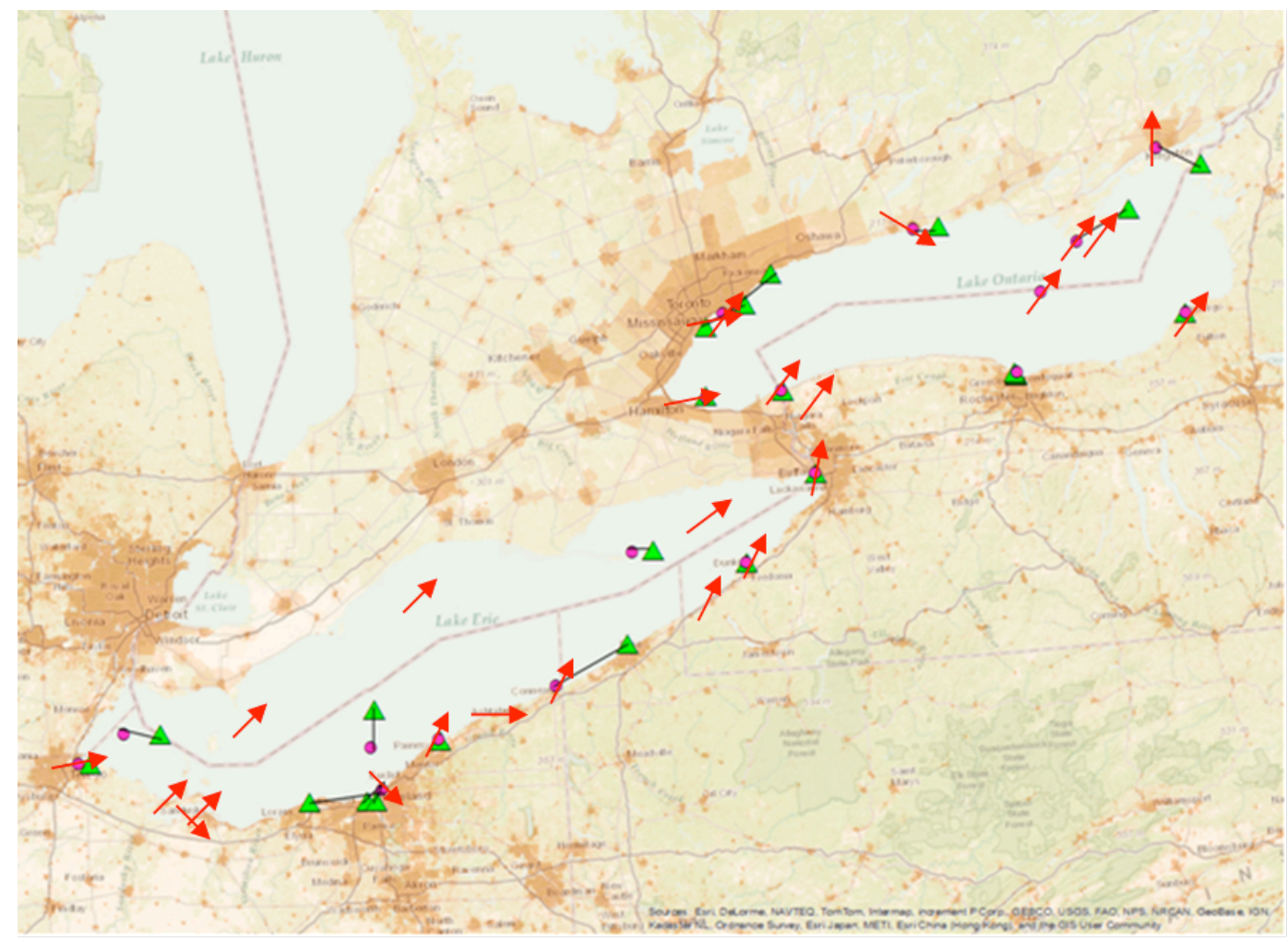



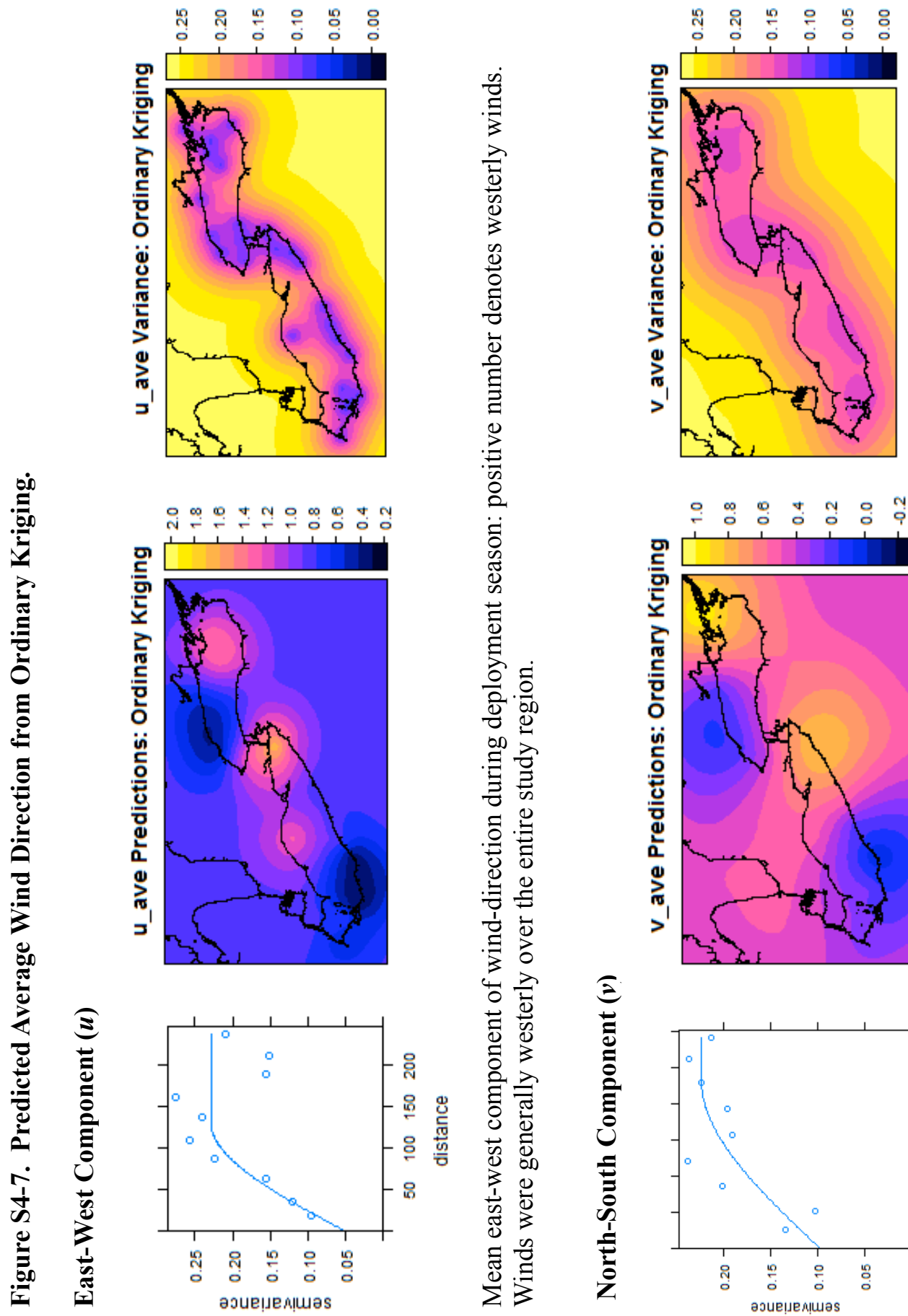

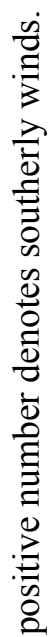

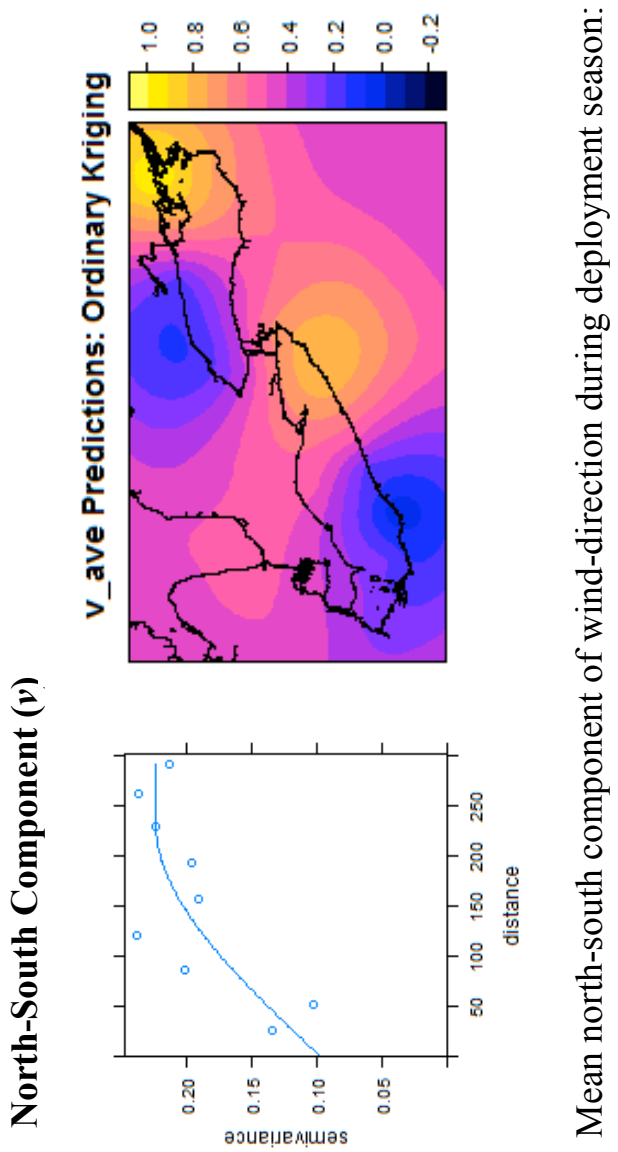


Table S4-17. Predicted Average Wind Direction at Sampling Sites.

\begin{tabular}{|l|c|c|c|c|c|}
\hline & u_pred & u_stdev & v_pred & v_stdev & $\begin{array}{c}\text { Direction wind coming } \\
\text { from ( }{ }^{\circ} \text { from 0 N) }\end{array}$ \\
\hline TOL & 0.12 & 0.32 & 0.1 & 0.38 & 231 \\
\hline SHL & 0.04 & 0.37 & 0.15 & 0.38 & 194 \\
\hline CLE & 0.04 & 0.34 & 0.15 & 0.38 & 194 \\
\hline CLV & 0.04 & 0.32 & 0.15 & 0.38 & 194 \\
\hline FH & 0.09 & 0.29 & 0.15 & 0.36 & 211 \\
\hline ERI & 0.12 & 0.41 & 0.18 & 0.4 & 214 \\
\hline DUN & 0.21 & 0.28 & 0.21 & 0.36 & 225 \\
\hline BUF & 0.19 & 0.29 & 0.18 & 0.36 & 227 \\
\hline CERI & 0.08 & 0.39 & 0.15 & 0.39 & 207 \\
\hline EERI & 0.18 & 0.41 & 0.18 & 0.39 & 225 \\
\hline NIA & 0.1 & 0.28 & 0.11 & 0.36 & 220 \\
\hline ROC1 & 0.16 & 0.44 & 0.14 & 0.41 & 229 \\
\hline ROC2 & 0.16 & 0.44 & 0.14 & 0.41 & 229 \\
\hline ROC3 & 0.16 & 0.44 & 0.14 & 0.41 & 229 \\
\hline OSW & 0.13 & 0.3 & 0.19 & 0.38 & 215 \\
\hline CV & 0.15 & 0.39 & 0.19 & 0.4 & 218 \\
\hline WTOR & 0.11 & 0.33 & 0.06 & 0.38 & 242 \\
\hline TOR & 0.08 & 0.32 & 0.05 & 0.37 & 239 \\
\hline ETOR & 0.07 & 0.33 & 0.03 & 0.37 & 243 \\
\hline CHB & 0.13 & 0.35 & 0.01 & 0.39 & 265 \\
\hline PEP & 0.18 & 0.34 & 0.16 & 0.37 & 229 \\
\hline GRI & 0.18 & 0.29 & 0.09 & 0.37 & 245 \\
\hline
\end{tabular}

Figure S4-8. Variance or Dissolved PBDE Predictions from Bayesian Kriging.

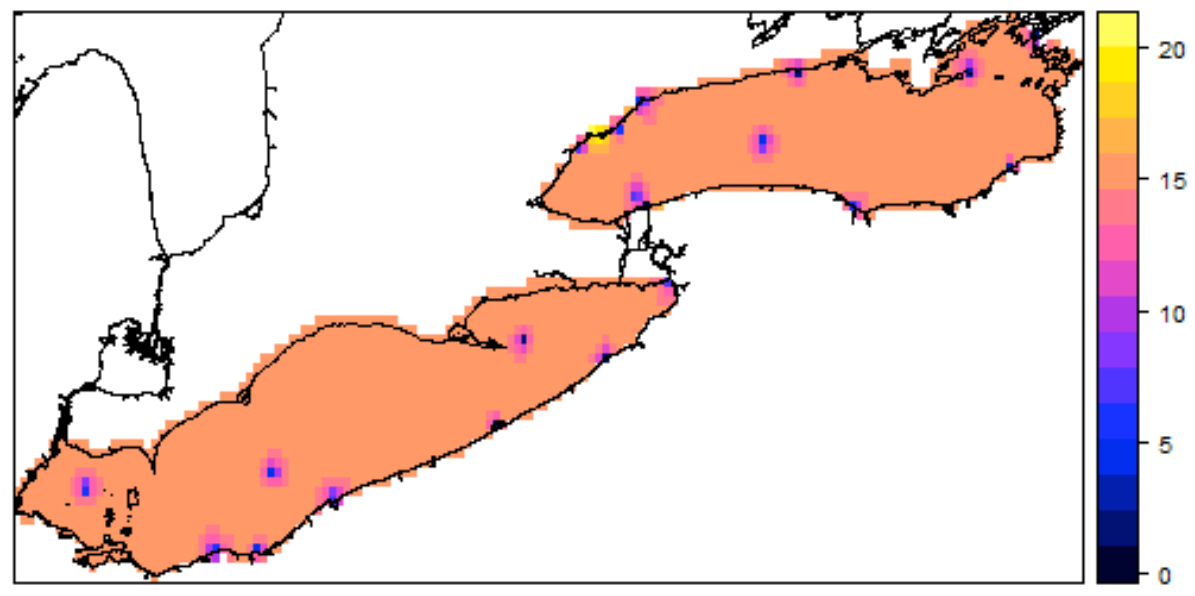


Figure S4-9. Distributions of Estimated Parameters for Bayesian Kriging.
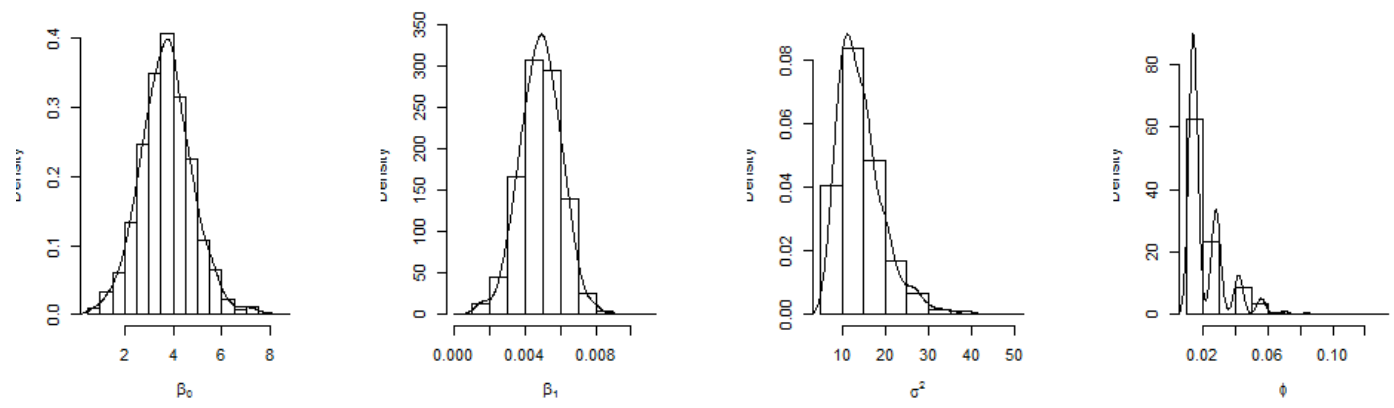

Figure S4-10. Cross-Validation for Bayesian Kriging of Dissolved PBDEs.

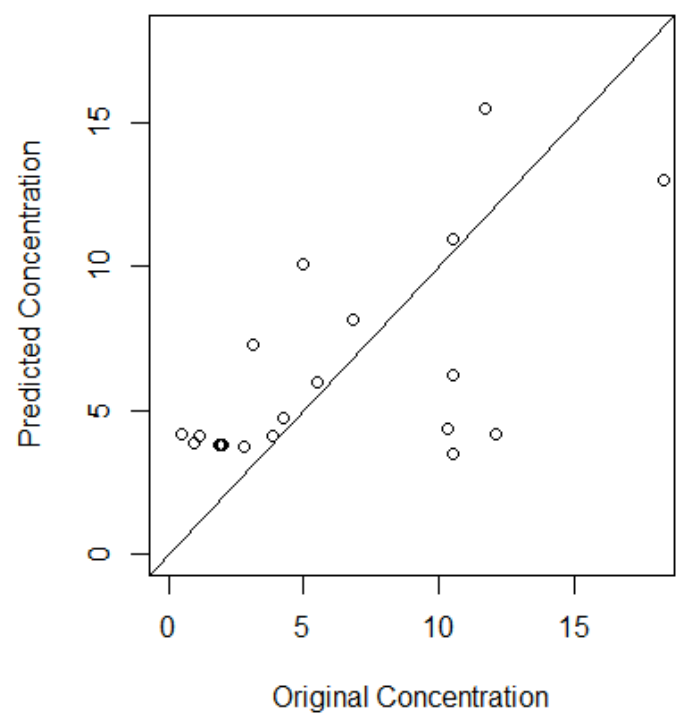

One location was removed at a time, and then a kriging model was created and concentration was predicted at the removed location. The plot above compares predicted concentrations based on the model to actual concentrations, with a 1:1 line for reference. 


\section{LITERATURE CITED IN SUPPORTING INFORMATION}

(1) Fuller, E. N.; Schettler, P. D.; Giddings, J. C. A new method for prediction of binary gas-phase diffusion coefficients. Ind. Eng. Chem. 1966, 58, 18-27, DOI:10.1016/0042-207X(66)90400-3.

(2) Schwarzenbach, R. P.; Gschwend, P. M.; Imboden, D. M. Environmental Organic Chemistry; 2nd ed.; Wiley Interscience, 2002.

(3) Rowe, M. D.; Perlinger, J. A. Micrometeorological measurement of hexachlorobenzene and polychlorinated biphenyl compound air-water gas exchange in Lake Superior and comparison to model predictions. Atmos. Chem. Phys. 2012, 12, 4607-4617, DOI:10.5194/acp-12-4607-2012.

(4) Le, N. D.; Zidek, J. V. Interpolation with uncertain spatial covariances : A Bayesian alternative to kriging. J. Multivar. Anal. 1992, 43, 351-374, DOI:10.1016/0047-259X(92)90040-M.

(5) R Core Team. R: A language and environment for statistical computing (version 3.1.0), 2014.

(6) Ribeiro Jr., P. J.; Diggle, P. J. geoR: A package for geostatistical analysis. $R$ NEWS 2001, 1, 15-18.

(7) Khairy, M. A.; Lohmann, R. Field calibration of low density polyethylene passive samplers for gaseous POPs. Environ. Sci. Process. Impacts 2014, 16, 414-421, DOI:10.1039/c3em00493g.

(8) Lohmann, R. Critical review of low-density polyethylene's partitioning and diffusion coefficients for trace organic contaminants and implications for its use as a passive sampler. Environ. Sci. Technol. 2012, 46, 606-618, DOI:10.1021/es202702y.

(9) Lohmann, R.; Muir, D. Global Aquatic passive sampling (AQUA-GAPS): using passive samplers to monitor POPs in the waters of the world. Environ. Sci. Technol. 2010, 44, 860-864, DOI:10.1021/es902379g.

(10) Yue, C.; Li, L. Y. Filling the gap : Estimating physicochemical properties of the full array of polybrominated diphenyl ethers (PBDEs). Environ. Pollut. 2013, 180, 312-323, DOI:10.1016/j.envpol.2013.05.029. 
(11) Bergman, A.; Rydén, A.; Law, R. J.; de Boer, J.; Covaci, A.; Alaee, M.; Birnbaum, L.; Petreas, M.; Rose, M.; Sakai, S.; Van den Eede, N.; van der Veen, I. A novel abbreviation standard for organobromine, organochlorine and organophosphorus flame retardants and some characteristics of the chemicals. Environ. Int. 2012, 49, 57-82, DOI:10.1016/j.envint.2012.08.003.

(12) Dirtu, A. C.; Covaci, A.; Abdallah, M. Advances in the sample preparation of brominated flame retardants and other brominated compounds. TrAC Trends Anal. Chem. 2013, 43, 189-203, DOI:10.1016/j.trac.2012.10.004.

(13) Wania, F.; Dugani, C. B. Assessing the long-range transport potential of polybrominated diphenyl ethers: A comparison of four multimedia models. Environ. Toxicol. Chem. 2003, 22, 1252-1261, DOI:10.1002/etc.5620220610.

(14) Beyer, A.; Wania, F.; Gouin, T.; Mackay, D.; Matthies, M. Selecting internally consistent physicochemical properties of organic compounds. Environ. Toxicol. Chem. 2002, 21, 941-953, DOI:10.1002/etc.5620210508.

(15) Thompson, J. M.; Hsieh, C.-H.; Luthy, R. G. Modeling uptake of hydrophobic organic contaminants into polyethylene passive samplers. Environ. Sci.

Technol. 2015, 49, 2270-2277, DOI:10.1021/es504442s.

(16) La Guardia, M. J.; Hale, R. C.; Harvey, E. Detailed polybrominated diphenyl ether (PBDE) congener composition of the widely used penta-, octa-, and decaPBDE technical flame-retardant mixtures. Environ. Sci. Technol. 2006, 40, 6247-6254, DOI:10.1021/es060630m.

(17) Liu, Y.; Wang, S.; McDonough, C. A.; Khairy, M.; Muir, D. C. G.; Helm, P. A.; Lohmann, R. Gaseous and freely-dissolved PCBs in the lower Great Lakes based on passive sampling: spatial trends and air-water exchange. Environ. Sci. Technol. 2016, 50, 4932-4939, DOI:10.1021/acs.est.5b04586.

(18) Melymuk, L.; Robson, M.; Csiszar, S. A.; Helm, P. A.; Kaltenecker, G.; Backus, S.; Bradley, L.; Gilbert, B.; Blanchard, P.; Jantunen, L.; Diamond, M. L. From the city to the lake: Loadings of PCBs, PBDEs, PAHs and PCMs from Toronto to Lake Ontario. Environ. Sci. Technol. 2014, 48, 3732-3741, DOI:10.1021/es403209z.

(19) Strandberg, B. O.; Dodder, N. G.; Basu, I.; Hites, R. A. Concentrations and spatial variations of polybrominated diphenyl ethers and other organohalogen compounds in Great Lakes air. 2001, 35, 1078-1083, DOI:10.1021/es001819f.

(20) Fernandez, L. A.; Lao, W.; Maruya, K. A.; White, C.; Burgess, R. M. Passive sampling to measure baseline dissolved persistent organic pollutant concentrations in the water column of the Palos Verdes Shelf Superfund site. Environ. Sci. Technol. 2012, 46, 11937-11947, DOI:10.1021/es302139y. 
(21) Hayward, S.; Gouin, T.; Wania, F. Comparison of four active and passive sampling techniques for pesticides in air. Environ. Sci. Technol. 2010, 44, 3410-3416, DOI:10.1021/es902512h.

(22) Allan, I. J.; Booij, K.; Paschke, A.; Vrana, B.; Mills, G. A.; Greenwood, R. Field performance of seven passive sampling devices for monitoring of hydrophobic substances. Environ. Sci. Technol. 2009, 43, 5383-5390, DOI:10.1021/es900608w.

(23) Gouin, T.; Harner, T.; Blanchard, P.; Mackay, D. Passive and active air samplers as complementary methods for investigating persistent organic pollutants in the Great Lakes basin. Environ. Sci. Technol. 2005, 39, 91159122, DOI:10.1021/es051397f.

(24) Hawker, D. W. Modeling the response of passive samplers to varying ambient fluid concentrations of organic contaminants. Environ. Toxicol. Chem. 2010, 29, 591-596, DOI:10.1002/etc.69.

(25) Venier, M.; Dove, A.; Romanak, K.; Backus, S.; Hites, R. A. Flame retardants and legacy chemicals in Great Lakes' water. Environ. Sci. Technol. 2014, 48, 9563-9572, DOI:10.1021/es501509r.

(26) Zarnadze, A.; Rodenburg, L. A. Water-column concentrations and partitioning of polybrominated diphenyl ethers in the New York/new Jersey Harbor, USA. Environ. Toxicol. Chem. 2008, 27, 1636-1642, DOI:10.1897/07-619.

(27) Cory, R. M.; Davis, T. W.; Dick, G. J.; Johengen, T.; Denef, V. J.; Berry, M.; Page, S. E.; Watson, S. B.; Yuhas, K.; Kling, G. W. Seasonal dynamics in dissolved organic matter, hydrogen peroxide, and cyanobacterial blooms in Lake Erie. Front. Mar. Sci. 2016, 3, 1-17, DOI:10.3389/FMARS.2016.00054.

(28) North, R. L.; Guildford, S. J.; Smith, R. E. H.; Havens, S. M.; Twiss, M. R. Evidence for phosphorus, nitrogen, and iron colimitation of phytoplankton communities in Lake Erie. Limnol. Oceanogr. 2007, 52, 315-328, DOI:10.4319/1o.2007.52.1.0315.

(29) Scully, N. M.; Lean, D. R. S.; McQueen, D. J.; Cooper, W. J. Photochemical formation of hydrogen peroxide in lakes : effects of dissolved organic carbon and ultraviolet radiation. Can. J. Fish. Aquat. Sci. 1995, 52, 2675-2681, DOI:10.1139/f95-856.

(30) Hafner, W. D.; Hites, R. A. Effects of wind and air trajectory directions on atmospheric concentrations of persistent organic pollutants near the Great Lakes. Environ. Sci. Technol. 2005, 39, 7817-7825, DOI:10.1021/es0502223. 


\section{CHAPTER 5}

INVESTIGATING ARYL HYDROCARBON-MEDIATED POTENCY OF GASPHASE AMBIENT AIR USING IN VITRO BIOASSAYS AND PASSIVE

SAMPLING

This manuscript is formatted for submission to the journal Environmental Health Perspectives.

Carrie A. McDonough ${ }^{\dagger *}$, Diana G. Franks ${ }^{\ddagger}$, Mark E. Hahn ${ }^{\ddagger}$, Rainer Lohmann ${ }^{\dagger}$

${ }^{\dagger}$ University of Rhode Island Graduate School of Oceanography, 215 South Ferry Road, Narragansett, RI, USA 02882

\$Biology Department, Woods Hole Oceanographic Institution, MS-32, Woods Hole, MA, USA 02543

*Corresponding author email: carriemc@my.uri.edu; phone: 401.874.6408; fax: 401.874 .6811 


\section{ABSTRACT}

Very few studies have reported on biological effects of hydrophobic organic contaminants (HOCs) in the gaseous fraction of ambient air, though health risks posed by particle-bound HOCs are well established, especially with regard to the polycyclic aromatic hydrocarbons (PAHs). Polyethylene passive samplers (PEs) were deployed in air throughout the greater Cleveland $(\mathrm{OH})$ area along the southern shore of Lake Erie. PE extracts were analyzed for PAHs and organophosphate esters (OPEs), two groups of contaminants prominent in ambient urban air, and were also analyzed via an in vitro bioassay to measure $\mathrm{AhR}$-mediated potency. Ambient gaseous concentrations of $\Sigma_{40}$ PAH ranged from $7.1 \mathrm{ng} / \mathrm{m}^{3}$ in Cuyahoga National Park to $36 \mathrm{ng} / \mathrm{m}^{3}$ in downtown Cleveland, and were dominated by the 2-3-ring methylphenanthrenes, phenanthrene, and fluorene. Gaseous concentrations of $\Sigma_{12} \mathrm{OPE}$ ranged from 0.02 $\mathrm{ng} / \mathrm{m}^{3}$ in Cuyahoga National Park to $1.2 \mathrm{ng} / \mathrm{m}^{3}$ in Kent. Dosing solutions used in bioassay experiments were enriched in hydrophobic compounds compared to ambient air. Bioassay-derived $\mathrm{BaP}$ equivalents $\left(\mathrm{BaPEq}_{\mathrm{bio}}\right)$, a measure of relative potency, ranged from 21-283 $\mathrm{ng} / \mu \mathrm{L} \mathrm{BaP}$, with greatest values in the downtown Cleveland area and lowest values at rural/residential sites further from the city center. BaPEq $q_{\text {bio }}$ was weakly correlated with concentrations of 2-ring alkyl/substituted PAHs as well as the OPEs TDCIPP and EHDPP. Potencies predicted based on literature-derived induction equivalency factors (IEFs) explained only $2-23 \%$ of the AhR-mediated potency observed in bioassay experiments. This suggests that biological effects predicted 
using $\mathrm{BaPEq}_{\text {chem }}$ may underestimate risks of exposure, perhaps due to synergism, or augmentation of potency by unmonitored chemicals in the mixture.

\section{INTRODUCTION}

Hydrophobic organic contaminants (HOCs) in the particulate phase of ambient air pose a health risk to humans, and polycyclic aromatic hydrocarbons (PAHs) are the predominant carcinogenic component of this fraction. ${ }^{1,2}$ However, there are very few studies investigating health risks associated with HOC mixtures present in the gaseous phase of ambient air. Humans are exposed to gaseous air pollution directly via respiration and dermal uptake. ${ }^{3}$ This is especially concerning in urban areas with greater traffic and population density, and also in indoor environments. Furthermore, gaseous HOCs are freely available to partition into other media including plants, ${ }^{4}$ so dietary uptake from crops could be a significant route of human exposure. ${ }^{5}$

The gaseous fraction of ambient air has a distinct composition compared to the particle-bound fraction. ${ }^{6}$ The total amount of PAHs in the gaseous phase is generally greater than in the particulate phase, though total PAHs in this phase are dominated by lower molecular weight 2-3-ring PAHs while the particulate-bound fraction is dominated by more hydrophobic PAHs. ${ }^{2,6-10}$ Recent studies have also demonstrated that organophosphate esters (OPEs), a group of compounds currently used as flame retardants and plasticizers in consumer goods, are present at unexpectedly high levels in ambient air in the Great Lakes region, and some chlorinated OPEs are expected to be predominantly in the gaseous phase. ${ }^{1-13}$ O'Connell et al. used silicone wristbands as personal monitoring devices for exposure to gas-phase HOCs and frequently detected several 2-3-ring PAHs, as well as some OPEs. ${ }^{14}$ Chronic exposure to gas- 
phase OPEs and PAHs in ambient air is of concern because these compounds have been associated with carcinogenicity, endocrine disruption, and other biological effects in previous in vitro and in vivo studies. ${ }^{6,15-18}$

Activation of the aryl hydrocarbon receptor (AhR) is linked to induction and repression of a large number of genes, modulation of cell growth and proliferation, tumor promotion, immunological effects, cardiotoxicity, and endocrine disruption, with the severity and type of response dependent upon the specific ligand and its binding affinity. ${ }^{19}$ Many previous studies have assessed health risks of ambient air pollution using induction equivalency factors (IEFs) to represent the relative AhRmediated potency of PAHs relative to benzo(a)pyrene $(\mathrm{BaP}){ }^{8,20}$ This approach assumes an additive, rather than synergistic or antagonistic, relationship between multiple ligands. AhR is activated by binding with variable affinity to several PAHs, with 4-5-ring PAHs generally more potent than the 2-3-ring PAHs that dominate gasphase air pollution. ${ }^{6}$

Highly carcinogenic PAHs such as benzo(a)pyrene $(\mathrm{BaP})$ are typically present only at very low concentrations in the gas phase due to low volatility. The lower molecular weight PAHs, especially phenanthrene, fluoranthene, and the methylated phenanthrenes/anthracenes, are expected to contribute more significantly to the potency of this fraction due to their high gas-phase concentrations. ${ }^{6}$ Despite this, previous studies have shown that the gaseous fraction of ambient air pollutants appears to be responsible for a significant portion of the AhR-mediated potency associated with ambient air. The majority of compounds responsible for this potency remain unidentified. In studies of gas-phase air pollution, Ramirez et al. found that, 
while concentrations of PAHs known to be most potent with respect to cytochrome P450 1A1 (CYP1A1) induction were low in the gaseous fraction, this fraction was estimated to contribute $34-86 \%$ of total carcinogenicity associated with 16 PAHs based on potency relative to $\mathrm{BaP}^{8}$ Previous studies by Klein et al. and Novak et al. also observed significant AhR activation from the gaseous, as well as the particulate, fraction of ambient air pollutants. ${ }^{10,21}$ Kennedy et al. found a statistically significant relationship between PAH concentrations and AhR activity in samples of gaseous and fine particulate contaminants, but determined that the specific PAHs targeted via GC/MS accounted for $<3 \%$ of the measured AhR activity. ${ }^{20}$ Similarly, Ersekova et al. found that quantified PAHs accounted for 3-33\% of measured AhR activity. ${ }^{22}$

Many previous studies have noted that gaseous HOCs should not be ignored in risk assessments, but they were all carried out using high-volume air samplers or passive polyurethane foam (PUF) samplers, which are less selective for gaseous HOCs than diffusive uptake by polyethylene. ${ }^{23}$ This study is the first to investigate AhR activation caused by the freely gaseous fraction of HOCs taken up by a single-phase sampler consisting only of pre-cleaned polyethylene, and will help contribute to our knowledge of the biological relevance of the truly gaseous fraction of ambient air. Passive samplers of this type have similar affinity for HOCs as organism lipids, and have been used in predicting the extent to which HOCs will bioaccumulate. ${ }^{24}$ The composition of HOCs taken up into the polyethylene matrix is similar to the composition that would be found in biological tissue.

Polyethylene passive samplers (PEs) were deployed throughout the Cleveland $(\mathrm{OH})$ area on the southern shore of Lake Erie during June-September, 2013. Extracts 
from PEs were analyzed for PAHs and OPEs and were also analyzed via an in vitro bioassay to measure AhR induction. The objectives of this study were to (i) investigate the use of PEs as a viable vehicle for isolating gaseous HOCs to use in bioassay exposures, (ii) explore whether AhR-mediated potency of the extracts correlated significantly with any compound or compound group measured in the extracts, and (iii) compare predicted potency based on chemical analysis to observed potency from bioassay analysis to determine what portion of AhR-mediated potency could be predicted from known chemical composition.

We expected that AhR-mediated potency and gaseous concentrations of OPEs and PAHs in PE extracts would be greatest at densely populated urban sites located near the city center, and that some correlation would be seen between gaseous PAH concentrations and relative potency. However, we also expected that BaP-equivalents calculated from targeted PAH chemical analysis $\left(\mathrm{BaPEq}_{\mathrm{chem}}\right)$ would likely underestimate the potency observed in bioassay experiments and that, unlike what is usually found for particulate air pollution, $\mathrm{BaP}$ concentration would not correlate significantly with the relative AhR-mediated potency of gas-phase extracts.

\section{METHODS}

Passive Air Sampler Deployment. $800-\mu \mathrm{m}$ low-density polyethylene sheeting (United Plastics, Inc.) was cut into approximately 3 in. $x 5$ in. pieces and cleaned in solvent (DCM and hexane) to remove background contamination. At each of nine sampling sites throughout the Cleveland area, four polyethylene sheets (PEs) were 
fastened inside an inverted stainless steel bowl using zip-ties and the bowl was suspended so that the PEs were hanging at approximately $2 \mathrm{~m}$ height.

In order to calculate ambient concentrations from deployed PEs, performance reference compounds (PRCs) are often added to the PE for in situ calibration of sampling rates. However, PRCs could not be added to the PEs intended for bioassays because these compounds could interfere with bioassay responses. A set of three 50$\mu$ m-thick PEs, preloaded with PRCs by incubation in an 80:20 methanol:water solution, were also co-deployed at each site to allow for sampling rate determination in all PEs after deployment.

A map of the study region is shown in Figure 5-1 and characteristics of the deployment sites are summarized in Table 5-1. Deployments took place during June to September of 2013, with each set of PEs deployed for about 60 days. After deployment, PEs were removed from the protective bowl, wrapped in precombusted aluminum foil, and shipped on ice overnight to the University of Rhode Island Graduate School of Oceanography, where they were frozen until extraction.

Sample Preparation. Each PE was extracted twice in pentane, each time for 18-24 hours, along with a laboratory blank, which was a PE that had been cleaned alongside the field samples and then stored frozen in precombusted aluminum foil while the other PEs were deployed. All four 800- $\mu \mathrm{m}$ PEs from the same site were composited into one extract and concentrated to $1 \mathrm{~mL}$ in a warm water bath under a gentle stream of nitrogen. Extracts from $800-\mu \mathrm{m}$ PEs appeared to contain a white precipitate, possibly from coextracted polyethylene material. To remove the particulate, extracts were serially frozen, causing the precipitate to solidify at the bottom of the vial, and 
then the overlying liquid was removed. After this, two aliquots were removed from the $1 \mathrm{~mL}$ solution: one for chemical analysis and the other for biological analysis. A schematic summarizing sample preparation is shown in Figure S5-1.

Chemical Analysis by GC/MS. Aliquots of $50 \mu \mathrm{L}$ were spiked with internal standards acenaphthene- $d_{10}$, phenanthrene- $d_{10}$, chrysene- $d_{12}$, and perylene- $d_{12}$ for quantification. These samples were analyzed on an Agilent 6890 GC coupled to an Agilent 5973 MSD in electron impact (EI, $70 \mathrm{eV}$ ) mode for 22 PAHs, 18 alkylated PAHs, and (in a separate GC/MS run) 12 organophosphate esters (OPEs) using an Agilent J\&W DB-5 fused capillary column (30 m x $0.25 \mathrm{~mm}$ I.D.). Extracts were also analyzed in negative chemical ionization (NCI) mode with methane reagent gas for 12 brominated diphenyl ethers (BDEs), 8 novel halogenated flame retardants (NHFRs), and 3 polybrominated biphenyls (PBBs). A complete list of target compounds and abbreviations is available in the SI (Table S5-1).

To avoid interference with biological assays, samples were not spiked with internal standard prior to extraction and so were not corrected for internal standard recoveries. Dosing solution concentrations were not blank-subtracted before use in data interpretation. This was considered appropriate as we were primarily interested in determining the actual concentration present in the bioassay exposure solution. Ambient Air Concentrations. The composition of HOCs in PEs differs from the ambient composition of gas-phase HOCs in air because the concentration in polyethylene is dependent not only on gas-phase concentrations, but also on the affinity of each compound for the PE matrix and the rate at which the compound is absorbed into the PE. In order to compare the composition of solutions used in 
bioassay experiments to the actual composition of gaseous HOCs expected in ambient air, air concentrations were calculated based on the results of the chemical analysis of PE extracts. Concentrations of PAHs and OPEs per weight PE were blank-subtracted using the co-extracted laboratory PE Blank. Concentrations below 25\% of the PE Blank were considered $<$ DL, and all $<$ DL values were replaced with 0 .

To translate concentrations within the PE to concentrations in ambient air, the volume of air sampled by each PE during deployment was estimated using data on the percent loss of labeled PRCs from co-deployed $50 \mu$ m-thick PEs. From the PRC loss data, the best-fit value for the thickness of the diffusive boundary layer (DBL) at the air-PE interface was determined. Because all PEs were deployed under the same conditions and the thickness of the PE sheet does not affect air-side resistance, the DBL thickness determined for thin sheets was then plugged into a two-film model describing PE-side and air-side mass transfer rates to calculate the percent equilibration reached by each target compound in the $800 \mu \mathrm{m}$-thick PEs. This approach for estimation of percent equilibration from PRC loss data has been described in detail in previous work. ${ }^{25,26}$

Biological Analysis by Reporter Cell Bioassay. Aliquots for biological analysis were transferred to $200 \mu \mathrm{L}$ of DMSO and blown down under a gentle stream of nitrogen to constant volume. This stock solution was used to create a 10-point dilution curve for each sample, including the PE blank.

The AhR reporter cell line used was H1G1.1c3, a murine hepatoma cell line consisting of Hepa-1c1c7 cells stably transfected with AhR-responsive green fluorescence protein (GFP) reporter gene developed by Nagy et al. ${ }^{27} 100 \mu \mathrm{L}$ of cells 
per well were treated with $1 \mu \mathrm{L}$ of each sample dilution in triplicate in a Costar 96well black plate with a clear bottom. For each test extract, the cells in three wells were treated with $1 \mu \mathrm{L}$ of DMSO as a negative control, and the cells in another set of three wells were left untreated to control for any natural cell fluorescence. On each plate, three wells were treated with benzo(a)pyrene $(\mathrm{BaP})$ at a final well concentration of $1.2 \times 10^{-7} \underline{\mathrm{M}}$ dissolved in DMSO as a positive control. On one plate, a 10-point dilution curve was also run for $\mathrm{BaP}\left(1.2 \times 10^{-12}-1.2 \times 10^{-3} \underline{\mathrm{M}}\right)$, and results were normalized to the positive control $1.2 \times 10^{-7} \underline{\mathrm{M} B a P}$ (Figure S5-2).

Cells were incubated at $33{ }^{\circ} \mathrm{C}$ and AhR-mediated potency was measured by reading the GFP fluorescence emitted by the cells at $515 \mathrm{~nm}$ using a Spectra Max M3 plate reader at 24 and 48 hours post dosing (hpd). The mean fluorescence value of the DMSO-treated negative control triplicate wells was subtracted from each sample's fluorescence readings, and then the response was expressed as a ratio over the mean fluorescence value of the triplicate $1.2 \times 10^{-7} \underline{\mathrm{M}} \mathrm{BaP}$ positive controls wells run on the same plate to control for plate-to-plate differences in cell response.

Determining Relative Potency. Data from 48-hpd readings were fitted to a fourparameter log-logistic dose-response model with the lower bound set to 0 using $\mathrm{R}$ package $d r c{ }^{28}$ The upper bound was set to the maximum observed response in all cases where response reached a plateau or decreased at highest dosages, but was not set for the extract from Cleveland Lakefront $\# 1$ because response continued increasing up to the maximum dose. The response $f$ occurring as a result of dosage $x$ is modeled as in Equation 1, where $c$ is the lower bound value (set to 0 ), $d$ is the upper bound 
value, $b$ determines slope steepness, and $e$ is the concentration achieving $50 \%$ of maximum efficacy $\left(\mathrm{EC}_{50}\right)$.

$$
f(x)=\frac{d-c}{1+\exp (b(\log (e)-\log (x))}
$$

In addition to the $\mathrm{EC}_{50}, \mathrm{EC}_{\mathrm{BaP} 20}$ and $\mathrm{EC}_{\mathrm{BaP} 50}$ were calculated as alternative measures of relative potency. The $\mathrm{EC}_{\mathrm{BaP} 20}$ and $\mathrm{EC}_{\mathrm{BaP} 50}$ are the doses achieving $20 \%$ and $50 \%$ of the effect observed for the positive control, $1.2 \times 10^{-7} \underline{\mathrm{M}} \mathrm{BaP}$. The $\mathrm{EC}_{\mathrm{BaP} 50}$ was identified as a more useful metric than $\mathrm{EC}_{50}$ because the extracts' dose-response curves were not parallel and maximum efficacy varied among curves.

Dosing solutions were prepared so that each sample was representative of the same amount of extracted PE to facilitate comparison with the PE blank. However, due to site-to-site variability in sampling rates, the volume of air represented by each sample was different (Table 5-1). For this reason, after determination of $\mathrm{EC}_{\mathrm{BaP} 50}$ from the dose-response curve fit, $\mathrm{EC}_{\mathrm{BaP} 50}$ values were normalized based on volume of air sampled at each site. Aliquots of PE extracts used in dosing solutions were representative of $1900-3100 \mathrm{~m}^{3}$ of air, and were all normalized to $2000 \mathrm{~m}^{3}$.

To compare predicted potency based on chemical composition and observed potency based on bioassay experiments, BaP equivalents had to be calculated for both sets of data. For concentrations measured via chemical analysis, $\mathrm{BaP}$ equivalents in each mixture $\left(\mathrm{BaPEq}_{\mathrm{chem}}\right)$ were determined as in Equation 2 by multiplying the concentration of each compound in the dosing solution $\left(\mathrm{C}_{n}\right)$ by the compound's potency relative to $\mathrm{BaP}$ (expressed as induction equivalency factor, $\mathrm{IEF}_{n}$ ) from Machala et al., ${ }^{16}$ and summing results for all compounds. Concentrations in the 
dosing solution were normalized based on volume of air sampled before BaPEq $\mathrm{Chem}_{\mathrm{c}}$ calculations were done.

$$
B a P E q_{c h e m}=\Sigma\left(I E F_{n} \cdot C_{n}\right)(n g / \mu L)
$$

For comparison to bioassay results, the relative potency of each sample extract was expressed as the amount of $\mathrm{BaP}$ that would be needed to achieve the same response. The bio-derived toxic equivalency $\left(\mathrm{BaPEq}_{\mathrm{bio}}\right)$ was calculated as in Equation 3 as the ratio of the $\mathrm{EC}_{\mathrm{BaP} 50}$ for the $\mathrm{BaP}$ curve, expressed in $\mathrm{ng} \mathrm{BaP}$ added to the well to achieve $50 \%$ of the $1.2 \times 10^{-7} \mathrm{BaP}$ positive control response, and the $\mathrm{EC}_{\mathrm{BaP} 50}$ of the extract, expressed as $\mu \mathrm{L}$ of dosing solution added to the well.

$$
B a P E q_{b i o}=\frac{E C_{B a P 50}[B a P](n g / \text { well })}{E C_{B a P 50}[\text { Extract }](\mu L / \text { well })}
$$

The degree to which chemical analysis can explain observed potency $\left(\%_{\text {chem }}\right)$ was then expressed as the percent of observed potency predicted by $\mathrm{BaPEq}_{\text {chem, }}$ as in Equation 4.

$$
\%_{\text {chem }}=\frac{B a P E q_{c h e m}}{B a P E q_{b i o}} \cdot 100
$$

\section{RESULTS AND DISCUSSION}

Chemical Composition of Bioassay Dosing Solutions. Concentrations of PAHs and OPEs in the bioassay dosing solution and estimated ambient air concentrations are displayed in Figure 5-2. Total PAHs and alkylated PAHs $\left(\Sigma_{40} \mathrm{PAH}\right)$ in the dosing solution ranged from $3.6 \mathrm{ng} / \mu \mathrm{L}$ for the extract from Cuyahoga National Park to 33.7 ng/ $\mu \mathrm{L}$ for University Heights. Concentrations were dominated by phenanthrene (10- 
$\left.57 \% \Sigma_{40} \mathrm{PAH} ; 0.6-16.3 \mathrm{ng} / \mu \mathrm{L}\right)$, fluoranthene (1-18\%; 0.1-6 ng/ $\left.\mu \mathrm{L}\right), 2-$

methylphenanthrene (1-6\%; 0.1-1 ng/ $\mu \mathrm{L})$, and fluorene $(3-9 \% ; 0.3-1 \mathrm{ng} / \mu \mathrm{L})$. Total OPEs $\left(\Sigma_{12} \mathrm{OPE}\right.$ ) ranged from $0.7 \mathrm{ng} / \mu \mathrm{L}$ for the extract from Cuyahoga National Park to $3.4 \mathrm{ng} / \mu \mathrm{L}$ for Kent, with concentrations generally dominated by TDCIPP $(10-51 \%$; 0.1-1 ng/ $\mu \mathrm{L})$ and TEHP $(8-40 \% ; 0.1-0.6 \mathrm{ng} / \mu \mathrm{L})$. All dosing solution concentrations for field samples were normalized to an air volume of $2000 \mathrm{~m}^{3}$. Concentrations of all compounds in dosing solutions are presented in the SI for PAHs (Table S5-2), OPEs (Table S5-3), and brominated flame retardants (BFRs; Table S5-4).

2-ring, 3-ring, and 4-ring PAHs, as well as their alkylated and substituted counterparts, were generally correlated in the different dosing solutions $\left(0.3 \leq \mathrm{r}^{2} \leq\right.$ 0.9), while 5-6-ring PAHs showed little correlation with the other compounds (Table S5-5). Correlation among PAHs was further confirmed by principal component analysis (PCA), which showed that $76 \%$ of variation in samples was explained by two principal components, the first with loadings primarily from 3-4-ring PAHs, and the second with loadings primarily from 2-ring and 4-5-ring PAHs (Figure S5-3). The OPEs generally varied independently of one another, though some degree of correlation $\left(\mathrm{r}^{2} \geq 0.3\right)$ was observed between some pairs, including TCEP and TCIPP, and TDCIPP and EHDPP (Table S5-6). There were few correlations found between the PAHs and OPEs, though TnBP was found to correlate with 2-4-ring PAHs (Table S5-7).

Ambient Air Concentrations. Ambient gaseous concentrations of $\Sigma_{40} \mathrm{PAH}$ ranged from $7.1 \mathrm{ng} / \mathrm{m}^{3}$ in Cuyahoga National Park to $36.2 \mathrm{ng} / \mathrm{m}^{3}$ at Cleveland Downtown 1, and were dominated by the methylnaphthalenes $\left(18-33 \% ; 1.7-8.8 \mathrm{ng} / \mathrm{m}^{3}\right)$, 
phenanthrene $\left(2-33 \% ; 0.3-9.8 \mathrm{ng} / \mathrm{m}^{3}\right)$, and fluorene $\left(5-14 \% ; 0.5-2.6 \mathrm{ng} / \mathrm{m}^{3}\right)$.

Concentrations were similar in range to those measured by Peverly in Chicago using polyurethane foam passive samplers (PUFs) in 2012-2014 $\left(\Sigma_{16} \mathrm{PAH}=9-52 \mathrm{ng} / \mathrm{m}^{3}\right)$, and by Melymuk et al. in Toronto in 2007-2008 $\left(\Sigma_{27} \mathrm{PAH}=0.3-51 \mathrm{ng} / \mathrm{m}^{3}\right)$, also using PUFs. ${ }^{12,29}$ Concentrations in this study were similar but lower than previous measurements of total gaseous PAHs using PEs in the downtown Cleveland area by McDonough et al. in $2012\left(\Sigma_{15} \mathrm{PAH}=23-80 \mathrm{ng} / \mathrm{m}^{3}\right){ }^{9}$ In larger-scale regional studies, atmospheric concentrations of PAHs have often been found to correlate with population density, ${ }^{9,30}$ but here, no significant $(\mathrm{p}<0.05)$ correlation between gaseous with population density within 5-30 km was observed.

Gaseous concentrations of $\Sigma_{12} \mathrm{OPE}$ ranged from $0.02 \mathrm{ng} / \mathrm{m}^{3}$ in Cuyahoga National Park to $1.2 \mathrm{ng} / \mathrm{m}^{3}$ in Kent. This was similar in range to measurements by Peverly et al. in Chicago using PUFs in 2012-2014 $\left(\Sigma_{13} \mathrm{OPE}=0.5-1.5 \mathrm{ng} / \mathrm{m}^{3}\right)$, and slightly lower than measurements of particulate $\Sigma_{12} \mathrm{OPE}$ in the Cleveland area by Salamova et al. in $2012\left(\right.$ mean $\left.\Sigma_{12} \mathrm{OPE}=2.1 \pm 0.4 \mathrm{ng} / \mathrm{m}^{3}\right){ }^{11,12}$ TCIPP was the most abundant OPE at most sites $\left(9-90 \% ; 0.01-1.0 \mathrm{ng} / \mathrm{m}^{3}\right)$ with the exception of University Heights, where TnBP dominated $\left(86 \% ; 0.6 \mathrm{ng} / \mathrm{m}^{3}\right)$. TCIPP was also found to be most abundant in Cleveland particulate $\Sigma_{12} \mathrm{OPE}$ by Salamova et al. $\left(0.85 \pm 0.3 \mathrm{ng} / \mathrm{m}^{3}\right) .{ }^{11}$

Figure 5-2 compares the composition of the dosing solutions used in bioassay experiments and of ambient gaseous PAHs and OPEs. Dosing solutions were enriched in more moderately hydrophobic compounds, such as fluoranthene and TDCIPP, which make up a lower percentage of total HOCs in the gaseous fraction of ambient air but have a greater affinity for the PE matrix. 
Dose-Response Curves for PE Extracts. Extracts from all PEs, including the PE Blank, induced dose-dependent activation of AhR-dependent GFP. All dose-response data are displayed along with curve fits and 95\% confidence intervals in Figure 5-3, with response represented as a ratio compared to response elicited by the BaP positive control. For all extracts, an initial increase in GFP induction was seen with increasing dosage. However, there was a precipitous decline in the fluorescence of all extracts (except Cleveland Lakefront 1) at the greatest dosing levels, possibly due to cytotoxicity or inhibition of the fluorescence response at high concentrations. These points were omitted during dose-response curve fitting, as we were interested in determining only the relative induction potency of the extracts. Most extracts did not exhibit a clear plateau in response, making determination of maximum efficacy, as well as $\mathrm{EC}_{50}$, somewhat uncertain. Furthermore, maximum efficacy of the samples varied from $94 \%-230 \%$ of $1.2 \times 10^{-7} \underline{\mathrm{M}}$ BaP response (Table 5-2). For this reason, $\mathrm{EC}_{\mathrm{BaP} 50}$, measured relative to the plate-specific positive control, was used to compare potency of samples.

The $\mathrm{EC}_{\mathrm{BaP} 50}$ and $\mathrm{EC}_{\mathrm{BaP} 20}$ of each extract, normalized for volume of air sampled during each deployment, are displayed in Table 5-2, along with each extract's maximum observed efficacy. The letters to the right of each $\mathrm{EC}_{\mathrm{BaP} 50}$ divide the values into 5 groups based on whether they are similar to each other within the range of the standard error. Values of $\mathrm{EC}_{\mathrm{BaP} 50}$ ranged from $0.5 \pm 0.1 \mathrm{~g} \mathrm{PE} / \mathrm{mL}$ at Downtown Cleveland 1 to $6.6 \pm 1.2 \mathrm{~g} \mathrm{PE} / \mathrm{mL}$ at Cuyahoga National Park.

The three rural/residential sites had the lowest potency (greatest $\mathrm{EC}_{\mathrm{BaP} 50}$ values), ranging from $2.6-6.6 \mathrm{~g} \mathrm{PE} / \mathrm{mL}$, followed by the two Cleveland Lakefront 
sites. The most potent extracts were from the three Cleveland Downtown sites and one semi-urban residential site (University Heights, a densely populated suburb). This contrasts with work by Klein et al., where no change in potency of gaseous extracts was observed between urban and rural samples with distinct chemical compositions, but is consistent with work by Ersekova et al, where extracts from impacted sites were found to be more potent in AhR bioassays than extracts from rural sites. ${ }^{10,22}$ The relative potency of the PE Blank $\left(\mathrm{EC}_{\mathrm{BaP} 50}=23 \pm 5 \mathrm{~g} \mathrm{PE} / \mathrm{mL}\right)$ was significantly lower than all field samples when compared using the $\mathrm{EC}_{\mathrm{BaP} 50}$ values, prior to adjusting for volume of air sampled. Blank comparisons were done before normalizing for the volume of air sampled so that each sample would be representative of the same mass of extracted polyethylene.

Relative potency and maximum efficacy of the extracts did not appear to be correlated. This is most likely due to a complex interplay between the unique composition of ligands in each sample, their affinity for the AhR, the resulting ligandreceptor complex's ability to bind other necessary transcription factors, and cytotoxicity of specific components. Response could also be affected by ligands interacting with other pathways that could amplify or dampen AhR response. Klein et al. also observed a lack of correlation between relative potency of extracts and maximum efficacy with respect to AhR binding of gas-phase extracts from active air sampling. ${ }^{10}$

Initial bioassay experiments demonstrated that treated cells' fluorescence responses increased over time from 16 to $48 \mathrm{hpd}$, so all responses reported here were measured at $48 \mathrm{hpd}$. This is in contrast to other studies of potency with respect to 
AhR activation for environmental samples, most of which have used a luciferase reporter rather than the GFP reporter used here. For example, Machala et al. measured greatest potency at $6 \mathrm{hpd}$, most likely due to PAH metabolism ${ }^{16}$ and Kennedy et al. observed steadily decreasing potency in extracts from 24 to 72 hpd. ${ }^{20}$ This difference is most likely due to differences in induction kinetics and increased stability of the GFP reporters compared to the luciferase reporter. ${ }^{31}$ It is also possible that some of the response observed in this study was due to compounds that were less readily metabolized than PAHs and OPEs.

Bioassay-Derived BaP Equivalents for PE Extracts. A map displaying results for $\mathrm{BaPEq}_{\mathrm{bio}}$ is displayed alongside maps of total concentrations of PAHs and OPEs in the dosing solution $\left(\Sigma_{40} \mathrm{PAH}\right.$ and $\left.\Sigma_{12} \mathrm{OPE}\right)$ in Figure 5-4. BaPEq $q_{\mathrm{bio}}$ values ranged from 21$283 \mathrm{ng} / \mu \mathrm{L} \mathrm{BaP}$ and were generally greatest in the downtown Cleveland area and lowest at the rural/residential sites further from the city center.

$\mathrm{BaPEq}_{\text {bio }}$ values were compared to concentrations of PAHs, OPEs, and halogenated flame retardants (PBDEs and NHFRs) measured in the dosing solutions to determine whether there was any significant correlation between relative potency of extracts and their chemical composition. Though some correlations were found, few seemed likely to be driving potency. No correlations with PBDE and NHFR content were observed. BaPEq $q_{\text {bio }}$ weakly correlated only with 2-ring alkyl/substituted PAHs $\left(\mathrm{r}^{2}\right.$ $=0.42 ; \mathrm{p}<0.1 ; \mathrm{SE}=64 ; \mathrm{N}=9$ ) and also displayed correlation with two OPEs, $\operatorname{TDCIPP}\left(\mathrm{r}^{2}=0.58 ; \mathrm{p}<0.05 ; \mathrm{SE}=54 ; \mathrm{N}=9\right)$ and EHDPP $\left(\mathrm{r}^{2}=0.73 ; \mathrm{p}<0.01 ; \mathrm{SE}=\right.$ 44; $\mathrm{N}=9$ ). TDCIPP is a known carcinogen and has previously been associated with altering expression of mRNA involved in AhR activation along with other 
pathways, ${ }^{17,18}$ while less is known about biological effects of EHDPP. Maximum efficacy of PE extracts showed some correlation with concentrations of 3-ring $\left(\mathrm{r}^{2}=\right.$ $0.61 ; \mathrm{p}<0.05 ; \mathrm{SE}=31 ; \mathrm{N}=9)$ and 4-ring non-alkylated PAHs $\left(\mathrm{r}^{2}=0.48 ; \mathrm{p}<0.05\right.$; $\mathrm{SE}=36 ; \mathrm{N}=9)$ and no relationship to OPE concentrations.

Predicted BaP Equivalents from Chemical Analysis. The BaPEq ${ }_{\mathrm{chem}}$ of each dosing solution was calculated based on PAH concentrations from GC/MS analysis. No dataset for the specific cell line used here was available, so IEFs were taken from Machala et al., ${ }^{16}$ who measured PAH-induced AhR-mediated response in a rat hepatoma H4IIE cell line stably transfected with luciferase reporter gene. IEFs were not available for all PAHs, so calculated $\mathrm{BaPEq}_{\mathrm{chem}}$ values are representative only of 14 PAHs (Table S5-8).

$\mathrm{BaPEq}_{\text {chem }}$ values calculated using potencies from Machala et al. ranged from 1.6 to $7.9 \mathrm{ng} / \mu \mathrm{L} \mathrm{BaP}$, as shown in Table 5-3. The percent of $\mathrm{BaPEq}_{\mathrm{bio}}$ accounted for by $\mathrm{BaPEq}_{\mathrm{chem}}$ is also displayed. The percent contribution of individual PAHs to the total predicted $\mathrm{BaPEq}_{\text {chem }}$ are displayed in Figure 5-5. Contributions to $\mathrm{BaPEq}_{\text {chem }}$ appear dominated by high molecular weight PAHs that were present at low concentrations in the dosing solution, including dibenz(a,h)anthracene (DBA), indeno(1,2,3-c,d)pyrene (IND), benzo(b/k)fluoranthene (BBKFLRA), and chrysene (CHRY).

Potencies calculated from known chemical composition using IEFs explained only $2-23 \%$ of the AhR-mediated potency observed in bioassay experiments, and $\mathrm{BaPEq}_{\mathrm{chem}}$ and $\mathrm{BaPEq}_{\mathrm{bio}}$ were not found to be significantly correlated. This suggests that other compound groups, including nitro- and oxy-PAHs, additional substituted 
PAHs, and persistent halogenated pollutants such as the polychlorinated biphenyls (PCBs) and other halogenated species, may also be influencing $\mathrm{BaPEq}_{\mathrm{bio}}$ of gas-phase extracts, along with other unknown pollutants and their transformation products. A major weakness of predicting potency based on compound IEFs is that it considers only additive interactions and ignores synergistic and antagonistic effects, which are highly probable in complex environmental mixtures. This, along with the scarcity of IEF values for the targeted compounds, most likely contributed to the discrepancy between observed and predicted relative potency.

\section{CONCLUSIONS}

This study demonstrated the use of PEs coupled with in vitro bioassays as an approach to measure cumulative biological effects of ambient gaseous air pollution. While some activity was seen in the PE blank, the relative potency of field samples was found to be significantly elevated above blank levels, suggesting that interference from the PE matrix or typical laboratory contamination did not prohibit the use of PE extracts in bioassays for AhR-mediated potency.

AhR-mediated potency was found to vary significantly between different sites, and was greatest in downtown Cleveland. Relative potency of the extracts displayed some correlation with PAHs common in the gaseous phase, though causative links are difficult to establish. This study agreed with previous studies that have suggested the $\mathrm{BaPEq}_{\text {chem }}$ approach underestimates risks of exposure, as AhR activation caused by PAHs in a mixture may be synergistic, or the potency predicted from target 
compounds could be augmented by other unmonitored chemicals in the mixture and their unforeseen interactions.

\section{ASSOCIATED CONTENT}

Supporting Information. Additional figures and tables are available in the Supporting Information. This material is available free of charge via the Internet at http://pubs.acs.org.

\section{AUTHOR INFORMATION}

\section{Corresponding Author}

* Rainer Lohmann: rlohmann@uri.edu

\section{ACKNOWLEDGMENTS}

We acknowledge funding from the US EPA Great Lakes Restoration Initiative (GLRI) GLAS \#00E00597-0, project officer Todd Nettesheim. Funding was also provided by National Institute of Environmental Health Sciences (NIEHS) grant P42ES007381 (Superfund Basic Research Program at Boston University). We thank Angela Slitt (URI) for consulting on experimental design and Mike Denison (UC Davis) for providing the H1G1 cells. 


\section{LITERATURE CITED}

(1) Grimmer, G.; Brune, H.; Dettbarn, G.; Jacob, J.; Misfeld, J.; Mohr, U.; Naujack, K.-W.; Timm, J.; Wenzel-Hartung, R. Relevance of polycyclic aromatic hydrocarbons as environmental carcinogens. Fresenius J. Anal. Chem. 1991, 339, 792-795, DOI:10.1007/BF00321747.

(2) Gungormus, E.; Tuncel, S.; Hakan Tecer, L.; Sofuoglu, S. C. Inhalation and dermal exposure to atmospheric polycyclic aromatic hydrocarbons and associated carcinogenic risks in a relatively small city. Ecotoxicol. Environ. Saf. 2014, 108, 106-113, DOI:10.1016/j.ecoenv.2014.06.015.

(3) Weschler, C. J.; Nazaroff, W. W. SVOC exposure indoors: Fresh look at dermal pathways. Indoor Air 2012, 22, 356-377, DOI:10.1111/j.1600-

0668.2012.00772.x.

(4) Kobayashi, R.; Cahill, T. M.; Okamoto, R. A.; Maddalena, R. L.; Kado, N. Y. Controlled exposure chamber study of uptake and clearance of airborne polycyclic aromatic hydrocarbons by wheat grain. Environ. Sci. Technol. 2007, 41, 7934-7940, DOI:10.1021/es071459x.

(5) Kobayashi, R.; Okamoto, R. A.; Maddalena, R. L.; Kado, N. Y. Polycyclic aromatic hydrocarbons in edible grain: A pilot study of agricultural crops as a human exposure pathway for environmental contaminants using wheat as a model crop. Environ. Res. 2008, 107, 145-151, DOI:10.1016/j.envres.2007.11.002.

(6) Boström, C.-E.; Gerde, P.; Hanberg, A.; Jernström, B.; Johansson, C.; Kyrklund, T.; Rannug, A.; Törnqvist, M.; Victorin, K.; Westerholm, R. Cancer risk assessment, indicators, and guidelines for polycyclic aromatic hydrocarbons in the ambient air. Environ. Health Perspect. 2002, 110, 451489, DOI:10.1289/ehp.02110s3451.

(7) Barrado, A. I.; García, S.; Sevillano, M. L.; Rodríguez, J. A.; Barrado, E. Vapor-phase concentrations of PAHs and their derivatives determined in a large city: Correlations with their atmospheric aerosol concentrations. Chemosphere 2013, 93, 1-7, DOI:10.1016/j.chemosphere.2013.05.031.

(8) Ramírez, N.; Cuadras, A.; Rovira, E.; Marcé, R. M.; Borrull, F. Risk assessment related to atmospheric polycyclic aromatic hydrocarbons in gas and particle phases near industrial sites. Environ. Health Perspect. 2011, 119, 1110 1116, DOI:10.1289/ehp.1002855. 
(9) McDonough, C. A.; Khairy, M. A.; Muir, D. C. G.; Lohmann, R. Significance of population centers as sources of gaseous and dissolved PAHs in the lower Great Lakes. Environ. Sci. Technol. 2014, 48, 7789-7797, DOI:10.1021/es501074r.

(10) Klein, G. P.; Hodge, E. M.; Diamond, M. L.; Yip, A.; Dann, T.; Stern, G.; Denison, M. S.; Harper, P. A. Gas-phase ambient air contaminants exhibit significant dioxin-like and estrogen-like activity in vitro. Environ. Health Perspect. 2005, 114, 697-703, DOI:10.1289/ehp.8496.

(11) Salamova, A.; Ma, Y.; Venier, M.; Hites, R. A. High levels of organophosphate flame retardants in the Great Lakes atmosphere. Environ. Sci. Technol. Lett. 2014, 1, 8-14, DOI:10.1021/ez400034n.

(12) Peverly, A. A.; Ma, Y.; Venier, M.; Rodenburg, Z.; Spak, S. N.; Hornbuckle, K. C.; Hites, R. A. Variations of flame retardant, polycyclic aromatic hydrocarbon, and pesticide concentrations in Chicago's atmosphere measured using passive sampling. Environ. Sci. Technol. 2015, 49, 5371-5379, DOI:10.1021/acs.est.5b00216.

(13) Brommer, S.; Jantunen, L. M.; Bidleman, T. F.; Harrad, S.; Diamond, M. L. Determination of vapor pressures for organophosphate esters. J. Chem. Eng. Data 2014, 59, 1441-1447, DOI:10.1021/je401026a.

(14) O’Connell, S. G.; Kincl, L. D.; Anderson, K. A. Silicone wristbands as personal passive samplers. Environ. Sci. Technol. 2014, 48, 3327-3335, DOI:10.1021/es405022f.

(15) McGee, S. P.; Konstantinov, A.; Stapleton, H. M.; Volz, D. C. Aryl phosphate esters within a major pentaBDE replacement product induce cardiotoxicity in developing zebrafish embryos: Potential role of the aryl hydrocarbon receptor. Toxicol. Sci. 2013, 133, 144-156, DOI:10.1093/toxsci/kft020.

(16) Machala, M.; Vondráček, J.; Bláha, L.; Ciganek, M.; Neča, J. Aryl hydrocarbon receptor-mediated activity of mutagenic polycyclic aromatic hydrocarbons determined using in vitro reporter gene assay. Mutat. Res. - Genet. Toxicol. Environ. Mutagen. 2001, 497, 49-62, DOI:10.1016/S1383-5718(01)00240-6.

(17) State of California Environmental Protection Agency Office of Environmental Health Hazard Assessment. Safe Drinking Water and Toxic Enforcement Act of 1986. Chemicals Known to the State to Cause Cancer of Reproductive Toxicity.; 2014. 
(18) Liu, C.; Wang, Q.; Liang, K.; Liu, J.; Zhou, B.; Zhang, X.; Liu, H.; Giesy, J. P.; $\mathrm{Yu}, \mathrm{H}$. Effects of tris(1,3-dichloro-2-propyl) phosphate and triphenyl phosphate on receptor-associated mRNA expression in zebrafish embryos/larvae. Aquat. Toxicol. 2013, 128-129, 147-157, DOI:10.1016/j.aquatox.2012.12.010.

(19) Denison, M. S.; Soshilov, A. A.; He, G.; Degroot, D. E.; Zhao, B. Exactly the same but different: Promiscuity and diversity in the molecular mechanisms of action of the aryl hydrocarbon (dioxin) receptor. Toxicol. Sci. 2011, 124, 1-22, DOI:10.1093/toxsci/kfr218.

(20) Kennedy, K.; Macova, M.; Bartkow, M. E.; Hawker, D. W.; Zhao, B.; Denison, M. S.; Mueller, J. F. Effect based monitoring of seasonal ambient air exposures in Australia sampled by PUF passive air samplers. Atmos Pollut Res. 2010, 1, 50-58, DOI:10.1007/s10661-014-3667-z.

(21) Novák, J.; Jálová, V.; Giesy, J. P.; Hilscherová, K. Pollutants in particulate and gaseous fractions of ambient air interfere with multiple signaling pathways in vitro. Environ. Int. 2009, 35, 43-49, DOI:10.1016/j.envint.2008.06.006.

(22) Érseková, A.; Hilscherová, K.; Klánová, J.; Giesy, J. P.; Novák, J. Effect-based assessment of passive air samples from four countries in Eastern Europe.

Environ. Monit. Assess. 2014, 186, 3905-3916, DOI:10.1007/s10661-0143667-z.

(23) Melymuk, L.; Robson, M.; Helm, P. A.; Diamond, M. L. Evaluation of passive air sampler calibrations: Selection of sampling rates and implications for the measurement of persistent organic pollutants in air. Atmos. Environ. 2011, 45, 1867-1875, DOI:10.1016/j.atmosenv.2011.01.011.

(24) Joyce, A. S.; Portis, L. M.; Parks, A. N.; Burgess, R. M. Evaluating the relationship between equilibrium passive sampler uptake and aquatic organism bioaccumulation. Environ. Sci. Technol. 2016, 50, 11437-11451, DOI:10.1021/acs.est.6b03273.

(25) McDonough, C. A.; Puggioni, G.; Helm, P. A.; Muir, D.; Lohmann, R. Spatial distribution and air-water exchange of organic flame retardants in the lower great lakes. Environ. Sci. Technol. 2016, 50, 9133-9141, DOI:10.1021/acs.est.6b02496.

(26) McDonough, C. A.; Helm, P. A.; Muir, D.; Puggioni, G.; Lohmann, R. Polycyclic musks in the air and water of the lower Great Lakes: Spatial distribution and volatilization from surface waters. Environ. Sci. Technol. 2016, 50, 11575-11583, DOI:10.1021/acs.est.6b03657. 
(27) Nagy, S. R.; Sanborn, J. R.; Hammock, B. D.; Denison, M. S. Development of a green fluorescent protein-based cell bioassay for the rapid and inexpensive detection and characterization of Ah receptor agonists. Toxicol. Sci. 2002, 65, 200-210, DOI:10.1093/toxsci/65.2.200.

(28) Ritz, C.; Baty, F.; Streibig, J. C.; Gerhard, D. Dose-response analysis using R. PLoS One 2015, 10, 1-13, DOI:10.1371/journal.pone.0146021.

(29) Melymuk, L.; Robson, M.; Helm, P. A.; Diamond, M. L. PCBs, PBDEs, and PAHs in Toronto air: Spatial and seasonal trends and implications for contaminant transport. Sci. Total Environ. 2012, 429, 272-280, DOI:10.1016/j.scitotenv.2012.04.022.

(30) Hafner, W. D.; Carlson, D. L.; Hites, R. A. Influence of local human population on atmospheric polycyclic aromatic hydrocarbon concentrations. Environ. Sci. Technol. 2005, 39, 7374-7379, DOI:10.1021/es0508673.

(31) Han, D.; Nagy, S. R.; Denison, M. S. Comparison of recombinant cell bioassays for the detection of Ah receptor agonists. BioFactors 2004, 20, 11-22, DOI:10.1002/biof.5520200102.

(32) Center for International Earth Science Information Network (CIEISIN); Columbia University; International Food Policy Research Institute (IFPRI); The World Bank; Centro Internacional de Agricultura Tropical (CIAT). Global Rural-Urban Mapping Project, Version 1 (GRUMPv1): Population Count Grid http://sedac.ciesin.columbia.edu/data/set/grump-v1-population-count. 


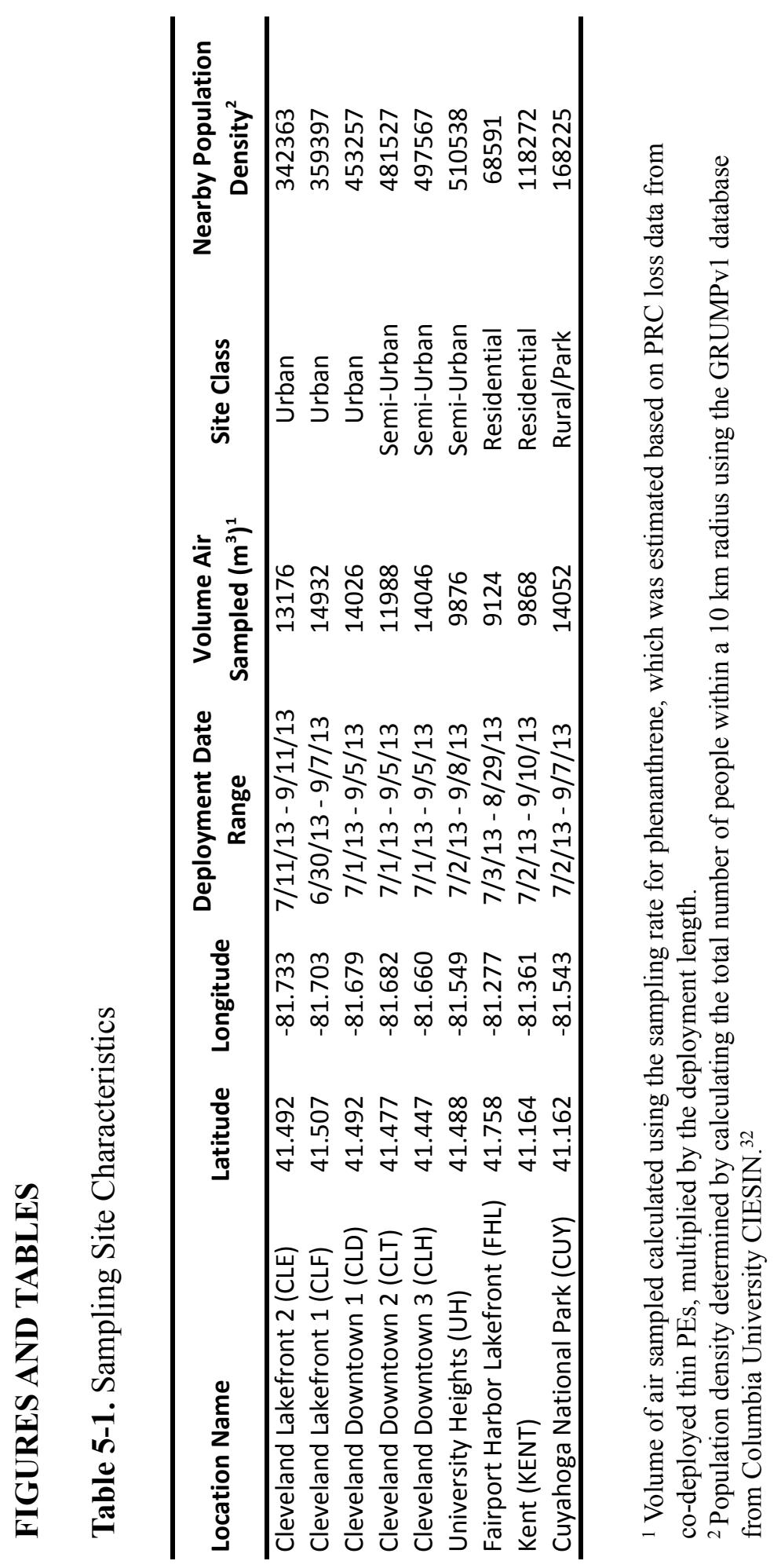




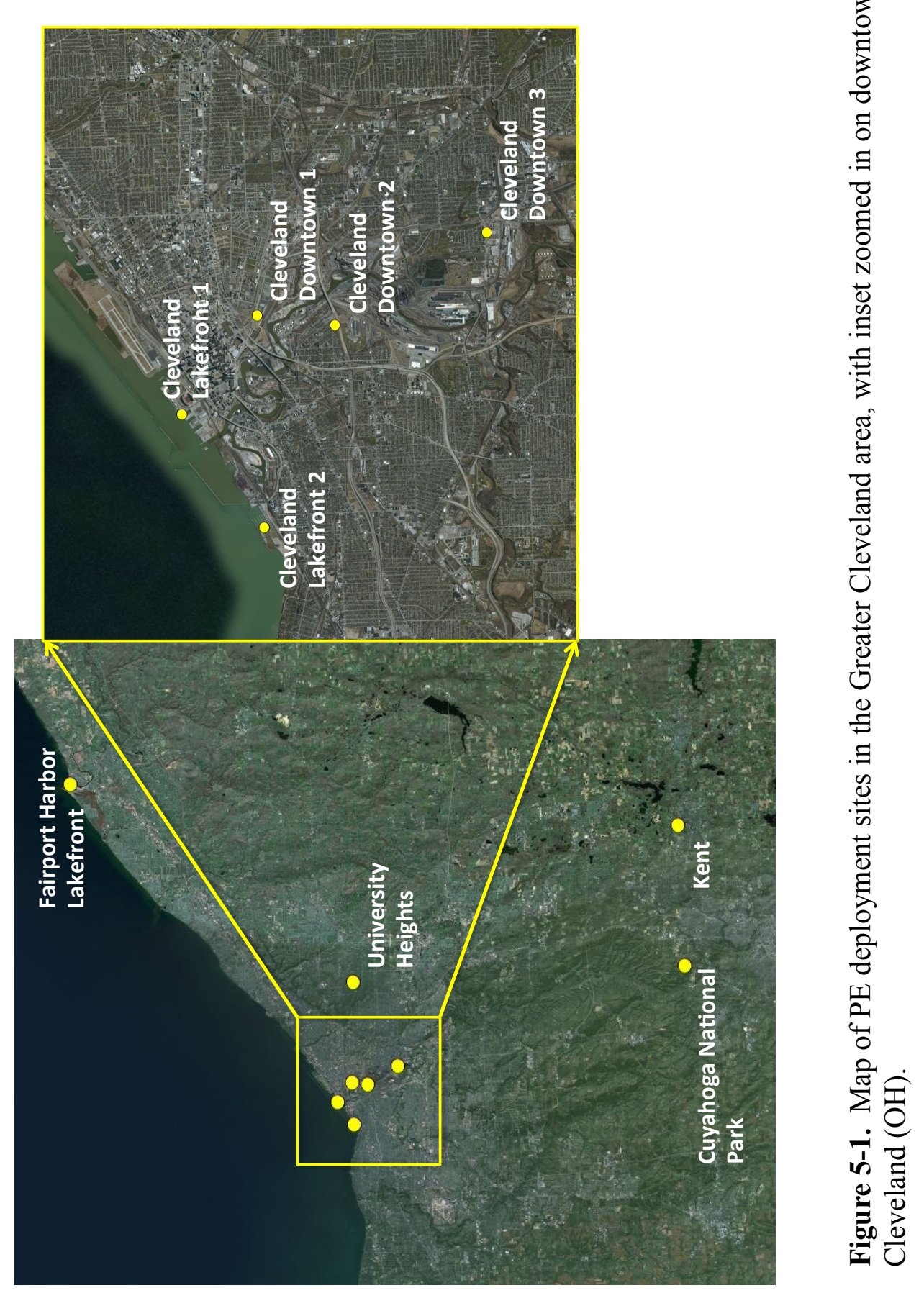



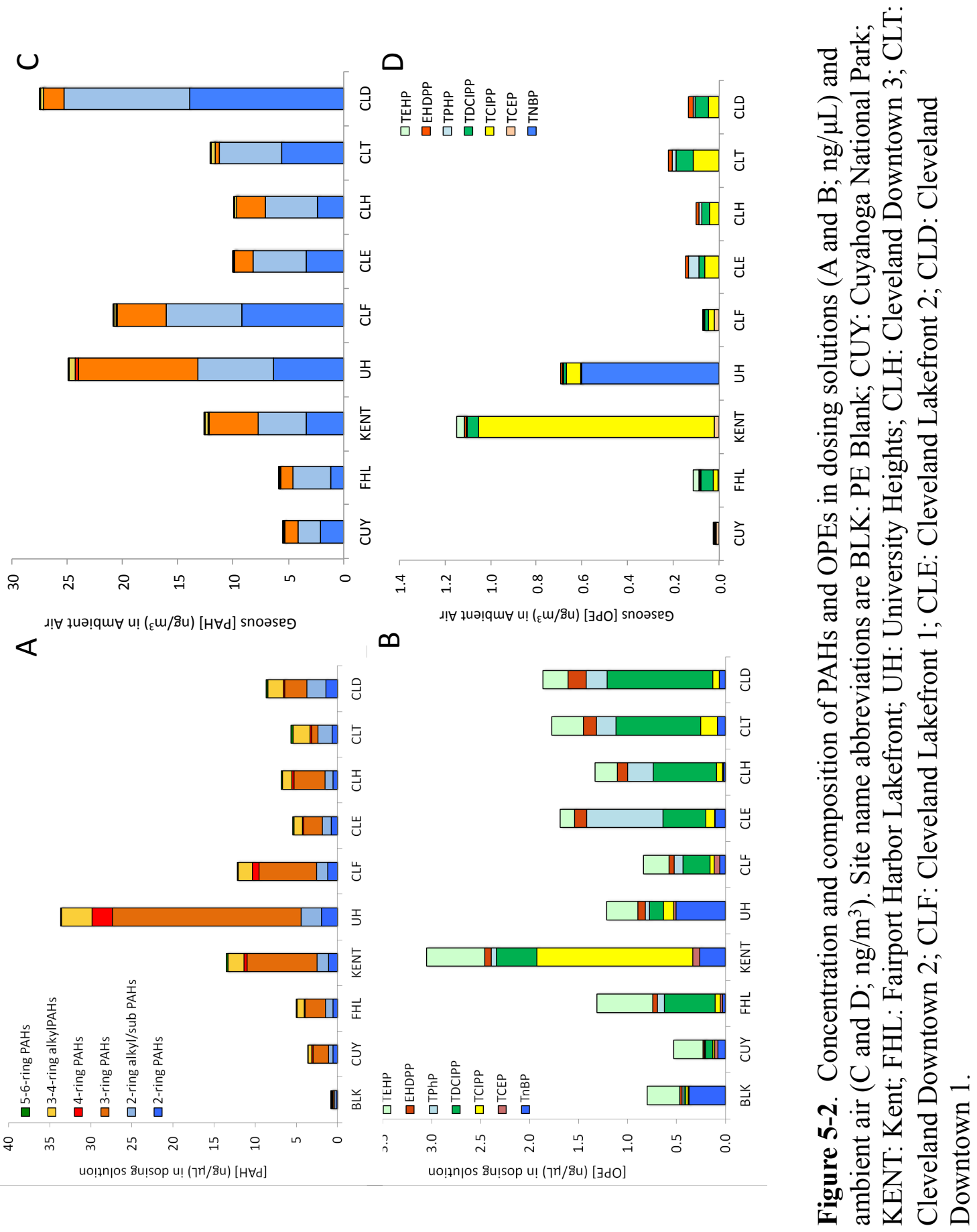

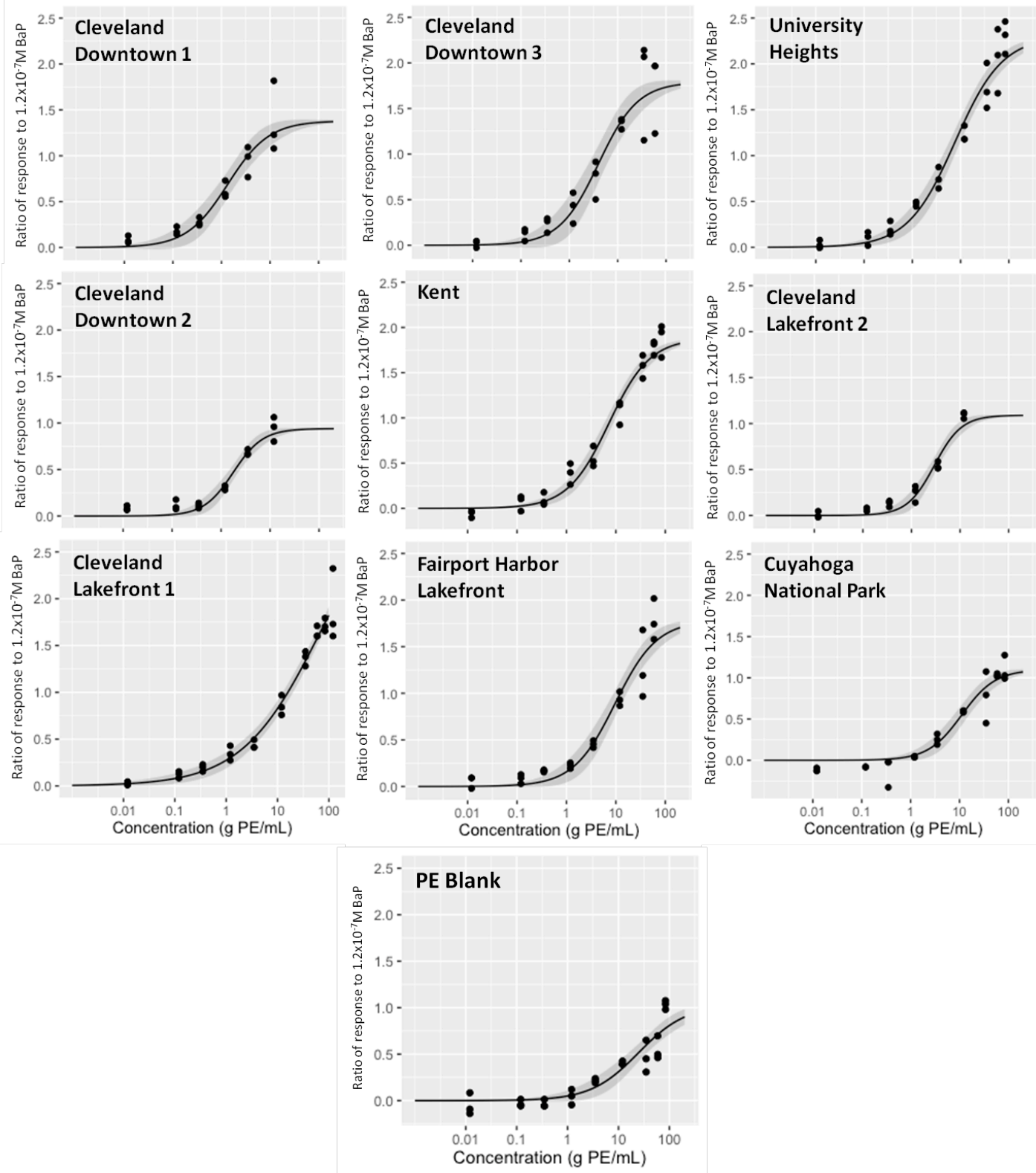

Figure 5-3. Dose-response curves for triplicate cell exposures to PE extract dilution curves, including the PE Blank. Relative potency was greatest for Cleveland Downtown 1 and lowest for the PE Blank. Dose is expressed as the mass of PE extracted per $\mathrm{mL}$ DMSO in each dosing solution. Efficacy is expressed as the ratio of the response to PE extract as compared to the response of the positive control (1.2 $\mathrm{x}$ $\left.10^{-7} \mathrm{MBaP}\right)$. 


\begin{tabular}{lcclc}
\hline Sample & $\begin{array}{c}\mathrm{EC}_{\text {BaP20 }} \\
(\mathrm{g} \mathrm{PE} / \mathrm{mL})\end{array}$ & $\begin{array}{c}\mathrm{EC}_{\mathrm{BaP50}} \\
(\mathrm{g} \mathrm{PE} / \mathrm{mL})\end{array}$ & $\begin{array}{c}\text { Max Efficacy } \\
(\%+\text { control })\end{array}$ \\
\hline Cuyahoga National Park & $2.3 \pm 0.6$ & $6.6 \pm 1.2$ & $\mathrm{a}$ & $110 \pm 15$ \\
Fairport Harbor Lakefront & $1.4 \pm 0.5$ & $4.1 \pm 0.9 \mathrm{~b}$ & $178 \pm 22$ \\
Kent & $0.9 \pm 0.2$ & $2.6 \pm 0.4 \mathrm{c}$ & $188 \pm 18$ \\
Cleveland Lakefront 1 & $0.4 \pm 0.1$ & $2.2 \pm 1.2 \mathrm{~b}, \mathrm{c}, \mathrm{d}, \mathrm{e}$ & $188 \pm 39$ \\
Cleveland Lakefront 2 & $0.8 \pm 0.2$ & $1.9 \pm 0.2 \mathrm{~d}$ & $109 \pm 4$ \\
Cleveland Downtown 2 & $0.6 \pm 0.1$ & $1.6 \pm 0.2 \mathrm{~d}, \mathrm{e}$ & $94 \pm 13$ \\
University Heights & $0.5 \pm 0.1$ & $1.6 \pm 0.3 \mathrm{~d}, \mathrm{e}$ & $230 \pm 18$ \\
Cleveland Downtown 3 & $0.4 \pm 0.2$ & $1.1 \pm 0.3 \mathrm{e}$ & $179 \pm 55$ \\
Cleveland Downtown 1 & $0.2 \pm 0.1$ & $0.5 \pm 0.1 \mathrm{f}$ & $138 \pm 39$ \\
\hline
\end{tabular}

Table 5-2. Relative potency and maximum efficacy of PE extracts, with relative potency values normalized based on volume of air sampled and maximum efficacy normalized to the response of the positive control $\left(1.2 \times 10^{-7} \mathrm{M} \mathrm{BaP}\right)$.

\begin{tabular}{lccc} 
Sample & BaPEq $_{\mathbf{b i o}}$ & $\mathbf{B a P E q}_{\mathbf{c h e m}}$ & $\mathbf{\% B a p E q}_{\mathbf{c h e m}} \mathbf{B}_{\mathbf{B}} \mathbf{P E q}_{\mathbf{b i o}}$ \\
\hline Cuyahoga National Park & 21 & 1.6 & $7 \%$ \\
Fairport Harbor Lakefront & 35 & 2.5 & $23 \%$ \\
Kent & 54 & 7.9 & $11 \%$ \\
Cleveland Lakefront 1 & 64 & 2.9 & $4 \%$ \\
Cleveland Lakefront 2 & 75 & 3.0 & $6 \%$ \\
Cleveland Downtown 2 & 89 & 6.1 & $7 \%$ \\
University Heights & 89 & 4.7 & $3 \%$ \\
Cleveland Downtown 3 & 129 & 5.8 & $2 \%$ \\
Cleveland Downtown 1 & 283 & 6.0 & $2 \%$ \\
\hline
\end{tabular}

Table 5-3. BaP equivalents derived from chemical analysis $\left(\mathrm{BaPEq}_{\mathrm{chem}}\right)$ and bioassays $\left(\mathrm{BaPEq}_{\mathrm{bio}}\right)$, and the percent $\mathrm{BaPEq}_{\mathrm{bio}}$ explained by PAHs for which IEF values were available. 


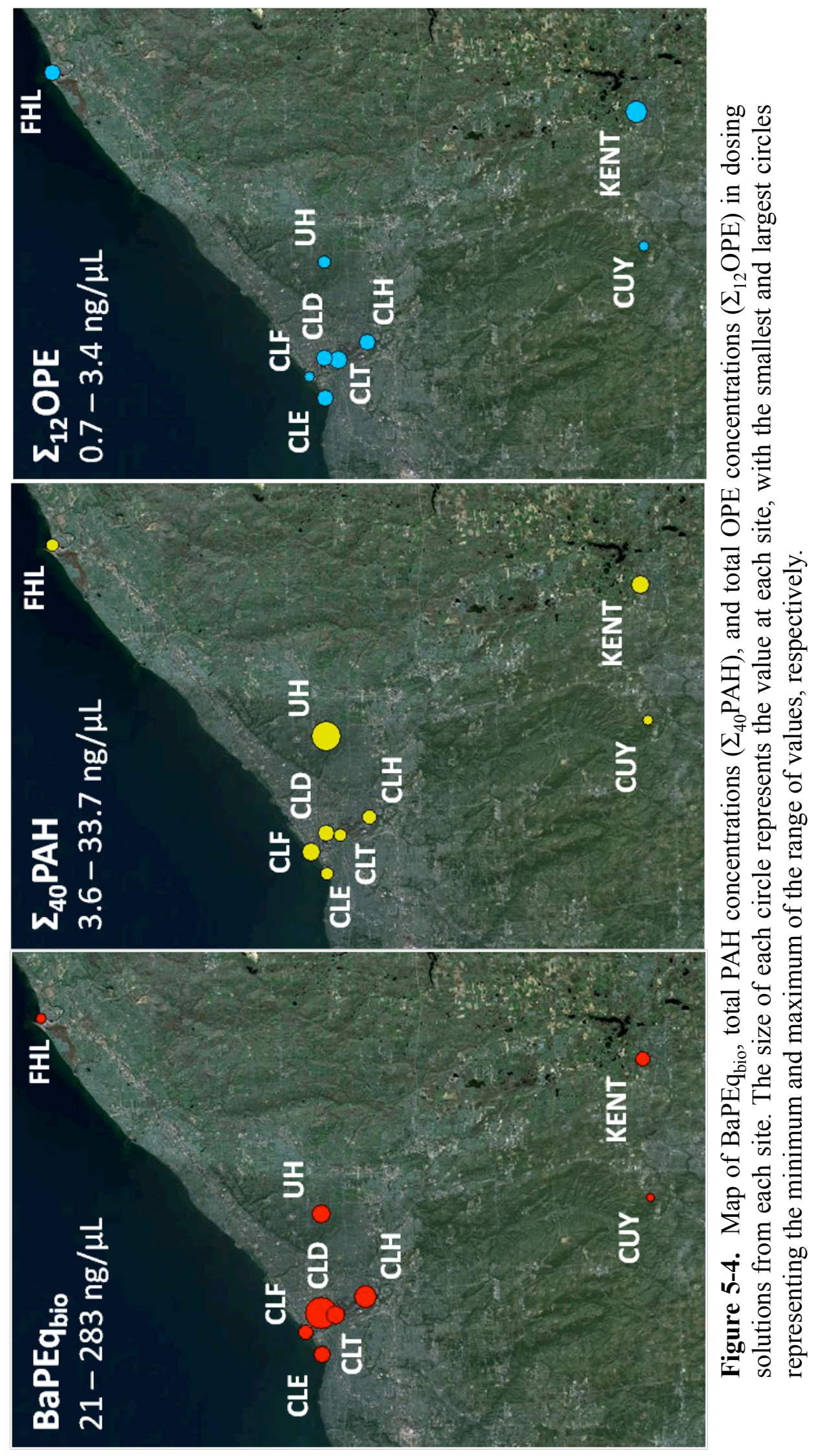




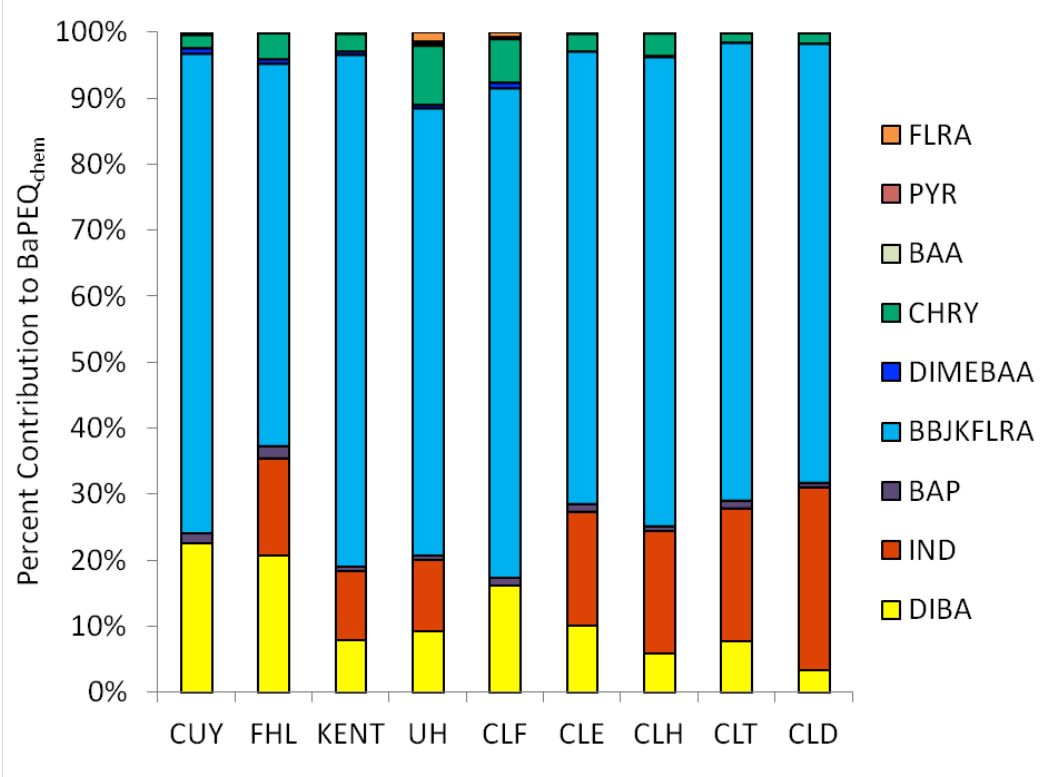

Figure 5-5. Relative contribution of $\mathrm{PAHs}$ to $\mathrm{BaPEQ}_{\mathrm{chem}}$, based on IEFs from Machala et al. 


\section{SUPPLEMENTARY INFORMATION:}

INVESTIGATING ARYL HYDROCARBON-MEDIATED POTENCY OF GAS-PHASE AMBIENT AIR USING IN VITRO BIOASSAYS AND PASSIVE SAMPLING

Carrie A. McDonough, Diana G. Franks, Mark E. Hahn, Rainer Lohmann

Total number of pages: 9

Total number of figures: 3

Total number of tables: 8 
Table S5-1. Target compounds and abbreviations used. Compounds marked with '*' were seldom detected and are omitted from figures in the discussion.

\begin{tabular}{|c|c|c|}
\hline \multicolumn{2}{|c|}{ Polycyclic Aromatic Hydrocarbons (PAHs) } & \multirow[t]{2}{*}{ CAS Number } \\
\hline \multicolumn{2}{|c|}{ 2-ring PAHs } & \\
\hline NAP & Naphthalene & $91-20-3$ \\
\hline BIP & Biphenyl & $92-52-4$ \\
\hline ACY & Acenaphthylene & $208-96-8$ \\
\hline ACE & Acenaphthene & $83-32-9$ \\
\hline FLR & Fluorene & $86-73-7$ \\
\hline \multicolumn{3}{|c|}{ 2-ring alkyl/substituted PAHs } \\
\hline 2MENAP & 2-methylnaphthalene & $91-57-6$ \\
\hline 1MENAP & 1-methylnaphthalene & $90-12-0$ \\
\hline 3MEFLR & 3-methyl fluorene & 2523-39-9 \\
\hline 2MEFLR & 2-methyl fluorene & $1430-97-3$ \\
\hline 1MEFLR & 1-methyl fluorene & $1730-37-6$ \\
\hline 4MEFLR & 4-methyl fluorene & $1556-99-6$ \\
\hline DBF & Dibenzofuran & $132-64-9$ \\
\hline DBT & Dibenzothiophene & $132-65-0$ \\
\hline \multicolumn{3}{|c|}{ 3-ring PAHs } \\
\hline PHN & Phenanthrene & $85-01-8$ \\
\hline ANT & Anthracene & $120-12-7$ \\
\hline FLRA & Fluoranthene & $205-99-2$ \\
\hline \multicolumn{3}{|c|}{ 4-ring PAHs } \\
\hline PYR & Pyrene & $129-00-0$ \\
\hline BAA & Benzo(a)anthracene & $96-55-3$ \\
\hline CHRY & Chrysene & $218-01-9$ \\
\hline BBKFLRA & Benzo(b,k)fluoranthene & $205-99-2 / 209-08-9$ \\
\hline \multicolumn{3}{|c|}{ 3-4-ring alkyIPAHs } \\
\hline 3MEPHN & 3-methyl phenanthrene & $832-71-3$ \\
\hline 2MEPHN & 2-methyl phenanthrene & $2531-84-2$ \\
\hline 2MEANT & 2-methyl anthracene & $613-12-7$ \\
\hline 9MEPHN & 9-methyl phenanthrene & $883-20-5$ \\
\hline 1MEPHN & 1-methylphenanthrene & $832-69-9$ \\
\hline 9MEANT & 9-methyl anthracene & $779-02-2$ \\
\hline 2MEFLRA & 2-methyl fluoranthene & $33543-31-6$ \\
\hline 1MEPYR & 1 methyl pyrene & 2381-21-7 \\
\hline RET & Retene & $483-65-8$ \\
\hline BCPHN & Benzo(c)phenanthrene & $195-19-7$ \\
\hline 6MECHRY & 6-methyl chrysene & $1705-85-7$ \\
\hline 7MEBAA & 7-methyl benz(a)anthracene & $2541-69-7$ \\
\hline DIMEBAA & 7,12-Dimethylbenz(a)anthracene & $57-97-6$ \\
\hline \multicolumn{3}{|c|}{ 5-6-ring PAHs } \\
\hline BEP & Benzo(e)pyrene & $192-97-2$ \\
\hline BAP & Benzo(a)pyrene & $50-32-8$ \\
\hline PER & Perylene & $198-55-0$ \\
\hline IND & Indeno(1,2,3-c,d)pyrene & $193-39-5$ \\
\hline DIBA & Dibenz(a,h)anthracene) & $57-70-3$ \\
\hline BGHIP & Benzo(g,h,i)pyrene & $191-24-2$ \\
\hline $\mathrm{COR}^{*}$ & Coronene & $191-07-1$ \\
\hline
\end{tabular}


Table S5-1, Cont'd. Target compounds and abbreviations used. Compounds marked with '*' were seldom detected and are omitted from figures in the discussion.

\begin{tabular}{|c|c|c|}
\hline \multicolumn{2}{|c|}{ Organophosphate Esters (OPEs) } & \multirow{2}{*}{$\begin{array}{l}\text { CAS Number } \\
126-73-8\end{array}$} \\
\hline $\operatorname{TnBP}$ & tri- $n$-butyl phosphate & \\
\hline TCEP & tris(2-chloroethyl) phosphate & $115-96-8$ \\
\hline TCIPP & tris(1-chloro-2-propyl) phos phate & $13674-84-5$ \\
\hline TDCIPP & tris(1,3-dichloro-2-propyl) phosphate & $13674-87-8$ \\
\hline TPhP & triphenyl phosphate & $115-86-6$ \\
\hline TBEP* & tris(butoxyethyl) phosphate & $78-51-3$ \\
\hline EHDPP & ethylhexyl diphenyl phosphate & $1241-94-7$ \\
\hline TEHP & tris(2-ethylhexyl) phosphate & $78-42-2$ \\
\hline ToCP* & tri-o-cresyl phosphate & $78-30-8$ \\
\hline TmCP* & tri-m-cresyl phosphate & $563-04-2$ \\
\hline ТрСР* & tri- $p$-cresyl phosphate & $78-32-0$ \\
\hline TDBPP* & tris(2,3-dibromo-2-propyl) phosphate & \\
\hline \multicolumn{3}{|c|}{ Brominated Diphenyl Ethers (BDEs) } \\
\hline BDE 2 & 3-bromodiphenyl ether & $6876-00-2$ \\
\hline BDE 8 & 2,4'-dibromodiphenyl ether & $147217-7-8$ \\
\hline BDE 15 & 4,4'-dibromodiphenyl ether & $2050-47-7$ \\
\hline BDE 30 & 2,4,6-tribromodiphenyl ether & $155999-95-4$ \\
\hline BDE 28 & 2,4,4'-tribromodiphenyl ether & $41318-75-6$ \\
\hline BDE 49 & $2,2^{\prime}, 4,5^{\prime}$-tetrabromodiphenyl ether & $243982-82-3$ \\
\hline BDE 47 & 2,2',4,4'-tetrabromodiphenyl ether & $5436-43-1$ \\
\hline BDE 100 & $2,2^{\prime}, 4,4^{\prime}, 6$-pentabromodiphenyl ether & $189084-64-8$ \\
\hline BDE 99 & $2,2^{\prime}, 4,4$ ',5-pentabromodiphenyl ether & $60348-60-9$ \\
\hline BDE 154 & 2,2',4,4',5,6'-hexabromodiphenyl ether & $207122-15-4$ \\
\hline BDE 153 & $2,2^{\prime}, 4,4^{\prime}, 5,5^{\prime}$-hexabromodiphenyl ether & $68631-49-2$ \\
\hline BDE 183 & 2,2',3,4,4',5',6-heptabromodiphenyl ether & $207122-16-5$ \\
\hline \multicolumn{3}{|c|}{ Novel Halogenated Flame Retardants (NHFRs) } \\
\hline pTBX & tetrabromo- $p$-xylene & $23488-38-2$ \\
\hline PBBz & pentabromobenzene & $608-90-2$ \\
\hline PBT & pentabromotoluene & $87-83-2$ \\
\hline PBEB & pentabromoethylbenzene & $85-22-3$ \\
\hline $\mathrm{HBBz}$ & hexabromobenzene & $87-82-1$ \\
\hline BTBPE & 1,2-bis(2,4,6-tribromophenoxy)ethane & $37853-59-1$ \\
\hline SDP & syn-Dechlorane Plus & $13560-89-9$ \\
\hline ADP & anti-Dechlorane Plus & $13560-89-9$ \\
\hline
\end{tabular}




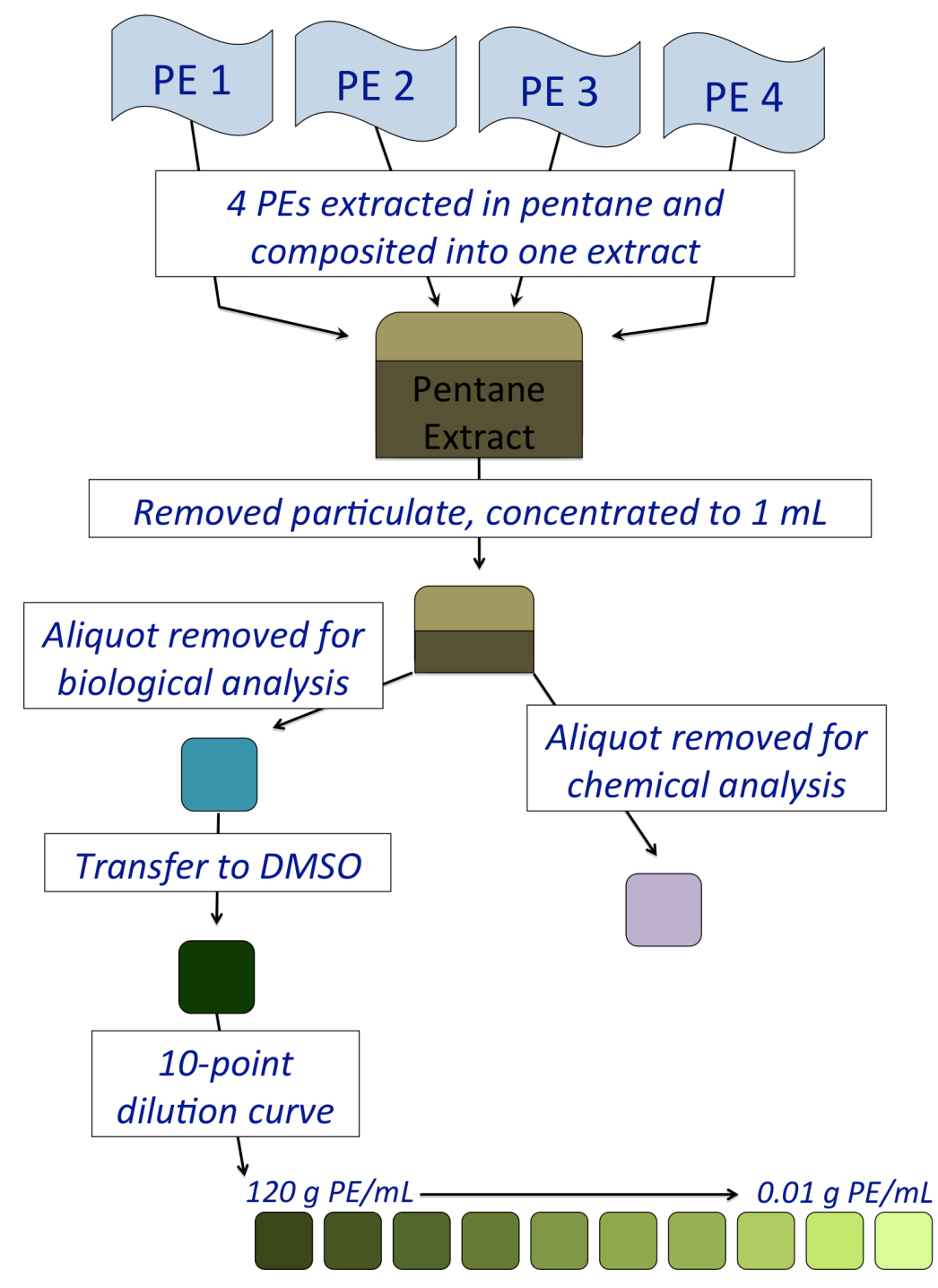

Figure S5-1. Schematic of sample treatment. Four 800- $\mu \mathrm{m}$ PEs were composited in pentane and concentrated to $1 \mathrm{~mL}$ of stock extract. An aliquot was removed and spiked for chemical analysis. Another aliquot was removed for biological analysis, and 


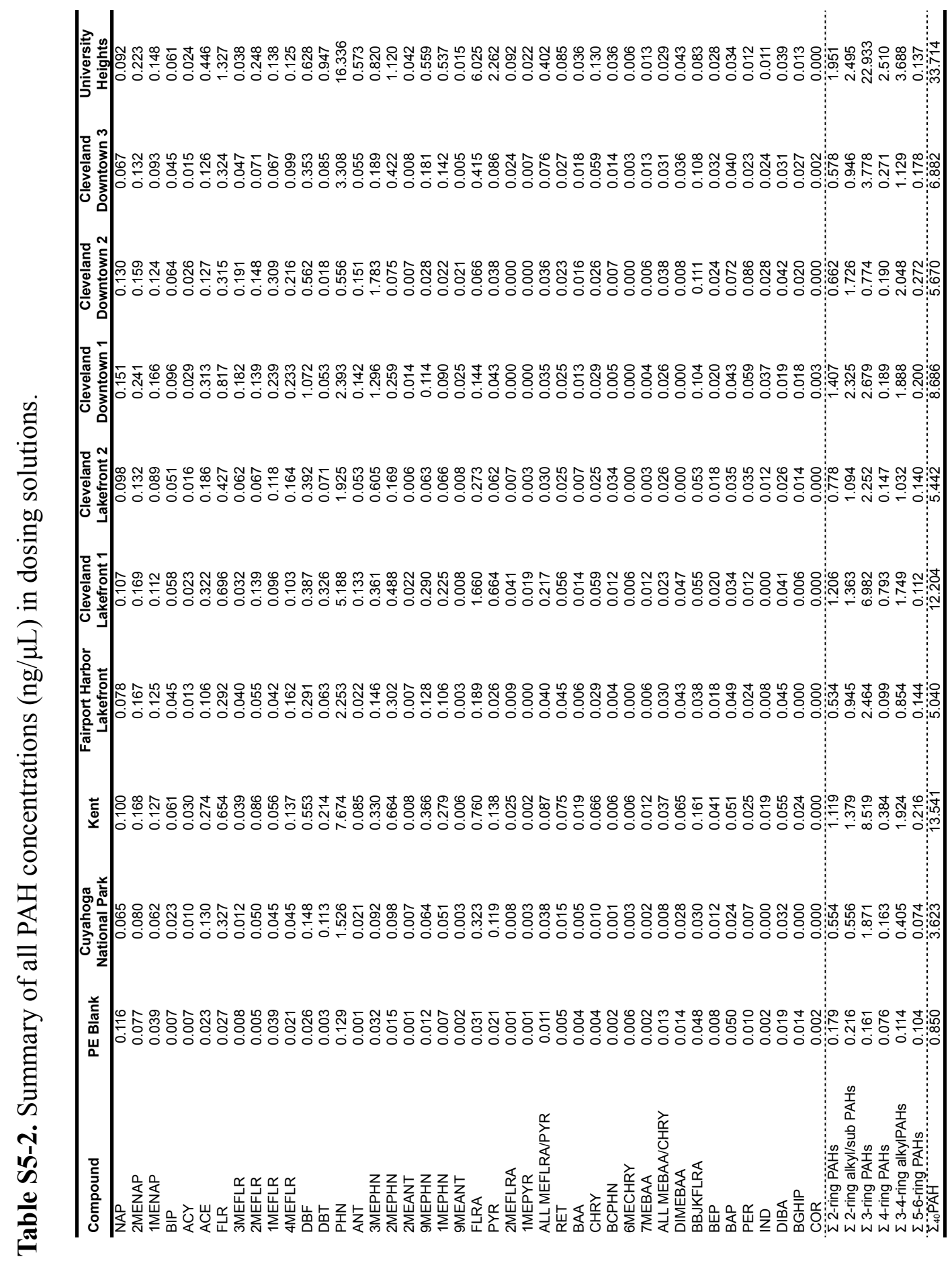




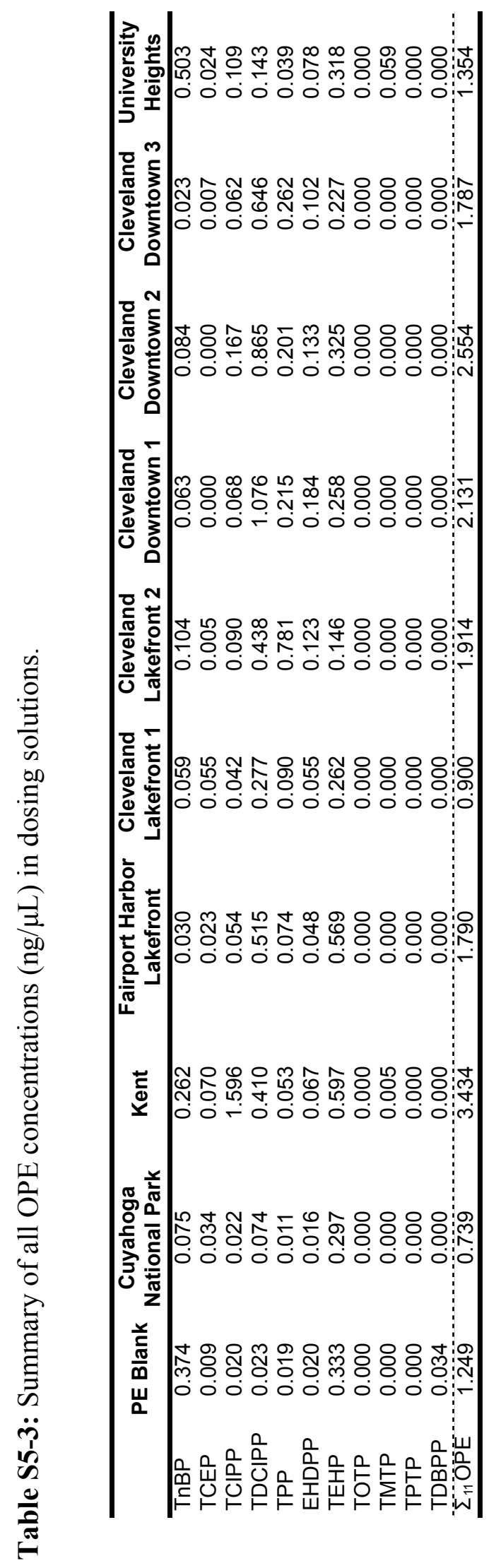




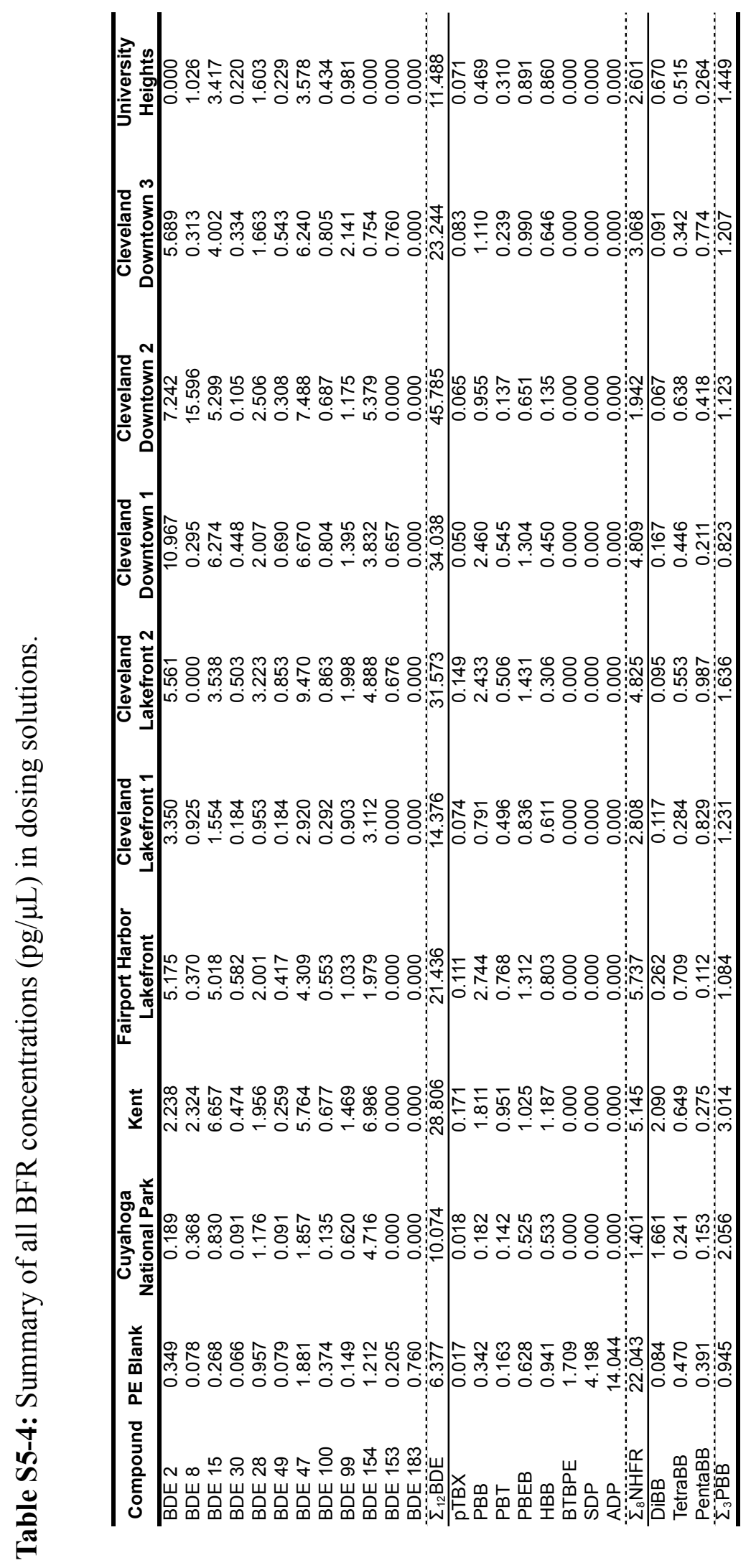




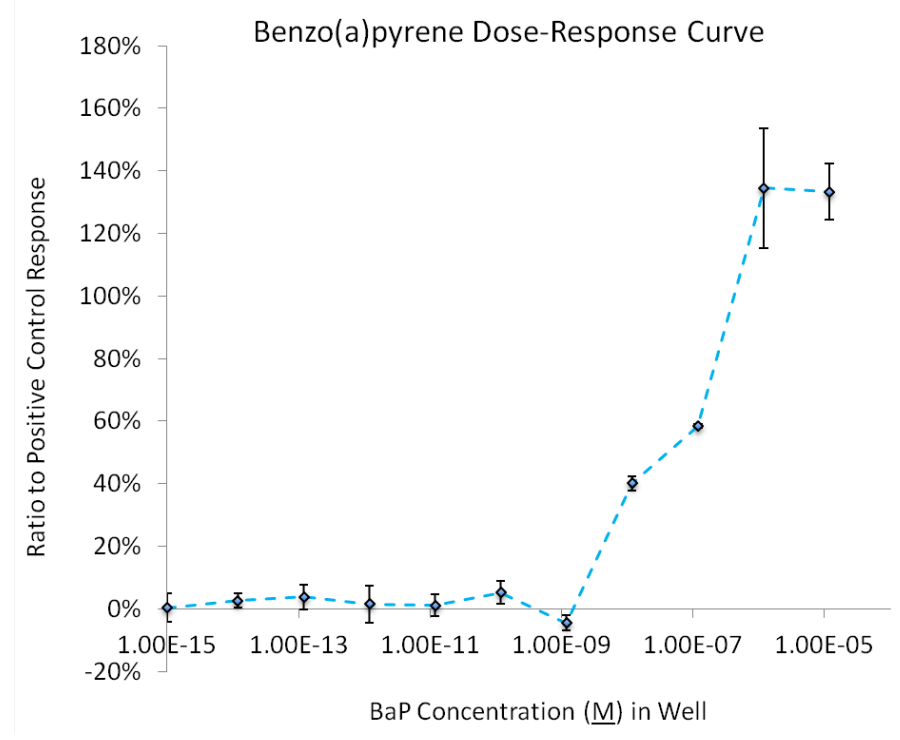

Figure S5-2. BaP Dose-Response Curve, normalized to plate-specific response to $1.2 \times 10^{-7} \mathrm{M} \mathrm{BaP}$. Error bars represent standard deviation of triplicate exposures.
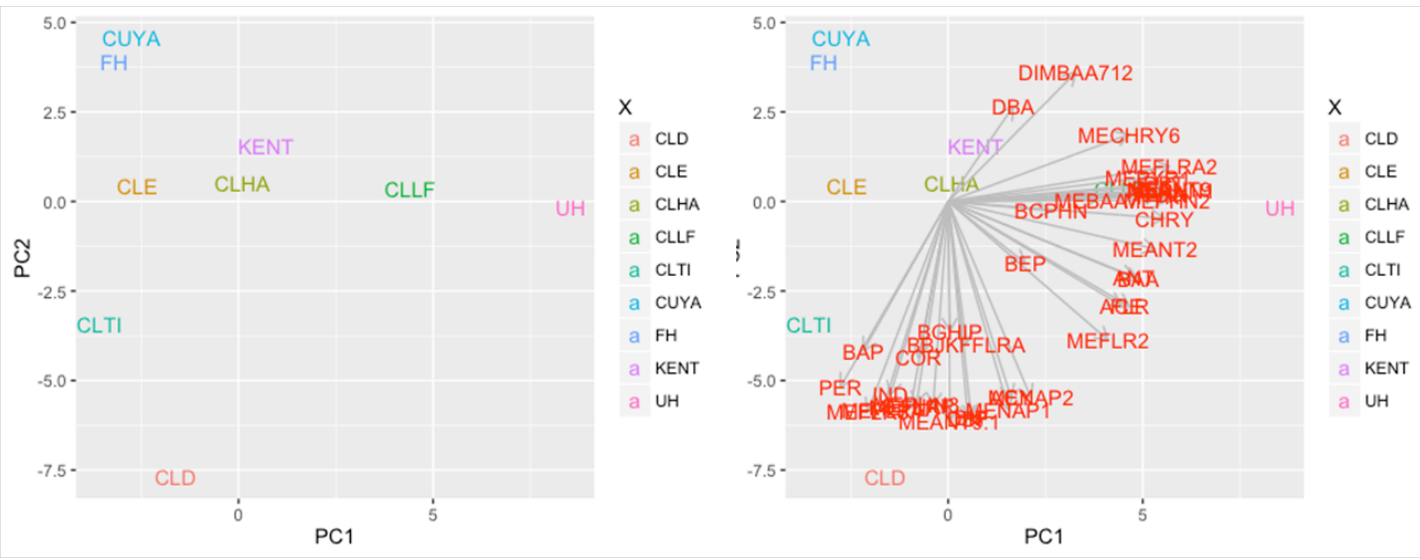

Figure S5-3. Principal component analysis (PCA) of PAHs in dosing solutions. 
Table S5-5. Correlation $\left(\mathrm{r}^{2}\right)$ between groups of PAHs in dosing solutions.

$\begin{array}{lcccccc} & \text { 2-ring PAHs } & \text { 2-ring alkyl/sub PAHs } & \text { 3-ring PAHs } & \text { 4-ring PAHs } & \text { 3-4-ring alkylPAHs } & \text { 5-6-ring PAHs } \\ \text { 2-ring PAHs } & & \mathbf{0 . 7 3} & \mathbf{0 . 6 9} & \mathbf{0 . 6 7} & 0.00 \\ \text { 2-ring alkyl/sub PAHs } & \mathbf{0 . 7 3} & & \mathbf{0 . 3 4} & \mathbf{0 . 3 8} & 0.76 \\ \text { 3-ring PAHs } & \mathbf{0 . 6 9} & \mathbf{0 . 3 4} & & \mathbf{0 . 9 4} & 0.16 \\ \text { 4-ring PAHs } & \mathbf{0 . 6 7} & \mathbf{0 . 3 8} & \mathbf{0 . 9 4} & & \mathbf{0 . 6 9} \\ \text { 3-4-ring alkylPAHs } & \mathbf{0 . 7 6} & \mathbf{0 . 7 9} & \mathbf{0 . 6 9} & \mathbf{0 . 7 1} & 0.71 \\ \text { 5-6-ring PAHs } & 0.00 & 0.16 & 0.03 & 0.04 & 0.10 & 0.10 \\ \end{array}$

Table S5-6. Correlation $\left(\mathrm{r}^{2}\right)$ between OPEs in dosing solutions.

\begin{tabular}{|c|c|c|c|c|c|c|c|c|c|c|c|}
\hline & TnBP & TCEP & TCIPP & TDCIPP & TPP & EHDPP & TEHP & TOTP & TMTP & TPTP & TDBPP \\
\hline TnBP & & 0.03 & 0.11 & 0.19 & 0.06 & 0.01 & 0.03 & NA & NA & NA & NA \\
\hline TCEP & 0.03 & & 0.48 & 0.10 & 0.34 & 0.27 & 0.32 & NA & NA & NA & NA \\
\hline TCIPP & 0.11 & 0.48 & & 0.00 & 0.04 & 0.02 & 0.42 & NA & NA & NA & NA \\
\hline TDCIPP & 0.19 & 0.10 & 0.00 & & 0.06 & 0.73 & 0.01 & NA & NA & NA & NA \\
\hline TPP & 0.06 & 0.34 & 0.04 & 0.06 & & 0.26 & 0.34 & NA & NA & NA & NA \\
\hline EHDPP & 0.01 & 0.27 & 0.02 & 0.73 & 0.26 & & 0.17 & NA & NA & NA & NA \\
\hline TEHP & 0.03 & 0.32 & 0.42 & 0.01 & 0.34 & 0.17 & & NA & NA & NA & NA \\
\hline TOTP & NA & NA & NA & NA & NA & NA & NA & & NA & NA & NA \\
\hline TMTP & NA & NA & NA & NA & NA & NA & NA & NA & & NA & NA \\
\hline TPTP & NA & NA & NA & NA & NA & NA & NA & NA & NA & & NA \\
\hline TDBPP & NA & NA & NA & NA & NA & NA & NA & NA & NA & NA & \\
\hline
\end{tabular}

Table S5-7. Correlation $\left(\mathrm{r}^{2}\right)$ between OPEs and PAH groups in dosing solutions.

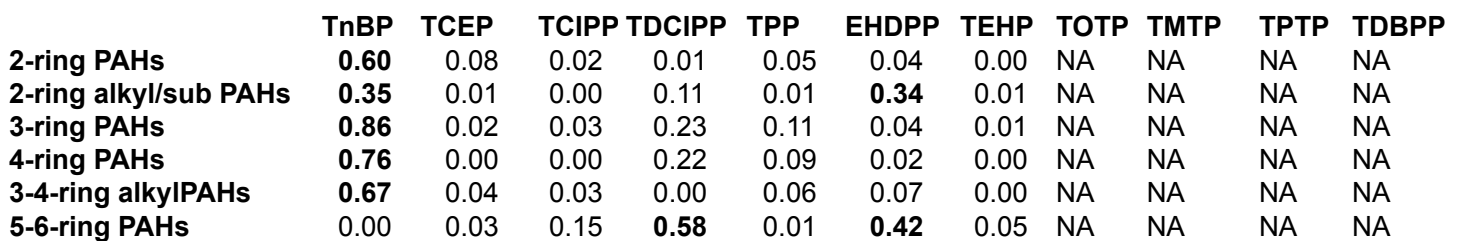


Table S5-8. Induction equivalency factors (IEFs) relative to BaP from Machala et al., collected by exposure of rat hepatoma HGIIE transfected with luciferase reporter and analyzed $6 \mathrm{hpd}$.

\begin{tabular}{lc}
\hline Compound & BaP IEF \\
\hline FLR & NA \\
ANT & NA \\
FLRA & 0.0105 \\
PYR & 0.00757 \\
BAA & 0.39 \\
CHRY & 3.25 \\
BBFLRA & 8.83 \\
BJFLRA & 2.25 \\
BKFLRA & 67.76 \\
BAP & 1 \\
DIBA & 11.46 \\
IND & 44.2 \\
BGHIP & 0.00547 \\
BCPHN & 0.00464 \\
BEP & 0.00227 \\
DIMEBAA & 0.46 \\
1MEPYR & 0.00854 \\
\hline
\end{tabular}




\section{CHAPTER 6}

\section{PARTITIONING OF DISSOLVED ORGANIC FLAME RETARDANTS AND SYNTHETIC FRAGRANCES FROM WASTEWATER INTO POLYETHYLENE PASSIVE SAMPLERS}

This manuscript is formatted for submission to the journal Environmental Science and Technology Letters.

Carrie A. McDonough ${ }^{\dagger}$, Rainer Lohmann ${ }^{\dagger *}$

${ }^{\dagger}$ Graduate School of Oceanography, University of Rhode Island, 215 South Ferry

Road, Narragansett, Rhode Island 02882, United States

*Corresponding Author email: rlohmann@uri.edu; phone: 401-874-6612; fax: 401$874-6811$ 


\section{ABSTRACT}

Polyethylene passive samplers (PEs) are increasingly being used as cost effective tools to measure time-weighted average concentrations of dissolved hydrophobic organic contaminants (HOCs). PEs could be useful for long-term monitoring of emerging wastewater-associated contaminants, including polycyclic musks (PCMs) and organophosphate esters (OPEs). However, the affinity of these compounds for the PE matrix, as well as their uptake rates into PEs, have not been measured. In this study, PEs were deployed along with an active water sampler at the South Kingstown Regional Wastewater Treatment Facility (SK WWTF) in Rhode Island and concentrations of PCMs, OPEs, and polycyclic aromatic hydrocarbons (PAHs) accumulated were measured over 21 days to compare dissolved concentrations derived from both sampling techniques and determine PE-water partitioning coefficients (K $\left.\mathrm{K}_{\mathrm{PEW}}\right)$. PE uptake profiles for HHCB, AHTN, ATII, AHMI, and ADBI suggested these compounds reached equilibrium during the deployment. The equilibrium stage reached by OPEs was more difficult to interpret based on PE uptake profiles though profiles of TpCP, TDBPP, and TEHP suggested they remained in a linear uptake phase, while TCEP equilibrated. $\mathrm{K}_{\mathrm{PEW}}$ values for PAHs, as well as the PCMs HHCB and AHTN, were similar to empirical literature values for equilibrated PAHs while other PCMs and OPEs had a lower affinity for PE than would be predicted from their chemical properties. This suggests that PCM and OPE concentrations derived from PEs deployed in the field using solubility- or $\mathrm{K}_{\mathrm{OW}}$ derived $\mathrm{K}_{\mathrm{PEW}}$ estimates may underestimate ambient dissolved concentrations. 


\section{INTRODUCTION}

Polyethylene passive samplers (PEs) are increasingly being used to measure concentrations of legacy and emerging dissolved organic contaminants in water. PEs accumulate organic contaminants passively over time via diffusion, selecting for the truly dissolved phase. They are gaining attention for their potential as a cost-effective tool to provide time-weighted average concentration measurements for hydrophobic contaminants in many applications, including analyzing spatial distributions, measuring diffusive air-water fluxes, predicting bioaccumulation in aqueous organisms, and monitoring of global waters, including the deep sea. ${ }^{1-6}$ Uptake of hydrophobic organic contaminants like polycyclic aromatic hydrocarbons (PAHs) and polychlorinated biphenyls (PCBs) is fairly well characterized, but uptake of more soluble, moderately polar emerging contaminants has been investigated by only a few recent studies. $^{7-11}$

Many emerging contaminants currently used in consumer products, including synthetic fragrances such as the polycyclic musks (PCMs) and organophosphate ester flame retardants (OPEs) are widespread in the environment, including remote polar and open ocean regions. ${ }^{12-15}$ However, these chemicals' physical properties are poorly constrained and their persistence and long-range transport capabilities are poorly understood. Recent studies have shown that both PCMs and OPEs are introduced to aquatic environments via wastewater, ${ }^{16-18}$ but there is little information about their spatial distribution in global waters. PEs could be useful for long-term, high spatial resolution monitoring programs to investigate global distributions and fluxes of these compounds. However, the affinity of these compounds for the passive sampling 
matrix (PE-water partitioning coefficient, or $\mathrm{K}_{\mathrm{PEW}}$ ), and the uptake rates of these compounds, need to be characterized.

In this study, PEs were deployed in a wastewater settling tank at the South Kingstown Regional Wastewater Treatment Facility (SK WWTF) in Rhode Island and concentrations of polycyclic musks (PCMs), organophosphate esters (OPEs), and polycyclic aromatic hydrocarbons (PAHs) accumulated in PEs were measured over 21 days. PAHs were included in the study because their chemical properties have been studied previously and are better defined than those of PCMs and OPEs. Ambient dissolved concentrations were determined from a simultaneously deployed active sampler and corrected to truly dissolved concentrations using daily dissolved organic carbon (DOC) measurements. The objectives of the study were to (i) measure levels of emerging wastewater-associated pollutants in WWTF effluent, (ii) compare dissolved concentrations derived from passive and DOC-corrected active sampling results, and (iii) determine PE-water partitioning coefficients for compounds that reached equilibrium in the PE membrane.

\section{METHODS}

Study Site. Sampling occurred from September $7^{\text {th }}$ to September $28^{\text {th }}, 2016$ at the SK WWTF. This facility treats, on average, 2.4 million gallons of wastewater per day by coarse screening, comminution, activated sludge, primary settling, fine bubble aeration, secondary settling, chlorination, and dechlorination, and releases treated effluent into the Rhode Island Sound. SK WWTF serves an estimated population of 29,400 people from the Rhode Island communities of South Kingstown (including the 
University of Rhode Island) and Narragansett. ${ }^{19}$ All sampling was done in the secondary settling tank, downstream from the aeration basin and upstream of chlorination.

Sampler Preparation and Deployment. Passive Sampling. $50-\mu \mathrm{m}$ polyethylene sheeting (Carlisle Plastics, Inc.) was cut into approximately 3 in. $x$ in. pieces. The sheets were pre-cleaned in solvent (DCM and hexane) and incubated in a solution of PRCs to load these compounds into the PEs prior to deployment. Deuterated PAHs (fluorene- $\mathrm{d}_{10}$, pyrene- $\mathrm{d}_{10}$, and benzo(a)pyrene- $\mathrm{d}_{12}$ ) and deuterated OPEs (tri-n-butyl phosphate- $\mathrm{d}_{27}$, tris(1-chloro-2-propyl)phosphate- $\mathrm{d}_{18}$, tris(1,3-dichloro-2-propyl) phosphate- $\mathrm{d}_{15}$, and triphenyl phosphate- $\mathrm{d}_{15}$ ) were added as PRCs.

All PEs were deployed on the same day in September 2016. Sheets were fastened to a rope with zip-ties and anchored so that they would remain at a depth of about $1.5 \mathrm{~m}$. On days $1,2,5,8,12,16$, and 21, PEs were collected in triplicate. PEs were wrapped in muffled aluminum foil onsite, packed on ice in a cooler, and transported to the University of Rhode Island Graduate School of Oceanography (URI GSO). PE field blanks were done weekly by transporting a PE to the site, unwrapping and handling the PEs in the same manner as those that were field deployed, and then immediately transporting them back to the laboratory. Active Sampling. Polyurethane foam plugs (PUFs, 10 x $8 \mathrm{~cm}$ diameter, Tisch Environmental) were pre-extracted on a Dionex 350 Accelerated Solvent Extractor (ASE, Dionex Corporation) using 2:1 hexane:DCM. Whatman GF/F glass fiber filters (GFFs) with $0.7 \mu \mathrm{m}$ retention were combusted at $450{ }^{\circ} \mathrm{C}$ for at least 4 hours before use. Active sampling was done using a hose to take in water adjacent to the passive 
samplers, with flow rate and total volume continually monitored. PUFs and filter were replaced once a day. Water flowed through the GFF and then through the foam sorbent phase, which consisted of 1-2 PUFs. Field blanks were collected by transporting cleaned PUFs and GFFs to the site, placing them inside the pumping apparatus, and then removing them and transporting them back to the lab for analysis.

Extraction and Analysis. All PEs were spiked with deuterated PAHs (acenaphthene$\mathrm{d}_{10}$, phenanthrene- $\mathrm{d}_{10}$, chrysene- $\mathrm{d}_{12}$, and perylene- $\mathrm{d}_{12}$ ) and extracted for $24 \mathrm{~h}$ in pentane. A laboratory blank and matrix spike sample (PE in pentane spiked with the target compounds at known mass) were extracted with each batch of PEs. Extracts were concentrated to $\sim 50 \mu \mathrm{L}$ and spiked with p-terphenyl- $\mathrm{d}_{14}$ injection standard before analysis.

PUFs were spiked with the same internal standard solutions as above and extracted on the Dionex 350 ASE with 2:1 hexane:DCM. Extracts were concentrated to $2 \mathrm{~mL}$ and shaken with sodium sulfate to remove water before being concentrated to $\sim 100 \mu \mathrm{L}$ under nitrogen and spiked with p-terphenyl- $\mathrm{d}_{14}$.

All extracts were analyzed on an Agilent 7890 GC equipped with an Agilent J\&W DB-5 fused capillary column (30 m x 0.25 mm I.D.), coupled to an Agilent 5977 MSD in EI mode for PAHs and PCMs in one run, and OPEs in another run. See Table S6-1 for a full list of target compounds. OPEs were analyzed with a helium flow of 1 $\mathrm{mL} / \mathrm{min}$ and injection port set at $240^{\circ} \mathrm{C}$, with temperature ramped from $70-315^{\circ} \mathrm{C}$ during the 40-minute run. PAHs and PCMs were analyzed with a helium flow of 1.8 $\mathrm{mL} / \mathrm{min}$ and injection port set at $280^{\circ} \mathrm{C}$, with temperature ramped from $90-320^{\circ} \mathrm{C}$ during the 52-minute run. For both methods, The MSD was operated in select ion 
monitoring (SIM) mode with the temperature of the ion source at $230{ }^{\circ} \mathrm{C}$, quadrupole at $150{ }^{\circ} \mathrm{C}$, and transfer line at $250{ }^{\circ} \mathrm{C}$. All concentrations were corrected for internal standard recoveries.

Quality Control. Passive Samplers. Concentrations were blank-subtracted using the average PE field blank concentration. Blank concentrations are summarized in Table S6-2. Detection limits were defined as 3 times the standard deviation of three PE field blanks. Concentrations $<$ DL were replaced with half the DL. Significant blank interference was seen for TBEP, and this compound is not reported in any samples. It is unknown whether this interference was due to the presence of large amounts of TBEP in the PE matrix, or caused by some other coeluting compound. Average matrix spike recoveries (N=2) ranged from $76 \%$ for TCEP to $173 \%$ for EHDPP (Table S6-3).

Active Samplers. Concentrations were blank-subtracted using a single PUF field blank. After blank subtraction, the detection limit was defined as $25 \%$ of the field blank value and concentrations $<$ DL were replaced with DL/2. Concentrations of target compounds in the field blank are shown in Table S6-4. No matrix spikes were performed during PUF extraction.

Calculation of Water Concentrations. Passive Sampling. In order to estimate ambient water concentrations from PE concentrations, PRC loss data was used to derive a best-fit value for the thickness of the aqueous diffusive boundary layer $\left(\delta_{\mathrm{DBL}}\right)$ at the PE-water interface, as described in previous work. ${ }^{2,3}$ Percent loss of PRCs over deployment was calculated to determine the PRC's percent equilibrium $(f)$ as in Equation 1, where $N_{0}$ is the mean concentration of PRC in the field blanks and $N$ is the 
concentration in the deployed PE. Loss of the majority of a PRC during deployment suggests the compound reached equilibrium, while little loss of a PRC indicates that the compound remained in the linear uptake phase.

Values for $f$ were plugged into Equation 2 along with known and estimated sampling parameters and PRC chemical properties to derive a best-fit $\delta_{\mathrm{DBL}}$ value using the $n l s$ function in R. Sampling parameters used in Equation 2 were the volume of the PE $\left(V_{\mathrm{PE}}\right)$, the surface area of the PE $\left(\mathrm{A}_{\mathrm{PE}}\right)$, the length of time the PE was deployed $(t)$, and the half-thickness of the PE sheet $\left(l_{\mathrm{PE}} ; 25 \mu \mathrm{m}\right)$. Chemical properties needed were the PE-matrix partitioning coefficient ( $\mathrm{K}_{\mathrm{PEM}}$, here the PE-water partitioning coefficient, or $\mathrm{K}_{\mathrm{PEW}}$ ), the molecular diffusivity of the compound in the surrounding matrix $\left(\mathrm{D}_{\mathrm{M}}\right.$, here the diffusivity in water $\left.\mathrm{D}_{\mathrm{W}}\right)$, and the diffusivity of the compound in polyethylene $\left(\mathrm{D}_{\mathrm{PE}}\right)$. Chemical properties of PRCs were assumed to be the same as for their nondeuterated counterparts.

$$
\begin{gathered}
f=1-\frac{N}{N_{0}} \\
f=1-e^{\frac{-t \cdot A_{P E}}{V_{P E} \cdot\left(\frac{\delta_{D B L} \cdot K_{P} E}{D_{M}}+\frac{l_{P E}}{D_{P E}}\right)}}
\end{gathered}
$$

The best-fit $\delta_{\mathrm{DBL}}$ was then used, along with estimated or measured chemical properties, to estimate $f$ for each target compound during deployment. Chemical properties were corrected for average water temperature during each PE's deployment period before calculations were done. Chemical properties compiled for all compounds are listed in Tables S6-5-S6-7. 
Active Sampling. Ambient concentrations were calculated by dividing the total ng of target compound accumulated in PUFs during deployment by the total water volume that passed through the active sampler. In some cases, the top and bottom PUF within the active sampler were found to have approximately equal concentrations of some target compounds, indicating that breakthrough may have occurred. In instances where the bottom PUF contained $\geq 60 \%$ of the total mass of accumulated, results are still displayed in figures, but were not used to calculate mean ambient concentrations of individual compounds used for comparison to PE uptake data.

To compare active sampling results to data from PEs, concentrations were corrected for the DOC-bound fraction sampled by active samplers that is not taken up by PEs. $\mathrm{K}_{\mathrm{DOC}}$ values used are listed in Tables S6-5-S6-7. When possible, empirical $\mathrm{K}_{\mathrm{DOC}}$ values were used. Otherwise, $\mathrm{K}_{\mathrm{DOC}}$ was assumed to be $10 \%$ of the $\mathrm{K}_{\mathrm{OW}}$, as in Burnhadt et al. ${ }^{20}$ Even in cases where empirical values are available, $\mathrm{K}_{\mathrm{DOC}}$ can vary depending on the composition of local DOC.

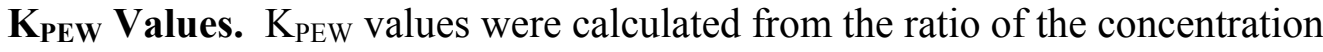
in PEs recovered at 21 days, converted to $\mathrm{ng} / \mathrm{L}$ using PE density $0.91 \mathrm{~kg} / \mathrm{L}$, divided by the DOC-corrected concentration in water derived from active sampling. Values of $\mathrm{K}_{\mathrm{PEW}}$ were corrected to $25^{\circ} \mathrm{C}$ from the average water temperature over the deployment, measured in the nearby aeration tanks $\left(22.2 \pm 0.5^{\circ} \mathrm{C}\right)$.

For compounds that reached equilibrium during deployment, no corrected for percent equilibration was needed, though confirming that equilibrium was reached was not straightforward in all cases. For non-equilibrated compounds, the equilibrium concentration in the PE could not be approximated without estimating physical 
properties, which would mean that calculated $\mathrm{K}_{\mathrm{PEW}}$ values would depend on other estimated properties, rather than on direct measurement. Any $\mathrm{K}_{\mathrm{PEW}}$ calculated for a non-equilibrated compound would be a "lower-bound" estimate, becoming further and further from the true value as distance from equilibrium increases. Calculated $\mathrm{K}_{\mathrm{PEW}} \mathrm{S}$ were compared to empirical $\mathrm{K}_{\mathrm{PEW}} \mathrm{S}$ reported in literature or estimated values from literature solubility and octanol-water partitioning coefficient $\left(\mathrm{K}_{\mathrm{OW}}\right)$ values (Tables S6-5-S6-7).

\section{RESULTS \& DISCUSSION}

Summary of Water Concentrations from Active Sampling. Concentrations of PCMs and OPEs calculated from high-volume active water sampling on eight days throughout the sampling period are shown in Figure 6-1. Concentrations of PAHs are shown in Figure S6-1. Mean $\Sigma_{19} \mathrm{PAH}$ was $42 \pm 23 \mathrm{ng} / \mathrm{L}$, dominated by fluorene, phenanthrene, fluoranthene, and pyrene, with greatest concentrations observed within the first $24 \mathrm{~h}$ of sampling.

Average $\Sigma_{7} \mathrm{PCM}$ (including the two nitromusks, musk xylene and musk ketone) was $2800 \pm 1900 \mathrm{ng} / \mathrm{L} . \quad \Sigma_{7} \mathrm{PCM}$ was greatest on the first sampling day (9/7-9/8; $\left.\Sigma_{7} \mathrm{PCM}=7195 \mathrm{ng} / \mathrm{L}\right)$ and was lower and less variable on the remainder of the days where active sampling data was available (mean $\Sigma_{7} \mathrm{PCM}=2172 \pm 730 \mathrm{ng} / \mathrm{L}$ ). HHCB was the most abundant PCM and made up $>85 \%$ of $\Sigma_{7} \mathrm{PCM}$ in all samples.

Average $\Sigma_{12} \mathrm{OPE}$ from active sampling data was $638 \pm 324 \mathrm{ng} / \mathrm{L}$, with concentrations dominated by the chlorinated OPEs TDCIPP and TCIPP, and the arylOPE TPhP. TnBP, TEHP, and TmCP were also detected $>$ DL in the majority of 
samples, while the other monitored OPEs (TCEP, EHDPP, TpCP, ToCP, and TDBPP) were generally below field blank levels in PUFs.

PE Uptake Profiles. Uptake profiles showing the concentration of target compound (ng/g) in PEs recovered at 7 time points over the deployment are shown in Figures 62, 6-3, and 6-4 for PCMs, OPEs, and PAHs. For comparison to observed uptake trends, predicted uptake profiles showing percent equilibration over time based on PRC loss data and solubility-derived $\mathrm{K}_{\mathrm{PEW}} \mathrm{S}$ are shown in Figure S6-2. Best-fit $\delta_{\mathrm{DBL}}$ used to construct predicted uptake profiles are shown in Figure S6-3. $\delta_{\mathrm{DBL}}$ values during deployment ranged from 63-101 $\mu \mathrm{m}$. PRC loss profiles are shown in Figure 65. PRC loss data for the deuterated chlorinated OPEs were omitted because concentrations were low in blanks and did not decrease appreciably over time, suggesting that these compounds may not be appropriate PRCs. Two extracts, one from Day 8 and one from Day 12, had abnormally low PRC concentrations and were not used in calculating averages, so these two time points are represented by duplicate PEs while the rest are represented by triplicate PEs.

Uptake profiles for HHCB, AHTN, ATII, AHMI, and ADBI (Figure 6-2) showed increasing concentrations for the initial 5-10 days before leveling off and beginning to decrease, suggesting that these compounds reached equilibrium during the deployment. This contradicts predictions made based on estimated chemical properties, which suggested that ATII, AHMI, and ADBI would not equilibrate during deployment. The decreasing concentrations during the second half of the study may be because these compounds equilibrated rapidly during the first few days of the study, when average concentrations appeared greater according to active sampling results 
(Figure 6-1). Predictions based on estimated properties suggest than MUX would have equilibrated during deployment and MUK would remain in linear uptake phase, but uptake profiles for these compounds were difficult to interpret.

Uptake profiles for the PAHs showed clear differences in uptake regime with increasing molecular size and affinity for PE. The 2-3-ring PAHs, such as PHN, appeared to rapidly equilibrate. FLRA and PYR both entered a curvilinear phase and equilibrated by the end of the deployment period, while the remaining 4-5-ring PAHs remained in the linear uptake phase. This is very similar to what was predicted based on modeled uptake in Figure S6-2.

The equilibrium stage reached by OPEs was more difficult to interpret based on PE uptake profiles. Profiles suggest that TpCP, TDBPP, and TEHP remained in a linear uptake phase. TCEP appears to have entered a curvilinear phase and equilibrated by the end of the deployment. The fluctuating concentrations of TnBP, TCIPP, and TDCIPP suggest these compounds may have equilibrated, which is likely, as they are known to be fairly soluble compounds and they were predicted to equilibrate based on modeled uptake profiles. TPhP and EHDPP may be in linear or equilibrium phases. The discrepancies between predicted and observed OPE uptake could be due to poorly constrained chemical properties used to make predictions. For example, the low diffusivity of OPEs in PE observed in previous studies could cause OPEs to be taken up more slowly than predicted here. ${ }^{8}$ This low diffusivity could cause PE membrane-side diffusivity to become the limiting factor in determining OPE uptake, in which case uptake may be better predicted by a more sophisticated model than Equation 2. ${ }^{9}$ 
Comparison to Active Sampling Results. To compare active and passive sampling results, active sampling results were corrected for the inclusion of the DOC-sorbed fraction. DOC concentrations and the fraction predicted to be in the freely dissolved phase for the compounds of interest are shown in Table S6-8 for each day during the sampling period. Average blank-corrected DOC was $8 \pm 1 \mathrm{mg} / \mathrm{L}$. For the majority of OPEs and all PCMs, the fraction in the truly dissolved phase was predicted to be $>90 \%$, suggesting that the discrepancy between the fractions collected by passive and active sampling would not be significant for these emerging contaminants.

Passive sampling results were interpreted as they would be in a field study if no active sampling data was available. PRC loss measured during deployment was used to estimate $f$ for each compound and, along with $\mathrm{K}_{\mathrm{PEW}}$ estimated from solubility, was used to correct PE concentrations to water concentrations. Results from this process are compared to active sampling-derived ambient concentrations using the ratio of PE-derived concentration to active-derived concentration $\left(\mathrm{C}_{\mathrm{PE}} / \mathrm{C}_{\mathrm{PUF}}\right)$ for PAHs and PCMs in Table S6-9 and for OPEs in Table S6-10.

Results for PE-derived PAH concentrations were generally within 40-200\% of active-derived concentrations, suggesting that uptake of PAHs into PEs is well characterized and fairly accurate concentrations can be derived using chemical properties from literature and the PRCs selected in this study. The majority of PEderived concentrations were lower than active-derived concentrations. Active sampling data was only representative of about one third of the sampling period. Results from the two approaches may have been closer if results for active sampling were representative of the entire PE sampling period. PAH concentrations were 
elevated during the first $24 \mathrm{~h}$ of sampling, and if no other spikes of this type occurred during the sampling period, the average concentrations estimated from active sampling data may be greater than the actual time-weighted average.

PCM concentrations predicted from passive sampling were found to be about four times lower than active-derived data for HHCB and AHTN. PE-derived concentrations for the other PCMs were generally $<10 \%$ of active-derived concentrations. PE-derived concentrations for OPEs, calculated for four sets of $\mathrm{K}_{\mathrm{PEW}}$ estimates, were also much lower than active-derived dissolved concentrations (Table S6-10). The difference between active and passive concentrations may be due, in part, to active sampling not capturing the entire passive sampling period, as mentioned above. In addition, for compounds that rapidly equilibrate, PE-derived concentrations may no longer representative of the entire deployment period. ${ }^{2}$ The discrepancy could also indicate that $K_{\text {PEW }}$ values used to estimate water concentrations were greater than the actual values. An additional source of uncertainty is the $\mathrm{K}_{\mathrm{DOC}}$ values used. If the affinity of PCMs and OPEs for DOC was greater than estimated in the settling tank, this would drive down active sampling-derived dissolved concentrations.

Kew $_{\text {Pealculation. }}$ K PEW values calculated for all compounds are listed in Table S611. $\mathrm{K}_{\mathrm{PEW}}$ values were calculated from DOC-corrected active-derived dissolved concentrations and from passives collected on Day 21 of the study, which were expected to be representative of time-weighted averaged for the entire deployment period. $\mathrm{K}_{\mathrm{PEW}}$ values for PAHs are compared to sets of $\mathrm{K}_{\mathrm{PEW}}$ values from literature in Figure 6-6. Values were very similar to empirical literature values for equilibrated PAHs. 
$\mathrm{K}_{\mathrm{PEW}}$ values for PCMs and OPEs are compared to values derived from literature $\mathrm{K}_{\mathrm{OW}}$ and aqueous solubility values in Figures 6-7 and 6-8. $\mathrm{K}_{\mathrm{PEW}}$ s calculated for both compound groups are generally lower than those from literature, suggesting that many PCMs and OPEs have a lower affinity for PE than would be predicted using their aqueous solubility or $\mathrm{K}_{\mathrm{Ow}}$. However, uptake profiles suggest that some compounds (MUK, TEHP, possibly TPhP) may not have equilibrated during deployment, in which case these values may be lower-bound estimates.

\section{IMPLICATIONS}

Values for $\mathrm{K}_{\mathrm{PEW}}$ derived from this field study were similar to previous empirical values for PAHs, suggesting that the study setup was adequate and PEs are able to measure truly dissolved concentrations that are in good agreement with DOCcorrected active sampling concentrations. This work suggests that PCM and OPE concentrations derived from PEs deployed in the field using solubility-derived $\mathrm{K}_{\mathrm{PEW}}$ estimates may underestimate ambient dissolved concentrations. However, the state of equilibrium was uncertain for some compounds. Analysis of additional thicker PEs $(800 \mu \mathrm{m})$ that were deployed alongside $50 \mu \mathrm{m}$ PEs could assist in confirming which OPEs reached equilibrium during the study. While low affinity of some OPEs for the PE matrix suggests that other passive sampling materials, such as the POCIS, may be more appropriate for measuring these compounds, improving our ability to measure them using PEs allows us to make use of valuable stores of archived PE samples from remote regions for retrospective analysis. More directly measured chemical properties, as well as additional PE partitioning experiments, are needed to more 
accurately calculate dissolved concentrations of OPEs and PCMs from concentrations accumulated in PEs.

\section{ACKNOWLEDGMENTS}

We acknowledge funding from the US EPA Great Lakes Restoration Initiative (GLRI) GLAS \#00E00597-0, project officer Todd Nettesheim, and from Rhode Island National Science Foundation Experimental Program to Stimulate Competitive Research (RI NSF EPSCoR). We thank David Adelman, Rachel Miller, Anna Robuck, and Erik Dixon Anderson (URI) for organizing and carrying out field deployments and sample preparation, Roxanne Johnson (US EPA) for DOC measurements, Kathy Perez (Wastewater Superintendent at SK WWTF) for granting access to the facilities and providing plant data, as well as all of the workers at SK WWTF for their assistance.

\section{ASSOCIATED CONTENT}

Supporting Information. Additional figures and tables are available in the Supporting Information. This material is available free of charge via the Internet.

\section{AUTHOR INFORMATION}

\section{Corresponding Author}

* Rainer Lohmann: rlohmann@uri.edu 


\section{LITERATURE CITED}

(1) Lohmann, R.; Muir, D. C. G.; Zeng, E. Y.; Bao, L.-J.; Allan, I. J.; Arinaitwe, K.; Booij, K.; Helm, P. A.; Kaserzon, S. L.; Mueller, J. F.; Shibata, Y.; Smedes, F.; Tsapakis, M.; Wong, C. S.; You, J. Aquatic global passive sampling (AQUA-GAPS) revisited - First steps towards a network of networks for organic contaminants in the aquatic environment. Environ. Sci. Technol. 2016, acs.est.6b05159, DOI:10.1021/acs.est.6b05159.

(2) McDonough, C. A.; Helm, P. A.; Muir, D.; Puggioni, G.; Lohmann, R. Polycyclic musks in the air and water of the lower Great Lakes: Spatial distribution and volatilization from surface waters. Environ. Sci. Technol. 2016, 50, 11575-11583, DOI:10.1021/acs.est.6b03657.

(3) McDonough, C. A.; Puggioni, G.; Helm, P. A.; Muir, D.; Lohmann, R. Spatial distribution and air-water exchange of organic flame retardants in the lower great lakes. Environ. Sci. Technol. 2016, 50, 9133-9141, DOI:10.1021/acs.est.6b02496.

(4) Fernandez, L. A.; Gschwend, P. M. Predicting bioaccumulation of polycyclic aromatic hydrocarbons in soft-shelled clams ( Mya arenaria ) using field deployments of polyethylene passive samplers. Environ. Toxicol. Chem. 2015, n/a-n/a, DOI:10.1002/etc.2892.

(5) Booij, K.; van Bommel, R.; van Aken, H. M.; van Haren, H.; Brummer, G. J. A.; Ridderinkhof, H. Passive sampling of nonpolar contaminants at three deepocean sites. Environ. Pollut. 2014, 195, 101-108, DOI:10.1016/j.envpol.2014.08.013.

(6) Sun, C.; Soltwedel, T.; Bauerfeind, E.; Adelman, D. A.; Lohmann, R. Depth profiles of persistent organic pollutants in the North and Tropical Atlantic Ocean. Environ. Sci. Technol. 2016, 50, 6172-6179, DOI:10.1021/acs.est.5b05891.

(7) Sacks, V. P.; Lohmann, R. Development and use of polyethylene passive samplers to detect triclosans and alkylphenols in an urban estuary. Environ. Sci. Technol. 2011, 45, 2270-2277, DOI:10.1021/es1040865.

(8) Pintado-Herrera, M. G.; Lara-Martín, P. A.; González-Mazo, E.; Allan, I. J. Determination of silicone rubber and low density polyethylene diffusion and polymer-water partition coefficients for emerging contaminants. Environ. Toxicol. Chem. 2016, 35, n/a-n/a, DOI:10.1002/etc.3390.

(9) Tcaciuc, P. A.; Apell, J. N.; Gschwend, P. M. Modeling the transport of organic chemicals between polyethylene passive samplers and water in finite and infinite bath conditions. Environ. Toxicol. Chem. 2015, DOI:10.1002/etc.3128. 
(10) Allan, I. J.; Harman, C.; Ranneklev, S. B.; Thomas, K. V; Grung, M. Passive sampling for target and nontarget analyses of moderately polar and nonpolar substances in water. Environ. Toxicol. Chem. 2013, 32, 1718-1726, DOI:10.1002/etc. 2260 .

(11) Perron, M. M.; Burgess, R. M.; Suuberg, E. M.; Cantwell, M. G.; Pennell, K. G. Performance of passive samplers for monitoring estuarine water column concentrations 2. Emerging contaminants. Environ. Toxicol. Chem. 2013, 32, DOI:10.1002/etc. 2248 .

(12) Xie, Z.; Ebinghaus, R.; Temme, C.; Heemken, O.; Ruck, W. Air-sea exchange fluxes of synthetic polycyclic musks in the North Sea and the Arctic. Environ. Sci. Technol. 2007, 41, 5654-5659, DOI:10.1021/es0704434.

(13) Salamova, A.; Hermanson, M. H.; Hites, R. A. Organophosphate and halogenated flame retardants in atmospheric particles from a European Arctic site. Environ. Sci. Technol. 2014, 48, 6133-6140, DOI:10.1021/es500911d.

(14) Sühring, R.; Diamond, M. L.; Scheringer, M.; Wong, F.; Pućko, M.; Stern, G.; Burt, A.; Hung, H.; Fellin, P.; Li, H.; Jantunen, L. M. Organophosphate esters in Canadian Arctic air: Occurrence, levels and trends. Environ. Sci. Technol. 2016, 50, 7409-7415, DOI:10.1021/acs.est.6b00365.

(15) Ferrario, C.; Finizio, A.; Villa, S. Legacy and emerging contaminants in meltwater of three Alpine glaciers. Sci. Total Environ. 2017, 574, 350-357, DOI:10.1016/j.scitotenv.2016.09.067.

(16) Sun, P.; Casteel, K.; Dai, H.; Wehmeyer, K. R.; Kiel, B.; Federle, T. Distributions of polycyclic musk fragrance in wastewater treatment plant (WWTP) effluents and sludges in the United States. Sci. Total Environ. 2014, 493, 1073-1078, DOI:10.1016/j.scitotenv.2014.04.038.

(17) Simonich, S. L.; Begley, W. M.; Debaere, G.; Eckhoff, W. S. Trace analysis of fragrance materials in wastewater and treated wastewater. Environ. Sci.

Technol. 2000, 34, 959-965, DOI:10.1021/es991018g.

(18) Regnery, J.; Püttmann, W. Occurrence and fate of organophosphorus flame retardants and plasticizers in urban and remote surface waters in Germany. Water Res. 2010, 44, 4097-4104, DOI:10.1016/j.watres.2010.05.024.

(19) Rhode Island DEM Office of Water Resources: January 2017 Wastewater Treatment Facilities/Locations and Officials in Charge http://www.dem.ri.gov/programs/water/wwtf/wwtf-officials.php (accessed Feb 23, 2017). 
(20) Burkhard, L. P. Estimating dissolved organic carbon partition coefficients for nonionic organic chemicals. Environ. Sci. Technol. 2000, 34, 4663-4668, DOI:10.1021/es0012691.

(21) Lohmann, R. Critical review of low-density polyethylene's partitioning and diffusion coefficients for trace organic contaminants and implications for its use as a passive sampler. Environ. Sci. Technol. 2012, 46, 606-618, DOI:10.1021/es202702y.

(22) Booij, K.; Hofmans, H. E.; Fischer, C. V.; van Weerlee, E. M. Temperaturedependent uptake rates of nonpolar organic compounds by semipermeable membrane devices and low-density polyethylene membranes. Environ. Sci. Technol. 2003, 37, 361-366, DOI:10.1021/es025739i.

(23) Cornelissen, G.; Pettersen, A.; Broman, D.; Mayer, P.; Breedveld, G. D. Field testing of equilibrium passive samplers to determine freely dissolved native polycyclic aromatic hydrocarbon concentrations. Environ. Toxicol. Chem. 2008, 27, 499-508, DOI:10.1897/07-253.1.

(24) Fernandez, L. A.; Macfarlane, J. K.; Tcaciuc, A. P.; Gschwend, P. M. Measurement of freely dissolved PAH concentrations in sediment beds using passive sampling with low-density polyethylene strips. Environ. Sci. Technol. 2009, 43, 1430-1436, DOI:10.1021/es802288w.

(25) Zhang, X.; Suhring, R.; Serodio, D.; Bonnell, M.; Sundin, N.; Diamond, M. L. Novel flame retardants: Estimating the physical-chemical properties and environmental fate of 94 halogenated and organophosphate PBDE replacements. Chemosphere 2016, 144, 2401-2407, DOI:10.1016/j.chemosphere.2015.11.017.

(26) Peck, A. M.; Hornbuckle, K. C. Synthetic musk fragrances in Lake Michigan. Environ. Sci. Technol. 2004, 38, 367-372, DOI:10.1021/es034769y.

(27) Rimkus, G. G. Polycyclic musk fragrances in the aquatic environment. Toxicol. Lett. 1999, 111, 37-56, DOI:10.1016/S0378-4274(99)00191-5.

(28) Posada-Ureta, O.; Olivares, M.; Navarro, P.; Vallejo, A.; Zuloaga, O.; Etxebarria, N. Membrane assisted solvent extraction coupled to large volume injection-gas chromatography-mass spectrometry for trace analysis of synthetic musks in environmental water samples. J. Chromatogr. A 2012, 1227, 38-47, DOI:10.1016/j.chroma.2011.12.104. 


\section{FIGURES AND TABLES}

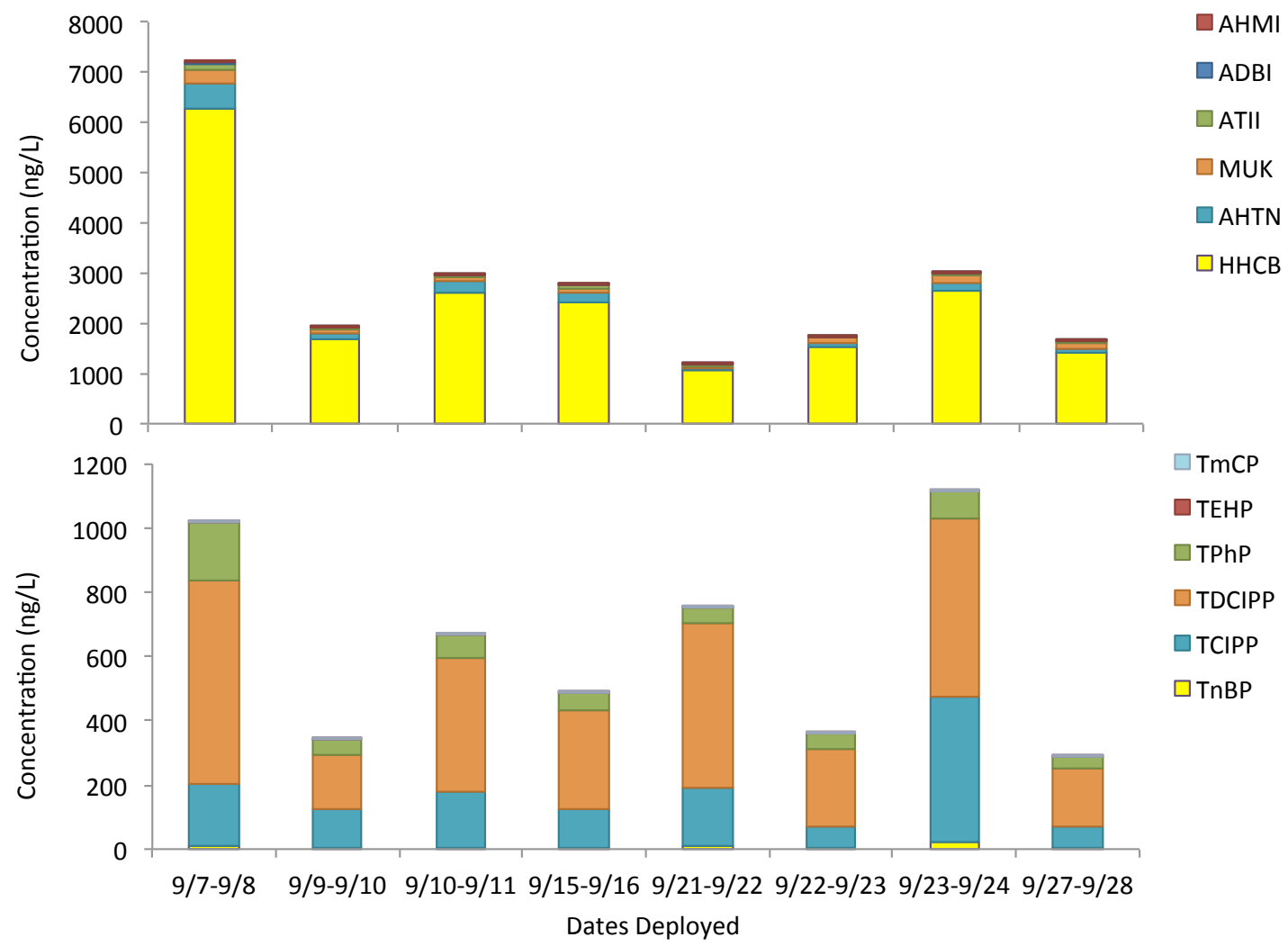

Figure 6-1. Ambient concentrations of PCMs and OPEs. Concentrations were calculated from high-volume active water sampling results, and include the DOCbound fraction. 

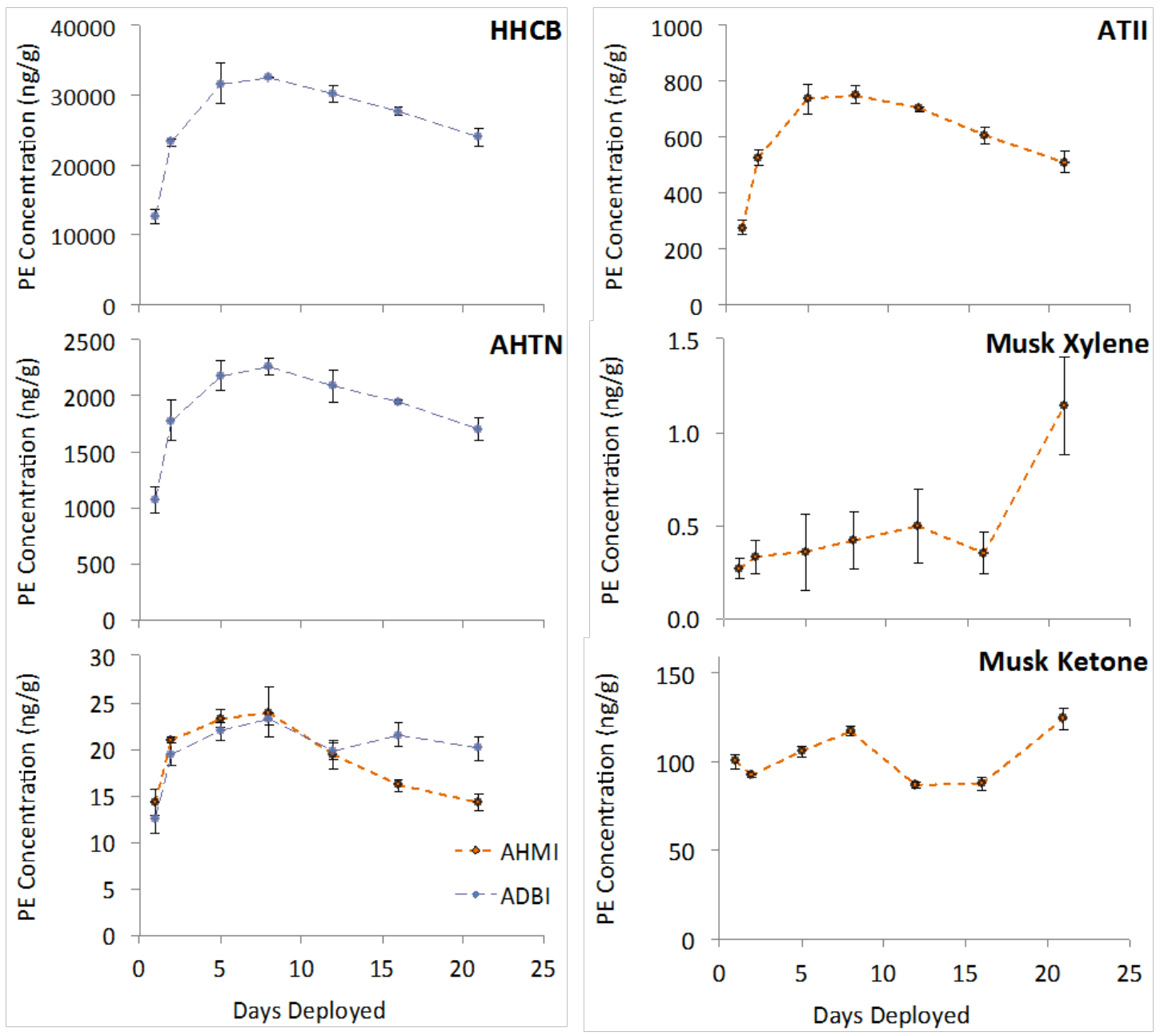

Figure 6-2. PCM and nitromusk concentration in PEs over the 21-day deployment. Profiles suggest that HHCB, AHTN, ATII, AHMI, and ADBI reached equilibrium by mid-way through the deployment, while results for MUX and MUK are less clear. The $\mathrm{X}$-axis represents the number of days the PE was deployed before recovery. Error bars show the standard deviation for replicate PEs collected on the same day. 


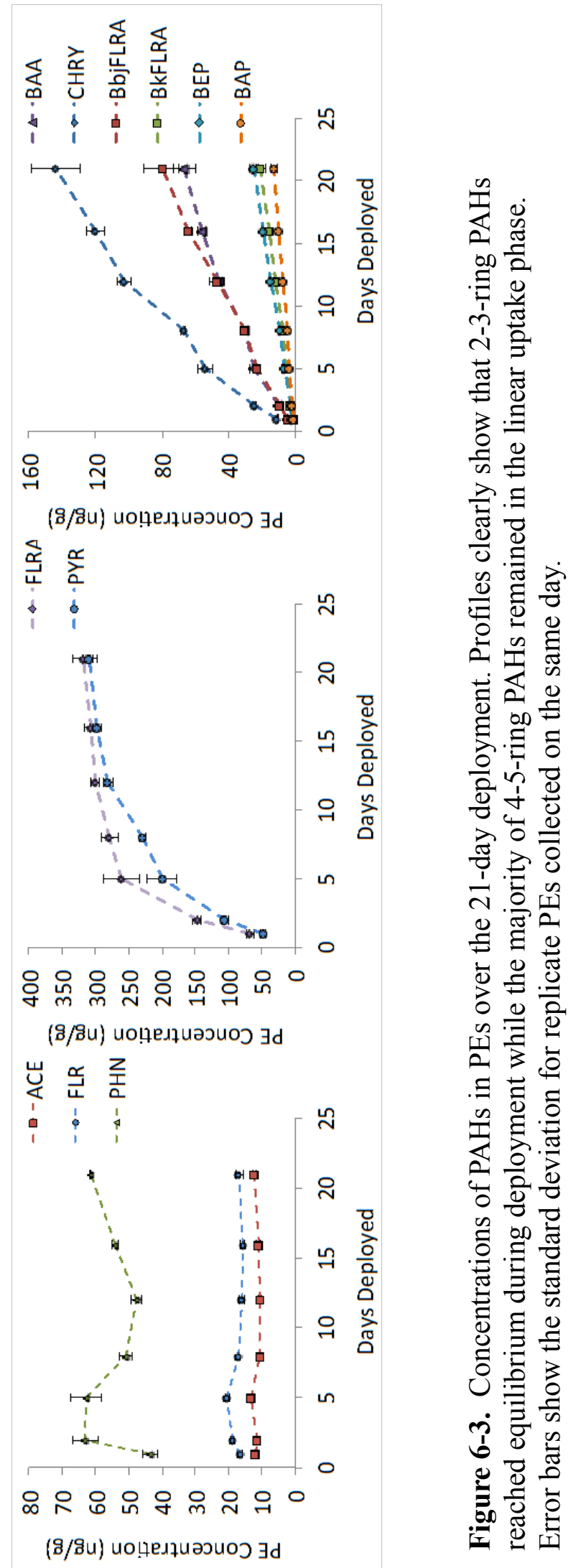




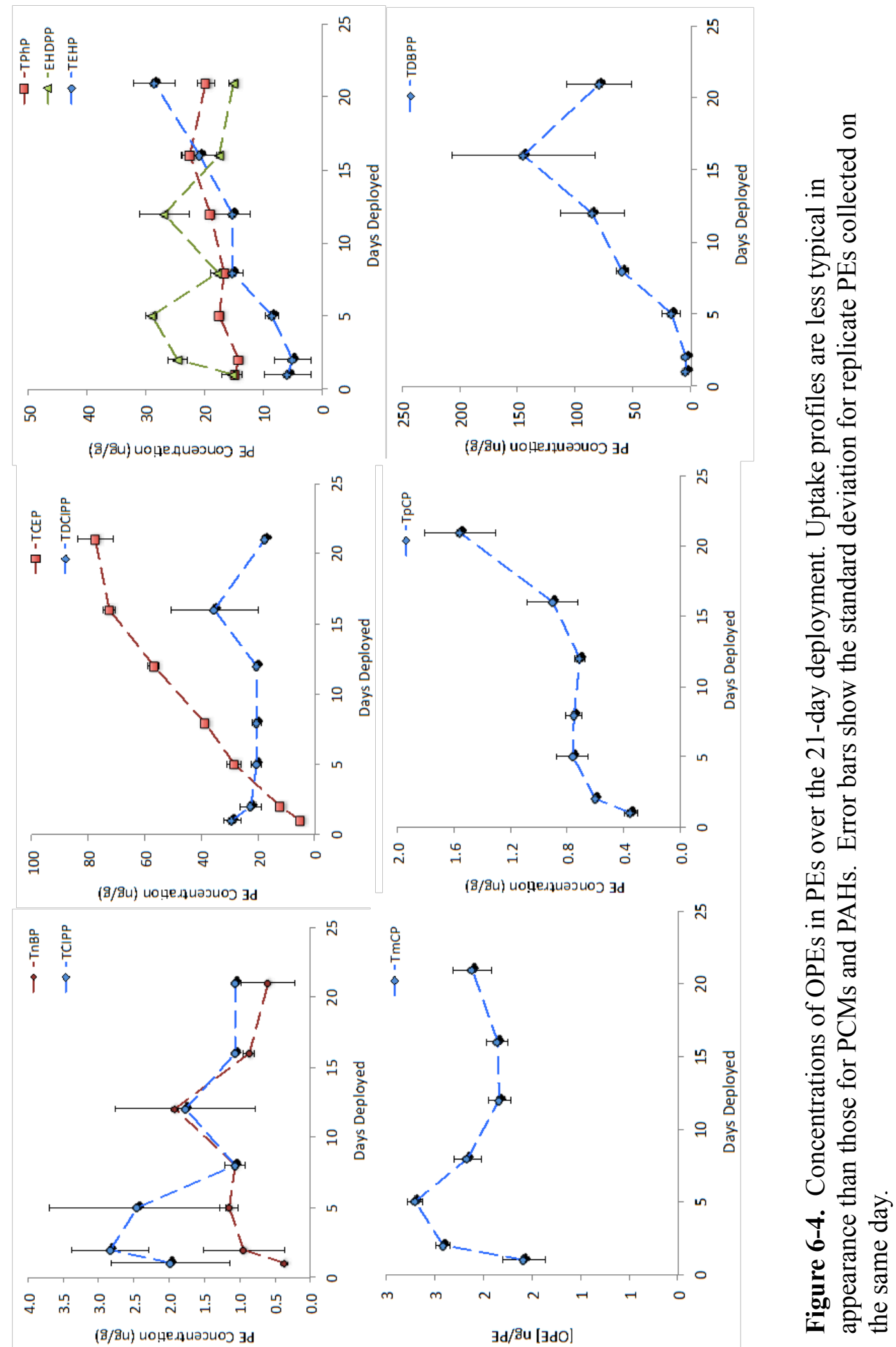



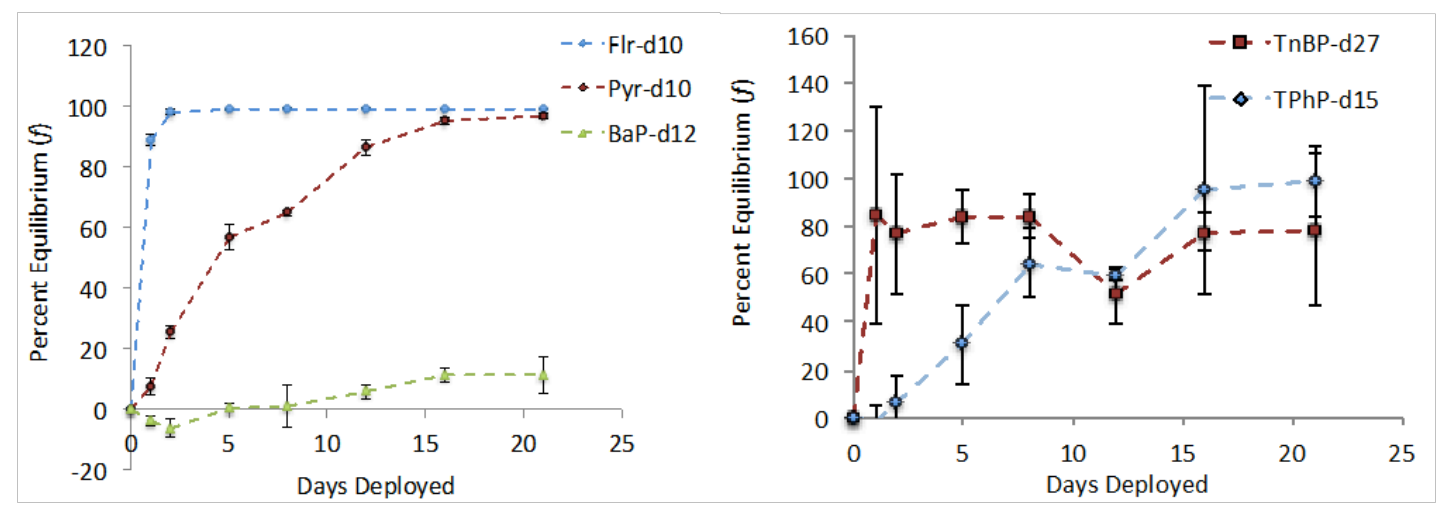

Figure 6-5. Percent equilibrium reached by PRCs during deployment.

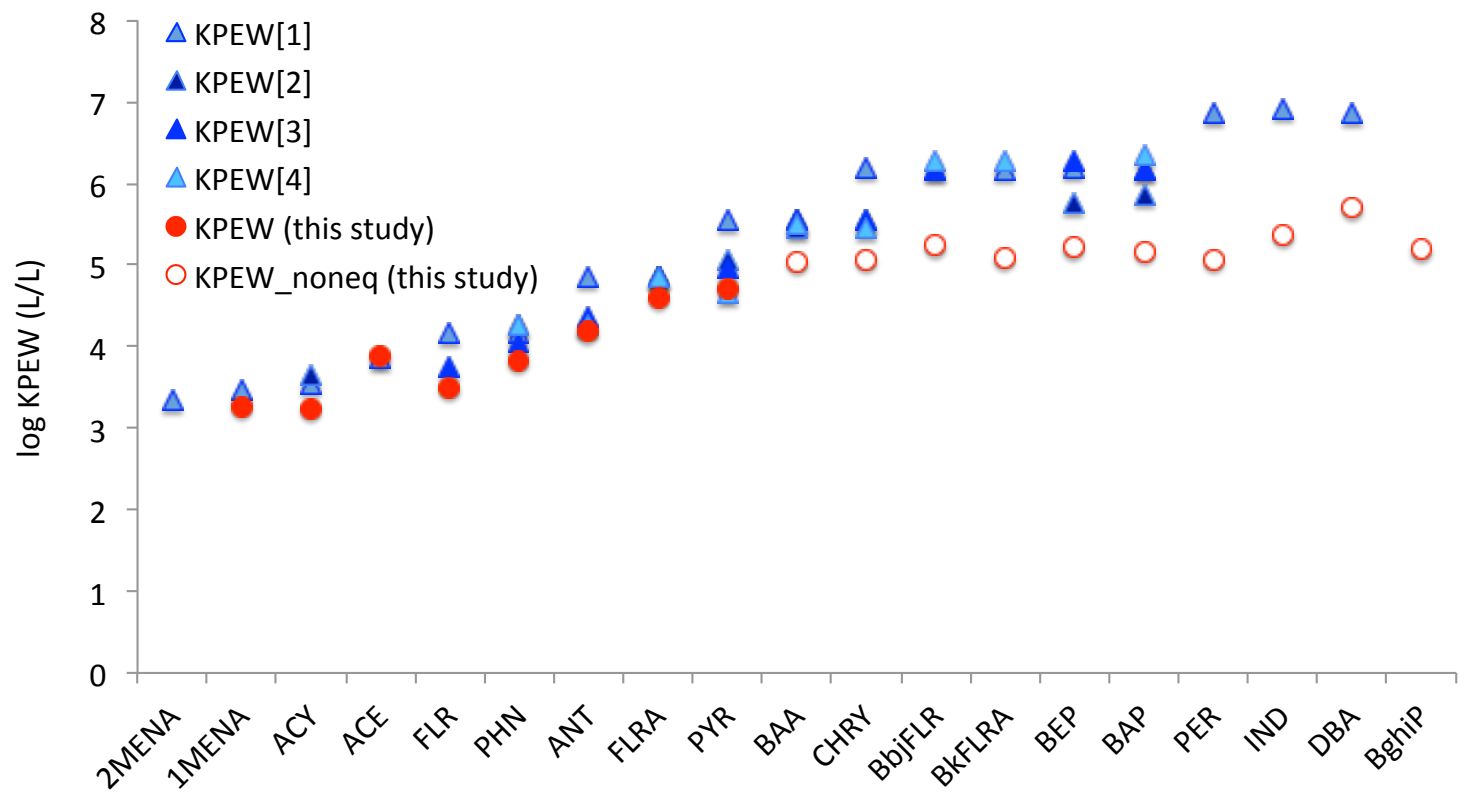

Figure 6-6. Comparison of $\mathrm{K}_{\mathrm{PEW}}$ values for PAHs from this study and from literature. Filled-in red dots mark values calculated from equilibrium concentrations, while empty red circles mark values for compounds that had not reached equilibrium, meaning that these values are lower-bound estimates. $\mathrm{K}_{\mathrm{PEW}}[1]$ was estimated from solubility as in Lohmann 2012. ${ }^{21} \mathrm{~K}_{\mathrm{PEW}}$ [2], $\mathrm{K}_{\mathrm{PEW}}$ [3], and $\mathrm{K}_{\mathrm{PEW}}$ [4] were from Booij et al., Cornelissen et al., and Fernandez et al., respectively. ${ }^{22-24}$ 


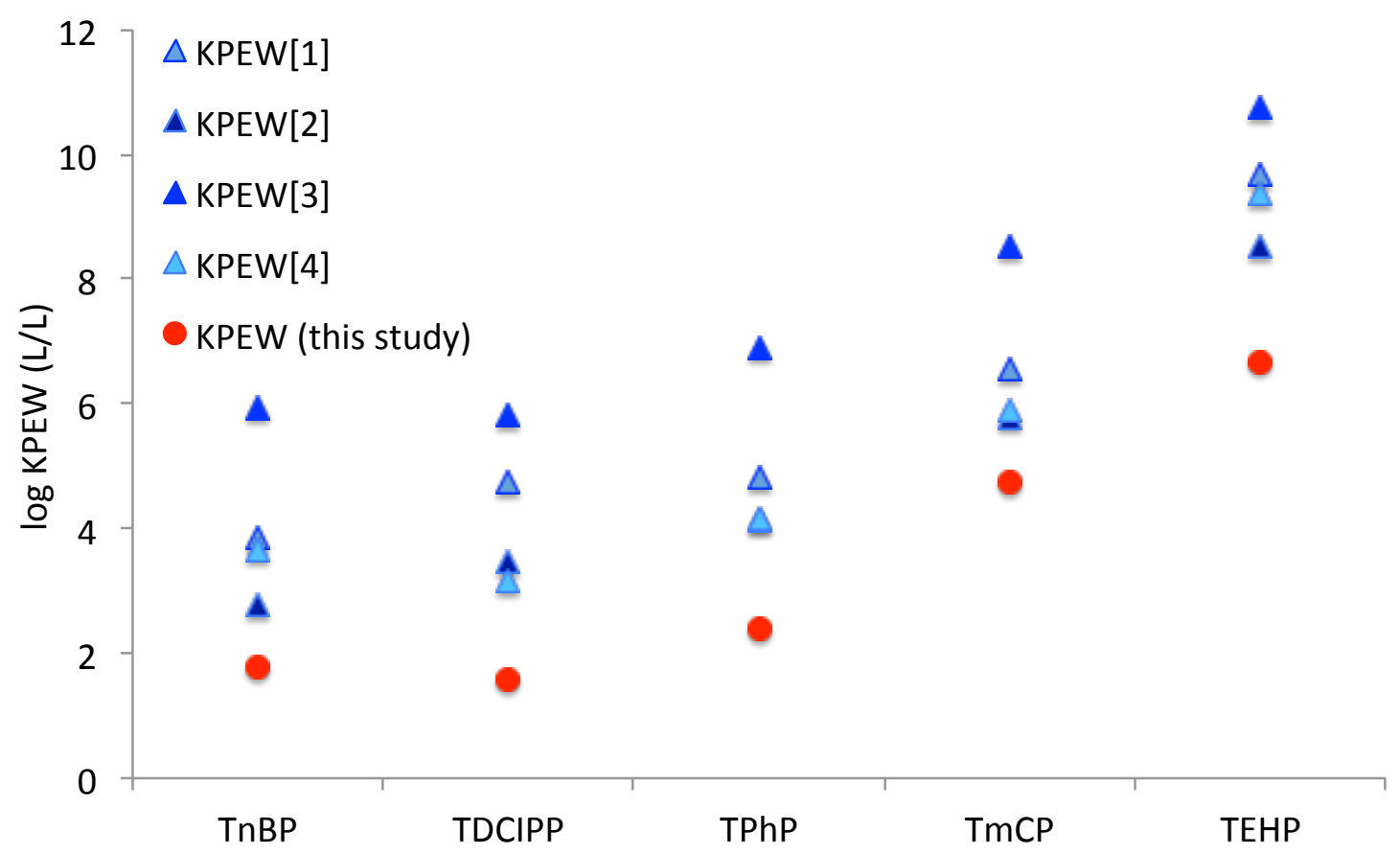

Figure 6-7. Comparison of $\mathrm{K}_{\mathrm{PEW}}$ values for OPEs from this study and derived from chemical properties from literature. $\mathrm{K}_{\mathrm{PEW}}[1], \mathrm{K}_{\mathrm{PEW}}[2]$, and $\mathrm{K}_{\mathrm{PEW}}$ [3] were calculated based on sub-cooled liquid solubility values estimated by Zhang et al. ${ }^{25}$ and $\mathrm{K}_{\mathrm{PEW}}$ [4] values were calculated from $\mathrm{K}_{\mathrm{OW}}$ values compiled by Pintado-Herrera et al. ${ }^{8}$ 


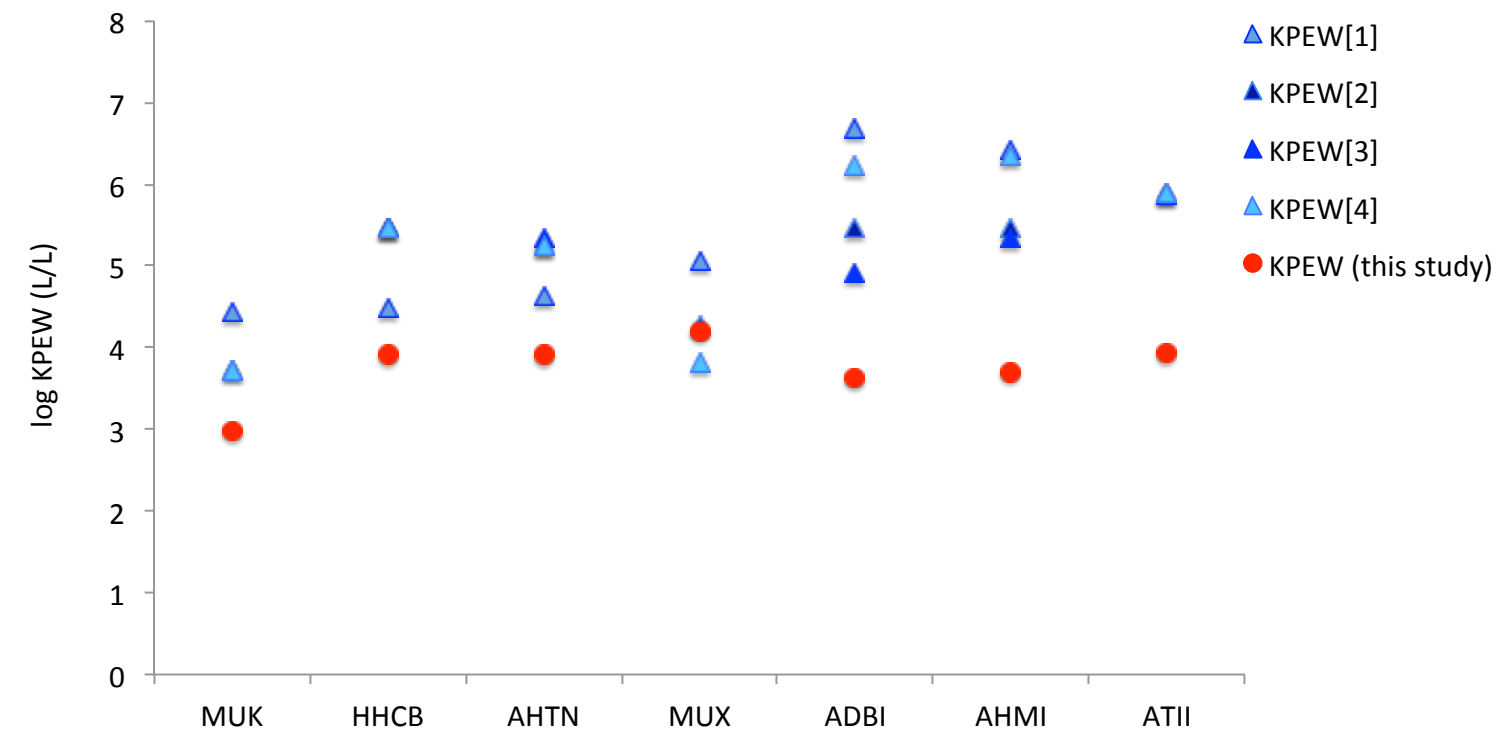

Figure 6-8. Comparison of $\mathrm{K}_{\mathrm{PEW}}$ values for PCMs from this study and derived from chemical properties from literature. $\mathrm{K}_{\mathrm{PEW}}[1]$ was estimated from solubility values compiled by Peck \& Hornbuckle using a regression from Lohmann $2012 .^{21,26} \mathrm{~K}_{\text {PEW }}$ [2], $\mathrm{K}_{\mathrm{PEW}}$ [3], and $\mathrm{K}_{\mathrm{PEW}}$ [4] were calculated from $\mathrm{K}_{\mathrm{OW}}$ values from Peck \& Hornbuckle, Rimkus et al., and Posada-Ureta et al., again using a regression from Lohmann $2012 .^{26-28}$ 


\title{
SUPPLEMENTARY INFORMATION: PARTITIONING OF DISSOLVED SYNTHETIC FRAGRANCES AND ORGANOPHOSPHATE ESTERS FROM WASTEWATER INTO POLYETHYLENE PASSIVE SAMPLERS
}

\author{
Carrie A. McDonough and Rainer Lohmann
}

Total number of pages: 16

Total number of figures: 3

Total number of tables: 11

Table S6-1. List of Study Target Compounds

\begin{tabular}{|c|c|c|}
\hline \multicolumn{2}{|c|}{ Polycyclic Aromatic Hydrocarbons (PAHs) } & \multirow{2}{*}{ CAS Number } \\
\hline 2-ring PAI & & \\
\hline$A C Y$ & Acenaphthylene & $208-96-8$ \\
\hline ACE & Acenaphthene & $83-32-9$ \\
\hline FLR & Fluorene & 86-73-7 \\
\hline \multicolumn{3}{|c|}{ 2-ring alkyl/substituted PAHs } \\
\hline 2MENAP & 2-methylnaphthalene & $91-57-6$ \\
\hline 1MENAP & 1-methylnaphthalene & $90-12-0$ \\
\hline \multicolumn{3}{|c|}{ 3-ring PAHs } \\
\hline PHN & Phenanthrene & 85-01-8 \\
\hline ANT & Anthracene & $120-12-7$ \\
\hline FLRA & Fluoranthene & 205-99-2 \\
\hline \multicolumn{3}{|c|}{ 4-ring PAHs } \\
\hline PYR & Pyrene & $129-00-0$ \\
\hline BAA & Benzo(a)anthracene & $96-55-3$ \\
\hline CHRY & Chrysene & 218-01-9 \\
\hline BBJFLRA & Benzo(b,j)fluoranthene & $205-99-2$ \\
\hline BKFLRA & Benzo(k)fluoranthene & 209-08-9 \\
\hline \multicolumn{3}{|c|}{ 5-6-ring PAHs } \\
\hline BEP & Benzo(e)pyrene & $192-97-2$ \\
\hline BAP & Benzo(a)pyrene & $50-32-8$ \\
\hline PER & Perylene & $198-55-0$ \\
\hline IND & Indeno(1,2,3-c,d)pyrene & $193-39-5$ \\
\hline DIBA & Dibenz(a,h)anthracene) & $57-70-3$ \\
\hline BGHIP & Benzo(g,h,i)pyrene & $191-24-2$ \\
\hline \multicolumn{3}{|c|}{ Polycyclic Musks } \\
\hline ADBI & Celestolide & $13171-00-1$ \\
\hline AHMI & Phantolide & $15323-35-0$ \\
\hline ATII & Traesolide & $68140-48-7$ \\
\hline HHCB & Galaxolide & $1222-05-5$ \\
\hline AHTN & Tonalide & $1506-02-1$ \\
\hline MUX & Musk xylene & $81-15-2$ \\
\hline MUK & Musk ketone & $81-14-1$ \\
\hline \multicolumn{3}{|c|}{ Organophosphate Esters (OPEs) } \\
\hline TnBP & tri- $n$-butyl phosphate & $126-73-8$ \\
\hline TCEP & tris(2-chloroethyl) phosphate & $115-96-8$ \\
\hline TCIPP & tris(1-chloro-2-propyl) phosphate & $13674-84-5$ \\
\hline TDCIPP & tris(1,3-dichloro-2-propyl) phosphate & $13674-87-8$ \\
\hline TPhP & triphenyl phosphate & $115-86-6$ \\
\hline TBEP & tris(butoxyethyl) phosphate & 78-51-3 \\
\hline EHDPP & ethylhexyl diphenyl phosphate & $1241-94-7$ \\
\hline TEHP & tris(2-ethylhexyl) phosphate & $78-42-2$ \\
\hline TOCP & tri-o-cresyl phosphate & 78-30-8 \\
\hline TmCP & tri- $m$-cresyl phosphate & $563-04-2$ \\
\hline ТрСР & tri- $p$-cresyl phosphate & $78-32-0$ \\
\hline TDBPP & tris(2,3-dibromo-2-propyl) phosphate & $126-72-7$ \\
\hline
\end{tabular}


Table S6-2. PE Field Blank results and detection limits (ng/g PE).

\begin{tabular}{|c|c|c|c|c|c|}
\hline & FIELD BLANK 1 & FIELD BLANK 2 & FIELD BLANK 3 & MEAN FIELD BLANK & $\overline{D L}$ \\
\hline \multicolumn{6}{|l|}{ PAHs } \\
\hline 2MENAP & 4.06 & 2.77 & 4.29 & $3.71 \pm 0.82$ & 2.5 \\
\hline 1MENAP & 2.87 & 1.91 & 3.18 & $2.65 \pm 0.66$ & 2.0 \\
\hline ACE & 0.275 & 0.141 & 0.322 & $0.246 \pm 0.094$ & 0.28 \\
\hline$A C Y$ & 0.717 & 0.326 & 0.698 & $0.580 \pm 0.22$ & 0.66 \\
\hline FLR & 2.05 & 1.19 & 1.98 & $1.74 \pm 0.48$ & 1.4 \\
\hline PHN & 9.98 & 5.71 & 9.22 & $8.30 \pm 2.3$ & 6.8 \\
\hline ANT & 0.0881 & 0.0504 & 0.123 & $0.0873 \pm 0.036$ & 0.11 \\
\hline FLRA & 1.87 & 1.59 & 2.02 & $1.83 \pm 0.22$ & 0.66 \\
\hline PYR & 0.600 & 0.612 & 0.713 & $0.641 \pm 0.062$ & 0.19 \\
\hline BAA & 0.0949 & 0.120 & 0.133 & $0.116 \pm 0.019$ & 0.058 \\
\hline CHRY & 0.106 & 0.174 & 0.220 & $0.167 \pm 0.057$ & 0.17 \\
\hline BBJFLRA & 0.0477 & 0.327 & 0.248 & $0.208 \pm 0.14$ & 0.43 \\
\hline BKFLRA & 0.188 & 0.161 & 0.109 & $0.153 \pm 0.040$ & 0.12 \\
\hline BEP & 0.0104 & 0.0231 & 0.00876 & $0.0141 \pm 0.0078$ & 0.024 \\
\hline BAP & 0.0427 & 0.0652 & 0.0235 & $0.0438 \pm 0.021$ & 0.063 \\
\hline PER & 0.0765 & 0.107 & 0.122 & $0.102 \pm 0.023$ & 0.070 \\
\hline IND & 0.109 & 0.111 & 0.0401 & $0.0869 \pm 0.041$ & 0.12 \\
\hline DBA & 0.103 & 0.133 & 0.100 & $0.112 \pm 0.018$ & 0.054 \\
\hline BGHIP & 0.0126 & 0.0949 & 0.0291 & $0.0455 \pm 0.044$ & 0.13 \\
\hline \multicolumn{6}{|c|}{ PCMs and Nitromusks } \\
\hline$\overline{A D B I}$ & 0.118 & 0.0617 & 0.0895 & $0.0898 \pm 0.028$ & 0.085 \\
\hline AHMI & 0.233 & 0.407 & 0.508 & $0.383 \pm 0.14$ & 0.42 \\
\hline ATII & 0.252 & 0.0755 & 0.212 & $0.180 \pm 0.092$ & 0.28 \\
\hline НHCB & 6.60 & 1.30 & 6.65 & $4.85 \pm 3.1$ & 9.2 \\
\hline AHTN & 1.66 & 0.610 & 1.77 & $1.35 \pm 0.64$ & 1.9 \\
\hline MUX & 0.0958 & 0.0780 & 0.0990 & $0.0910 \pm 0.011$ & 0.034 \\
\hline MUK & 0.197 & 0.174 & 0.331 & $0.234 \pm 0.085$ & 0.25 \\
\hline \multicolumn{6}{|l|}{ OPES } \\
\hline TnBP & 0.700 & 0.449 & 0.940 & $0.696 \pm 0.25$ & 0.74 \\
\hline TCEP & 1.97 & 1.65 & 2.67 & $2.10 \pm 0.52$ & 1.6 \\
\hline TCIPP & 3.36 & 3.23 & 4.52 & $3.70 \pm 0.71$ & 2.1 \\
\hline TDCIPP & 5.55 & 6.55 & 7.31 & $6.47 \pm 0.88$ & 2.6 \\
\hline TPhP & 3.22 & 1.15 & 1.39 & $1.92 \pm 1.13$ & 3.4 \\
\hline TBEP & 6495 & 5878 & 6931 & $6435 \pm 529$ & 1586 \\
\hline EHDPP & 0.608 & 0.710 & 0.822 & $0.714 \pm 0.11$ & 0.32 \\
\hline TEHP & 1.05 & 0.710 & 0.361 & $0.706 \pm 0.34$ & 1.0 \\
\hline ToCP & 0.530 & 0.763 & 0.481 & $0.591 \pm 0.15$ & 0.45 \\
\hline TmCP & 0.0149 & 0.0232 & 0.0294 & $0.0225 \pm 0.0073$ & 0.022 \\
\hline ТрСP & 0.00421 & 0.0121 & 0.0210 & $0.0124 \pm 0.0084$ & 0.025 \\
\hline TDBPP & 10.3 & 13.3 & 16.3 & $13.3 \pm 3.0$ & 9.0 \\
\hline
\end{tabular}


Table S6-3. Percent extraction efficiency for target compounds during PE extractions.

\section{1/17/17 01/20/17 \\ Matrix Spike Matrix Spike}

\begin{tabular}{|c|c|c|}
\hline 2MENAP & 68 & 87 \\
\hline 1MENAP & 72 & 86 \\
\hline$A C Y$ & 89 & 84 \\
\hline ACE & 86 & 90 \\
\hline FLR & 81 & 90 \\
\hline PHN & 55 & 99 \\
\hline ANT & 100 & 99 \\
\hline FLRA & 102 & 108 \\
\hline PYR & 97 & 100 \\
\hline BAA & 106 & 111 \\
\hline CHRY & 113 & 111 \\
\hline BbjFLRA & 122 & 123 \\
\hline BkFLRA & 111 & 113 \\
\hline BEP & 114 & 116 \\
\hline BAP & 115 & 112 \\
\hline PER & 102 & 105 \\
\hline IND & 109 & 113 \\
\hline DBA & 109 & 116 \\
\hline BghiP & 108 & 110 \\
\hline TnBP & 125 & 111 \\
\hline TCEP & 84 & 68 \\
\hline TCIPP & 113 & 104 \\
\hline TDCIPP & 131 & 125 \\
\hline TPhP & 74 & 79 \\
\hline TBEP $^{a}$ & - & - \\
\hline EHDPP & 178 & 168 \\
\hline TEHP $\mathrm{b}$ & - & - \\
\hline ТoCP & 136 & 130 \\
\hline $\mathrm{TmCP}^{\mathrm{b}}$ & - & - \\
\hline $\mathrm{TpCP}$ & 148 & 142 \\
\hline TDBPP & 123 & 149 \\
\hline ADBI & 97 & 100 \\
\hline AHMI & 100 & 101 \\
\hline ATII & 109 & 114 \\
\hline HHCB & 119 & 156 \\
\hline AHTN & 97 & 104 \\
\hline MUX & 111 & 100 \\
\hline MUK & 121 & 117 \\
\hline
\end{tabular}

${ }^{\text {a }}$ TBEP was found at high concentrations in blanks and were not found above blank levels in matrix spikes. ${ }^{\mathrm{b}}$ TEHP and TmCP were not available for inclusion in the matrix spike solution. 
Table S6-4. PUF Field Blank Concentrations (ng/PUF)

\begin{tabular}{lc}
\hline \multicolumn{2}{l}{ PUF \#27:FIELD BLANK } \\
\hline PAHs & \\
\hline 2MENAP & 4.71 \\
1MENAP & 4.90 \\
ACY & 0.921 \\
ACE & 2.25 \\
FLR & 4.17 \\
PHN & 19.4 \\
ANT & 4.73 \\
FLRA & 2.62 \\
PYR & 1.74 \\
BAA & 0.430 \\
CHRY & 2.28 \\
BbjFLRA & 0.239 \\
BkFLRA & 0.676 \\
BEP & 0.215 \\
BAP & 1.26 \\
PER & 0.0586 \\
IND & 0.621 \\
DBA & 0.189 \\
BghiP & 0.0351 \\
\hline PCMs and Nitromusks \\
\hline ADBI & 0.798 \\
AHMI & 11.2 \\
ATII & 0.650 \\
HHCB & 7.58 \\
AHTN & 7.14 \\
MUX & 0.103 \\
MUK & 1.68 \\
\hline OPES & \\
\hline TnBP & 2.78 \\
TCEP & 103 \\
TCIPP & 14.8 \\
TDCIPP & 48.1 \\
TPhP & 21.4 \\
TBEP & 19.8 \\
EHDPP & 41.5 \\
TEHP & 5.29 \\
ToCP & 0.524 \\
TmCP & 1.26 \\
TpCP & 3.54 \\
TDBPP & 2.92 \\
\hline
\end{tabular}




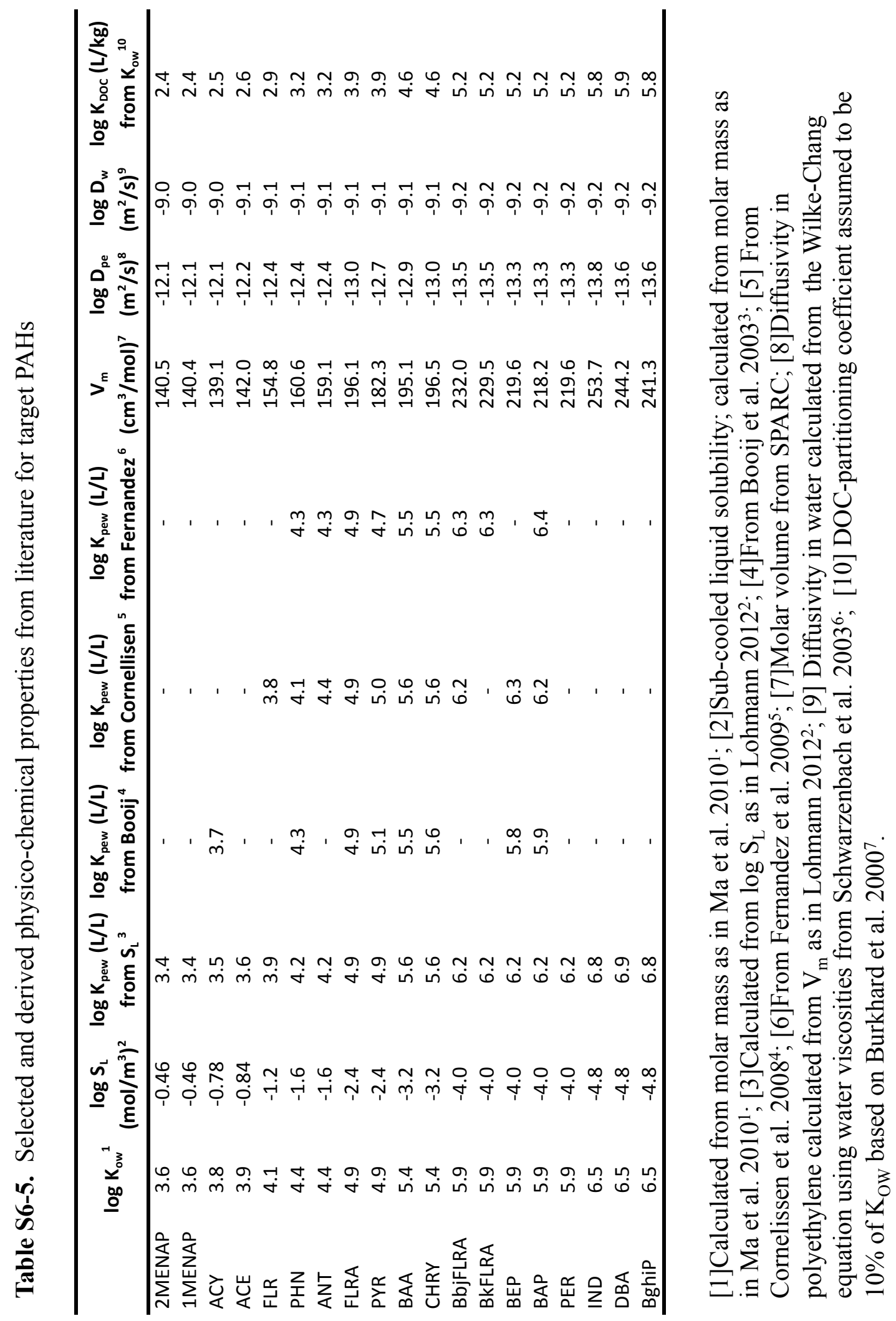




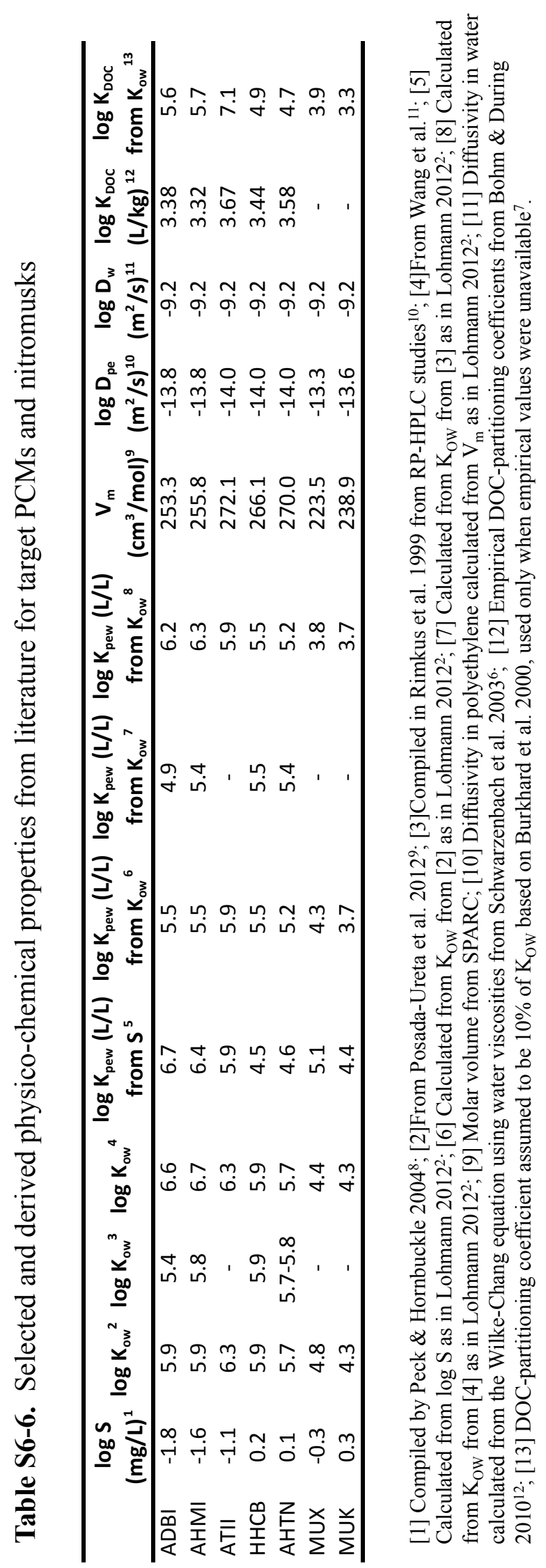




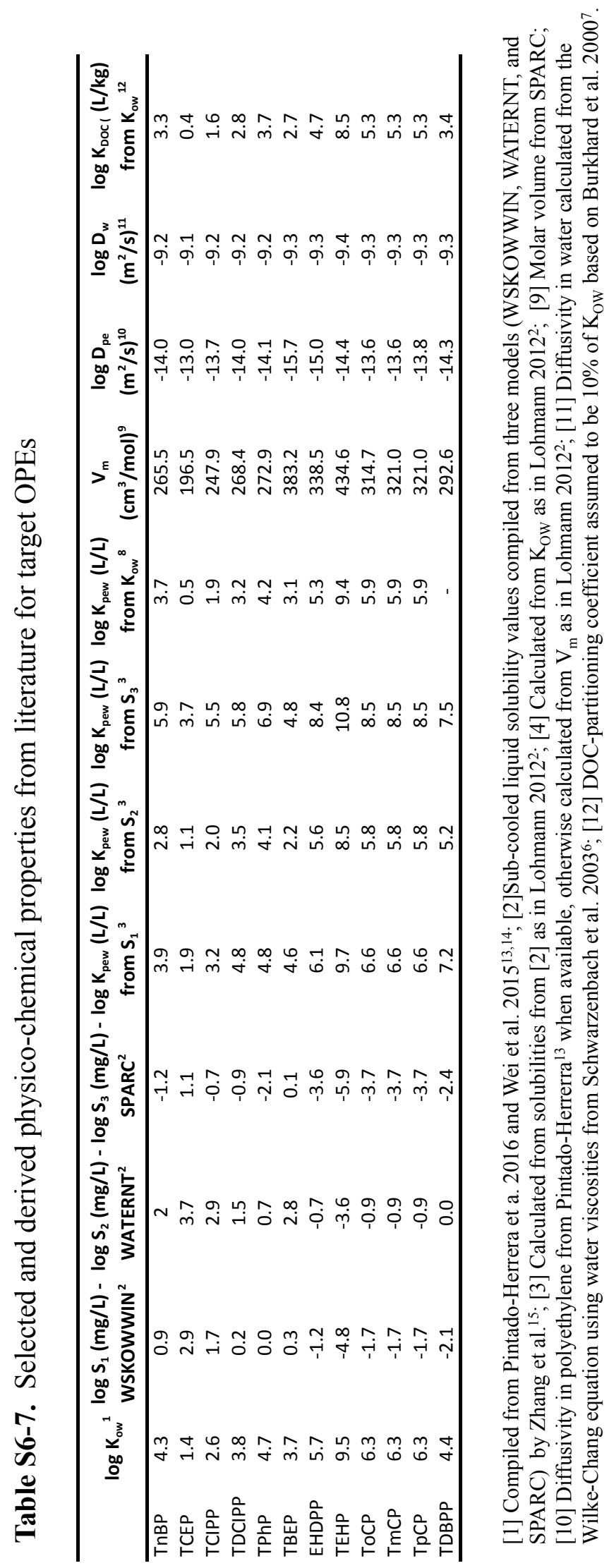




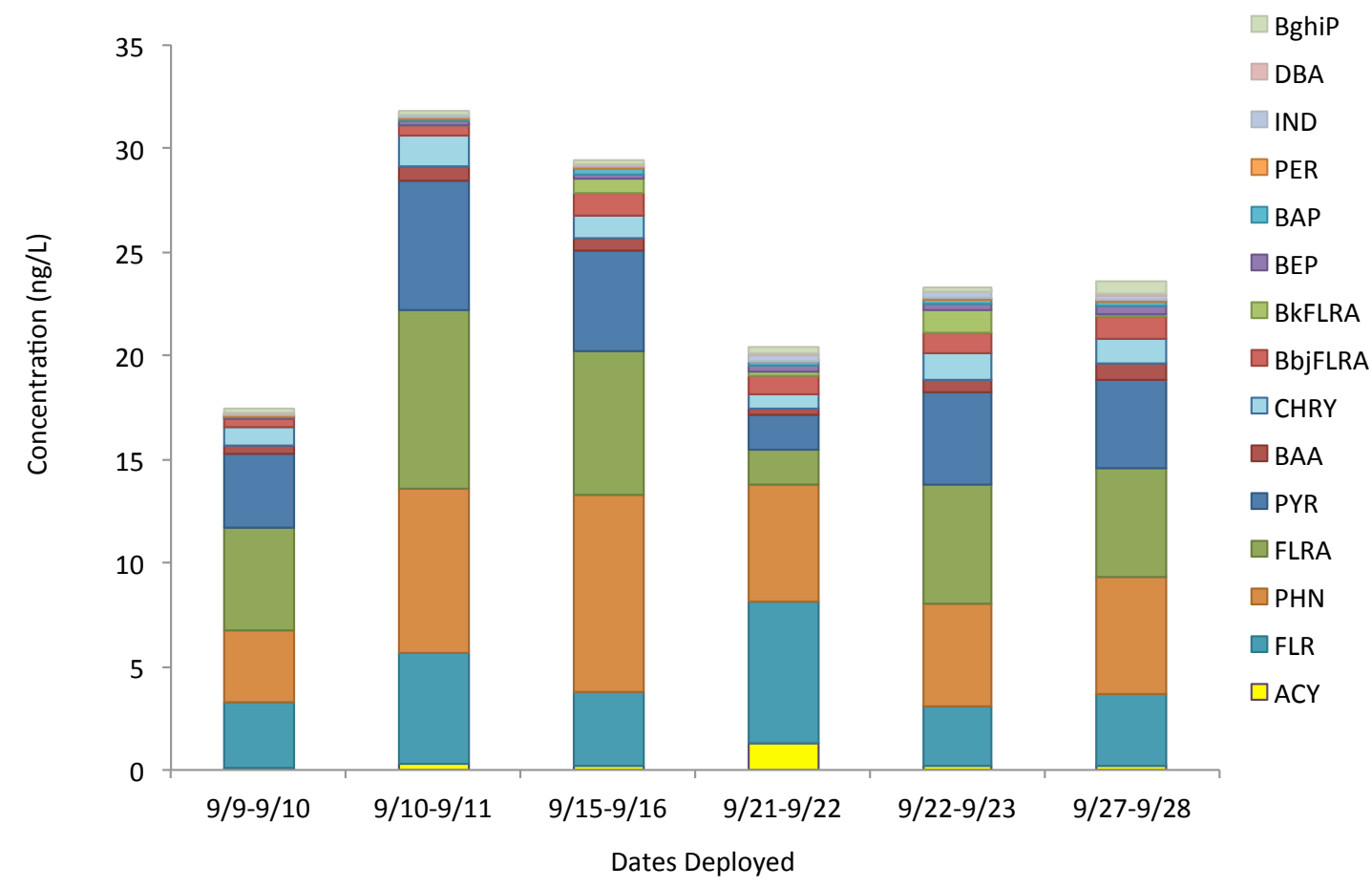

Figure S6-1. Water concentrations of most abundant PAHs calculated from highvolume active water sampling. 


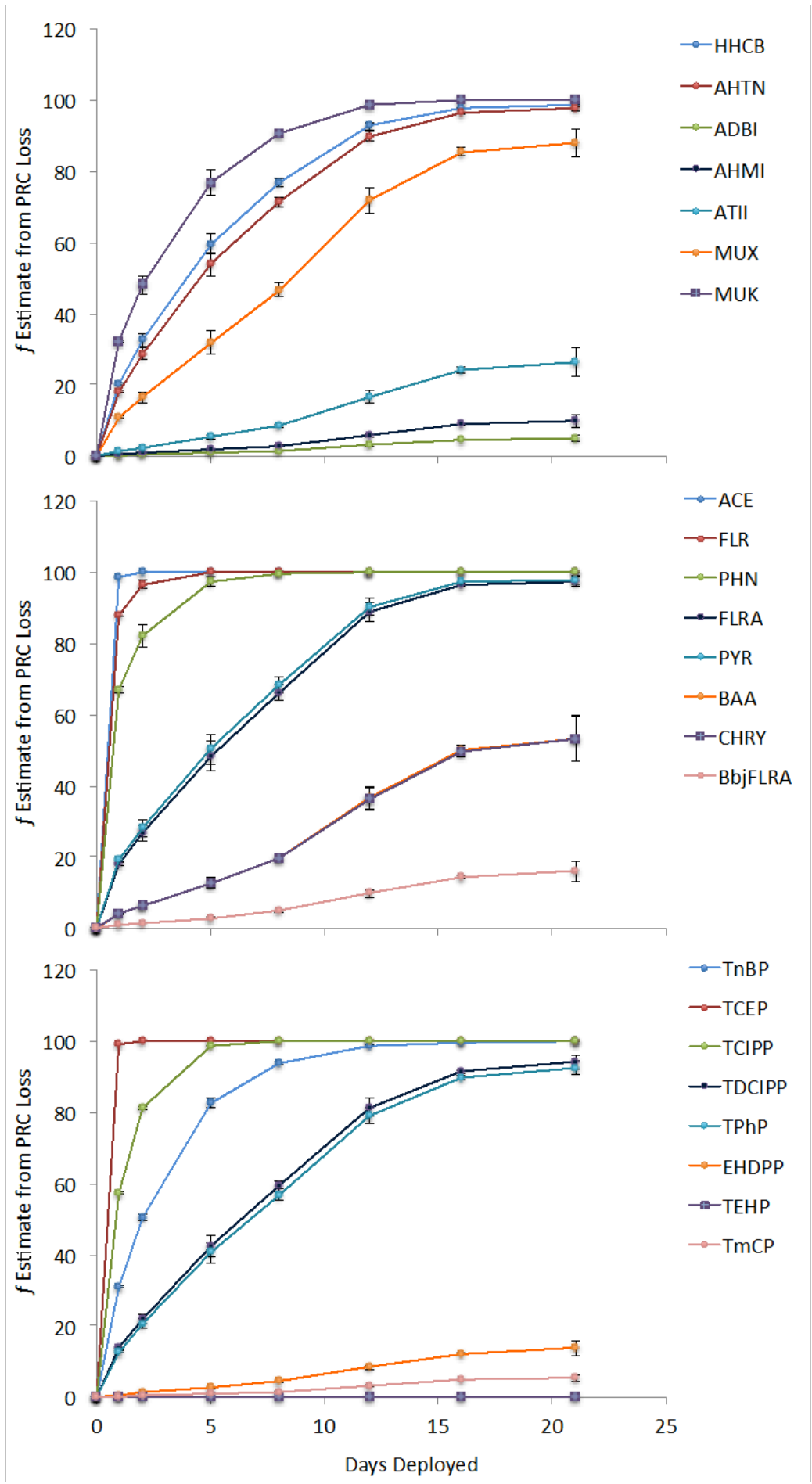

Figure S6-2. Predicted PE uptake profiles. Percent equilibration $(f)$ reached at each time point was calculated based on best-fit $\delta_{\mathrm{DBL}}$ values from PRC loss data and estimated chemical properties for target compounds. These predictions were made using $K_{\text {PEW }}$ calculated from solubility, with values for OPEs calculated using $S_{1}$, the solubility estimated by Zhang et al. from EPI Suite's WSKOWWIN. 


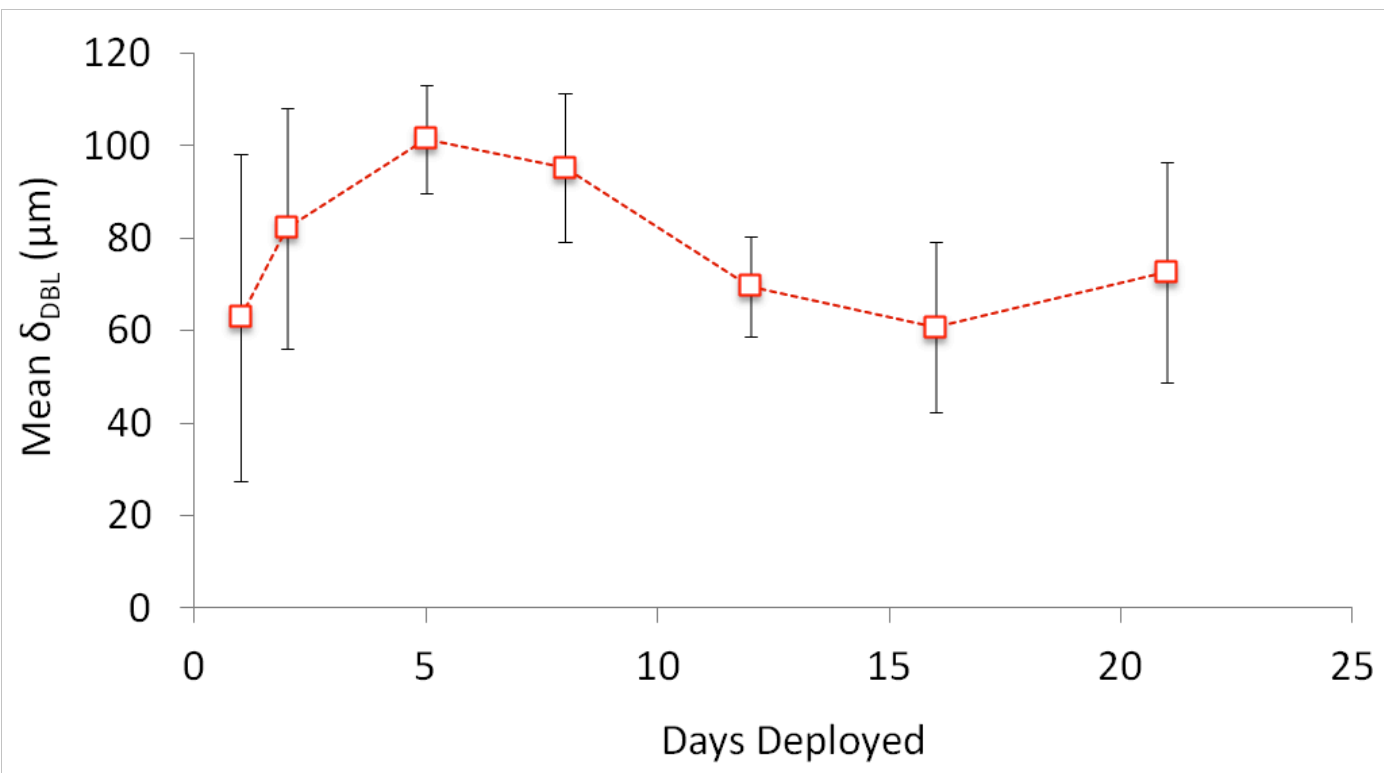

Figure S6-3. Average best-fit value for the thickness of the diffusive boundary layer at the PE-water interface for each set of PEs, estimated from PRC loss data and literature values for chemical properties. Markers represent the average of 2-3 values. Error bars represent stdev derived from model fit. 


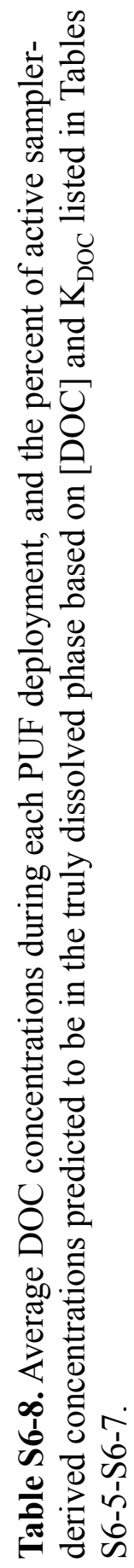

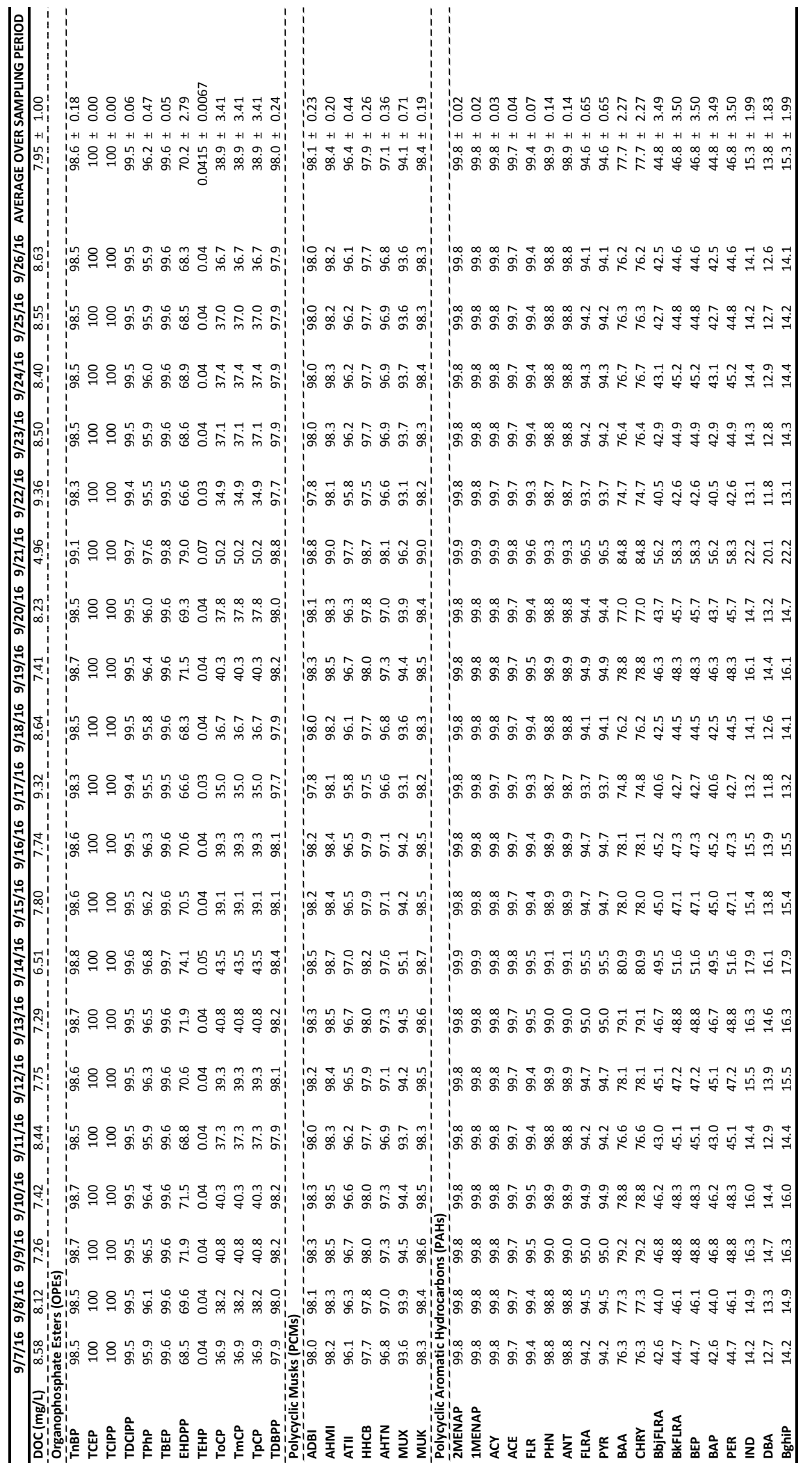


Table S6-9. Comparison of PE-derived (Conc $\mathrm{CE}_{\mathrm{PE}}$ ) and active sampling-derived (Conc $\mathrm{PUF}_{\text {P }}$ ) water concentrations for PAHs and PCMs. Conc $\mathrm{PE}_{\mathrm{P}} / \mathrm{Conc}_{\mathrm{PUF}}$ was calculated by comparing the mean PUF concentration for all available PUF samples and water concentrations derived from the PEs recovered on Day 21 of sampling. Conc $_{\mathrm{PE}} /$ Conc $_{\mathrm{PUF}}{ }^{*}$ was calculated in the same manner except that the first $24 \mathrm{~h}$ of active sampling, when elevated concentrations were seen, was removed. Grayed out values are $<$ DL.

\begin{tabular}{|c|c|c|c|c|}
\hline & Conc $_{P E}(\mathrm{ng} / \mathrm{L})$ & Conc $_{\text {PUF }}(\mathrm{ng} / \mathrm{L})$ & Conc $_{\mathrm{PE}} /$ Conc $_{\mathrm{PUF}}$ & Conc $_{\mathrm{PE}} /$ Conc $_{\mathrm{PUF}}{ }^{*}$ \\
\hline \multicolumn{5}{|l|}{ PAHs } \\
\hline 2MENAP & 0.406 & 0.398 & 1.0 & 1.1 \\
\hline 1MENAP & 0.570 & 0.861 & 0.66 & 0.85 \\
\hline$A C Y$ & 0.173 & 0.342 & 0.51 & 0.60 \\
\hline ACE & 2.53 & 1.43 & 1.8 & 1.9 \\
\hline FLR & 1.75 & 4.97 & 0.35 & 0.43 \\
\hline PHN & 3.23 & 8.16 & 0.40 & 0.53 \\
\hline ANT & 0.247 & 0.282 & 0.87 & 0.95 \\
\hline FLRA & 3.44 & 7.21 & 0.48 & 0.60 \\
\hline PYR & 3.30 & 5.46 & 0.60 & 0.76 \\
\hline BAA & 0.261 & 0.549 & 0.48 & 0.54 \\
\hline CHRY & 0.568 & 1.116 & 0.51 & 0.61 \\
\hline BbjFLRA & 0.264 & 0.420 & 0.63 & 0.71 \\
\hline BkFLRA & 0.0673 & 0.156 & 0.43 & 0.46 \\
\hline BEP & 0.0788 & 0.140 & 0.56 & 0.62 \\
\hline BAP & 0.0395 & 0.0780 & 0.51 & 0.60 \\
\hline PER & 0.0160 & 0.0381 & 0.42 & 0.45 \\
\hline IND & 0.0269 & 0.0322 & 0.84 & 0.80 \\
\hline DBA & 0.00582 & 0.00330 & 1.8 & 1.6 \\
\hline BghiP & 0.0261 & 0.0489 & 0.53 & 0.56 \\
\hline \multicolumn{5}{|l|}{ PCMs } \\
\hline$\overline{\mathrm{ADBI}}$ & 0.0670 & 3.95 & 0.017 & 0.021 \\
\hline $\mathrm{AHMI}$ & 0.0488 & 2.31 & 0.021 & 0.030 \\
\hline ATII & 2.04 & 48.3 & 0.042 & 0.055 \\
\hline HHCB & 637 & 2402 & 0.27 & 0.34 \\
\hline AHTN & 36.4 & 176 & 0.21 & 0.28 \\
\hline MUX & 0.00852 & 0.0600 & 0.14 & 0.17 \\
\hline MUK & 4.12 & 108 & 0.038 & 0.048 \\
\hline
\end{tabular}




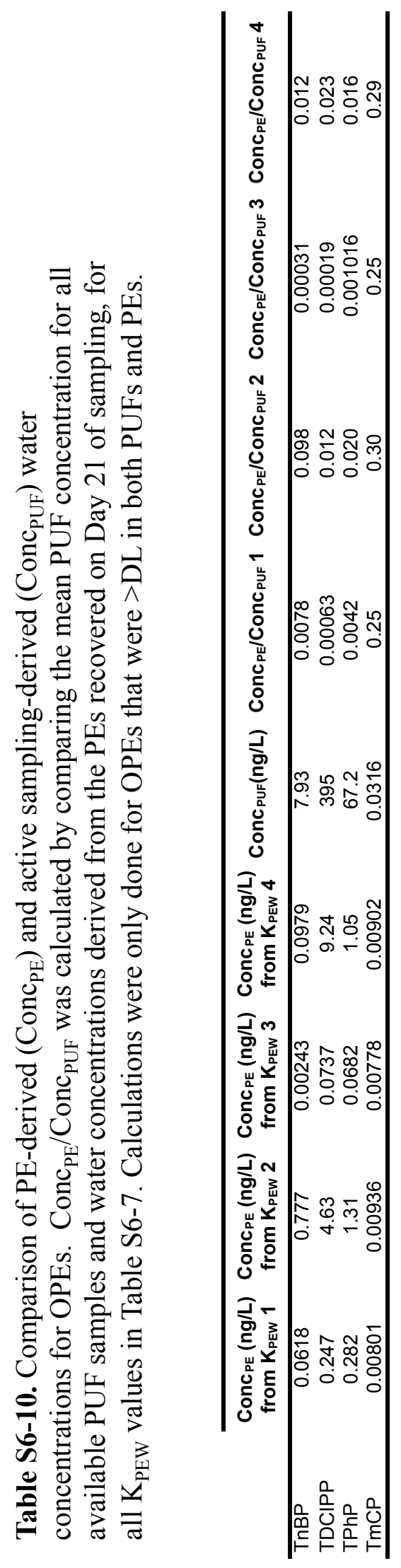


Table S6-11. Log $\mathrm{K}_{\mathrm{PEW}}$ values derived from active and passive sampling data, corrected to $298 \mathrm{~K}$. Values for compounds with uptake profiles suggesting equilibrium was not reached are listed as lower bounds. Compounds with unclear equilibrium state are marked with an asterisk.

\begin{tabular}{|c|c|}
\hline & $\log K_{\text {PEW }}(298 \mathrm{~K})$ \\
\hline \multicolumn{2}{|l|}{ PAHs } \\
\hline 1MENAP & 3.3 \\
\hline $\mathrm{ACY}$ & 3.2 \\
\hline ACE & 3.9 \\
\hline FLR & 3.5 \\
\hline PHN & 3.8 \\
\hline ANT & 4.2 \\
\hline FLRA & 4.6 \\
\hline PYR & 4.7 \\
\hline BAA & $>5.0$ \\
\hline $\mathrm{CHRY}$ & $>5.1$ \\
\hline BbjFLRA & $>5.2$ \\
\hline BkFLRA & $>5.1$ \\
\hline BEP & $>5.2$ \\
\hline BAP & $>5.2$ \\
\hline PER & $>5.1$ \\
\hline IND & $>5.4$ \\
\hline DBA & $>5.7$ \\
\hline BghiP & $>5.2$ \\
\hline \multicolumn{2}{|l|}{ PCMs } \\
\hline MUK & $3.0^{*}$ \\
\hline MUX & $4.2^{*}$ \\
\hline $\mathrm{HHCB}$ & 3.9 \\
\hline AHTN & 3.9 \\
\hline $\mathrm{ADBI}$ & 3.6 \\
\hline AHMI & 3.7 \\
\hline ATII & 3.9 \\
\hline \multicolumn{2}{|l|}{ OPEs } \\
\hline TnBP & 1.8 \\
\hline TDCIPP & 1.6 \\
\hline TPhP & $2.4^{*}$ \\
\hline $\mathrm{TmCP}$ & $4.7^{*}$ \\
\hline TEHP & $>6.7$ \\
\hline
\end{tabular}




\section{LITERATURE CITED IN THE SUPPLEMENTARY INFORMATION}

(1) Ma, Y.-G.; Lei, Y. D.; Xiao, H.; Wania, F.; Wang, W.-H. Critical Review and Recommended Values for the Physical-Chemical Property Data of 15 Polycyclic Aromatic Hydrocarbons at $25^{\circ} \mathrm{C}$. J. Chem. Eng. Data 2010, 55, 819-825, DOI:10.1021/je900477x.

(2) Lohmann, R. Critical review of low-density polyethylene's partitioning and diffusion coefficients for trace organic contaminants and implications for its use as a passive sampler. Environ. Sci. Technol. 2012, 46, 606-618, DOI:10.1021/es202702y.

(3) Booij, K.; Hofmans, H. E.; Fischer, C. V.; van Weerlee, E. M. Temperaturedependent uptake rates of nonpolar organic compounds by semipermeable membrane devices and low-density polyethylene membranes. Environ. Sci. Technol. 2003, 37, 361-366, DOI:10.1021/es025739i.

(4) Cornelissen, G.; Pettersen, A.; Broman, D.; Mayer, P.; Breedveld, G. D. Field testing of equilibrium passive samplers to determine freely dissolved native polycyclic aromatic hydrocarbon concentrations. Environ. Toxicol. Chem. 2008, 27, 499-508, DOI:10.1897/07-253.1.

(5) Fernandez, L. A.; Macfarlane, J. K.; Tcaciuc, A. P.; Gschwend, P. M. Measurement of freely dissolved PAH concentrations in sediment beds using passive sampling with low-density polyethylene strips. Environ. Sci. Technol. 2009, 43, 1430-1436, DOI:10.1021/es802288w.

(6) Schwarzenbach, R. P.; Gschwend, P. M.; Imboden, D. M. Environmental Organic Chemistry; 2nd ed.; Wiley Interscience, 2002.

(7) Burkhard, L. P. Estimating dissolved organic carbon partition coefficients for nonionic organic chemicals. Environ. Sci. Technol. 2000, 34, 4663-4668, DOI:10.1021/es0012691.

(8) Peck, A. M.; Hornbuckle, K. C. Synthetic musk fragrances in Lake Michigan. Environ. Sci. Technol. 2004, 38, 367-372, DOI:10.1021/es034769y.

(9) Posada-Ureta, O.; Olivares, M.; Navarro, P.; Vallejo, A.; Zuloaga, O.; Etxebarria, N. Membrane assisted solvent extraction coupled to large volume injection-gas chromatography-mass spectrometry for trace analysis of synthetic musks in environmental water samples. J. Chromatogr. A 2012, 1227, 38-47, DOI:10.1016/j.chroma.2011.12.104.

(10) Rimkus, G. G. Polycyclic musk fragrances in the aquatic environment. Toxicol. Lett. 1999, 111, 37-56, DOI:10.1016/S0378-4274(99)00191-5. 
(11) Wang, I.-T. I.; Cheng, S.-F.; Tsai, S.-W. Determinations of airborne synthetic musks by polyurethane foam coupled with triple quadrupole gas chromatography tandem mass spectrometer. J. Chromatogr. A 2014, 1330, 6168, DOI:10.1016/j.chroma.2014.01.011.

(12) Böhm, L.; Düring, R.-A. Partitioning of polycyclic musk compounds in soil and aquatic environment - experimental determination of KDOC. J. Soils Sediments 2010, 10, 708-713, DOI:10.1007/s11368-010-0200-z.

(13) Pintado-Herrera, M. G.; Lara-Martín, P. A.; González-Mazo, E.; Allan, I. J. Determination of silicone rubber and low density polyethylene diffusion and polymer-water partition coefficients for emerging contaminants. Environ. Toxicol. Chem. 2016, 35, n/a-n/a, DOI:10.1002/etc.3390.

(14) Wei, G.-L.; Li, D.-Q.; Zhuo, M.-N.; Liao, Y.-S.; Xie, Z.-Y.; Guo, T.-L.; Li, J.J.; Zhang, S.-Y.; Liang, Z.-Q. Organophosphorus flame retardants and plasticizers: sources, occurrence, toxicity and human exposure. Environ. Pollut. 2015, 196, 29-46, DOI:10.1016/j.envpol.2014.09.012.

(15) Zhang, X.; Suhring, R.; Serodio, D.; Bonnell, M.; Sundin, N.; Diamond, M. L. Novel flame retardants: Estimating the physical-chemical properties and environmental fate of 94 halogenated and organophosphate PBDE replacements. Chemosphere 2016, 144, 2401-2407, DOI:10.1016/j.chemosphere.2015.11.017. 


\section{CHAPTER 7}

\section{DIFFUSIVE UPTAKE OF GASEOUS HYDROPHOBIC ORGANIC CONTAMINANTS FROM AMBIENT AIR INTO POLYETHYLENE PASSIVE \\ SAMPLERS}

This manuscript is formatted for submission to the journal Chemosphere.

Carrie A. McDonough ${ }^{\dagger}$, Rainer Lohmann ${ }^{\dagger *}$

${ }^{\dagger}$ Graduate School of Oceanography, University of Rhode Island, 215 South Ferry

Road, Narragansett, Rhode Island 02882, United States

"Corresponding Author email: rlohmann@uri.edu; phone: 401-874-6612; fax: 401$874-6811$ 


\section{ABSTRACT}

Passive polyethylene samplers (PEs) are an increasingly popular tool to analyze spatial trends and identify sources of emerging and legacy gas-phase semivolatile organic contaminants (SVOCs) on global, regional, and citywide scales. In order to apply PEs to the measurement of emerging contaminants with poorly constrained chemical properties, PE-air partitioning coefficients $\left(\mathrm{K}_{\mathrm{PEA}}\right)$ must be determined. In this study, the uptake of a wide variety of SVOCs was measured over a 21-day deployment at a Rhode Island Department of the Environment (RI DEM) station in East Providence (RI) during September, 2016. Concentrations of SVOCs in PEs were tracked over time, along with loss of performance reference compounds (PRCs), to determine whether compounds reached equilibrium during the deployment. Results were compared to concentrations from a codeployed high-volume active air sampler to derive $\mathrm{K}_{\mathrm{PEA}}$ values for equilibrated compounds, and lower-bound estimates of $\mathrm{K}_{\mathrm{PEA}}$ for non-equilibrated compounds. Active sampler-derived gaseous $\Sigma_{32} \mathrm{PAH}$ ranged from $8.2 \mathrm{ng} / \mathrm{m}^{3}$ to $90.5 \mathrm{ng} / \mathrm{m}^{3}$. The musks HHCB and AHTN had mean concentrations of $1.2 \pm 1.7 \mathrm{ng} / \mathrm{m}^{3}$ and $0.5 \pm 0.6 \mathrm{ng} / \mathrm{m}^{3}$ respectively. Organophosphate ester (OPE) concentrations ranged from $2 \mathrm{ng} / \mathrm{m}^{3}$ to $54 \mathrm{ng} / \mathrm{m}^{3}$ and were dominated by aryl OPE TPhP. Gaseous PBDE and novel halogenated flame retardant (NHFR) concentrations were an order of magnitude lower than OPEs, PAHs, and PCMs, from $13 \mathrm{pg} / \mathrm{m}^{3}$ to $96 \mathrm{pg} / \mathrm{m}^{3}$. K $\mathrm{KEA}_{\text {PE }}$ values calculated in this study were similar to literature for some equilibrated PAHs and BDE 15, but were an order of magnitude lower than 
literature-derived values for most other compounds. The reason for this discrepancy is unknown.

\section{INTRODUCTION}

Polyethylene passive samplers (PEs) and other passive samplers, including semi-permeable membrane devices (SPMDs) and polyurethane foam disks (PUFs), are an increasingly popular option for air pollutant monitoring projects. Passive samplers have been used to analyze spatial trends and identify probable sources of emerging and legacy semi-volatile organic contaminants (SVOCs) on global, regional, and citywide scales, ${ }^{1-5}$ and to analyze seasonal and long-term temporal trends in concentrations of gaseous SVOCs. ${ }^{6,7}$ They are also being deployed indoors and worn on the body to assess health risks associated with occupational exposures in workplaces and homes. ${ }^{8-10}$ Passive samplers simultaneously deployed in different media are becoming an increasingly popular tool for measuring fluxes of SVOCs, including air-water diffusive fluxes. ${ }^{11-13}$

PEs accumulate SVOCs from air passively, selecting for the non-particlebound portion of ambient air contaminants. PEs and other passive samplers are promising tools because they are cost effective and simple to deploy; they accumulate SVOCs via diffusion, so they require no power source to operate, enabling long-term monitoring at unprecedented high resolution and in remote locations. They tend to have lower detection limits than active samplers, allowing quantification of trace-level contaminants in the gaseous phase that would be challenging to detect using a traditional sampling apparatus on feasible timescales. 
Despite ease of use, there are some drawbacks to choosing passive samplers rather than traditional active samplers for a monitoring project. Unlike active samplers, the rate at which air is sampled by passive samplers cannot be set at a constant value. One main concern inherent in the use of passive samplers is accurately estimating sampling rates so that concentrations in the sampling matrix can be dependably converted to ambient air concentrations. This is especially challenging for emerging contaminants with poorly constrained chemical properties.

PEs are usually contained with protective housing, and so transfer is thought of as a three-step process by which (i) air is transferred from the surroundings to within the sampler housing, (ii) air is transported to the PE-air interface, and (iii) exchange occurs at the PE-air interface. ${ }^{14}$ At the PE-air interface, turbulent mixing becomes less important and the exchange process is dominated by molecular diffusion. The diffusion process is described by Fick's First Law (Equation 1), which states that chemical flux is a function of diffusivity $\left(\mathrm{D} ; \mathrm{m}^{2} / \mathrm{s}\right)$, surface area through which the flux $\operatorname{occurs}\left(\mathrm{A} ; \mathrm{m}^{2}\right)$, and the perpendicular concentration gradient $\left(\mathrm{dC} / \mathrm{dx} ; \mathrm{ng} / \mathrm{m}^{4}\right) .{ }^{14-16}$

$$
F=-D A \frac{d C}{d x}
$$

The model for uptake of gaseous compounds into the passive sampler matrix is based on Whitman Two-Film Theory, originally developed to describe the "driving potential" behind absorption of a gaseous solute into the liquid phase, which was known to be proportional to the "distance from equilibrium". ${ }^{17}$ Whitman described the gas-liquid interface through which absorption occurs (here the air-PE interface) as a series of two films with definite thicknesses, with the chemical potential of the gas 
and liquid phase equal at the boundary between the two films. According to this model (Equation 2), the flux $(\mathrm{F} ; \mathrm{ng} / \mathrm{s})$ into the PE is a function of the concentration in the sampler $\left(\mathrm{C}_{\mathrm{PE}} ; \mathrm{ng} / \mathrm{m}^{3}\right)$, the air concentration $\left(\mathrm{C}_{\mathrm{A}} ; \mathrm{ng} / \mathrm{m}^{3}\right)$, the sampler area $\left(\mathrm{A}_{\mathrm{S}} ; \mathrm{m}^{2}\right)$, the sampler-air partitioning coefficient, $\left(\mathrm{K}_{\mathrm{PEA}}\right)$ and the overall mass transfer coefficient $\left(\mathrm{k}_{\mathrm{o}} ; \mathrm{m} / \mathrm{s}\right){ }^{14}$

$$
F=k_{o} \cdot A_{S} \cdot\left(C_{A}-\frac{C_{P E}}{K_{P E A}}\right)
$$

A number of approaches have been developed to determine the rate of uptake $\left(k_{o}\right)$, also referred to as the sampling rate $\left(R_{s}=A_{S} k_{o}\right)$, for a wide array of contaminants. Many common approaches for PEs rely on monitoring loss of performance reference compounds (PRCs) during deployment. These compounds are loaded into PEs prior to deployment and their percent loss over the deployment period gives the percent equilibration that would be reached for a target compound with identical properties. For compounds that do not have identical properties to the chosen PRCs, models are used to describe how percent equilibration depends on compound properties, and these models can be informed by PRC loss data in order to predict percent equilibration reached by each compound. ${ }^{18}$

In this study, the uptake of a wide variety of SVOCs was measured over a 21day deployment at a Rhode Island Department of the Environment (RI DEM) station in East Providence (RI) during September, 2016. Concentrations of SVOCs in PEs over time were tracked to determine whether compounds reached equilibrium during the deployment. Results were compared to gaseous concentrations derived from a codeployed high-volume active air sampler to derive PE-air partitioning coefficients 
$\left(\mathrm{K}_{\mathrm{PEA}}\right)$ for equilibrated compounds, and lower-bound estimates of $\mathrm{K}_{\mathrm{PEA}}$ for nonequilibrated compounds.

\section{METHODS}

Sampler Preparation and Deployment. Passive Sampling. $50-\mu \mathrm{m}$ polyethylene sheeting (Carlisle Plastics, Inc.) was cut into approximately 3 in. $x$ in. pieces. The sheets were incubated in solvent (DCM and hexane) to remove any background contamination. PE sheets were then incubated in a solution of PRCs to load these compounds into the polyethylene prior to deployment. The PRCs used were a series of deuterated PAHs (fluorene- $\mathrm{d}_{10}\left(\right.$ Flr- $\left.\mathrm{d}_{10}\right)$, pyrene- $\mathrm{d}_{10}\left(\right.$ Pyr- $\left.\mathrm{d}_{10}\right)$, and benzo(a)pyrene- $\mathrm{d}_{12}$ $\left(\right.$ BaP- $\left.\mathrm{d}_{12}\right)$ ), polybrominated biphenyls (2,5-dibromobiphenyl (DiBB), 2,2',5,5'tetrabromobiphenyl (TetraBB), 2,2',4,5',6-pentabromobiphenyl (PentaBB)), octachloronaphthalene (OCN), and deuterated organophosphate esters (tri-n-butyl phosphate- $\mathrm{d}_{27}\left(\right.$ TnBP-d $\left.\mathrm{d}_{27}\right)$ tris(1-chloro-2-propyl)phosphate- $\mathrm{d}_{18}\left(\mathrm{TCIPP}-\mathrm{d}_{18}\right)$, tris(1,3dichloro-2-propyl) phosphate- $\mathrm{d}_{15}\left(\right.$ TDCIPP- $\left.\mathrm{d}_{15}\right)$, and triphenyl phosphate- $\mathrm{d}_{15}(\mathrm{TPhP}-$ $\left.\left.d_{15}\right)\right)$.

All sheets were deployed on the same day in September 2015 on the roof of the Rhode Island Department of Environmental Monitoring (DEM) station in East Providence (RI). Sheets were fastened within inverted stainless steel bowls (3 sheets per bowl) using stainless steel wire and zip-ties, and bowls were hung from a railing on the roof (Figure S7-1). On days 1, 2, 3, 5, 9, 13, 17, and 21, one bowl containing three PEs were collected. PEs were removed from the protective bowl and wrapped in muffled aluminum foil onsite, then packed on ice in a cooler and transported to the 
laboratory at the University of Rhode Island Graduate School of Oceanography (URI GSO).

Active Sampling. Polyurethane foam plugs (PUFs, $10 \times 8 \mathrm{~cm}$ diameter, Tisch Environmental) were pre-cleaned by extraction in a Dionex 350 Accelerated Solvent Extractor (ASE, Dionex Corporation) using 3:1 hexane:DCM. 20 x $25 \mathrm{~cm}$ Whatman glass fiber filters (GFFs) were wrapped in aluminum foil and combusted at $450{ }^{\circ} \mathrm{C}$ for at least 4 hours before use.

The high-volume active air sampler (HV-AAS; Tisch Environmental) was set up directly below the PE bowls on the ground adjacent to the DEM structure. Two PUFs and one GFF were loaded into the HV-AAS and were changed every $24 \mathrm{~h}$ for the first three days, and then every $48 \mathrm{~h}$. Each time the PUF and GFF were changed, the flow rate on the active sampler was read before taking out the previous materials, and again once the new materials were added. The rate of uptake was determined by averaging the flow rate at the beginning and end of each sampling period.

Extraction and Analysis. All PEs were spiked with deuterated PAHs (acenaphthene$d_{10}$, phenanthrene- $d_{10}$, chrysene- $d_{12}$, and perylene- $d_{12}$ ) and non-native BDEs (BDE 35, BDE 77, BDE 128, and BDE 190)) and extracted twice for 24 hours, once in pentane and once in ethyl acetate. Extraction solutions were combined and concentrated down to $1 \mathrm{~mL}$ in a warm water bath under a gentle stream of nitrogen, then transferred to hexane and concentrated to $\sim 50 \mu \mathrm{L}$. A laboratory blank and two matrix spike samples were extracted alongside each batch of PEs. All extracts were spiked with $40 \mathrm{ng}$ of pterphenyl- $\mathrm{d}_{14}$ injection standard before analysis. 
PUFs were spiked with internal standard and extracted on the Dionex 350 ASE

with 3:1 hexane:DCM. Extracts were passed through a $1000 \mathrm{mg}(6 \mathrm{~mL})$ silica gel SPE cartridge (Restek) with a thin layer of sodium sulfate (baked at $450{ }^{\circ} \mathrm{C}$ for at least 6 hours) and eluted with $20 \mathrm{~mL}$ of $3: 2$ pentane:DCM followed by $20 \mathrm{~mL}$ of $1: 1$ acetone:DCM. They were concentrated down to $\sim 0.5 \mathrm{~mL}$ in a warm water bath under a gentle stream of nitrogen. Extracts were then transferred to spring-bottom inserts and concentrated down to $\sim 100 \mu \mathrm{L}$ under nitrogen and spiked with p-terphenyl- $\mathrm{d}_{14}$ as an injection standard.

All extracts were analyzed on an Agilent 7890 GC coupled to an Agilent 5977 MSD in EI mode for polycyclic aromatic hydrocarbons (PAHs), polycyclic musks (PCMs), and organophosphate esters (OPEs), and in negative chemical ionization (NCI) mode with methane reagent gas for novel halogenated flame retardants (NHFRs) and polybrominated diphenyl ethers (PBDEs). See Table S7-1 for a full list of target compounds and their abbreviations.

Quality Control. Concentrations in PE extracts were blank-subtracted using the PE field blank. Concentrations under field blank levels were replaced with $25 \%$ of the field blank value, as multiple blanks were not available for estimation of blank variance. For PUFs, concentrations were blank-subtracted using the average of the PUF field blank. After blank subtraction, the detection limit was defined as 3 times the standard deviation of three PUF laboratory blanks. Concentrations $<$ DL were replaced with half the DL.

Sampling Rates \& Ambient Concentrations. Passive Sampling. To determine percent equilibration reached by SVOCs during the 21-day PE deployment, PRC loss 
over the deployment was measured by comparing field-deployed PEs to non-deployed field blanks. Percent loss of PRCs, which is equal to percent equilibration $(f)$ reached by a target compound with identical properties, was used along with PRC chemical properties to determine the best-fit value of the thickness of the diffusive boundary layer $\left(\delta_{\mathrm{DBL}}\right)$ at the PE-air interface via non-linear least squares fitting using the $n l s$ function in $\mathrm{R}$ for Equation 3, where $\mathrm{V}_{\mathrm{PE}}$ is the volume of the PE sheet, $\mathrm{A}_{\mathrm{PE}}$ is the area of the PE sheet, $t$ is the length of the PE deployment, $l_{\mathrm{PE}}$ is half the thickness of the PE sheet $(\sim 25 \mu \mathrm{m}), \mathrm{K}_{\mathrm{PEM}}$ is the PE-matrix partitioning coefficient (here the PE-air partitioning coefficient $\left.\mathrm{K}_{\mathrm{PEA}}\right)$, $\mathrm{D}_{\mathrm{M}}$ is the molecular diffusivity of the compound in the surrounding matrix (air), and $\mathrm{D}_{\mathrm{PE}}$ is the diffusivity of the compound in PE. After $\delta_{\mathrm{DBL}}$ was determined from using this equation with PRC data, the $\delta_{\mathrm{DBL}}$ was plugged back into Eq 2 with chemical properties for target compounds from literature (Table S7-2) to estimate $f$ for each target compound during deployment.

$$
f=1-e^{\frac{-t \cdot A_{P E}}{V_{P E} \cdot\left(\frac{\delta_{D B L} \cdot K_{P E M}}{D_{M}}+\frac{l_{P E}}{D_{P E}}\right)}}
$$

Active Sampling. Ambient concentrations were calculated from HV-AAS samples by dividing the total weight of target compound accumulated in both PUFs by the total volume of air sampled during deployment. In some cases, the top and bottom PUF deployed within the active sampler were found to have approximately equal concentrations of some target compounds, indicating that breakthrough may have occurred. In instances where the bottom PUF contained $\geq 40 \%$ of the total mass of accumulated, ambient air concentration was determined by assuming the PUFs had reached equilibrium with the air and using the PUF-air partitioning coefficient (K $\mathrm{K}_{\mathrm{PUF}}$ 
A), determined from the octanol-air partitioning coefficient $\left(\mathrm{K}_{\mathrm{OA}}\right)$ as in Shoeib and Harner 2002, and correcting for average temperature during the sampling period. Concentrations in PUFs were converted to $\mathrm{ng} / \mathrm{m}^{3}$ using a PUF density of $2.7 \times 10^{4}$ $\mathrm{g} / \mathrm{m}^{3} \cdot{ }^{19} \mathrm{~K}_{\mathrm{OA}}$ values used and their sources are listed in Table S7-2.

$\mathbf{K}_{\mathrm{PEA}}$ Values. $\mathrm{K}_{\mathrm{PEA}}$ values were directly calculated for compounds that equilibrated during deployment by calculating the ratio of the concentration in PEs recovered at 21 days over the average concentration in air derived from continuous active sampling. For compounds identical to PRCs, $\mathrm{K}_{\mathrm{PEA}}$ was determined by correcting this ratio using the percent loss value for the matching PRC. However, for other non-equilibrated compounds, the equilibrium concentration in the PE could not be approximated without estimating physical properties, which would mean that calculated $\mathrm{K}_{\mathrm{PEA}}$ values would depend on other estimated properties, rather than on direct measurement. Any $\mathrm{K}_{\mathrm{PEA}}$ calculated for a non-equilibrated compound were "lower-bound" estimates, becoming further and further from the true value as distance from equilibrium increased.

\section{RESULTS \& DISCUSSION}

Summary of HV-AAS Concentrations. Ambient gaseous concentrations derived from HV-AAS samples are shown for PAHs, PCMs, OPEs (Figure 7-1) and for BDEs and NHFRs (Figure 7-2), with additional PAH profiles in Figure S7-2. No active sampling data was available for September 10-12 because there was a severe storm and power outage and no viable samples were collected during this time. Table S7-3 shows all compound concentrations in all PUF samples. 
Gaseous PAHs. Gaseous PAHs were dominated by low molecular weight (LMW) PAHs, particularly naphthalene, acenaphthene, fluorene, and phenanthrene, with mean concentrations over deployment of $4.9 \pm 10 \mathrm{ng} / \mathrm{m}^{3}, 1.9 \pm 2.4 \mathrm{ng} / \mathrm{m}^{3}, 2.9 \pm 2.7$ $\mathrm{ng} / \mathrm{m}^{3}$, and $7.6 \pm 3.7 \mathrm{ng} / \mathrm{m}^{3}$, respectively. Total $\Sigma_{32} \mathrm{PAH}$ concentrations (including alkyl and substituted PAHs) ranged from $8.2 \mathrm{ng} / \mathrm{m}^{3}$ for September $26-28$ to $90.5 \mathrm{ng} / \mathrm{m}^{3}$ for September 16-18. Concentration and composition was generally similar from day to day, with a slight decrease in concentrations on later sampling days, though there was a dramatic spike in concentration observed in HV-AAS samples deployed September 16-18, due mostly to increased concentrations of naphthalene, acenaphthene, and fluorene. Concentrations of several LMW alkylated and substituted PAHs also increased markedly during this period, but the spike was not observed in data for HMW PAHs (Figure S7-2).

Gaseous PCMs. HHCB and AHTN had mean concentrations of $1.2 \pm 1.7 \mathrm{ng} / \mathrm{m}^{3}$ and $0.5 \pm 0.6 \mathrm{ng} / \mathrm{m}^{3}$ respectively. These were the two most abundant PCMs, making up $>90 \%$ of total gaseous $\Sigma_{7} \mathrm{PCM}$ in all samples, which is consistent with previous studies. $^{12,20}$ The lowest $\Sigma_{7} \mathrm{PCM}$ was observed in the last 6 days of the sampling period, and a large spike in concentrations $\left(\Sigma_{7} \mathrm{PCM}=8.5 \mathrm{ng} / \mathrm{m}^{3}\right)$ was seen for the HVAAS sample deployed September 18-20.

Gaseous OPEs. Five OPEs (TnBP, TPhP, TCEP, TCIPP, and TDCIPP) were found above detection limits in most HV-AAS extracts, while the remaining compounds were rarely detected $>\mathrm{DL}$ and are omitted from discussion. $\Sigma_{5} \mathrm{OPE}$ ranged from $2 \mathrm{ng} / \mathrm{m}^{3}$ for September 20-22 to $54 \mathrm{ng} / \mathrm{m}^{3}$ for September 14-16. Most extracts were dominated by aryl OPE TPhP (mean concentration $11 \pm 15 \mathrm{ng} / \mathrm{m}^{3}$ ), while alkyl 
OPE TnBP was intermittently detected at high concentrations, and the chlorinated OPEs (TCEP, TCIPP, and TDCIPP) were generally present at lower levels (mean $\Sigma_{3} \mathrm{Cl}-\mathrm{OPE}=2.4 \pm 1.3 \mathrm{ng} / \mathrm{m}^{3}$ ). Concentrations were highly variable from sample to sample.

Gaseous PBDEs and NHFRs. Gaseous PBDE and NHFR concentrations derived from HV-AAS data were generally an order of magnitude lower than OPEs, PAHs, and PCMs. $\Sigma_{12}$ BDE ranged from $9.6 \mathrm{pg} / \mathrm{m}^{3}$ for September $20-22$ to $69 \mathrm{pg} / \mathrm{m}^{3}$ for September 12-14. $\Sigma_{12} \mathrm{BDE}$ was dominated by lower-brominated congeners (BDEs $2,8,15$, and 47) and was greatest at the beginning of the deployment period and lowest in the middle of the deployment period (September 18-22). NHFR concentrations were dominated by bromobenzenes HBBz, PBEB, PBT, and PBBz. $\Sigma_{8}$ NHFR followed a similar trend to $\Sigma_{12} \mathrm{BDE}$, ranging from $3.0 \mathrm{pg} / \mathrm{m}^{3}$ for September 20-22 to $27 \mathrm{pg} / \mathrm{m}^{3}$ for September 12-14.

PRC Loss in PEs. PRC loss data is shown in Figure S7-3. Flr- $\mathrm{d}_{10}$ and TnBP- $\mathrm{d}_{27}$ reached equilibrium within the first five days of sampling. DiBB and Pyr- $\mathrm{d}_{10}$ also reached equilibrium by the end of the 21-day sampling period. The remaining PRCs appeared to remain in linear uptake phase. Best-fit $\delta_{\mathrm{DBL}}$ were calculated using all PRCs except BaP- $\mathrm{d}_{12}$. Results for $\mathrm{BaP}-\mathrm{d}_{12}$ showed an atypical loss profile, possibly due to photodegradation within the PE, ${ }^{21}$ while the other two PAHs showed typical loss profiles. The mean DBL thickness estimate from triplicate 21-day PEs was $0.11 \pm 0.03 \mathrm{~mm}$.

Uptake Profiles in PEs. Concentration of OPEs, BDEs, NHFRs, and PCMs in PEs collected at different times are plotted in Figure 7-3. Data for PAHs is shown in 
Figure S7-4. All concentration data for PEs are displayed in Table S7-4. Uptake profiles for TnBP, TCEP, and TCIPP suggested that they had reached equilibrium during deployment, while the state of TPhP and EHDPP was less clear, and TDCIPP appeared to remain in a linear uptake phase. BDE 15 and pTBX also most likely equilibrated, while the other brominated flame retardants shown (BDE 28 and 99, and PBBz and PBT) look to have remained in a linear uptake phase.

All PCMs appear to have equilibrated. This was fairly clear for HHCB and AHTN, as they increased in concentration over the first several days before beginning to decrease, possibly in response to the peaking concentrations seen in the middle of the study in active-derived data. A similar peak was seen in PE concentrations for many of the equilibrated PAHs, and some of the equilibrated OPEs. For the other PCMs, the equilibrium phase was less clear because little variability in PE concentrations was seen over the deployment, and concentrations accumulated were fairly low $(<0.4 \mathrm{ng} / \mathrm{g})$.

Profiles for TPhP and TDCIPP showed a decline in PE concentration during the first two days of deployment, suggesting that these compounds were present in the PE matrix initially. The reason for this interference, and for why it would be greater than PE blank levels, is unknown. OPEs detected at fewer than half of the time points (TBEP, TEHP, ToCP, TmCP, TpCP, and TDBPP) provided insufficient information on PE uptake and were omitted from interpretation and discussion.

PE-Air Partitioning Coefficients. Concentrations derived from HV-AAS are shown along with concentrations accumulated in 21-day PEs and $f$ estimated based on PRC loss data in Table 7-1. $\mathrm{K}_{\mathrm{PEA}}$ estimates calculated from passive and active data are also 
displayed. Partitioning coefficients were only calculated for compounds that were $>$ DL in both passive and active samplers. Presented $\mathrm{K}_{\mathrm{PEA}}$ values are lower bounds for compounds that did not reach equilibrium or have an identical PRC counterpart. $f$ values were used as a guide to help determine which compounds may not have reached equilibrium, but $f$ is dependent on estimated physical properties, and so is not certain in all cases where PE uptake profiles did not clearly indicate whether or not equilibrium was reached.

$\mathrm{K}_{\mathrm{PEA}}$ values from this study were generally lower than values measured in Khairy and Lohmann, or derived using the regression with vapor pressure presented in that work, ${ }^{22}$ though values for some low molecular weight, equilibrated PAHs (NAP $\left.\log \mathrm{K}_{\mathrm{PEA}}=4.9, \mathrm{ACE} \log \mathrm{K}_{\mathrm{PEA}}=5.7, \mathrm{PHN} \log \mathrm{K}_{\mathrm{PEA}}=6.8\right)$ and $\mathrm{BDE} 15\left(\log \mathrm{K}_{\mathrm{PEA}}=7.5\right)$ were close to those from Khairy \& Lohmann. The explanation for lower $\mathrm{K}_{\mathrm{PEA}}$ values observed in this study for equilibrated compounds is unknown. This study was done in much warmer weather than the study by Khairy \& Lohmann (conducted in November-December, 2012), which would have caused the affinity of organic contaminants for the PE matrix to be lower in this study than the previous work. However, values in both studies were corrected for mean temperature, so this should not have caused a difference in final $\mathrm{K}_{\mathrm{PEA}}(298 \mathrm{~K})$ values.

\section{CONCLUSIONS}

HV-AAS data for gaseous SVOCs demonstrated that, for many compounds, concentrations in air at the East Providence DEM site varied from day to day, with pulses of elevated PAH and PCM concentrations evident from September 16 to 18. PE uptake profiles for many equilibrated compounds likely responded to this pulse, as 
concentrations in PEs increased initially, and then began to decrease later in the study. Values of $\mathrm{K}_{\mathrm{PEA}}$ calculated for the majority of equilibrated compounds based on activeand passive-derived data from this study were lower than those derived from vapor pressure or previous empirical measurement, though the reason for this discrepancy is unknown.

\section{ACKNOWLEDGMENTS}

We acknowledge funding from the US EPA Great Lakes Restoration Initiative (GLRI) GLAS \#00E00597-0, project officer Todd Nettesheim and from Rhode Island National Science Foundation Experimental Program to Stimulate Competitive Research (RI NSF EPSCoR). We thank David Adelman (URI) for organizing field deployments, Rachel Miller (URI) for help with field deployments, Anna Robuck and Erik Dixon Anderson (URI) for help with sample preparation, Michael Vansco (URI) for thin-film diffusivity experiments, and Melinda Viera (RI DOH) for meteorological data and access to the facilities.

\section{ASSOCIATED CONTENT}

Supporting Information. Additional figures and tables are available in the Supporting Information. This material is available free of charge via the Internet.

\section{AUTHOR INFORMATION}

\section{Corresponding Author}

* Rainer Lohmann: rlohmann@uri.edu 


\section{LITERATURE CITED}

(1) Melymuk, L.; Robson, M.; Helm, P. A.; Diamond, M. L. Application of land use regression to identify sources and assess spatial variation in urban SVOC concentrations. Environ. Sci. Technol. 2013, 47, 1887-1895, DOI:10.1021/es3043609.

(2) McDonough, C. A.; Khairy, M. A.; Muir, D. C. G.; Lohmann, R. Significance of population centers as sources of gaseous and dissolved PAHs in the lower Great Lakes. Environ. Sci. Technol. 2014, 48, 7789-7797, DOI:10.1021/es501074r.

(3) Khairy, M. A.; Lohmann, R. Field validation of polyethylene passive air samplers for parent and alkylated PAHs in Alexandria, Egypt. Environ. Sci. Technol. 2012, 46, 3990-3998, DOI:10.1021/es300012u.

(4) Hearn, L. K.; Kennedy, K.; Hawker, D. W.; Toms, L.-M. L.; Alberts, V.; Mueller, J. F. Spatial mapping of city-wide PBDE levels using an exponential decay model. J. Environ. Monit. 2012, 14, 643-650, DOI:10.1039/c2em10656f.

(5) Gawor, A.; Shunthirasingham, C.; Hayward, S. J.; Lei, Y. D.; Gouin, T.; Mmereki, B. T.; Masamba, W.; Ruepert, C.; Castillo, L. E.; Shoeib, M.; Lee, S. C.; Harner, T.; Wania, F. Neutral polyfluoroalkyl substances in the global atmosphere. Environ. Sci. Process. Impacts 2014, 16, 404-413, DOI:10.1039/c3em00499f.

(6) Motelay-Massei, A.; Harner, T.; Shoeib, M.; Diamond, M.; Stern, G.; Rosenberg, B. Using passive air samplers to assess urban-rural trends for persistent organic pollutants and polycyclic aromatic hydrocarbons. 2. Seasonal trends for PAHs, PCBs, and organochlorine pesticides. Environ. Sci. Technol. 2005, 39, 5763-5773, DOI:10.1021/es0504183.

(7) Kennedy, K.; Macova, M.; Bartkow, M. E.; Hawker, D. W.; Zhao, B.; Denison, M. S.; Mueller, J. F. Effect based monitoring of seasonal ambient air exposures in Australia sampled by PUF passive air samplers. Atmos Pollut Res. 2010, 1, 50-58, DOI:10.1007/s10661-014-3667-z.

(8) Kennedy, K.; Macova, M.; Leusch, F.; Bartkow, M. E.; Hawker, D. W.; Zhao, B.; Denison, M. S.; Mueller, J. F. Assessing indoor air exposures using passive sampling with bioanalytical methods for estrogenicity and aryl hydrocarbon receptor activity. Anal. Bioanal. Chem. 2009, 394, 1413-1421, DOI:10.1007/s00216-009-2825-6. 
(9) Wilford, B. H.; Harner, T.; Zhu, J.; Shoeib, M.; Jones, K. C. Passive sampling survey of polybrominated diphenyl ether flame retardants in indoor and outdoor air in Ottawa, Canada: implications for sources and exposure. Environ. Sci. Technol. 2004, 38, 5312-5318, DOI:10.1021/es049260x.

(10) O’Connell, S. G.; Kincl, L. D.; Anderson, K. A. Silicone wristbands as personal passive samplers. Environ. Sci. Technol. 2014, 48, 3327-3335, DOI:10.1021/es405022f.

(11) Morgan, E. J.; Lohmann, R. Detecting air-water and surface-deep water gradients of PCBs using polyethylene passive samplers. Environ. Sci. Technol. 2008, 42, 7248-7253, DOI:10.1021/es800518g.

(12) McDonough, C. A.; Helm, P. A.; Muir, D.; Puggioni, G.; Lohmann, R. Polycyclic musks in the air and water of the lower Great Lakes: Spatial distribution and volatilization from surface waters. Environ. Sci. Technol. 2016, 50, 11575-11583, DOI:10.1021/acs.est.6b03657.

(13) McDonough, C. A.; Puggioni, G.; Helm, P. A.; Muir, D.; Lohmann, R. Spatial distribution and air-water exchange of organic flame retardants in the lower great lakes. Environ. Sci. Technol. 2016, 50, 9133-9141, DOI:10.1021/acs.est.6b02496.

(14) Bartkow, M. E.; Booij, K.; Kennedy, K. E.; Müller, J. F.; Hawker, D. W. Passive air sampling theory for semivolatile organic compounds. Chemosphere 2005, 60, 170-176, DOI:10.1016/j.chemosphere.2004.12.033.

(15) Schwarzenbach, R. P.; Gschwend, P. M.; Imboden, D. M. Environmental Organic Chemistry; 2nd ed; Wiley Interscience, 2002.

(16) Castellan, G. W. Physical Chemistry: 3rd Edition; 3rd ed.; Adison-Wesley Publishing Company: Reading, MA, 1983.

(17) Whitman, W. G. A preliminary experimental confirmation of the two-film theory of gas absorption. Chem. Metall. Eng. 1923, 29, 146-148, DOI:10.1016/0017-9310(62)90032-7.

(18) Booij, K.; Smedes, F. An improved method for estimating in situ sampling rates of nonpolar passive samplers. Environ. Sci. Technol. 2010, 44, 6789-6794, DOI:10.1021/es101321v.

(19) Shoeib, M.; Harner, T. O. M. Characterization and comparison of three passive air samplers for persistent organic pollutants. 2002, 36, 4142-4151, DOI:10.1021/es020635t. 
(20) Peck, A.; Hornbuckle, K. Synthetic musk fragrances in urban and rural air of Iowa and the Great Lakes. Atmos. Environ. 2006, 40, 6101-6111, DOI:10.1016/j.atmosenv.2006.05.058.

(21) Allan, I. J.; Christensen, G.; Bæk, K.; Evenset, A. Photodegradation of PAHs in passive water samplers. Mar. Pollut. Bull. 2016, 105, 249-254, DOI:10.1016/j.marpolbul.2016.02.018.

(22) Khairy, M. A.; Lohmann, R. Field calibration of low density polyethylene passive samplers for gaseous POPs. Environ. Sci. Process. Impacts 2014, 16, 414-421, DOI:10.1039/c3em00493g. 


\section{FIGURES AND TABLES}

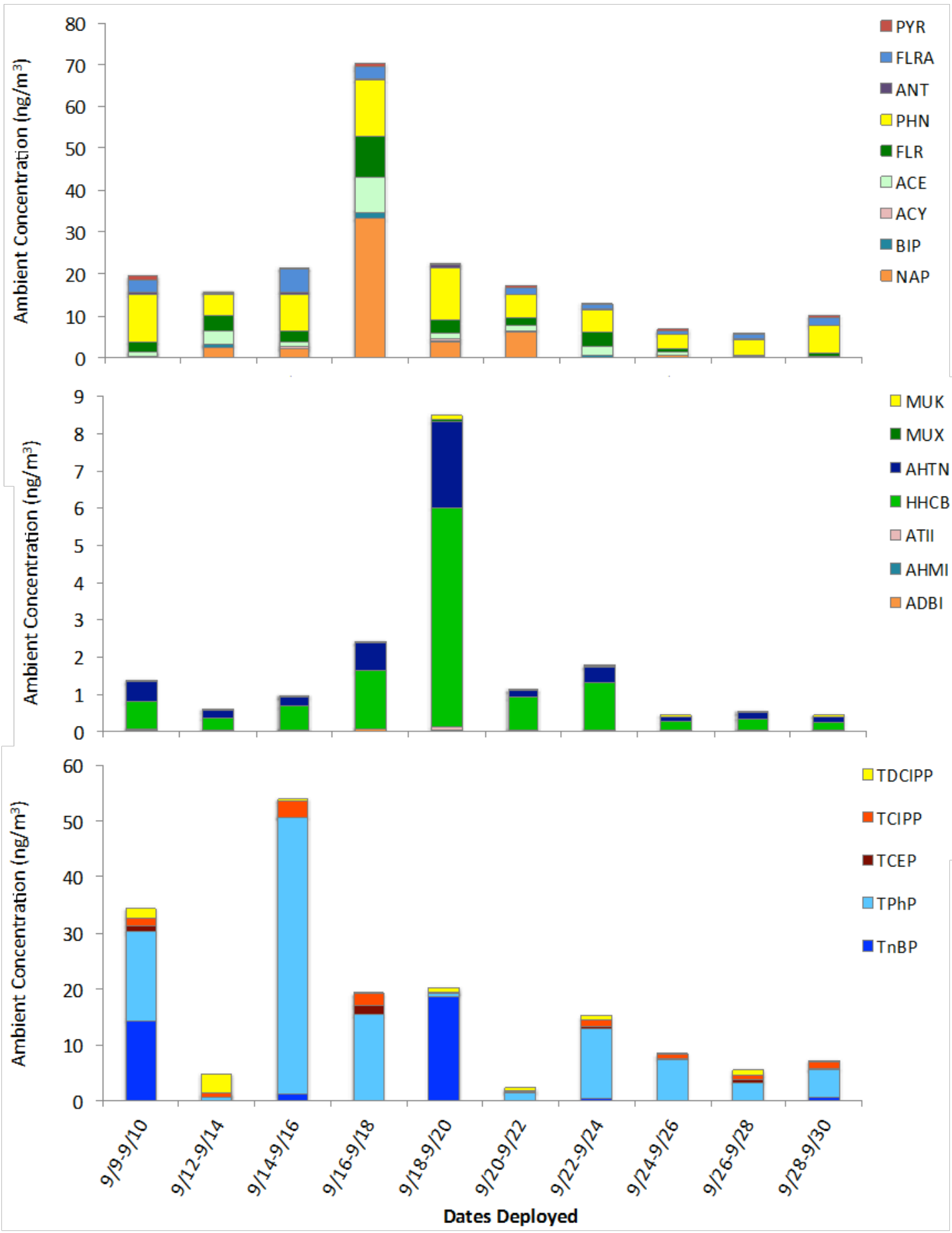

Figure 7-1. Gaseous concentrations of low molecular weight PAHs (top), PCMs (middle), and OPEs (bottom) in East Providence air from active sampling. 


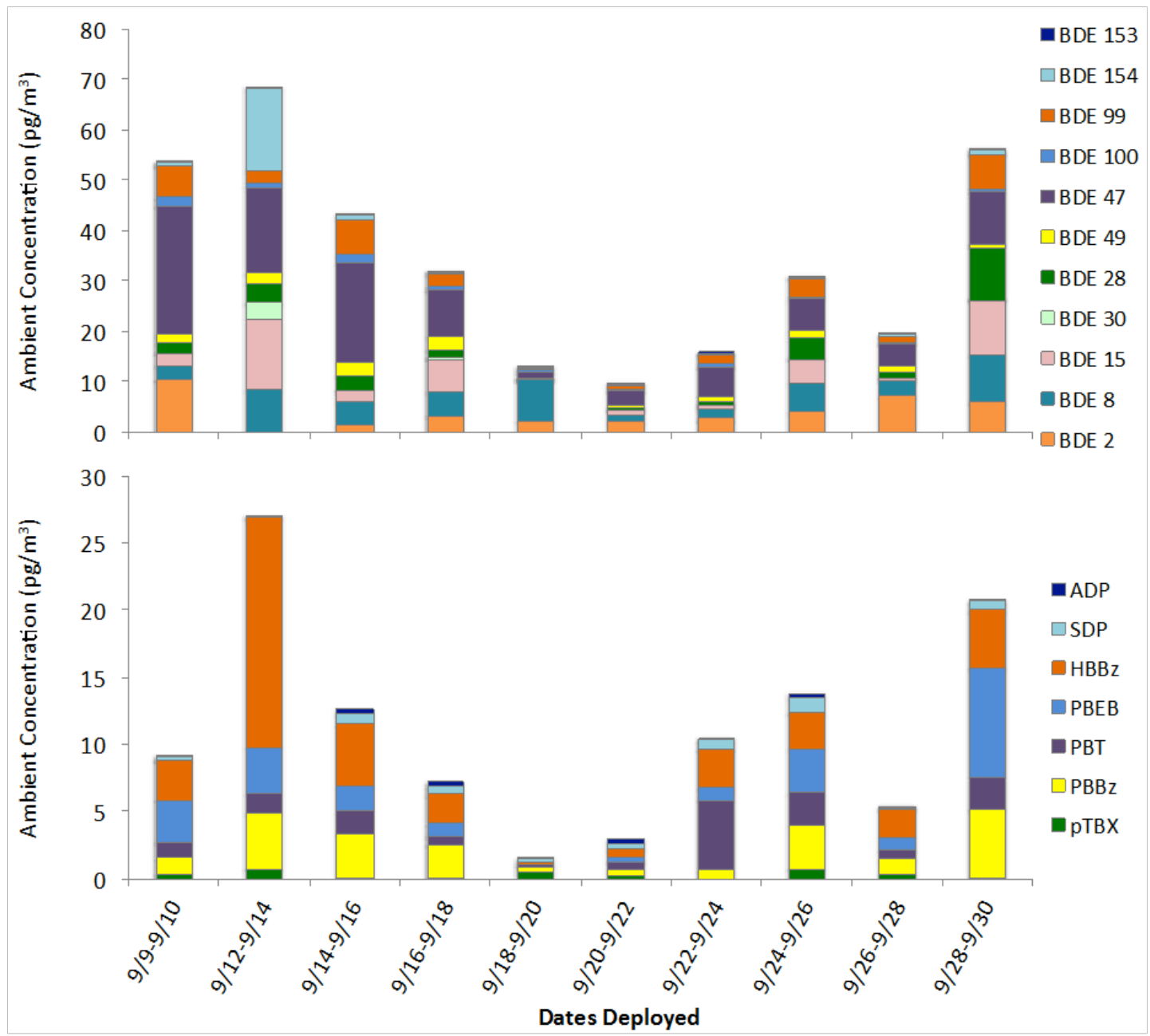

Figure 7-2. Gaseous concentrations of BDEs (top) and NHFRs (bottom) in East Providence air from active sampling. 

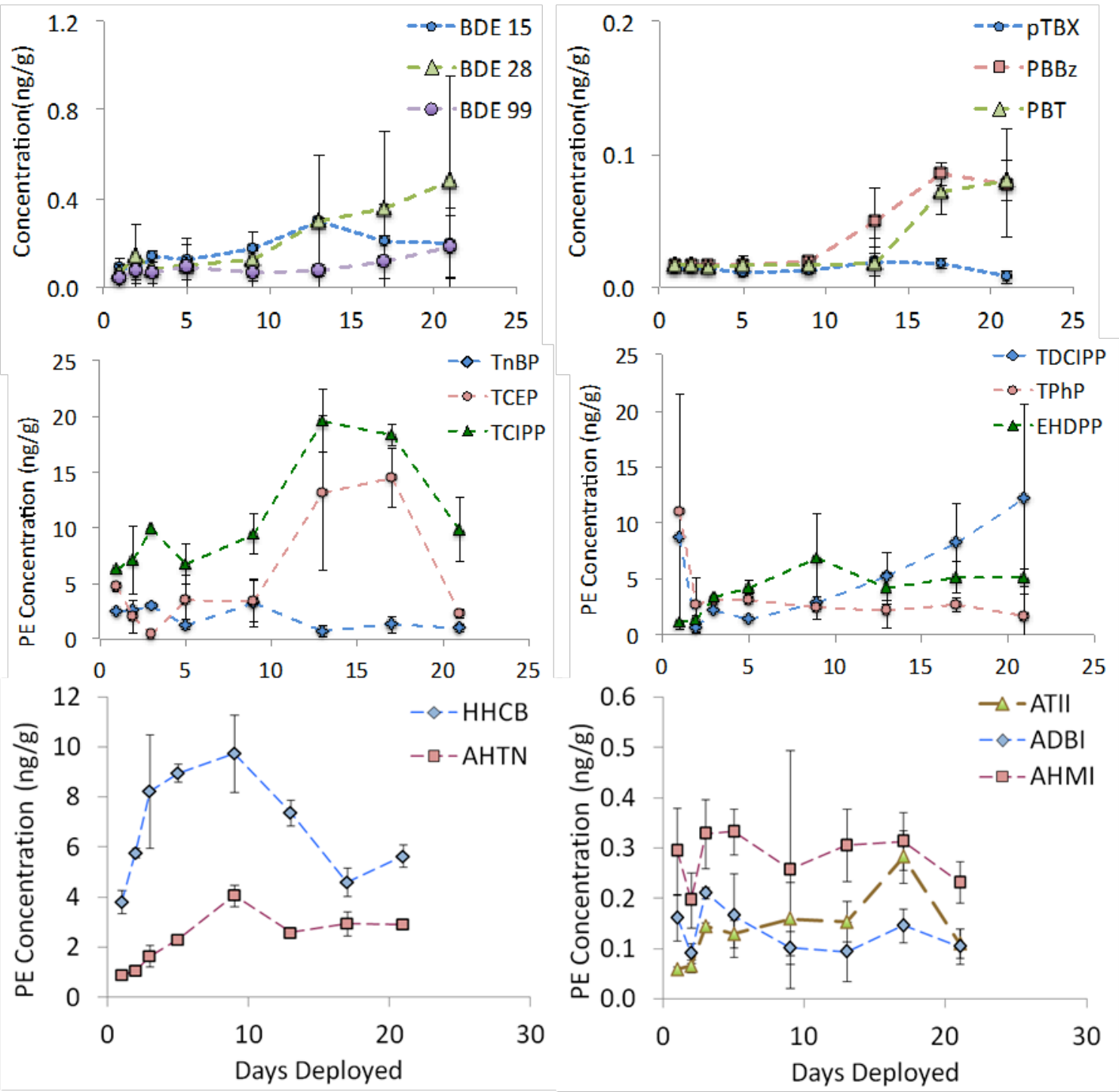

Figure 7-3. Uptake profiles OPEs, BDEs, NHFRs, and PCMs in PEs over 21-day deployment. 
Table 7-1. $K_{\text {PEA }}(298 \mathrm{~K})$ or lower-bound estimates derived from 21-day PEs and mean active-derived gaseous concentration.

\begin{tabular}{|c|c|c|c|c|c|}
\hline Compound & $\begin{array}{c}\text { Final PE Conc } \\
(\mathrm{ng} / \mathrm{g})\end{array}$ & $\begin{array}{c}\text { PUF-Derived Mean } \\
\text { Ambient Conc }\left(\mathrm{ng} / \mathrm{m}^{3}\right)\end{array}$ & $\begin{array}{l}\text { PRC-based } \\
f \text { estimate }\end{array}$ & $\log \mathrm{K}_{\mathrm{PEA}, 298}$ & $\begin{array}{c}\text { Literature } \\
\log \mathrm{K}_{\mathrm{PEA}}{ }^{1}\end{array}$ \\
\hline \multicolumn{6}{|l|}{ PAHs } \\
\hline NAP & 0.641 & 4.87 & 100 & 4.9 & 4.9 \\
\hline 2MENAP & $<\mathrm{DL}$ & 1.54 & 100 & - & - \\
\hline 1MENAP & $<\mathrm{DL}$ & 0.663 & 100 & - & - \\
\hline BIP & $<\mathrm{DL}$ & 0.371 & 100 & - & - \\
\hline $\mathrm{ACY}$ & 0.138 & 0.128 & 100 & 5.7 & 5.8 \\
\hline ACE & 1.11 & 1.93 & 100 & 5.4 & 6.0 \\
\hline DBF & 1.08 & 1.56 & 100 & - & - \\
\hline FLR & 3.63 & 2.88 & 100 & 5.8 & 6.4 \\
\hline 1MEFLR & 65.6 & 0.279 & 100 & 8.0 & 7.2 \\
\hline DBT & 7.51 & 0.535 & 100 & 6.8 & 7.4 \\
\hline PHN & 116 & 7.56 & 100 & 6.8 & 7.0 \\
\hline ANT & 2.02 & 0.311 & 100 & 6.5 & 7.2 \\
\hline 2MEPHN & 25.5 & 0.701 & 100 & 7.2 & 7.7 \\
\hline 4/9MEANT & $<\mathrm{DL}$ & 0.341 & 100 & - & - \\
\hline 1MEPHN & $<\mathrm{DL}$ & 0.136 & 100 & - & - \\
\hline FLRA & 79.6 & 1.69 & 99.7 & 7.3 & 8.0 \\
\hline PYR & 15.6 & 0.547 & 99.4 & 7.0 & 8.1 \\
\hline 1MEPYR & 19.6 & 0.0200 & 53.3 & $>8.6$ & 8.9 \\
\hline RET & 2.61 & 0.133 & 19.1 & $>6.9$ & 9.4 \\
\hline BAA & 1.33 & 0.0246 & 44.0 & $>7.3$ & 9.0 \\
\hline CHRY & 4.40 & 0.0541 & 20.6 & $>7.5$ & 9.4 \\
\hline 7MEBAA & 2.36 & 0.0102 & 6.51 & $>7.9$ & 9.9 \\
\hline 6MECHRY & $<\mathrm{DL}$ & 0.00394 & 6.49 & - & - \\
\hline 712DIMEBAACHRY & $<D L$ & 0.00317 & 1.22 & - & - \\
\hline BbjkF & 4.31 & 0.0710 & 2.42 & $>7.3$ & 10.3 \\
\hline BEP & 1.12 & 0.0185 & 1.98 & $>7.3$ & 10.4 \\
\hline BAP & 0.454 & 0.0122 & 1.99 & $>7.2$ & 10.4 \\
\hline PER & $<\mathrm{DL}$ & 0.00141 & 1.98 & - & - \\
\hline IND & 0.998 & 0.00501 & 0.21 & $>7.8$ & 11.3 \\
\hline DBA & 0.169 & $<\mathrm{DL}$ & 0.11 & - & - \\
\hline BghiP & 0.677 & 0.00410 & 0.17 & $>7.7$ & 11.4 \\
\hline $\mathrm{COR}$ & 0.0751 & 0.00123 & 0.01 & $>7.2$ & 12.5 \\
\hline \multicolumn{6}{|l|}{ PCMs } \\
\hline ADBI & 0.104 & 0.0144 & 99.7 & 6.5 & 7.6 \\
\hline AHMI & 0.232 & 0.00332 & 99.8 & 7.5 & 7.5 \\
\hline ATII & 0.111 & 0.0176 & 99.7 & 6.6 & 6.1 \\
\hline HHCB & 5.64 & 1.22 & 99.5 & 6.3 & 7.1 \\
\hline AHTN & 2.93 & 0.510 & 99.5 & 6.4 & 7.1 \\
\hline MUX & 0.0353 & 0.00871 & 6.28 & $>6.1$ & 9.9 \\
\hline MUK & 2.32 & 0.0246 & 7.65 & $>7.7$ & 9.8 \\
\hline
\end{tabular}

${ }^{1}$ Literature $\mathrm{K}_{\mathrm{PEA}}$ values provided for comparison are, for BDEs and parent $\mathrm{PAHs}$, empirical values from Khairy \& Lohmann. $\mathrm{K}_{\mathrm{PEA}}$ values for other compounds were calculated from $\mathrm{p}_{\mathrm{L}}$ using the regression presented in Khairy \& Lohmann. ${ }^{22}$ 
Table 7-1 Cont'd.

\begin{tabular}{|c|c|c|c|c|c|}
\hline Compound & $\begin{array}{l}\text { Final PE Conc } \\
(\mathrm{ng} / \mathrm{g})\end{array}$ & $\begin{array}{c}\text { PUF-Derived Mean } \\
\text { Ambient Conc }\left(\mathrm{ng} / \mathrm{m}^{3}\right)\end{array}$ & $\begin{array}{l}\text { PRC-based } \\
f \text { estimate }\end{array}$ & $\log K_{\mathrm{PEA}, 298}$ & $\begin{array}{c}p_{\mathrm{L}} \text {-derived } \\
\log \mathrm{K}_{\mathrm{PEA}}\end{array}$ \\
\hline \multicolumn{6}{|l|}{ PCMs } \\
\hline$\overline{\mathrm{ADBI}}$ & 0.104 & 0.0144 & 99.7 & 6.5 & 7.6 \\
\hline AHMI & 0.232 & 0.00332 & 99.8 & 7.5 & 7.5 \\
\hline ATII & 0.111 & 0.0176 & 99.7 & 6.6 & 6.1 \\
\hline HHCB & 5.64 & 1.22 & 99.5 & 6.3 & 7.1 \\
\hline AHTN & 2.93 & 0.510 & 99.5 & 6.4 & 7.1 \\
\hline MUX & 0.0353 & 0.00871 & 6.28 & $>6.1$ & 9.9 \\
\hline MUK & 2.32 & 0.0246 & 7.65 & $>7.7$ & 9.8 \\
\hline \multicolumn{6}{|l|}{ HFRs } \\
\hline BDE 2 & $<\mathrm{DL}$ & 3.87 & 100 & - & - \\
\hline BDE 8 & $<\mathrm{DL}$ & 5.04 & 100 & - & - \\
\hline BDE 15 & 0.197 & 4.23 & 100 & 7.5 & 7.5 \\
\hline BDE 30 & 0.0644 & 0.389 & 78.0 & $>8.0$ & 8.6 \\
\hline BDE 28 & 0.477 & 2.79 & 89.6 & $>7.8$ & 8.4 \\
\hline BDE 49 & $<D L$ & 1.35 & 19.3 & - & - \\
\hline BDE 47 & 0.187 & 10.3 & 19.0 & $>6.4$ & 9.4 \\
\hline BDE 100 & $<\mathrm{DL}$ & 0.758 & 3.77 & - & - \\
\hline BDE 99 & 0.181 & 3.28 & 1.96 & $>7.4$ & 10.4 \\
\hline BDE 154 & $<\mathrm{DL}$ & 2.08 & 0.45 & - & - \\
\hline BDE 153 & $<D L$ & 0.192 & 0.56 & - & - \\
\hline BDE 183 & $<\mathrm{DL}$ & $<\mathrm{DL}$ & 0.07 & - & - \\
\hline pTBX & 0.00775 & 0.299 & 99.0 & 6.9 & 8.0 \\
\hline PBBz & 0.0778 & 2.23 & 31.9 & $>7.3$ & 9.2 \\
\hline РBT & 0.0806 & 1.63 & 58.0 & $>7.4$ & 8.8 \\
\hline PBEB & 0.0419 & 2.28 & 23.9 & $>7.2$ & 9.3 \\
\hline $\mathrm{HBBz}$ & $<\mathrm{DL}$ & 4.01 & 19.8 & - & - \\
\hline BTBPE & $<D L$ & 0.0324 & 0.02 & - & - \\
\hline SDP & $<\mathrm{DL}$ & 0.445 & 0.00 & - & - \\
\hline ADP & $<D L$ & 0.193 & 0.00 & - & - \\
\hline \multicolumn{6}{|l|}{ OPES } \\
\hline$\overline{T n B P}$ & 0.988 & 3.59 & 99.6 & 4.9 & 6.9 \\
\hline TCEP & 2.30 & 0.468 & 100 & 6.4 & 7.3 \\
\hline TCIPP & 9.83 & 1.13 & 100 & 6.6 & 7.4 \\
\hline TDCIPP & 12.2 & 0.823 & 37.4 & $>6.8$ & 9.0 \\
\hline TPhP & 1.66 & 11.1 & 30.9 & $>3.9$ & 9.1 \\
\hline TBEP & 6281 & $<\mathrm{DL}$ & 4.66 & - & - \\
\hline EHDPP & 5.05 & $<\mathrm{DL}$ & 10.6 & - & - \\
\hline TEHP & $<\mathrm{DL}$ & $<\mathrm{DL}$ & 0.21 & - & - \\
\hline ToCP & $<D L$ & $<\mathrm{DL}$ & 8.42 & - & - \\
\hline TmCP & $<\mathrm{DL}$ & $<\mathrm{DL}$ & 4.18 & - & - \\
\hline TpCP & $<\mathrm{DL}$ & $<\mathrm{DL}$ & 2.59 & - & - \\
\hline TDBPP & $<\mathrm{DL}$ & $<\mathrm{DL}$ & 0.01 & - & - \\
\hline
\end{tabular}




\section{SUPPORTING INFORMATION: \\ DIFFUSIVE UPTAKE OF GASEOUS HYDROPHOBIC ORGANIC CONTAMINANTS FROM AMBIENT AIR INTO POL YETHYLENE PASSIVE SAMPLERS}

Carrie A. McDonough and Rainer Lohmann

Total number of pages: 14

Total number of tables: 4

Total number of figures: 4

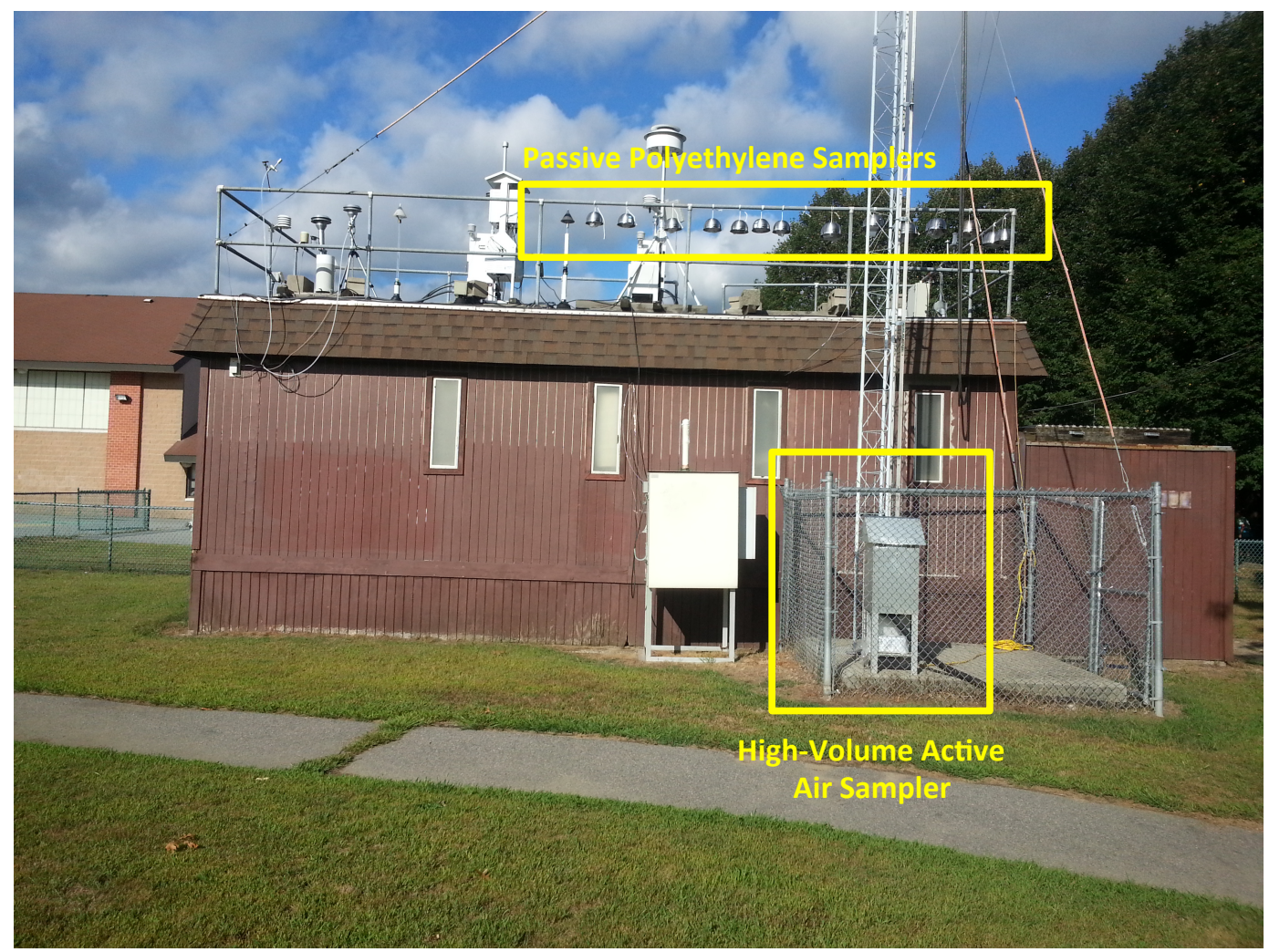

Figure S7-1. Sampling set up at the East Providence Rhode Island Department of the Environment (RI DEM) station. 
Table S7-1. List of target compounds.

\begin{tabular}{|c|c|c|}
\hline \multicolumn{2}{|c|}{ Polycyclic Aromatic Hydrocarbons (PAHs) } & \multirow[t]{2}{*}{ CAS Number } \\
\hline \multicolumn{2}{|l|}{ 2-ring PAHs } & \\
\hline NAP & Naphthalene & $91-20-3$ \\
\hline BIP & Biphenyl & $92-52-4$ \\
\hline $\mathrm{ACY}$ & Acenaphthylene & $208-96-8$ \\
\hline ACE & Acenaphthene & $83-32-9$ \\
\hline FLR & Fluorene & $86-73-7$ \\
\hline \multicolumn{3}{|c|}{ 2-ring alkyl/substituted PAHs } \\
\hline 2MENAP & 2-methylnaphthalene & $91-57-6$ \\
\hline 1MENAP & 1-methylnaphthalene & $90-12-0$ \\
\hline 1MEFLR & 1-methyl fluorene & $1730-37-6$ \\
\hline DBF & Dibenzofuran & $132-64-9$ \\
\hline DBT & Dibenzothiophene & $132-65-0$ \\
\hline \multicolumn{3}{|l|}{ 3-ring PAHs } \\
\hline PHN & Phenanthrene & $85-01-8$ \\
\hline ANT & Anthracene & $120-12-7$ \\
\hline FLRA & Fluoranthene & $205-99-2$ \\
\hline \multicolumn{3}{|l|}{ 4-ring PAHs } \\
\hline PYR & Pyrene & $129-00-0$ \\
\hline BAA & Benzo(a)anthracene & $96-55-3$ \\
\hline CHRY & Chrysene & $218-01-9$ \\
\hline BBJKFLRA & Benzo(b,j,k)fluoranthene & $205-99-2 / 209-08-9$ \\
\hline \multicolumn{3}{|c|}{ 3-4-ring alkyIPAHs } \\
\hline 2MEPHN & 2-methyl phenanthrene & $2531-84-2$ \\
\hline 1MEPHN & 1-methylphenanthrene & $832-69-9$ \\
\hline 9MEANT & 9-methyl anthracene & $779-02-2$ \\
\hline 1MEPYR & 1 methyl pyrene & $2381-21-7$ \\
\hline RET & Retene & $483-65-8$ \\
\hline 6MECHRY & 6-methyl chrysene & $1705-85-7$ \\
\hline 7MEBAA & 7-methyl benz(a)anthracene & $2541-69-7$ \\
\hline 712DIMEBAA & 7,12-Dimethylbenz(a)anthracene & $57-97-6$ \\
\hline \multicolumn{3}{|l|}{ 5-6-ring PAHs } \\
\hline BEP & Benzo(e)pyrene & $192-97-2$ \\
\hline BAP & Benzo(a)pyrene & $50-32-8$ \\
\hline PER & Perylene & $198-55-0$ \\
\hline IND & Indeno(1,2,3-c,d)pyrene & $193-39-5$ \\
\hline DBA & Dibenz(a,h)anthracene) & $57-70-3$ \\
\hline BghiP & Benzo(g,h,i)pyrene & $191-24-2$ \\
\hline $\mathrm{COR}$ & Coronene & $191-07-1$ \\
\hline
\end{tabular}


Table S7-1 Cont'd. List of target compounds.

\begin{tabular}{lll}
\multicolumn{2}{l}{ Organophosphate Esters (OPEs) } & CAS Number \\
\hline TnBP & tri- $n$-butyl phosphate & $126-73-8$ \\
TCEP & tris(2-chloroethyl) phosphate & $115-96-8$ \\
TCIPP & tris(1-chloro-2-propyl) phos phate & $13674-84-5$ \\
TDCIPP & tris(1,3-dichloro-2-propyl) phosphate & $13674-87-8$ \\
TPhP & triphenyl phosphate & $115-86-6$ \\
TBEP & tris(butoxyethyl) phosphate & $78-51-3$ \\
EHDPP & ethylhexyl diphenyl phosphate & $1241-94-7$ \\
TEHP & tris(2-ethylhexyl) phosphate & $78-42-2$ \\
ToCP & tri- 0 -cresyl phosphate & $78-30-8$ \\
TmCP & tri- $m$-cresyl phosphate & $563-04-2$ \\
TpCP & tri- $p$-cresyl phosphate & $78-32-0$ \\
TDBPP & tris(2,3-dibromo-2-propyl) phosphate & $126-72-7$
\end{tabular}

\section{Brominated Diphenyl Ethers (BDEs)}

\begin{tabular}{lll}
\hline BDE 2 & 3-bromodiphenyl ether & $6876-00-2$ \\
BDE 8 & $2,4^{\prime}$-dibromodiphenyl ether & $147217-7-8$ \\
BDE 15 & $4,4^{\prime}$-dibromodiphenyl ether & $2050-47-7$ \\
BDE 30 & $2,4,6$-tribromodiphenyl ether & $155999-95-4$ \\
BDE 28 & $2,4,4^{\prime}$-tribromodiphenyl ether & $41318-75-6$ \\
BDE 49 & $2,2^{\prime}, 4^{\prime}, 5^{\prime}$-tetrabromodiphenyl ether & $243982-82-3$ \\
BDE 47 & $2,2^{\prime}, 4,4^{\prime}$ 'tetrabromodiphenyl ether & $5436-43-1$ \\
BDE 100 & $2,2^{\prime}, 4,4^{\prime}, 6-$-pentabromodiphenyl ether & $189084-64-8$ \\
BDE 99 & $2,2^{\prime}, 4,4^{\prime}, 5-$-pentabromodiphenyl ether & $60348-60-9$ \\
BDE 154 & $2,2^{\prime}, 4,4^{\prime}, 5,6^{\prime}$-hexabromodiphenyl ether & $207122-15-4$ \\
BDE 153 & $2,2^{\prime}, 4,4^{\prime}, 5,5^{\prime}$-hexabromodiphenyl ether & $68631-49-2$ \\
BDE 183 & $2,2^{\prime}, 3,4,4^{\prime}, 5^{\prime}, 6$-heptabromodiphenyl ether & $207122-16-5$
\end{tabular}

\section{Novel Halogenated Flame Retardants (NHFRs)}

$\begin{array}{lll}\text { pTBX } & \text { tetrabromo- } p \text {-xylene } & 23488-38-2 \\ \text { PBBz } & \text { pentabromobenzene } & 608-90-2 \\ \text { PBT } & \text { pentabromotoluene } & 87-83-2 \\ \text { PBEB } & \text { pentabromoethylbenzene } & 85-22-3 \\ \text { HBBz } & \text { hexabromobenzene } & 87-82-1 \\ \text { BTBPE } & 1,2-\text { bis(2,4,6-tribromophenoxy)ethane } & 37853-59-1 \\ \text { SDP } & \text { syn } \text {-Dechlorane Plus } & 13560-89-9 \\ \text { ADP } & \text { anti } i \text {-Dechlorane Plus } & 13560-89-9\end{array}$

\section{Polycyclic Musks}

$\begin{array}{lll}\text { ADBI } & \text { Celestolide } & 13171-00-1 \\ \text { AHMI } & \text { Phantolide } & 15323-35-0 \\ \text { ATII } & \text { Traesolide } & 68140-48-7 \\ \text { HHCB } & \text { Galaxolide } & 1222-05-5 \\ \text { AHTN } & \text { Tonalide } & 1506-02-1 \\ \text { MUX } & \text { Musk xylene } & 81-15-2 \\ \text { MUK } & \text { Musk ketone } & 81-14-1\end{array}$


Table S7-2. Selected and derived physico-chemical properties for target compounds.

\begin{tabular}{|c|c|c|c|c|c|c|c|c|}
\hline & $\begin{array}{c}\text { Molar Mass } \\
(\mathrm{g} / \mathrm{mol})\end{array}$ & $\begin{array}{c}V_{m} \\
\left(\mathrm{~cm}^{3} / \mathrm{mol}\right)^{1}\end{array}$ & $\begin{array}{c}\Delta \mathrm{H}_{\mathrm{vap}} \\
(\mathrm{kJ} / \mathrm{mol})^{2}\end{array}$ & $\begin{array}{c}\log K_{\text {PEA }} \\
(\mathrm{L} / \mathrm{L})^{3}\end{array}$ & $\begin{array}{l}\log D_{P E} \\
\left(\mathrm{~m}^{2} / \mathrm{s}\right)^{4}\end{array}$ & $\begin{array}{c}D_{A} \\
\left(\mathrm{~m}^{2} / \mathrm{s}\right)^{5}\end{array}$ & $\log K_{\text {oa }}^{6}$ & $\begin{array}{l}\log p_{L} \\
(P a)^{7}\end{array}$ \\
\hline \multicolumn{9}{|l|}{ PAHs } \\
\hline NAP & 128.2 & 124.6 & 56 & 4.9 & -11.9 & -5.1 & 5.2 & 1.60 \\
\hline 2MENAP & 142.2 & 140.5 & 63 & 5.5 & -12.1 & -5.2 & 5.9 & 0.84 \\
\hline 1MENAP & 142.2 & 140.4 & 63 & 5.5 & -12.1 & -5.2 & 5.9 & 0.84 \\
\hline BIP & 154.2 & 151.0 & 68 & 6.0 & -12.3 & -5.2 & 6.5 & 0.19 \\
\hline $\mathrm{ACY}$ & 152.2 & 139.1 & 67 & 5.8 & -12.1 & -5.2 & 6.4 & 0.30 \\
\hline ACE & 154.2 & 142.0 & 68 & 6.0 & -12.2 & -5.2 & 6.5 & 0.19 \\
\hline DBF & 168.2 & 145.5 & 75 & 6.6 & -12.2 & -5.2 & 7.2 & -0.56 \\
\hline FLR & 166.2 & 154.8 & 74 & 6.4 & -12.4 & -5.2 & 7.1 & -0.46 \\
\hline 1MEFLR & 180.2 & 169.8 & 81 & 7.2 & -12.6 & -5.2 & 7.8 & -1.21 \\
\hline DBT & 184.3 & 154.6 & 83 & 7.4 & -12.3 & -5.2 & 8.0 & -1.43 \\
\hline PHN & 178.2 & 160.6 & 80 & 7.0 & -12.4 & -5.2 & 7.7 & -1.10 \\
\hline ANT & 178.2 & 159.1 & 80 & 7.2 & -12.4 & -5.2 & 7.7 & -1.10 \\
\hline 2MEPHN & 192.3 & 176.5 & 86 & 7.7 & -12.7 & -5.2 & 8.4 & -1.86 \\
\hline 4/9MEANT & 192.3 & 174.7 & 86 & 7.7 & -12.6 & -5.2 & 8.4 & -1.86 \\
\hline 1MEPHN & 192.3 & 176.3 & 86 & 7.7 & -12.7 & -5.2 & 8.4 & -1.86 \\
\hline FLRA & 202.3 & 196.1 & 91 & 8.0 & -13.0 & -5.2 & 8.9 & -2.40 \\
\hline PYR & 202.3 & 182.3 & 91 & 8.1 & -12.7 & -5.2 & 8.9 & -2.40 \\
\hline 1MEPYR & 216.3 & 198.1 & 98 & 8.9 & -13.0 & -5.2 & 9.6 & -3.16 \\
\hline RET & 234.3 & 226.5 & 106 & 9.4 & -13.4 & -5.3 & 10.5 & -4.13 \\
\hline BAA & 228.3 & 195.1 & 104 & 9.0 & -12.9 & -5.2 & 10.2 & -3.81 \\
\hline CHRY & 228.3 & 196.5 & 104 & 9.4 & -13.0 & -5.2 & 10.2 & -3.81 \\
\hline 7MEBAA & 242.3 & 210.7 & 110 & 9.9 & -13.2 & -5.3 & 10.9 & -4.56 \\
\hline 6MECHRY & 242.3 & 212.3 & 110 & 9.9 & -13.2 & -5.3 & 10.9 & -4.56 \\
\hline 712DIMEBAACHRY & 256.3 & 226.4 & 117 & 10.6 & -13.4 & -5.3 & 11.6 & -5.32 \\
\hline BbjkF & 252.3 & 232.0 & 115 & 10.3 & -13.5 & -5.3 & 11.4 & -5.10 \\
\hline BEP & 252.3 & 219.6 & 115 & 10.4 & -13.3 & -5.3 & 11.4 & -5.10 \\
\hline BAP & 252.3 & 218.2 & 115 & 10.4 & -13.3 & -5.3 & 11.4 & -5.10 \\
\hline PER & 252.3 & 219.6 & 115 & 10.4 & -13.3 & -5.3 & 11.4 & -5.10 \\
\hline IND & 276.3 & 253.7 & 126 & 11.3 & -13.8 & -5.3 & 12.6 & -6.40 \\
\hline DBA & 278.4 & 244.2 & 127 & 11.6 & -13.6 & -5.3 & 12.7 & -6.51 \\
\hline BghiP & 276.3 & 241.3 & 126 & 11.4 & -13.6 & -5.3 & 12.6 & -6.40 \\
\hline COR & 300.4 & 263.0 & 138 & 12.5 & -13.9 & -5.3 & 13.8 & -7.70 \\
\hline
\end{tabular}

[1] Molar volume calculated from SPARC; [2] Enthalpy of vaporization calculated from $\mathrm{p}_{\mathrm{L}}$ as in Schwarzenbach $2003^{1}$; [3] PE-Air partitioning coefficient taken from Khairy \& Lohmann 2014 when available, otherwise calculated from $\mathrm{p}_{\mathrm{L}}$ using the regression from Khairy \& Lohmann $2014^{2} ;[4]$ Empirical $\mathrm{D}_{\mathrm{PE}}$ for OPEs from PintadoHerrera et al. ${ }^{3}$ or Vansco thin-film experiments (unpublished) when available, otherwise calculated from $\mathrm{V}_{\mathrm{m}}$ as in Lohmann $2012^{4} ;[5] \mathrm{D}_{\mathrm{A}}$ calculated as in Fuller $1966^{5} ;[6]$ Octanol-air partitioning coefficient from molecular weight as in Ma et al. 2010 for PAHs; ${ }^{6}$ Calculated from $\mathrm{K}_{\mathrm{AW}}{ }^{7}$ and $\mathrm{K}_{\mathrm{OW}}{ }^{8}$ for PCMs; From Khairy \& Lohmann 2014 for PBDEs ${ }^{2}$ From Zhang et al. 2016 (SPARC estimates) for NHFRs and OPEs. ${ }^{9}$ [7] Solubility from molecular weight as in Ma et al. 2010 for $\mathrm{PAHs}^{6}$; From Peck \& Hornbuckle 2004 for PCMs $^{7}$; From Yue \& Li 2013 for BDEs ${ }^{10}$; OPE values from Reemstma et al. 2008 or Brommer et al. 2014 when available, ${ }^{11,12}$ otherwise from SPARC; BFR values from Bergman et al. 2012 and Dirtu et al. 2013,,$^{13,14}$ otherwise from SPARC. 
Table S7-2 Cont'd. Selected and derived physico-chemical properties for target compounds.

\begin{tabular}{|c|c|c|c|c|c|c|c|c|}
\hline & $\begin{array}{c}\text { Molar Mass } \\
(\mathrm{g} / \mathrm{mol})\end{array}$ & $\begin{array}{c}V_{m} \\
\left(\mathrm{~cm}^{3} / \mathrm{mol}\right)^{1}\end{array}$ & $\begin{array}{c}\Delta \mathrm{H}_{\mathrm{vap}} \\
(\mathrm{kJ} / \mathrm{mol})^{2}\end{array}$ & $\begin{array}{c}\log \mathrm{K}_{\mathrm{PEA}} \\
(\mathrm{L} / \mathrm{L})^{3} \\
\end{array}$ & $\begin{array}{l}\log D_{P E} \\
\left(\mathrm{~m}^{2} / \mathrm{s}\right)^{4} \\
\end{array}$ & $\begin{array}{c}D_{A} \\
\left(\mathrm{~m}^{2} / \mathrm{s}\right)^{5} \\
\end{array}$ & $\log \mathrm{K}_{\mathrm{oa}}{ }^{6}$ & $\begin{array}{c}\log p_{L} \\
(P a)^{7}\end{array}$ \\
\hline \multicolumn{9}{|l|}{ PCMs } \\
\hline ADBI & 244.4 & 253.3 & 85 & 7.6 & -13.8 & -5.3 & 6.7 & -1.70 \\
\hline AHMI & 244.4 & 255.8 & 84 & 7.5 & -13.8 & -5.3 & 7.3 & -1.62 \\
\hline ATII & 258.4 & 272.1 & 69 & 6.1 & -14.0 & -5.3 & 7.8 & 0.08 \\
\hline HHCB & 258.4 & 266.1 & 80 & 7.1 & -14.0 & -5.3 & 8.2 & -1.14 \\
\hline AHTN & 258.4 & 270.0 & 80 & 7.1 & -14.0 & -5.3 & 8.0 & -1.17 \\
\hline MUX & 297.3 & 223.5 & 110 & 9.9 & -13.3 & -5.3 & 9.5 & -4.52 \\
\hline MUK & 294.3 & 238.9 & 109 & 9.8 & -13.6 & -5.3 & 9.9 & -4.40 \\
\hline \multicolumn{9}{|l|}{ OFRs } \\
\hline \multicolumn{9}{|l|}{ PBDEs } \\
\hline BDE 2 & 249.1 & 174.7 & 76 & 6.6 & -12.6 & -5.2 & 7.8 & -0.67 \\
\hline BDE 8 & 328.0 & 189.9 & 89 & 7.5 & -12.9 & -5.2 & 8.7 & -2.15 \\
\hline BDE 15 & 328.0 & 189.9 & 88 & 7.5 & -12.9 & -5.2 & 8.6 & -2.02 \\
\hline BDE 30 & 406.9 & 203.8 & 91 & 8.6 & -13.1 & -5.3 & 9.5 & -2.35 \\
\hline BDE 28 & 406.9 & 203.8 & 96 & 8.4 & -13.1 & -5.3 & 9.4 & -2.93 \\
\hline BDE 49 & 485.8 & 217.6 & 100 & 9.4 & -14.0 & -5.3 & 10.3 & -3.45 \\
\hline BDE 47 & 485.8 & 217.6 & 102 & 9.4 & -14.0 & -5.3 & 10.4 & -3.61 \\
\hline BDE 100 & 564.7 & 232.0 & 109 & 10.1 & -14.7 & -5.3 & 11.0 & -4.47 \\
\hline BDE 99 & 564.7 & 232.1 & 108 & 10.4 & -14.7 & -5.3 & 11.3 & -4.30 \\
\hline BDE 154 & 643.6 & 246.5 & 116 & 11.0 & -15.1 & -5.3 & 12.0 & -5.18 \\
\hline BDE 153 & 643.6 & 246.6 & 117 & 10.9 & -15.1 & -5.3 & 11.9 & -5.29 \\
\hline BDE 183 & 722.5 & 260.5 & 121 & 11.8 & -15.3 & -5.3 & 12.8 & -5.84 \\
\hline \multicolumn{9}{|l|}{ NHFRs } \\
\hline pTBX & 421.8 & 179.3 & 90 & 8.0 & -13.6 & -5.2 & 8.8 & -2.24 \\
\hline PBBz & 472.6 & 165.0 & 102 & 9.2 & -13.5 & -5.2 & 8.4 & -3.65 \\
\hline PBT & 486.6 & 179.4 & 98 & 8.8 & -13.9 & -5.2 & 9.2 & -3.22 \\
\hline PBEB & 500.7 & 195.3 & 104 & 9.3 & -13.9 & -5.2 & 9.5 & -3.81 \\
\hline $\mathrm{HBBz}$ & 551.5 & 179.4 & 105 & 9.4 & -14.1 & -5.2 & 9.6 & -3.94 \\
\hline BTBPE & 687.6 & 281.6 & 136 & 12.3 & -14.2 & -5.3 & 14.5 & -7.49 \\
\hline SDP & 653.7 & 398.7 & 159 & 14.5 & -15.7 & -5.4 & 12.3 & -10.13 \\
\hline ADP & 653.7 & 398.7 & 159 & 14.5 & -15.8 & -5.4 & 12.3 & -10.13 \\
\hline \multicolumn{9}{|l|}{ OPES } \\
\hline TnBP & 266.3 & 265.5 & 77 & 6.9 & -14.0 & -5.3 & 7.0 & -0.82 \\
\hline TCEP & 285.5 & 196.5 & 82 & 7.3 & -13.0 & -5.2 & 7.0 & -1.32 \\
\hline TCIPP & 327.6 & 247.9 & 83 & 7.4 & -13.7 & -5.3 & 7.6 & -1.46 \\
\hline TDCIPP & 430.9 & 268.4 & 100 & 9.0 & -14.0 & -5.3 & 10.3 & -3.38 \\
\hline TPhP & 326.3 & 272.9 & 101 & 9.1 & -14.1 & -5.3 & 10.3 & -3.57 \\
\hline TBEP & 398.5 & 383.2 & 108 & 9.7 & -15.7 & -5.4 & - & -4.31 \\
\hline EHDPP & 362.4 & 338.5 & 106 & 9.5 & -15.0 & -5.4 & 10.6 & -4.05 \\
\hline TEHP & 434.6 & 434.6 & 124 & 11.2 & -14.4 & -5.4 & - & -6.13 \\
\hline ТоCP & 368.4 & 314.7 & 108 & 9.7 & -13.6 & -5.3 & - & -4.29 \\
\hline $\mathrm{TmCP}$ & 368.4 & 321.0 & 111 & 10.0 & -13.6 & -5.3 & - & -4.68 \\
\hline ТрСР & 368.4 & 321.0 & 114 & 10.2 & -13.8 & -5.3 & - & -4.95 \\
\hline TDBPP & 697.6 & 292.6 & 137.5 & 12.5 & -14.3 & -5.3 & - & -7.67 \\
\hline
\end{tabular}

[1] Molar volume calculated from SPARC; [2] Enthalpy of vaporization calculated from $\mathrm{p}_{\mathrm{L}}$ as in Schwarzenbach $2003^{1}$; [3] PE-Air partitioning coefficient taken from Khairy \& Lohmann 2014 when available, otherwise calculated from $\mathrm{p}_{\mathrm{L}}$ using the regression from Khairy \& Lohmann $2014^{2}$; [4] Empirical $\mathrm{D}_{\mathrm{PE}}$ for OPEs from PintadoHerrera et al. ${ }^{3}$ or Vansco thin-film experiments (unpublished) when available, otherwise calculated from $\mathrm{V}_{\mathrm{m}}$ as in Lohmann $2012^{4}$; [5] $\mathrm{D}_{\mathrm{A}}$ calculated as in Fuller $1966^{5}$; [6] Octanol-air partitioning coefficient from molecular weight as in Ma et al. 2010 for PAHs; ${ }^{6}$ Calculated from $\mathrm{K}_{\mathrm{AW}}{ }^{7}$ and $\mathrm{K}_{\mathrm{OW}}{ }^{8}$ for PCMs; From Khairy \& Lohmann 2014 for PBDEs ${ }^{2}$ From Zhang et al. 2016 (SPARC estimates) for NHFRs and OPEs. ${ }^{9}$ [7] Solubility from molecular weight as in Ma et al. 2010 for $\mathrm{PAHs}^{6}$; From Peck \& Hornbuckle 2004 for PCMs ${ }^{7}$; From Yue \& Li 2013 for BDEs ${ }^{10}$; OPE values from Reemstma et al. 2008 or Brommer et al. 2014 when available, ${ }^{11,12}$ otherwise from SPARC; BFR values from Bergman et al. 2012 and Dirtu et al. 2013, ${ }^{13,14}$ otherwise from SPARC. 


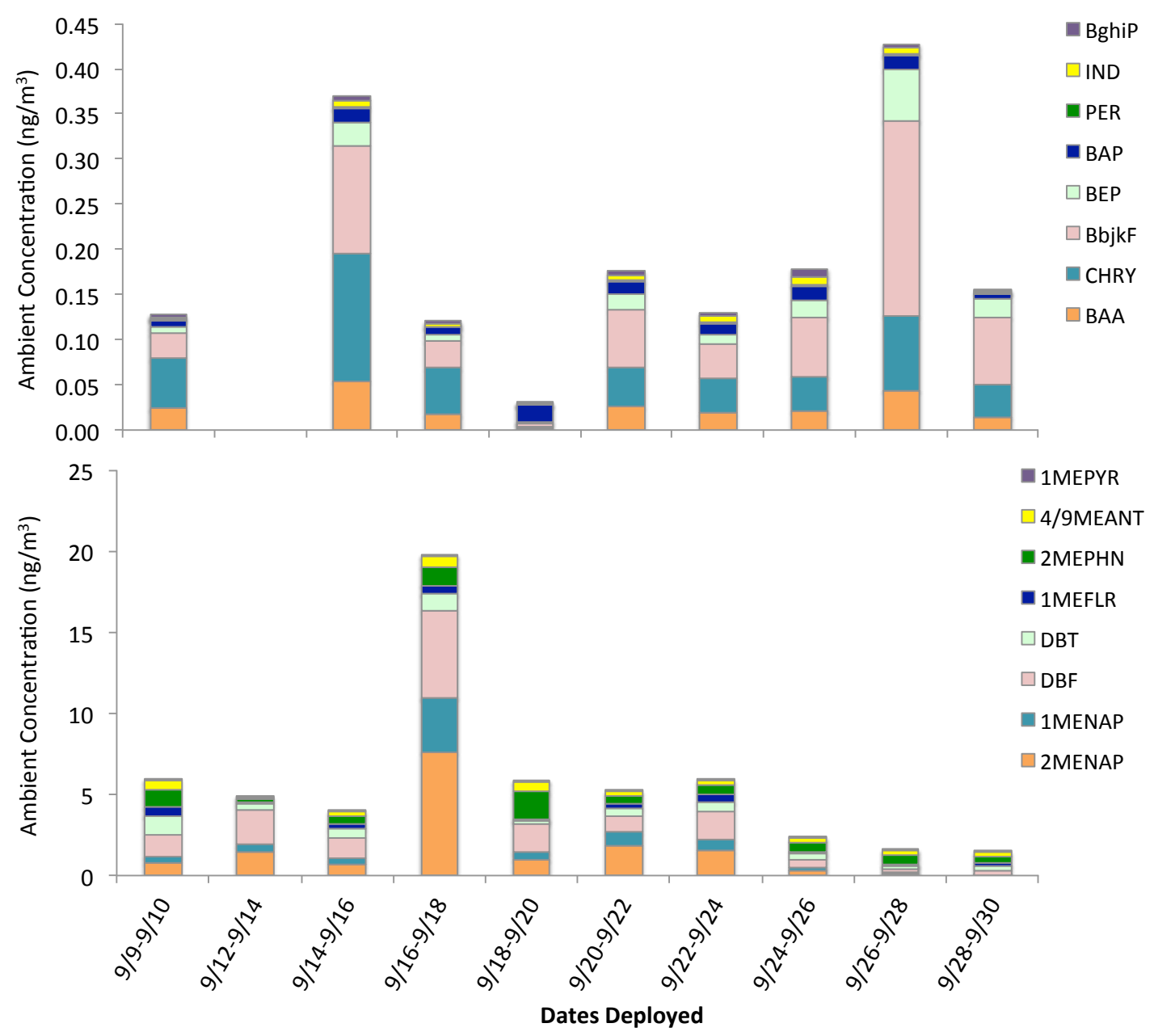

Figure S7-2. Concentrations of gaseous high molecular weight (HMW) PAHs and alkyl/substituted PAHs derived from active air sampling. No concentrations were available for HMW PAHs from 9/12-9/14 due to interference in the PE extract. 
Table S7-3. Ambient Concentrations Derived from Active Sampling. Numbers in red were calculated assuming equilibrium due to evidence of break-through.

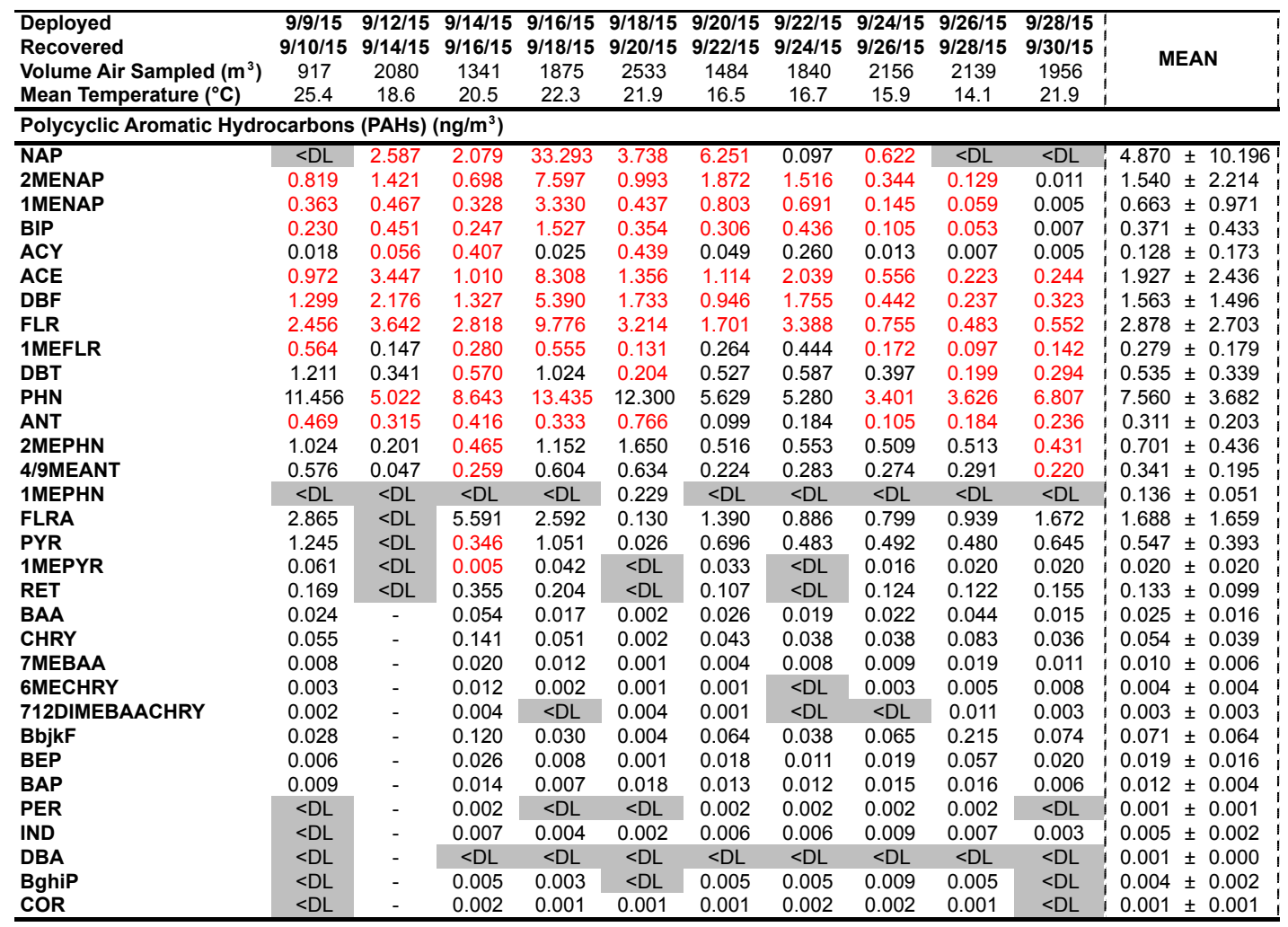



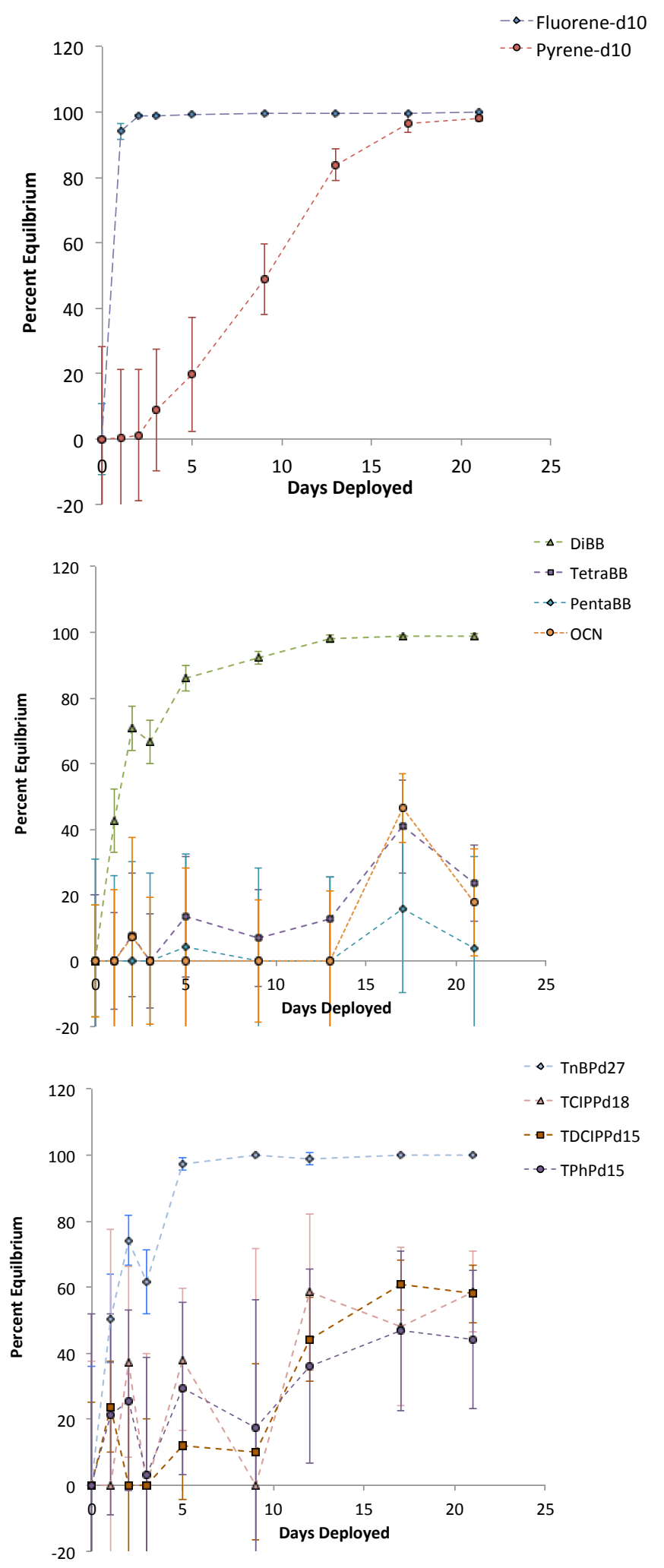

Figure S7-3. Percent equilibration of performance reference compounds (PRCs) over time during PE deployments. 


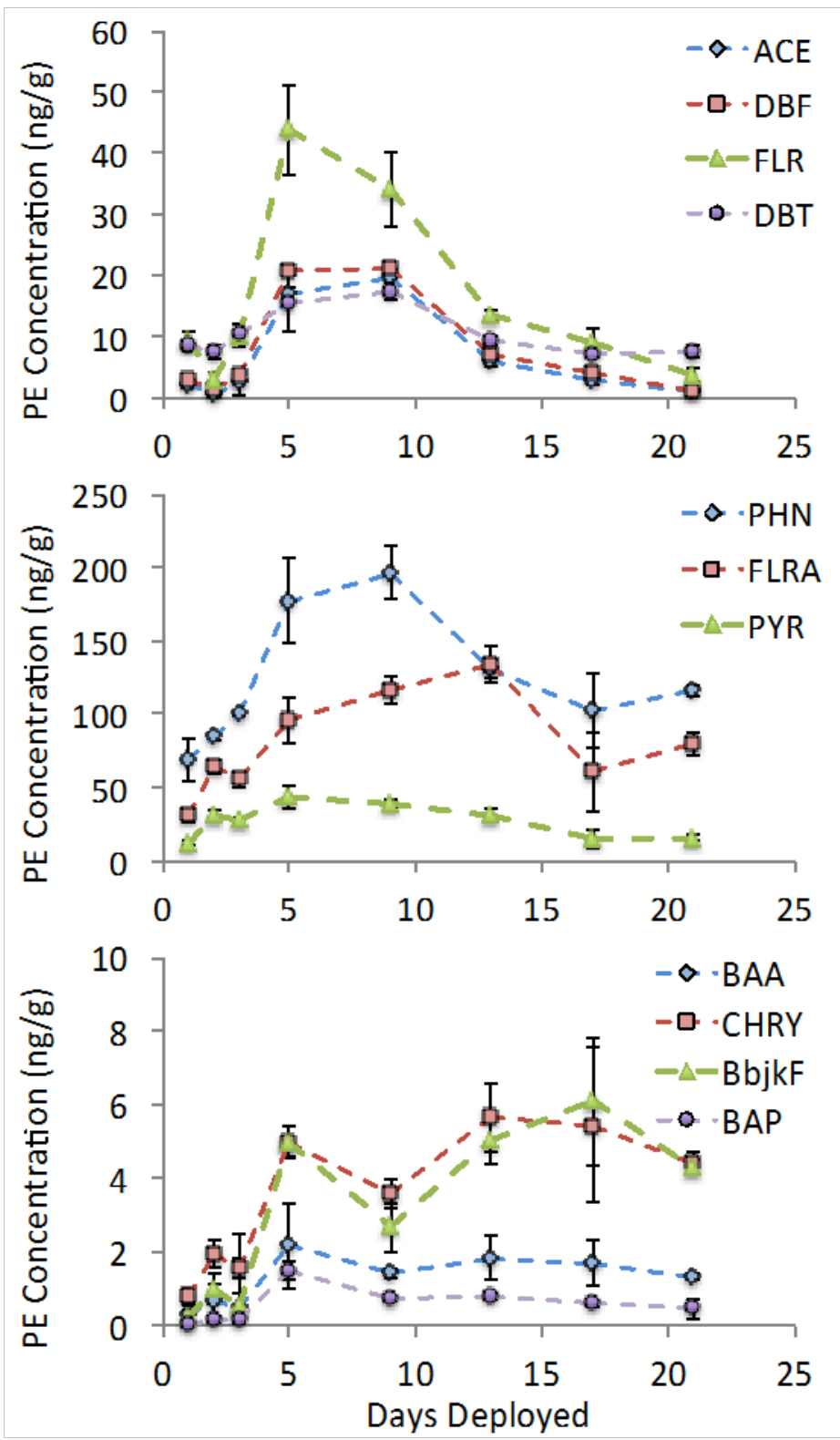

Figure S7-4. Uptake profile examples for PAHs in PEs over the 21-day deployment. 


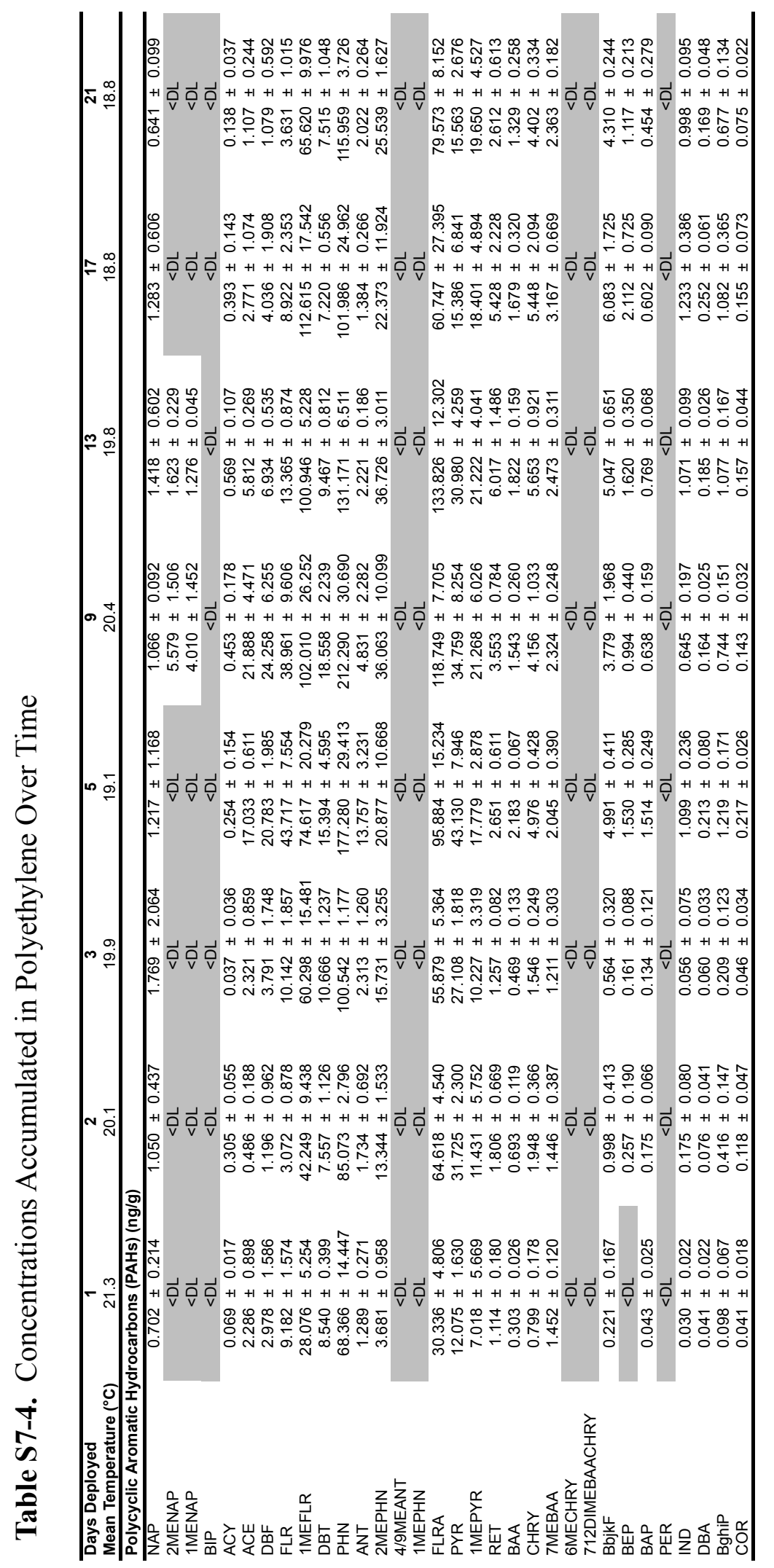




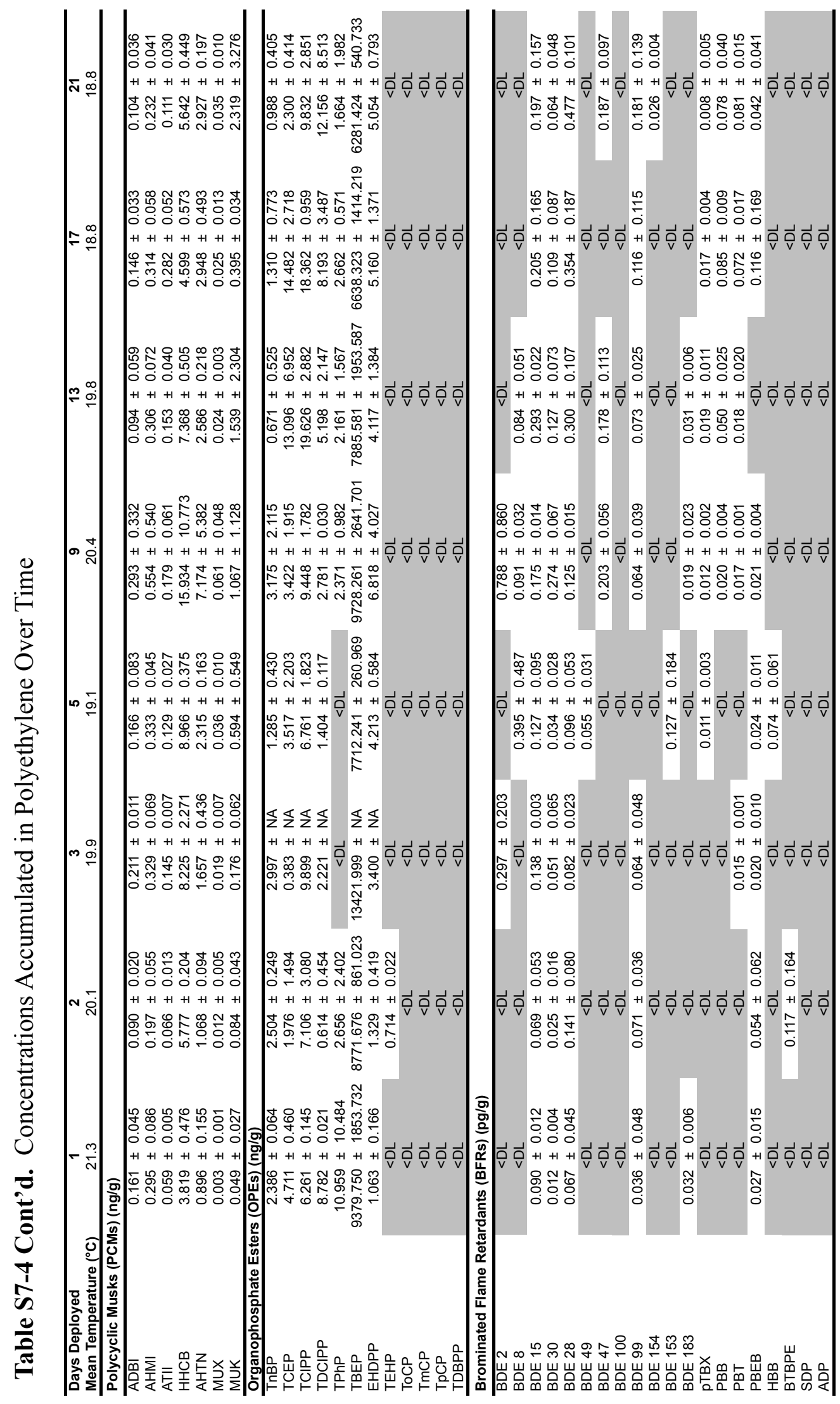




\section{LITERATURE CITED IN THE SUPPORTING INFORMATION}

(1) Schwarzenbach, R. P.; Gschwend, P. M.; Imboden, D. M. Environmental Organic Chemistry; 2nd ed.; Wiley Interscience, 2002.

(2) Khairy, M. A.; Lohmann, R. Field calibration of low density polyethylene passive samplers for gaseous POPs. Environ. Sci. Process. Impacts 2014, 16, 414-421, DOI:10.1039/c3em00493g.

(3) Pintado-Herrera, M. G.; Lara-Martín, P. A.; González-Mazo, E.; Allan, I. J. Determination of silicone rubber and low density polyethylene diffusion and polymer-water partition coefficients for emerging contaminants. Environ. Toxicol. Chem. 2016, 35, n/a - n/a, DOI:10.1002/etc.3390.

(4) Lohmann, R. Critical review of low-density polyethylene's partitioning and diffusion coefficients for trace organic contaminants and implications for its use as a passive sampler. Environ. Sci. Technol. 2012, 46, 606-618, DOI:10.1021/es202702y.

(5) Fuller, E. N.; Schettler, P. D.; Giddings, J. C. A new method for prediction of binary gas-phase diffusion coefficients. Ind. Eng. Chem. 1966, 58, 18-27, DOI:10.1016/0042-207X(66)90400-3.

(6) Ma, Y.-G.; Lei, Y. D.; Xiao, H.; Wania, F.; Wang, W.-H. Critical review and recommended values for the physical-chemical property data of 15 polycyclic aromatic hydrocarbons at $25^{\circ} \mathrm{C}$. J. Chem. Eng. Data 2010, 55, 819-825, DOI:10.1021/je900477x.

(7) Peck, A. M.; Hornbuckle, K. C. Synthetic musk fragrances in Lake Michigan. Environ. Sci. Technol. 2004, 38, 367-372, DOI:10.1021/es034769y.

(8) Wang, I.-T. I.; Cheng, S.-F.; Tsai, S.-W. Determinations of airborne synthetic musks by polyurethane foam coupled with triple quadrupole gas chromatography tandem mass spectrometer. J. Chromatogr. A 2014, 1330, 6168, DOI:10.1016/j.chroma.2014.01.011.

(9) Zhang, X.; Suhring, R.; Serodio, D.; Bonnell, M.; Sundin, N.; Diamond, M. L. Novel flame retardants: Estimating the physical-chemical properties and environmental fate of 94 halogenated and organophosphate PBDE replacements. Chemosphere 2016, 144, 2401-2407, DOI:10.1016/j.chemosphere.2015.11.017.

(10) Yue, C.; Li, L. Y. Filling the gap : Estimating physicochemical properties of the full array of polybrominated diphenyl ethers ( PBDEs ). Environ. Pollut. 2013, 180,312-323, DOI:10.1016/j.envpol.2013.05.029. 
(11) Reemtsma, T.; Quintana, J. B.; Rodil, R.; Garcia-López, M.; Rodriguez, I. Organophosphorus flame retardants and plasticizers in water and air I. Occurrence and fate. TrAC Trends Anal. Chem. 2008, 27, 727-737, DOI:10.1016/j.trac.2008.07.002.

(12) Brommer, S.; Jantunen, L. M.; Bidleman, T. F.; Harrad, S.; Diamond, M. L. Determination of vapor pressures for organophosphate esters. J. Chem. Eng. Data 2014, 59, 1441-1447, DOI:10.1021/je401026a.

(13) Bergman, A.; Rydén, A.; Law, R. J.; de Boer, J.; Covaci, A.; Alaee, M.; Birnbaum, L.; Petreas, M.; Rose, M.; Sakai, S.; Van den Eede, N.; van der Veen, I. A novel abbreviation standard for organobromine, organochlorine and organophosphorus flame retardants and some characteristics of the chemicals. Environ. Int. 2012, 49, 57-82, DOI:10.1016/j.envint.2012.08.003.

(14) Dirtu, A. C.; Covaci, A.; Abdallah, M. Advances in the sample preparation of brominated flame retardants and other brominated compounds. TrAC Trends Anal. Chem. 2013, 43, 189-203, DOI:10.1016/j.trac.2012.10.004. 


\section{CHAPTER 8}

\section{DISSOLVED ORGANOPHOSPHATE ESTERS IN THE NORTH ATLANTIC}

OCEAN AND ARCTIC OCEAN

This manuscript is formatted for submission to the journal Environmental Science and Technology.

Carrie A. McDonough ${ }^{\dagger *}$; Caoxin Sun ${ }^{\ddagger}$; David Adelman ${ }^{\dagger}$; Thomas Soltwedel ${ }^{\S}$; Eduard Bauerfeind $^{\S}$; Derek C. G. Muir $"$; Rainer Lohmann ${ }^{\dagger}$

${ }^{\dagger}$ Graduate School of Oceanography, University of Rhode Island, 215 South Ferry Road, Narragansett, Rhode Island 02882, United States

${ }^{\dagger}$ Department of Computer Science and Statistics, University of Rhode Island, Kingston, Rhode Island 02881, United States

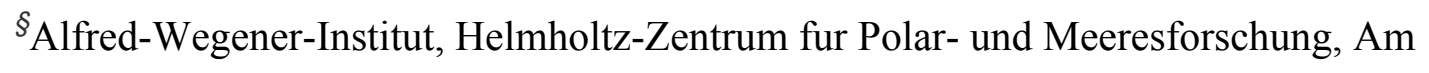
Handelshafen 12, 27570 Bremerhaven, Germany

" Environment and Climate Change Canada, Aquatic Contaminants Research Division, Ontario, Canada L7S 1A1

*Corresponding author email: carriemc@my.uri.edu; phone: 401-874-6612; fax: 401874-6811 


\section{ABSTRACT}

Recent studies have detected organophosphate esters (OPEs) in remote regions, including the Arctic atmosphere, suggesting that they are capable of longrange transport. The exact transport mechanisms and ultimate fates of these OPEs remain poorly understood and few measurements of open ocean concentrations are available. In this study, polyethylene passive samplers (PEs) deployed at deep mooring monitoring stations in Fram Strait from 2014-2015 and surface water sites in the Canadian Arctic in 2015 and 2016 were analyzed for OPEs to investigate their occurrence in remote environments and learn more about marine transport and fate of these emerging contaminants. Chlorinated OPEs $\left(\Sigma_{3}\right.$ Cl-OPE $)$ were generally present at much greater concentrations $(<\mathrm{DL}-7,390 \mathrm{pg} / \mathrm{L})$ than alkyl- and aryl-OPEs $\left(\Sigma_{7} \mathrm{Alkyl} /\right.$ aryl-OPE $\left.0.05-143 \mathrm{pg} / \mathrm{L}\right)$, with the greatest concentrations found at Arctic Ocean surface water sites. Depth profiles from about $200 \mathrm{~m}$ to 2,500 m obtained from deep moorings in eastern and western Fram Strait showed unexpectedly flat vertical profiles, possibly due to a high degree of vertical mixing and/or release of particlebound compounds into the dissolved phase at depth. Dissolved OPEs were found at much greater concentrations in North Atlantic and Arctic Ocean waters than other emerging flame retardants, highlighting their significance as a widespread contaminant of emerging concern with unknown impacts on remote marine environments. 


\section{INTRODUCTION}

Organophosphate esters (OPEs) have been measured in Arctic air at

unexpectedly high concentrations, ${ }^{1,2}$ suggesting that they are capable of long-range transport to remote regions, though the transport mechanisms and ultimate fates of these OPEs are poorly understood. Very few measurements of seawater concentrations are available for OPEs, and none are available in subsurface seawater. More information on water concentrations of OPEs is urgently needed to better understand the transport and fate of these emerging contaminants in the marine environment. Here we present the first estimates of marine dissolved OPE concentrations from deep moorings in the North Atlantic Fram Strait and surface waters in the Canadian Arctic, which were obtained using passive polyethylene samplers (PEs).

Passive sampling is a low-cost approach to obtain time-weighted average measurements of dissolved organic contaminants in water. Because passive samplers do not require electricity and can be left out for a long time to obtain long-term measurements at multiple remote locations, they are gaining attention as tools for measuring deep water distributions of organic contaminants. Booij et al. ${ }^{3}$ used semipermeable membrane devices (SPMDs) to measure time-integrated vertical distributions of various persistent organic pollutants (POPs) in the North Atlantic and Indian Oceans. Sun et al. ${ }^{4}$ also deployed PEs on a deep mooring at a similar location to this study from 2012 to 2013 to investigate depth profiles of several POPs.

In this study, extracts from PEs deployed at two deep mooring monitoring stations in the east and west Fram Strait were retrospectively analyzed for OPEs to 
investigate depth profiles and learn more about marine transport and fate of these emerging contaminants. Several PEs deployed in surface waters of the Arctic Ocean and Arctic freshwater lakes were also analyzed for OPEs so that levels and composition of dissolved OPEs in these two remote environments could be compared.

\section{METHODS}

Passive Sampler Preparation. PE sheets of 50- $\mu \mathrm{m}$ thickness were cut into $10 \times 30$ $\mathrm{cm}$ strips weighing about $2 \mathrm{~g}$ and precleaned by incubation in methylene chloride and hexane for $24 \mathrm{~h}$ each. Performance reference compounds (PRCs; dibromobiphenyl (PBB 9), tetrabromobiphenyl (PBB 52), pentabromobiphenyl (PBB 103), and octachloronaphthalene $(\mathrm{OCN})$ ) were loaded into the PEs for estimation of in situ sampling rates. PRC loading was done via a 1-month incubation in an 80:20 methanol:water solution containing the PRCs. PEs for field deployments were shipped out for deployment while additional PEs from the same batch were stored in the freezer for use as laboratory blanks.

Deep Mooring PE Deployments. Deep mooring PEs were deployed for about one year at two locations at moorings maintained by the HAUSGARTEN long-term ecological research (LTER) observatory in the Fram Strait, the region between the western coast of Svalbard and the eastern coast of Greenland where water is exchanged between the North Atlantic and Arctic Ocean basins. Meridional transport in the upper water column brings warm Atlantic Ocean water north to the Arctic Ocean along the eastern side of Fram Strait via the West Spitsbergen Current, while cold, fresh Polar Water from the Arctic Ocean is brought south along the western side 
of Fram Strait via the East Greenland Current. ${ }^{5}$ Fram Strait deep water results from mixing of end members including Greenland Sea Deep Water and Eurasian Basin Deep Water from the Arctic Ocean, though the degree of mixing changes considerably depending on location within the strait, and other water masses may also be involved. ${ }^{6}$ Locations of deep moorings used in this study are marked by yellow triangles in Figure 8-1. PEs were deployed at 4 depths (221 m, $446 \mathrm{~m}, 1151 \mathrm{~m}$, and $2513 \mathrm{~m})$ at a site east of the Fram Strait (79.010 N, 4.328 E) from June 23, 2014 to July 27, 2015, and at 5 depths $(341 \mathrm{~m}, 504 \mathrm{~m}, 1184 \mathrm{~m}, 1690 \mathrm{~m}, 2439 \mathrm{~m})$ at a site west of the Fram Strait (78.528 N, 2.764 W) from June 20, 2014 to July 31, 2015. PE sheets were strung on stainless steel wire and deployed attached to stainless steel cages, with one PE deployed at each depth. Current meters were deployed to track current velocities at each depth, as were temperature monitors. This data was averaged over the entire deployment to calculate mean temperature and horizontal current velocity at each sampler depth. Samples are summarized along with meteorological data in Table S81.

Surface Water PE Deployments. Surface water PEs were deployed 4-5 m below the water's surface at three lake sites and three ocean sites in the Eastern Arctic Ocean during the summer of 2015 and 2016. Lake sites and ocean sites are marked by green circles and orange pentagons, respectively, in Figure 8-1. At most sites, duplicate PEs were deployed and ambient concentrations from both samples were averaged to calculate a single final concentration. Deployment dates and meteorological data are summarized in Table S8-1. 
Sampler Extraction and Analysis. Each batch of PEs was extracted overnight in hexane. Extracts were concentrated to $\sim 50 \mu \mathrm{L}$ and analyzed on an Agilent $7890 \mathrm{GC}$ coupled to an Agilent 5977 MSD for 3 chlorinated OPEs (tris(2-chloroethyl) phosphate (TCEP), tris(1-chloro-2-propyl) phosphate (TCIPP), and tris(1,3dichloropropyl) phosphate (TDCIPP)), one brominated OPE (tris (2,3-dibromopropyl) phosphate (TDBPP)), and 8 alky/aryl-OPEs (tri $n$ butyl phosphate (TnBP), triphenyl phosphate (TPhP), tris(2-butoxyethyl) phosphate (TBEP), ethylhexyldiphenyl phosphate (EHDPP), tris(2-ethylhexyl) phosphate (TEHP), tris(o-cresyl) phosphate (ToCP), tris $(m$-cresyl) phosphate (TmCP), and tris $(p$-cresyl) phosphate $(\mathrm{TpCP}))$.

OPE analysis of deep mooring and surface water PE extracts from 2015 was done retrospectively, so labeled OPEs were not added as internal standards prior to extraction and data was not corrected for extraction recoveries. Deuterated OPEs (TnBP- $\mathrm{d}_{27}$, TCIPP- $\mathrm{d}_{18}$, TDCIPP- $\mathrm{d}_{15}$, and TPhP- $\left.\mathrm{d}_{15}\right)$ were spiked into these extracts just prior to analysis. However, Arctic surface water PEs from the 2016 sampling campaign were spiked with internal standards prior to extraction. Quantification was done using a 9-point curve and standards were run after every 10 samples as continuing calibration verification. Samples were run on a 30-m Agilent DB-5MS column with a $0.5 \mathrm{~m}$ guard column and $1 \mathrm{~mL} / \mathrm{min}$ helium flow, with temperature ramped from 70 to $315^{\circ} \mathrm{C}$ over about 40 minutes. Extracts were injected at a volume of $2 \mu \mathrm{L}$ with the injection port set at $240^{\circ} \mathrm{C}$. The MSD was operated in select ion monitoring (SIM) mode with source temperature at $230{ }^{\circ} \mathrm{C}$, quadrupole at $150{ }^{\circ} \mathrm{C}$, and transfer line at $250^{\circ} \mathrm{C}$. 
Concentrations of OPEs in PE blanks are shown in Table S8-2. All concentrations in field samples were blank-subtracted using the co-extracted PE laboratory blank or field blank based on availability. After blank subtraction, values below $50 \%$ of blank values were considered non-detects and replaced with zero. In cases where OPEs were not found in the PE blank, instrumental noise was integrated to define detection limits.

Two blank PE samples spiked with several OPEs were taken through the extraction procedure to evaluate typical compound recoveries. Recoveries were 109\% for TnBP, $102-103 \%$ for TCEP, $117-118 \%$ for TCIPP, $73-88 \%$ for TDCIPP, $84-89 \%$ for TPhP, 127-128\% for EHDPP, 103-107\% for ToCP, 92-105\% for TpCP, and 4892\% for TDBPP. There was too much interference present in the PE matrix to quantify spiked TBEP, so this compound was omitted from further interpretation. Quantification of OPEs by our analytical method was also checked against an external standard provided for an inter-laboratory comparison, and results showed that the analytical method provided concentrations within $73-133 \%$ of actual concentrations for all OPEs.

Sampling Rate Determination. The rate of OPE absorptive uptake $\left(\mathrm{k}_{\mathrm{o}}\right)$ into the PE was modeled as inversely proportional to the sum of the mass transfer resistance in the PE membrane and the water boundary layer, as shown in Eq 1. This required estimating the molecular diffusivity of each OPE in polyethylene $\left(\mathrm{D}_{\mathrm{PE}}\right)$ and in water $\left(\mathrm{D}_{\mathrm{W}}\right)$, as well as the PE-water partitioning coefficient $\left(\mathrm{K}_{\mathrm{PEW}}\right)$. The thickness of the PE boundary layer $\left(\delta_{\mathrm{PE}}\right)$ was half the thickness of the PE sheet $(25 \mu \mathrm{m})$ and the thickness of the water boundary layer $\left(\delta_{\mathrm{WBL}}\right)$ was estimated by fitting loss data for the four 
PRCs to Eq 1 using the non-linear least squares regression function $n l s$ in R. This was only done for PEs from deep mooring sites, as PRC data was not available for surface water PEs.

$$
\frac{1}{k_{O}}=\frac{\delta_{W B L}}{D_{W}}+\frac{\delta_{P E}}{D_{P E} \cdot K_{P E W}}
$$

Percent equilibration reached by each PRC during deployment was determined by calculating the percent lost in the field samples, using the amount of PRCs in the PE blank to determine the initial mass. $\mathrm{K}_{\mathrm{PEW}} \mathrm{S}$ of all PRCs were corrected for salinity using a Setschenow constant of $0.27 \underline{\mathrm{M}}^{-1}$ and assuming a generic salt concentration of $0.5 \underline{\mathrm{M}}$ (34.2 psu). ${ }^{7}$ Physico-chemical properties for PRCs were corrected for site- and depth-specific mean temperature.

Fitting of PRC data yielded $\delta_{\mathrm{WBL}} \mathrm{S}$ of 57-199 $\mu \mathrm{m}$ for deep mooring PEs (Figure S8-1; Table S8-3). Based on these results, a $\delta_{\mathrm{WBL}}$ of $60 \mu \mathrm{m}$ was assumed for all Arctic surface water PEs (PRC loss data not available). The $\delta_{\mathrm{WBL}}$ value was plugged into Eq 1 along with the relevant physico-chemical properties for each target OPE to determine the percent equilibration reached during the deployment. Percent equilibration predicted for each OPE at each site is presented in Tables S8-4 for deep mooring deployments and S8-5 for surface water deployments. The five smallest OPEs $\left(\mathrm{V}_{\mathrm{m}}<290 \mathrm{~cm}^{3} / \mathrm{mol} ; \log \mathrm{K}_{\mathrm{PEW}}<5\right)$ were generally estimated to reach $>90 \%$ equilibrium during deployment (Table S8-4). Among the non-equilibrated compounds, sampling rates calculated from best-fit $\mathrm{r} \delta_{\mathrm{WBL}}$ ranged from about 1-10 L/day at deep mooring sites. Mean current velocity for all PEs at all depths ranged from $7-13 \mathrm{~cm} / \mathrm{s}$. The greatest sampling rates and fastest current velocities were observed at the shallowest deep mooring sites. The lowest sampling rates and slowest 
current velocities were both found at the two deepest sites in the Eastern Fram Strait. Boundary layer thickness is plotted with depth in Figure S8-1.

Physico-Chemical Properties. One of the major challenges in understanding the transport and fate of OPEs is the paucity of data on their physico-chemical properties. ${ }^{8}$ Here, PE-water partitioning coefficients $\left(\mathrm{K}_{\mathrm{PEW}}\right)$ were estimated from subcooled liquid aqueous solubility $\left(\log \mathrm{C}_{\mathrm{w}, \mathrm{sat}}(\mathrm{L}) ; \mathrm{mol} / \mathrm{m}^{3}\right)$ as in Lohmann $2012 .{ }^{9}$ Lohmann reported that this regression exhibited a good fit $\left(\mathrm{r}^{2}=0.92 ; \mathrm{SE}=0.35 ; \mathrm{N}=100\right)$ for a wide variety of compounds with diverse properties, including PAHs, PCBs, PBDEs, OCPs, nonylphenols, and triclosan. Recent unpublished work measuring OPE $\mathrm{K}_{\mathrm{PEW}}$ values via passive and active sampling at a wastewater treatment plant suggested that solubility-derived $\mathrm{K}_{\mathrm{PEW}}$ values may be greater than empirical $\mathrm{K}_{\mathrm{PEW}} \mathrm{S}$, which would mean that values presented here are lower than actual dissolved concentrations. However, more work needs to be done to confirm empirical OPE $\mathrm{K}_{\mathrm{PEW}}$ values. Physico-chemical properties used to calculate ambient concentrations are presented in Table S8-6. Values of $\mathrm{C}_{\mathrm{w} \text {,sat }}(\mathrm{L})$ used in $\mathrm{K}_{\mathrm{PEW}}$ calculations were taken from a collection of estimated properties by Zhang et al. ${ }^{10}$ Values calculated from EPI Suite WSKOWWIN were used because this model performed best in predicting $\mathrm{C}_{\mathrm{w}, \text { sat }}(\mathrm{L})$ for a wide range of compounds. ${ }^{10}$ However, these $\mathrm{C}_{\mathrm{w}, \mathrm{sat}}(\mathrm{L})$ values were often biased low, meaning that ambient concentrations estimated using these values may also be underestimated. To interpret results for PEs deployed in seawater, values of $\mathrm{C}_{\mathrm{w}, \text { sat }}(\mathrm{L})$ were corrected for salinity, as described above for the PRCs. ${ }^{7}$ All K $\mathrm{PEwS}$ were also corrected for mean deployment temperature as previously described, ${ }^{9}$ assuming an energy of solvation of $25 \mathrm{~kJ} / \mathrm{mol}$. As mentioned previously by Booij et 
al., ${ }^{3}$ the effect of pressure in deep ocean regions on physico-chemical properties of organic chemicals is not well characterized, so parameters were not adjusted for pressure effects.

The molecular diffusivity of each OPE in water was calculated for each deployment's mean temperature using the Wilke-Chang equation with 2.6 as the association parameter for water and determining viscosity of water using a table provided by Schwarzenbach et al. ${ }^{7}$ Molecular diffusivity in polyethylene was taken from Pintado-Herrera et al. ${ }^{11}$ when experimental values were available, and was otherwise calculated from molar volume as in Lohmann $2012,{ }^{9}$ and subsequently corrected for mean deployment temperature using the Arrhenius equation, assuming an activation energy of $100 \mathrm{~kJ} / \mathrm{mol}$.

\section{RESULTS \& DISCUSSION}

Dissolved Concentrations of Halogenated OPEs. Depth profiles and composition of dissolved chlorinated and brominated OPEs from the deep mooring deployments are shown in Figure 8-2. $\Sigma_{3}$ Cl-OPE (the sum of TCEP, TCIPP, and TDCIPP) in deep mooring samples ranged from $25 \mathrm{pg} / \mathrm{L}$ at $221 \mathrm{~m}$ depth at Eastern Fram Strait to 393 pg/L at $341 \mathrm{~m}$ depth at Western Fram Strait. TCEP was the most abundant Cl-OPE in deep mooring samples when detected, but was only found above detection limits at Western Fram Strait sites. Concentrations of TCEP in Eastern Fram Strait were only slightly lower than in Western Fram Strait, but were blank-censored. While TCEP usage has been restricted in Europe under REACH, the compound is still used in North America and Asia, and was found to be dominant in Canadian Arctic air in a 
study by Suhring et al. ${ }^{2}$ TDBPP was only detected at the most shallow site from Eastern Fram Strait at $4.7 \mathrm{pg} / \mathrm{L}$.

Surface water concentrations of $\Sigma_{3} \mathrm{Cl}$-OPE are shown in Figure 8-3. In surface water samples, $\Sigma_{3} \mathrm{Cl}$-OPE reached much greater concentrations, with mean $\Sigma_{3} \mathrm{Cl}-\mathrm{OPE}$ ranging from $<\mathrm{DL}$ in Resolute North Lake to 7,390 pg/L at East Lake. $\Sigma_{3} \mathrm{Cl}-\mathrm{OPE}$ was elevated at sites in Cape Bounty and Sach's Harbour, where TCEP, the most abundant OPE, was $>$ DL, while at sites near Resolute, TCEP was $<$ DL, TCIPP was most abundant at 250-300 pg/L, and levels were more similar to those found in deep mooring samples.

No data on concentrations of dissolved OPEs in polar ocean water was found for comparison to this study. Previous studies measuring OPEs via active sampling methods in coastal, estuarine, and lacustrine environments generally reported OPE concentrations at least an order or magnitude greater than concentrations measuring at deep moorings. ${ }^{12,13}$ Surface concentrations measured here were comparable, but on the lower end, of what has been measured in other regions. Venier et al. measured $\Sigma_{3}$ Cl-OPEs from $2,100-17,500 \mathrm{pg} / \mathrm{L}$ in the surface waters of the Great Lakes, with TCIPP most abundant. In German Bight surface waters, $\Sigma_{3}$ Cl-OPEs ranged from about $1,000-10,000 \mathrm{pg} / \mathrm{L}$, again with TCIPP most abundant. ${ }^{13}$

Dissolved Concentrations of Alkyl- and Aryl-OPEs. Depth profiles and composition of alkylated and aryl OPEs at deep mooring sites are shown in Figure 8-4. $\Sigma_{7} \mathrm{Alkyl} /$ aryl-OPE (sum of TnBP, TPhP, EHDPP, TEHP, ToCP, TmCP, and TpCP) ranged from $0.05 \mathrm{pg} / \mathrm{L}$ at $221 \mathrm{~m}$ depth at Eastern Fram Strait to $56 \mathrm{pg} / \mathrm{L}$ at $341 \mathrm{~m}$ depth in Western Fram Strait. TnBP was dominant at all deep mooring sites except 
the two shallowest sites in Eastern Fram Strait, where TnBP was $<$ DL. It was expected that alkyl/aryl-OPEs would be present at lower concentrations than Cl-OPEs, as they have been shown to be more readily degradable than Cl-OPEs by numerous routes, including biodegradation and hydrolysis. ${ }^{14,15}$

Surface water concentrations of dissolved $\Sigma_{7} \mathrm{Alkyl} /$ aryl-OPE are shown in Figure 8-5. In Arctic Ocean surface water samples, $\Sigma_{7}$ Alkyl/aryl-OPE were comparable to concentrations in the Fram Strait deep moorings, ranging from $2.6 \mathrm{pg} / \mathrm{L}$ in Sach's Harbour to $143 \mathrm{pg} / \mathrm{L}$ in East Lake. As with deep mooring sites, TnBP was most abundant when it was found above detection limits. TnBP is known to be much more susceptible to photodegradation than Cl-OPEs, and so the degree of ice cover could be a factor determining its persistence in Arctic waters. ${ }^{14}$

Again, previous studies of other regions have generally reported much greater concentrations of dissolved OPEs than were found in Arctic surface water or Fram Strait deep mooring samples. Venier et al. measured $\Sigma_{3}$ Alky/aryl-OPEs (TnBP, TPhP, and TBEP) from 3,300 - 78,300 pg/L in the surface waters of the Great Lakes, with TBEP most abundant. ${ }^{16}$ In German Bight surface waters, $\Sigma_{3}$ Alky/aryl-OPEs were only intermittently detected by Andresen et al. above detection limits at sites distant from shore, and ranged from $<\mathrm{DL}-3,500 \mathrm{pg} / \mathrm{L}$ in the plume of the River Elbe. ${ }^{13}$ Depth Profiles of OPEs. Based on what is known about circulation within the Fram Strait, samples from Eastern Fram Strait, particularly from the upper water column, were expected to be more representative of Atlantic Ocean water masses, while samples from the Western Fram Strait site were expected to be more representative of colder, fresher water leaving the Arctic Ocean and entering the North Atlantic. The 
absence of TCEP from the Eastern Fram Strait may be due to its decreased usage in Western Europe, resulting in lower concentrations in newer surface waters entering the Arctic.

For the most part, little variation in dissolved OPE concentration was observed with depth. These flat depth profiles could be due to a high degree of vertical mixing, or the release of particle-bound contaminants to the dissolved phase with depth. ${ }^{17}$ Booij et al. ${ }^{3}$ observed little concentration change over a depth range of $0.1-3 \mathrm{~km}$ in the Irminger Sea when measuring vertical profiles of dissolved-phase PCBs, PAHs, and OCPs. However, Sun et al. ${ }^{4}$ observed declining vertical profiles for PBDEs, as well as some PAHs, at the same Eastern Fram Strait site utilized here.

Physical properties are not well constrained, so dissolved OPE concentrations are somewhat uncertain. As in Castro-Jimenez et al., calculations based on physical properties from different estimation tools varied by 1-2 orders of magnitude. ${ }^{8}$ However, trends with depth were found to be similar for a wide range of estimated chemical properties (Figure S8-2), and regardless of the set of solubility values used, dissolved OPE concentrations from deep moorings were generally lower than what has been measured in more developed regions. ${ }^{12,13}$

\section{IMPLICATIONS}

Concentrations of dissolved OPEs, especially Cl-OPEs, were generally much greater than concentrations of other dissolved flame retardants in the North Atlantic and Arctic Ocean, highlighting the importance of OPEs as an emerging contaminant of

concern. At some sites in this study, concentrations of dissolved OPEs were much 
greater than those of other currently and recently used flame retardants. Sun et al. measured polybrominated diphenyl ethers (PBDEs) at a deep mooring in Eastern Fram Strait in 2014, and found all concentrations below $1.5 \mathrm{pg} / \mathrm{L} .{ }^{4}$ Concentrations of OPEs were also much greater than surface water concentrations of the novel halogenated flame retardant Dechlorane Plus $(<1 \mathrm{pg} / \mathrm{L})$ in the Fram Strait and several novel

brominated flame retardants (all $<2 \mathrm{pg} / \mathrm{L})$ in the European Arctic. ${ }^{18,19}$ This suggests that, though OPEs were originally expected to be incapable of long-range transport, they are in fact being delivered to remote Arctic regions, either by local aqueous sources or long-range waterborne or atmospheric transport.

\section{ASSOCIATED CONTENT}

Supporting Information. Detailed information on sampler deployments, site characteristics, and compound properties can be found along with calculated sampling rates, table of concentrations, and plots describing the results of principal component analysis. This material is available free of charge via the Internet at http://pubs.acs.org.

\section{AUTHOR INFORMATION}

Corresponding Author. Rainer Lohmann

Author Contributions. The manuscript was written through contributions of all authors. All authors have given approval to the final version of the manuscript. 


\section{ACKNOWLEDGMENTS}

We would like to acknowledge funding from the NSF ARC 1203486. We would like to thank Peter August (URI) for assistance with GIS, Mohammed Khairy for laboratory work, and Ana Cabrerizo, Camilla Teixeira, and the field staff of the Emergencies, Operational Analytical Laboratories, and Research Support group (Environment Canada Burlington) for surface water PE deployments.

\section{LITERATURE CITED}

(1) Salamova, A.; Hermanson, M. H.; Hites, R. a. Organophosphate and halogenated flame retardants in atmospheric particles from a European Arctic site. Environ. Sci. Technol. 2014, 48, 6133-6140, DOI:10.1021/es500911d.

(2) Sühring, R.; Diamond, M. L.; Scheringer, M.; Wong, F.; Pućko, M.; Stern, G.; Burt, A.; Hung, H.; Fellin, P.; Li, H.; Jantunen, L. M. Organophosphate esters in Canadian Arctic air: Occurrence, levels and trends. Environ. Sci. Technol. 2016, 50, 7409-7415, DOI:10.1021/acs.est.6b00365.

(3) Booij, K.; van Bommel, R.; van Aken, H. M.; van Haren, H.; Brummer, G. J. A.; Ridderinkhof, H. Passive sampling of nonpolar contaminants at three deepocean sites. Environ. Pollut. 2014, 195, 101-108, DOI:10.1016/j.envpol.2014.08.013.

(4) Sun, C.; Soltwedel, T.; Bauerfeind, E.; Adelman, D. A.; Lohmann, R. Depth profiles of persistent organic pollutants in the North and Tropical Atlantic Ocean. Environ. Sci. Technol. 2016, 50, 6172-6179, DOI:10.1021/acs.est.5b05891.

(5) Beszczynska-Moller, A.; Fahrbach, E.; Schauer, U.; Hansen, E. Variability in Atlantic water temperature and transport at the entrance to the Arctic Ocean, 1997-2010. ICES J. Mar. Sci. 2012, 69, 852-863, DOI:10.1093/icesjms/fss056.

(6) Appen, W. J.; Von Schauer, U.; Cabrillo, R. S. .; Bauerfeind, E.; BeszczynskaMoller, A. Exchange of warming deep waters across Fram Strait. Deep Sea Res, Pt 1 2015, 103, 86-100.

(7) Schwarzenbach, R. P.; Gschwend, P. M.; Imboden, D. M. Environmental Organic Chemistry; 2nd ed.; Wiley Interscience, 2002. 
(8) Castro Jimenez, J.; González-Gaya, B.; Pizarro, M.; Casal, P.; Pizarro-Alvarez, C.; Dachs, J. Organophosphate ester flame retardants and plasticizers in the global oceanic atmosphere. Environ. Sci. Technol. 2016, acs.est.6b04344, DOI:10.1021/acs.est.6b04344.

(9) Lohmann, R. Critical review of low-density polyethylene's partitioning and diffusion coefficients for trace organic contaminants and implications for its use as a passive sampler. Environ. Sci. Technol. 2012, 46, 606-618, DOI:10.1021/es202702y.

(10) Zhang, X.; Suhring, R.; Serodio, D.; Bonnell, M.; Sundin, N.; Diamond, M. L. Novel flame retardants: Estimating the physical-chemical properties and environmental fate of 94 halogenated and organophosphate PBDE replacements. Chemosphere 2016, 144, 2401-2407, DOI:10.1016/j.chemosphere.2015.11.017.

(11) Pintado-Herrera, M. G.; Lara-Martín, P. A.; González-Mazo, E.; Allan, I. J. Determination of silicone rubber and low density polyethylene diffusion and polymer-water partition coefficients for emerging contaminants. Environ. Toxicol. Chem. 2016, 35, n/a - n/a, DOI:10.1002/etc.3390.

(12) Bollmann, U. E.; Möller, A.; Xie, Z.; Ebinghaus, R.; Einax, J. W. Occurrence and fate of organophosphorus flame retardants and plasticizers in coastal and marine surface waters. Water Res. 2012, 46, 531-538, DOI:10.1016/j.watres.2011.11.028.

(13) Andresen, J. A.; Muir, D.; Ueno, D.; Darling, C.; Theobald, N.; Bester, K. Emerging pollutants in the North Sea in comparison to Lake Ontario, Canada, data. Environ. Toxicol. Chem. 2007, 26, 1081-1089, DOI:10.1897/06-416R.1.

(14) Regnery, J.; Püttmann, W. Occurrence and fate of organophosphorus flame retardants and plasticizers in urban and remote surface waters in Germany. Water Res. 2010, 44, 4097-4104, DOI:10.1016/j.watres.2010.05.024.

(15) Su, G.; Letcher, R. J.; Yu, H. Organophosphate flame retardants and plasticizers in aqueous solution: $\mathrm{pH}$-dependent hydrolysis, kinetics, and pathways. Environ. Sci. Technol. 2016, 50, 8103-8111, DOI:10.1021/acs.est.6b02187.

(16) Venier, M.; Dove, A.; Romanak, K.; Backus, S.; Hites, R. A. Flame retardants and legacy chemicals in Great Lakes' water. Environ. Sci. Technol. 2014, 48, 9563-9572, DOI:10.1021/es501509r.

(17) Sobek, A.; Gustafsson, O. Deep water masses and sediments are main compartments for PCBs in the Arctic Ocean. Environ. Sci. Technol. 2014, 48, 6719-6725, DOI:10.1021/es500736q. 
(18) Möller, A.; Xie, Z.; Sturm, R.; Ebinghaus, R. Large-scale distribution of dechlorane plus in air and seawater from the Arctic to Antarctica. Environ. Sci. Technol. 2010, 44, 8977-8982, DOI:10.1021/es103047n.

(19) Möller, A.; Xie, Z.; Sturm, R.; Ebinghaus, R. Polybrominated diphenyl ethers (PBDEs) and alternative brominated flame retardants in air and seawater of the European Arctic. Environ. Pollut. 2011, 159, 1577-1583, DOI:10.1016/j.envpol.2011.02.054. 


\section{FIGURES AND TABLES}

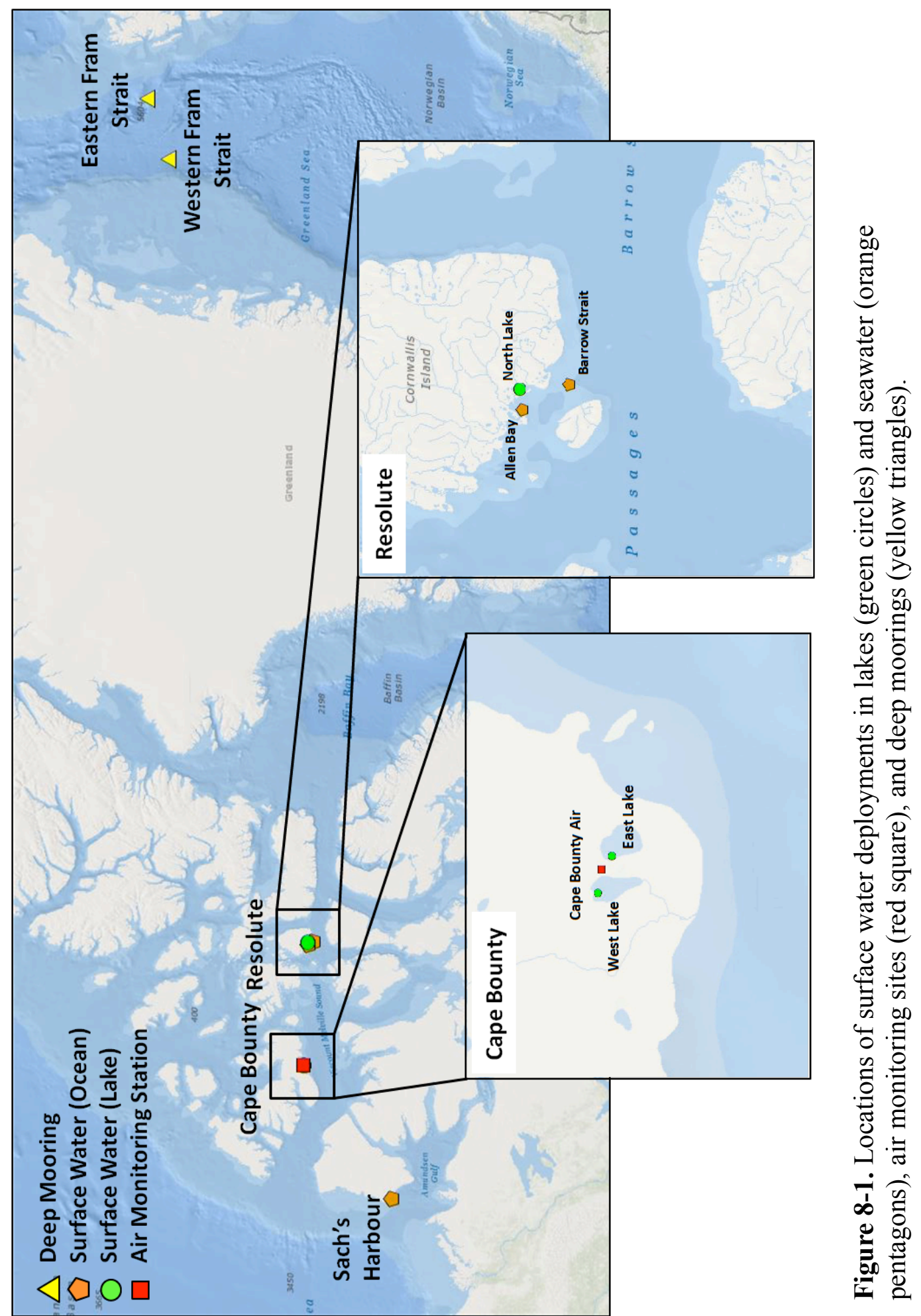


WESTERNFRAM STRAIT

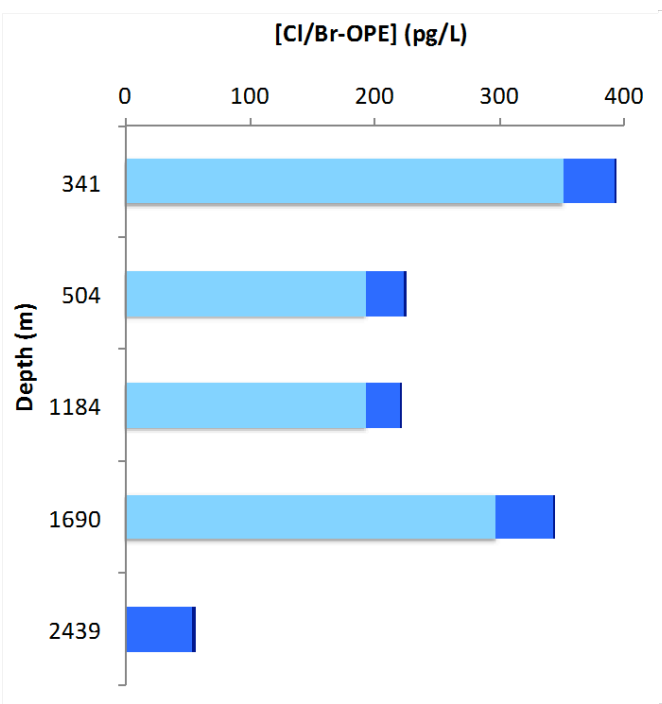

EASTERN FRAM STRAIT

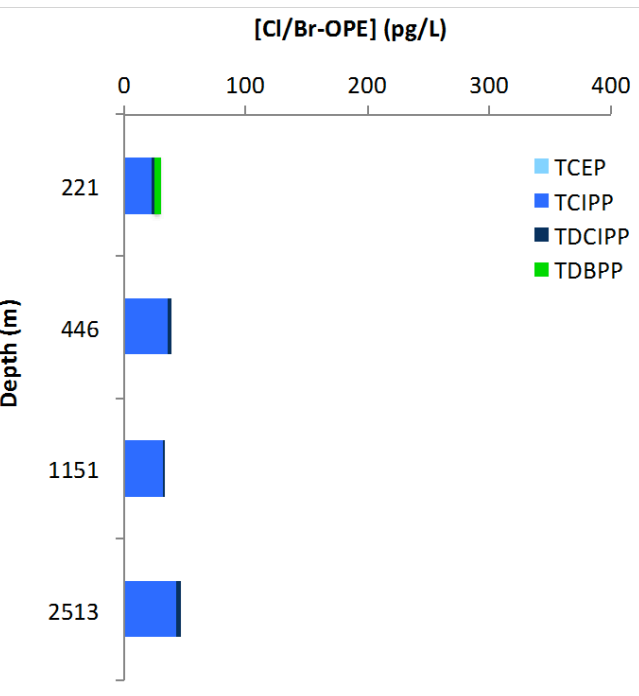

Figure 8-2. Depth profiles showing estimated dissolved concentrations of $\mathrm{Cl} / \mathrm{Br}$ OPEs (light blue: TCEP, blue: TCIPP, dark blue: TDCIPP, bright green: TDBPP) in $\mathrm{pg} / \mathrm{L}$ in Western and Eastern Fram Strait.

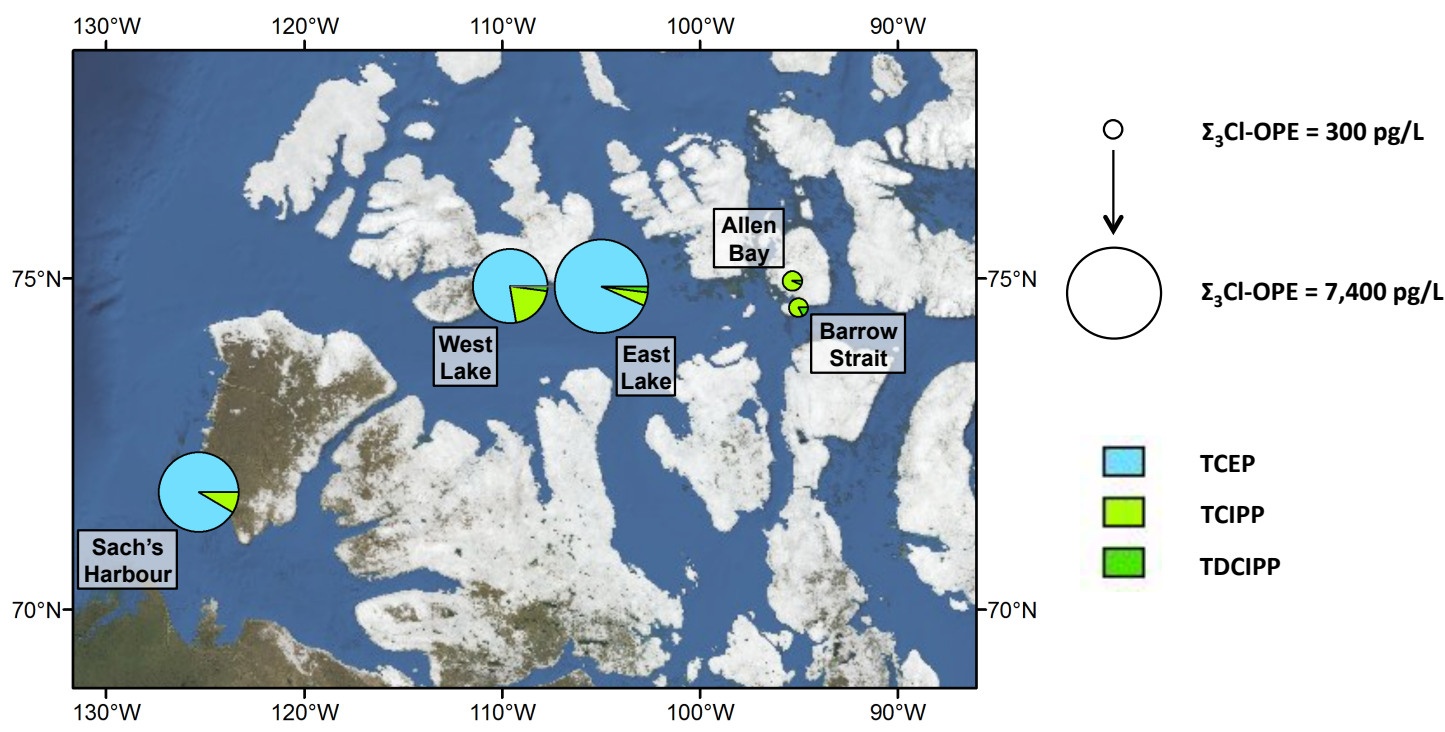

Figure 8-3. Surface water concentrations of Cl-OPEs (light blue: TCEP, light green: TCIPP, green: TDCIPP) in $\mathrm{pg} / \mathrm{L}$. The size of the circle is representative of total $\Sigma_{3} \mathrm{Cl}$ OPE ranging from $300-7,390 \mathrm{pg} / \mathrm{L}$. The North Lake, Resolute site is not shown because $\Sigma_{3} \mathrm{Cl}-\mathrm{OPE}<\mathrm{DL}$. 

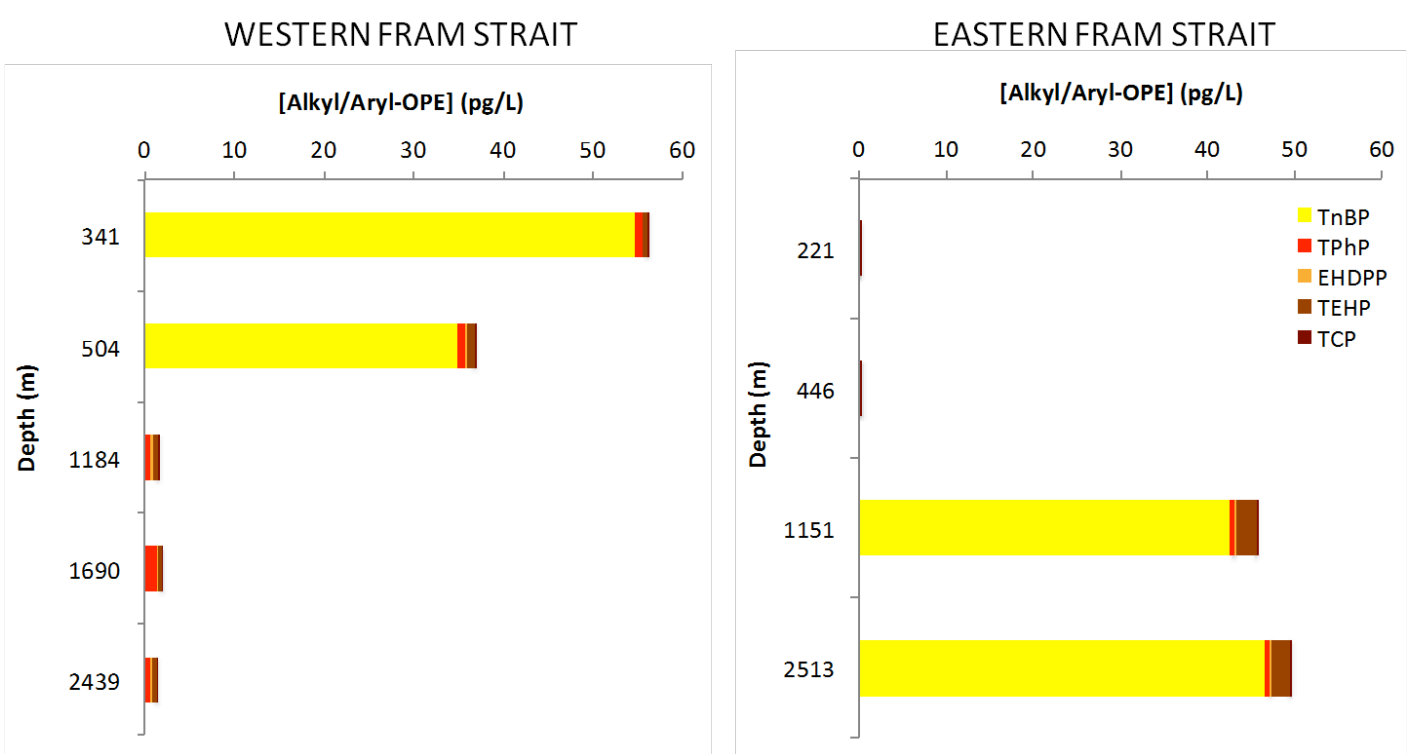

Figure 8-4. Depth profiles showing estimated dissolved concentrations of Alkyl/arylOPEs (yellow: TnBP, red: TPhP, light orange: EHDPP, brown: TEHP, maroon: TCP (sum of ToCP, TmCP, TpCP)) in pg/L in Western and Eastern Fram Strait.

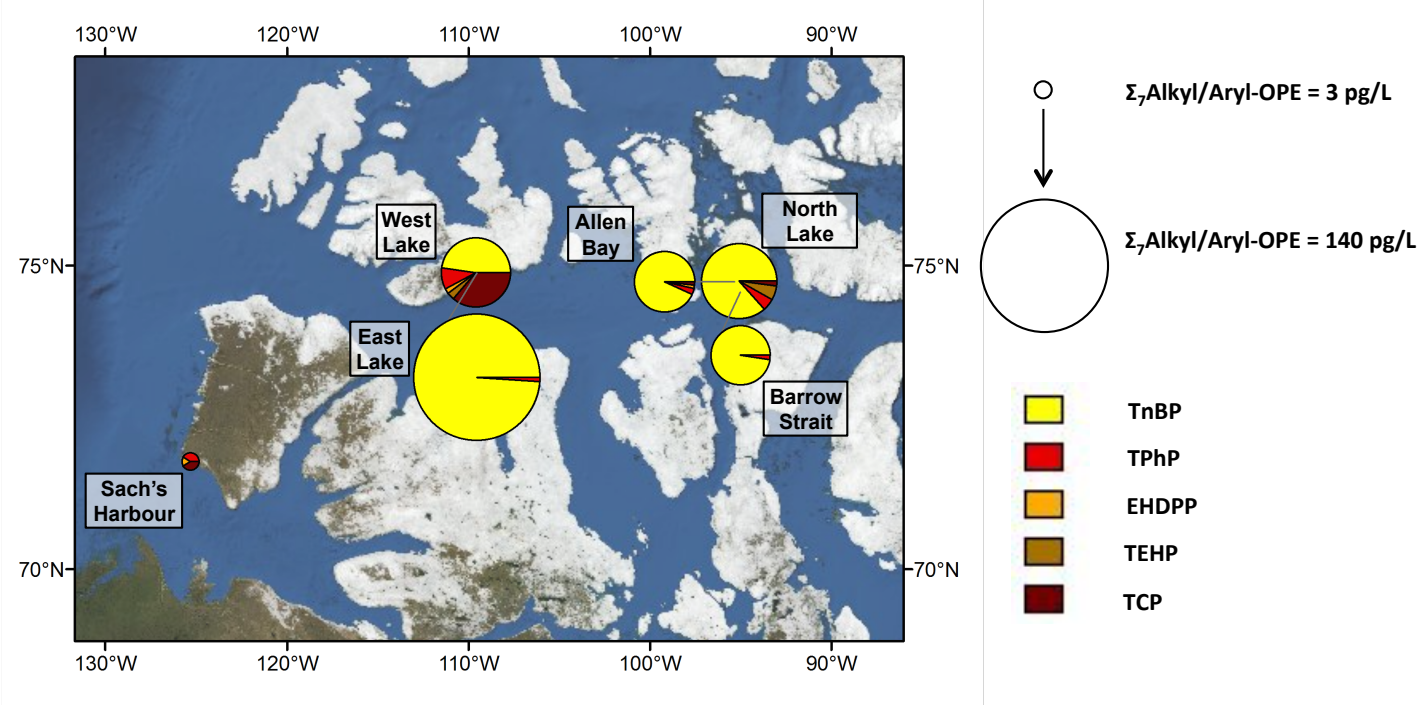

Figure 8-5. Surface water concentrations of alkyl/aryl-OPEs (yellow: TnBP, red: TPhP, light orange: EHDPP, brown: TEHP, maroon: TCP (sum of ToCP, TmCP, $\mathrm{TpCP})$ ) in $\mathrm{pg} / \mathrm{L}$. The size of the circle is representative of total $\Sigma_{7} \mathrm{Alkyl} /$ aryl-OPE ranging from $2.6-143 \mathrm{pg} / \mathrm{L}$. 


\section{SUPPLEMENTARY INFORMATION: DISSOLVED ORGANOPHOSPHATE ESTERS IN THE NORTH ATLANTIC OCEAN AND ARCTIC OCEAN}

Carrie A. McDonough; Caoxin Sun; David Adelman; Thomas Soltwedel; Eduard Bauerfeind; Derek C. G. Muir; Rainer Lohmann

Total number of pages: 6

Total number of figures: 2

Total number of tables: 6

\section{Table S8-1. Summary of Samples Taken from Fram Strait Deep Mooring Sites and Canadian Arctic Surface Water Sites}

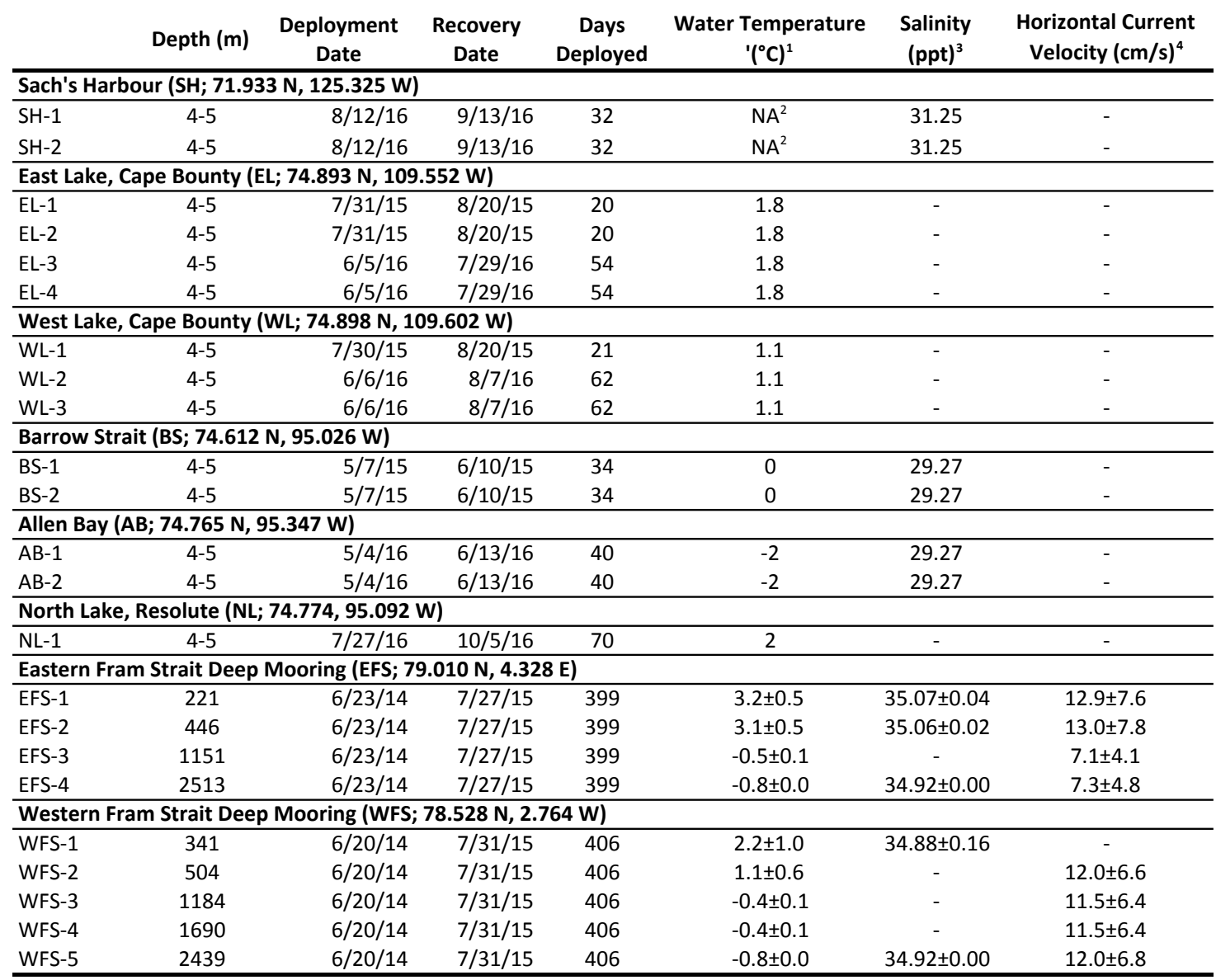

${ }^{1,3,4}$ Water temperature, and salinity for surface water sites were obtained by using any available measurements taken at the site over the relevant time period. For deep moorings, water temperature, salinity, and current speed data from continuous temperature monitoring at similar depths to the PEs were averaged over the deployment period and are presented \pm stdev. ${ }^{2}$ No water temperature measurements available; physical parameters adjusted using the temperature for Allen Bay. 


\begin{tabular}{|lcccccccccc|}
\hline \multicolumn{4}{c}{ Blank for Deep Mooring PE Extractions } & \multicolumn{7}{c|}{ Blanks for Arctic Surface Water PE Extractions } \\
\hline Type & LAB BLK & 800 um FB & 1600 um FB & WEST LAKE FB & AlR BOUNTY FB & SACHS FB & ALLEN FB & RESOLUTE FB & FB-WATER & FB-AIR \\
Year & 2016 & 2015 & 2015 & 2016 & 2016 & 2016 & 2016 & 2016 & 2015 & 2015 \\
\hline TrBP & 0.968 & 0.003 & 0.024 & 1.389 & 2.039 & 5.241 & 1.616 & 0.717 & 0.144 & 0.369 \\
TCEP & 0.093 & 0.003 & 0.008 & 1.307 & 1.331 & 0.723 & 1.545 & 3.068 & 0.493 & 0.376 \\
TCIPP & 0.131 & 0.003 & 0.012 & 0.239 & 0.277 & 0.196 & 0.203 & 0.772 & 0.710 & 0.657 \\
TDCIPP & 0.050 & 0.070 & 0.198 & 6.142 & 2.801 & 0.090 & 2.362 & 1.014 & 0.356 & 0.207 \\
TPhP & 0.092 & 0.016 & 0.114 & 0.052 & 0.019 & 0.047 & 0.055 & 0.143 & 0.013 & 0.085 \\
TBEP & 0.955 & 0.254 & 0.081 & 0.000 & 0.000 & 0.000 & 0.000 & 0.000 & 0.000 & 2.249 \\
EHDPP & 0.005 & 0.004 & 0.044 & 0.075 & 0.023 & 0.035 & 0.055 & 0.817 & 0.108 & 0.155 \\
TEHP & 0.390 & 0.008 & 0.112 & 1.434 & 0.373 & 0.000 & 0.980 & 2.083 & 0.754 & 0.193 \\
TOTP & 0.173 & 0.011 & 0.071 & 0.236 & 0.074 & 0.029 & 0.173 & 0.137 & 0.043 & 0.075 \\
TMTP & 0.007 & 0.000 & 0.000 & 0.005 & 0.002 & 0.006 & 0.008 & 0.042 & 0.022 & 0.018 \\
TPTP & 0.011 & 0.000 & 0.000 & 0.001 & 0.001 & 0.022 & 0.051 & 0.025 & 0.028 & 0.031 \\
TDBPP & 3.044 & 0.083 & 0.306 & 0.000 & 0.000 & 0.000 & 0.000 & 0.000 & 2.190 & 2.287 \\
\hline
\end{tabular}

Table S8-2. Blank concentrations (ng/g PE). PE blanks used in blank subtraction and censoring. Field blanks taken during the field sampling campaign were used for surface water samples. In 2016, location-specific field blanks were available, while in 2015, a single water and a single air field blank were available. No field blanks from the relevant sampling year (2014-2015) were available from the deep mooring field deployments, so a laboratory blank was used, as values in the lab blank were greater than concentrations in the only available field blanks (from a 2013-2014 sampling campaign).

\begin{tabular}{|c|c|c|c|c|c|c|c|c|c|}
\hline & FEVI-213 & FEVI-468 & FEVI-1173 & FEVI-2535 & TD-241 & TD-511 & TD-1242 & TD-1767 & TD-2496 \\
\hline Percent Loss (DiBB) & 99.9 & 99.7 & 99.6 & 98.7 & 99.9 & 99.8 & 99.8 & 99.8 & 99.8 \\
\hline Percent Loss (TetraBB) & 87.4 & 74.4 & 49.3 & 35.6 & 86.7 & 72.1 & 70.1 & 74.3 & 73.8 \\
\hline Percent Loss (PentaBB) & 47.3 & 7.4 & -38.1 & -30.1 & 29.4 & 9.2 & 17.7 & 20.1 & 23.1 \\
\hline Best-fit $\delta_{\mathrm{DBL}}(\mu \mathrm{m})$ & 56.7 & 147.9 & 190.3 & 199.3 & 62.5 & 90.3 & 80.2 & 65.3 & 61.7 \\
\hline Stdev of $\delta_{\mathrm{DBL}}(\mu \mathrm{m})$ & 21.1 & 172.1 & 245.2 & 190.7 & 22.7 & 43.1 & 38.3 & 21.6 & 16.1 \\
\hline Residual Standard Error & 0.19 & 0.47 & 0.51 & 0.38 & 0.18 & 0.21 & 0.21 & 0.15 & 0.12 \\
\hline
\end{tabular}

Table S8-3. PRC loss data from deep mooring PEs, and best-fit values of the diffusive boundary layer thickness $\left(\delta_{\mathrm{DBL}}(\mu \mathrm{m})\right)$ 


\begin{tabular}{lccccccccc}
\hline & EFS-1 & EFS-2 & EFS-3 & EFS-4 & WFS-1 & WFS-2 & WFS-3 & WFS-4 & WFS-5 \\
\hline TnBP & 100.0 & 100.0 & 99.7 & 99.6 & 100.0 & 100.0 & 99.9 & 99.9 & 99.8 \\
TCEP & 100.0 & 100.0 & 100.0 & 100.0 & 100.0 & 100.0 & 100.0 & 100.0 & 100.0 \\
TCIPP & 100.0 & 100.0 & 100.0 & 100.0 & 100.0 & 100.0 & 100.0 & 100.0 & 100.0 \\
TDCIPP & 99.9 & 99.0 & 93.2 & 92.5 & 99.8 & 99.1 & 98.4 & 98.8 & 98.7 \\
TPhP & 99.8 & 97.6 & 88.7 & 87.9 & 99.4 & 97.9 & 96.7 & 97.4 & 97.3 \\
TBEP & 21.2 & 20.6 & 12.2 & 11.7 & 18.7 & 15.8 & 12.7 & 12.8 & 12.1 \\
EHDPP & 42.3 & 26.3 & 16.5 & 16.0 & 37.7 & 29.0 & 26.7 & 28.9 & 28.9 \\
TEHP & 0.02 & 0.01 & 0.004 & 0.004 & 0.02 & 0.01 & 0.01 & 0.01 & 0.01 \\
ToCP & 25.3 & 10.6 & 6.52 & 6.36 & 22.1 & 14.7 & 15.0 & 18.0 & 19.3 \\
TmCP & 25.0 & 10.5 & 6.44 & 6.29 & 21.8 & 14.6 & 14.8 & 17.8 & 19.1 \\
TpCP & 24.9 & 10.5 & 6.43 & 6.27 & 21.7 & 14.5 & 14.7 & 17.7 & 18.9 \\
TDBPP & 5.89 & 2.31 & 1.39 & 1.36 & 5.06 & 3.26 & 3.32 & 4.05 & 4.35 \\
\hline
\end{tabular}

Table S8-4. Percent equilibrium predicted to be reached by each OPE during deep mooring deployments.

\begin{tabular}{|c|c|c|c|c|c|c|c|c|}
\hline & EL-1 \& EL-2 & EL-3 \& EL-4 & WL-1 & WL-2 \& WL-3 & $\mathrm{SH}-1$ and $\mathrm{SH}-2$ & $A B-1$ and $A B-2$ & NL-1 & BS-1 \& BS-2 \\
\hline$\overline{T n B P}$ & 100.0 & 100.0 & 100.0 & 100.0 & 100.0 & 100.0 & 100.0 & 100.0 \\
\hline TCEP & 100.0 & 100.0 & 100.0 & 100.0 & 100.0 & 100.0 & 100.0 & 100.0 \\
\hline TCIPP & 100.0 & 100.0 & 100.0 & 100.0 & 100.0 & 100.0 & 100.0 & 100.0 \\
\hline TDCIPP & 89.1 & 99.7 & 88.7 & 99.8 & 87.1 & 92.0 & 100.0 & 90.5 \\
\hline TPhP & 74.0 & 97.4 & 73.5 & 98.0 & 71.2 & 78.5 & 99.1 & 76.1 \\
\hline TBEP & 84.0 & 99.3 & 84.5 & 99.6 & 85.9 & 91.1 & 99.8 & 88.7 \\
\hline ToCP & 1.94 & 5.15 & 1.91 & 5.53 & 1.79 & 2.20 & 6.68 & 2.06 \\
\hline $\mathrm{TmCP}$ & 1.92 & 5.09 & 1.89 & 5.47 & 1.77 & 2.18 & 6.60 & 2.03 \\
\hline TpCP & 1.92 & 5.09 & 1.89 & 5.47 & 1.77 & 2.18 & 6.60 & 2.03 \\
\hline TDBPP & 0.77 & 2.06 & 0.76 & 2.22 & 0.71 & 0.87 & 2.68 & 0.81 \\
\hline
\end{tabular}

Table S8-5. Percent equilibrium predicted to be reached by each OPE during surface water deployments. 
Table S8-6: Selected Physicochemical Properties of Target Compounds at 298 K

\begin{tabular}{|c|c|c|c|c|c|c|c|c|}
\hline & $\begin{array}{c}\text { CAS } \\
\text { Number }\end{array}$ & $\begin{array}{l}\log S_{1}(\mathrm{mg} / \mathrm{L}) \text { - } \\
\text { WSKOWWIN }^{1}\end{array}$ & $\begin{array}{c}\log \mathrm{S}_{2}(\mathrm{mg} / \mathrm{L}) \text { - } \\
\text { WATERNT }^{1}\end{array}$ & $\begin{array}{c}\log K_{\text {pew }}(L / L) \\
\text { from } S_{1}{ }^{2}\end{array}$ & $\begin{array}{c}\log K_{\text {pew }}(L / L) \\
\text { from } S_{2}{ }^{2}\end{array}$ & $\begin{array}{c}V_{m} \\
\left(\mathrm{~cm}^{3} / \mathrm{mol}\right)^{3}\end{array}$ & $\begin{array}{l}\log D_{p e} \\
\left(\mathrm{~m}^{2} / \mathrm{s}\right)^{4}\end{array}$ & $\begin{array}{r}\log D_{w} \\
\left(\mathrm{~m}^{2} / \mathrm{s}\right)^{5}\end{array}$ \\
\hline TnBP & $126-73-8$ & 0.9 & 2 & 3.9 & 2.8 & 265.5 & -14.0 & -9.2 \\
\hline TCEP & $115-96-8$ & 2.9 & 3.7 & 1.9 & 1.1 & 196.5 & -13.0 & -9.1 \\
\hline TCIPP & $13674-84-5$ & 1.7 & 2.9 & 3.2 & 2.0 & 247.9 & -13.7 & -9.2 \\
\hline TDCIPP & $13674-87-8$ & 0.2 & 1.5 & 4.8 & 3.5 & 268.4 & -14.0 & -9.2 \\
\hline TPhP & $115-86-6$ & 0 & 0.7 & 4.8 & 4.1 & 272.9 & -14.1 & -9.2 \\
\hline TBEP & $78-51-3$ & 0.3 & 2.8 & 4.6 & 2.2 & 383.2 & -15.7 & -9.3 \\
\hline EHDPP & $1241-94-7$ & -1.2 & -0.7 & 6.1 & 5.6 & 338.5 & -15.0 & -9.3 \\
\hline TEHP & $78-42-2$ & -4.8 & -3.6 & 9.7 & 8.5 & 434.6 & -14.4 & -9.4 \\
\hline ТоCP & $78-30-8$ & -1.7 & -0.9 & 6.6 & 5.8 & 314.7 & -13.6 & -9.3 \\
\hline TmCP & $563-04-2$ & -1.7 & -0.9 & 6.6 & 5.8 & 321.0 & -13.6 & -9.3 \\
\hline $\mathrm{TpCP}$ & $78-32-0$ & -1.7 & -0.9 & 6.6 & 5.8 & 321.0 & -13.8 & -9.3 \\
\hline TDBPP & $126-72-7$ & -2.1 & 0 & 7.2 & 5.2 & 292.6 & -14.3 & -9.3 \\
\hline
\end{tabular}

${ }^{1}$ Aqueous solubility estimates were taken from Zhang et al. ${ }^{10}$ Ambient concentrations were calculated using two sets of solubility values, one determined from the WSKOWWIN model and the other from the WATERNT model. Results using the WSKOWWIN model were identified as most appropriate and used in the ambient concentrations presented in the article. ${ }^{2} \mathrm{PE}$-water partitioning coefficients $\left(\mathrm{K}_{\mathrm{PEW}}\right)$ were calculated from aqueous solubility as in Lohmann 2012. ${ }^{9}$ Molar volume was determined using SPARC. ${ }^{4}$ Molecular diffusivity in polyethylene was taken from Pintado-Herrera et al. when available (TEHP, ToCP, TmCP, and TpCP), and were otherwise calculated from $\mathrm{V}_{\mathrm{m}}$ as in Lohmann. ${ }^{9}$ Molecular diffusivity in water was calculated from $\mathrm{V}_{\mathrm{m}}$ using the Wilke-Change equation. 
Figure S8-1. Best-fit value for the thickness of the water boundary layer for each PE: Error bars represent the standard deviation calculated from the fitting function.

\section{Western Site}

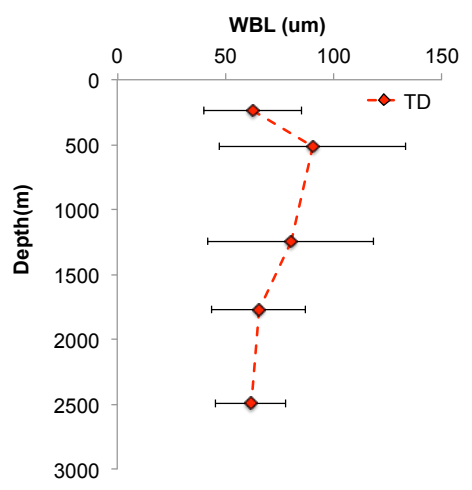

\section{Eastern Site}

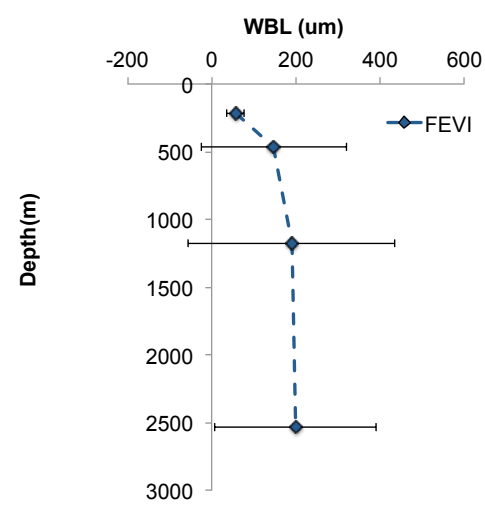


Figure S8-2. Range of OPE concentrations estimated depending on physico-chemical properties chosen

Concentrations Derived from EPI Suite WISKOWWIN $C_{W}$ Estimation

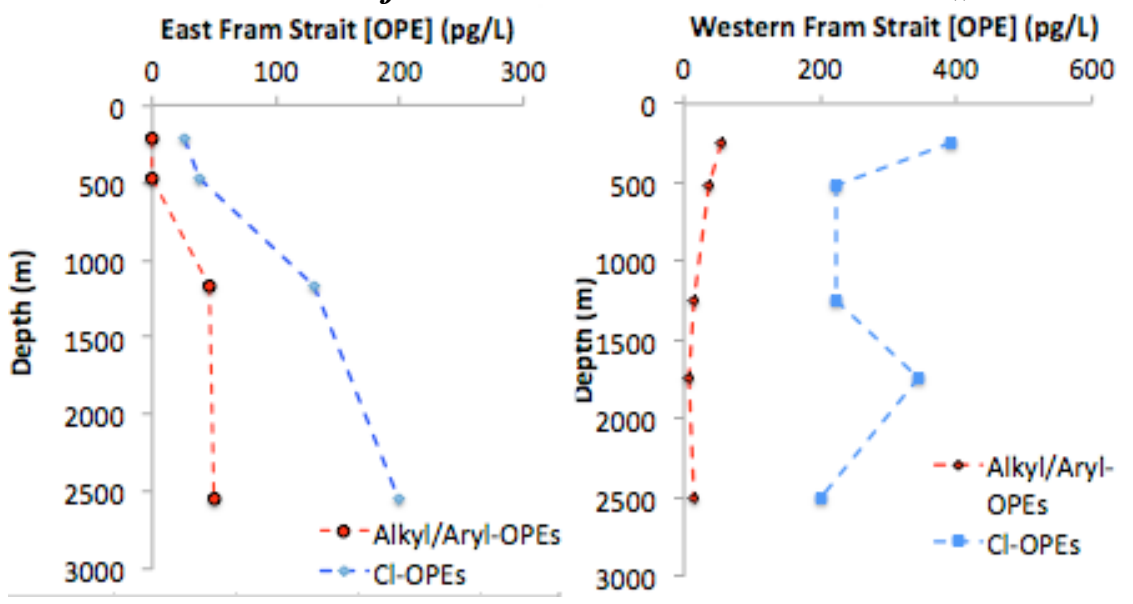

Concentrations Derived from EPI Suite WATERNT $C_{W}$ Estimation East Fram Strait [OPE] (pg/L)

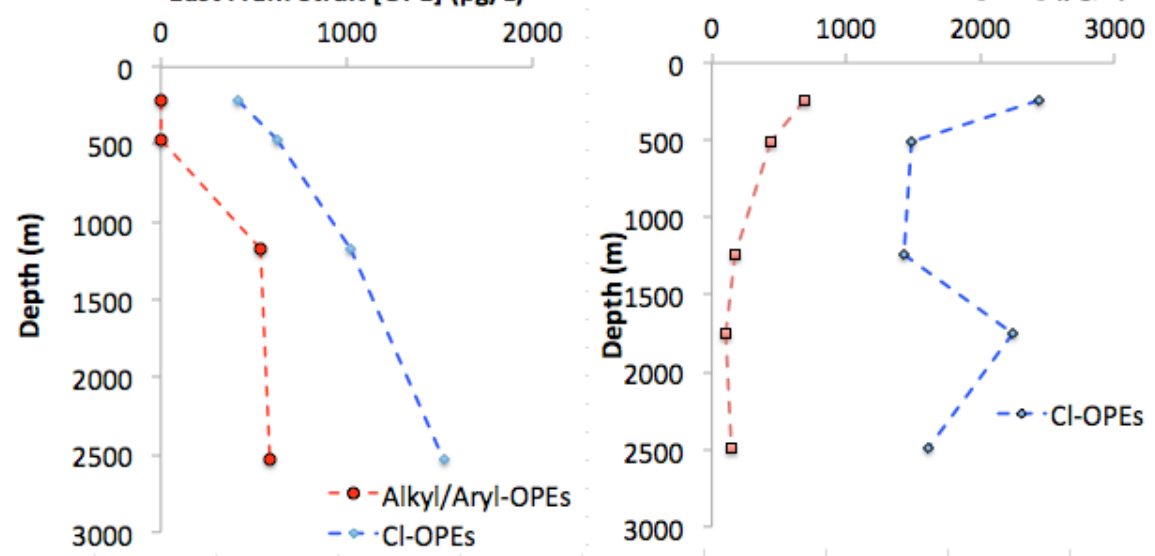

\section{Concentrations Derived from SPARC $C_{W}$ Estimation}

East Fram Strait [OPE] (pg/L)

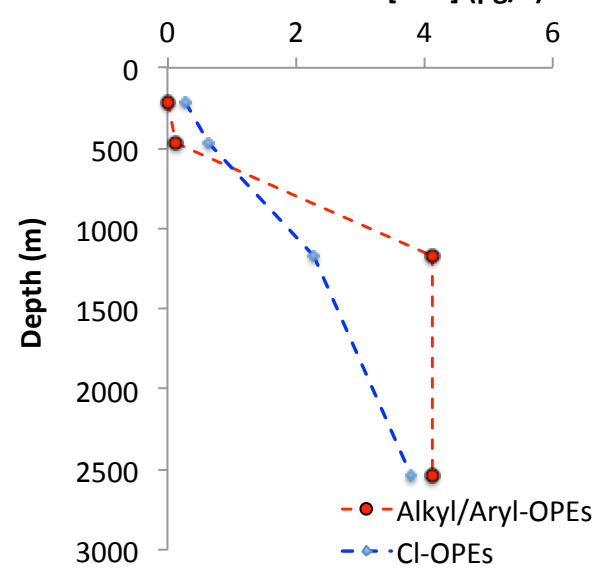

Western Fram Strait [OPE] (pg/L)

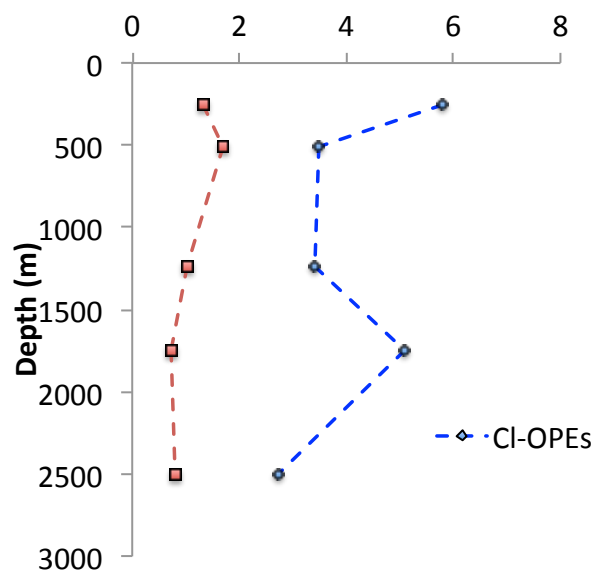




\section{CHAPTER 9}

\section{CONCLUSION}

Spatial Distribution of HOCs. The spatial distribution of gaseous PAHs, PBDEs, and PCMs was found to be influenced by nearby population density. The influence of population centers on ambient concentrations of air pollutants is a significant consideration to regional and global modeling studies, as well as predictions of human health risk. While previous studies demonstrated correlations between concentrations of HOCs in air and population within $25 \mathrm{~km},{ }^{1-3}$ here the effect of compound vapor pressure on spatial distribution was explored by using two additional metrics: the radii of site characterization at which maximum correlation was seen, and the maximum distance at which a statistically significant correlation with population remains. Results implied that more volatile compounds were influenced by more distant population, while less volatile compounds were influenced only by local population. Questions remain as to how concentrations of gas-phase HOCs change in response to differences in the levels and composition of ambient aerosol from site to site, a consideration that could only be addressed if particulate samples were collected alongside freely gaseous samples. Gustafson et al. hypothesized that HOCs traveling

from urban to rural areas may re-condense on background aerosol, causing pronounced urban-rural gradients in gas-phase HOCs. ${ }^{4}$ The spatial distribution of particle-bound HOCs with respect to population centers, and its interaction with spatial distributions of gas-phase HOCs, is an important missing piece of the puzzle. 
Additionally, investigating the role of atmospheric lifetime differences among different gas-phase HOCs, and the role of aerosols in prolonging these lifetimes by retarding degradation, ${ }^{5}$ would add further nuance to the observations made here. Future work should also include exploration of how the relationship between population and gas-phase HOC concentrations changes seasonally depending on air temperature, which can greatly affect the partitioning of many HOCs between the gasand particle-phase. Additionally, this study should be repeated in other areas of the world and on other scales, as choice of site and resolution of data may factor in to the observations made.

Diffusive Air-Water Exchange of HOCs. PAH air-water exchange was found to vary by compound and deployment period, while PCMs were lost from Great Lakes surface waters via volatilization and PBDEs were absorbed. More work needs to be done in the Great Lakes region to quantify other inputs and losses of dissolved HOCs in order to understand the role played by diffusive air-water exchange in the lakes, and to construct budgets for these toxic pollutants. Additionally, the importance of DOC sorption, gas-phase photodegradation, degradation in surface waters, and settling processes in influencing air-water diffusive exchange, and how these processes change seasonally, require further investigation to better understand observations in this study. Total losses of PCMs were estimated in Chapter 3 by averaging volatilization fluxes over the coastal boundary zone, arriving at loss estimates for $\Sigma_{5} \mathrm{PCM}$ of 41-138 $\mathrm{kg} / \mathrm{yr}$ for Lake Ontario and 22-74 kg-yr for Lake Erie. Loss and input estimates of PCMs can also be calculated by interpolating dissolved PCM concentrations across the lakes using human population as an auxiliary variable (Figure 9-1), and then 
extrapolating fluxes across the lake based on the correlation between volatilization fluxes of PCMs and the dissolved concentrations that drive them (Figure 9-2). This approach led to similar loss estimates for $\Sigma_{5} \mathrm{PCM}$, amounting to $150 \pm 230 \mathrm{~kg} / \mathrm{yr}$ from Lake Ontario and $120 \pm 380 \mathrm{~kg} / \mathrm{yr}$ from Lake Erie. A similar approach was taken to calculate total inputs of $\Sigma_{12} \mathrm{BDE}$ due to absorption using data from Chapter 4. Gaseous $\Sigma_{12} \mathrm{BDE}$ over the lakes was interpolated (Figure 9-3) and used to estimate absorptive fluxes using the regression with gas-phase concentrations shown in Figure 9-4. Further exploration of how spatial distributions of dissolved and gaseous HOCs influence trends in air-water exchange fluxes could be very useful in predicting the role played by diffusive exchange in lake budgets.

AhR-Mediated Potency of Gaseous HOCs. Targeted analysis of PAHs, including many high molecular weight PAHs that contribute significantly to the AhR-mediated potency of the particulate fraction (BaP, DBA, IND), explained little of gaseous fraction potency. This study highlights the need for a better understanding of mixture potency. AhR-mediated potency of gas-phase samples varied between locations on a regional scale, unlike some previous studies, ${ }^{6}$ but did not correlate very strongly with measured compounds. Further work should investigate whether concentrations of additional substituted PAH species, such as nitro- or oxy-PAHs, help to explain the trends observed here. Additionally, bioassays using cells with a luciferase reporter, or experiments comparing these results to potency of acid-treated extracts, could help shed light on the portion of AhR-mediated potency being caused by PAH-like compounds that can be metabolized. 
PE Uptake of HOCs. Results from PE uptake experiments in water suggest that we are capable of adequately calculating dissolved concentrations of PAHs and PCMs, while field-derived concentrations of dissolved OPEs may be lower than actual concentrations. Uptake of emerging contaminants, especially OPEs, into PEs needs to be further characterized with additional measurements of diffusivity in polyethylene $\left(D_{P E}\right)$ and modeling of uptake for membrane-limited compounds to see if this helps explain uptake profiles seen here. Modeling of PE concentrations over time, such as was used in Chapters 3 and 4 to investigate the use of PEs in air-water diffusive flux calculations, could be useful in helping to compare passive and active results, and find out how equilibration times and responses to fluctuating concentrations postequilibration are affected by compound properties. Additional studies with other types of passives co-deployed, like recent work by Allan et al. and Abdollahi et al., ${ }^{7,8}$ could be useful to help understand how to use retrospective analysis of PEs to get accurate ambient concentrations of OPEs. Grab water samples could be a useful addition in wastewater-impacted environments, as they remove complications associated with active sampling (pump failure, uncertain recorded volume, break-through). Additional experiments are needed to understand depuration of deuterated chlorinated OPEs. Inclusion of data for PEs of multiple thickness could also help to confirm whether equilibrium was reached during deployment, and could be used to investigate whether a single diffusive boundary layer thickness estimate, derived from PEs of one thickness, can provide accurate ambient concentrations for PEs of another thickness. OPEs in Arctic and North Atlantic Waters. Finally, this work demonstrated an important application of PEs: obtaining time-weighted average concentrations of 
trave-level emerging contaminants in remote regions. This work provided the first estimates of dissolved OPE concentrations in Arctic Ocean waters. Though concentrations are uncertain due to poorly constrained chemical properties, OPEs are very likely present at elevated concentrations relative to other flame retardant chemicals. Additional field studies to establish levels of OPEs in ocean waters, as well as lab studies to help define their chemical properties and behavior with respect to degradation in natural waters, are needed to fully understand how these compounds are capable of long-range transport, and what transport pathways (atmospheric or waterborne transport) they are primarily being delivered by. Elevated dissolved OPE concentrations measured here also highlight the importance of understanding how OPEs may interact with marine ecosystems as a source of organic phosphate, as was previously noted by Castro-Jimenez et al. ${ }^{9}$ More information about the affinity of OPEs for the PE matrix, and their diffusivity in PE, would again be helpful in constraining concentrations, as would air-water diffusive exchange calculations and modeling simulations based on empirical chemical properties. 


\section{LITERATURE CITED IN CONCLUSION}

(1) Hafner, W. D.; Carlson, D. L.; Hites, R. A. Influence of local human population on atmospheric polycyclic aromatic hydrocarbon concentrations. Environ. Sci. Technol. 2005, 39, 7374-7379, DOI:10.1021/es0508673.

(2) Sun, P.; Blanchard, P.; Brice, K. A.; Hites, R. A. Trends in polycyclic aromatic hydrocarbon concentrations in the Great Lakes atmosphere. Environ. Sci. Technol. 2006, 40, 6221-6227, DOI:10.1021/es0607279.

(3) Venier, M.; Hites, R. Flame retardants in the atmosphere near the Great Lakes. Environ. Sci. Technol. 2008, 42, 4745-4751. DOI:

(4) Gustafson, K. E.; Dickhut, R. M. Particle / Gas Concentrations and Distributions of PAHs in the Atmosphere of Southern Chesapeake. Environ. Sci. Technol. 1997, 31, 140-147, DOI:10.1021/es9602197.

(5) Liu, Y.; Liggio, J.; Harner, T.; Jantunen, L.; Shoeib, M.; Li, S.-M. Heterogeneous $\mathrm{OH}$ initiated oxidation: a possible explanation for the persistence of organophosphate flame retardants in air. Environ. Sci. Technol. 2014, 48, 1041-1048, DOI:10.1021/es404515k.

(6) Klein, G. P.; Hodge, E. M.; Diamond, M. L.; Yip, A.; Dann, T.; Stern, G.; Denison, M. S.; Harper, P. A. Gas-phase ambient air contaminants exhibit significant dioxin-like and estrogen-like activity in vitro. Environ. Health Perspect. 2005, 114, 697-703, DOI:10.1289/ehp.8496.

(7) Allan, I. J.; Harman, C.; Ranneklev, S. B.; Thomas, K. V; Grung, M. Passive sampling for target and nontarget analyses of moderately polar and nonpolar substances in water. Environ. Toxicol. Chem. 2013, 32, 1718-1726, DOI:10.1002/etc.2260.

(8) Abdollahi, A.; Eng, A.; Jantunen, L. M.; Ahrens, L.; Shoeib, M.; Parnis, J. M.; Harner, T. Characterization of polyurethane foam (PUF) and sorbent impregnated PUF (SIP) disk passive air samplers for measuring organophosphate flame retardants. Chemosphere 2017, 167, 212-219, DOI:10.1016/j.chemosphere.2016.09.111.

(9) Castro Jimenez, J.; González-Gaya, B.; Pizarro, M.; Casal, P.; Pizarro-Alvarez, C.; Dachs, J. Organophosphate ester flame retardants and plasticizers in the global oceanic atmosphere. Environ. Sci. Technol. 2016, acs.est.6b04344, DOI:10.1021/acs.est.6b04344. 


\section{FIGURES AND TABLES}

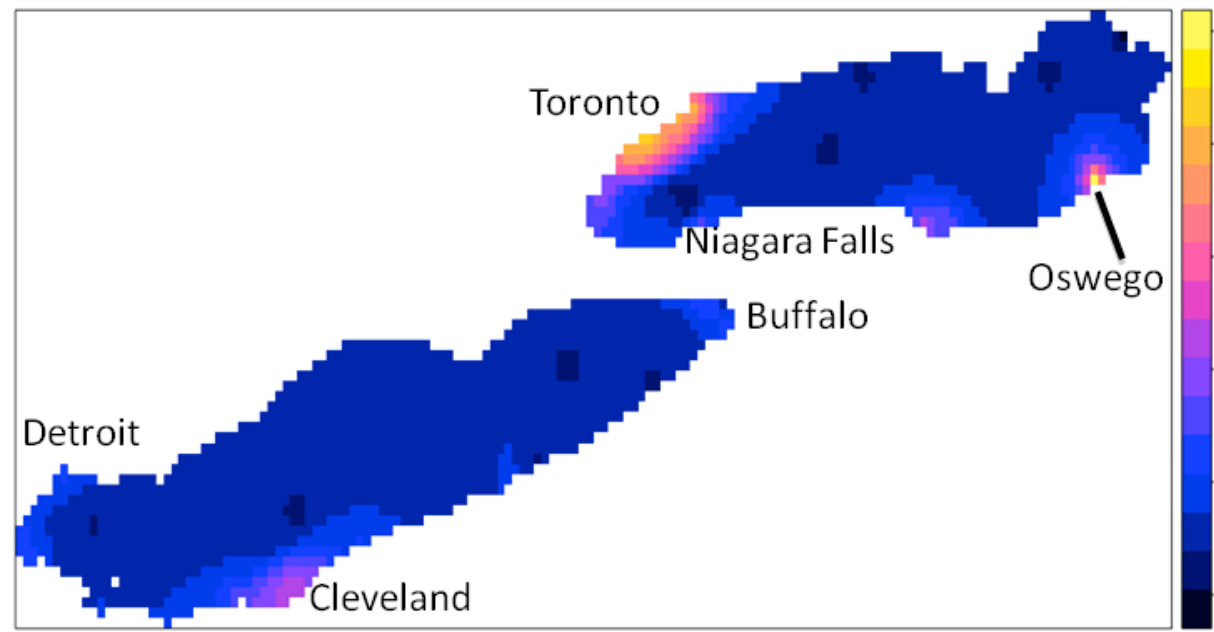

Figure 9-1. Interpolated dissolved $\Sigma_{5} \mathrm{PCM}$ concentrations (ng/L) across Lake Erie and Lake Ontario using Bayesian kriging with population within $25 \mathrm{~km}$ as an auxiliary variable.

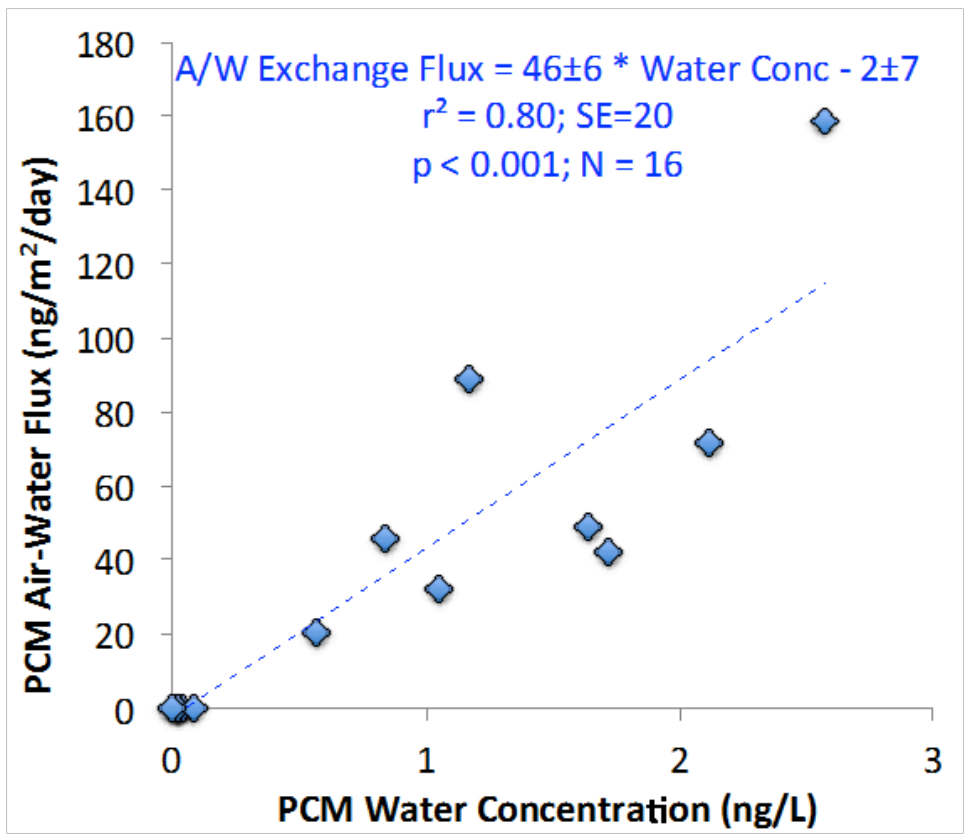

Figure 9-2. Linear correlation between dissolved $\Sigma_{5} \mathrm{PCM}$ concentrations (ng/L) and PCM volatilization fluxes ( $\mathrm{ng} / \mathrm{m}^{2} /$ day). 


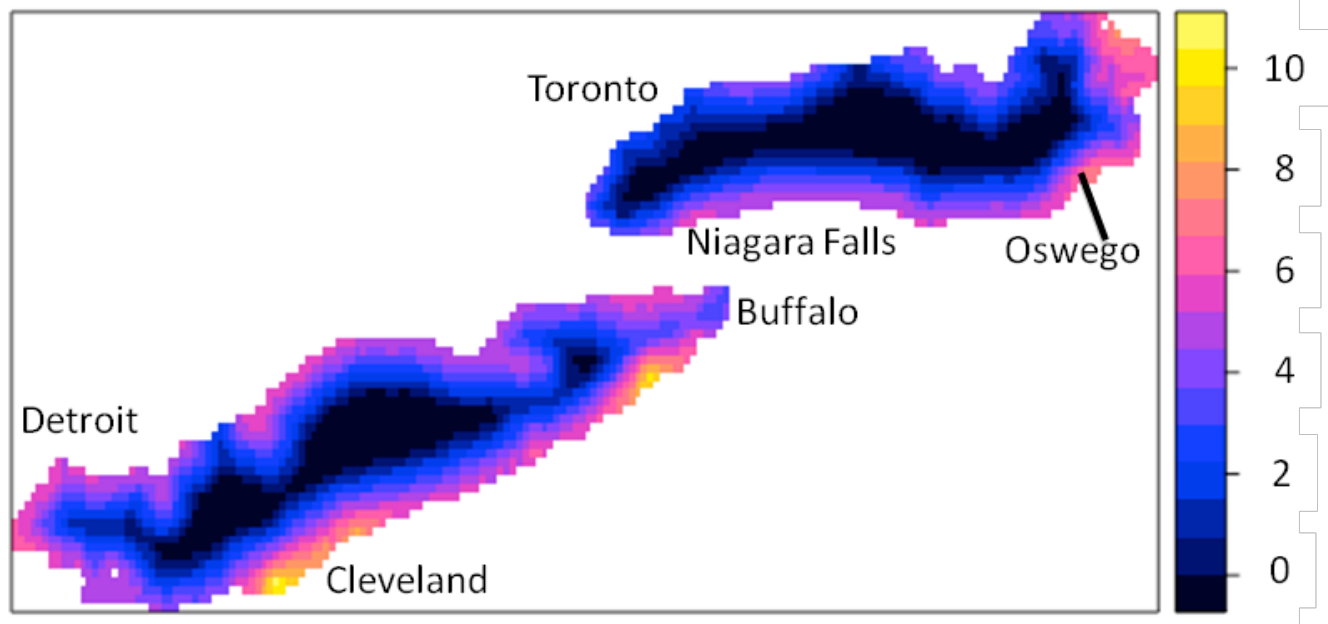

Figure 9-3. Interpolated gaseous $\Sigma_{12} \mathrm{BDE}$ concentrations $\left(\mathrm{pg} / \mathrm{m}^{3}\right)$ across Lake Erie and Lake Ontario using Bayesian kriging.

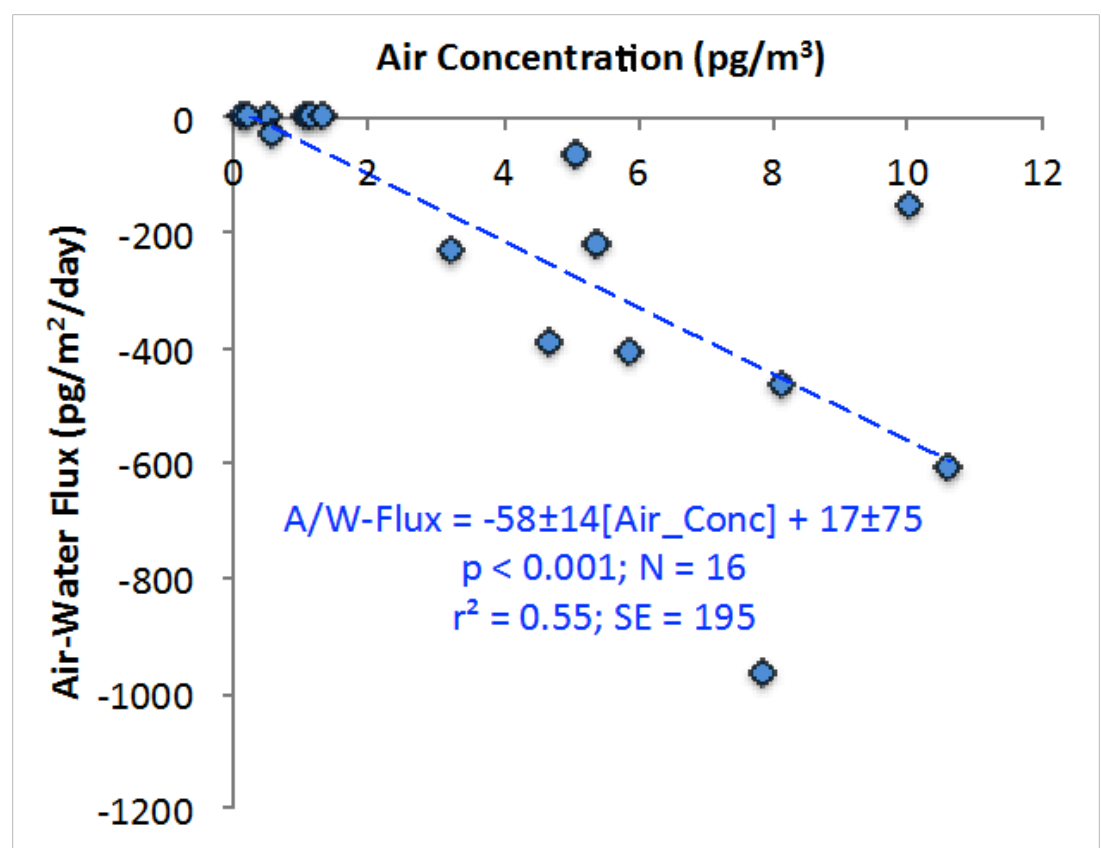

Figure 9-4. Inverse linear correlation between gaseous $\Sigma_{12} \mathrm{BDE}$ concentrations $\left(\mathrm{pg} / \mathrm{m}^{3}\right)$ and absorptive BDE fluxes into surface waters $\left(\mathrm{pg} / \mathrm{m}^{2} /\right.$ day). 


\section{APPENDIX A}

\section{LIST OF ABBREVIATIONS}

\begin{tabular}{|c|c|}
\hline AhR & Aryl hydrocarbon receptor \\
\hline $\mathrm{AOC}$ & Areas of concern \\
\hline $\mathrm{BDE}$ & Brominated diphenyl ether \\
\hline BFRs & Brominated flame retardants \\
\hline $\mathrm{C}_{\infty}$ & Concentration in polyethylene at equilibrium \\
\hline $\mathrm{C}_{\mathrm{a}}{ }^{\prime}$ & Ambient concentration \\
\hline CIESIN & Center for International Earth Science Information Network \\
\hline $\mathrm{C}_{\mathrm{PE}}$ & Concentration in polyethylene \\
\hline $\mathrm{C}_{\mathrm{w}, \mathrm{sat}}(\mathrm{L})$ & Sub-cooled liquid aqueous solubility \\
\hline $\mathrm{D}_{\mathrm{a}}$ & Molecular diffusivity in air \\
\hline DBL & Diffusive boundary layer \\
\hline DCM & Dichloromethane \\
\hline$\delta_{\mathrm{DBL}}$ & Thickness of the diffusive boundary layer \\
\hline DL & Detection limit \\
\hline DOC & Dissolved organic carbon \\
\hline $\mathrm{D}_{\mathrm{PE}}$ & Molecular diffusivity in polyethylene \\
\hline $\mathrm{D}_{\mathrm{w}}$ & Molecular diffusivity in water \\
\hline EI & Electron ionization mode \\
\hline$f$ & Percent equilibration in PE sampler \\
\hline $\mathrm{F}_{a / w}$ & Air-water exchange flux \\
\hline $\mathrm{GC}$ & Gas chromatograph \\
\hline GFF & Glass fiber filter \\
\hline GFP & Green fluorescent protein \\
\hline GLIN & Great Lakes Information Network \\
\hline GRUMP & Global Rural-Urban Mapping Project \\
\hline HV-AAS & High volume active air sampler \\
\hline$\Delta \mathrm{H}_{\mathrm{vap}}$ & Enthalpy of vaporization \\
\hline HMW PAHs & High molecular weight polycyclic aromatic hydrocarbons \\
\hline HOCs & Hydrophobic organic contaminants \\
\hline Hpd & Hours post dosing \\
\hline IADN & Integrated Atmospheric Deposition Network \\
\hline IEF & Induction equivalency factor \\
\hline $\mathrm{K}_{\mathrm{AW}}$ & Air-water partitioning coefficient \\
\hline $\mathrm{k}_{\mathrm{o}}$ & Mass transfer coefficient \\
\hline $\mathrm{K}_{\mathrm{DOC}}$ & Dissolved organic carbon partitioning coefficient \\
\hline Kow & Octanol-water partitioning coefficient \\
\hline$K_{\text {PEA }}$ & PE-air partitioning coefficient \\
\hline $\mathrm{K}_{\text {PEM }}$ & PE-matrix partitioning coefficient \\
\hline $\mathrm{K}_{\text {PEW }}$ & PE-water partitioning coefficient \\
\hline
\end{tabular}




$\begin{array}{ll}\text { LDPE } & \text { Low-density polyethylene } \\ \text { LMW PAHs } & \text { Low molecular weight polycyclic aromatic hydrocarbons } \\ \text { MRM } & \text { Multiple reaction monitoring } \\ \text { MSD } & \text { Mass spectrometric detector } \\ \text { MS/MS } & \text { Tandem mass spectrometry } \\ \text { NCDC } & \text { National Climate Data Center } \\ \text { NDBC } & \text { National Data Buoy Center } \\ \text { NHFRs } & \text { Novel halogenated flame retardants } \\ \text { NOAA } & \text { National Oceanic and Atmospheric Administration } \\ \text { NPDES } & \text { National Pollutant Discharge Elimination System } \\ \text { OFRs } & \text { Organic flame retardants } \\ \text { OPEs } & \text { Organophosphate esters } \\ \text { PEs } & \text { Passive polyethylene samplers } \\ \text { PAHs } & \text { Polycyclic aromatic hydrocarbons } \\ \text { PBDEs } & \text { Polybrominated diphenyl ethers } \\ \text { PCA } & \text { Principal component analysis } \\ \text { PCBs } & \text { Polychlorinated biphenyls } \\ \text { PCMs } & \text { Polycyclic musks } \\ p_{L} & \text { Sub-cooled liquid vapor pressure } \\ \text { POPs } & \text { Persistent organic pollutants } \\ \text { PRCs } & \text { Performance reference compounds } \\ \text { PUF } & \text { Polyurethane foam } \\ \text { RI DEM } & \text { Rhode Island Department of Environmental Monitoring } \\ \text { R } & \text { Sampling rate } \\ \text { RPD } & \text { Relative percent difference } \\ \text { RSD } & \text { Relative standard deviation } \\ \text { RSE } & \text { Residual standard error } \\ \text { SI } & \text { Supplementary/Supporting Information } \\ \text { SIM } & \text { Selected ion monitoring mode } \\ \text { SPMD } & \text { Semi-permeable membrane device } \\ \text { SVOC } & \text { Semi-volatile organic contaminant } \\ \text { TRI } & \text { Toxic Release Inventory } \\ \Delta U_{w} & \text { Internal energy of dissolution } \\ v_{\mathrm{a} / \mathrm{w}} & \text { Mass transfer coefficient } \\ \text { WWTF } & \text { Wastewater treatment facility } \\ \text { WWTP } & \text { Wastewater treatment plant } \\ & \end{array}$




\section{APPENDIX B}

\section{ADDITIONAL GREAT LAKES HOC CONCENTRATIONS FROM 2011-2014 PASSIVE SAMPLER CAMPAIGNS IN AIR AND WATER}

Table B-1. 2011 Dissolved BDE Concentrations (pg/L). Mean concentrations for each location over Spring-Fall, 2011. <DL concentrations replaced with 0.

$\begin{array}{lccccccc}\text { LOC } & \text { BDE-2 } & \text { BDE-8 } & \text { BDE-15 } & \text { BDE-30 } & \text { BDE-28 } & \text { BDE-49 } & \text { BDE-47 } \\ \text { BUF } & 0.00 & 0.00 & 0.00 & 0.00 & 0.00 & 0.05 & 0.53 \\ \text { CLE } & 0.00 & 0.00 & 0.00 & 0.00 & 0.00 & 0.15 & 1.30 \\ \text { SHF } & 0.00 & 0.00 & 0.00 & 0.00 & 0.22 & 0.10 & 0.58 \\ \text { DUN } & 2.44 & 1.62 & 1.78 & 0.42 & 0.43 & 0.20 & 0.43 \\ \text { ERI } & 0.00 & 0.00 & 0.00 & 0.00 & 0.00 & 0.27 & 0.81 \\ \text { STN357 } & 0.00 & 0.00 & 0.00 & 0.00 & 0.00 & 0.51 & 1.69 \\ \text { STN880 } & 0.00 & 0.00 & 0.00 & 0.00 & 0.00 & 0.09 & 0.80 \\ \text { STN452 } & 0.66 & 0.00 & 0.00 & 0.00 & 0.00 & 0.00 & 0.00 \\ \text { GIB } & 0.00 & 0.00 & 0.00 & 0.00 & 0.00 & 0.23 & 1.18 \\ \text { NIA } & 0.00 & 0.00 & 0.00 & 0.00 & 0.00 & 0.40 & 4.72 \\ \text { GRI } & 0.00 & 0.00 & 0.00 & 0.00 & 0.00 & 0.24 & 2.22 \\ \text { OSW } & 10.23 & 6.66 & 6.95 & 1.83 & 2.08 & 1.54 & 3.57 \\ \text { CV } & 0.00 & 0.00 & 0.00 & 0.00 & 0.00 & 0.37 & 1.07 \\ \text { TOL } & 0.00 & 0.00 & 0.00 & 0.00 & 0.00 & 0.32 & 1.92\end{array}$

$\begin{array}{rr}\text { BDE-100 } & \text { BDE-99 } \\ 0.12 & 0.28 \\ 0.21 & 0.60 \\ 0.15 & 0.37 \\ 0.24 & 0.23 \\ 0.12 & 0.36 \\ 0.38 & 0.93 \\ 0.14 & 0.51 \\ 0.00 & 0.27 \\ 0.24 & 0.71 \\ 0.90 & 3.05 \\ 0.40 & 1.22 \\ 1.08 & 1.80 \\ 0.23 & 0.63 \\ 0.39 & 0.81\end{array}$

$\begin{array}{cccc}\text { BDE-154 } & \text { BDE-153 } & \text { BDE-183 } & \text { SUM_BDE } \\ 0.02 & 0.00 & 0.00 & 1.002 \\ 0.03 & 0.02 & 0.00 & 2.296 \\ 0.09 & 0.05 & 0.09 & 1.651 \\ 0.14 & 0.12 & 0.12 & 8.173 \\ 0.00 & 0.00 & 0.00 & 1.565 \\ 0.12 & 0.08 & 0.00 & 3.703 \\ 0.00 & 0.00 & 0.00 & 1.544 \\ 0.00 & 0.00 & 0.00 & 0.928 \\ 0.00 & 0.00 & 0.00 & 2.355 \\ 0.08 & 0.07 & 0.00 & 9.223 \\ 0.08 & 0.07 & 0.06 & 4.287 \\ 0.70 & 0.66 & 0.71 & 37.823 \\ 0.03 & 0.05 & 0.04 & 2.424 \\ 0.07 & 0.05 & 0.00 & 3.563\end{array}$

Table B-2. 2011 Gaseous BDE Concentrations $\left(\mathrm{pg} / \mathrm{m}^{3}\right)$. Mean concentrations for each location over Spring-Fall, 2011. $<$ DL concentrations replaced with 0 .

\begin{tabular}{|c|c|c|c|c|c|c|c|c|c|c|c|c|c|}
\hline LOC & BDE-2 & BDE-8 & BDE-15 & BDE-30 & BDE-28 & BDE-49 & BDE-47 & BDE-100 & BDE-99 & BDE-154 & BDE-153 & BDE-183 & SUM_BDE \\
\hline BUF & 0.30 & 0.00 & 0.00 & 0.00 & 0.00 & 0.14 & 0.00 & 0.00 & 0.13 & 0.00 & 0.00 & 0.00 & $0 . \overline{5} 6$ \\
\hline CLE-EDG & 1.31 & 0.00 & 0.00 & 0.00 & 0.51 & 0.17 & 2.53 & 0.18 & 0.85 & 0.00 & 0.00 & 0.00 & 5.55 \\
\hline CLE-GTC & 0.00 & 1.88 & 2.40 & 0.35 & 0.57 & 0.64 & 4.27 & 0.69 & 2.02 & 0.20 & 0.41 & 0.38 & 13.81 \\
\hline CV & 0.00 & 0.00 & 0.00 & 0.00 & 0.00 & 0.00 & 0.00 & 0.00 & 0.00 & 0.00 & 0.00 & 0.00 & 0.00 \\
\hline DUN & 0.67 & 0.00 & 0.00 & 0.00 & 0.00 & 0.00 & 0.00 & 0.00 & 0.00 & 0.00 & 0.00 & 0.00 & 0.67 \\
\hline ERI & 0.00 & 0.00 & 0.00 & 0.00 & 0.00 & 0.00 & 0.00 & 0.00 & 0.39 & 0.00 & 0.00 & 0.00 & 0.39 \\
\hline SHLH & 0.00 & 0.00 & 0.00 & 0.00 & 0.00 & 0.00 & 0.00 & 0.00 & 0.00 & 0.00 & 0.00 & 0.00 & 0.00 \\
\hline PTCO & 0.00 & 0.00 & 0.00 & 0.00 & 0.00 & 0.00 & 2.03 & 0.41 & 1.26 & 0.00 & 0.00 & 0.53 & 4.23 \\
\hline PTST & 0.00 & 0.00 & 0.00 & 0.00 & 0.00 & 0.00 & 1.59 & 0.30 & 1.00 & 0.00 & 0.00 & 0.00 & 2.89 \\
\hline $\mathbf{F H}$ & 0.00 & 0.00 & 0.00 & 0.00 & 0.00 & 0.20 & 0.69 & 0.00 & 0.00 & 0.00 & 0.00 & 0.00 & 0.89 \\
\hline GIB & 0.25 & 0.44 & 0.40 & 0.24 & 0.21 & 0.16 & 1.26 & 0.26 & 0.57 & 0.26 & 0.19 & 0.38 & 4.63 \\
\hline GRI & 3.21 & 0.00 & 0.00 & 0.00 & 0.19 & 0.23 & 0.38 & 0.12 & 0.22 & 0.03 & 0.07 & 0.12 & 4.56 \\
\hline NIA & 2.82 & 0.00 & 0.00 & 0.00 & 0.00 & 0.11 & 0.00 & 0.00 & 0.00 & 0.00 & 0.00 & 0.00 & 2.93 \\
\hline OSW & 1.25 & 0.41 & 0.59 & 0.23 & 0.15 & 0.14 & 1.46 & 0.00 & 0.30 & 0.00 & 0.00 & 0.21 & 4.74 \\
\hline ROC & 0.76 & 0.00 & 0.00 & 0.15 & 0.00 & 0.12 & 0.00 & 0.00 & 0.00 & 0.00 & 0.14 & 0.00 & 1.17 \\
\hline SHF & 0.00 & 0.00 & 0.00 & 0.00 & 0.00 & 0.00 & 0.00 & 0.00 & 0.00 & 0.00 & 0.00 & 0.00 & 0.00 \\
\hline TOL & 0.23 & 0.36 & 0.32 & 0.18 & 0.16 & 0.12 & 0.91 & 0.19 & 0.41 & 0.18 & 0.14 & 0.27 & 3.47 \\
\hline
\end{tabular}


Table B-3. 2013 Dissolved BDE Concentrations (pg/L). Mean concentrations for each location over Spring-Fall, 2013. <DL concentrations replaced with 0.

$\begin{array}{lccccccccccccc}\text { LOC } & \text { BDE 2 } & \text { BDE 8 } & \text { BDE 15 } & \text { BDE 30 } & \text { BDE 28 } & \text { BDE 49 } & \text { BDE 47 } & \text { BDE 100 } & \text { BDE 99 } & \text { BDE 154 } & \text { BDE 153 } & \text { BDE 183 } & \text { SUM_BDE } \\ \text { BUF } & 43.48 & 0.00 & 0.39 & 0.21 & 0.17 & 0.18 & 4.24 & 0.67 & 4.26 & 0.56 & 0.46 & 0.13 & 54.74 \\ \text { CERI } & 0.00 & 0.00 & 0.00 & 0.00 & 0.00 & 0.32 & 7.64 & 0.00 & 9.38 & 1.41 & 1.51 & 0.32 & 20.58 \\ \text { CHB } & 0.00 & 0.00 & 0.79 & 0.00 & 0.00 & 0.00 & 0.00 & 5.58 & 0.00 & 0.00 & 0.00 & 0.00 & 6.37 \\ \text { CLE } & 0.00 & 0.00 & 0.00 & 0.00 & 0.00 & 0.11 & 1.26 & 0.00 & 0.69 & 0.03 & 0.01 & 0.12 & 2.23 \\ \text { CLLF } & 0.00 & 0.00 & 0.00 & 0.00 & 0.22 & 0.79 & 7.06 & 0.87 & 5.67 & 0.68 & 0.45 & 0.14 & 15.88 \\ \text { CONT } & 0.00 & 0.00 & 0.00 & 0.00 & 0.00 & 0.00 & 1.53 & 0.00 & 0.94 & 0.00 & 0.08 & 0.00 & 2.55 \\ \text { CV } & 0.00 & 1.16 & 0.55 & 0.00 & 0.47 & 0.19 & 10.10 & 3.73 & 13.62 & 1.60 & 1.45 & 0.13 & 33.01 \\ \text { DUN } & 0.00 & 0.00 & 1.39 & 0.00 & 0.00 & 0.00 & 0.00 & 0.00 & 0.00 & 0.00 & 0.04 & 0.00 & 1.43 \\ \text { EERI } & 0.00 & 0.00 & 0.00 & 0.00 & 0.00 & 0.00 & 0.00 & 0.00 & 0.00 & 0.00 & 0.00 & 0.00 & 0.00 \\ \text { ERI } & 0.00 & 0.00 & 0.00 & 0.00 & 0.00 & 0.25 & 1.45 & 1.34 & 0.66 & 0.13 & 0.07 & 0.00 & 3.90 \\ \text { ETOR } & 0.00 & 0.00 & 0.83 & 0.00 & 0.21 & 0.00 & 2.17 & 3.98 & 0.69 & 0.09 & 0.15 & 0.00 & 8.12 \\ \text { FH } & 0.00 & 0.80 & 0.99 & 0.00 & 0.00 & 0.12 & 1.24 & 1.02 & 0.97 & 0.14 & 0.10 & 0.18 & 5.57 \\ \text { NIA } & 0.00 & 1.32 & 1.10 & 0.06 & 0.30 & 0.73 & 3.60 & 0.00 & 2.85 & 0.47 & 0.26 & 0.21 & 10.89 \\ \text { OSW } & 50.48 & 0.00 & 0.76 & 0.00 & 0.37 & 0.39 & 4.13 & 1.02 & 2.69 & 0.86 & 0.38 & 0.58 & 61.68 \\ \text { TOR } & 0.00 & 0.00 & 0.88 & 0.00 & 0.25 & 0.00 & 2.32 & 4.70 & 2.16 & 0.10 & 0.09 & 0.00 & 10.50 \\ \text { WERI } & 0.00 & 1.40 & 0.00 & 0.00 & 0.15 & 0.30 & 2.76 & 0.00 & 1.66 & 0.34 & 0.19 & 0.23 & 7.04 \\ \text { WONT } & 0.00 & 0.00 & 0.00 & 0.00 & 0.00 & 0.32 & 1.86 & 0.00 & 1.16 & 0.30 & 0.10 & 0.00 & 3.75 \\ \text { WTOR } & 0.00 & 0.00 & 8.49 & 0.00 & 0.51 & 0.37 & 9.96 & 5.93 & 12.42 & 1.56 & 1.27 & 0.00 & 40.52\end{array}$

Table B-4. 2013 Dissolved NHFR Concentrations (pg/L). Mean concentrations for each location over Spring-Fall, 2013. $<$ DL concentrations replaced with 0.

$\begin{array}{lccccccccc}\text { LOC } & \text { PTBX } & \text { PBB } & \text { PBT } & \text { PBEB } & \text { HBB } & \text { HCDBCO } & \text { BTBPE } & \text { SDP } & \text { ADP } \\ \text { BUF } & 0.009 & 0.000 & 0.000 & 0.123 & 0.067 & 0.000 & 0.133 & 0.045 & 0.068 \\ \text { CERI } & 0.000 & 0.000 & 0.000 & 0.108 & 0.417 & 0.000 & 0.000 & 0.000 & 0.000 \\ \text { CHB } & 0.000 & 0.000 & 0.000 & 0.037 & 0.000 & 10.220 & 0.000 & 0.000 & 0.000 \\ \text { CLE } & 0.000 & 1.008 & 0.000 & 0.009 & 0.071 & 0.000 & 0.000 & 0.099 & 0.180 \\ \text { CLLF } & 0.000 & 0.710 & 0.000 & 0.338 & 0.721 & 0.602 & 0.000 & 0.000 & 0.408 \\ \text { CONT } & 0.000 & 0.000 & 0.335 & 0.000 & 0.000 & 2.020 & 0.000 & 0.000 & 0.000 \\ \text { CV } & 0.000 & 0.826 & 0.000 & 0.227 & 0.000 & 0.000 & 0.000 & 0.293 & 0.117 \\ \text { DUN } & 0.000 & 0.000 & 0.000 & 0.000 & 0.000 & 0.000 & 0.000 & 0.000 & 0.000 \\ \text { EERI } & 0.000 & 0.000 & 0.000 & 0.000 & 0.000 & 0.000 & 0.000 & 0.000 & 0.000 \\ \text { ERI } & 0.000 & 0.000 & 0.000 & 0.172 & 0.167 & 0.000 & 0.000 & 0.000 & 0.000 \\ \text { ETOR } & 0.000 & 0.000 & 0.000 & 0.000 & 0.000 & 0.931 & 0.000 & 0.000 & 0.000 \\ \text { FH } & 0.024 & 0.000 & 0.000 & 0.048 & 0.658 & 0.000 & 0.000 & 0.108 & 0.000 \\ \text { NIA } & 0.017 & 0.837 & 0.000 & 0.115 & 0.000 & 0.000 & 0.000 & 0.112 & 0.114 \\ \text { OSW } & 0.000 & 1.843 & 0.000 & 0.394 & 0.331 & 0.000 & 1.434 & 0.000 & 0.000 \\ \text { TOR } & 0.000 & 2.843 & 0.000 & 0.000 & 0.000 & 0.924 & 0.000 & 0.000 & 0.000 \\ \text { WERI } & 0.022 & 1.147 & 0.000 & 0.163 & 0.000 & 0.000 & 0.146 & 0.000 & 0.000 \\ \text { WONT } & 0.000 & 0.000 & 0.000 & 0.000 & 0.000 & 0.000 & 0.000 & 0.000 & 0.000 \\ \text { WTOR } & 0.000 & 0.000 & 0.000 & 0.120 & 0.000 & 0.000 & 0.000 & 0.000 & 0.000\end{array}$


Table B-4. 2013 Dissolved PAH Concentrations (ng/L). Mean concentrations for each location over Spring-Fall, 2013. $<$ DL concentrations replaced with 0.

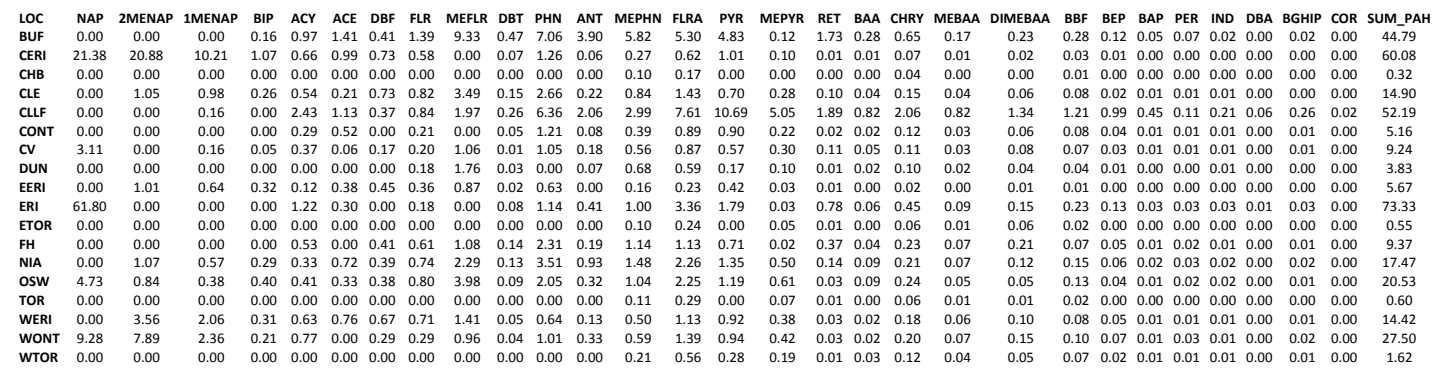

Table B-5. 2013 Gaseous BDE Concentrations $\left(\mathrm{pg} / \mathrm{m}^{3}\right)$. Mean concentrations for each location over Spring-Fall, 2013. $<$ DL concentrations replaced with 0 .

\begin{tabular}{|c|c|c|c|c|c|c|c|c|c|c|c|c|c|}
\hline LOC & BDE 2 & BDE 8 & BDE 15 & BDE 30 & BDE 28 & BDE 49 & BDE 47 & BDE 100 & BDE 99 & BDE 154 & BDE 153 & BDE 183 & SUM_BDE \\
\hline BUF & 0.00 & 3.69 & 0.00 & 0.00 & 0.00 & 0.00 & 0.16 & 0.00 & 0.00 & 0.00 & 0.00 & 0.18 & 4.02 \\
\hline CHB & 0.00 & 0.00 & 0.00 & 0.00 & 0.00 & 0.00 & 0.00 & 0.00 & 0.00 & 0.00 & 0.00 & 0.01 & 0.01 \\
\hline CLD & 0.00 & 2.64 & 4.14 & 0.00 & 0.00 & 0.02 & 0.47 & 0.33 & 0.29 & 0.05 & 0.01 & 0.00 & 7.95 \\
\hline CLE & 0.00 & 14.23 & 0.65 & 0.00 & 0.27 & 0.06 & 0.67 & 0.00 & 0.22 & 0.00 & 0.00 & 0.05 & 16.16 \\
\hline CLHA & 0.00 & 0.52 & 1.75 & 0.00 & 0.42 & 0.07 & 0.68 & 0.00 & 0.21 & 0.06 & 0.03 & 0.05 & 3.79 \\
\hline CLLF & 0.00 & 3.32 & 0.85 & 0.00 & 0.13 & 0.05 & 0.46 & 0.11 & 0.14 & 0.01 & 0.01 & 0.02 & 5.10 \\
\hline CLTI & 0.00 & 0.00 & 9.61 & 0.00 & 0.23 & 0.05 & 0.65 & 0.60 & 0.19 & 0.10 & 0.02 & 0.00 & 11.44 \\
\hline CUYA & 0.00 & 2.72 & 0.00 & 0.00 & 0.06 & 0.00 & 0.38 & 3.15 & 0.08 & 0.00 & 0.00 & 0.15 & 6.55 \\
\hline CV & 0.00 & 0.33 & 0.00 & 0.00 & 0.00 & 0.00 & 0.00 & 0.64 & 0.00 & 0.18 & 0.70 & 0.15 & 2.00 \\
\hline DUN & 0.00 & 5.46 & 0.00 & 0.00 & 2.97 & 0.00 & 0.00 & 3.96 & 0.00 & 0.00 & 0.00 & 27.38 & 39.78 \\
\hline EERI & 0.00 & 0.86 & 0.00 & 0.00 & 0.00 & 0.00 & 0.00 & 0.00 & 0.16 & 0.02 & 0.01 & 0.06 & 1.12 \\
\hline ERI & 0.00 & 1.20 & 0.00 & 0.00 & 0.00 & 0.00 & 0.00 & 0.00 & 0.00 & 0.00 & 0.00 & 0.03 & 1.23 \\
\hline ETOR & 0.00 & 0.00 & 0.00 & 0.00 & 0.00 & 0.00 & 0.06 & 0.00 & 0.00 & 0.00 & 0.01 & 0.03 & 0.10 \\
\hline FH & 0.00 & 1.99 & 0.81 & 0.00 & 0.00 & 0.00 & 0.00 & 1.02 & 0.00 & 0.00 & 0.00 & 0.01 & 3.83 \\
\hline GRI & 0.00 & 0.00 & 5.50 & 0.00 & 0.00 & 0.00 & 0.00 & 0.00 & 0.00 & 0.00 & 0.00 & 0.00 & 5.50 \\
\hline HB & 0.00 & 6.34 & 0.00 & 0.00 & 0.00 & 0.00 & 0.00 & 0.00 & 0.00 & 0.00 & 0.00 & 0.76 & 7.10 \\
\hline KENT & 0.00 & 11.56 & 1.13 & 0.00 & 0.40 & 0.06 & 1.40 & 0.00 & 0.41 & 0.06 & 0.00 & 0.11 & 15.12 \\
\hline LEW & 0.00 & 12.99 & 0.00 & 0.00 & 0.00 & 0.00 & 0.00 & 0.00 & 0.00 & 0.00 & 0.01 & 0.03 & 13.03 \\
\hline NIA & 0.00 & 12.36 & 0.00 & 0.00 & 0.00 & 0.00 & 0.00 & 0.00 & 0.00 & 0.02 & 0.01 & 0. & 12.51 \\
\hline osw & 0.00 & 1.05 & 0.00 & 0.00 & 0.07 & 0.00 & 0. & 2.65 & $0 . C$ & 0.00 & 0. & 0. & 4.49 \\
\hline PIB & 0.00 & 2.51 & 0.00 & 0.00 & 0.00 & 0.00 & 0.00 & 0.00 & 0.00 & 0.00 & 0.01 & 0.45 & 2.97 \\
\hline ROC & 0.00 & 0.65 & 0.00 & 0.00 & 0.07 & 0.00 & 1.27 & 0.00 & 0.00 & 0.00 & 0.00 & 0.39 & 2.38 \\
\hline SAN & 0.00 & 0.00 & 0.00 & 0.00 & 0.00 & 0.00 & 0.63 & 0.00 & 0.00 & 0.00 & 0.00 & 0.08 & 0.71 \\
\hline TOR & 0.00 & 0.00 & 0.00 & 0.00 & 0.27 & 0.00 & 0.21 & 0.00 & 0.11 & 0.00 & 0.02 & 0.00 & 0.61 \\
\hline UH & 0.00 & 10.02 & 3.19 & 0.00 & 0.36 & 0.00 & 0.49 & 0.00 & 0.00 & 0.00 & 0.00 & 0.45 & 14.50 \\
\hline WERI & 0.00 & 12.65 & 0.00 & 0.00 & 0.00 & 0.03 & 0.18 & 0.00 & 0.05 & 0.02 & 0.00 & 0.01 & 12.94 \\
\hline WTOR & 0.00 & 0.00 & 0.00 & 0.00 & 0.08 & 0.02 & 0.24 & 0.00 & 0.06 & 0.00 & 0.01 & 0.02 & 0.43 \\
\hline
\end{tabular}


Table B-6. 2013 Gaseous NHFR Concentrations (pg/m³). Mean concentrations for each location over Spring-Fall, 2013. $<$ DL concentrations replaced with 0.

$\begin{array}{lccccccccc}\text { LOC } & \text { PTBX } & \text { PBB } & \text { PBT } & \text { PBEB } & \text { HBB } & \text { HCDBCO } & \text { BTBPE } & \text { SDP } & \text { ADP } \\ \text { BUF } & 0.00 & 0.01 & 0.00 & 0.00 & 0.02 & 0.00 & 0.00 & 0.00 & 0.68 \\ \text { CHB } & 0.00 & 0.00 & 0.00 & 0.00 & 0.00 & 0.00 & 0.00 & 0.02 & 0.00 \\ \text { CLD } & 0.15 & 0.03 & 0.00 & 0.06 & 0.00 & 0.00 & 0.00 & 0.00 & 0.04 \\ \text { CLE } & 0.03 & 0.03 & 0.00 & 0.06 & 0.00 & 0.00 & 0.00 & 0.12 & 0.00 \\ \text { CLHA } & 0.04 & 0.02 & 0.00 & 0.04 & 0.00 & 0.00 & 0.00 & 0.04 & 0.06 \\ \text { CLLF } & 0.00 & 0.01 & 0.00 & 0.06 & 0.01 & 1.81 & 0.04 & 0.03 & 0.03 \\ \text { CLTI } & 0.00 & 0.03 & 0.00 & 0.02 & 0.00 & 0.00 & 0.00 & 0.03 & 0.11 \\ \text { CUYA } & 0.05 & 0.04 & 0.00 & 0.00 & 0.00 & 0.00 & 0.00 & 0.00 & 0.09 \\ \text { CV } & 0.00 & 0.00 & 0.00 & 0.00 & 0.00 & 0.00 & 0.00 & 0.00 & 0.47 \\ \text { DUN } & 27.99 & 0.00 & 0.00 & 20.51 & 0.00 & 0.00 & 0.00 & 0.00 & 0.16 \\ \text { EERI } & 0.00 & 0.00 & 0.00 & 0.00 & 0.00 & 0.00 & 0.00 & 0.00 & 0.00 \\ \text { ERI } & 0.00 & 0.00 & 0.00 & 0.00 & 0.00 & 0.00 & 0.00 & 0.00 & 0.00 \\ \text { ETOR } & 0.00 & 0.01 & 0.00 & 0.00 & 0.00 & 0.00 & 0.00 & 0.13 & 0.14 \\ \text { FH } & 0.00 & 0.03 & 0.00 & 0.00 & 0.00 & 0.00 & 0.13 & 0.00 & 0.12 \\ \text { GRI } & 0.00 & 0.02 & 0.00 & 0.02 & 0.00 & 0.00 & 0.00 & 0.00 & 0.00 \\ \text { HB } & 0.00 & 0.00 & 0.00 & 0.00 & 0.00 & 0.00 & 0.00 & 0.00 & 0.00 \\ \text { KENT } & 0.06 & 0.08 & 0.10 & 0.06 & 0.03 & 0.00 & 0.00 & 0.00 & 0.00 \\ \text { LEW } & 0.00 & 0.01 & 0.00 & 0.00 & 0.00 & 0.00 & 0.00 & 0.24 & 0.93 \\ \text { NIA } & 0.00 & 0.07 & 0.00 & 0.00 & 0.01 & 0.00 & 0.00 & 0.07 & 0.07 \\ \text { OSW } & 0.05 & 0.00 & 0.00 & 0.01 & 0.00 & 0.00 & 0.00 & 0.00 & 0.07 \\ \text { PIB } & 0.00 & 0.00 & 0.00 & 0.02 & 0.00 & 0.00 & 0.00 & 0.00 & 0.00 \\ \text { ROC } & 0.00 & 0.00 & 0.00 & 0.00 & 0.00 & 0.00 & 0.00 & 0.00 & 0.05 \\ \text { SAN } & 0.00 & 0.02 & 0.00 & 0.04 & 0.00 & 0.00 & 0.00 & 0.00 & 0.00 \\ \text { TOR } & 0.00 & 0.02 & 0.00 & 0.01 & 0.07 & 0.00 & 0.00 & 0.03 & 0.05 \\ \text { UH } & 0.05 & 0.02 & 0.00 & 0.07 & 0.00 & 0.00 & 0.00 & 0.09 & 0.00 \\ \text { WERI } & 0.00 & 0.00 & 0.00 & 0.00 & 0.00 & 0.00 & 0.00 & 0.03 & 0.00 \\ \text { WTOR } & 0.00 & 0.01 & 0.00 & 0.00 & 0.01 & 0.00 & 0.00 & 0.04 & 0.08\end{array}$

Table B-7 2013 Gaseous PAH Concentrations (ng/m³). Mean concentrations for each location over Spring-Fall, 2013. $<$ DL concentrations replaced with 0.

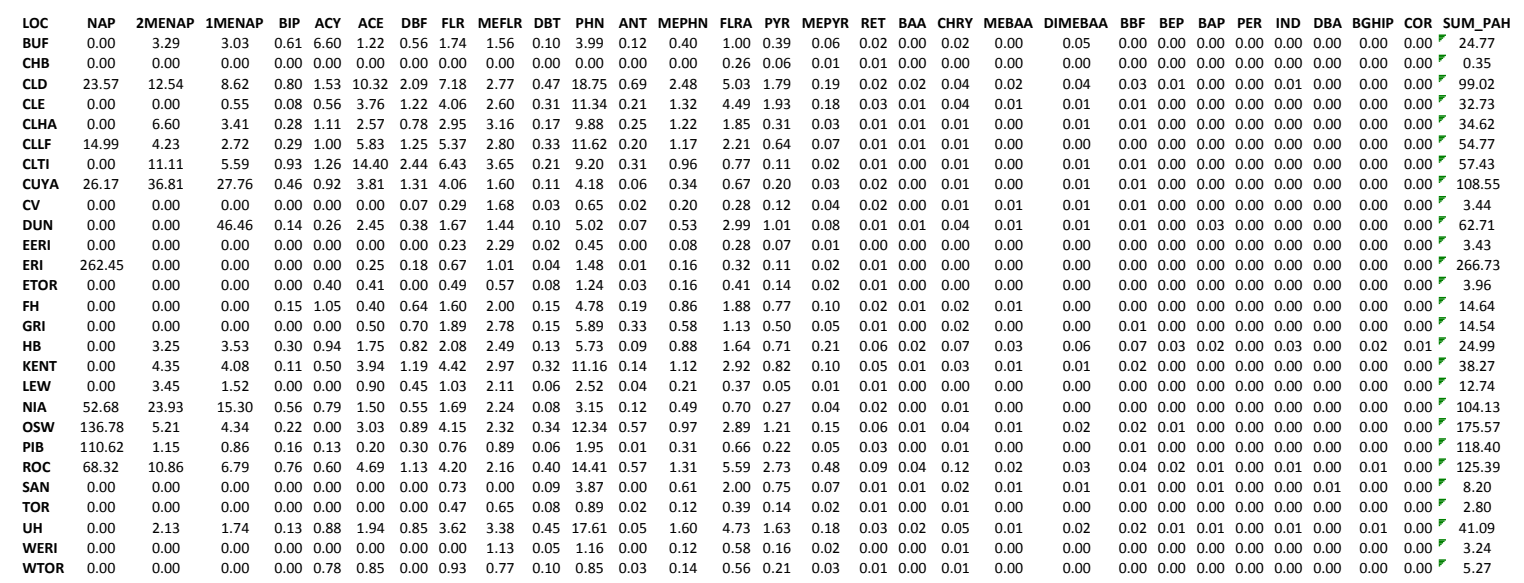

